\title{
Plasma Spray and Pack Cementation Process Optimization and Oxidation Behaviour of Novel Multilayered Coatings
}

\author{
By \\ Feng Gao \\ B. Eng., M.A.Sc. Materials \\ A thesis submitted to the Faculty of Graduate and Postdoctoral Affairs \\ in partial fulfilment of \\ the degree requirements of \\ Doctor of Philosophy \\ Ottawa-Carleton Institute for \\ Mechanical and Aerospace Engineering \\ Department of Mechanical and Aerospace Engineering \\ Carleton University \\ Ottawa, Ontario, Canada \\ December, 2012 \\ Copyright (C) \\ 2012 Feng Gao
}


Library and Archives

Canada

Published Heritage

Branch

395 Wellington Street

Ottawa ON K1A ON4

Canada
Bibliothèque et

Archives Canada

Direction du

Patrimoine de l'édition

395 , rue Wellington

Ottawa ON K1A ON4

Canada
Your file Votre référence

ISBN: 978-0-494-94216-1

Our file Notre référence

ISBN: 978-0-494-94216-1
NOTICE:

The author has granted a nonexclusive license allowing Library and Archives Canada to reproduce, publish, archive, preserve, conserve, communicate to the public by telecommunication or on the Internet, loan, distrbute and sell theses worldwide, for commercial or noncommercial purposes, in microform, paper, electronic and/or any other formats.

The author retains copyright ownership and moral rights in this thesis. Neither the thesis nor substantial extracts from it may be printed or otherwise reproduced without the author's permission.
AVIS:

L'auteur a accordé une licence non exclusive permettant à la Bibliothèque et Archives Canada de reproduire, publier, archiver, sauvegarder, conserver, transmettre au public par télécommunication ou par l'Internet, prêter, distribuer et vendre des thèses partout dans le monde, à des fins commerciales ou autres, sur support microforme, papier, électronique et/ou autres formats.

L'auteur conserve la propriété du droit d'auteur et des droits moraux qui protege cette thèse. $\mathrm{Ni}$ la thèse ni des extraits substantiels de celle-ci ne doivent être imprimés ou autrement reproduits sans son autorisation.
In compliance with the Canadian Privacy Act some supporting forms may have been removed from this thesis.

While these forms may be included in the document page count, their removal does not represent any loss of content from the thesis.
Conformément à la loi canadienne sur la protection de la vie privée, quelques formulaires secondaires ont été enlevés de cette thèse.

Bien que ces formulaires aient inclus dans la pagination, il n'y aura aucun contenu manquant. 


\section{ABSTRACT}

The hot section components in gas turbines are subjected to a harsh environment with the temperature being increased continuously. The higher temperature has directly resulted in severe oxidation of these components. Monolithic coatings such as MCrAlY and aluminide have been traditionally used to protect the components from oxidation; however, increased operating temperature quickly deteriorates the coatings due to accelerated diffusion of aluminum in the coatings. To improve the oxidation resistance a group of multilayered coatings are developed in this study. The multilayered coatings consist of a Cr-Si co-deposited layer as the diffusion barrier, a plasma sprayed NiCrAlY coating as the middle layer and an aluminized top layer. The $\mathrm{Cr}$-Si and aluminized layers are fabricated using pack cementation processes and the NiCrAlY coatings are produced using the Mettech Axial III ${ }^{\mathrm{TM}}$ System. All of the coating processes are optimized using the methodology of Design of Experiments (DOE) and the results are analyzed using statistical method. The optimal processes are adopted to fabricate the multilayered coatings for oxidation tests. The coatings are exposed in air at $1050^{\circ} \mathrm{C}$ and $1150^{\circ} \mathrm{C}$ for $1000 \mathrm{hr}$. The results indicate that a $\mathrm{Cr}$ layer and a silicon-rich barrier layer have formed on the interface between the $\mathrm{Cr}$-Si coating and the NiCrAlY coating. This barrier layer not only prevents aluminum and chromium from diffusing into the substrate, but also impedes the diffusion of other elements from the substrate into the coating. The results also reveal that, for optimal oxidation resistance at $1050^{\circ} \mathrm{C}$, the top layer in a multilayered coating should have at least $\mathrm{Al} / \mathrm{Ni}$ ratio of one; whereas the multilayered coating with the $\mathrm{Al} / \mathrm{Ni}$ ratio of two in the top layer exhibits the best oxidation resistance at $1150^{\circ} \mathrm{C}$. The DOE methodology provides an excellent means for process optimization 
and the selection of oxidation test matrix, and also offers a more thorough understanding of the effects of process parameters on the coating microstructure, and the effects of layers and their interactions on the oxidation behavior of the multilayered coatings. 


\section{ACKNOWLEDGEMENTS}

I owe my sincere gratitude to my supervisors, Prof. Xiao Huang, Prof. Rong Liu (Carleton University, Canada), and Dr. Qi Yang (National Research Council, Canada), for their constant support and valuable suggestions. Thank you for being there for me when I needed your advice or recommendations.

I would like to express my great appreciation to my family for their continuous support and patience.

I am grateful to Mr. Fred Barrett (Carleton University, Canada) for spraying all specimens and to Mr. Yunfen Qian for his help in the preparation of the metallographic specimens.

I thank the staff of the Mechanical and Aerospace Engineering at Carleton University and Institute of Aerospace Research at National Research Council Canada (NRC) for all the help that they have provided me with throughout my studies at Carleton University. 


\section{TABLE OF CONTENTS}

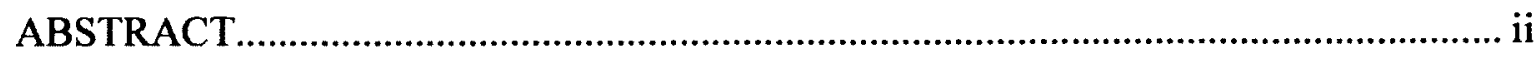

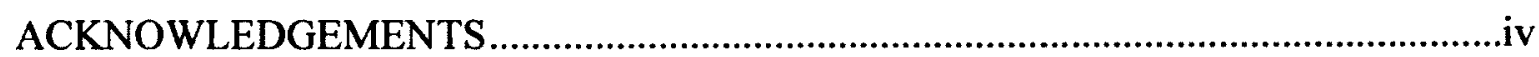

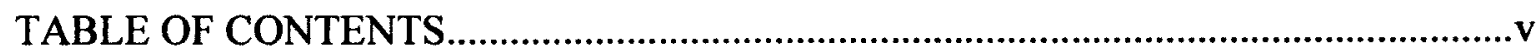

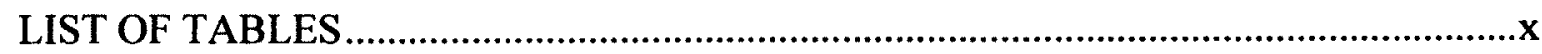

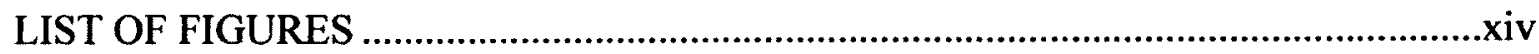

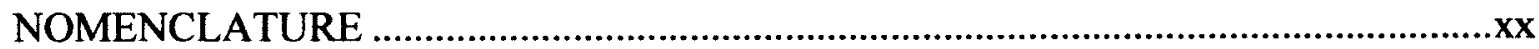

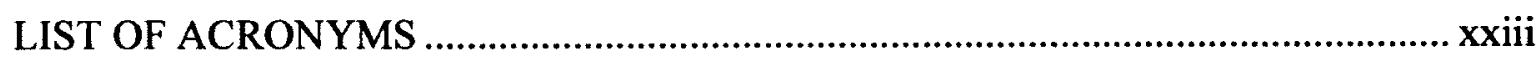

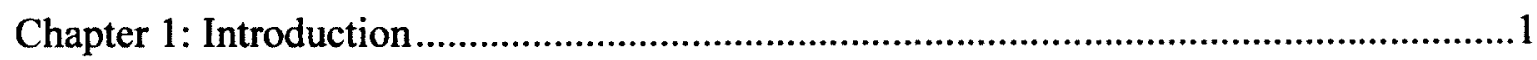

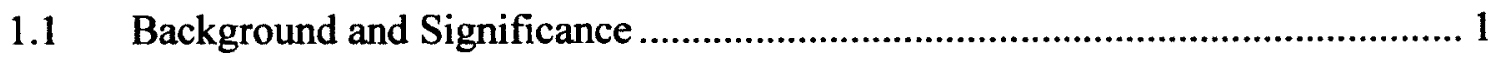

1.1.1 Temperature Environments of Hot Section in Gas Turbines....................... 1

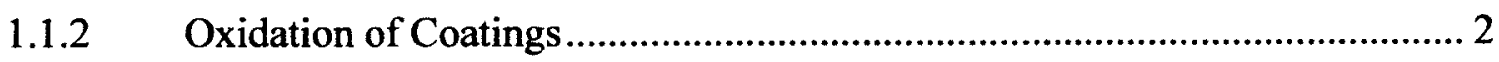

1.1.3 Development of Coatings with Oxidation Resistance ................................ 2

1.2 Research Objectives and Methodologies .................................................. 3

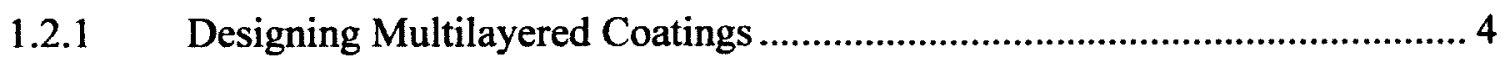

1.2.2 Optimizing Coating Processes ........................................................... 4

1.2.3 Fabricating Multilayered Coatings ..................................................... 5

1.2.4 Investigating the Oxidation Behavior of Multilayered Coatings .................. 5

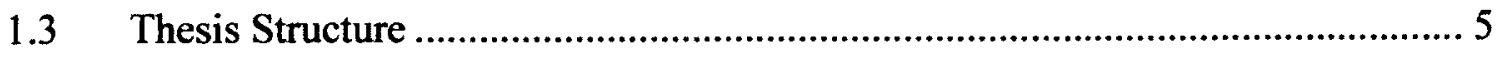

Chapter 2: Literature Review.............................................................................

2.1 Operating Conditions of the Hot Section Components in Gas Turbines............ 8 


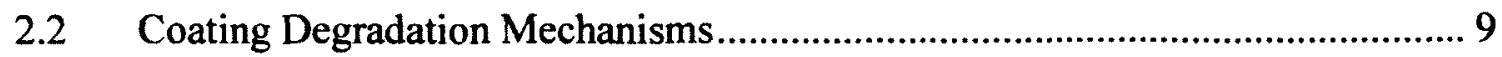

2.2.1 Oxidation of Metals ......................................................................... 10

2.2.2 Oxidation of Coatings...................................................................... 12

2.2.3 Requirements for Oxidation Resistant Coatings....................................... 15

2.3 Coating Processes ...................................................................................... 16

2.3.1 Diffusion Coatings ................................................................................ 17

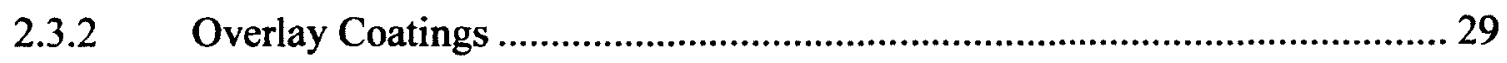

2.3.3 Diffusion between Coating and Substrate ................................................... 36

2.3.4 Duplex Layer and Multilayered Coatings.................................................... 40

2.4 Design of Experiments Methodology ........................................................... 42

2.4.1 Two-Level Full Factorial Design................................................................... 43

2.4.2 Two-level Fractional Factorial Design ........................................................ 44

2.4.3 Response Surface Methodology (RSM) ..................................................... 45

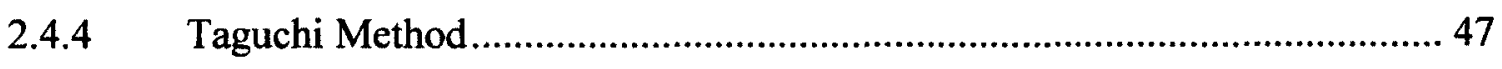

2.4.5 Analysis of Variance (ANOVA) Table .................................................... 52

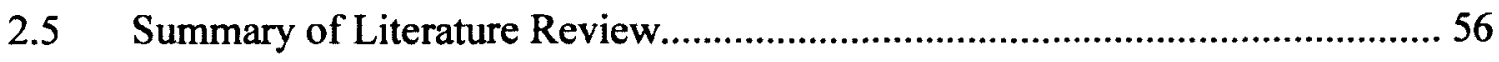

Chapter 3: Coating and Process Design.......................................................................58

3.1 Design of Multilayered Coatings ................................................................ 58

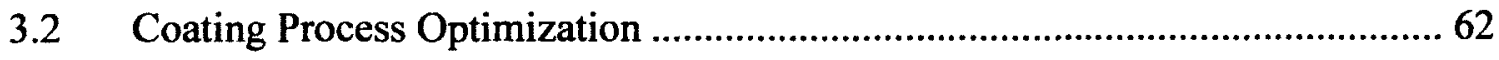

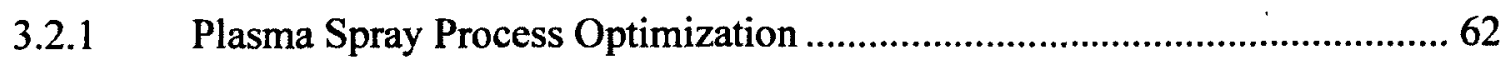

3.2.2 Pack Cementation Process Optimization......................................................... 62

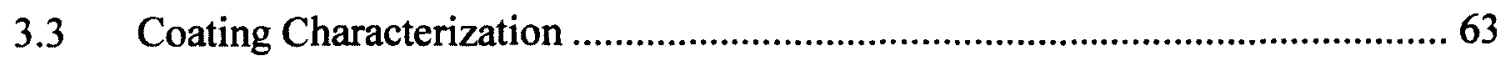

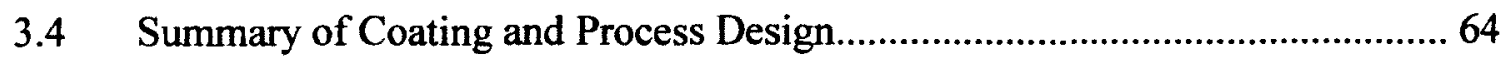




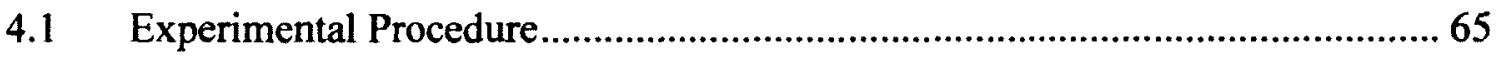

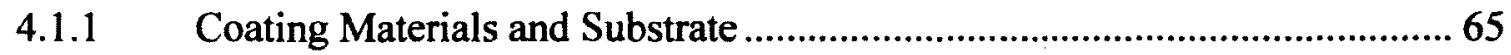

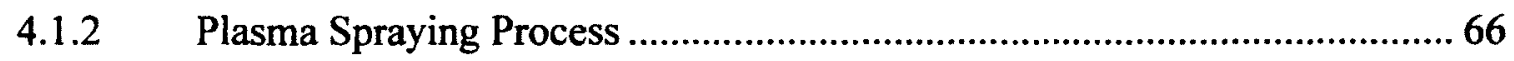

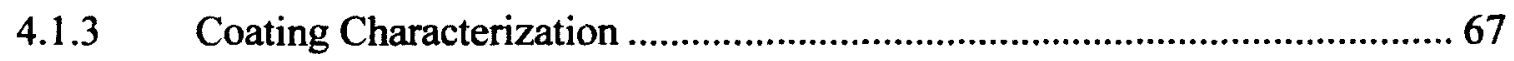

4.2 Regression Analysis.................................................................................. 72

4.3 Results and Discussion for Process Optimization ............................................. 73

4.3.1 Microstructures of NiCrAlY Coatings........................................................... 73

4.3.2 Results from First Set of Experiments....................................................... 76

4.3.3 Discussion on Results from First Set of Experiments ................................. 84

4.3.4 Results from Second Set of Experiments ................................................... 93

4.3.5 Concept of Process Index ....................................................................... 94

4.3.6 Regression Analysis and Validity of Process Index ..................................... 97

4.3.7 PI Development Guidelines for Other Thermal Spray Processes............... 106

4.4 Summary of Process Optimization for NiCrAlY Coatings .............................. 108

Chapter 5: Process Optimization for Diffusion Coatings ................................................110

5.1 Process Optimization for the Aluminide Coatings ....................................... 110

5.1.1 Experimental Procedure ..................................................................... 111

5.1.2 Elemental Distribution and Microstructure ............................................... 114

5.1.3 Coating Thickness and Al/Ni Ratio .......................................................... 118

5.1.4 Analysis of Variance for Coating Thickness and Al/Ni Ratio.................... 119

5.1.5 Regression Equation for Coating Thickness and Al/Ni Ratio ................... 120

5.2 Process Development for $\mathrm{Cr}$-Si Coatings ................................................... 128 
5.2.1 Experimental Procedure ................................................................. 128

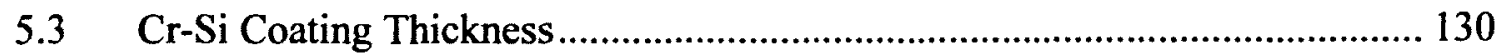

5.3.1 Optimization of Cr-Si Coating Process ..................................................... 130

5.3.2 Microstructures of $\mathrm{Cr}$-Si Coatings.......................................................... 135

5.4 Summary of Process Optimization for Diffusion Coatings ............................. 138

Chapter 6: Fabrication of Coatings ................................................................................139

6.1 Coatings for Oxidation Tests ................................................................... 139

6.2 Fabrication of Multilayered Coatings .............................................................. 141

6.2.1 Fabrication Procedures ...................................................................... 141

6.2.2 Elemental Distributions in Multilayered Coatings .................................... 142

6.2.3 Microstructures of Multilayered Coatings................................................. 144

$6.3 \quad$ Fabrication of Baseline Coatings ................................................................ 148

6.4 Summary of Coating Fabrication............................................................... 159

Chapter 7: Oxidation Tests and Results Discussion .....................................................160

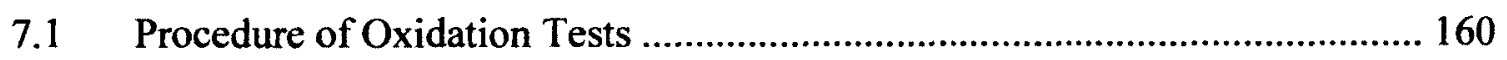

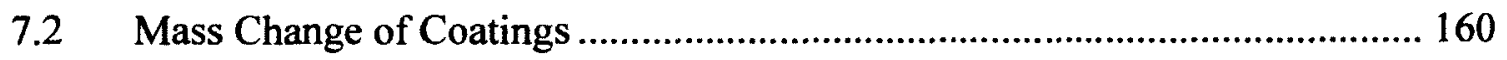

7.3 Microstructure and Morphology of Oxidized Coating Surfaces ...................... 168

7.4 Effects of Coating Layer on Area of Oxide Scales........................................ 178

7.5 Characterization of Cr-Si Barrier Layer .................................................... 185

7.5.1 Structure of Barrier Layer....................................................................... 185

7.5.2 Elemental Distributions in Coatings without NiCrAlY Layer..................... 186

7.5.3 Formation of Barrier Layer....................................................................... 193

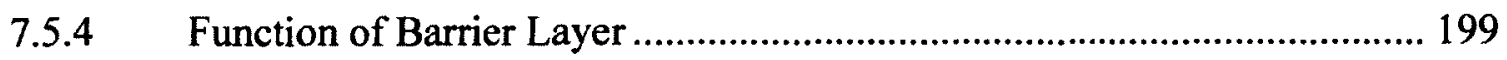


7.5.5 Effectiveness of Barrier Layer .............................................................. 202

7.5.6 Effects of Barrier Layer on the Formation of Interdiffusion Zone ............. 204

7.5.7 Effects of Barrier Layer at Different Exposure Temperatures ................... 205

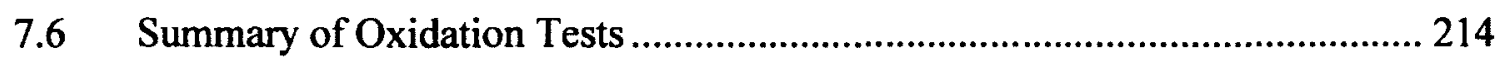

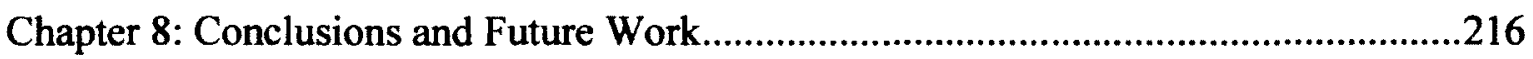

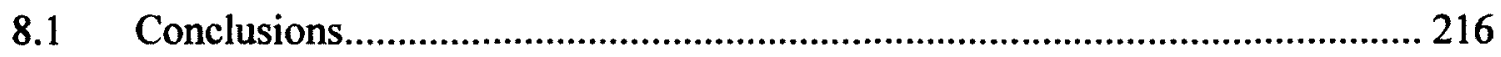

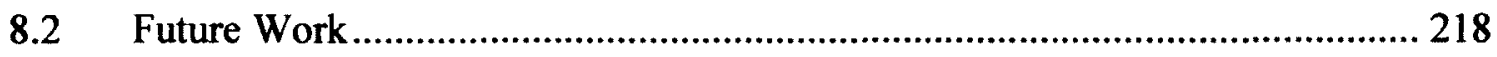

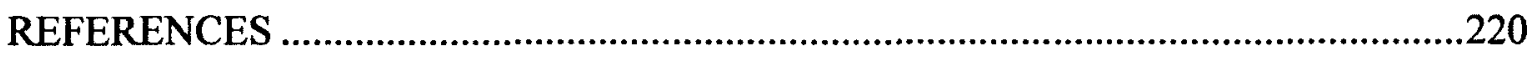

APPENDIX 


\section{LIST OF TABLES}

Table 1.1 Rotor inlet temperatures for typical gas turbine engines ...................................1

Table 2.1 Oxides formed at various temperatures ............................................................12

Table 2.2 Optimal aluminum and chromium contents for high-temperature oxidation

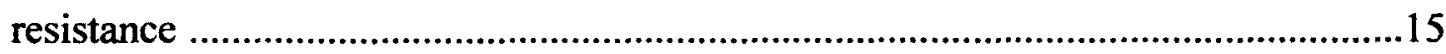

Table 2.3 Reactions for aluminizing, chromizing and siliconizing process ......................18

Table 2.4 Pack components, process parameters, pack cementation processes, and phases

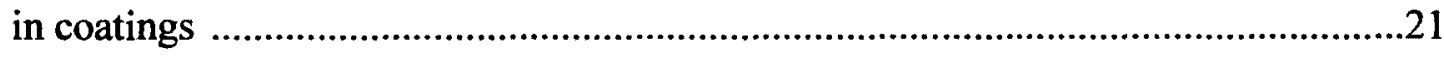

Table 2.5 Pack compositions and process parameters for co-deposition processes ...........26

Table 2.6 Oxides formed with temperature for MCrAlY coatings....................................35

Table 2.7 Diffusion barriers and their performance ………..............................................39

Table $2.82^{2}$ design with 4 treatment combinations and two main effects and one

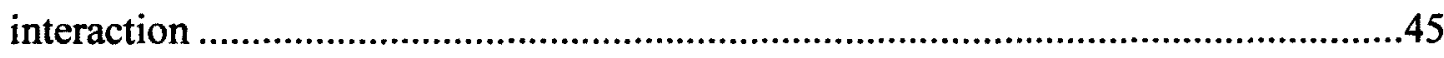

Table 2.9 ANOVA table of the yield for the example in section $2.4 .5 \ldots \ldots \ldots \ldots \ldots \ldots \ldots \ldots \ldots . . .54$

Table 3.1 Processes for the multilayered coating ……...................................................61

Table 3.2 Compositions of key elements for various layers of multilayered coatings ......61

Table 4.1 Powder parameters and powder feed rate ..........................................................65

Table 4.2 Taguchi matrix and process parameters .........................................................67

Table 4.3 Percentages of crack, pore, unmelted particle and oxide in coatings .................76

Table 4.4 Optimal parameters for minimizing coating features according SNRs .............80

Table 4.5 Values of $x_{1}, x_{2}, x_{3}$ and $x_{4}$ used in regression equation..................................81

Table 4.6 Procedure of stepwise regression analysis for porosity .....................................82

Table 4.7 Regression equations for four coating microstructure features ..........................83 
Figure 2.18 Overlay plot for the three responses

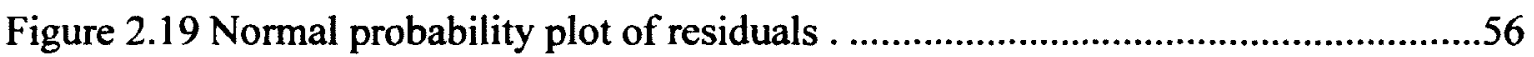

Figure 3.1 Strategy to improve oxidation resistance of a coating. ......................................58

Figure 3.2 Phase diagram of a Si-Cr-Ni ternary system ..................................................60

Figure 4.1 Image of a coating specimen in the group of coating 1-1...............................68

Figure 4.2 Microstructure of coatings for first set of experiments. ....................................70

Figure 4.3 EDS mapping images of coating 1-2 and coating 1-7.....................................71

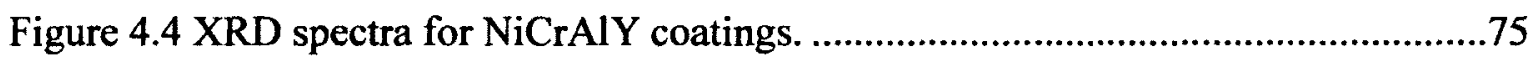

Figure 4.5 Results of the experiments for the first Taguchi matrix...................................80

Figure 4.6 Normality and independence test of the regression equation for crack. ..........84

Figure 4.7 Pareto diagrams showing the effects of process parameters on coating features.

Figure 4.8 Plot of the $\Omega$ value vs. exponents $a, b$, and $c$, respectively, in the range of 0.5 to 3.0 .

Figure 4.9 Plot of the $\Omega$ value vs. exponent $b$ and $c$, respectively, in the range of 0.25 to 0.50 . .101

Figure $4.10 \Omega$ value vs. exponent $b$ and $c$, respectively, in the range of 0 to $0.25 \ldots \ldots \ldots . .101$

Figure 4.11 Comparison of predicated and measured values of the four microstructure features for the three sets of experiment. 104

Figure 5.1 Pictorial representation of a three-level Box-Behnken response surface design for the aluminizing process.

Figure 5.2 Image of coating 4-1 and 4-7 .................................................................114

Figure 5.3 Cross section images of the coating $4-1$ and $4-7 \ldots \ldots \ldots \ldots \ldots \ldots \ldots \ldots \ldots \ldots \ldots \ldots \ldots \ldots \ldots . . .115$ 
Table 4.8 Comparison of the experimental results with the values calculated from the

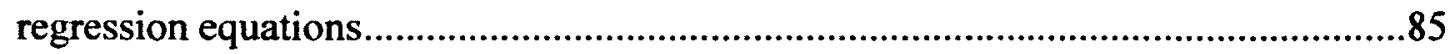

Table 4.9 Effects of process parameters on coating features..............................................86

Table 4.10 Sequential sums of squares of process parameters on coating features...........87

Table.4.11 Parameters of the experiments used to assess the validity of the regression equations

Table 4.12 Results of the second set of the Taguchi matrix .............................................94

Table 4.13 Summary of associated process parameters, normalized parameters..............95

Table 4.14 Results of the regression analysis of the enthalpy .........................................97

Table 4.15 Half of two-level factorial design for determining $P I$ values ..........................98

Table 4.16 Summary of $P I \mathbf{s}$ ' values for the two-level factorial matrix .............................98

Table 4.17 Coefficients of determination of regression equations for coating features with

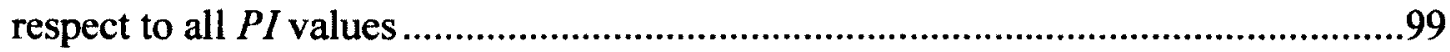

Table 4.18 Coefficients of determination for the microstructural features of NiCrAlY coatings with respect to the $P I$ values for $b$ from 0.50 to 3.00 100

Table 4.19 Coefficients of determination with respect to $P I$ values from the two-level full factorial design.

Table 4.20 Regression equations for coating features with respect to $P I \ldots \ldots . . . . . . . . . . . . . . . .102$

Table 4.21 Relation of coating features to $P I$ values .....................................................105

Table 4.22 Comparison between the predicted and experimental results for the second set of experiments 106

Table 5.1 Conditions of the specimens for the aluminizing process .

Table 5.2 Compositions of SS304L and IN738 
Table 5.3 Box-Behnken design for the aluminizing process ........................................112

Table 5.4 Parameters for aluminizing process..............................................................113

Table 5.5 Coating thickness and the maximum ratio of aluminum to nickel content .....118

Table 5.6 ANOVA table for coating thickness .........................................................119

Table 5.7 ANOVA table for ratio of Al to Ni............................................................120

Table 5.8 Values or formulas of the partial derivatives..................................................121

Table 5.9 Process parameters of additional tests for model verification ..........................128

Table 5.10 Comparison between the predicted and experimental results.........................128

Table 5.11 Taguchi L4 array for the process development of $\mathrm{Cr}$-Si coating....................129

Table 5.12 Parameters for the L4 array ......................................................................129

Table 5.13 Coating thickness for Cr-Si coating ...........................................................130

Table 5.14 Concentrations of $\mathrm{Si}$ and $\mathrm{Cr}$ and the differences between measured data and ideal values in $\mathrm{Cr}-\mathrm{Si}$ coatings ............................................................................132

Table 5.15 Parameters for optimizing both silicon and chromium contents ...................132

Table 5.16 EDS results for the phases in the coating ………………...........................138

Table 6.1 Two-level full factorial design for determining coating layers for oxidation tests

Table 6.2 Design matrix for oxidation test coatings .......................................................140

Table 6.3 Pack cementation parameters for multilayered coatings .................................141

Table 6.4 Plasma spray parameters for multilayered coatings ........................................142

Table 6.5 Parameters of diffusion processes .................................................................149

Table 6.6 Summary of coating processes ....................................................................149

Table 7.1 Mass change for individual coating specimen.................................................162 
Table 7.2 ANOVA table for mass change 163

Table 7.3 Effect, sequential SS, and percent contribution of factors and interactions for mass change 165

Table 7.4 Maximum and surface aluminum contents after the oxidation tests 168

Table 7.5 EDS results of various phases on the surface of coatings 169

Table 7.6 Average areas of oxide scales for the seven micrographs in each group 180

Table 7.7 Area calculation of oxide scale in a coating specimen 181

Table 7.8 ANOVA results for oxide scales 182

Table 7.9 Effect, sequential SS, and percent contribution of factors and interactions for the total areas of oxide scales 183

Table 7.10 EDS results of various phases in the coatings 189

Table 7.11 Phases in the coatings after exposure at $1050^{\circ} \mathrm{C}$ and $1150^{\circ} \mathrm{C}$ 213 


\section{LIST OF FIGURES}

Figure 2.1 Gas turbine inlet temperature trends

Figure 2.2 Effects of major cycle parameters on micro-turbine performance 10

Figure 2.3 Schematic representation of the oxidation stages of NiCrAlY coatings 14

Figure 2.4 Cross-sectional morphology of an Amdry 962 coating after oxidized at $1200^{\circ} \mathrm{C}$ for $50 \mathrm{hr}$.

Figure 2.5 Contact pack and out-of-pack process schematic diagrams 19

Figure 2.6 Schematic diagram of an above-the-pack device . 20

Figure $2.7 \mathrm{Al}-\mathrm{Ni}-\mathrm{Cr}$ phase diagram at $1000^{\circ} \mathrm{C}$ 26

Figure 2.8 Comparison of the temperature and velocity of particles in plasma spray and HVOF processes.

Figure 2.9 Configurations of traditional radial plasma gun and axial III gun . 32

Figure 2.10 Comparison of temperature and velocity of particles in thermal spray systems

Figure 2.11 Relative oxidation and corrosion resistance of high-temperature systems ...33

Figure 2.12 Diffusion directions of elements in a Ni-based coating and substrate system.

Figure 2.13 Micrograph of a smart coat showing the three-layer microstructure

Figure 2.14 An example of the response surface and contour plot

Figure 2.15 Graphical representations of the Box-Behnken and central composite design.

Figure 2.16 Response surface and contour plots for the viscosity .51

Figure 2.17 Response surface and contour plots for molecular weight .52 
Figure 5.4 Concentration distribution and XRD spectra for coating 4-1 and 4-7.

Figure 5.5 Ratio of $\mathrm{Al}$ at.\% to $\mathrm{Ni}$ at.\% versus the distance from coating surface for coating 4-1 and 4-7.

Figure 5.6 Contour plots of the coating thickness. 123

Figure 5.7 Response surface and contour plots of the $\mathrm{Al} / \mathrm{Ni}$ ratio. 125

Figure 5.8 Overlapped contour plots for response surface models at $1000^{\circ} \mathrm{C}$. 127

Figure 5.9 Image of coating 5-4

Figure 5.10 Coating thickness versus process parameters.....................................131

Figure 5.11 Effects of process parameters on Si content and SNRs..........................133

Figure 5.12 Effects of process parameters on $\mathrm{Cr}$ content and SNRs............................134

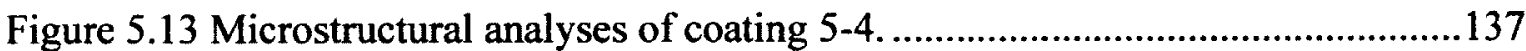

Figure 6.1 Pictorial representation of a two-level full factorial design for the aluminizing process.

Figure 6.2 Two multilayered coatings 142

Figure 6.3 Concentration profiles of major elements in multilayer coatings. 144

Figure 6.4 Structure and phase analyses of the multilayered coating with aluminide I top coat. 146

Figure 6.5 Structure and phase analyses of the multilayered coating with aluminide II top coat. 148

Figure 6.6 SEM image and concentration profiles of major elements for coating $\mathrm{Ol}(\mathrm{Cr}-$ Si coating/aluminide I) before oxidation tests. 151

Figure 6.7 SEM image and concentration profiles of major elements for coating $\mathrm{O} 8 \mathrm{Cr}$ Si coating/aluminide II) before oxidation tests. 152 
Figure $6.8 \mathrm{Al} / \mathrm{Ni}$ ratio in coating $\mathrm{O} 1, \mathrm{O} 3, \mathrm{O} 7$ and 08 .

Figure 6.9 XRD spectra of coating $\mathrm{Ol}$ and $\mathrm{O} 8$

Figure 6.10 SEM image and concentration profiles of major elements for coating $\mathrm{O} 3$ (aluminide I) before oxidation tests. 155

Figure 6.11 SEM image and concentration profiles of major elements for coating $\mathrm{O} 7$ (aluminide II) before oxidation tests 156

Figure 6.12 SEM image and concentration profiles of major elements for coating $\mathrm{O} 4$ (NiCrAlY/aluminide II) before oxidation tests. 157

Figure 6.13 SEM image and concentration profiles of major elements for coating O6 (NiCrAlY/aluminide I) before oxidation tests. 158

Figure 7.1 Specimens for the oxidation test at $1050^{\circ} \mathrm{C}$. 161

Figure 7.2 Contour plots of mass changes for multilayered coatings. 167

Figure 7.3 Surface morphologies of and XRD spectra of coating $\mathrm{O} 2$. 171

Figure 7.4 Surface morphologies and XRD spectra of coating 05 . .173

Figure 7.5 Morphology on the top surface of the coating $01 \ldots \ldots \ldots \ldots \ldots \ldots \ldots \ldots \ldots \ldots \ldots \ldots \ldots \ldots \ldots . . . . .175$

Figure 7.6 Morphology of coating $\mathrm{O} 3$ surface. ..............................................................175

Figure 7.7 Morphology the coating O4 surface...............................................................176

Figure 7.8 Morphology of coating O6 surface. ………….............................................176

Figure 7.9 Morphology of coating 07 surface. ..............................................................177

Figure 7.10 Morphology of coating $\mathrm{O8}$ surface. ……….................................................177

Figure 7.11 Morphology specimen O9 surface ............................................................178

Figure 7.12 Morphology of coating O10 surface. ...........................................................178

Figure 7.13 Binarized cross sectional image for coating 01 ............................................179 
Figure 7.14 Contour plots of the oxide scale area. 185

Figure $7.15 \mathrm{Al}$ and $\mathrm{Cr}$ concentration analyses in coating $\mathrm{O} 1(\mathrm{Cr}-\mathrm{Si}$ coating/aluminide $\mathrm{I})$ after $1000 \mathrm{hr}$ exposure at $1050^{\circ} \mathrm{C}$. 188

Figure 7.16 Concentration analyses in coating $\mathrm{O} 3$ (aluminide I) after $1000 \mathrm{hr}$ exposure at $1050^{\circ} \mathrm{C}$

Figure 7.17 Concentration analyses in coating $\mathrm{O} 8$ ( $\mathrm{Cr}$-Si coating/aluminide II) after 1000 hr exposure at $1050^{\circ} \mathrm{C}$.

Figure 7.18 Concentration analyses in coating $\mathrm{O} 7$ (aluminide II) after $1000 \mathrm{hr}$ exposure at $1050^{\circ} \mathrm{C}$. 192

Figure 7.19 Concentration analyses in coating $\mathrm{O} 2$ (aluminide II) after $1000 \mathrm{hr}$ exposure at $1050^{\circ} \mathrm{C}$. 196

Figure 7.20 Concentration analyses of coating $\mathrm{O} 5$ ( $\mathrm{Cr}-\mathrm{Si}$ coating/NiCrAlY/aluminide I) after $1000 \mathrm{hr}$ exposure at $1050^{\circ} \mathrm{C}$. 198

Figure 7.21 SEM image of coating O6 (NiCrAlY/aluminide I) after $1000 \mathrm{hr}$ exposure at $1050^{\circ} \mathrm{C}$ 199

Figure 7.22 Concentration analyses in coating $\mathrm{O} 4$ (aluminide II) after $1000 \mathrm{hr}$ exposure at $1050^{\circ} \mathrm{C}$ 202

Figure 7.23 Concentration analyses in coating $\mathrm{O} 2$ ( $\mathrm{Cr}-\mathrm{Si}$ coating/ NiCrAlY/aluminide II) after $1000 \mathrm{hr}$ exposure at $1150^{\circ} \mathrm{C}$ 208

Figure 7.24 Concentration analyses in coating O5 (Cr-Si coating/NiCrAlY/aluminide I) after $1000 \mathrm{hr}$ exposure at $1150^{\circ} \mathrm{C}$ 210

Figure 7.25 SEM image of coating O4 (NiCrAlY/aluminide II) after $1000 \mathrm{hr}$ exposure at $1150^{\circ} \mathrm{C}$ 210 
Figure 7.26 Concentration analyses in coating O6 (NiCrAlY/aluminide I) after $1000 \mathrm{hr}$

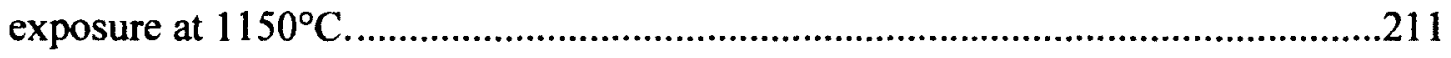

Figure 7.27 Concentration analyses in coating $\mathrm{O} 7$ (aluminide II) after $1000 \mathrm{hr}$ exposure at

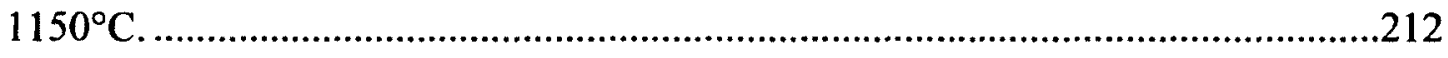




\section{NOMENCLATURE}

$a$ exponent for the equation of process index

$A$ aluminum content in the powder mixture for the aluminizing process

$b$ exponent for the equation of process index

$c \quad$ exponent for the equation of process index

C ratio of $\mathrm{H}_{2}+\mathrm{N}_{2}$ over total gas flow

$C_{H} \quad$ hydrogen proportion for working gas of ASP

$C_{N} \quad$ nitrogen proportion for working gas of ASP

D diameter of nozzle

$D_{o} \quad$ normalized diameter of nozzle in inch

E NiCrAlY in regression equation of mass loss

F $\quad$ Fisher value

$\bar{F} \quad$ mean value of response functions

$G \quad$ total flow rate

$G_{o} \quad$ normalized total flow rate

$H \quad$ enthalpy per liter of working gas

I current

$I_{o} \quad$ normalized current

L $\quad$ spray distance

$L_{o} \quad$ normalized spray distance

$m$ regression freedom

$n \quad$ residual freedom

$N \quad$ nickel content in the powder mixture for the aluminizing process 
p p-value

PI process index

$r \quad$ exponent the polynomial equation for coating features

$R \quad$ coefficient of determination

$S \quad$ powder size

$\mathrm{S}_{\mathrm{o}} \quad$ normalized powder size

$T \quad$ temperature for the aluminizing process

$U$ barrier coating in the regression equation of mass loss

$V \quad \mathrm{NiCrAlY}$ in the regression equation of mass loss

$W \quad$ aluminized coating in the regression equation of mass loss

$Y \quad$ regression equation for $P I$

$Y_{M} \quad$ regression equation of mass loss

$Y_{O} \quad$ regression equation of the total areas of oxide scales

$Y_{R} \quad$ regression equation of $\mathrm{Al} / \mathrm{Ni}$ ratio for the aluminizing process

$Y_{T} \quad$ regression equation of coating thickness for the aluminizing process

$x_{I}$ particle size in the regression equations of $\mathrm{NiCrAlY}$ coatings

$x_{2} \quad$ nozzle size in the regression equations of NiCrAlY coatings

$x_{3} \quad$ total gas rate in the regression equations of $\mathrm{NiCrAlY}$ coatings

$x_{4} \quad$ ratio of $H_{2}+N_{2}$ over gas flow in the regression equations

a critical value for an $F$ distribution

$\beta \quad \mathrm{NiAl}$ phase

$\beta_{0} \quad$ constant in the regression equation for $P I$

$\beta_{1} \quad$ variable in the regression equation for $P I$ 
$\beta_{2} \quad$ variable in the regression equation for $P I$

$\beta_{3} \quad$ variable in the regression equation for $P I$

$\gamma \quad$ Ni solution

$\gamma^{\prime} \quad \mathrm{Ni}_{3} \mathrm{Al}$ phase

$\Omega \quad$ geometrical mean of the coefficients of determination 


\section{LIST OF ACRONYMS}
APS atmospheric plasma spraying
CTE coefficient of thermal expansion
CVD chemical vapor deposition
DOE design of experiment
DOF degree of freedom
EB-PVD electron beam physical vapor deposition
EDS energy dispersive spectroscopy
HTHC high-temperature hot corrosion
HTHA high-temperature high-activity (CVD process)
HTLA high-temperature low-activity (CVD process)
HVOF high-velocity-oxy-fuel thermal spray
IGT industrial gas turbines
LPPS low pressure plasma spraying
LTHC low-temperature hot- corrosion
LTHA low-temperature high-activity (CVD process)
MWM meandering minding magnetometer
PI process index
PVD physical vapor deposition
RIT rotor-inlet temperatures
RSM response of surface methodology
SEM scanning electron microscopy 


$\begin{array}{ll}\text { SNR } & \text { signal-noise ratio } \\ \text { SPS } & \text { shrouded plasma spraying } \\ \text { TBC } & \text { thermal barrier coating } \\ \text { TCP } & \text { topologically closed packed } \\ \text { TGO } & \text { thermally grown oxide } \\ \text { VPS } & \text { vacuum plasma spraying } \\ \text { XRD } & \text { X-ray diffraction } \\ \text { YSZ } & \text { yttria stabilized zirconia }\end{array}$




\section{Chapter 1: Introduction}

\subsection{Background and Significance}

\subsubsection{Temperature Environments of the Hot Section in Gas Turbines}

Over the last decade, intensive research has been carried out on the coatings for the hot section components in gas turbine engines in order to enable a further increase in turbine rotor-inlet temperatures [ 1 ]. Higher rotor-inlet temperatures (RITs) are imperative for gas turbine engines to operate more efficiently. Currently, the temperatures at the entrance to the turbine for modern gas turbine engines can be as high as $1650^{\circ} \mathrm{C}$ [2] and RITs can be over $1400^{\circ} \mathrm{C}$, as shown in Table 1.1[3]. Moreover the temperatures at the leading edges of rotor airfoils can exceed $1100^{\circ} \mathrm{C}$, which is close to the incipient melting point of most superalloys.

Table 1.1 Rotor inlet temperatures for typical gas turbine engines [3]

\begin{tabular}{lccc}
\hline \multicolumn{1}{c}{ Engine } & $\begin{array}{c}\text { Rotor inlet temp. } \\
{ }^{\circ} \mathrm{C}\end{array}$ & $\begin{array}{c}\text { Power output, } \\
\text { MW }\end{array}$ & $\begin{array}{c}\text { Efficiency, } \\
\%\end{array}$ \\
\hline Westinghouse 501G & 1426 & 240 & 58 \\
Siemens V84/3a & 1310 & 170 & 57 \\
Alstom GT26 & 1240 & 281 & 57 \\
GE 7FA & 1290 & 150 & 55 \\
\hline
\end{tabular}

Owing to the limited chromium and aluminum contents in superalloys, which result in their relatively low intrinsic resistance to high temperature oxidation, most superalloys cannot survive at temperatures over $1100^{\circ} \mathrm{C}$. Therefore, various coatings are extensively implemented on the hot section components in gas turbines. 


\subsubsection{Oxidation of Coatings}

The mechanism of the oxidation depends on the exposure temperature and the composition of coatings. At a temperature below $800^{\circ} \mathrm{C}$, coatings suffer lowtemperature oxidation and some of the most active elements, such as $\mathrm{Al}, \mathrm{Cr}, \mathrm{Si}$, are selectively oxidized to form a dense oxide scale, which protects the coatings from further oxidation. At a temperature above $800^{\circ} \mathrm{C}$, nickel, along with aluminum and chromium, is also oxidized. Porous $\mathrm{Ni}(\mathrm{Al}, \mathrm{Cr})_{2} \mathrm{O}_{4}$ scales form when the aluminum content in the coatings is depleted, leading to the spallation of the scales during cooling [4].

The aluminum depletion in the coatings results from aluminum diffusing into the substrate and the continuous spallation of the aluminum-rich oxide scales. Furthermore, extensive internal oxidation of both the substrate and the surface scale takes place due to inward diffusion of oxygen [5]. When aluminum is depleted, the protective oxide layer on the coatings breaks down and the growth of the porous nickel-rich oxides is increased. Therefore various coatings have been developed with the objective to overcome aluminum depletion.

\subsubsection{Development of Coatings with Oxidation Resistance}

Since the early 1960s, continuing research efforts have been made to develop coatings to protect the hot section components from oxidation. However, failures of coated components still occur from time to time as a result of severe oxidation at high temperatures. One of the noticeable reasons for the failure of the coatings under oxidation environments is the diffusion of the coating elements into the substrate and also the alloying elements from the substrate into the coating. Previous research has 
proved that diffusion occurs between the coating and the substrate. For example, the work by Gao et al. [6] on Sermaloy 1515 (a Si modified aluminide coating) coating showed that aluminum depletion occurred and Kirkendall pores appeared along the interface of the coating and the substrate.

Although research has been carried out to study the phenomenon of the elemental diffusion between the coating and the substrate $[7,8]$, a solution is urgently needed for gas turbine industry to prevent this diffusion as much as possible. The formation of an effective diffusion barrier between a coating and a substrate has the potential to prevent aluminum from diffusing into the substrate and to offer the better protection against oxidation. This concept has been utilized in the present research to develop multilayered coatings.

In more details, multilayered coatings, composed of an aluminum-rich top layer, a NiCrAlY intermediate layer and a barrier layer, are proposed. The aluminum-rich top layer acting as an aluminum reservoir is imperative for the formation of protective scales and for the replenishment of aluminum in the top layer where aluminum is depleted due to the continuous spallation of oxide scales. The chromium enriched NiCrAlY layer works as a chromium reservoir for inward chromium diffusion to form a Cr-rich layer at the interface between the NiCrAlY, and the barrier layer impedes aluminum diffusion into the substrate.

\subsection{Research Objectives and Methodologies}

This research is aimed at developing multilayered coatings with improved oxidation resistance for the hot section components in gas turbines. The major tasks towards the completion of the objective include designing multilayered coatings, optimizing coating 
processes, fabricating the multilayered coatings, and investigating the oxidation behavior of the multilayered coatings at two temperatures.

\subsubsection{Designing Multilayered Coatings}

To resist oxidation at high temperatures, a multilayered coating is expected to possess the functions of an aluminum reservoir, a chromium reservoir, and a diffusion barrier. Aluminized and chromized coatings applied via CVD or pack cementation are ideal for providing the aluminum and chromium reservoir. Another option for the chromium reservoir is the overlay MCrAlY coatings. The advantage of the MCrAlY coatings is the flexibility in adjusting the composition of the coatings [9]. The goal for the three layer structure is to form a $\mathrm{Cr}$-rich layer between the chromium reservoir layer and the diffusion barrier layer [10]. As this Cr-rich layer contains less than 0.3 at.\% aluminum [11], this layer is thought to be able to impede aluminum diffusion. To maintain this Cr-rich barrier layer stable at high temperatures without chromium diffusion into the substrate, the diffusion barrier layer must contain stable chromium intermetallics. Most $\mathrm{Cr}$-Si intermetallics are very stable at high temperatures; for example, the melting temperatures for $\mathrm{C}_{3} \mathrm{Si}$ and $\mathrm{CrSi}_{2}$ are $1770^{\circ} \mathrm{C}$ and $1490^{\circ} \mathrm{C}$, respectively [12]. Therefore a $\mathrm{Cr}$ and $\mathrm{Si}$-rich diffusion barrier layer deposited directly onto the substrate is necessary. Consequently a multilayered coating consists of an aluminized top layer, a NiCrAlY middle layer, and a chromizing and siliconizing barrier layer.

\subsubsection{Optimizing Coating Processes}

For each coating process development, DOE methodology is employed. The Mettech Axial III ${ }^{\mathrm{TM}}$ system is used to produce the NiCrAlY coating and the target of 
the process optimization is to achieve a coating with minimum pores, unmelted particles and oxides, and also free of cracks. A pack cementation process is employed for the aluminizing. chromizing and siliconizing coatings. The target of the process optimization is to produce coatings with expected compositions and microstructure integrity.

\subsubsection{Fabricating Multilayered Coatings}

The optimized processes are used to fabricate two types of multilayered coatings. The difference between the two multilayered coatings is that the aluminum content in the top layer of one coating is as twice as that in the top layer of another. The multilayered coatings are examined on the basis of the elemental distributions in the coatings, and the multilayered coatings satisfy the design requirements if the elemental distributions are within the desired design ranges.

\subsubsection{Investigating the Oxidation Behavior of Multilayered Coatings}

Multilayered coatings with baseline coatings are exposed at $1050^{\circ} \mathrm{C}$ and $1150^{\circ} \mathrm{C}$ for $1000 \mathrm{hr}$. Mass change and the area of oxide scales are measured after the tests. Models relating the mass change and the area of oxide scales are then developed and used to evaluate the effects of each layer and the interactions between each layer on the oxidation behavior of all coatings.

\subsection{Thesis Structure}

Chapter 1 is the introduction to this research, covering the background, significance, objectives of this research, and the methodologies used to accomplish the research objectives. 
Chapter 2 is the literature review, containing a survey of the existing coatings and the coating processes for the gas turbine hot section components with a focus on the performance of the existing multilayer coatings. The literature review has revealed that the existing coatings in the market have limited oxidation resistance and therefore there is a strong demand from the gas turbine industry for developing multilayered coatings with a diffusion barrier.

Chapter 3 provides the details of coating design and process selection. The requirements for the multilayered coatings and their individual layers are proposed, and the structure and composition of the multilayered coatings are then designed.

Chapter 4 describes the methods and procedures of optimizing the plasma spray process for NiCrAlY coatings using Mettech Axial III ${ }^{\mathrm{TM}}$ system. Two Taguchi arrays are used to optimize the plasma spray process so that the effects of the spray process parameters on coating features can be characterized. The results from the arrays are used to create regression equations to predict the required coating features. Further to the regression analysis, a process index $(P I)$ is proposed as a complex variable incorporating a number of process parameters. The regression equations employing $P I$ as the only variable are then correlated with additional experimental data.

Chapter 5 presents the details of the optimization procedure of the pack cementation process for the aluminized top layer on the $\mathrm{NiCrAlY}$ coating and a $\mathrm{Cr}-\mathrm{Si}$ coating on the IN738 substrate. The optimization of the aluminizing process is based on the experiment that is designed using a response surface methodology, in which three parameters, the aluminum content, nickel content in the pack powder and the temperature of the process, are investigated. The effects of three parameters on the 
thickness and $\mathrm{Al} / \mathrm{Ni}$ ratio of the coatings are analyzed and subsequently modeled. The process to produce the $\mathrm{Cr}-\mathrm{Si}$ coating with $25-30$ at.\% $\mathrm{Si}$ and $25-30$ at.\% $\mathrm{Cr}$ on the IN738 substrate is optimized by a Taguchi L4 array with two-levels and three factors.

Chapter 6 outlines the steps of the fabrication process for multilayered coatings. The multilayered coatings are fabricated through a combination of plasma spray process and pack cementation process. The fabrication process for the multilayered coatings is divided into three steps. The first step is to co-diffuse chromium and silicon on the IN738 substrate using pack cementation process. The second step is to deposit a NiCrAlY coating onto the $\mathrm{Cr}-\mathrm{Si}$ coating using plasma spray process. The final step is an aluminizing treatment on the NiCrAlY coating, in order to develop an aluminumrich layer. To characterize the oxidation behavior of the multilayered coatings, other traditional coatings are also produced for comparison. A two-level full factorial design will be employed to select other coatings.

Chapter 7 describes the details of the oxidation tests and presents the test results. The models developed for the mass change and the total area of oxide scales are explained.

Chapter 8 summarizes experimental and analytical results and highlights the conclusions drawn from this research. It also elaborates on the contributions of this work with regard to the oxidation resistance improvement provided by the developed coatings. The future work of this research is also recommended. 


\section{Chapter 2: Literature Review}

\subsection{Operating Conditions of the Hot Section Components in Gas Turbines}

The demand for fossil fuel power generation is expected to grow to almost $1600 \mathrm{GW}$ capacity by 2015 and to about $2000 \mathrm{GW}$ by 2020 globally [13]. The market for industrial gas turbines (IGT) continues to increase due to the attractive price of electricity generated by IGTs. In the meantime, recent efforts to use less expensive fuels in industrial gas turbines significantly impact the performance of the hot section components in gas turbines. Since these components are expensive and have finite life; their durability plays an important role in controlling the maintenance intervals, life span and the life cycle costs of a gas turbine unit. Therefore a thorough understanding of the operating conditions of the hot section components in gas turbines and exploring effective protection is very important.

For gas turbines, one of the most important operating conditions is the rotor inlet temperature (RIT). Currently, RITs can be over $1400^{\circ} \mathrm{C}$ and eventually reach 1600 $1700^{\circ} \mathrm{C}$ in the future (Figure 2.1) [14] since increasing rotor inlet temperatures can promote higher efficiency and power generation capability of gas turbine engines (Figure 2.2) [15]. A considerable increase in RIT can be achieved by a combination of the applications of cooling processes and thermal barrier coatings (TBCs) so that the maximum metal temperatures can be maintained below $1000^{\circ} \mathrm{C}$. Given the soaring RITs, however, the coatings on the hot section components, metallic bond coatings for TBC and coatings in internal passages must withstand more severe oxidation attack due to the higher temperatures. 


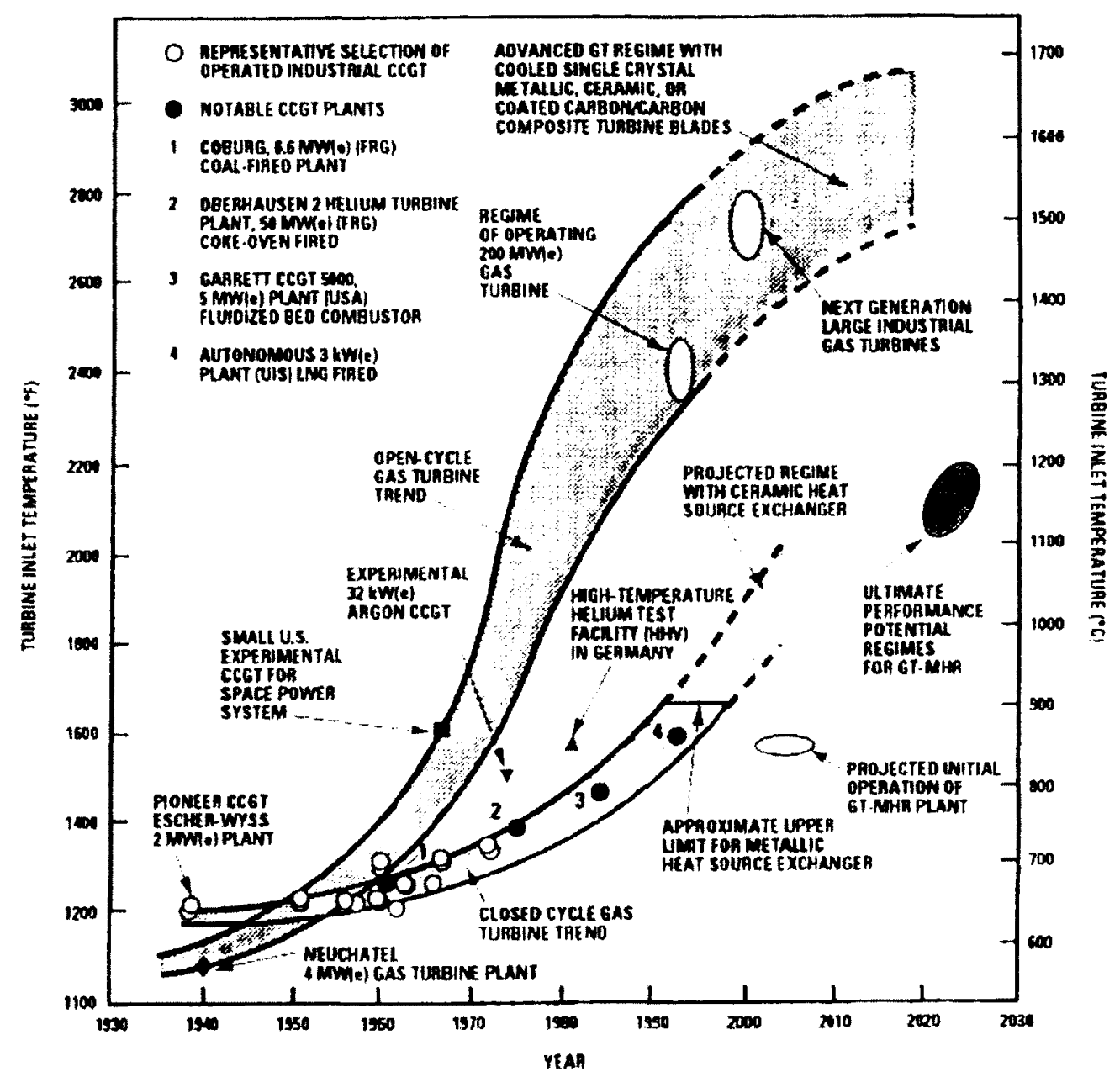

Figure 2.1 Gas turbine inlet temperature trends [14].

\subsection{Coating Degradation Mechanisms}

The degradation mechanisms of coatings are complex and affected by various factors such as coating microstructure, alloy composition, surface condition, oxygen and sulfur partial pressures, service atmosphere, and temperature. In general, most coatings fail due to high temperature oxidation and hot corrosion. Three accelerated degradation processes can be defined in the order of increasing temperature as: Type II hot corrosion, Type I hot corrosion and high temperature oxidation [16]. Hot corrosion occurs due to the reactions of chemicals that are associated with impurities in fuels, such as vanadium compounds and sulfates. During combustion these impurities can 
form compounds with a low melting point. These melted salts are highly corrosive for coatings. This research, however, focuses on the oxidation behavior of coatings under high temperatures.

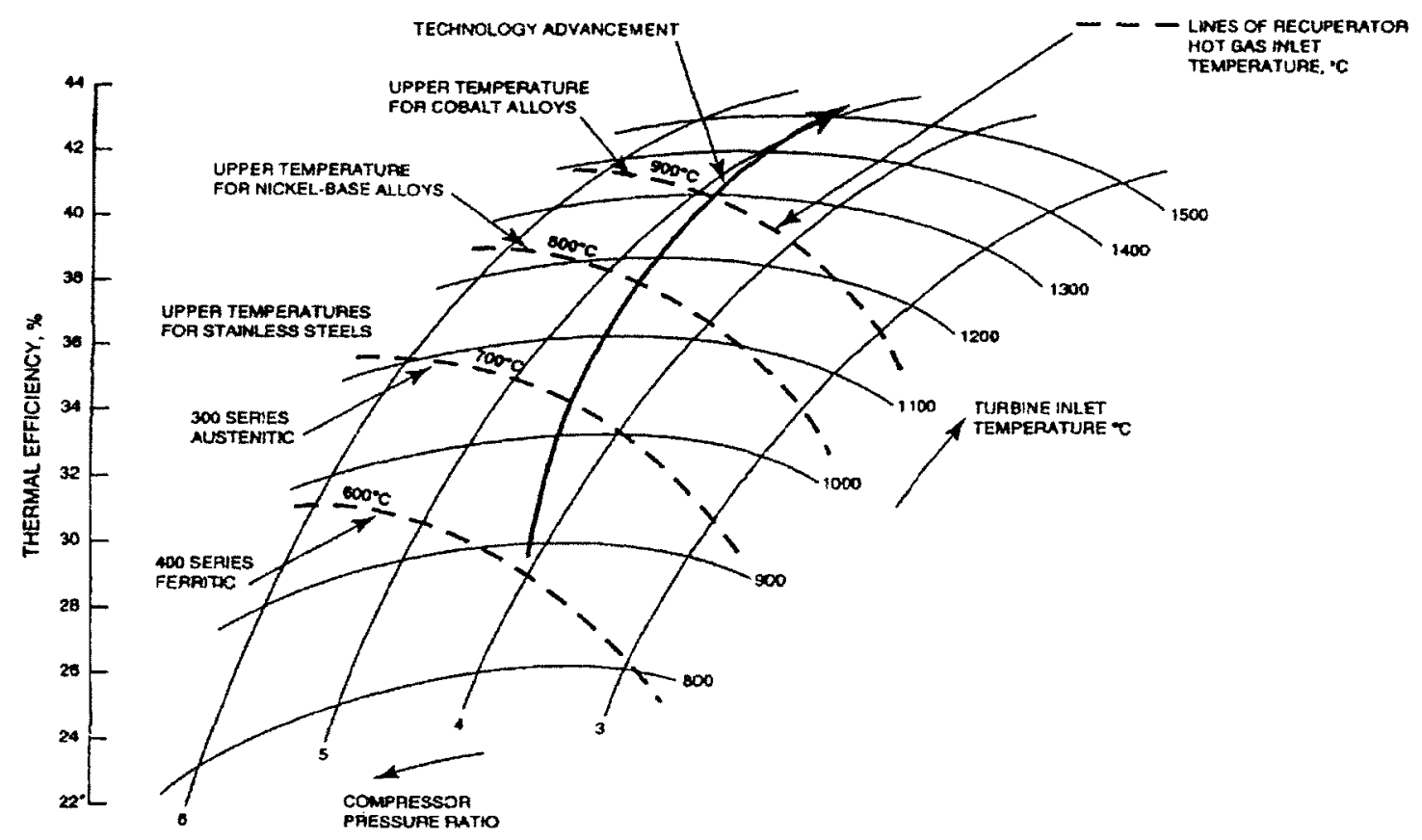

Figure 2.2 Effects of major cycle parameters on micro-turbine performance [15].

\subsubsection{Oxidation of Metals}

Most coatings for hot section components are metal-based, and the oxidation of the coatings literally is the oxidation of metallic elements. Oxidation of a metal falls into a five-step sequence [17]:

(1) adsorption of molecular oxygen onto the metal surface from the environment

(2) dissociation of molecular oxygen into atomic oxygen

(3) combination of oxygen atoms and metal atoms

(4) formation of islands of oxide and growth of the islands

(5) formation of a continuous oxide film 
The rate of oxidation depends on the rate of oxygen access to the metal atoms. There are three equations to describe the rate of metal oxidation [18]. Some metals, such as aluminum and chromium, exhibit oxide growth behavior described by the logarithmictype rate equation at low temperature $\left(<500^{\circ} \mathrm{C}\right)$. This equation is valid only for very thin oxide scales, which form rapidly upon exposure to an oxidizing environment and then grow slowly with time. At high temperatures $\left(>500^{\circ} \mathrm{C}\right)$, the growth of oxide scales is usually limited by diffusion. The growth rate is then proportional to the thickness of the oxide scales, and parabolic-type rate equations apply. Moreover the growth rate of the oxide scales is proportional to the flux of ionic species through the oxide scales. This flux is proportional to the diffusion coefficient and the oxygen gradient. The metals that exhibit the parabolic-type oxide growth behaviour in include iron, cobalt and nickel. A linear rate is observed when oxide scales undergo extensive cracking, spalling, or the oxide scales are porous.

The formation of a dense, continuous, and adherent oxide scale that allows slow diffusion represents the best means of protection for metals. At high temperatures, $\mathrm{Al}_{2} \mathrm{O}_{3}, \mathrm{Cr}_{2} \mathrm{O}_{3}$ and $\mathrm{SiO}_{2}$, are almost exclusively employed. Aluminum oxide scales, formed by selective oxidation of aluminum in alloys or in coatings, are the primary means of protection for nickel-based superalloys in gas turbines. Chromium oxide scales are used in heat-resistant alloys where sulfidation is a major concern. Silicidebased coatings are used to protect some alloys which are unable to form protective $\mathrm{Al}_{2} \mathrm{O}_{3}$ scales [19]. Consequently the coatings for hot section components usually consist of these active elements. 


\subsubsection{Oxidation of Coatings}

The formation of oxide scales of an alloy or a coating under high temperatures usually depends on the composition of the alloy or the coating, temperature and exposure time. The oxides formed at various temperatures for different elements and coatings are listed in Table 2.1 .

In the temperature range of $700-850^{\circ} \mathrm{C}, \gamma-\mathrm{Al}_{2} \mathrm{O}_{3}$ and $\mathrm{Cr}_{2} \mathrm{O}_{3}$ grow at a relatively high rate and form protective oxide scales [20]. In the temperature range of $850-1050^{\circ} \mathrm{C}, \theta-$ $\mathrm{Al}_{2} \mathrm{O}_{3}$ and $\mathrm{CrO}_{3}$ are formed. $\mathrm{CrO}_{3}$ is volatile and becomes gas at temperatures above $1100^{\circ} \mathrm{C}[21], \mathrm{SiO}_{2}$ is very stable even when the temperature exceeds $1100^{\circ} \mathrm{C}$ [19].

The temperature for a coating to form a protective oxide scale can be as high as $800^{\circ} \mathrm{C}$ because of high aluminum and chromium contents in the coating. At temperatures above $800^{\circ} \mathrm{C}$, the formation of porous $\mathrm{Ni}(\mathrm{Al}, \mathrm{Cr})_{2} \mathrm{O}_{4}$ scales leads to the spallation of the scales during cooling [22]. Therefore, a coating with high chromium content could fail due to the formation of porous $\mathrm{Ni}(\mathrm{Al}, \mathrm{Cr})_{2} \mathrm{O}_{4}$ scales or $\mathrm{CrO}_{3}$. Both diffusion coatings and overlay coatings are limited to $1100^{\circ} \mathrm{C}$ because further oxidation promotes the formation of porous $\mathrm{Ni}(\mathrm{Al}, \mathrm{Cr})_{2} \mathrm{O}_{4}$ scales, which leads to spallation of the scale during cooling.

Table 2.1 Oxides formed at various temperatures

\begin{tabular}{|c|c|c|c|c|c|}
\hline Temp, ${ }^{\circ} \mathrm{C}$ & $\mathrm{Al} \mathrm{[20]}$ & $\mathrm{Cr}[21]$ & $\mathrm{Si}[19]$ & Aluminide [23] & NiCrAlY [22] \\
\hline $700-850$ & $\gamma-\mathrm{Al}_{2} \mathrm{O}_{3}$ & $\mathrm{Cr}_{2} \mathrm{O}_{3}$ & & $\gamma-\mathrm{Al}_{2} \mathrm{O}_{3}$ & $\gamma-\mathrm{Al}_{2} \mathrm{O}_{3}, \mathrm{Cr}_{2} \mathrm{O}_{3}$ \\
\hline $850-1100$ & $\theta-\mathrm{Al}_{2} \mathrm{O}_{3}$ & $\mathrm{CrO}_{3}, \mathrm{Cr}_{2} \mathrm{O}_{3}$ & $\mathrm{SiO}_{2}$ & $\theta-\mathrm{Al}_{2} \mathrm{O}_{3}, \mathrm{NiO}$ & $\begin{array}{l}\theta-\mathrm{Al}_{2} \mathrm{O}_{3}, \mathrm{Cr}_{2} \mathrm{O}_{3} \\
\mathrm{NiO}\end{array}$ \\
\hline$>1100$ & $\alpha-\mathrm{Al}_{2} \mathrm{O}_{3}$ & $\mathrm{CrO}_{3}$ (gas) & & $\begin{array}{l}\alpha-\mathrm{Al}_{2} \mathrm{O}_{3} \\
\mathrm{NiAl}_{2} \mathrm{O}_{4}\end{array}$ & $\begin{array}{l}\alpha-\mathrm{Al}_{2} \mathrm{O}_{3}, \mathrm{NiAl}_{2} \mathrm{O}_{4}, \\
\mathrm{Cr}_{2} \mathrm{O}_{3}, \mathrm{CrO}_{3} \text { (gas) }\end{array}$ \\
\hline
\end{tabular}


In general, when exposure temperatures exceed $800^{\circ} \mathrm{C}$, the oxidation behavior of diffusion coatings and MCrAlY coatings follows a four stage process [22]:

(1) Transient oxidation. At this oxidation stage, $\mathrm{NiO}, \mathrm{Cr}_{2} \mathrm{O}_{3}$ and $\alpha-\mathrm{Al}_{2} \mathrm{O}_{3}$ form on the coating surface simultaneously. The $\alpha-\mathrm{Al}_{2} \mathrm{O}_{3}$ grains are small and equiaxed in the outer region.

(2) Steady-state oxidation. At this oxidation stage, a continuous $\alpha-\mathrm{Al}_{2} \mathrm{O}_{3}$ scale forms and reduces the diffusion rate of oxygen. Coarse and columnar $\alpha-\mathrm{Al}_{2} \mathrm{O}_{3}$ is formed in the inner region.

(3) Aluminum depletion and nickel outward diffusion. As the oxidation time is increased, aluminum depletion causes the formation of $\mathrm{Ni}(\mathrm{Al}, \mathrm{Cr})_{2} \mathrm{O}_{4}$ layer and porous $\mathrm{Ni}(\mathrm{Al}, \mathrm{Cr})_{2} \mathrm{O}_{4}$ scales spall off during cooling.

(4) Internal $\mathrm{Cr}_{2} \mathrm{O}_{3}$ oxide formation. Further depletion of aluminum causes the formation of internal $\mathrm{Cr}_{2} \mathrm{O}_{3}$, and the $\mathrm{Cr}_{2} \mathrm{O}_{3}$ evaporate (when transformed to $\mathrm{CrO}_{3}$ ) and exhausts the chromium in the coatings.

A schematic diagram presenting the four stages is illustrated in Figure 2.3, and Figure 2.4 shows the cross-sectional morphology of the corresponding oxide scales formed on the surface of Amdry 962 coating (Ni-22Cr-10Al-1Y) after oxidation testing at $1200^{\circ} \mathrm{C}$ for $50 \mathrm{hr}[24]$.

Kirkendall pores (interfacial cavity) are observed in the coating, as shown in Figure 2.4. When the supply of aluminum is exhausted as a result of both further oxidation at the coating surface and diffusion into the substrate, extensive internal oxidation of both the substrate and surface scale occurs due to inward diffusion of oxygen and outward diffusion of metallic elements such as $\mathrm{Ni}$ and $\mathrm{Ti}$. The alumina scales break down and 
growth of nickel-rich oxides is enhanced. The cracks initiate within the nickel-rich oxide nodular region at the coating surface, eventually propagate through the coating into the substrate and cause the spallation of the oxide scales [24].

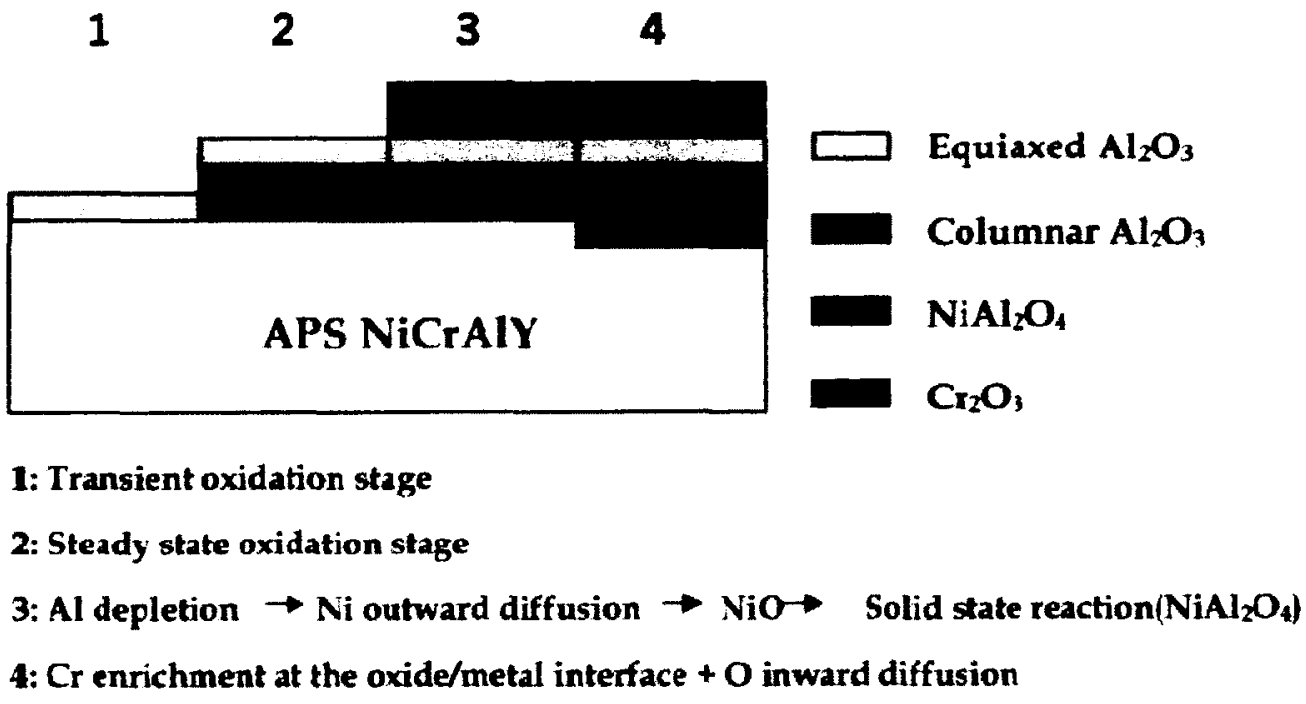

Figure 2.3 Schematic representation of the oxidation stages of NiCrAlY coatings [24].

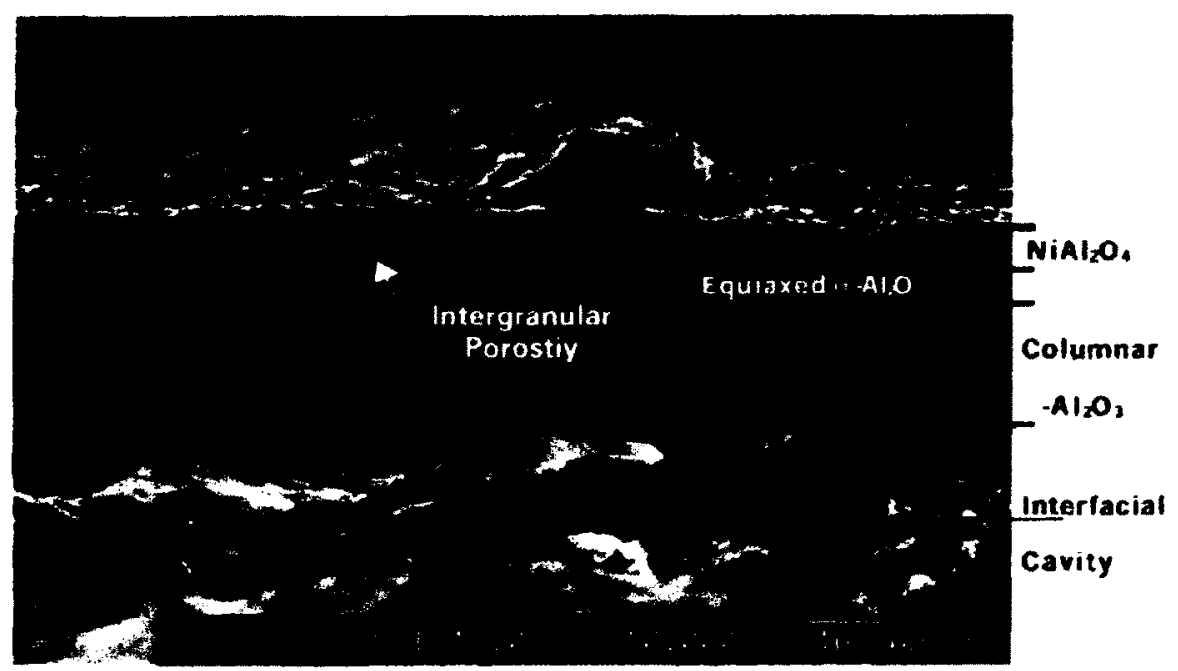

Figure 2.4 Cross-sectional morphology of an Amdry 962 coating after oxidized at $1200^{\circ} \mathrm{C}$ for $50 \mathrm{hr}[24]$. 


\subsubsection{Requirements for Oxidation Resistant Coatings}

To prevent the oxide scales on coatings from spalling, some basic requirements for coating composition must be taken into consideration [25]:

(1) The coating should form thermodynamically stable protective phases on its surface by reacting with the operating environment.

(2) These protective phases should grow slowly in order to keep coating reservoir depletion rates at a low level.

(3) Diffusion between the coating and the substrate should not occur or proceed as slowly as possible.

(4) The coating should contain elements $\mathrm{Al}, \mathrm{Cr}$, and $\mathrm{Si}$, or maybe $\mathrm{Ti}$. For $\mathrm{Al}$ and $\mathrm{Cr}$, the optimal contents to achieve the best oxidation resistance at corresponding temperatures are given in Table 2.2 [26].

Table 2.2 Optimal aluminum and chromium contents for high-temperature oxidation resistance [26]

\begin{tabular}{rcc}
\hline Temp., ${ }^{\circ} \mathrm{C}$ & $\mathrm{Cr}, \mathrm{wt} . \%$ & $\mathrm{Al}, \mathrm{wt} . \%$ \\
\hline 950 & $16-24$ & $13-18$ \\
1100 & $25-30$ & $14-16$ \\
\hline
\end{tabular}

(5) Highly pure alumina scale offers the best protection under high temperature oxidation. Sustainable aluminum content in the coating should be a major driving force for the development of coating technology [10].

(6) There should be a diffusion barrier between the coating and the substrate to block inward diffusion of aluminum into the substrate. The diffusion barrier consists of slow diffusion elements such as $\mathrm{Cr}, \mathrm{Si}$ and $\operatorname{Re}[10]$. 
(7) The coefficients of thermal expansion of the coating and the substrate should be as close as possible so that thermal cyclic stresses can be minimized in the system during the temperature changes [26].

\subsection{Coating Processes}

In the development of superalloys for the hot section components in gas turbines, optimization of their high-temperature mechanical properties has been progressed toward reducing chromium content (to avoid TCP phase formation) with the increased refractory element additions, such as $\mathrm{Mo}, \mathrm{Re}$ and $\mathrm{W}$. Therefore most of the superalloy compositions contain a lower chromium content (and limited Al) with respect to providing adequate oxidation resistance through the formation of a slow growing and stable oxide scale. To compensate for this limited oxidation resistance, coatings enriched with aluminum, and perhaps chromium, are applied to the alloys. The types of coatings currently used on the hot section components of turbine engines fall into three basic groups $[27,28]$ :

- diffusion coatings

- overlay coatings

- thermal barrier coatings

Diffusion coatings and overlay coatings are of major concern in this study and are discussed in the following sections since these two processes are used to produce coatings in this research. 


\subsubsection{Diffusion Coatings}

\subsubsection{Fundamentals of Diffusion Coating Process}

The techniques for forming diffusion coatings can be true chemical vapor deposition, slurry or pack cementation process [27]:

(1) Chemical vapor deposition (CVD). The reactions to produce chemical vapors occur in a gas generator placed remotely from the deposition zone; the reactive species are then transported in a gaseous form into the process chamber and diffuse into the substrate.

(2) Slurry process. Slurry process is comprised of dipping the substrate into a slurry onto and drying the coated substrate followed by heating (sintering) the coating/substrate component in a furnace. The slurry consists of pure aluminum, silicon, magnesium, inert filler and resin. Usually Si-modified aluminide coatings are fabricated by a slurry process.

(3) Pack cementation process. Pack cementation process is also essentially a chemical vapor deposition process. The components to be coated are placed in a sealed or semi-sealed container (retort) together with a powder mixture that consists of metal elements to be deposited, halide activators and inert fillers. The halide activators are usually added in small quantities (1-6 wt.\%) [29]. The sealed container is then heated under a protective atmosphere of argon to a temperature between $700^{\circ} \mathrm{C}$ and $1150^{\circ} \mathrm{C}$, and held for a specified duration. At the elevated temperatures, the halide activators (such as $\mathrm{NH}_{4} \mathrm{Cl}$ or $\mathrm{NH}_{4} \mathrm{~F}$ ) react with the metal elements in the powder mixture and form a series of metal halide vapor species such as $\mathrm{AlCl}, \mathrm{AlCl}_{2}, \mathrm{AlCl}_{3}, \mathrm{Al}_{2} \mathrm{Cl}_{6}$, and $\mathrm{CrAl}_{2}$ with a characteristic partial pressure distribution that is determined by their 
thermodynamic stability in a particular powder pack and atmosphere [29]. The coating is formed via reactions of metal halide vapors on the substrate surface and subsequent solid state diffusion between the diffusing elements and the substrate. Pack cementation process will be discussed in more detail in section 2.3.1.2.

In all these processes, coatings are formed at elevated temperatures via diffusion transport of one or more elements from the gas phase to the substrate surface, and then the element(s) are deposited and consequently interact with the substrate to form a coating. Diffusion coatings have better adherence to the substrate than that by other coating processes such as thermal spray and PVD, because diffusion coatings are usually regarded as a part of the substrate. Therefore diffusion coatings can be implemented as single coatings as well as base or bond coats in multilayered coating systems.

\subsubsection{Chemical Reactions in Pack Cementation Processes}

A pack cementation process, based on the metallic species in the powder mixture, is also called aluminizing process, chromizing process and siliconizing process. The reactions for these processes are quite similar and summarized in Table 2.3 [17].

Table 2.3 Reactions for aluminizing, chromizing and siliconizing process

\begin{tabular}{ll}
\hline Process & Reactions \\
\hline \multirow{5}{*}{ Aluminizing } & $\mathrm{NH}_{4} \mathrm{Cl}=\mathrm{NH}_{3}+\mathrm{HCl}$ \\
& $2 \mathrm{Al}+6 \mathrm{HCl}=2 \mathrm{AlCl}_{3}+3 \mathrm{H}_{2}$ \\
& $\mathrm{AlCl} l_{3}+2 \mathrm{Al}=3 \mathrm{AlCl}$ \\
& $3 \mathrm{AlCl}+2 \mathrm{Ni}=2 \mathrm{NiAl}+\mathrm{AlCl}_{3}$ \\
\hline \multirow{3}{*}{ Chromizing } & $\mathrm{NH}_{4} \mathrm{Cl}=\mathrm{NH}_{3}+\mathrm{HCl}$ \\
& $\mathrm{Cr}+2 \mathrm{HCl}=\mathrm{CrCl}_{2}+\mathrm{H}_{2}$ \\
& $2 \mathrm{CrCl}_{2}+\mathrm{H}_{2}=2 \mathrm{HCl}+2 \mathrm{Cr}$ \\
\hline \multirow{3}{*}{ Siliconizing } & $\mathrm{NH}_{4} \mathrm{Cl}=\mathrm{NH}_{3}+\mathrm{HCl}$ \\
& $\mathrm{Si}+2 \mathrm{HCl}=\mathrm{SiCl}_{2}+\mathrm{H}_{2}$ \\
& $\mathrm{SiCl}+\mathrm{H}_{2}=2 \mathrm{HCl}+\mathrm{Si}$ \\
\hline
\end{tabular}




\subsubsection{Pack Cementation Processes}

Pack cementation processes can be classified into contact pack, out-of-pack, and above-the-pack process. For the contact pack process, components are loaded into an alumina crucible and directly embedded in the powder mixture for the contact arrangement (Figure 2.5a) [30]. For the out-of-pack process, components are separated from the pack powder by either porous alumina paper or foam disks (Figure 2.5b). For the above-the-pack process, components are placed or hung above a powder tray that contains the powder mixture (Figure 2.6) [31]. The advantages of the out-of-pack and the above-the-pack process are achieving uniform coating thickness and the ability to coat the internal passages. The disadvantage of the above-the-pack process is that the partial pressure of some metal halide vapor species is so low that the metal contents in resulted coating are insufficient to protect the components. Of these processes, the contact pack process is the most versatile and cost effective process and is thus used in this research.

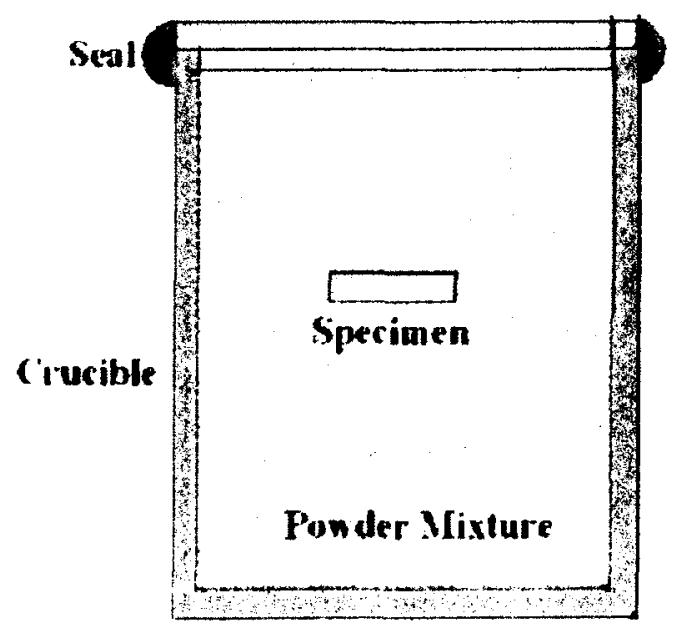

a) contact arrangement

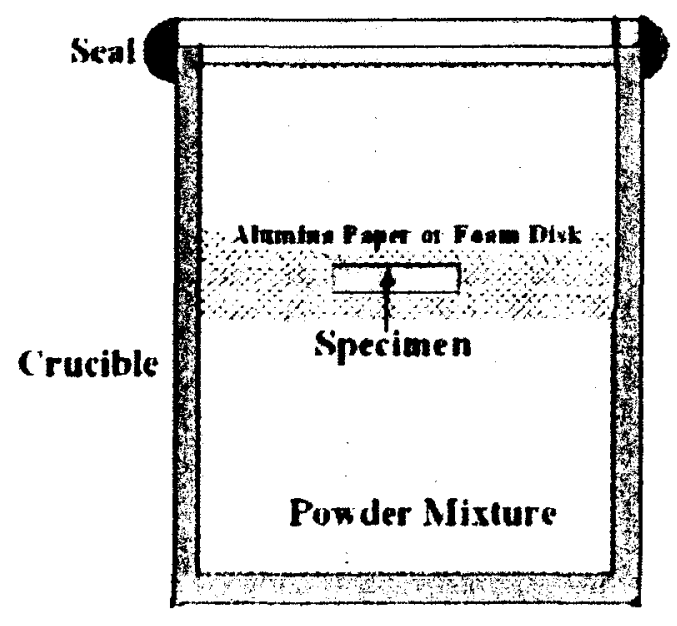

b) out-of-pack arrangement

Figure 2.5 Contact pack and out-of-pack process schematic diagrams [30]. 


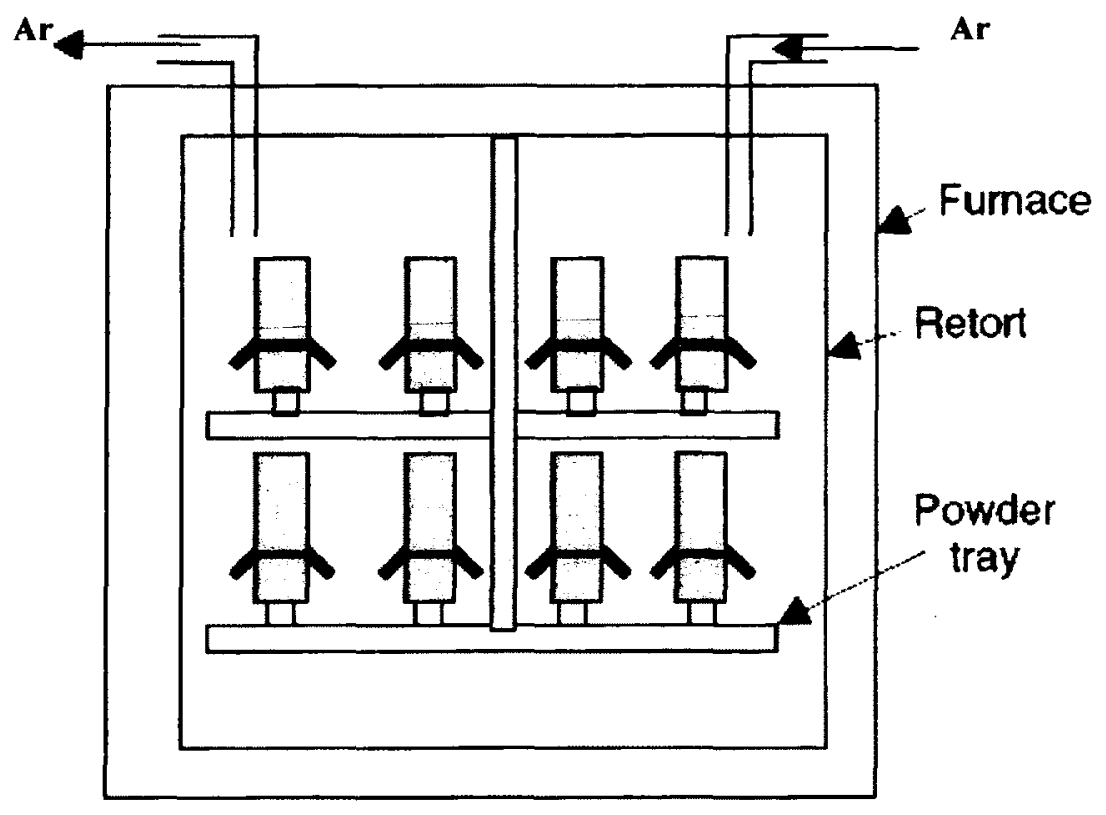

Figure 2.6 Schematic diagram of an above-the-pack device [17].

\subsubsection{Parameters of Pack Cementation Processes}

Atmosphere in retort, the composition of the pack, and process temperature and duration are of major concern for developing a successful pack cementation process. The examples of the parameters for aluminizing chrominizing and siliconizing processes are given in Table $2.4[32,33,34]$. The constituents of a pack cementation mixture include metallic powder $(\mathrm{Al}, \mathrm{Cr}, \mathrm{Si}$, and $\mathrm{Ni})$, halide activator $\left(\mathrm{NH}_{4} \mathrm{Cl}\right.$ or $\left.\mathrm{MgF}_{2}\right)$ and inert filler $\left(\mathrm{Al}_{2} \mathrm{O}_{3}\right.$ or $\left.\mathrm{SiO}_{2}\right)$.

\section{(1) Aluminzing process}

The most important parameters for aluminizing processes are the aluminum activity in the aluminum source (metallic powder or master alloy) and the temperature of the process. In a high-activity pack aluminizing process, the aluminum concentration is often greater than 60 at.\% in the aluminum source and the process results in aluminum 
inward-diffusion into the substrate surface where the formed aluminide layer contains several other alloying elements from the substrate. On the other hand, when the aluminum concentration is less than 60 at.\% in the source, it is classified as a lowactivity pack aluminizing process, where a nickel outward-diffusion occurs predominantly and the aluminide layer formed contains less amounts of alloying elements from the substrate [33].

Table 2.4 Pack components, process parameters, pack cementation processes, and phases in coatings $[32,33,34]$

\begin{tabular}{|c|c|c|c|}
\hline Process & $\begin{array}{l}\text { Pack components } \\
\text { (wt.\%) }\end{array}$ & $\begin{array}{l}\text { Temperature } \\
\text { and time }\end{array}$ & Phases in coating \\
\hline $\begin{array}{l}\text { Low-temperature high- } \\
\text { activity (LTHA) }\end{array}$ & $\begin{array}{l}\mathrm{NiAl}(15 \%), \mathrm{NH}_{4} \mathrm{Cl} \\
(2 \%), \mathrm{Al}_{2} \mathrm{O}_{3}(83 \%)\end{array}$ & $\begin{array}{l}800^{\circ} \mathrm{C}, 2 \mathrm{hr} \\
1100^{\circ} \mathrm{C}, 4 \mathrm{hr}\end{array}$ & $\begin{array}{l}\mathrm{Ni}_{2} \mathrm{Al}_{3} \text { and } \mathrm{NiAl} \\
\mathrm{NiAl}\end{array}$ \\
\hline $\begin{array}{l}\text { High-temperature low- } \\
\text { activity (HTLA) }\end{array}$ & $\begin{array}{l}\mathrm{NiAl}(15 \%), \mathrm{NH}_{4} \mathrm{Cl} \\
(2 \%), \mathrm{Al}_{2} \mathrm{O}_{3}(83 \%)\end{array}$ & $\begin{array}{l}1100^{\circ} \mathrm{C} \\
3-4 \mathrm{hr}\end{array}$ & $\mathrm{NiAl}$ \\
\hline $\begin{array}{l}\text { High-temperature high- } \\
\text { activity (HTHA) }\end{array}$ & $\begin{array}{l}\mathrm{NiAl}(15 \%), \mathrm{NH}_{4} \mathrm{Cl} \\
\left.(2 \%), \mathrm{Al}_{2} \mathrm{O}_{3}(83 \%)\right)\end{array}$ & $1034^{\circ} \mathrm{C}, 4 \mathrm{hr}$ & $\begin{array}{l}\mathrm{Ni}_{2} \mathrm{Al}_{3} \text { and } \mathrm{NiAl} \\
\text { with precipitates }\end{array}$ \\
\hline Aluminizing & $\begin{array}{l}\mathrm{Al}(20 \%), \mathrm{Ni}(10 \%) \\
\mathrm{NH}_{4} \mathrm{Cl}(1.5 \%), \mathrm{Al}_{2} \mathrm{O}_{3} \\
(68.5 \%)\end{array}$ & $900^{\circ} \mathrm{C}, 4 \mathrm{hr}$ & $\mathrm{Ni}_{2} \mathrm{Al}_{3}$ and $\mathrm{NiAl}$ \\
\hline Chromizing & $\begin{array}{l}\mathrm{Cr}(25 \%), \mathrm{NH}_{4} \mathrm{Cl}(4 \%), \\
\mathrm{Al}_{2} \mathrm{O}_{3}(71 \%)\end{array}$ & $1150^{\circ} \mathrm{C}, 1 \mathrm{hr}$ & $\begin{array}{l}\text { Cr-Ni enrichment } \\
\text { solid solution }\end{array}$ \\
\hline \multirow[t]{2}{*}{ Siliconizing } & $\begin{array}{l}\mathrm{Si}(10 \%), \mathrm{Ni}(6 \%) \\
\mathrm{MgF}_{2}(1 \%), \mathrm{Al}_{2} \mathrm{O}_{3} \\
(80 \%)\end{array}$ & $1000^{\circ} \mathrm{C}, 1 \mathrm{hr}$ & $\mathrm{Ni}_{2} \mathrm{Si}$ and $\mathrm{Ni}_{3} \mathrm{Si}$ \\
\hline & $\begin{array}{l}\mathrm{Si}(35 \%), \mathrm{NH}_{4} \mathrm{Cl}(5 \%) \\
\mathrm{Al}_{2} \mathrm{O}_{3}(60 \%)\end{array}$ & $1100^{\circ} \mathrm{C}, 10 \mathrm{hr}$ & $\mathrm{Ni}_{2} \mathrm{Si}$ and $\mathrm{Ni}_{3} \mathrm{Si}$ \\
\hline
\end{tabular}

In addition to the aluminum activity, the process temperature plays a significant role in the formation of the aluminide coating. An aluminizing process can be carried out at either a low temperature $\left(700\right.$ to $\left.850^{\circ} \mathrm{C}\right)$ or a high temperature $\left(900\right.$ to $\left.1100^{\circ} \mathrm{C}\right)$. The temperature determines the diffusion rates of aluminum, nickel and other elements, and has strong influence on the composition and thickness of the alumina layer. Different 
combination of the aluminum activity and the process temperature leads to three common aluminizing processes: low-temperature high-activity (LTHA), hightemperature low-activity (HTLA), and high-temperature high-activity (HTHA).

1) Low-temperature high-activity (LTHA)

Typically, the low-temperature high-activity process is a two-step process, which is carried out at temperatures in a range of $700^{\circ} \mathrm{C}$ to $850^{\circ} \mathrm{C}$, followed by a diffusion treatment above $1000^{\circ} \mathrm{C}$ to achieve a $\mathrm{NiAl}$ structure. In the low-temperature highactivity (LTHA) process, aluminum inward-diffusion dominates the growth of the aluminide coating and $\mathrm{a} \mathrm{Ni}_{2} \mathrm{Al}_{3}$ phase is formed in the coating (the ratio of the diffusion coefficients for aluminum and nickel $\left(\mathrm{D}_{\mathrm{Al}} / \mathrm{D}_{\mathrm{Ni}}\right.$ is about 10 in an aluminum-rich $\mathrm{Ni}_{2} \mathrm{Al}_{3} / \mathrm{NiAl}$ phase structure). In the LTHA process, aluminum is the leading diffusing species [9] and a subsequent heat treatment is applied to convert the aluminum-rich $\mathrm{Ni}_{2} \mathrm{Al}_{3}$ phase to a $\mathrm{NiAl}$ phase. Accordingly the coating formed using the LTHA process is composed of an outer layer of an aluminum-rich phase, which is typically NiAl or a mixture of $\mathrm{Ni}_{2} \mathrm{Al}_{3}$ and $\mathrm{NiAl}$, and an inner diffusion layer formed on the substrate side.

\section{2) High-temperature high-activity (HTHA)}

The high-temperature high-activity (HTHA) process is a one step process carried out at a temperature above $1000^{\circ} \mathrm{C}$ for a predetermined duration to produce a $\mathrm{NiAl}$ coating layer [33]. In the high-temperature high-activity (HTHA) process, the coating growth takes place by aluminum inward-diffusion initially, followed by an intermediate stage where the growth involves both aluminum inward-diffusion and nickel outwarddiffusion. In the final stage, nickel outward-diffusion dominates the coating formation process. Thus, a typical coating produced by the HTHA process consists of three layers: 
an outer layer of $\mathrm{Ni}_{2} \mathrm{Al}_{3}$ or a mixture of $\mathrm{Ni}_{2} \mathrm{Al}_{3}$ and $\mathrm{NiAl}$, an intermediate $\mathrm{NiAl}$ layer, and a diffusion layer adjacent to the substrate [33]. A subsequent diffusion heat treatment can convert the $\mathrm{Ni}_{2} \mathrm{Al}_{3}$ phase to a $\mathrm{NiAl}$ phase if $\mathrm{Ni}_{2} \mathrm{Al}_{3}$ phase dominates the coating.

3) High-temperature low-activity (HTLA)

Similarly the high-temperature low-activity (HTLA) process is also a one step carried out at a temperature above $1000^{\circ} \mathrm{C}$. In HTLA process, nickel outward-diffusion dominates the growth of the coating due to the higher ratio ( 3 to 3.5 ) of the diffusion coefficients for nickel and aluminum $\left(\mathrm{D}_{\mathrm{Ni}} / \mathrm{D}_{\mathrm{Al}}\right)$ at temperatures above $1000^{\circ} \mathrm{C}$ [35]. A nickel-rich $\beta$-NiAl phase is formed in this process. Therefore a typical coating produced by the HTLA process consists of two layers: an outer NiAl layer and an inner diffusion layer.

An important difference between the outward growth and the inward growth of coatings is that there will be less of the slowly diffusing elements (W, Mo and Ta) in the coating in the former case. Therefore the outward growing coating provides better resistance to the spallation of the oxide scales due to a high purity of the alumina scale formed.

The aluminum pickup by the substrate is very fast during early stages of aluminizing and diminishes with time. Most of the aluminum is picked up by the specimen during the first hour of aluminizing [33].

(2) Chromizing process

Simple chromizing process can be identified as chromium inward-diffusion. For nickel based superalloys, chromizing is used to produce $\mathrm{Ni}-\mathrm{Cr}$ solid solution layers, 
usually containing $20-25 \mathrm{wt} . \% \mathrm{Cr}$. However in some instances the concentration of chromium at the surface can reach up to $35 \mathrm{wt} \%$ for a detrimental $\alpha-\mathrm{Cr}$ to form. This problem can be avoided by utilizing the above-the-pack process, in which the chromium is transported to the substrate as a vapor phase from non-contact source. The pack mixture usually contains $30-60 \mathrm{wt} . \%$ of $\mathrm{Cr}$ powder, $40-60 \mathrm{wt.} \%$ of refractory powder (kaolin, alumina, or magnesia), and 1-3 wt.\% ammonium chloride as activator [36]. The temperature for chromizing ranges from 1000 to $1200^{\circ} \mathrm{C}$ and the duration is typically 1 to $4 \mathrm{hr}$. Increasing temperature will enhance chromium diffusion and the temperature should be controlled to avoid the formation of detrimental $\alpha$-Cr phase. As reported in literature [37], both the total chromium uptake and the chromium supplied by the reduction reaction were almost linear with time for a short period but became parabolic as the treatment continued, similar to the aluminizing process.

\section{(3) Siliconizing process}

Simple siliconizing process can be identified as silicon inward-diffusion or nickel outward-diffusion [38]. When silicon is deposited on nickel, $\mathrm{Ni}_{2} \mathrm{Si}$ is the first phase to form, followed by $\mathrm{Ni}_{5} \mathrm{Si}_{2}$ and $\mathrm{Ni}_{3} \mathrm{Si}[32,34]$. It is also known that nickel is distributed uniformly in the substrate and the coating layer, while a sharp change in silicon concentration is observed from the coating to substrate interface. Siliconized coatings contain voids in the interface, which deteriorate the bonding between the substrate and the coating. The process temperature will influence the nickel and silicon concentrations and microstructure. The pack mixture usually contains $10-40 \mathrm{wt} . \% \mathrm{Si}$ powder, 50-80 wt.\% alumina, and 3-10 wt.\% ammonium chloride. The temperature for 
siliconizing process ranges from $1000^{\circ} \mathrm{C}$ to $1200^{\circ} \mathrm{C}$ [32] and duration is between 1 to 4 hr.

The temperature range and the process duration for both chromizing process and siliconizing process are similar $\left(1000^{\circ} \mathrm{C}\right.$ to $1200^{\circ} \mathrm{C}$ and 1 to $\left.4 \mathrm{hr}\right)$. Therefore a $\mathrm{Cr}$-Si codeposition process is possible to produce a coating with high chromium and silicon contents at the same time.

\subsubsection{Co-Depositions Processes}

Applications of monolithic aluminized, chromized or siliconized coatings are often limited in their mechanical property and oxidation resistance. Therefore co-deposition processes have been developed in order to obtain combined performance of coatings. Comparisons of the co-diffused coating with a standard commercial aluminized coating reveal many beneficial effects of the two element or multiple element co-diffusion coatings [39]. Typical co-deposition processes are to form chromium or silicon modified aluminide, where the diffusion of aluminum is combined with chromium or silicon by incorporating appropriate amount of metal halides into the aluminizing atmosphere or $\mathrm{Cr} / \mathrm{Si}$ powder into the pack. Several pack compositions and process parameters for co-deposition are provided Table 2.5.

(1) $\mathrm{Al}-\mathrm{Cr}$ co-deposition process

The Al-Cr co-deposition process can be either high-temperature low-activity (HTLA) or low-temperature high-activity (LTHA) or single step high-temperature high-activity (HTHA) [40]. The primary phases in the coating produced by a codeposition process are similar to phases produced by the corresponding aluminizing 
process except that there are other precipitates in the coating or elements in the solid solution of the coating.

Table 2.5 Pack compositions and process parameters for co-deposition processes

\begin{tabular}{|c|c|c|c|}
\hline Process & $\begin{array}{l}\text { Pack components } \\
\text { (wt.\%) }\end{array}$ & Temp. and time & Phase \\
\hline Al-Cr co-deposition [39] & $\begin{array}{l}\mathrm{Al} / \mathrm{Cr} \text { master alloys } \\
\mathrm{NH}_{4} \mathrm{Cl}, \mathrm{CrCl}_{3}, \mathrm{AlCl}_{3} \text {, } \\
\mathrm{Al}_{2} \mathrm{O}_{3}\end{array}$ & $\begin{array}{l}1000-1150^{\circ} \mathrm{C}, \\
4-6 \mathrm{hr}\end{array}$ & $\begin{array}{l}\mathrm{Ni}_{2} \mathrm{Al}_{3} \\
\mathrm{NiAl}\end{array}$ \\
\hline $\begin{array}{l}\text { Al-Cr-Hf co-deposition } \\
{[40]}\end{array}$ & $\begin{array}{l}\mathrm{Al} / \mathrm{Cr} \text { master alloys, } \\
\mathrm{Hf} / \mathrm{HfO}_{2}, \mathrm{NH}_{4} \mathrm{Cl}, \\
\mathrm{CrCl}_{3}, \mathrm{AlCl}_{3}, \mathrm{Al}_{2} \mathrm{O}_{3}\end{array}$ & $\begin{array}{l}1000-1150^{\circ} \mathrm{C}, \\
4-6 \mathrm{hr}\end{array}$ & $\begin{array}{l}\mathrm{Ni}_{2} \mathrm{Al}_{3}, \mathrm{NiAl}, \\
\mathrm{Al}_{3} \mathrm{Hf}, \mathrm{Al}{ }_{3} \mathrm{Hf} \\
\text { and AlHf }\end{array}$ \\
\hline Al-Si co-deposition [41] & $\begin{array}{l}\mathrm{Al}, \mathrm{Si} \text { powder, } \\
\mathrm{NH}_{4} \mathrm{Cl}, \mathrm{Al}_{2} \mathrm{O}_{3}\end{array}$ & $1000^{\circ} \mathrm{C}, 4 \mathrm{hr}$ & $\begin{array}{l}\mathrm{Ni}_{2} \mathrm{Al}_{3}, \mathrm{NiAl}, \\
\mathrm{Ni}_{2} \mathrm{Si}, \mathrm{Ni}_{3} \mathrm{Si}\end{array}$ \\
\hline Cr-Si co-deposition [42] & $\begin{array}{l}\mathrm{Cr} / \mathrm{Si} \text { master alloys, } \\
\mathrm{NH}_{4} \mathrm{Cl}, \mathrm{CrCl}_{2}, \mathrm{Al}_{2} \mathrm{O}_{3}\end{array}$ & $\begin{array}{l}1050^{\circ} \mathrm{C}, \\
6 \mathrm{hr}\end{array}$ & $\begin{array}{l}\mathrm{Cr}_{2} \mathrm{Si}_{3} \\
\mathrm{Cr}_{3} \mathrm{Ni}_{2} \mathrm{Si}\end{array}$ \\
\hline
\end{tabular}

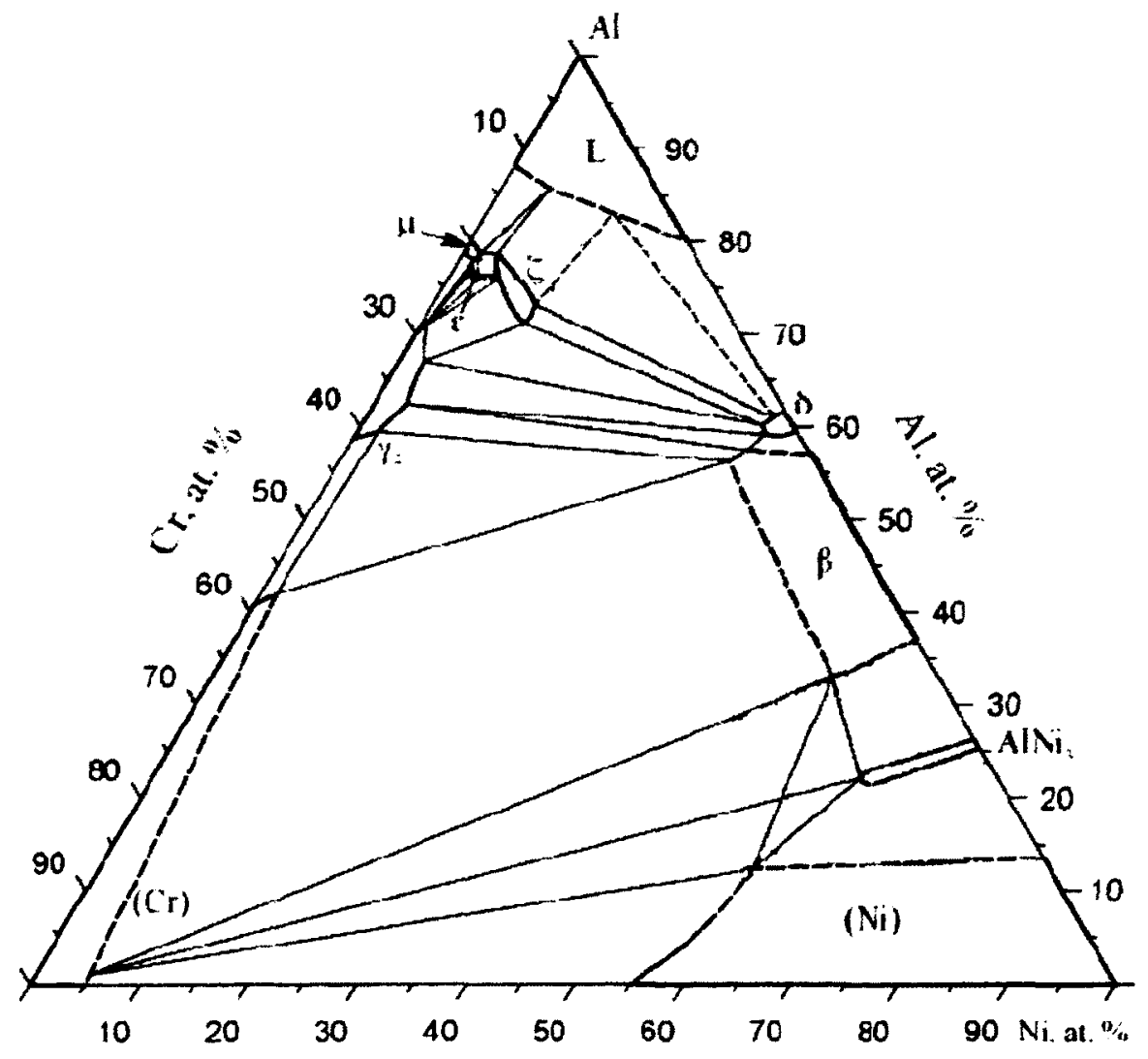

Figure 2.7 Al-Ni-Cr phase diagram at $1000^{\circ} \mathrm{C}$ [43]. 
The chromium modified aluminide can also be produced by stepwise aluminizing and chromizing. However the second step chromizing may significantly reduce aluminum content in the outer layer due to the formation of volatile aluminum chloride during chromizing. Consequently chromium content in the outer layer can reach as high as 70 at.\%, leading to $\alpha-\mathrm{Cr}$ formation [32].

A two-step process with first chromizing and then aluminizing has been employed to create a chromium diffusion barrier to prevent aluminum from diffusing into the substrate [44]. When aluminum is deposited on chromium, chromium solid solution is the first phase to form, followed by $\eta\left(\mathrm{Cr}_{2} \mathrm{Al}\right)$ and $\zeta\left(\mathrm{Cr}_{5} \mathrm{Al}_{8}\right)$ [45]. The $\eta$ phase is stable at a temperature below $910^{\circ} \mathrm{C}$ and the $\zeta$ phase below $1350^{\circ} \mathrm{C}$. Both of them can retard further aluminum diffusion when the aluminum content reaches the point where $\eta$ $\left(\mathrm{Cr}_{2} \mathrm{Al}\right)$ and $\zeta\left(\mathrm{Cr}_{5} \mathrm{Al}_{8}\right)$ phases form.

\section{(2) Al-Si co-deposition process}

Al-Si co-deposition process generally yields low silicon contents due to high activity of aluminum present in the pack mixture. One example given in literature [46] showed that the maximum silicon content of about 1 at.\% was obtained with a pack mixture of $90 \mathrm{wt} . \% \mathrm{Si}$ and $10 \mathrm{wt} . \% \mathrm{Al}$. Employing $95 \mathrm{wt} . \% \mathrm{Si}$ in the pack could lead to a much higher concentration of about $50 \mathrm{wt} \%$ silicon in the top layer [46]. The silicon modified aluminide coatings are comprised of nickel aluminide phases in the coating and fine nickel silicide precipitates in the outer zone.

A two-step process with first aluminizing and then siliconizing was also adopted to produce silicon-containing coatings. However this process may reduce the aluminum content of the outer layer significantly since the formation of volatile aluminum 
chloride during siliconizing leads to the replacement of nickel aluminides by nickel silicides. Nickel silicides are generally not considered effective as protective coatings for the intended application due to their brittleness. Therefore single-step co-deposition process with a well-adjusted pack mixture is a more practical and cost-effective process [46].

Of the several diffusion coatings, silicon-containing diffusion aluminides such as Sermaloy J and Sermaloy 1515 [47] performed well under either type I or type II hot corrosion conditions. This is attributed to the formation of a continuous oxide layer with a low defect concentration on the coating surface. However, the silicon content must be greater than $10 \mathrm{wt} . \%$ in order to enhance the hot corrosion resistance of nickel based alloys $[36,48]$.

\section{(3) $\mathrm{Cr}$-Si co-deposition process}

A number of studies of the $\mathrm{Cr}$-Si co-deposition process on Fe-based alloys were reported [42] and the process parameters are summarized in Table 2.5 [49]. It seems that the chromium content can easily reach around 50 at.\% [50], whereas silicon content cannot reach beyond 10 at.\% [49]. No report was found for $\mathrm{Cr}$-Si co-deposition process on Ni-based alloys.

\subsubsection{Heat Treatments of Diffusion Coatings}

Heat treatments can increase the coating thickness for all diffusion coatings. The concentrations of elements become uniform after certain heat treatments. The temperature for heat treatment of diffusion coatings ranges from $950-1150^{\circ} \mathrm{C}$ and the duration is $2-8 \mathrm{hr}$. For certain coatings, heat treatments are imperative in order to obtain optimal coating performance. Of the various diffusion coatings, heat treatments are 
most important for aluminide coatings or modified aluminide coatings because heat treatments can promote the transformation of $\mathrm{Ni}_{2} \mathrm{Al}_{3}$ into $\mathrm{NiAl}$ phase which offers superior oxidation resistance [51].

Heat treatment media can also be a factor that influences coating properties. It has been demonstrated that the coatings treated in an argon atmosphere are less susceptible to cracking than the coatings treated in air [51].

\subsubsection{Overlay Coatings}

Overlay coatings for the hot section components in gas turbine engines are usually referred to MCrAlY coatings, which can be fabricated using thermal spray processes, including air plasma spray (APS), high-velocity-oxy-fuel (HVOF) thermal spray, vacuum plasma spraying, low-pressure plasma spraying (LPPS), and cold spray (CP). These processes offer a significant advantage of flexibility in the composition of the coatings that can be deposited. However the disadvantage of these overlay processes is that they are impractical to coat internal diameter or deep groove.

Generally speaking, all these thermal spray processes can be used to produce overlay coatings; but only air plasma spray process (APS) is pertinent to this research and will be further discussed in detail.

\subsubsection{Air Plasma Spray Process}

Air plasma spray process is a coating deposition process in which molten, semimolten or solid particles are deposited onto a substrate in air, with or without the protection of Ar. This process uses ionized gas to accelerate the particles and to heat them up at the same time. The temperature and velocity of the particles influence several key coating properties such as coating roughness, coating thickness, porosity 
and the formation of cracks. Plasma spray process has the advantage of being able to deposit any material in the form of powder at a rate of $20-50 \mu \mathrm{m} / \mathrm{min}$ [17].

A comparison between the air plasma spray process and the High Velocity Oxygen Fuel (HVOF) spray process can highlight an advantage of the plasma spray process (Figure 2.8). For HVOF spray process, the fuel (mainly acetylene) is burnt with oxygen under a high pressure and generates a high-velocity exhaust jet; and the particles reach the surface of the component through the exhaust jet. The main advantages of this process are a shorter residence time for the particles in flame and a higher kinetic energy of the particles; hence a denser coating can be created with fewer oxides [52]. However, as the temperature of the HVOF flame is much lower than that of the plasmas spray flame, HVOF process is limited to fabricate metallic coatings. Recently a novel air plasma spray device, the Mettech Axial IIITM System, combines the advantages of regular APS and HVOF process and can produce much better metallic coatings as well as ceramic coatings.

\subsubsection{Mettech Axial IITM System}

A Mettech Axial III ${ }^{\mathrm{TM}}$ System employed in this research is a type of the air plasma spray apparatus. This system has a novel axial powder injection system, in which powder is carried through the center powder port and ejects co-axially with the plasma gases, while the conventional plasma spray system injects powder through the radial powder port (Figure 2.9).

A comparison of temperature and kinetic energy for conventional plasma spray, HVOF and Mettech Axial III ${ }^{\mathrm{TM}}$ System is illustrated in Figure 2.10. The advantages of 
the Mettech Axial III ${ }^{\mathrm{TM}}$ system over conventional plasma spray system (radial powder injection) can be summarized as:

- full entrainment of powder in the plasma jet, which increases deposition efficiency [53]

- more thermal and kinetic energy, which enhances the density and adhesion between the coating and substrate, and reduces oxidation

The increased kinetic energy, however, shortens the dwelling time for particles in plasma gas and unmelted particles increase. Therefore the size of metallic powders should not exceed $100 \mu \mathrm{m}$.

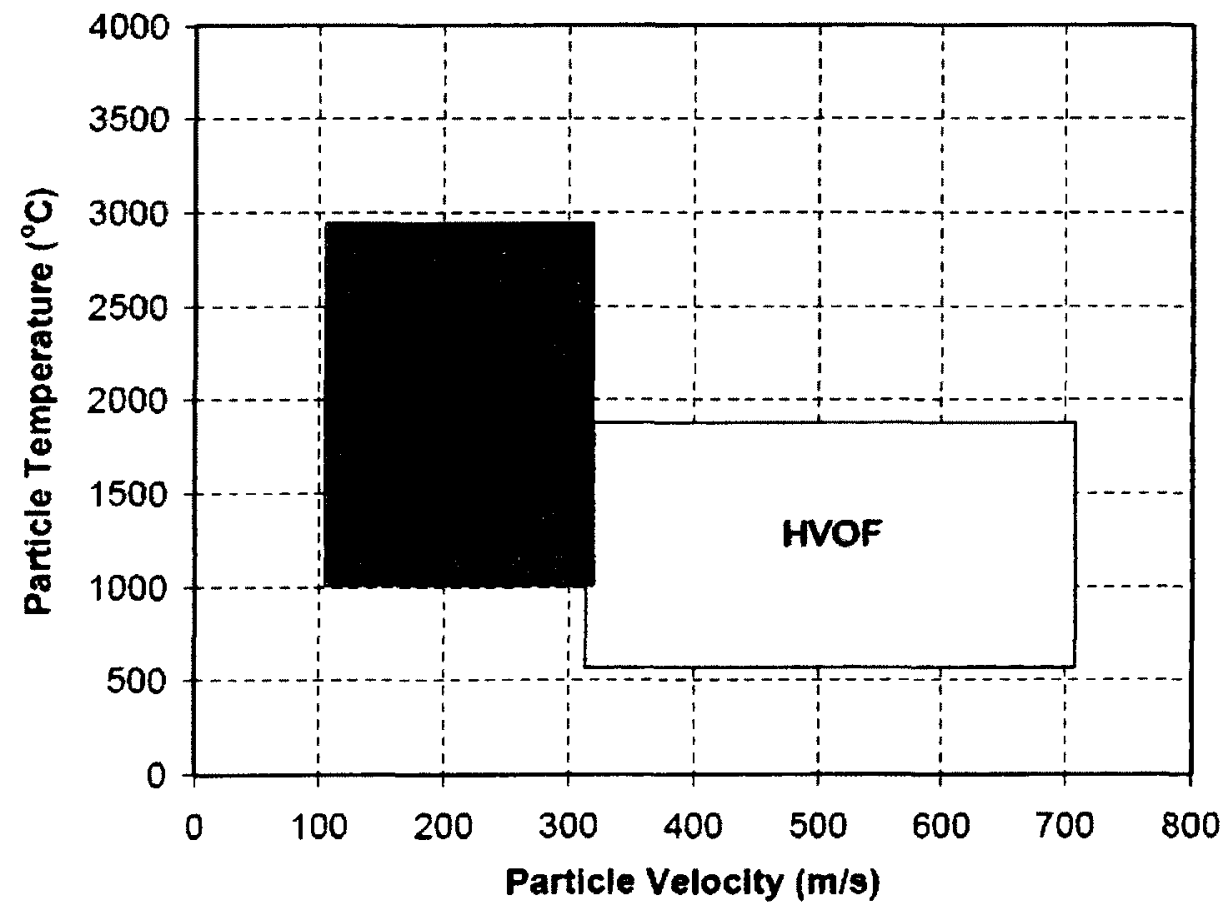

Figure 2.8 Comparison of the temperature and velocity of particles in plasma spray and HVOF processes [54]. 


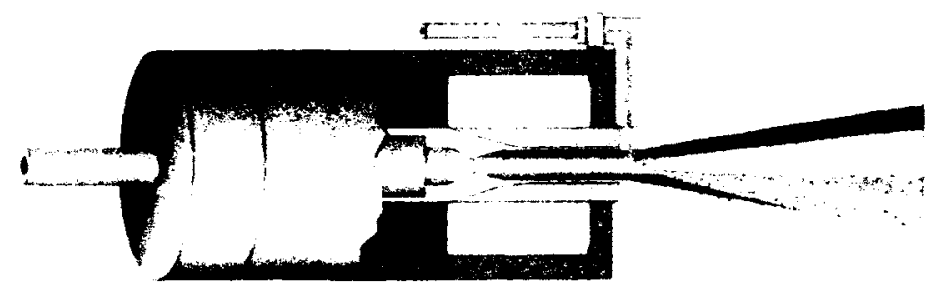

Traditional Radial Plasma Gun

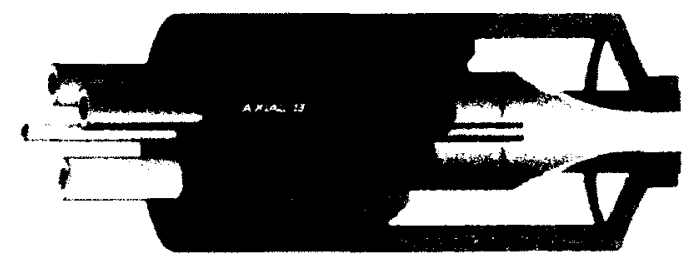

Axial III Plasma Gun

Figure 2.9 Configurations of traditional radial plasma gun and axial III gun [54].

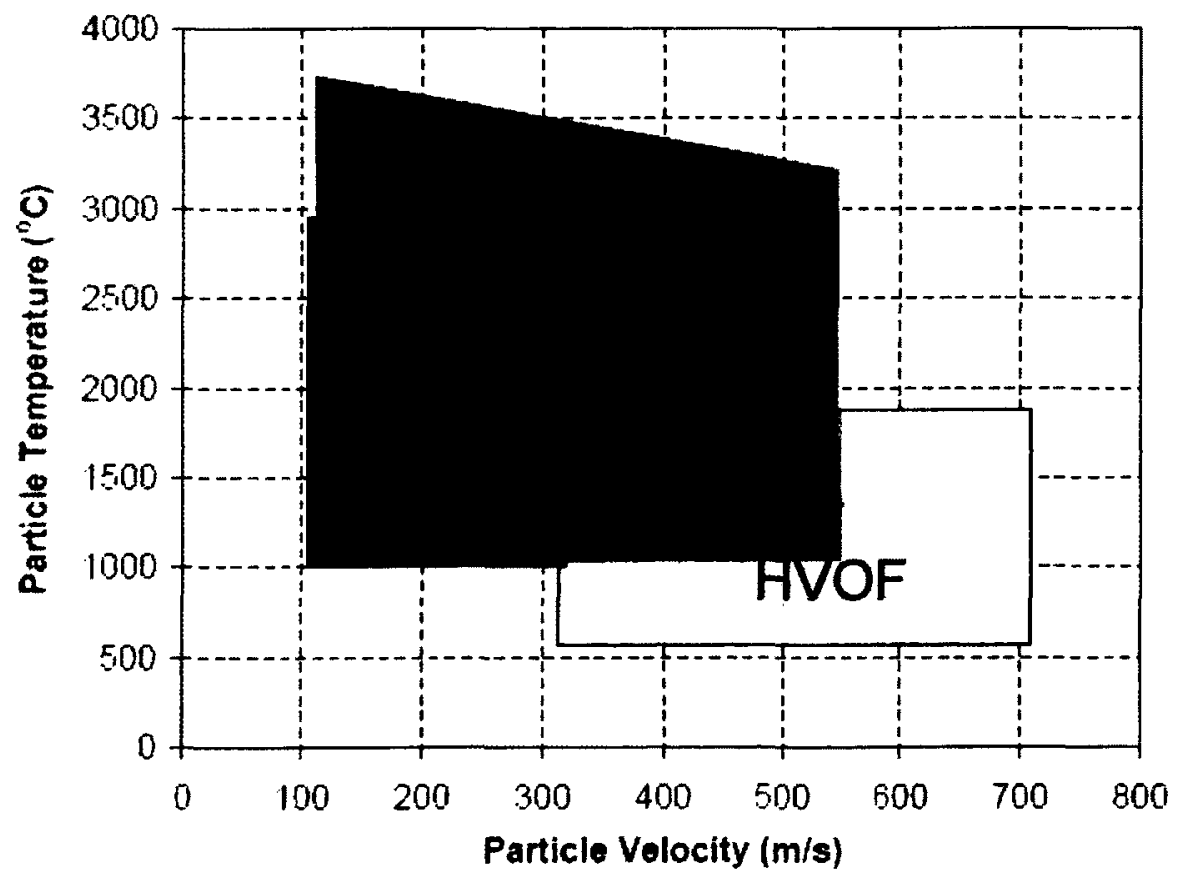

Figure 2.10 Comparison of temperature and velocity of particles in thermal spray systems [54]. 


\subsubsection{Overlay Coating Compositions}

Overlay coatings have the composition configuration of $\mathrm{MCrAlX}$, where $\mathrm{M}=\mathrm{Ni}$, $\mathrm{Co}, \mathrm{Fe}$ or a combination of these, and $\mathrm{X}=\mathrm{Y}, \mathrm{Hf}, \mathrm{Zr}$. The elements in the coatings are selected based on the requirements for the ductility and oxidation of the coatings. The composition ranges of common overlay coatings are typically $15-28 \mathrm{wt} . \% \mathrm{Cr}, 4-18 \mathrm{wt} . \%$ $\mathrm{Al}, 0.5-0.8 \mathrm{wt} . \% \mathrm{Y}$ with balance of $\mathrm{Ni}$ or $\mathrm{Co}[9]$.

The coatings with $18-22$ wt.\% $\mathrm{Cr}$ and 8-12 wt.\% $\mathrm{Al}$ generally perform better at higher temperatures where oxidation is the dominant failure mode (above $900^{\circ} \mathrm{C}$ ) [22]. Under high-temperature oxidizing conditions, NiCrAlYs and NiCoCrAlYs perform better than cobalt-based CoCrAlYs or CoNiCrAlYs, as illustrated schematically in Figure 2.11 [55].

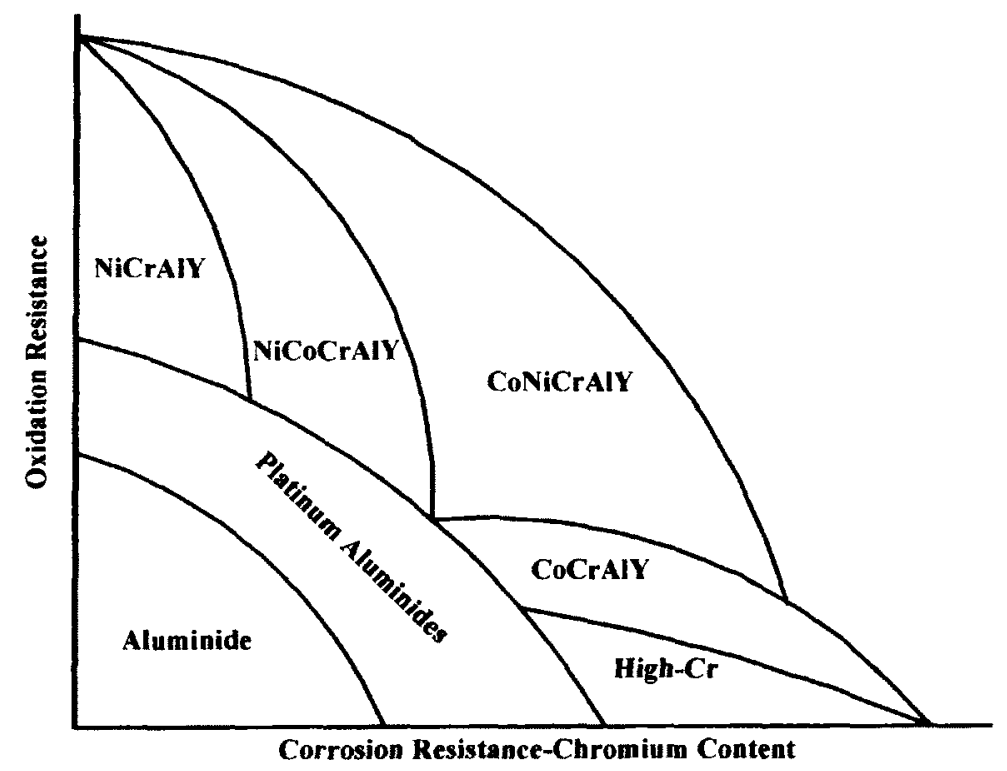

Figure 2.11 Relative oxidation and corrosion resistance of high-temperature systems [55]. 
However, at relatively low temperatures $\left(650-800^{\circ} \mathrm{C}\right)$ where hot corrosion predominates, CoNiCrAlYs and CoCrAlYs systems with high $\mathrm{Cr}$ (15-20\%) usually outperform NiCrAlY-based systems [56, 57]. Therefore nickel-based systems should be used when oxidation is the major concern, whereas cobalt-based systems should be considered when hot corrosion must be coped with. For NiCrAlY coatings, aluminum and chromium are main elements contributing to the formation of protective oxide scales. Aluminum content is to balance the need for forming a continuous and adherent thermal growth oxide (TGO) with an adequate reservoir of aluminum and to prevent embrittlement with excessive aluminum [22]. To improve the adherence of the alumina scales, active elements such as $\mathrm{Y}$ are incorporated in these coatings in a small amount (less than 1 wt.\%). NiCrAlY coatings with $18-22$ wt.\% $\mathrm{Cr}$ and $8-12$ wt.\% Al typically consist of a cubic $\beta$ (NiAl) phase, a brittle $\sigma-\mathrm{Cr}$ phase and the $\gamma^{\prime} / \gamma$ matrix. Although yttrium is often observed in the oxides, it is also present at grain boundaries in the form of $\mathrm{Ni}_{5} \mathrm{Y}$ yttride [58].

The oxidation behavior of NiCrAlY coatings depends on various factors: alloy composition, temperature and exposure time. Higher chromium content significantly reduces the oxidation resistance of NiCrAlY, especially when the temperature exceeds $1100^{\circ} \mathrm{C}$. Comparing the first coating and the third coating in Table 2.6 , spallation occurs after $10 \mathrm{hr}$ exposure at $1100^{\circ} \mathrm{C}$ for Amdry 962 coating (Ni-31Cr-11 Al-0.6Y) [32], whereas spallation does not occur even after $100 \mathrm{hr}$ at $1200^{\circ} \mathrm{C}$ for Amdry 964 coating (Ni-23Cr-11 Al-1 Y). Apparently higher chromium content at high temperatures leads to the formation of $\mathrm{CrO}_{3}$ (gas), which is formed due to the oxidation of $\mathrm{Cr}_{2} \mathrm{O}_{3}$ [59], and causes the spallation of the scales. More oxide protrusions, which results from the 
formation of $\mathrm{Cr}_{2} \mathrm{O}_{3}$, are observed on the surface of Amdry 964 coating than on the Amdry 962 coating.

Also shown in Table 2.6 low aluminum content causes rapid coating failure at high temperatures (comparing the second coating and third coating in Table 2.6). At $1200^{\circ} \mathrm{C}$, $\mathrm{Ni}-23 \mathrm{Cr}-6 \mathrm{Al}-0.4 \mathrm{Y}$ coating with $6 \mathrm{wt} . \% \mathrm{Al}$ fails after $30 \mathrm{hr}$, whereas no spallation is found for $\mathrm{Ni}-22 \mathrm{Cr}-10 \mathrm{Al}-1 \mathrm{Y}$ with $10 \mathrm{wt} . \% \mathrm{Al}$ after $100 \mathrm{hr}$. Some studies have indicated that increasing aluminum from $8 \%$ to 12 wt.\% in MCrAlY coatings could significantly reduce the dissolution of $\mathrm{NiAl}$ in the substrate and diffusion zone since the high aluminum content in $\mathrm{MCrAlY}$ coatings acted an aluminum reservoir to replenish aluminum depletion in the subsurface and in the diffusion zone [60].

The effects of other alloying elements on the oxidation resistance of MCrAlY coatings have been reported as well. Yttrium, cerium, lanthanum, zirconium, and scandium significantly increase the oxidation resistance by improving the adhesion between the coating and the protective oxide [61]. Also, elements Re and Hf have been found to impede the diffusion between the coating and the substrate [62].

Table 2.6 Oxides formed with temperature for MCrAlY coatings

\begin{tabular}{|c|c|c|c|c|}
\hline Coating & Process & $\begin{array}{l}\text { Oxidation } \\
\text { condition }\end{array}$ & Oxides & $\begin{array}{l}\text { Time of scale } \\
\text { spallation, } \mathrm{hr}\end{array}$ \\
\hline \multirow{3}{*}{$\begin{array}{l}\mathrm{Ni}-31 \mathrm{Cr}- \\
11 \mathrm{Al}-0.6 \mathrm{Y} \\
{[32]}\end{array}$} & \multirow{3}{*}{ APS } & $1100^{\circ} \mathrm{C}, 5 \mathrm{hr}$ & $\alpha-\mathrm{Al}_{2} \mathrm{O}_{3}$ & No spallation \\
\hline & & $1100^{\circ} \mathrm{C}, 50 \mathrm{hr}$ & $\alpha-\mathrm{Al}_{2} \mathrm{O}_{3}, \mathrm{Cr}_{2} \mathrm{O}_{3}, \mathrm{NiAl}_{2} \mathrm{O}_{4}$ & Spallation at 10 \\
\hline & & $1100^{\circ} \mathrm{C}, 100 \mathrm{hr}$ & $\alpha-\mathrm{Al}_{2} \mathrm{O}_{3}, \mathrm{Cr}_{2} \mathrm{O}_{3}, \mathrm{NiAl}_{2} \mathrm{O}_{4}$ & Spallation at 10 \\
\hline \multirow{2}{*}{$\begin{array}{l}\mathrm{Ni}-23 \mathrm{Cr}-6 \mathrm{Al}- \\
0.4 \mathrm{Y}[63]\end{array}$} & \multirow{2}{*}{ APS } & $1200^{\circ} \mathrm{C}, 10 \mathrm{hr}$ & $\mathrm{a}-\mathrm{Al}_{2} \mathrm{O}_{3}$ & No spallation \\
\hline & & $1200^{\circ} \mathrm{C}, 100 \mathrm{hr}$ & $\alpha-\mathrm{Al}_{2} \mathrm{O}_{3} \mathrm{Cr}_{2} \mathrm{O}_{3}, \mathrm{NiAl}_{2} \mathrm{O}_{4}$ & Spallation at 30 \\
\hline \multirow{3}{*}{$\begin{array}{l}\mathrm{Ni}-22 \mathrm{Cr}- \\
10 \mathrm{Al}-1[32]\end{array}$} & \multirow{3}{*}{ APS } & $1200^{\circ} \mathrm{C}, 5 \mathrm{hr}$ & $\alpha-\mathrm{Al}_{2} \mathrm{O}_{3}$ & No spallation \\
\hline & & $1200^{\circ} \mathrm{C}, 50 \mathrm{hr}$ & $\alpha-\mathrm{Al}_{2} \mathrm{O}_{3}, \mathrm{Cr}_{2} \mathrm{O}_{3}, \mathrm{NiAl}_{2} \mathrm{O}_{4}$ & No spallation \\
\hline & & $1200^{\circ} \mathrm{C}, 100 \mathrm{hr}$ & $\alpha-\mathrm{Al}_{2} \mathrm{O}_{3}, \mathrm{Cr}_{2} \mathrm{O}_{3}, \mathrm{NiAl}_{2} \mathrm{O}_{4}$ & No spallation \\
\hline
\end{tabular}




\subsubsection{Heat Treatments of NiCrAlY Coatings}

The purpose of post-coating heat treatment on NiCrAlY coatings is to promote the formation of $\gamma^{\prime} / \gamma$ two-phase structure in NiCrAlYs since only meta-stable $\gamma$ phase can be obtained in NiCrAlYs due to high cooling rate that is required for cooling melting particles during spraying [64]. Heat treatments can also help seal pores in the coatings $[65,66,67]$ and release the residual stresses within the coatings. Consequently heat treatments can improve the adhesion between the coating and the substrate, and alter the behavior of oxide formation, which in turn improve the coating oxidation resistance. The NiCrAlY coatings without any heat treatment are prone to the formation of spineltype oxides instead of pure $\mathrm{Al}_{2} \mathrm{O}_{3}$ [68]. Heat treatments for NiCrAlY coatings are usually carried out at $1100^{\circ} \mathrm{C}$ for $3-5 \mathrm{hr}$ in vacuum or in air followed by furnace cooling.

\subsubsection{Diffusion between Coating and Substrate}

\subsubsection{Synopsis}

In both MCrAlY and diffusion coatings, aluminum-rich phase serves as an aluminum reservoir for the formation of continuous, stable, and protective $\mathrm{Al}_{2} \mathrm{O}_{3}$ scales. During high temperature exposure, aluminum content decreases with time due to the diffusion of aluminum toward the substrate, and meanwhile the elements from the substrate diffuse into the coating. Such a phenomenon is called interdiffusion. Previous studies have shown that interdiffusion may contribute more to the overall aluminum depletion $[69,70]$ than to oxidation and spallation. When aluminum concentration in the coating falls below 10 at.\%, the coating can no longer maintain the continuity of alumina scale and thus lose its effectiveness. Furthermore, the diffusion of alloying elements from the substrate into the coating can be detrimental to the coating 
performance. Figure 2.12 illustrates the diffusion directions of various elements [71]. $\mathrm{Cr}, \mathrm{Al}$ and Co diffuse into the nickel based substrate, whereas $\mathrm{Ni}, \mathrm{Ti}, \mathrm{W}$ and $\mathrm{Ta}$ diffuse into the coating. In addition to aluminum depletion, Kirkendall voids also form in the diffusion zone, which is responsible for a substantial reduction in the coating strength and subsequent coating spalling. Large brittle precipitates are also found in the diffusion zone, increasing the tendency for crack formation and the rate of crack growth.

Considering the significance of diffusion in determining the lifetime of coatings, diffusion barrier layers have gained particular interest lately and will be further discussed in the next section.

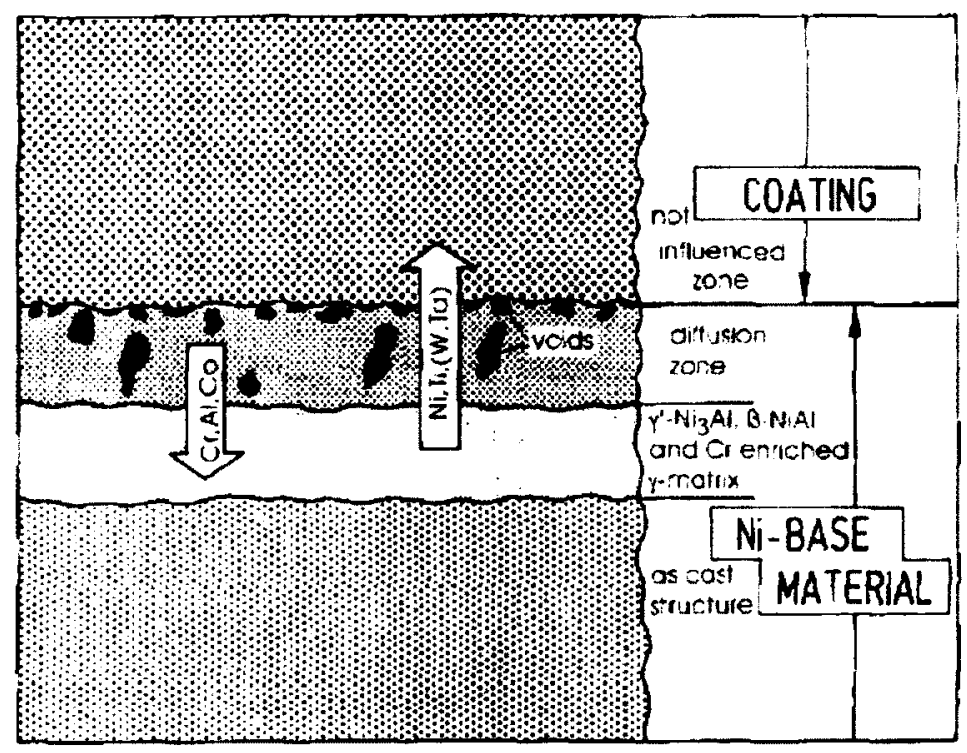

Figure 2.12 Diffusion directions of elements in a Ni-based coating and substrate system [71].

\subsubsection{Diffusion Barrier}

Applying a diffusion barrier actually is not a new concept since platinum in aluminide coatings has been regarded as a barrier to prevent aluminum diffusion. This 
barrier greatly reduces aluminum depletion and accordingly improves oxidation resistance of the coatings. Basic requirements for the diffusion barriers are [71]:

- low diffusivity for elements in both coating and substrate and no change of properties to the coating and substrate

- low aluminum solubility in the diffusion barrier layers

- long durability at high temperatures with constant thickness

- capability of good adhesion between coating and substrate

Several diffusion barriers are described in Table 2.7. The assessment method for the effectiveness of a diffusion barrier usually is to examine the profiles of the elements in the coating and the substrate before and after oxidation testing. The weight gain/loss measurements help to characterize coating performance.

Current diffusion barriers fall into two groups: oxides ( $\mathrm{Al}-\mathrm{O}-\mathrm{N}, \mathrm{Al}_{2} \mathrm{O}_{3}, \mathrm{Cr}-\mathrm{O}-\mathrm{N}$, $\left.\mathrm{ZrO}_{2}\right)[71,72,73,74]$ and intermetallics $[72,73]$. Ion-plated $\mathrm{Al}-\mathrm{O}-\mathrm{N}$ films exhibit excellent inhibition for diffusion of alloying elements between the coating and the substrate. The diffusion of aluminum and chromium into the substrate and cobalt, titanium and nickel into the coating is effectively retarded by these barrier coatings [71, 74]. However oxide barriers are reported to deteriorate the cohesion between the coating and the substrate due to the difference of thermal expansion coefficient between coatings and superalloys substrate, and to induce considerable residual stresses at the interface [75].

Most metallic diffusion barriers are $\mathrm{M}-\mathrm{Ni}-(\mathrm{Cr})$ based alloys. $\mathrm{M}$ represents $\mathrm{Re}[76$, 77], W [82], or Hf [78]. The barrier mechanism of these elements is that these elements form a layer that consists of phases with these elements such as $\sigma$ phase (Re-Cr-Ni), 
$\mathrm{NW}$ phase, and $\mathrm{Ni}_{3} \mathrm{Hf}$ phase; the layer containing one or more of these phases is reported to be an effective barrier for aluminum.

Table 2.7 Diffusion barriers and their performance

\begin{tabular}{|c|c|c|c|c|}
\hline Coating & Process & Structure & $\begin{array}{l}\text { Oxidation } \\
\text { conditions }\end{array}$ & $\begin{array}{l}\text { Diffusion } \\
\text { reaction }\end{array}$ \\
\hline \multirow{2}{*}{$\begin{array}{l}\text { A1-O-N } \\
+ \\
\text { MCrAlY [71] }\end{array}$} & \multirow[b]{2}{*}{ RF sputtering } & \multirow[b]{2}{*}{$\begin{array}{l}\text { amorphous } \\
\mathrm{Al}_{2} \mathrm{O}_{3}\end{array}$} & $1100^{\circ} \mathrm{C}$ at $400 \mathrm{hr}$ & No diffusion \\
\hline & & & $\begin{array}{l}30 \mathrm{~s} \text { at } 1115^{\circ} \mathrm{C} \text { at } \\
\text { ambient up to } 2500 \\
\text { cycles }\end{array}$ & No diffusion \\
\hline $\mathrm{Al}-\mathrm{O}-\mathrm{N}$ & \multirow{2}{*}{ Arc ion plating } & \multirow{2}{*}{$\begin{array}{l}\alpha-\mathrm{Al}_{2} \mathrm{O}_{3}+ \\
\text { hexagonal - } \\
\text { AlN }\end{array}$} & $1050^{\circ} \mathrm{C}$ at $100 \mathrm{hr}$ & Ti diffusion \\
\hline $\begin{array}{l}+ \\
\text { NiCoCrAlY } \\
{[62]}\end{array}$ & & & $900^{\circ} \mathrm{C}$ at $1400 \mathrm{hr}$ & Ti diffusion \\
\hline \multirow{2}{*}{$\begin{array}{l}\mathrm{Al}-\mathrm{O}-\mathrm{N} \\
+ \\
\mathrm{MCrAlY}[79]\end{array}$} & \multirow{2}{*}{$\begin{array}{l}\text { Magnetron } \\
\text { sputtering } \\
\text { plating }\end{array}$} & \multirow{2}{*}{$\begin{array}{l}\text { amorphous } \\
\mathrm{Al}_{2} \mathrm{O}_{3} \text { or } \\
\text { hexagonal } \\
\text { AIN }\end{array}$} & $1200^{\circ} \mathrm{C}$ at $4 \mathrm{hr}$ & $\begin{array}{l}\text { Reacted with } \\
\mathrm{Ti}\end{array}$ \\
\hline & & & $1100^{\circ} \mathrm{C}$ at $4 \mathrm{hr}$ & No diffusion \\
\hline $\begin{array}{l}\gamma-\mathrm{Al}_{2} \mathrm{O}_{3}+ \\
\mathrm{MCrAlY}[79]\end{array}$ & $\begin{array}{l}\text { Magnetron } \\
\text { sputtering ion } \\
\text { plating, annealing } \\
\text { at } 1100^{\circ} \mathrm{C} \text { for } 4 \mathrm{~h}\end{array}$ & $\alpha-\mathrm{Al}_{2} \mathrm{O}_{3}$ & $1100^{\circ} \mathrm{C}$ at $4 \mathrm{hr}$ & Ti diffusion \\
\hline \multirow{2}{*}{$\begin{array}{l}\mathrm{Cr}-\mathrm{O}-\mathrm{N} \\
+ \\
\mathrm{NiCoCrAlY} \\
{[80]}\end{array}$} & \multirow{2}{*}{ Arc ion plating } & \multirow{2}{*}{$\begin{array}{l}\mathrm{Cr}_{2} \mathrm{O}_{3} \\
\mathrm{CrN}\end{array}$} & $1050^{\circ} \mathrm{C}$ at $100 \mathrm{hr}$ & No diffusion \\
\hline & & & $900^{\circ} \mathrm{C}$ at $1400 \mathrm{hr}$ & No diffusion \\
\hline \multirow[b]{2}{*}{$\begin{array}{l}\sigma-\mathrm{Re}-\mathrm{Cr}-\mathrm{Ni} \\
+\quad \text { aluminide } \\
{[81]}\end{array}$} & \multirow{2}{*}{$\begin{array}{l}\text { Electroplating } \mathrm{Re} \text {, } \\
\text { Cr-pack } \\
\text { cementation, } \\
\text { electroplating } \mathrm{Ni} \text {, } \\
\text { Al-pack } \\
\text { cementation }\end{array}$} & \multirow[b]{2}{*}{$\mathrm{Re}-\mathrm{Cr}-\mathrm{Ni}$} & $1200^{\circ} \mathrm{C}$ at $100 \mathrm{hr}$ & No diffusion \\
\hline & & & $1100^{\circ} \mathrm{C}$ at $100 \mathrm{hr}$ & No diffusion \\
\hline $\mathrm{Ni}-\mathrm{W}[82]$ & $\begin{array}{l}\text { Electroplating W, } \\
\text { electroless plating } \\
\text { MCrAlY, } \\
\text { Electroplating } \mathrm{Pt} \text {, } \\
\text { Al-pack } \\
\text { cementation }\end{array}$ & $\mathrm{W}-\mathrm{Cr}-\mathrm{Ni}$ & $\begin{array}{l}850^{\circ} \mathrm{C}, \mathrm{Na}_{2} \mathrm{SO}_{4} \\
\text { At } 2000 \mathrm{hr}\end{array}$ & $\begin{array}{l}\text { No } \mathrm{Al} \text { and } \mathrm{Cr} \\
\text { diffusion into } \\
\text { substrate, W } \\
\text { diffusion into } \\
\mathrm{MCrAIY}, \mathrm{Cr} \\
\text { diffusion into } \\
\text { NiW }\end{array}$ \\
\hline
\end{tabular}


However, there are several drawbacks in these barriers. Chromium can easily penetrate through $\sigma$ phase to the substrate and form a needle-like precipitation zone [77]; and this zone deteriorates the properties of the substrate. Although the barrier layer with $\mathrm{NiW}$ phase can act as a diffusion barrier for both aluminum and chromium, the presence of $\mathrm{W}$-rich phase can result in a low adherence of the $\mathrm{Al}_{2} \mathrm{O}_{3}$ scale [82]. The barrier layer with $\mathrm{Ni}_{3} \mathrm{Hf}$ phase has limited high-temperature stability [78].

Recent studies have found the occurrence of self-formed $\mathrm{Cr}$-rich layers when coatings contained aluminum and chromium underwent isothermal oxidation cycles [10]; and this layer almost did not dissolve any aluminum [11], which made this layer very promising being a barrier layer. However, the Cr-rich layer could not preserve required thickness and composition without careful control of the process parameters. Therefore one of the main objectives of this study is to obtain any self-formed $\mathrm{Cr}$-rich layer with certain thickness and composition and to stabilize it during high temperature exposure.

\subsubsection{Duplex Layer and Multilayered Coatings}

\subsubsection{Aluminized MCrAlY Overlay Coatings}

The stringent requirements for gas turbine coatings can seldom be met by using a single-layered coating. Therefore multilayered coatings have been developed for decades to accomplish the required roles. In a simpler form, duplex coatings are usually aluminized MCrAlY coatings [83]. The advantage of duplex coatings is that they provide better oxidation resistance due to extra aluminum reservoir from aluminide coating; and improved bonding strength of the coating and enhanced resistance to thermal fatigue from a more compliant inner layer. It has been demonstrated that the 
service lives of duplex coatings are increased by a factor of 1.4 to 2 under high temperature oxidation condition, compared with single ones [84]. MCrAlYs in duplex coatings are usually produced by a plasma spray process, and an aluminizing process can be achieved by pack cementation or CVD [85]. CVD usually produces cleaner aluminized layer and longer cyclic lives.

Other duplex coating structures are also reported to offer better oxidation resistance [86]. An over-siliconizing MCrAlY with an outer layer of silicides exhibits improved oxidation resistance due to the formation of continuous $\mathrm{SiO}_{2}$.

\subsubsection{Multilayered Coatings}

One of well-known multilayered coatings is the smart coating that was designed to maintain a stable protective oxide and self-healing [26,87]. Both aluminum and chromium reservoirs were incorporated into the smart coating to compensate any active element depletion. This smart coating was produced using a combination of plasma spray and diffusion process. As illustrated in Figure 2.13, there are three coating layers in a smart coating, including an overlayer of a $\beta$-NiAl rich zone (A zone: outer aluminide diffusion layer) to provide high-temperature oxidation resistance and resistance to high-temperature hot corrosion, a chromium enriched region (B zone: chromium-rich layer by HVOF) midway through the coating, which limits low temperature hot corrosion attack, and a standard NiCrAlY overlay coating ( $\mathrm{C}$ zone: $\mathrm{Co}-$ 32Ni-21Cr-8A1-0.5Y layer by argon-shrouded plasma spraying). 


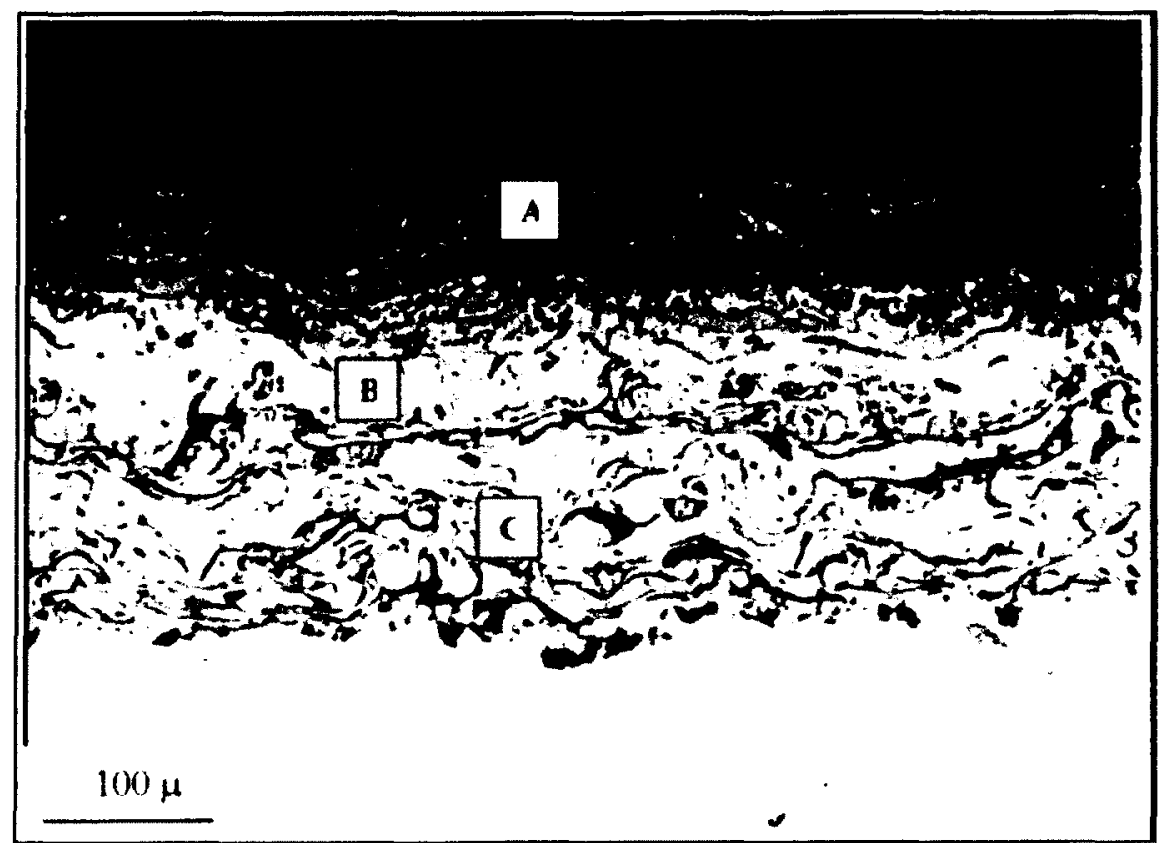

Figure 2.13 Micrograph of a smart coat showing the three-layer microstructure [26].

\subsection{Design of Experiments Methodology}

As the optimization of a coating microstructure requires a full control of the numerous operating parameters, design of experiments (DOE) may provide a useful tool for the process development and later on the interpretation of the results. DOE methodologies used in the past to optimize the air plasma coating process can be categorized into the following groups $[88,89,90]$ :

- two-level full factorial designs

- two-level fractional factorial designs

- response of surface methodology (RSM) designs

- Taguchi method 


\subsubsection{Two-Level Full Factorial Design}

A two-level full factorial design is the design in which two settings of every factor appear with every setting of every other factor. Two-level factorial designs are used when interactions between factors are considered [91]. The performance characteristic or the properties of products (responses) can be represented as a polynomial equation (regression equation) of following form [88]:

$$
Y=b_{0}+\sum b_{i} X_{i}+\sum b_{i j} X_{i} X_{j}+\sum b_{i j k} X_{i} X_{j} X_{k}
$$

where $i, j, k$ vary from 1 to the number of variables; coefficient $b_{0}$ is the mean of responses of all the experiment; $b_{i}$ coefficient represents the effect of the variable $X_{i}$, and $b_{i j}, b_{i j k}$ are the coefficients of regression which represent the effects of interactions of variables $X_{j} X_{j}, X_{i} X_{j} X_{k}$ respectively. The regression coefficient is half of the effect estimate [91]. The magnitude and direction of the factor effects on the performance characteristic are based on the sign and magnitude of the regression coefficient of the factor. Another way to examine the factor effects on the performance characteristic is to evaluate the response surface and contour plot obtained from the regression equation. If the interaction terms are in the regression equation the response surface is a curve plane and the contour lines of constant value are curved as well (Figure 2.14) [91]. Full factorial designs are not recommended when 5 or more factors are involved because of large numbers of the combinations of the setting for all factors. 


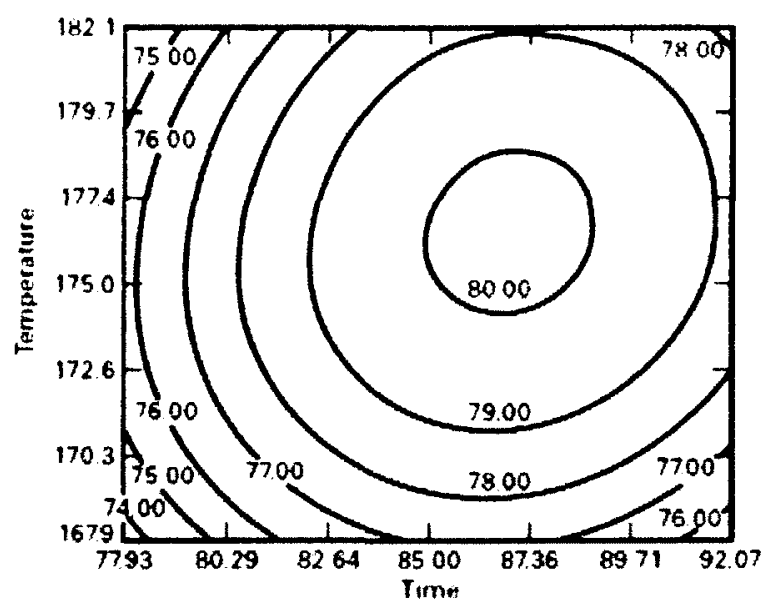

a) Contour plot

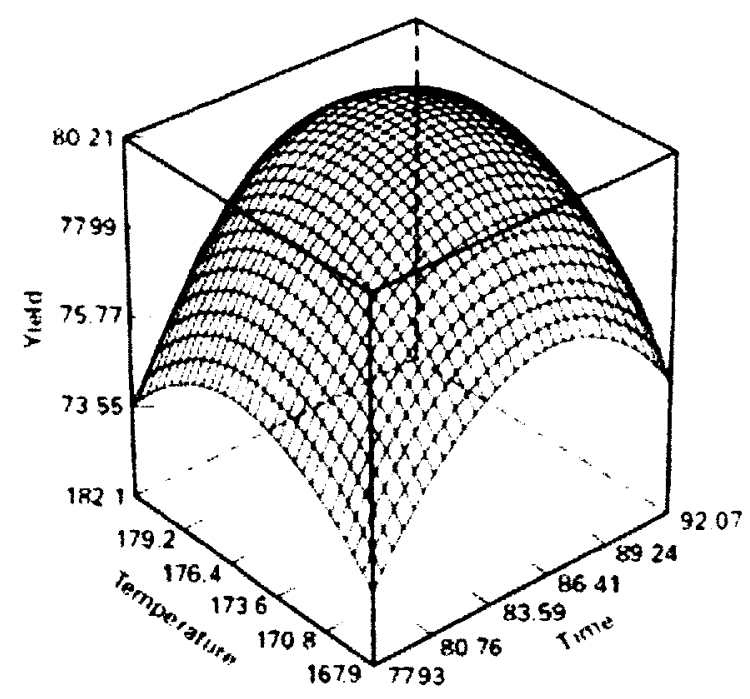

b) Response surface plot

Figure 2.14 An example of the response surface and contour plot [91].

\subsubsection{Two-level Fractional Factorial Design}

The purpose of the fractional factorial design is to extract part of experiments from the full factorial design, which enables the realization of main effects of variables. For example, a complete $2^{5}$ design requires 32 runs, and only 5 of the 31 degrees of freedom correspond to the main effects, and only 7 degrees correspond to two-factor interactions; therefore, there are only 12 degrees of freedom associated with the effects that are likely to be of major interest. The remaining 19 degrees of freedom are associated with three-factor and higher interactions, which are sometime reasonably assumed to be negligible. Therefore these interactions have to be confounded with blocks and only the blocks with the factors of major interest are investigated. For example, a $2^{2}$ design with 4 treatment combinations and two main effects and an interaction is given in Table 2.8, and 4 treatment combinations, (1), $a, b$, and $a b$, are confounded into two blocks. There is an identity column $I$, which is always plus. In the 
design, the defining relation for confounding is $I=A B$, which means the combinations with the plus sign [ab and (1)] are in block 1 and the combination with the minus sign ( $a$ and $b$ ) are in block $2 . A B$ is called the generator of this fraction. Only block 2 is investigated if the high order interaction $(A B)$ is negligible. The generators should be carefully chosen so that the estimates of main and interaction effects cannot be neglected [91].

Table $2.82^{2}$ design with 4 treatment combinations and two main effects and one interaction

\begin{tabular}{cccccc}
\hline Treatment & \multicolumn{5}{c}{ Factorial effect } \\
\cline { 2 - 6 } combination & $\boldsymbol{I}$ & $\boldsymbol{A}$ & $\boldsymbol{B}$ & $\boldsymbol{A B}$ & Block \\
\hline$(1)$ & + & - & - & + & 1 \\
$a$ & + & + & - & - & 2 \\
$b$ & + & - & + & - & 2 \\
$a b$ & + & + & + & + & 1 \\
\hline
\end{tabular}

The effects of each factor on the performance characteristic are analyzed based on the regression equation from the design and the response surface and contour plot obtained from the regression equation. However, some terms in the regression equation are eliminated due to confounding.

\subsubsection{Response Surface Methodology (RSM)}

Response surface designs are applied when the relationship between the response and factors is not linear and a RSM design must be used to determine quadratic or cubic terms. Therefore a regression equation for RSM includes quadratic or cubic terms beside linear and interaction terms [92]:

$$
Y=b_{0}+\sum b_{i} X_{i}+\sum b_{i i} X_{i}^{2}+\sum b_{i i i} X_{i}^{3}+\sum b_{i j} X_{i} X_{j}+\sum b_{i j k} X_{i} X_{j} X_{k}
$$


The regression coefficients in the regression equation are estimated using the method of least squares. If the response is well modeled by a linear function of the independent variables, then the function will be considered to be the first-order model. If there is a curvature in the system, then a polynomial of higher order, such as the second-order model and the third-order model, must be used.

The response surface analysis is then performed using the fitted surface (fitted model). If the fitted surface is an adequate approximation of the true response function, the analysis of the fitted surface will be approximately equivalent to the analysis of the actual system. Designs for fitting response surfaces are called response surface designs. The most common methods for response surface designs are the Box-Behnken design and the central composite design [88]. A Box-Behnken design is formed by combining $2^{k}$ factorials with incomplete block designs, which includes all middle points of the edges of the $k$ factors cube and no points at the vertices of the cubic (Figure 2.15a). The Box-Behnken design is also called a spherical design since all points lie on a sphere. A central composite design (CCD) consists of a $2^{k}$ factorial with $2 k$ axial runs, and some center runs (Figure 2.15b).

The analysis of a fitted model to find the optimum set of operating conditions for the factors includes [92]:

1) Finding some special points such as the maximum point, the minimum point, or the saddle point

2) Constructing and evaluating response surface and contour plots

3) Optimizing multiple responses by overlaying the contour plots 


\subsubsection{Taguchi Method}

Taguchi method is a statistical technique developed by Genichi Taguchi to improve the quality of manufactured goods, and more recently found wide applications in process design and optimization [93]. One of the advantages of using Taguchi method in process optimization is to minimize experimental runs using saturated fractional factorials for two-level screening designs or three-level designs. Another advantage is that Taguchi method has proposed the Signal-to-Noise ratio (SNR) to optimize a process. The process is optimized by controlling the factors that maximize the Signalto-Noise ratios.

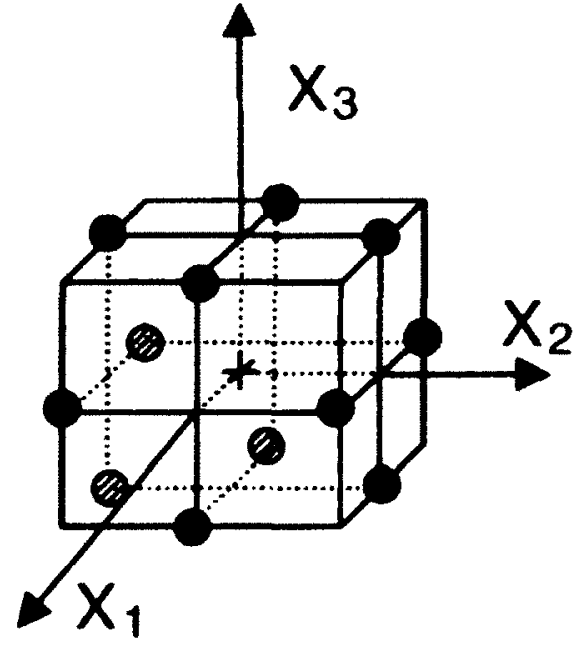

a) Box-Behnken design

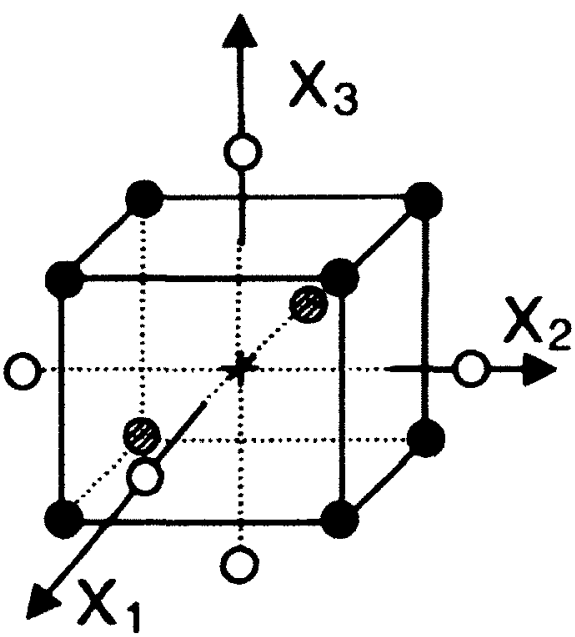

b) Central composite design

Figure 2.15 Graphical representations of the Box-Behnken and central composite design [88].

\subsubsection{Taguchi Arrays}

All Taguchi arrays are orthogonal and most of Taguchi arrays are saturated. An orthogonal array is a matrix in which its transpose is equal to its inverse; a fractional factorial design is saturated if the number of treatment combinations is equal to that of 
parameters in the model to be estimated. All two-level designs, such as L4, L8, L12, L16 and L32, are saturated [93]. The advantage of using saturated fractional factorials is to that this method can minimize experimental runs. For example, a process with 7 variables, each with 2 levels, would require $128\left(2^{7}\right)$ experiments to test all variables in a full factorial design. However using Taguchi's saturated fractional factorials, only 8 experiments are necessary. This allows for the identification of key parameters that have the most effect on the performance characteristic value so that further experimentation on these parameters can be performed while the parameters which have little effect can be ignored.

\subsubsection{Signal-to-Noise Ratio}

The Signal-to-Noise ratio is defined as: [94]

$$
S N=10 \log \frac{\bar{y}_{i}^{2}}{s_{i}^{2}}
$$

where $\bar{y}=\frac{1}{N} \sum_{u=1}^{N_{i}} y_{i, u} ; s_{i}^{2}=\frac{1}{N_{i}-1} \sum_{u=1}^{N_{i}}\left(y_{i, u}-\bar{y}_{i}\right) ; \bar{y}$ is the mean of measured results; $y_{i, u}$ is a measured result; $s_{i}$ is the variance; $i$ is experiment number; $u$ is trial number; $N_{i}$ is the number of trials for experiment $i$. There are three Signal-to-Noise ratios of common interest for process optimization: normal-the-best, smaller-the-better, and larger-thebetter.

(1) Normal-the-best

This case arises when an ideal response varies around a setting target level, meaning that neither a smaller nor a larger value is desirable. The equation for this case is equation (2-3).

(2) Smaller-the-better 
This applies to cases where an ideal response is zero, meaning that this is usually the SNR for all undesirable characteristics such as pores, cracks etc. In the case of minimizing the undesirable characteristics, the following definition of the SN ratio should be calculated [94]:

$$
S N=-10 \log \left(\sum_{u=1}^{N_{i}} \frac{y_{u}^{2}}{N_{i}}\right)
$$

where $y_{u}$ is a measured result. Also, when an ideal value is finite and its maximum or minimum value is defined, then the difference between measured data and ideal value is expected to be as small as possible. The equation of SNR then becomes [94]:

$$
S N=-10 \log \left(\sum_{u=1}^{N_{i}} \frac{\left(y_{u}-y_{l}\right)^{2}}{N_{i}}\right)
$$

where $y_{I}$ is the ideal value.

(3) Larger-the-better

In this scenario, an ideal response is required to reach the maximum, meaning that this is usually the SNR for all desirable characteristics such as oxidation resistance, corrosion and wear resistance. To maximize the desirable characteristics, the following equation of the $\mathrm{SN}$ ratio should be applied [94]:

$$
S N=-10 \log \left(\frac{1}{N_{i}} \sum_{u=1}^{N_{i}} \frac{1}{y_{u}^{2}}\right)
$$

\subsubsection{Disadvantage of Taguchi}

One disadvantage of the Taguchi method is that the SNRs are only relative and cannot exactly determine the highest effect on the performance characteristic value by parameters [95]. Also, as orthogonal arrays do not test all variable combinations, Taguchi method has no scope for estimation of interactions between parameters; therefore this method should not be used to examine the relationships between all 
variables [95], and the performance characteristic is represented by a simple first order polynomial.

\subsubsection{Procedure of Taguchi Method}

Taguchi proposed a standard 8-step procedure for applying his method for optimizing any process [94]:

(1) Identification of the main function, side effects, and failure mode

(2) Identification of the noise factors, testing conditions, and quality characteristics

(3) Identification of the objective function to be optimized

(4) Identification of the control factors and their levels

(5) Selections of the orthogonal array

(6) Conduct of the experiment

(7) Analysis of the data and prediction of the optimal levels

(8) Verification of the experiment

In summary, the process optimization follows 8-steps of planning, conducting and evaluating results of array experiments to determine the best levels of control factors. Orthogonal arrays are used to determine the best levels of control factors. The best levels of control factors are those that maximize the Signal-to-Noise ratios. Three Signal-to-Noise ratios are used to optimize a process. The optimized process is the process with the maxim Signal-to-Noise ratio.

\subsubsection{Optimization of Several Responses}

An approach to optimizing several responses is to overlay the contour plots for each response and to figure out the regions that are of common interest for all response. For example, in a chemical process optimization, the operating conditions that maximize 
the yield of a process are of interest. Other responses in this case are the viscosity and the molecular weight $(\mathrm{Mn})$ of the product. Two controllable variables are reaction time and reaction temperature. The response surface and contour plots for the yield, viscosity, and molecular weight are illustrated in Figure 2.14, Figure 2.16 and Figure 2.17 , respectively.

Figure 2.18 shows an overlay plot for the three responses with contours for the conditions: $78.5<$ yield, $62<$ viscosity $<68$, and molecular weight $<3400$. The unshaded portion of Figure 2.18 shows the combinations of time and temperature that result in a satisfactory outcome.

Another approach to optimizing several responses is to use a global desirability to incorporate the desirability factor of all responses; the global desirability is geometrical mean value of the desirability factors. Determination of the maximum point of the global desirability is a way to optimize several responses simultaneously [88].

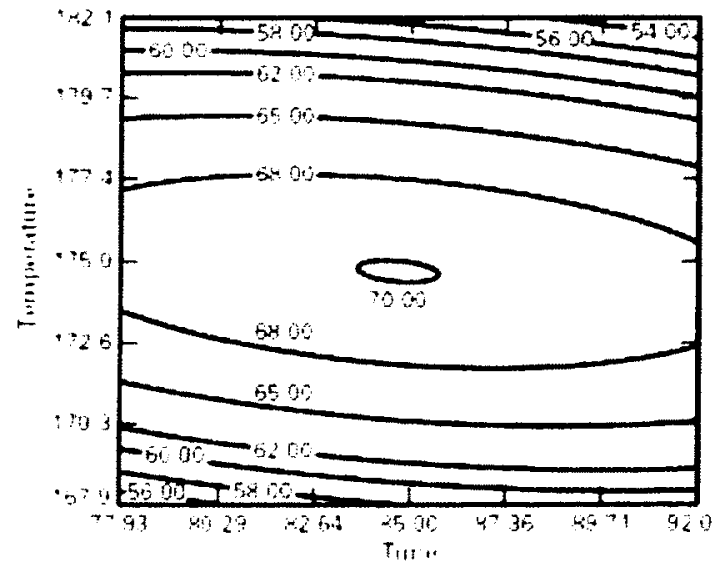

c) Contour plot

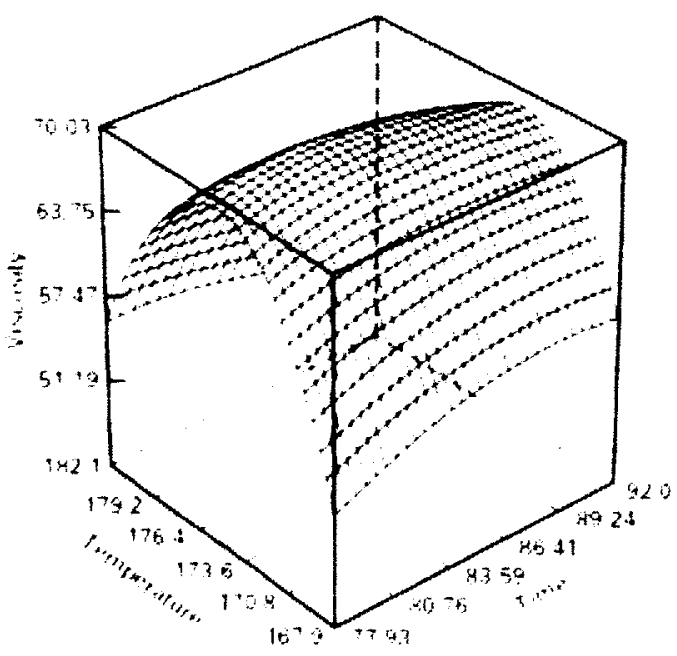

d) Response surface plot

Figure 2.16 Response surface and contour plots for the viscosity [91]. 


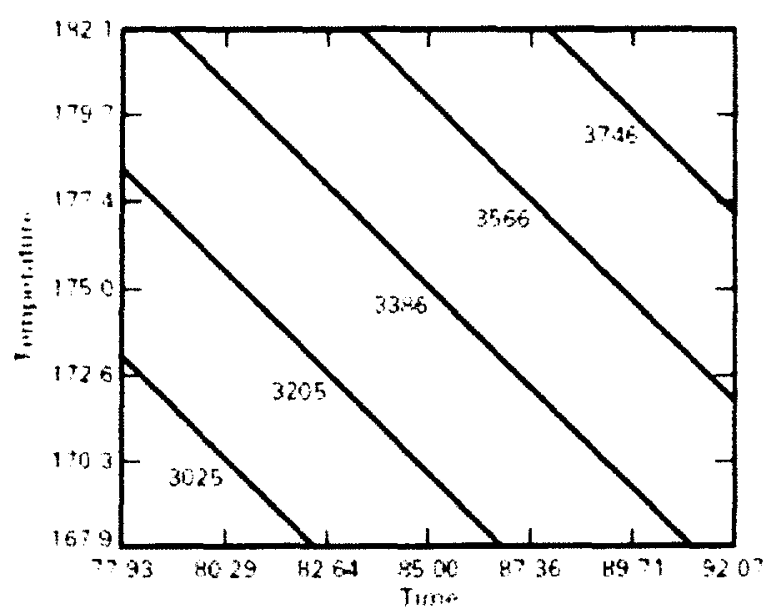

a) Contour plot

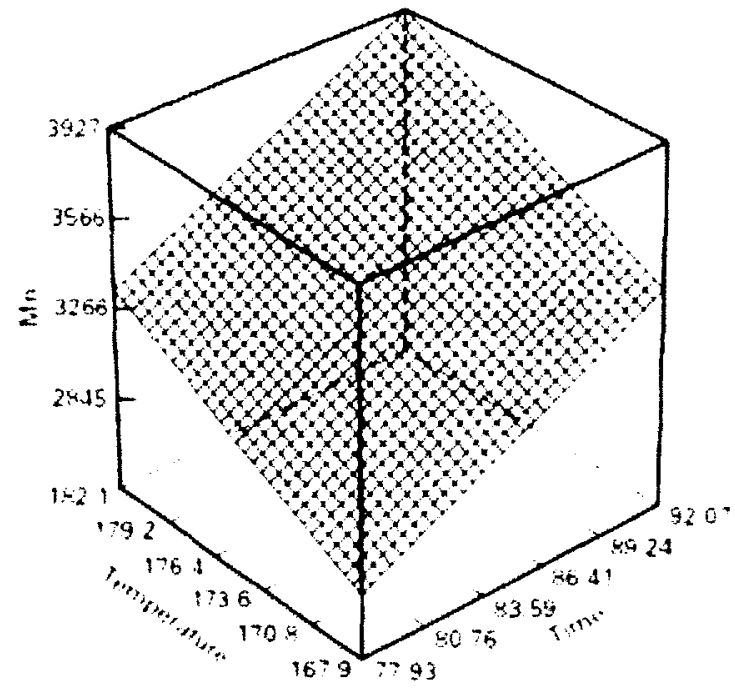

b) Response surface plot

Figure 2.17 Response surface and contour plots for molecular weight [91].

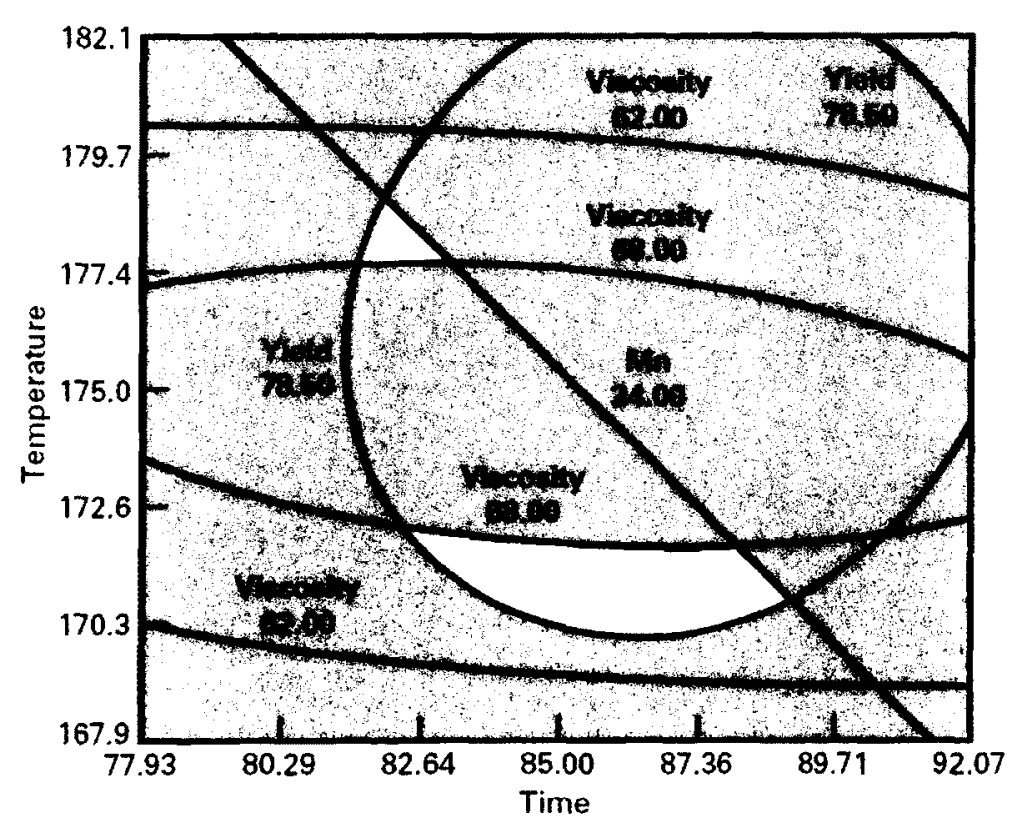

Figure 2.18 Overlay plot for the three responses [91].

\subsubsection{Analysis of Variance (ANOVA) Table}

An effective regression equation should meet the following requirements [96]: a high confidence level, the effectiveness of the regression equation, and error prediction. 
The confidence level could be determined from the Fisher value of the regression equation. Fisher value of the regression equation can be calculated using the following equation [97]:

$$
F_{0}=\frac{M S_{T}}{M S E}
$$

where $M S_{T}$ is the treatment mean square, and $M S E$ is the residual mean square. If the Fisher value $\left(F_{0}\right)$ of the regression equation is larger than the threshold $F$ value, $F(m, n$, $1-\alpha$ ), its confidence level would be higher than $1-\alpha$, where $m$ is the freedom of the regression equation, $n$ is residual degrees, and $\alpha$ is the critical value for an $F$ distribution, which is usually set 0.05 . The threshold value, $F(m, n, 1-\alpha)$, can be found in most statistics computational resources when the numerator $(m)$, denominator $(n)$ and $\alpha$ values are given [98]. The $p$-value of the regression equation can be calculated if $F_{0}$, $m$, and $n$ are known. If $p$-value of the regression equation is less than $0.05(\alpha)$, the regression equation is significant. The $p$-value of factors and their interactions can also be calculated if the $F_{0}$ values of the factors and their interactions are known. Similarly if $p$-value of a factor is less than $0.05(\alpha)$, the factor is considered significant.

The effectiveness of a regression equation can also be determined by the coefficient of determination, $R^{2}$, of the regression equation $[93,99]$. This coefficient describes the percentage of the response variation that the equation can account for, i.e., it is a statistical measure of how well the regression line approximates the real data points. The general acceptable value of $R^{2}$ is $75 \%$ [93].

A proper prediction of error should be consistent with the reliability of the experimental data, i.e., the error should be within certain confidence interval of the experimental data. It can be measured by the residual mean square value. If the process 
parameters are $X_{1}, X_{2}, X_{3}$ and $X_{4}$, there would be a probability of $1-\alpha$ that the predicted response function is among $F\left(X_{1}, X_{2}, X_{3}, X_{4}\right) \pm 2 \times(\text { residual mean square })^{1 / 2}$ [96]. The confidence intervals of the measured data at 1- $\alpha$ confidence level are calculated by the following formula:

$$
F\left(X_{1}, X_{2}, X_{3}, X_{4}\right)=\bar{F} \pm t(1-\alpha / 2, n) \times \sqrt{M S E}
$$

where $\bar{F}$ is mean value of response functions, $t(1-\alpha / 2, n)$ is $100(1-\alpha / 2, n)$ percentile of the $t$ distribution with $n$ degrees of freedom, and MSE is residual mean square.

An analysis of variance (ANOVA) table provides all values that are needed to determine the effectiveness of a regression equation for a response. Table 2.9 is an example of the ANOVA table of the chemical process described in section 2.4.5 [91]. The $p$-values for the regression equation (model) and all terms except the interaction term $A B$ are much less than 0.05 , therefore the regression equation and all terms except $A B$ are significant. The $A B$ term should be eliminated from the regression equation based on its $p$-value.

Table 2.9 ANOVA table of the yield for the example in section 2.4 .5 [91]

\begin{tabular}{lcrrrr}
\hline Source & DOF & $\begin{array}{l}\text { Sum of } \\
\text { squares }\end{array}$ & $\begin{array}{l}\text { Mean } \\
\text { square }\end{array}$ & $F$ value & Prob $>F$ \\
\hline Model & 5 & 28.25 & 5.68 & 79.85 & $<0.0001$ \\
\hline$A$, Time & 1 & 7.92 & 7.92 & 111.93 & $<0.0001$ \\
\hline$B$, Temperature & 1 & 2.12 & 2.12 & 30.01 & 0.0009 \\
\hline$A^{2}$ & 1 & 13.18 & 13.18 & 186.22 & $<0.0001$ \\
\hline$B^{2}$ & 1 & 6.97 & 6.97 & 98.56 & $<0.0001$ \\
\hline$A B$ & 1 & 0.25 & 0.25 & 3.53 & 0.1022 \\
\hline Residual & 7 & 0.50 & 0.071 & & \\
\hline Lack of fit & 3 & 0.28 & 0.094 & 1.78 & 0.2897 \\
\hline Pure error & 4 & 0.21 & 0.053 & & \\
\hline Total & 12 & 28.47 & & & \\
\hline$R^{2}$ & $98.28 \%$ & & & & \\
\hline
\end{tabular}


A lack of fit output appears in the variance table. If the $p$-value is greater than 0.05 $(\alpha)$, it is concluded that there is not enough evidence at given $\alpha$ level to support that there is a lack of fit. In this example case, the $p$-value of the lack of fit is 0.2897 , which suggests that the regression equation fits results well. The $R^{2}$ at $98.28 \%$ confirms the fitness of the regression equation.

As with most of the statistical analysis methods, analysis of variance is based on several assumptions, including that the errors are normally and independently distributed with zero mean; therefore examination of the residuals, which represent errors in a regression equation, should be an imperative part of analysis of variance. A verification of the normality assumption can be made by plotting the normal probability of the residuals. If the residual distribution is normal, this plot will resemble a straight line (Figure 2.19) [92].

Unfortunately, with the small amount of samples, a considerable fluctuation around the straight line often occurs; therefore, a moderate departure from the straight line does not necessarily mean a serious violation of the normality assumption. Substantial deviations from the straight line are a cause for concern [92]. A check of the independence assumption can be made by plotting the residuals versus the fitted (predicted) values. If the model is correct and the independence assumption will be satisfied, the plot of the residuals versus the fitted (predicted) values should not reveal any obvious pattern. 


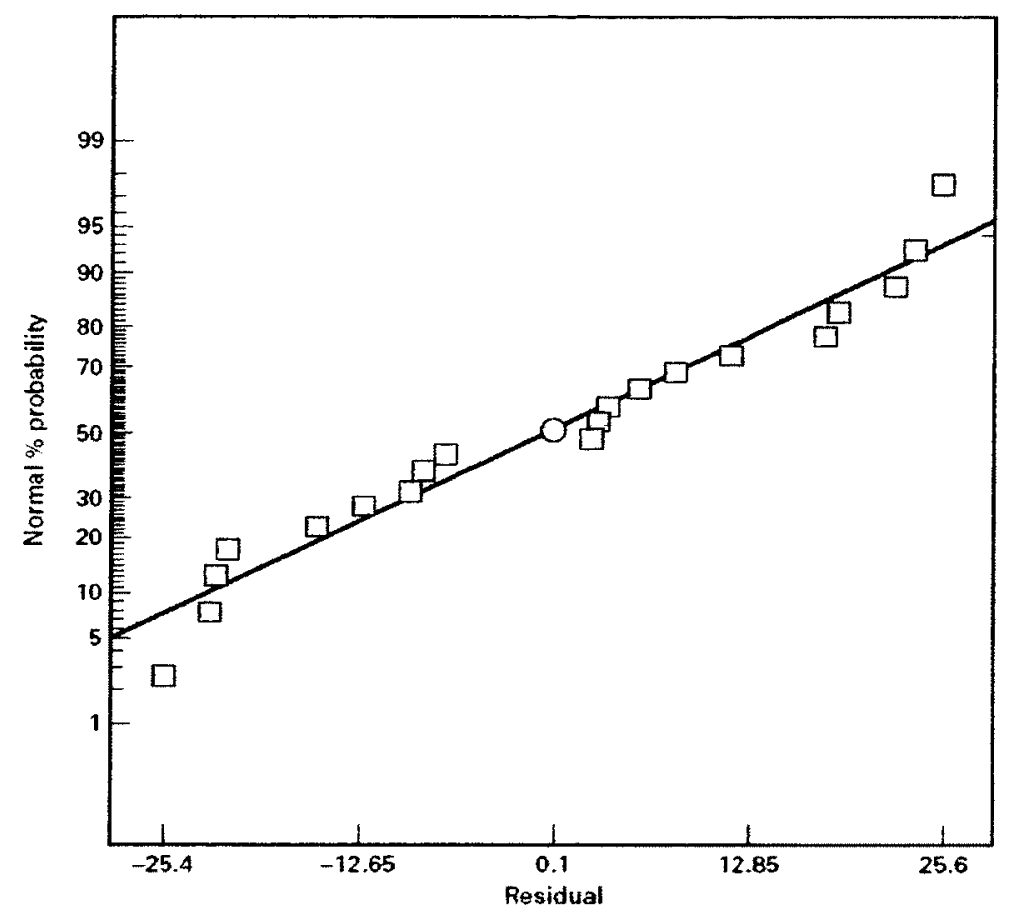

Figure 2.19 Normal probability plot of residuals [91].

\subsection{Summary of Literature Review}

Despite the progress in coating development, the necessity of advanced coating systems for hot section gas turbine components continues to be the top priority in various high-temperature material projects due to the ever increasing RITs [100]. The higher RITs accelerate the oxidation of coatings [101].The advanced coating systems with increased resistance to high-temperature oxidation will rely on the microstructure stability of the coating and the superalloy substrate, especially in terms of reducing the effects of diffusion on the stability of the alloy microstructure and the life of the coating. These requirements call for significantly different composition and microstructure designs from modern gas turbines.

In this research, multilayered coatings will be developed to achieve better hightemperature oxidation resistance compared to the existing coatings, and the outcomes 
of this research are expected to provide a new coating system and associated coating processes. 


\section{Chapter 3: Coating and Process Design}

\subsection{Design of Multilayered Coatings}

Aluminum forms a protective scale on coating surface upon reacting with oxygen, which protects the coating and substrate from further oxidation. However, aluminum eventually exhausts because of two reasons: diffusion of aluminum into the substrate and the formation of new alumina scale due to the spallation of existing oxide scale. Therefore the strategy used to improve oxidation resistance is to prevent aluminum from diffusing into the substrate and to increase aluminum content in the coating (Figure 3.1).

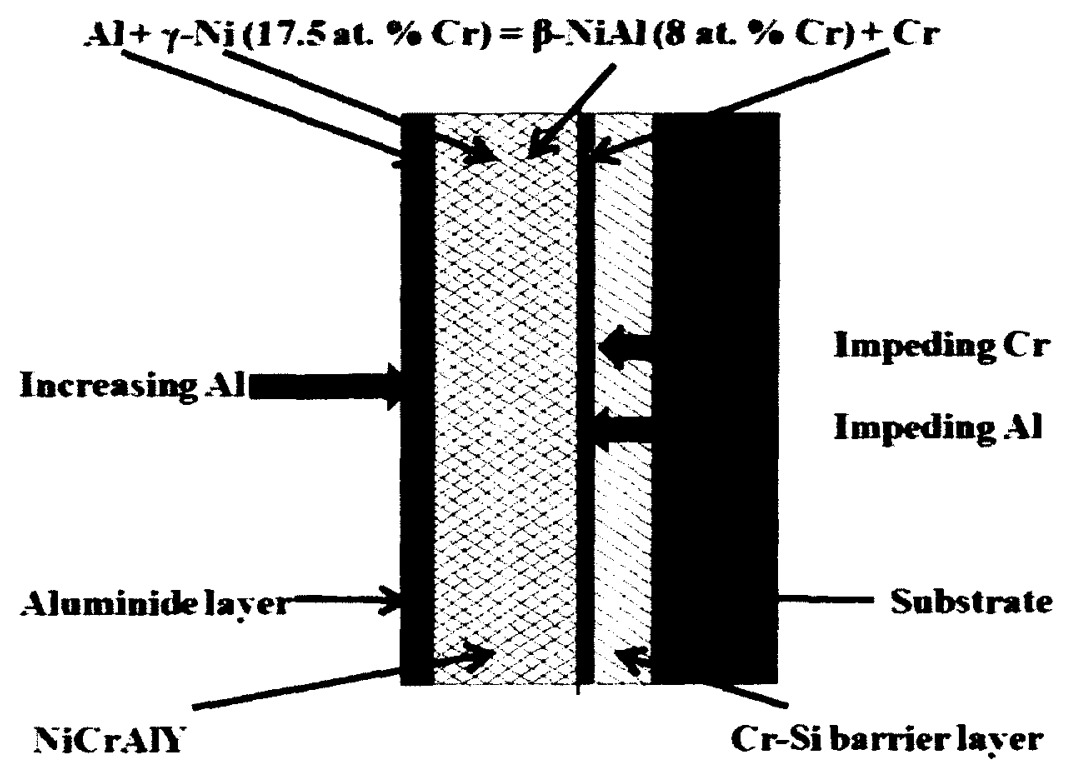

Figure 3.1 Strategy to improve oxidation resistance of a coating.

The common approach to impede aluminum diffusion in a coating is to apply a diffusion barrier between the coating and the substrate. The diffusion barriers could be aluminum and chromium oxides or $\mathrm{Ni}$ based intermetallics. The top coatings are usually aluminide and MCrAlY. Previous research indicates that when the top layer is 
the Al-rich phase, a $\mathrm{Cr}$ layer can form because of the oxidation of the Al-rich phase and the transition of the $\beta$ phase; this $\mathrm{Cr}$ layer hardly contains aluminum [11]. This phenomenon suggests that a $\mathrm{Cr}$ layer can be artificially made to impede aluminum diffusion.

Therefore this research is to develop a coating system that can self-form a $\mathrm{Cr}$ layer during coating process or exposure at high temperatures. There are two approaches to obtain a Cr-layer. One is to oxidize a $\mathrm{Cr}$ contained coating that consists of the $\mathrm{Al}$-rich phase to form the $\mathrm{Cr}$ layer. Another approach is to aluminize a $\mathrm{Cr}$ contained coating to promote $\beta$ phase transition and $\mathrm{Cr}$ atom release. No matter which approach is employed, a $\mathrm{Cr}$ contained coating and an aluminized layer on the coating are required. When the $\mathrm{Cr}$ contained coating is aluminized, the Cr-layer forms in the coating to impede aluminum diffusion, and another layer is needed to prevent $\mathrm{Cr}$ from diffusing into the substrate. Therefore a three-layer structure is necessary to achieve these goals: an $\mathrm{Al}$-rich top layer to provide sufficient aluminum and to promote chromium release; a $\gamma$ phase middle layer with high chromium content to provide chromium atoms, and a bottom layer to prevent chromium from diffusing into the substrate.

Apparently an aluminized layer is the best candidate for the top layer; the NiCrAlY coating was selected since the chromium content in NiCrAlYs is easily manipulated. The bottom layer should consist of a chromium containing intermetallics and be very stable at high temperature. The isothermal phase diagram of the Si-Cr-Ni ternary system at $1050^{\circ} \mathrm{C}$ [102], shown in Figure 3.2, indicates that a $\psi$-phase $\left(\mathrm{Cr}_{2} \mathrm{Ni}_{3} \mathrm{Si}\right)$ exists within the composition range of $20-30$ at. $\% \mathrm{Si}$ and $50-60$ at. $\% \mathrm{Cr}$ at $1050^{\circ} \mathrm{C}$. At $900^{\circ} \mathrm{C}$, the composition ranges of the $\psi$-phase $\left(\mathrm{Cr}_{2} \mathrm{Ni}_{3} \mathrm{Si}\right)$ hardly substantially diminish, which 
suggests that the $\psi$-phase has good stability between $900{ }^{\circ} \mathrm{C}$ and $1050^{\circ} \mathrm{C}$. As such, a chromium and silicon-rich barrier layer was considered in this study as a diffusion barrier.

A Cr-Si co-deposition using the pack cementation process was selected based on its simplicity and the popularity in industry. The NiCrAlY coating was produced by atmospheric plasma spray with a Mettech Axial III'T System. Following plasma spraying, the aluminum-rich top coat was deposited using the pack cementation process. A summary of the processes for the multilayered coatings is shown in Table 3.1.

A diffusion coating could also be produced using slurry. The disadvantage of using slurry is a need for application of the slurry by hand. It causes uneven coatings on a specimen surface. The variation in thickness between the specimens of one batch is usually 20 to $50 \mu \mathrm{m}$ [103]. Such variation is too large for the most diffusion coatings that are usually around $100 \mu \mathrm{m}$ thick in this study. Therefore all diffusion coatings in this study are produced using pack cementation process.

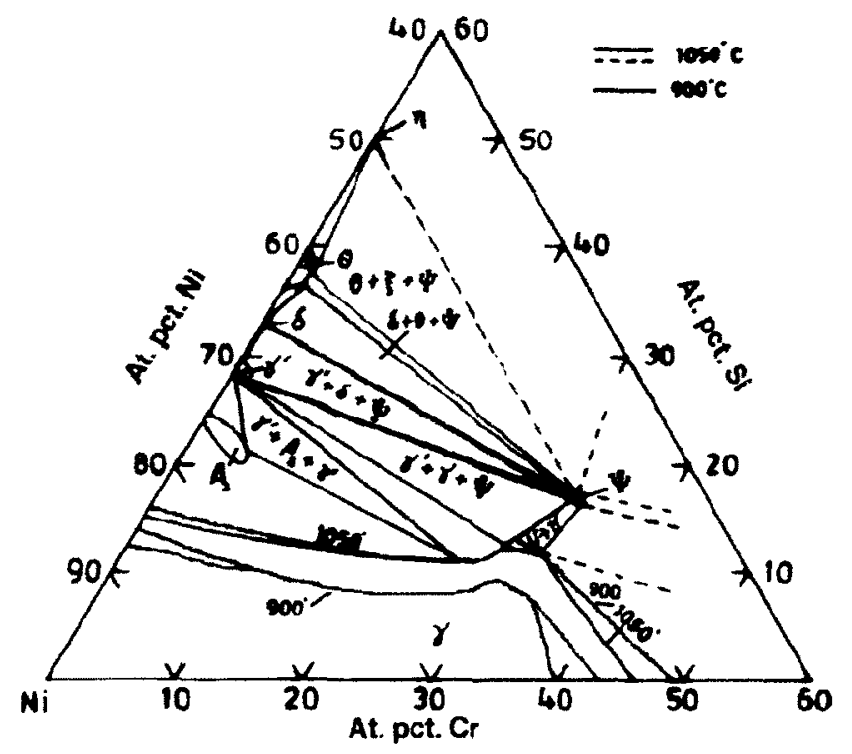

Figure 3.2 Phase diagram of a Si-Cr-Ni ternary system [102]. 
Table 3.1 Processes for the multilayered coating

\begin{tabular}{llll}
\hline Layer & Diffusion barrier & NiCrAlY & Top layer \\
\hline Composition & $\mathrm{Cr}-\mathrm{Si}$ & Ni-22Cr-10Al-1Y & Aluminizing \\
Process & Pack cementation & Atmospheric plasma spray & Pack cementation \\
\hline
\end{tabular}

The composition ranges of each layer in the multilayered coatings are summarized in Table 3.2. For multilayered coating I and II, $20-30$ at.\% $\mathrm{Cr}$ and $20-30$ at.\% Si in the diffusion barrier were targeted; $20-30$ at.\% $\mathrm{Cr}$ plus the chromium released from the NiCrAlY layer ensured sufficient chromium to form a chromium and silicon-rich $\psi$ phase layer. The NiCrAlY coating with about $10 \mathrm{wt} . \% \mathrm{Al}$ and $20 \mathrm{wt} . \% \mathrm{Cr}$ was used as the intermediate layer. For the top aluminized coating, the concept of the $\mathrm{Al} / \mathrm{Ni}$ ratio was proposed for control the aluminum content in the aluminized layer. The $\mathrm{Al} / \mathrm{Ni}$ ratios for multilayered coating I and multilayered coating II are 1 and 2 respectively. The $\mathrm{Al} / \mathrm{Ni}$ ratio at 1 promotes $\beta$ phase transition to form a $\mathrm{Cr}$ layer in multilayered coating I during aluminizing process. The $\mathrm{Al} / \mathrm{Ni}$ ratio at 2 promotes the formation of the Al-rich phase in multilayered coating II during aluminizing process, and the Al-rich phase is oxidized during oxidation tests to form a $\mathrm{Cr}$ layer. The substrate for all multilayered coatings is IN738.

Table 3.2 Compositions of key elements for various layers of multilayered coatings

\begin{tabular}{lllll}
\hline Layer & Diffusion barrier & NiCrAlY & $\begin{array}{l}\text { Al/Ni ratio } \\
\text { in top layer }\end{array}$ & Substrate \\
\hline $\begin{array}{l}\text { Multilayered } \\
\text { coating I }\end{array}$ & $\begin{array}{l}20-30 \text { at.\% Cr, 20 } \\
\begin{array}{l}\text { Multilayered } \\
\text { coating II }\end{array}\end{array}$ & $\begin{array}{l}\text { Ni-22Cr-10Al-1Y } \\
(17.5 \text { at.\% } \% \text { Cr, bal. } 15.4 \text { at.\% }\end{array}$ & 1 & IN738 \\
\hline
\end{tabular}




\subsection{Coating Process Optimization}

\subsubsection{Plasma Spray Process Optimization}

The Taguchi method was used to optimize plasma spray process, and the target of the optimization of the plasma spray process was to obtain NiCrAlY coatings with the fewest number of pores, unmelted particles and oxides, and with no cracks. The typical parameters of a plasma spray process are as follows:

- $\quad$ powder size

- current

- flow rate and composition of working gas

- $\quad$ spray distance

- nozzle size

Two Taguchi arrays were introduced and two sets of experiments for NiCrAlY coatings were conducted to determine the influence of these parameters on the coating microstructural features. Regression equations for predicting the microstructural features of NiCrAlY coatings were developed based on the experimental results.

\subsubsection{Pack Cementation Process Optimization}

The response surface methodology was employed to optimize the aluminum content and nickel content in the pack powder mixture, and process temperature so that the coatings with the expected $\mathrm{Al} / \mathrm{Ni}$ ratios were obtained. The typical parameters for a pack cementation process are as follows:

- the composition of a pack powder mixture

- process temperature

- process duration 
- atmosphere

The optimization of the aluminizing process was implemented by controlling the aluminum activity during diffusion process, and the aluminum activity was associated with the aluminum content and nickel content in the pack powder mixture, and process temperature. The target of the optimizations of the aluminizing processes was to obtain aluminized coatings with $\mathrm{Al} / \mathrm{Ni}$ ratios at 1 and 2 .

A Taguchi array was used for Cr-Si co-deposition process to optimize the chromium content and silicon content in the pack powder mixture, and process temperature so that the coatings with the expected compositions were obtained. The target of the optimizations of the Cr-Si co-deposition process was to obtain $\mathrm{Cr}$-Si coatings with 2030 at.\% $\mathrm{Cr}, 20-30$ at.\% Si. Argon purging was used for all process settings.

\subsection{Coating Characterization}

All coating specimens were characterized to investigate the effects of deposition processes on the coating microstructural features and properties. For diffusion coatings, the thicknesses, compositions, phases, and elemental distributions are essential for the coating characterization. For NiCrAlY coatings, coating thickness, formation of oxide, pores, and occurrence of cracks and unmelted particles were examined. The methods that were used to characterize the coatings include:

- measurements of coating thickness, the percentage of pores, cracks, oxides, and unmelted particles using an optical microscope with image analysis software

- mapping of elemental distributions in various layers of the coating structures using energy dispersive spectroscopy (EDS)

- identification of phases in the coatings using XRD 
Coating characterization after oxidation tests includes:

- weight change

- examination of the oxide scales after oxidation tests

- elemental (particularly $\mathrm{Al}, \mathrm{Si}$ and $\mathrm{Cr}$ ) redistribution after testing

A comparison of coating microstructural features before and after oxidation tests provided insight in oxidation mechanisms.

\subsection{Summary of Coating and Process Design}

Multilayered coatings consist of three layers, which include an aluminized layer, a $\mathrm{NiCrAlY}$ layer and a $\mathrm{Cr}-\mathrm{Si}$ layer. The aluminized layer provides sufficient aluminum in the top layer and promotes chromium release; the NiCrAlY layer with high chromium content provide chromium atoms to release and to form a $\mathrm{Cr}$ layer that is the barrier layer for $\mathrm{Al}$ diffusion; and the $\mathrm{Cr}-\mathrm{Si}$ layer prevents chromium from diffusing into the substrate. The targets of the optimizations of the coating processes for the three layers are to obtain:

- aluminized coatings with $\mathrm{Al} / \mathrm{Ni}$ ratios at 1 and 2

- NiCrAlY coatings with the fewest number of pores, unmelted particles and oxides, and with no cracks

- $\mathrm{Cr}$-Si coatings with $20-30$ at.\% $\mathrm{Cr}, 20-30$ at.\% $\mathrm{Si}$ 


\section{Chapter 4: Process Optimization for NiCrAlY Coatings}

\subsection{Experimental Procedure}

\subsubsection{Coating Materials and Substrate}

Three different commercially available spherical, gas atomized powders were used in this study and the nominal composition and size for each powder are listed in Table . The powder feed rates were measured for each powder at four settings, which were defined as the numbers at $4,5,6$, and 7 , respectively. 304 stainless steel plates were used as the substrate based on the reasons below:

(1) The microstructure of SS304 is $\gamma$ phase, which is similar to IN738. Therefore the coefficients of thermal expansion for SS304 and IN738 are close.

(2) There is no diffusion between a plasma spray coating and the substrate, thus the microstructure of the substrate hardly affects the microstructural features of the coating.

(3) SS304 is much cheaper than IN738.

Table 4.1 Powder parameters and powder feed rate

\begin{tabular}{lllllllll}
\hline $\begin{array}{l}\text { Trade } \\
\text { name of } \\
\text { Praxair }\end{array}$ & $\begin{array}{l}\text { Powder } \\
\text { size, }\end{array}$ & $\begin{array}{l}\text { Composition, } \\
\text { wt.\% }\end{array}$ & & $\begin{array}{l}\text { Carrier } \\
\text { flow }\end{array}$ & $\begin{array}{l}\text { gas } \\
\text { rate, }\end{array}$ & $\begin{array}{l}\text { Powder } \\
\text { gl/min }\end{array}$ & feed & rate, \\
\hline NI-246-4 & $-90+38$ & Ni-31Cr-11Al-0.1Y & 12 & 7 & 6 & 5 & 4 \\
NI-164-2 & $-75+45$ & Ni-22Cr-10Al-1Y & 12 & 102 & 82 & 57 & 43 \\
NI-343 & $-45+10$ & Ni-22Cr-10Al-1Y & 12 & 102 & 84 & 72 & 48 \\
\hline
\end{tabular}

The 304 stainless steel plates were cut to a size of $25 \times 80 \mathrm{~mm}$; then the cut plates were blasted using 46 grit alumina abrasive with a nozzle pressure at $80 \mathrm{psi}$. The plate surface was blasted around one minute until there was no sign of non-blasted areas and a uniform grit blasted and rough surface was to achieve for $2 \mathrm{hr}$ before plasma 
spraying. The surface roughness $R_{a}$, for all specimens used in this study, ranges from 2.5 to $3.0 \mu \mathrm{m}$.

\subsubsection{Plasma Spraying Process}

The coatings were produced using the Mettech Axial III ${ }^{\mathrm{TM}}$ system with different powder feed rates as listed in Table 4.2. The specimens were clamped onto a turn table with a rotational speed of $220 \mathrm{rpm}$ and a vertical motion speed of $17 \mathrm{~mm} / \mathrm{s}$. The vertical motion distance was $120 \mathrm{~mm}$, which allowed specimens to be heated and coated evenly. An up-down motion of the table during spraying is defined as a heating cycle, while the heating cycle before spraying is defined as a preheating cycle. The purpose of preheating was to eliminate any moisture in the substrate and to increase the temperature of the substrate because the heated substrate enabled better adhesion between the coating and substrate. Immediately before the spraying, the substrates were moved up and down five times to be pre-heated. Argon gas was used as the primary and powder carrier gas. Hydrogen $\left(\mathrm{H}_{2}\right)$ and nitrogen $\left(\mathrm{N}_{2}\right)$ were employed as the secondary gases for spraying.

The first Taguchi matrix was designed to systematically vary the settings of the following four parameters: powder size, the internal diameter of the nozzle, the total flow rate of secondary gas, and the ratio of $\mathrm{H}_{2}+\mathrm{N}_{2}$ flow rate over the total secondary gas flow rate. Based on the results from the first set of experiments, the second set of Taguchi matrix was designed to examine the effects of total flow rate of secondary gas, the ratio of $\mathrm{H}_{2}+\mathrm{N}_{2}$ flow rate over the total secondary gas flow rate, the current, and the spray distance. Finally an extra set of tests were conducted to verify the validity of the regression equations derived from the first and second set of experiments and to 
examine the process repeatability. All parameters for the three sets of experiments are summarized in Table 4.2. The following parameters were kept constant for this study: primary gas (Ar: $225 \mathrm{sl} / \mathrm{min}$ ), powder carrier gas flow rate (Ar:12 sl/min), total spraying time ( $2 \mathrm{~min})$, and preheating cycle ( 5 cycles).

Table 4.2 Taguchi matrix and process parameters

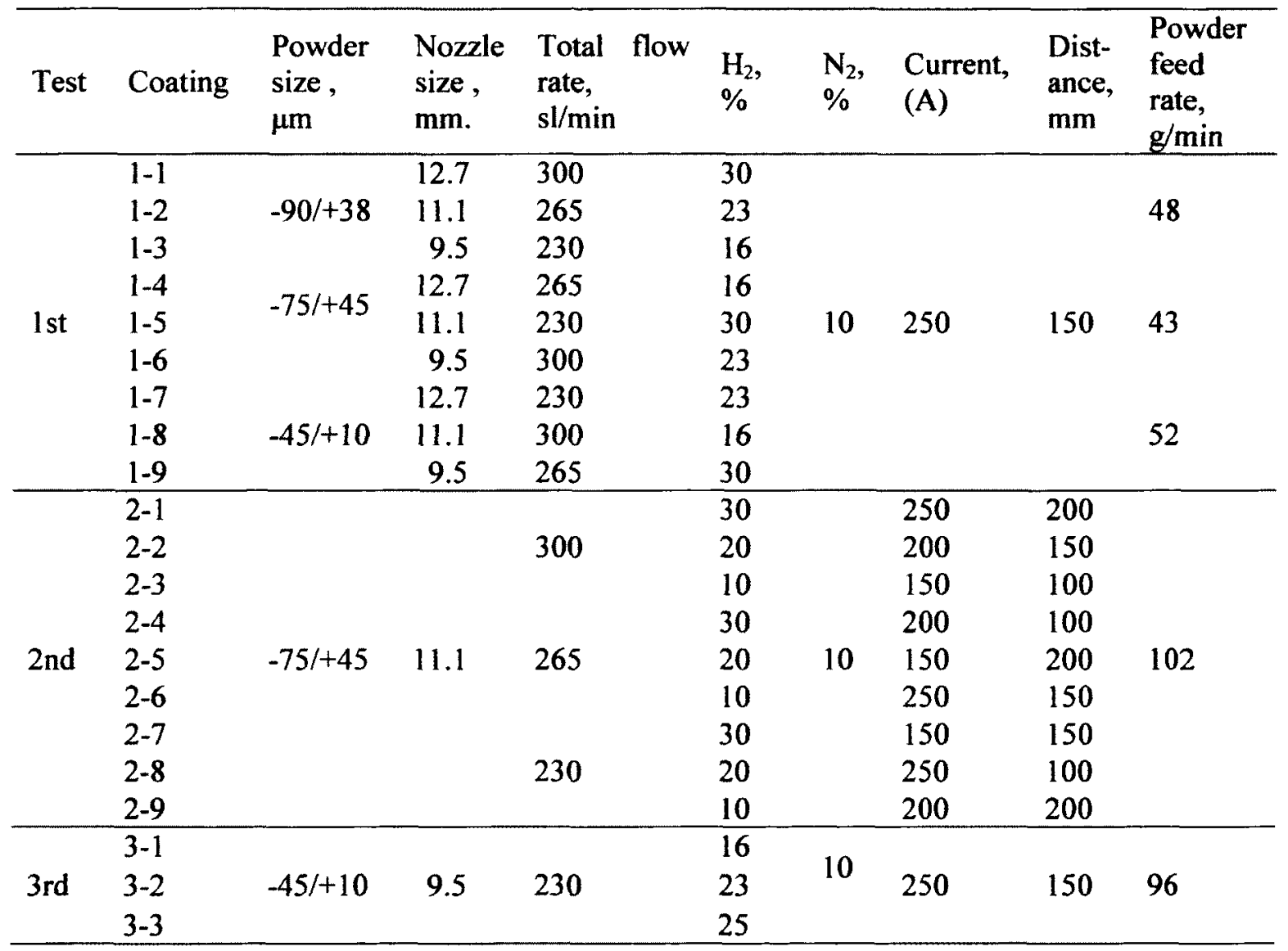

\subsubsection{Coating Characterization}

The groups for the specimens of the first set of experiments were designated from coating 1-1 to coating 1-9 according to the spraying parameters assigned. There were 8 specimens in each group. One of the specimens in the group of coating 1-1 is presented in Figure 4.1 The coated specimens were cross-sectioned, mounted, ground and 
polished. The microstructure analyses were performed using a Philips XL30 SEM to obtain images of the coatings. The SEM images of the coatings generated in the first set of the experiments are presented in Figure 4.2. The microstructural features of the coatings, such as pores, cracks, unmelted particles, and oxides can be identified. Energy dispersive X-ray (EDS) mappings (of elements $\mathrm{Al}$ and $\mathrm{O}$ ) were used to distinguish pores and oxides, as shown in Figure 4.3. In particular, three levels of contrast were identified. The darkest regions in the Al map represent pores (some small size pores were accompanied by oxides), while bright contrasted regions are oxides, and the intermediate contrasted regions correspond to the bulk of the NiCrAlY coatings. The oxide is assumed to be alumina $\left(\mathrm{Al}_{2} \mathrm{O}_{3}\right)$ since the distributions of $\mathrm{Al}$ and $\mathrm{O}$ on EDS elemental maps are identical, as shown in Figure 4.3.

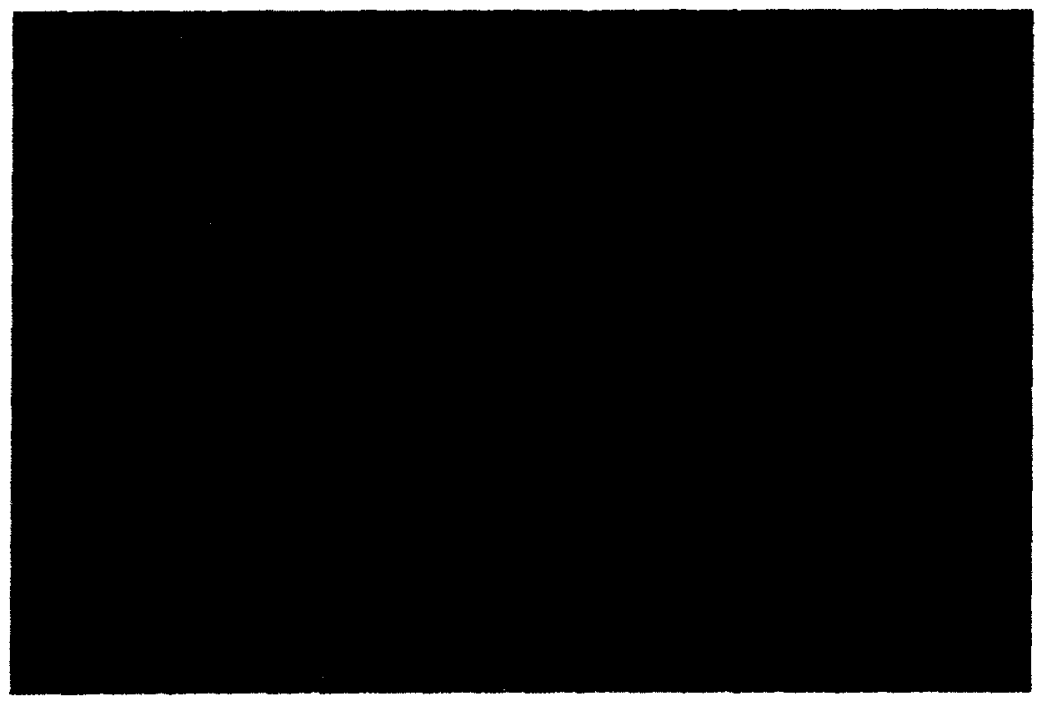

Figure 4.1 Image of a coating specimen in the group of coating 1-1. 

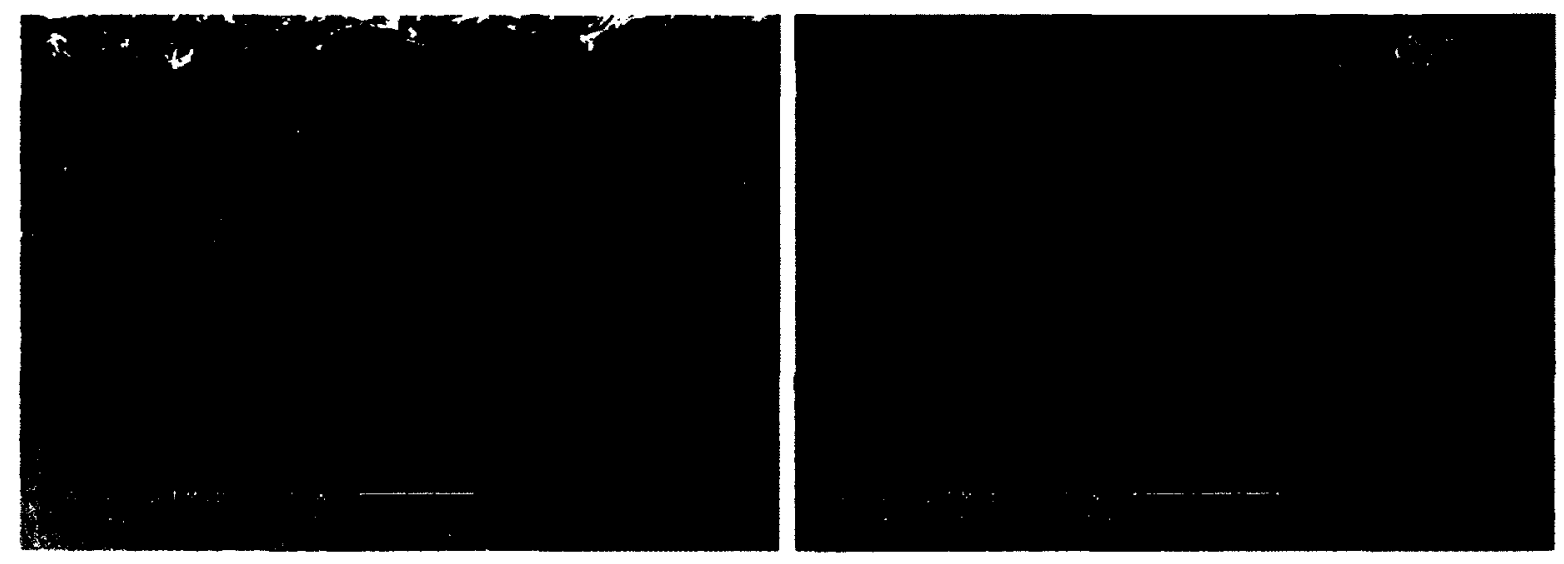

a) Microstructure of specimen 1-1

b) Microstructure of specimen 1-2

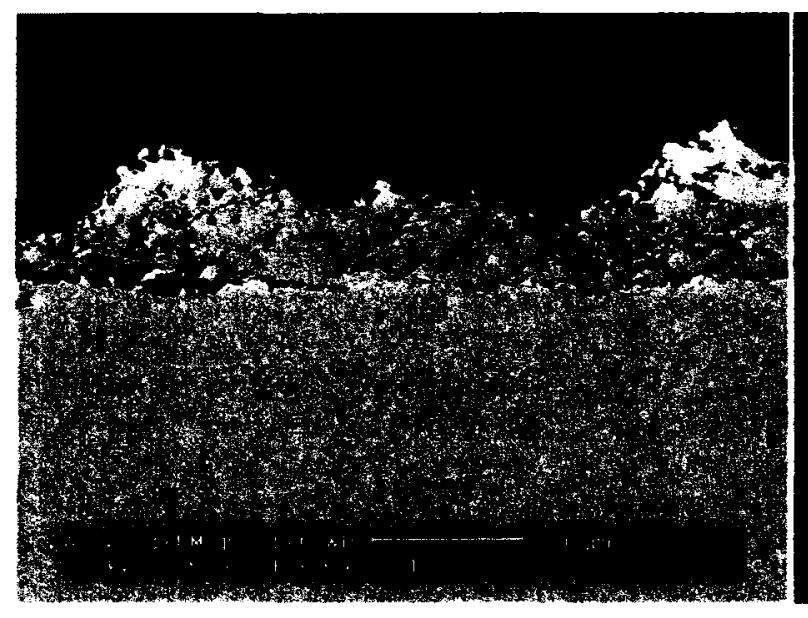

c) Microstructure of specimen 1-3

d) Microstructure of specimen 1-4
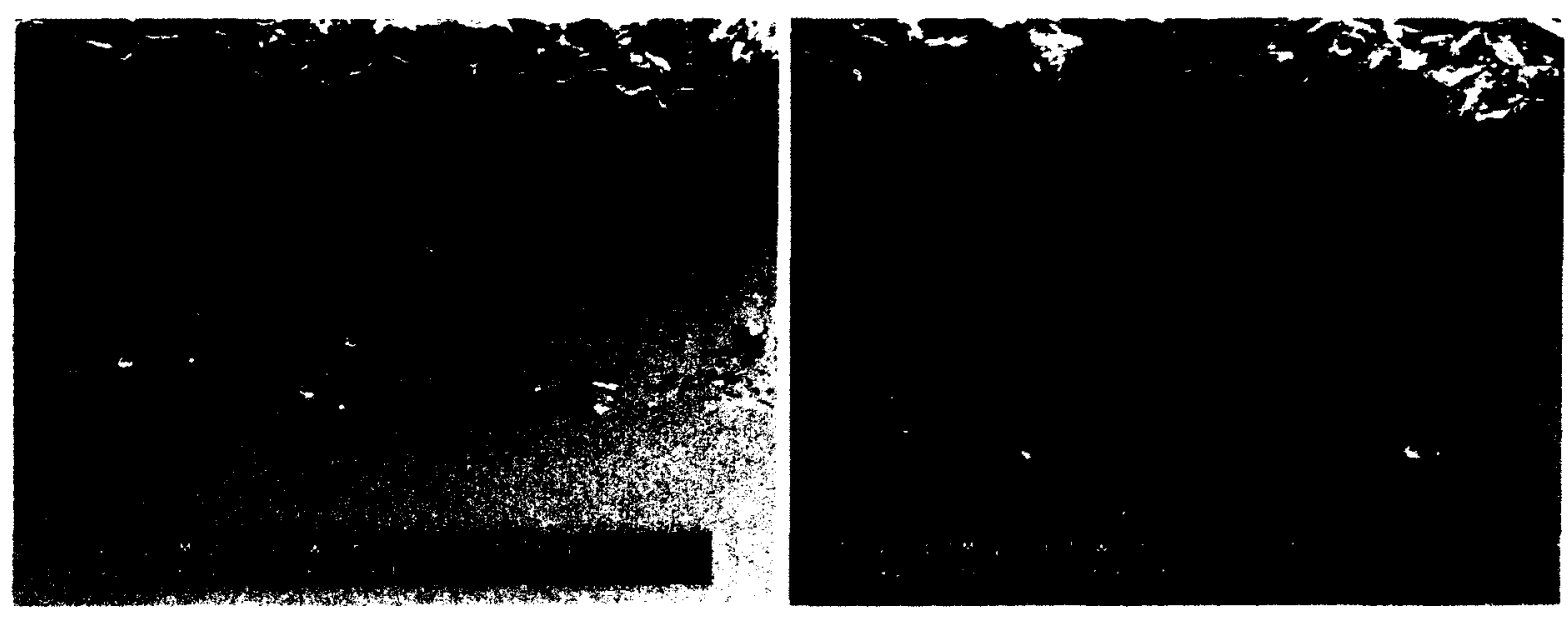

e) Microstructure of specimen 1-5

f) Microstructure of specimen 1-6 


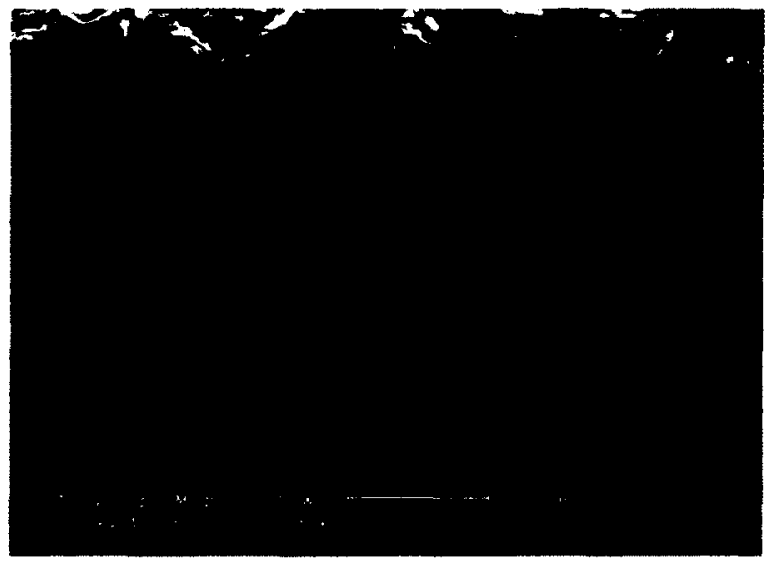

g) Microstructure of specimen 1-7

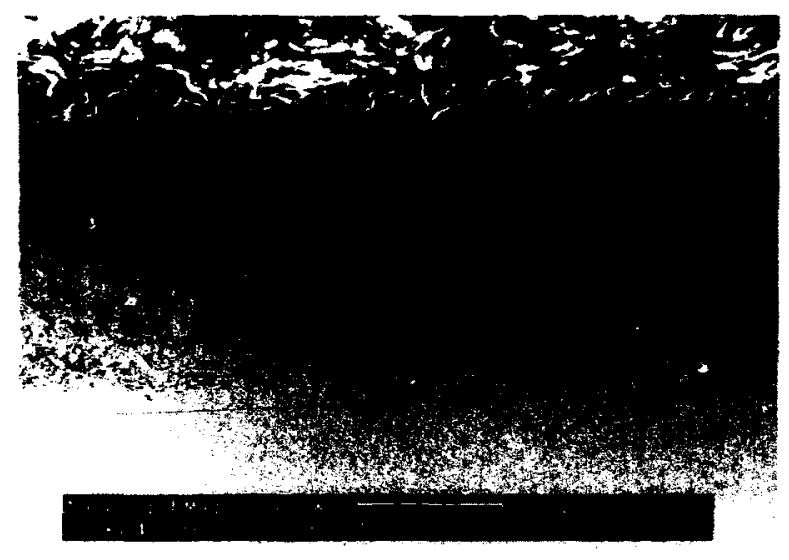

h) Microstructure of specimen 1-8

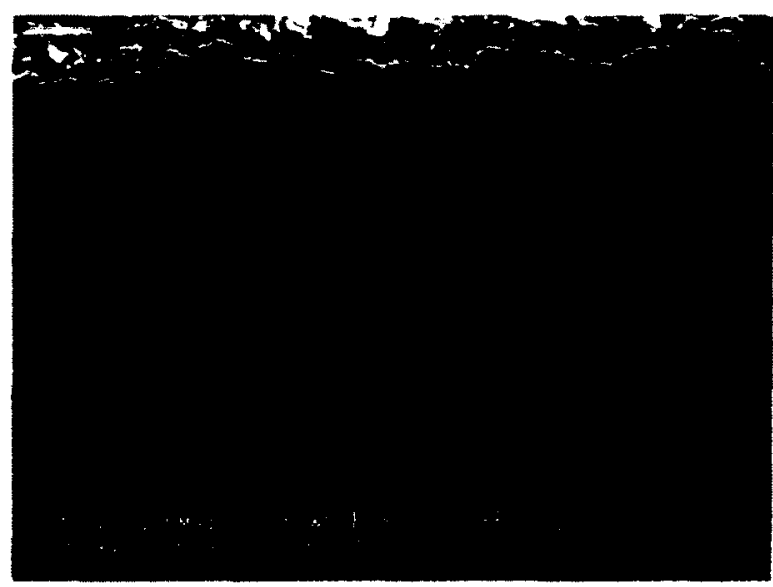

i) Microstructure of specimen 1-9

Figure 4.2 Microstructure of coatings for first set of experiments.

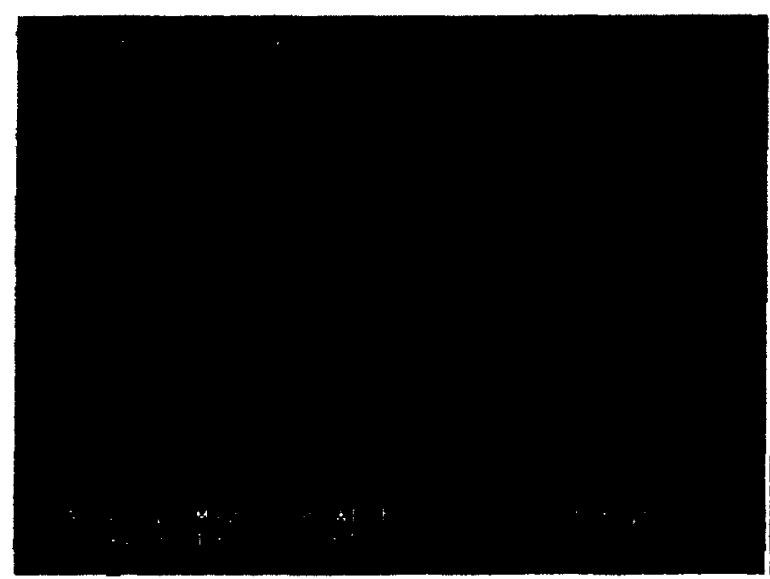

a) SEM image of specimen 1-2

b) EDS mapping image for $\mathrm{O}$ 

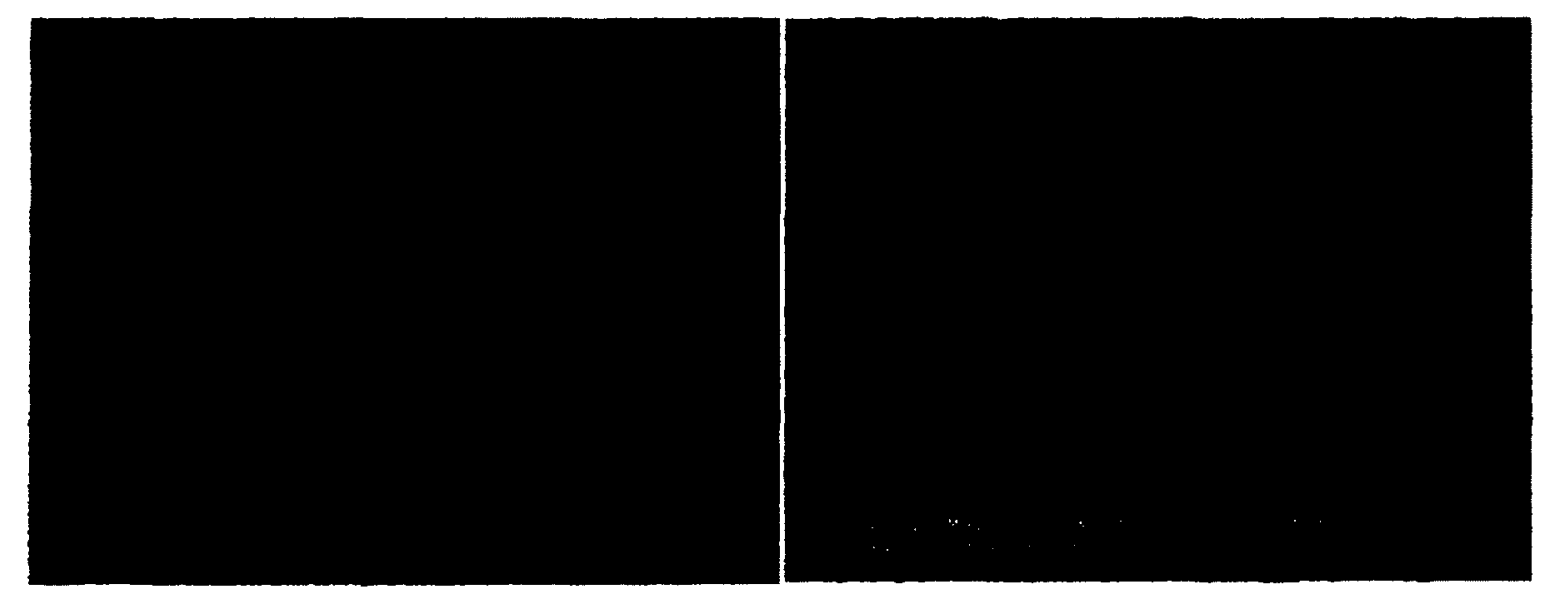

c) EDS mapping image for $\mathrm{Al}$

d) SEM image of specimen 1-7

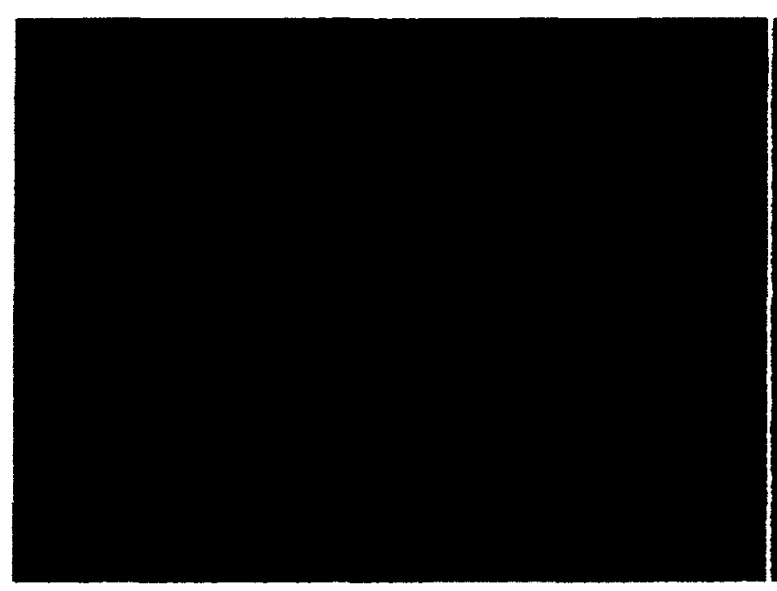

e) EDS mapping image for $\mathrm{O}$

f) EDS mapping image for $\mathrm{Al}$

Figure 4.3 EDS mapping images of coating 1-2 and coating 1-7.

Image analysis software (Clemex Technologies Inc. Canada) was used to determine the percentage of pores, unmelted particles and oxide phases in the coatings. The image processing started with a routine that consists of four steps:

- Image acquisition: importing a stored image of a coating

- Binarization: creating a bitplane of the microstructural features of the coating to be measured 
- Binary operations: modifying the bitplane to ensure that it accurately represents one of the microstructural features of the coating

- Measurements: measuring the size and area percentage of the bitplane for the particular microstructural feature of the coating over the whole field

For measuring unmelted particles, the following microstructural characteristics were used: spherical or semispherical shaped particles, and clear boundaries with surrounding regions as shown in Figure 4.2.

The percentage for cracks was based on the length of the crack over the length of the interface between the coating and the substrate for each image, and the percentage of other microstructural features of the coating was taken from the area of the coating feature over the whole area of the field (image) analyzed.

Twenty SEM images at a magnification of $500 \mathrm{X}$ taken along the coating layer were imported to the image analysis program for measuring the percentages of the microstructural features of the coating. The final data are the average of the results from the twenty images. The final data were used for regression analysis.

\subsection{Regression Analysis}

Theoretically, the measured percentages of crack, porosity, unmelted particle and oxide can be considered as the response functions of the four process parameters investigated in this study. Polynomial equations of the four process parameters can be expressed as [98]:

$$
\begin{aligned}
& F\left(x_{1}, x_{2}, x_{3}, x_{4}\right)=A+\sum_{i=1}^{4} x_{i}+\sum_{i=1}^{4} \sum_{i<j}^{4} x_{i} x_{j}+\cdots+\sum_{i=1}^{4} \sum_{i<j}^{4} x_{i}^{r-1} x_{j}^{r-1}+ \\
& \sum_{i=1}^{4} x_{i}^{r}
\end{aligned}
$$


where $A$ is a constant, $F\left(x_{1}, x_{2}, x_{3}, x_{4}\right)$ stands for the percentage of crack, porosity, unmelted particle and oxides, $x_{1}, x_{2}, x_{3}, x_{4}$ are powder size, nozzle size, total gas flow rate, the ratio of $\mathrm{H}_{2}$ plus $\mathrm{N}_{2}$ over total gas flow rate, respectively, and $r$ is the order of the polynomial equation. The larger the exponent $r$, the more accurate the polynomial equation is. However, a value of $r$ equivalent to one is generally used to simplify the calculations and analysis. In the present analysis, $r$ values from one to two were used to generate the equations and the results were compared.

After the crack, porosity, unmelted particle and oxide data of the experimental trials were obtained, the polynomial equations related to the investigated process parameters were generated by regression analysis. However, nine trials, shown in Table 4.2, were insufficient to conduct a regression of the experimental results with an order of more than one in a regression equation. Therefore the variables in the regression equation must be shifted using statistical testing to eliminate the terms that influence the response functions negligibly, and retain only those statistically significant to the response function. In the present analysis, a stepwise regression method was used. It started with a simple model and gradually more parameters, higher orders of parameters and their interactions were incorporated until the model became significant.

\subsection{Results and Discussion for Process Optimization}

\subsubsection{Microstructures of NiCrAlY Coatings}

As observed in Figure 4.2, NiCrAlY coatings have a typical splat microstructure with pores, oxides and unmelted particles. Cracks are observed in some coating specimens (Figure 4.2c and Figure 4.2d) at the coating/substrate interface. The amounts of cracks, pores and unmelted particles vary significantly with the powder size and 
other process parameters. On basis of the analysis of the XRD spectra in Figure 4.4, The microstructure of the as-sprayed NiCrAlY coating contains single $\beta$-NiAl phase (with a fraction of dissolved chromium) when chromium content is $32 \%$ in Ni 246 , whereas the NiCrAlY coating is composed of $\beta(\mathrm{NiAl})+\gamma(\mathrm{Ni}) / \gamma^{\prime}\left(\mathrm{Ni}_{3} \mathrm{Al}\right)$ when $\mathrm{Cr}$ content is $22 \%$ in $\mathrm{Ni} 164$ and 343. Instead of $\mathrm{Cu} k_{\alpha}$ radiation, in this research the $\mathrm{Co} k_{\alpha}$ radiation was used for XRD.

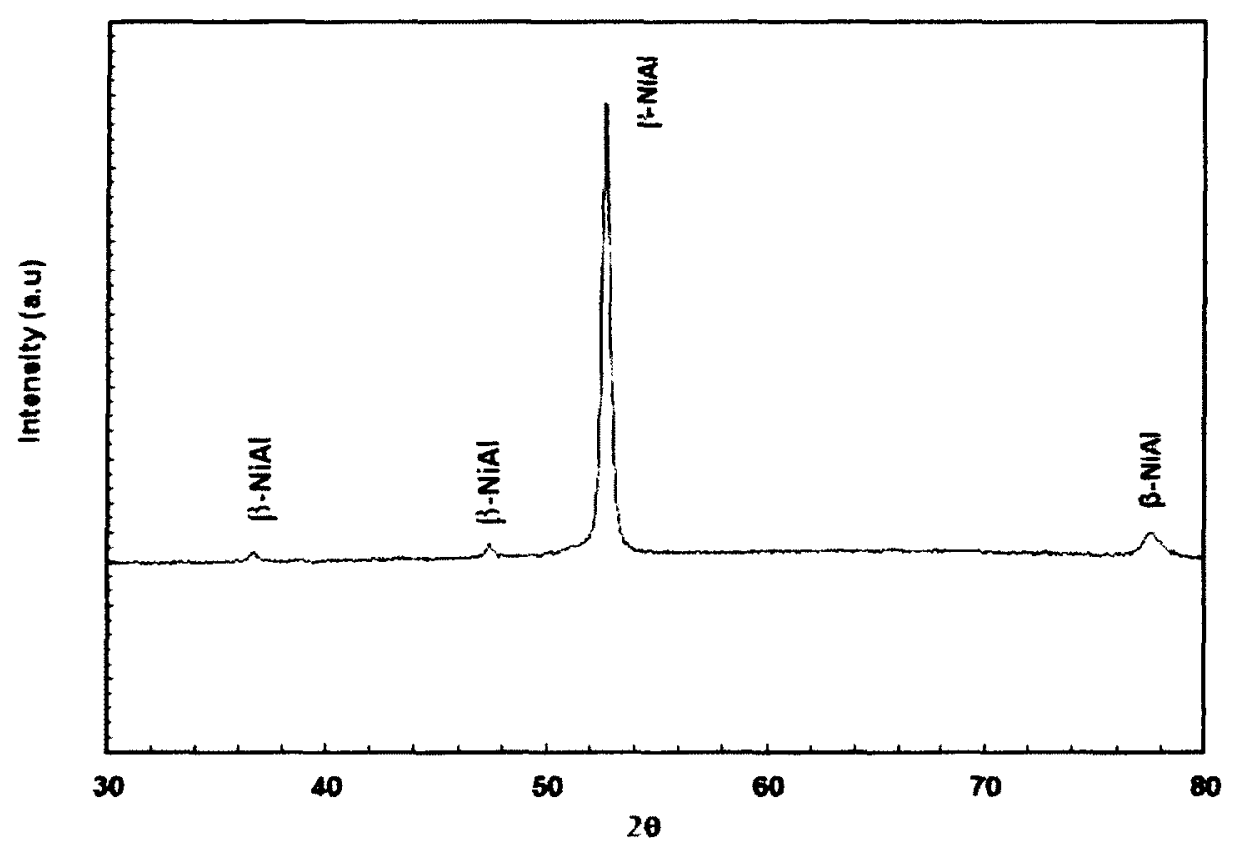

a) XRD spectrum for coating $1-1$ 


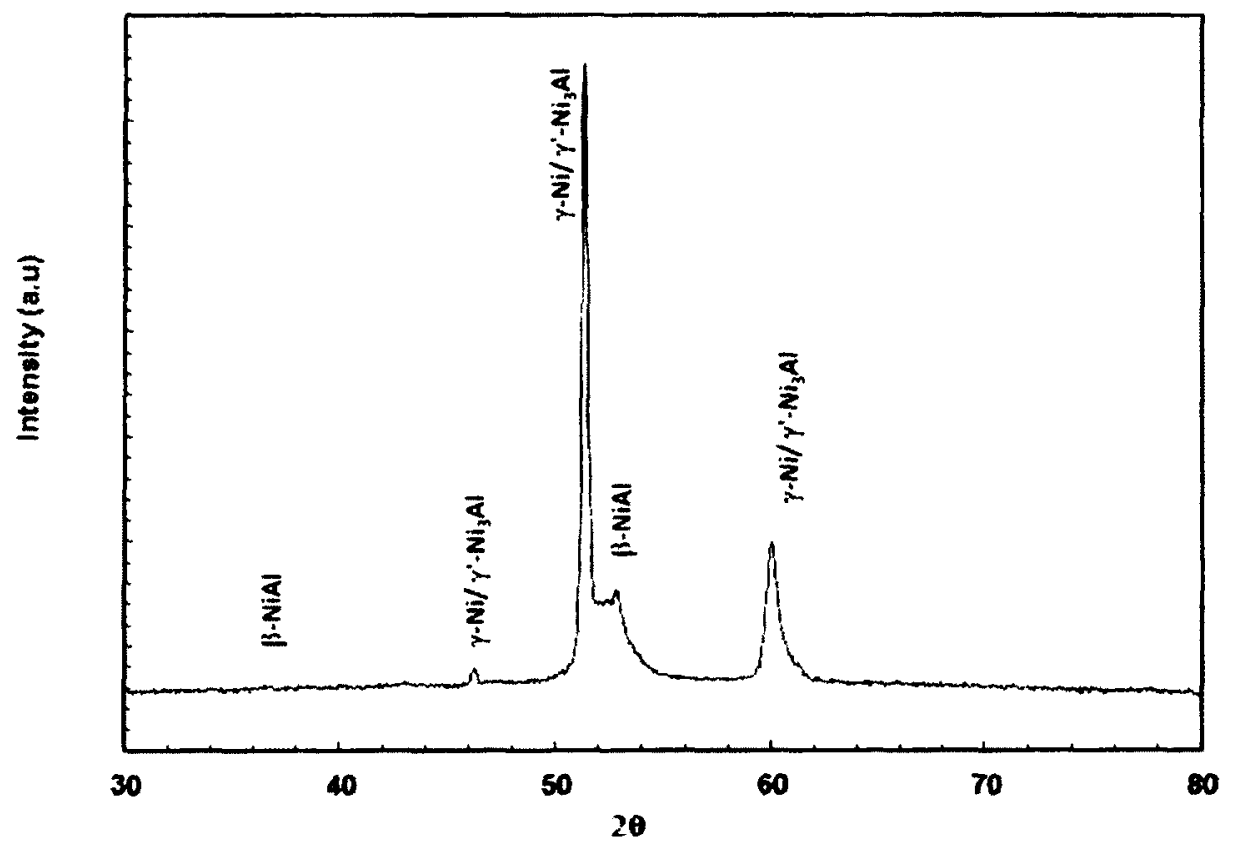

b) XRD spectrum for coating 1-5

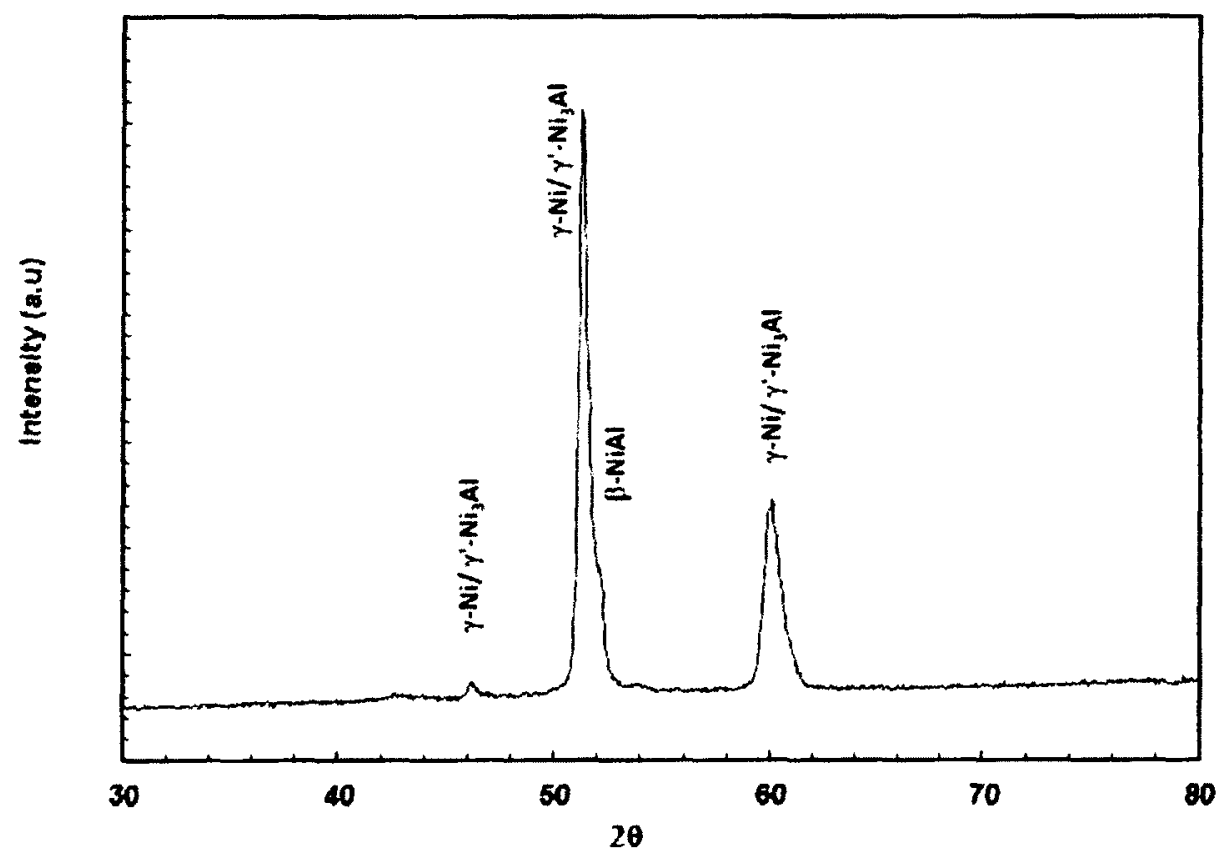

c) XRD spectrum for coating 1-9

Figure 4.4 XRD spectra for NiCrAIY coatings. 


\subsubsection{Results from the First Set of Experiments}

The quantitative results for four coating features are summarized in Table 4.3. Based on the results, the influences of each spraying process parameter on these coating features are illustrated in Figure 4.5.

Table 4.3 Percentages of crack, pore, unmelted particle and oxide in coatings

\begin{tabular}{lcccc}
\hline Coating & $\begin{array}{l}\text { Crack } \\
\text { interface, } \%\end{array}$ & $\begin{array}{l}\text { at } \\
\text { \%orosity*, }\end{array}$ & $\begin{array}{l}\text { Unmelted } \\
\text { particles, } \%\end{array}$ & $\begin{array}{l}\text { Oxide, } \\
\%\end{array}$ \\
\hline $1-1$ & 40.2 & 8.17 & 6.10 & 2.87 \\
$1-2$ & 56.3 & 10.83 & 10.30 & 1.10 \\
$1-3$ & 100.0 & 20.84 & 45.00 & 0.00 \\
$1-4$ & 100.0 & 18.06 & 15.35 & 0.00 \\
$1-5$ & 0.0 & 7.70 & 4.40 & 6.77 \\
$1-6$ & 0.0 & 5.20 & 12.13 & 4.50 \\
$1-7$ & 0.0 & 5.10 & 0.00 & 12.67 \\
$1-8$ & 0.0 & 4.80 & 2.93 & 8.73 \\
$1-9$ & 0.0 & 4.00 & 0.00 & 14.20 \\
\hline
\end{tabular}

* Measured based on area percentage of pores over total area analyzed.

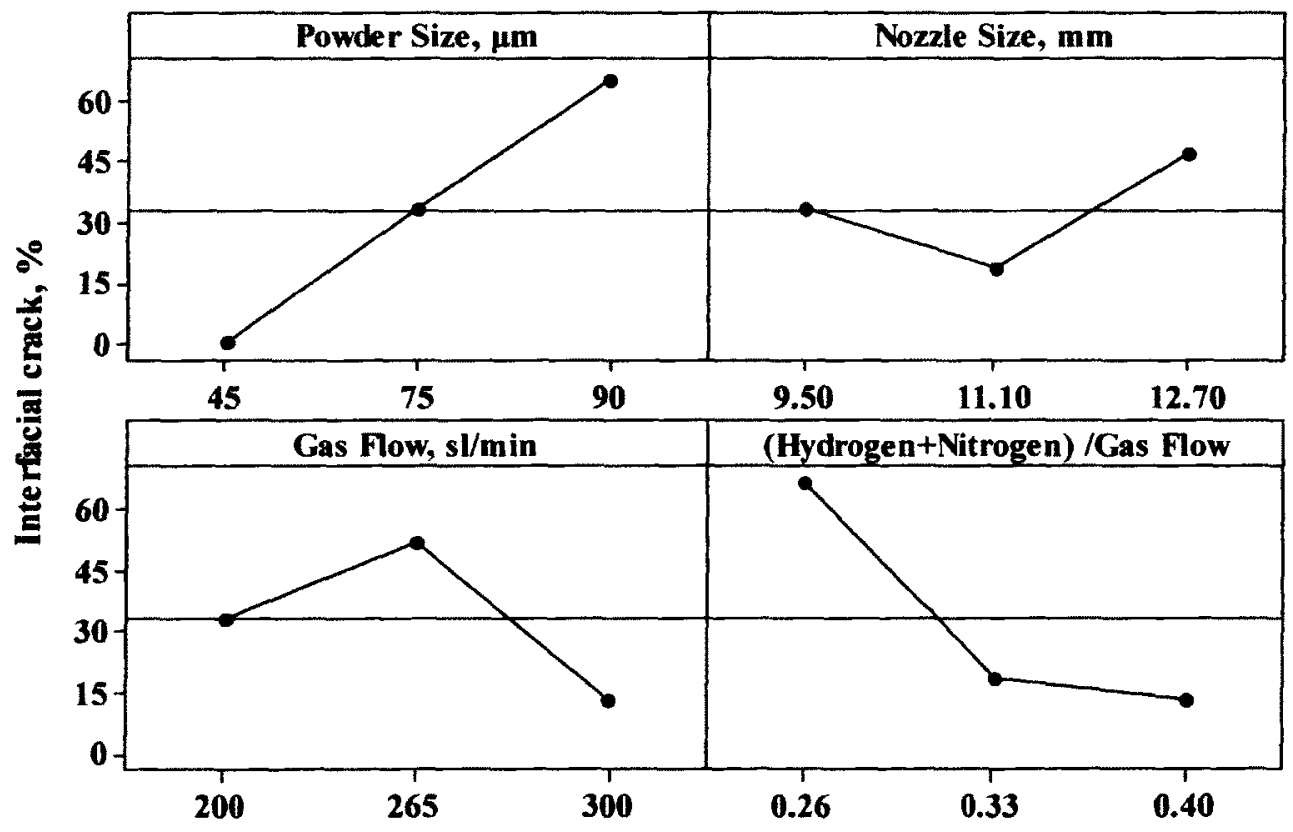

a) Influences of spraying process parameters on cracking 

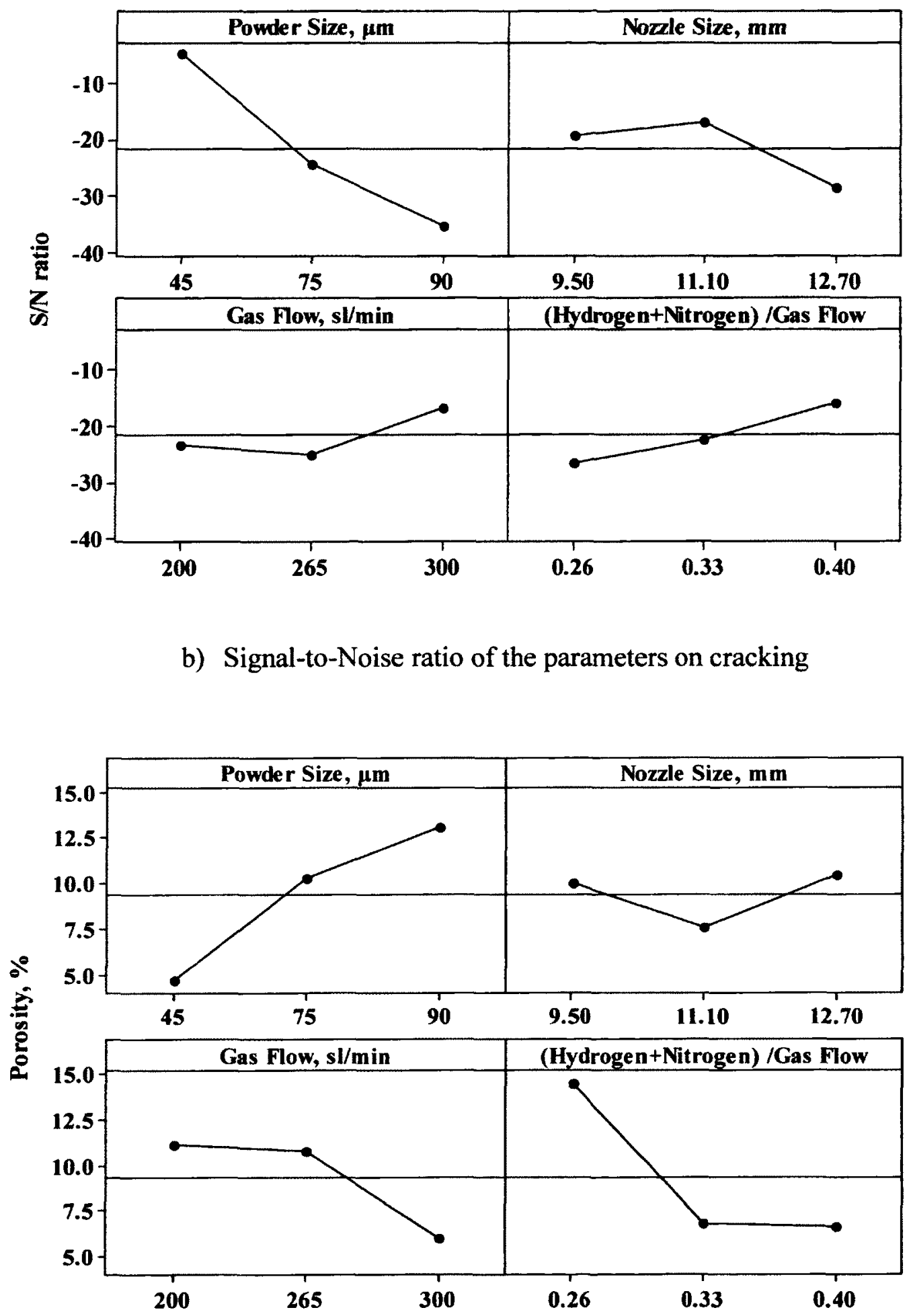

c) Influence of spraying process parameters on porosity 


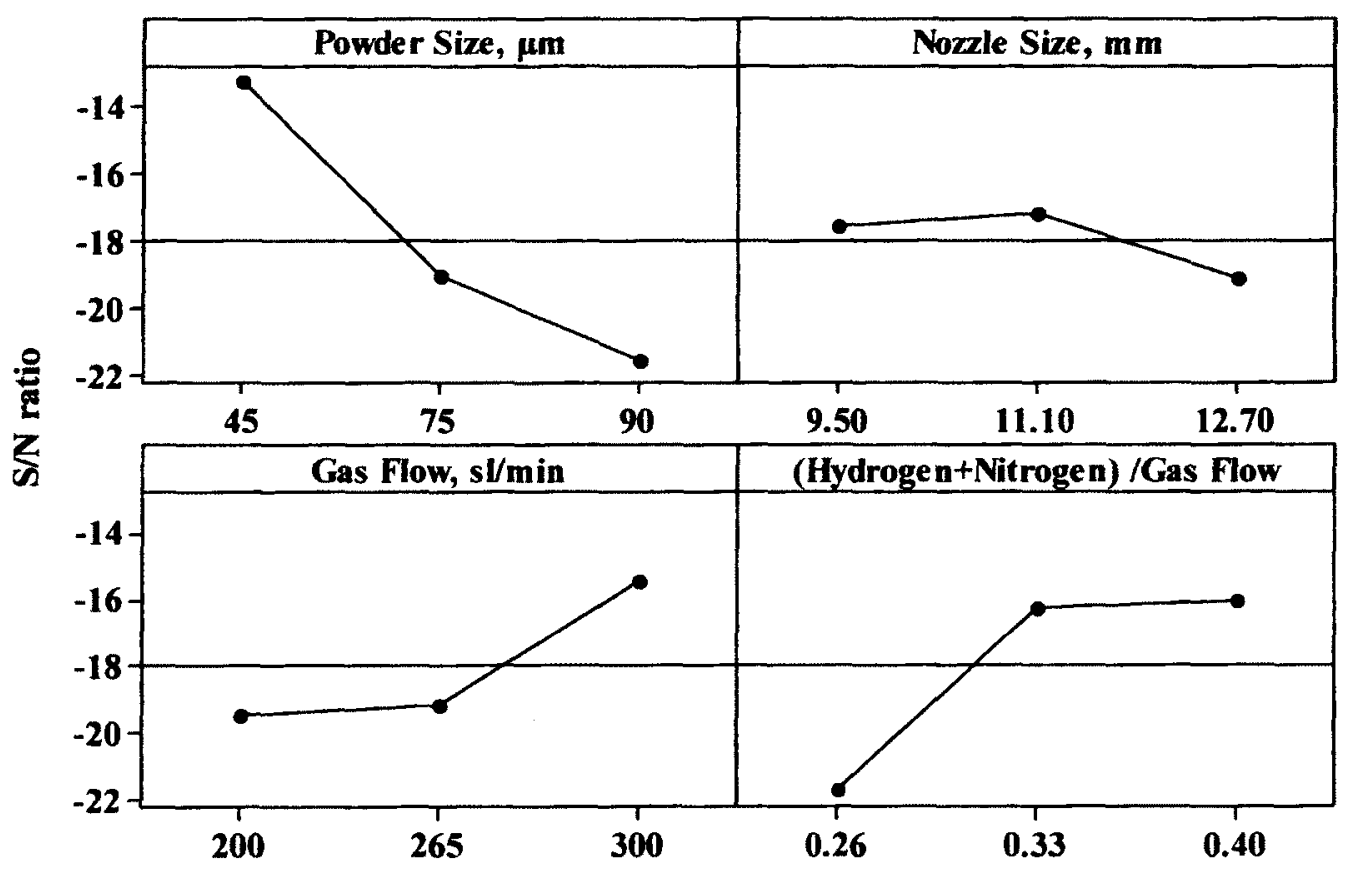

d) Signal-to-Noise ratio of the parameters on porosity

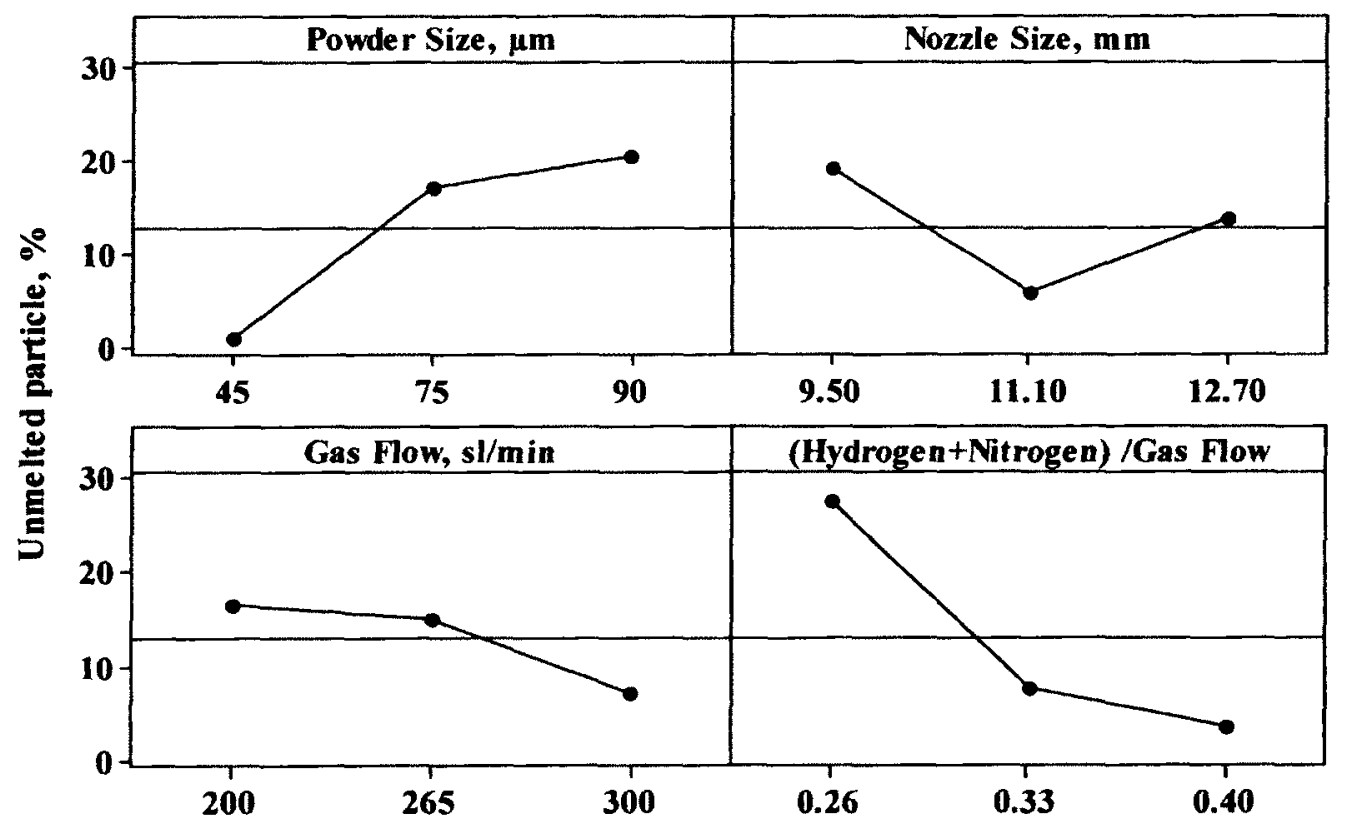

e) Influence of spraying process parameters on unmelted particles 


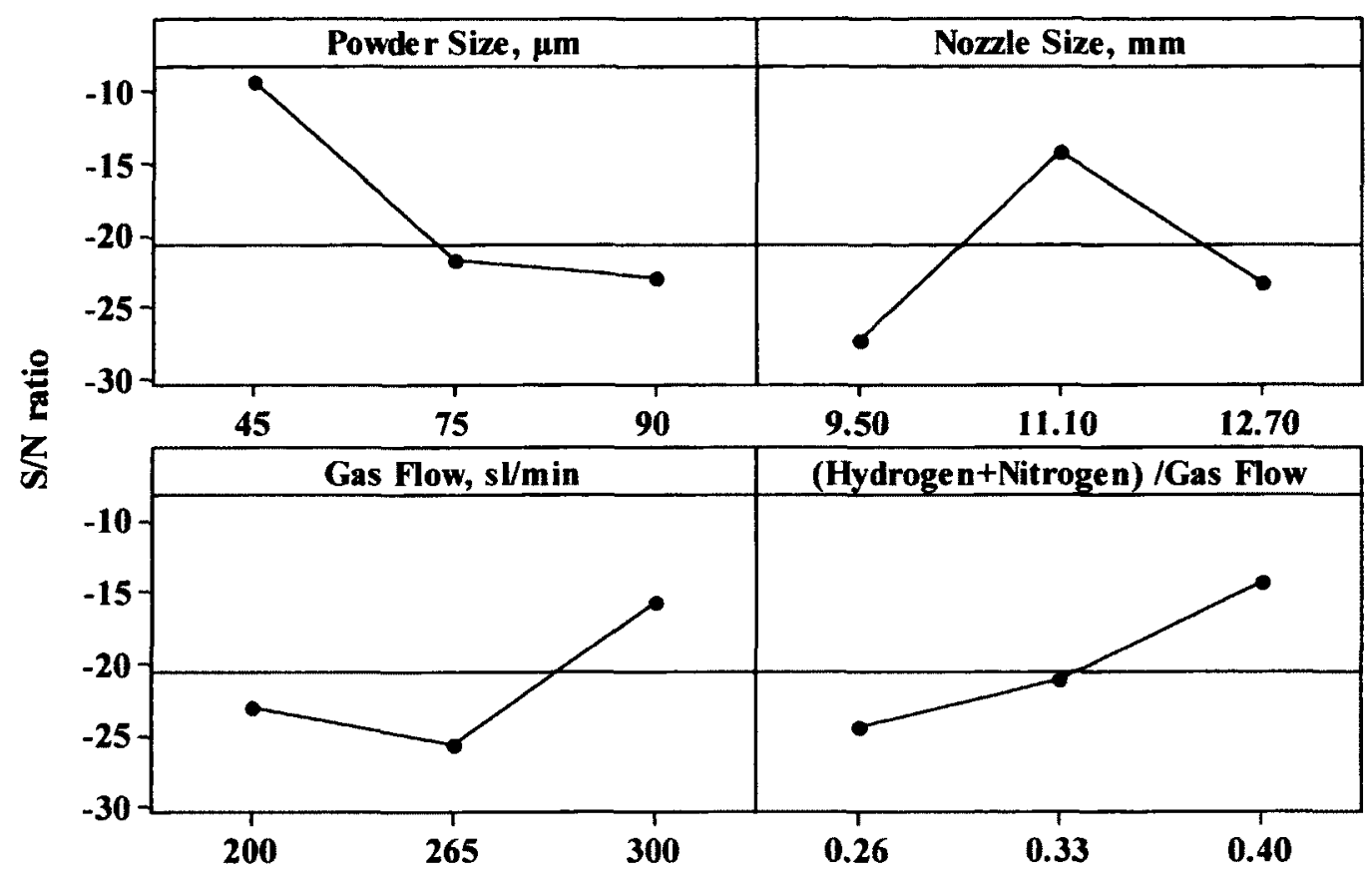

f) Signal-to-Noise ratio of the parameters on unmelted particles

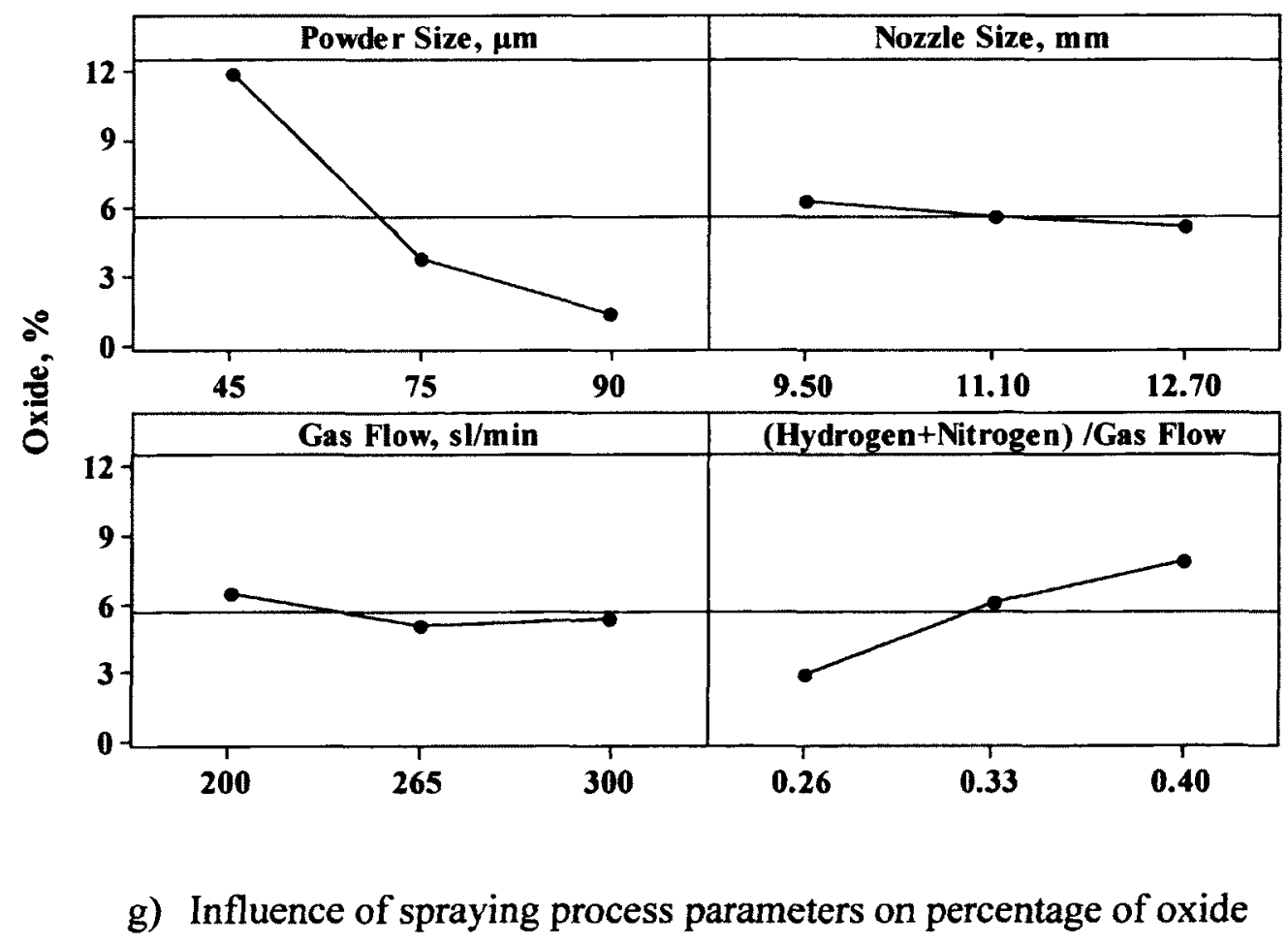




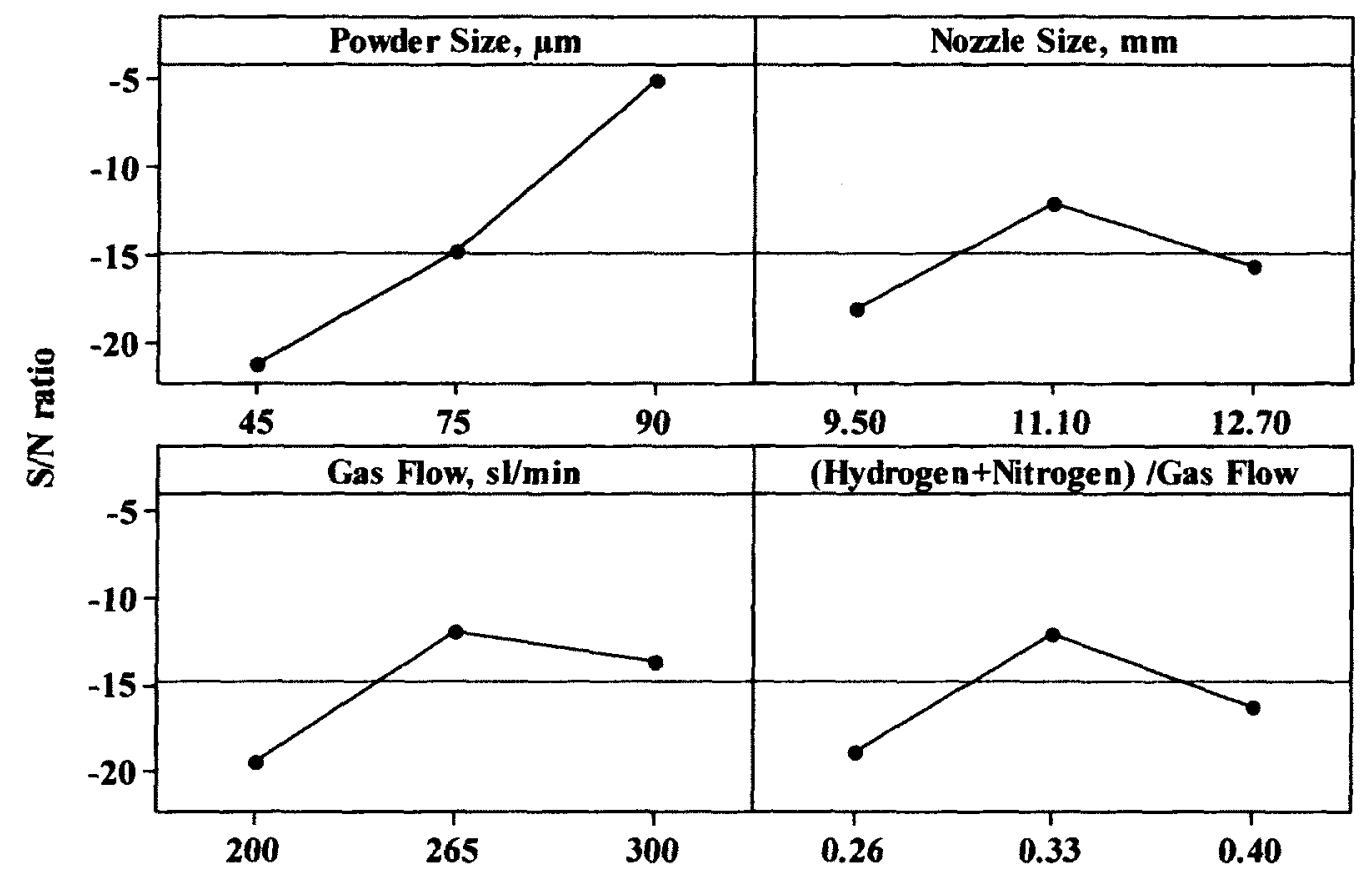

h) Signal-to-Noise ratio of the parameters on unmelted particles

Figure 4.5 Results of the experiments for the first Taguchi matrix.

All coating features are defects that should be minimized using the smaller-thebetter SNRs for each spraying process parameter. The optimal parameters for minimizing coating features are summarized in Table 4.4 based in the plot of the SNRs versus process parameters (Figure 4.5). The optimal parameters for minimizing all coating features are almost identical except that the optimal powder size for minimizing oxides is $90 \mu \mathrm{m}$ instead of $45 \mu \mathrm{m}$.

Table 4.4 Optimal parameters for minimizing coating features according SNRs

\begin{tabular}{lllll}
\hline Coating feature & $\begin{array}{l}\text { Powder } \\
\text { size, } \mu \mathrm{m}\end{array}$ & $\begin{array}{l}\text { Nozzle } \\
\text { size, } \mathrm{mm}\end{array}$ & $\begin{array}{l}\text { Total gas } \\
\text { rate, sl/min }\end{array}$ & $\begin{array}{l}\text { flow } \\
\mathrm{H}_{2}+\mathrm{N}_{2} \text { over total } \\
\text { gas flow rate }\end{array}$ \\
\hline Cracking & 45 & 11.10 & 300 & 0.40 \\
Porosity & 45 & 11.10 & 300 & 0.40 \\
Unmelted particles & 45 & 11.10 & 300 & 0.40 \\
Oxide & 90 & 11.10 & 265 & 0.33 \\
\hline
\end{tabular}


The four process parameters used in regression equations are given in Table 4.5. The influences of parameters on coating features cannot be accurately predicated using simple linear regressions based on the curves in Figure 4.5. Therefore the combination of process parameters (such as $x_{1} x_{2}, x_{1} x_{3}, x_{3} x_{4}$ ) and higher orders of these process variables (such as $x_{l}^{2}$ ) need to be incorporated into the regression equation in order to correlate the parameters with the coating features more accurately.

Table 4.5 Values of $x_{1}, x_{2}, x_{3}$ and $x_{4}$ used in regression equation

\begin{tabular}{llll}
\hline$x_{1}, \quad$ maximum & $x_{2}$, nozzle size in & $\begin{array}{l}x_{3}, \text { total flow rate at } \\
\text { sl/min }\end{array}$ & $\begin{array}{l}x_{4}, \text { ratio of } \mathrm{H}_{2}+\mathrm{N}_{2} \\
\text { over total gas }\end{array}$ \\
\hline 90 & $\mathrm{~mm}$ & 300 & 0.40 \\
75 & 12.7 & 265 & 0.33 \\
45 & 11.1 & 230 & 0.26 \\
\hline
\end{tabular}

A stepwise regression analysis started with a simple linear regression model for the powder size, which is illustrated in Table 4.6. A set criterion, $p=0.65$, was applied for removing and adding parameters. Some parameters were eliminated if $p$-value was too low. In each step the parameters were added in the equation when the $p$-values of the parameters were greater than 0.65 , and the parameters were removed from the equation when the $p$-values of the parameters were less than 0.65 . In the meanwhile the standard deviation $(S)$ and coefficient of determination $\left(R^{2}\right)$ were also calculated and included in Table 4.6. These parameters remained in the last step created the regression equations for all four coating features summarized in Table 4.6. Also included in this table are other statistic values such as $S, R^{2}, F, m, n$, and $p$-value as well as $R S S$ and MSE. RSS represents residual sum of squares. All regression equations have five degree of freedom $(m)$ and residuals have three degrees of freedom $(n)$. 
Table 4.6 Procedure of stepwise regression analysis for porosity

\begin{tabular}{lllccc}
\hline $\begin{array}{l}\text { Parameter } \\
\text { statistical } \\
\text { values }\end{array}$ & 1 & 2 & 3 & 4 & 5 \\
\cline { 2 - 6 } Constant & -3.84 & -3.84 & -21.10 & -50.31 & 13.53 \\
$x_{1}$ & $1.88 \times 10^{5}$ & $4.81 \times 10^{5}$ & $9.28 \times 10^{5}$ & $1.24 \times 10^{6}$ & $1.14 \times 10^{6}$ \\
$p\left(x_{1}\right)$ & 0.11 & 0.072 & 0.036 & 0.134 & 0.769 \\
$x_{1} x_{4}$ & & $-8.86 \times 10^{5}$ & $-2.24 \times 10^{6}$ & $-3.19 \times 10^{6}$ & $-2.84 \times 10^{6}$ \\
$p\left(x_{1} x_{4}\right)$ & & 0.015 & 0.054 & 0.012 & 0.006 \\
$x_{4}{ }^{2}$ & & & 154.00 & 254.00 & $7.61 \times 10^{2}$ \\
$p\left(x_{4}{ }^{2}\right)$ & & & 0.177 & 0.033 & 0.018 \\
$x_{2}$ & & & & 1.53 & 1.38 \\
$p\left(x_{2}\right)$ & & & & 0.068 & 0.026 \\
$x_{4}$ & & & & & $-3.60 \times 10^{2}$ \\
$p\left(x_{4}\right)$ & & & 3.01 & 2.62 & 0.047 \\
$S$ & & & 87.98 & 93.19 & 98.75 \\
$R^{2}$ & 4.57 & 4.10 & & & 1.11 \\
\hline
\end{tabular}

In the polynomial equations containing the process parameters concerned in this study, all $F$ values in Table 4.7 are greater than the threshold $F(5,3,0.95)=9.01$. In all cases $R^{2}$ values are over $96 \%$, which indicate that less than $4 \%$ of the total variations are not explained by the regression relationships. Thus, it can be concluded that the regression equations are all significant. It should be noted that $x_{3}$ (total gas flow rate) has not been included in the regression equations because of its insignificant influence.

Normality test and independence test of the regression equations for the coating features verified the validity of the equations. An example of the test is illustrated on Figure 4.5, and the residuals are correlated with the line of normality test and the distribution of the residuals is random and independent. 
Table 4.7 Regression equations for four coating microstructure features

\begin{tabular}{|c|c|c|c|c|c|c|c|}
\hline Feature & Regression equations & $S$ & $R^{2}$ & $F$ & $p$-value & $R S S$ & $M S E$ \\
\hline Crack & $\begin{array}{l}\mathrm{C}\left(x_{1}, x_{2}, x_{3}, x_{4}\right)=-3.00+ \\
7.78 \times 10^{6} \times x_{1}-1.88 \times \\
10^{3} \times x_{4}-1.96 \times \\
10^{7} \times x_{1} \times x_{4}+0.57 \times x_{2}{ }^{2}+ \\
4.35 \times 10^{3} \times x_{4}{ }^{2}\end{array}$ & 11.8 & 97.2 & 21.0 & 0.015 & 14584.7 & 138.7 \\
\hline Porosity & $\begin{array}{c}\mathrm{P}\left(x_{1}, x_{2}, x_{3}, x_{4}\right)=13.53+ \\
1.14 \times 10^{6} \times x_{1}+1.38 \times \\
x_{2}-3.60 \times 10^{2} \times x_{4}- \\
2.84 \times 10^{6} \times x_{1} \times x_{4}+ \\
7.61 \times 10^{2} \times x_{4}^{2}\end{array}$ & 1.1 & 98.7 & 47.4 & 0.005 & 293.8 & 1.2 \\
\hline $\begin{array}{l}\text { Un- } \\
\text { melted } \\
\text { particle }\end{array}$ & $\begin{array}{l}\mathrm{U}\left(x_{1}, x_{2}, x_{3}, x_{4}\right)=49.00+ \\
3.32 \times 10^{6} \times x_{1}- \\
8.53 \times 10^{2} \times x_{4}- \\
5.84 \times 10^{7} \times x_{1} \times x_{4}- \\
7.13 \times 10^{9} \times x^{2}+ \\
1.65 \times 10^{3} \times x_{4}{ }^{2}\end{array}$ & 4.7 & 96.7 & 22.0 & 0.005 & 1989.5 & 22.7 \\
\hline Oxide & $\begin{array}{l}\mathrm{O}\left(x_{1}, x_{2}, x_{3}, x_{4}\right)=-5.50+ \\
1.42 \times 10^{5} \times x_{1}+0.44 \times \\
x_{2}+43.4 \times x_{4}-0.87 \times x_{1} \\
\times x_{2}-6.80 \times 10^{-2} \times x_{2}{ }^{2}\end{array}$ & 0.9 & 99.0 & 59.6 & 0.003 & 224.4 & 0.8 \\
\hline
\end{tabular}

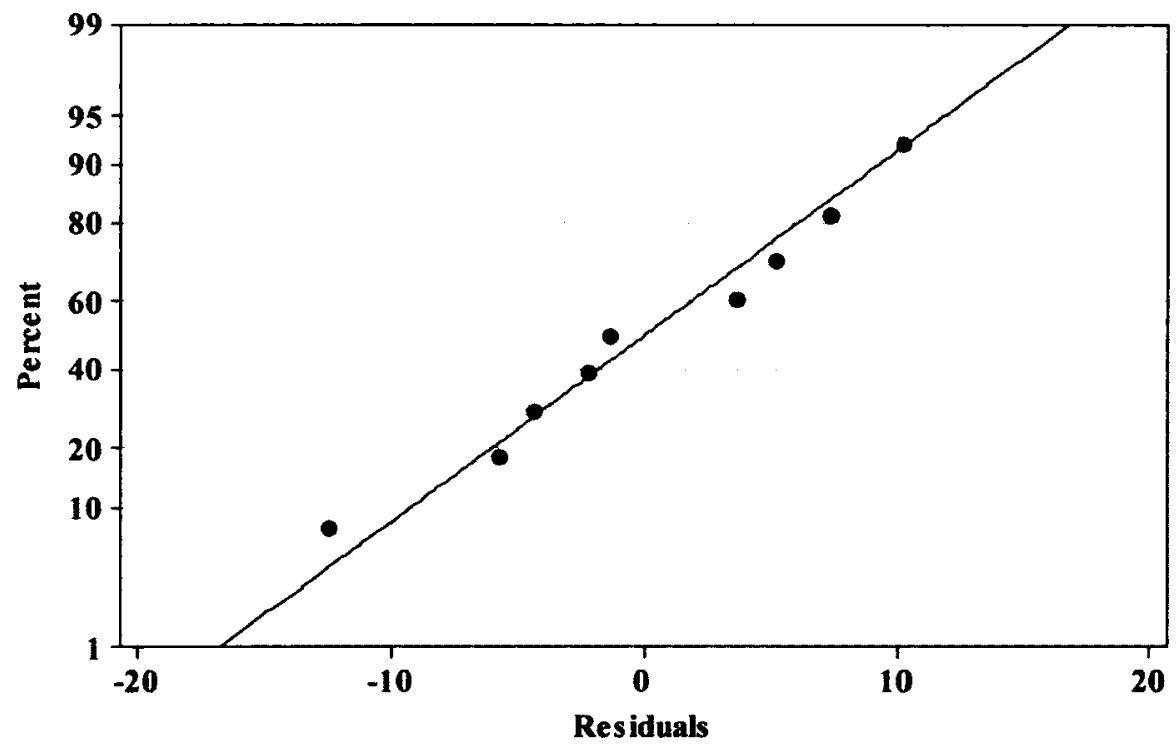

a) Normal probability plot of the residuals 


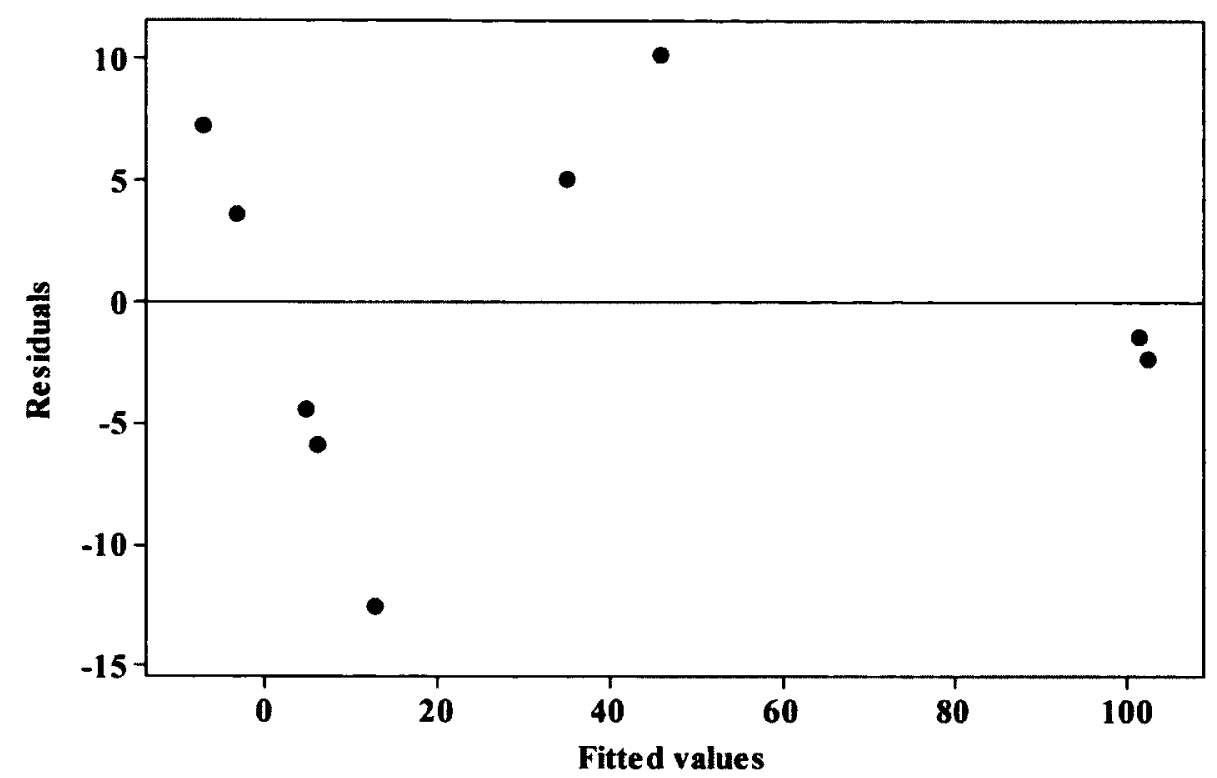

b) Independence test

Figure 4.6 Normality and independence test of the regression equation for crack.

Table 4.8 compares the measured results of the coating features from the experiment with the values calculated from the regression equations. The calculated values agree well with the experimental results and the predicted errors fall into the confidence interval of the measured data at $95 \%$ confidence level $(\alpha=0.05)$.

\subsubsection{Discussion on the Results from the First Set of Experiments}

Table 4.9 summarizes the effects of the process parameters on the microstructural features of NiCrAlY coatings based on the regression equations. It is generally accepted that the spray parameters could be ranked based on their $p$-values on coating features [104] and accordingly the ranking has been made as shown in Table 4.9. All parameters are categorized into three levels: the most significant, medium significant and least significant. The most significant process parameters found in this study are the particle size $\left(x_{1}\right)$, the ratio of $\mathrm{H}_{2}+\mathrm{N}_{2}$ over total gas $\left(x_{4}\right)$, their interaction $\left(x_{1} x_{4}\right)$ and their 
squared values $\left(x_{1}{ }^{2}\right.$ and $\left.x_{4}{ }^{2}\right)$. The next important parameters are nozzle size $\left(x_{2}\right)$ and parameters related to the nozzle size.

Table 4.8 Comparison of the experimental results with the values calculated from the regression equations

\begin{tabular}{|c|c|c|c|c|}
\hline \multirow[b]{2}{*}{ Coating } & \multicolumn{4}{|c|}{ Crack at interface, $\%$} \\
\hline & E-value* & C- value ${ }^{\wedge}$ & $\begin{array}{l}\text { Predicted } \\
\text { error }\end{array}$ & $\begin{array}{l}\text { Confidence interval } \\
\text { at } 95 \%\end{array}$ \\
\hline $1-1$ & 39.15 & 34.80 & $16.44-63.56$ & $2.55-77.45$ \\
\hline $1-2$ & 56.36 & 45.80 & $32.44-79.56$ & $18.55-93.45$ \\
\hline $1-3$ & 100.00 & 100.00 & $76.44-100.00$ & $62.55-100.00$ \\
\hline $1-4$ & 100.00 & 100.00 & $76.44-100.00$ & $62.55-100.00$ \\
\hline $1-5$ & 0 & 12.57 & $0.00-23.56$ & $0.00-37.45$ \\
\hline $1-6$ & 0 & 5.78 & $0.00-23.56$ & $0.00-37.45$ \\
\hline $1-7$ & 0 & 4.42 & $0.00-23.56$ & $0.00-37.45$ \\
\hline $1-8$ & 0 & 0.00 & $0.00-23.56$ & $0.00-37.45$ \\
\hline \multirow[t]{3}{*}{$1-9$} & 0 & 0.00 & $0.00-23.56$ & $0.00-37.45$ \\
\hline & \multicolumn{4}{|c|}{ Porosity, $\%$} \\
\hline & E-value & C-value & $\begin{array}{l}\text { Predicted } \\
\text { error }\end{array}$ & $\begin{array}{l}\text { Confidence interval } \\
\text { at } 95 \%\end{array}$ \\
\hline $1-1$ & 8.17 & 8.62 & $5.94-10.4$ & $4.63-11.71$ \\
\hline $1-2$ & 10.30 & 10.64 & $8.07-12.53$ & $6.76-13.84$ \\
\hline $1-3$ & 20.84 & 20.11 & $18.61-23.07$ & $17.30-24.38$ \\
\hline $1-4$ & 18.06 & 18.70 & $15.83-20.29$ & $14.52-21.60$ \\
\hline $1-5$ & 7.70 & 8.57 & $5.47-9.93$ & $4.16-11.24$ \\
\hline $1-6$ & 5.20 & 5.61 & $2.97-7.43$ & $1.66-8.74$ \\
\hline $1-7$ & 5.10 & 4.36 & $2.87-7.33$ & $1.56-8.64$ \\
\hline $1-8$ & 4.80 & 4.89 & $2.57-7.03$ & $1.26-8.34$ \\
\hline \multirow[t]{2}{*}{$1-9$} & 4.00 & 4.68 & $1.77-6.23$ & $0.46-7.54$ \\
\hline & \multicolumn{4}{|c|}{ Unmelted particles, $\%$} \\
\hline Coating & E-value & C- value & $\begin{array}{l}\text { Predicted } \\
\text { error }\end{array}$ & $\begin{array}{l}\text { Confidence interval } \\
\text { at } 95 \%\end{array}$ \\
\hline $1-1$ & 6.10 & 4.30 & $0.00-15.63$ & $0.00-21.26$ \\
\hline $1-2$ & 10.30 & 15.07 & $0.77-19.83$ & $0.00-25.46$ \\
\hline $1-3$ & 45.00 & 44.78 & $35.47-54.53$ & $29.84-60.16$ \\
\hline $1-4$ & 15.35 & 31.92 & $5.82-24.88$ & $0.19-30.51$ \\
\hline $1-5$ & 4.40 & 3.70 & $0.00-13.93$ & $0.00-19.56$ \\
\hline $1-6$ & 12.13 & 9.72 & $2.60-21.66$ & $0.00-27.29$ \\
\hline $1-7$ & 0.00 & 0.00 & $0.00-9.53$ & $0.00-15.16$ \\
\hline $1-8$ & 2.93 & 6.20 & $0.00-12.46$ & $0.00-18.09$ \\
\hline $1-9$ & 0.00 & 2.50 & $0.00-9.53$ & $0.00-15.16$ \\
\hline
\end{tabular}


Table 4.8 continued

\begin{tabular}{lcccc}
\hline Coating & \multicolumn{4}{c}{ Oxide, \% } \\
\cline { 2 - 5 } & E-value & C- value & $\begin{array}{l}\text { Predicted } \\
\text { error }\end{array}$ & $\begin{array}{l}\text { Confidence interval } \\
\text { at } 95 \%\end{array}$ \\
\hline $1-1$ & 2.87 & 2.39 & $1.13-4.61$ & $0.10-5.64$ \\
$1-2$ & 1.10 & 0.74 & $0.00-2.84$ & $0.00-3.87$ \\
$1-3$ & 0.00 & 0.00 & $0.00-1.74$ & $0.00-2.77$ \\
$1-4$ & 0.00 & 0.69 & $0.00-1.74$ & $0.00-2.77$ \\
$1-5$ & 6.77 & 7.37 & $5.03-8.51$ & $4.00-9.54$ \\
$1-6$ & 4.50 & 5.30 & $2.76-6.24$ & $1.73-7.27$ \\
$1-7$ & 12.67 & 12.47 & $10.93-14.41$ & $9.90-15.44$ \\
$1-8$ & 8.73 & 8.48 & $6.99-10.47$ & $5.96-11.50$ \\
$1-9$ & 14.20 & 13.96 & $12.46-15.94$ & $11.43-16.97$ \\
\hline
\end{tabular}

*E-value: Experimentally measured value

${ }^{\wedge} \mathrm{C}$-value: Calculated value from regression equation

Table 4.9 Effects of process parameters on coating features

\begin{tabular}{lllllllll}
\hline $\begin{array}{l}\text { Para- } \\
\text { meter }\end{array}$ & \multicolumn{7}{c}{$p$-value and rank } \\
\cline { 2 - 9 } & $\begin{array}{l}\text { Crack at } \\
\text { interface }\end{array}$ & Rank & Porosity & Rank & $\begin{array}{l}\text { Unmelted } \\
\text { powder }\end{array}$ & Rank & Oxide & Rank \\
\hline$x_{1}$ & 0.012 & 1 & 0.004 & 1 & 0.060 & 2 & 0.465 & 3 \\
$x_{2}$ & 0.000 & & 0.026 & 4 & 0.000 & - & 0.955 & 5 \\
$x_{4}$ & 0.204 & 5 & 0.042 & 5 & 0.165 & 4 & 0.006 & 1 \\
$x_{1} x_{2}$ & 0.000 & - & 0.000 & - & 0.000 & - & 0.105 & 2 \\
$x_{1} x_{4}$ & 0.020 & 2 & 0.006 & 2 & 0.029 & 1 & 0.000 & - \\
$x_{1}{ }^{2}$ & 0.000 & - & 0.000 & - & 0.419 & 5 & 0.000 & - \\
$x_{2}{ }^{2}$ & 0.036 & 3 & 0.000 & - & 0.000 & - & 0.797 & 4 \\
$x_{4}{ }^{2}$ & 0.083 & 4 & 0.018 & 3 & 0.096 & 3 & 0.000 & - \\
\hline
\end{tabular}

The sequential sums of squares $(S S)$ for parameters included in the regression equations (Table 4.10) can be quantitatively calculated to provide comparison of the significance of various parameters on coating microstructural features. The sequential $S S$ measures the reduction in the residual sums of squares $(R S S)$ provided by each additional parameter in the regression equation. If the sequential $S S$ of a parameter substantially reduces the residual sums of squares in a regression equation, this parameter becomes significant in the equation. Based on the percentage of the 
sequential sums of squares over total sums of squares for each parameter (Table 4.10), Pareto diagrams can be generated to analyze the impact of various process parameters, as shown in Figure 4.7. Pareto diagrams are simple bar charts that rank related process parameters in decreasing order of significance. The principle of Pareto diagram is based on the unequal distribution of things in the universe. It is the law of the "more important few versus the trivial many" [105]. By graphing each coating feature with respect of the sequential $S S$ for all process parameters, the most significantly parameter could be identified.

Table 4.10 Sequential sums of squares of process parameters on coating features

\begin{tabular}{|c|c|c|c|c|}
\hline \multirow{2}{*}{$\begin{array}{l}\text { Process } \\
\text { parameter }\end{array}$} & \multicolumn{2}{|c|}{ Crack at interface } & \multicolumn{2}{|c|}{ Porosity } \\
\hline & Sequential SS & Percent, \% & Sequential SS & Percent,\% \\
\hline$x_{I}$ & 6202.02 & 42.50 & 111.82 & 38.06 \\
\hline$x_{2}$ & 0.00 & 0.00 & 0.28 & 0.10 \\
\hline$x_{4}$ & 4266.70 & 29.50 & 94.65 & 32.22 \\
\hline$x_{1} x_{2}$ & 0.00 & 9.44 & 0.00 & 0.00 \\
\hline$x_{1} x_{4}$ & 1376.20 & 0.00 & 59.24 & 20.16 \\
\hline$x_{l}^{2}$ & 0.00 & 6.24 & 0.00 & 0.00 \\
\hline & 1829.60 & 12.50 & 0.00 & 0.00 \\
\hline & 10.20 & 0.00 & 27.80 & 9.46 \\
\hline Total $S S$ & 14584.70 & & 293.79 & \\
\hline \multirow{2}{*}{$\begin{array}{l}\text { Process } \\
\text { parameter }\end{array}$} & \multicolumn{2}{|c|}{ Unmelted powder } & \multicolumn{2}{|c|}{ Oxide } \\
\hline & Sequential SS & Percent,\% & Sequential SS & Percent,\% \\
\hline$x_{1}$ & 633.97 & 31.55 & 180.60 & 80.47 \\
\hline$x_{2}$ & 0.00 & 0.00 & 1.66 & 0.74 \\
\hline$x_{4}$ & 873.63 & 43.48 & 38.05 & 16.95 \\
\hline$x_{1} x_{2}$ & 0.00 & 0.00 & 4.05 & 1.80 \\
\hline$x_{1} x_{4}$ & 350.96 & 17.47 & 0.00 & 0.00 \\
\hline$x_{l}^{2}$ & 19.87 & 0.99 & 0.00 & 0.00 \\
\hline$x_{2}^{2}$ & 0.00 & 0.00 & 0.06 & 0.03 \\
\hline$x_{4}^{2}$ & 130.90 & 6.51 & 0.00 & 0.00 \\
\hline Total SS & 2009.23 & & 224.43 & \\
\hline
\end{tabular}

Examining Table 4.10 , it is found that over $80 \%$ of sequential $S S$ is accumulated from the sequential $S S$ of particle size $\left(x_{1}\right)$, the ratio of $\mathrm{H}_{2}+\mathrm{N}_{2}$ over total gas $\left(x_{4}\right)$, and 
parameters related to them. This suggests that powder particle size and the ratio of $\mathrm{H}_{2}+$ $\mathrm{N}_{2}$ over total gas are the most dominating factors for all coating microstructural features. Within the range of the experimental parameters used in this study, smaller powder particle size and higher ratio of $\mathrm{H}_{2}+\mathrm{N}_{2}$ over total gas reduce the percentages of cracks, pores, unmelted particles but increase the percentage of oxides. Nozzle size has certain influence on oxides. The trend observed from the percentage of $S S$ also coincides with that found from the graphic illustrations of Figure 4.5g.

The effects of the process parameters on the coating features are reflected through investigating their influences on the powder particle velocity and temperature. In order to understand the particle melting process, the influences of the parameters on the particle flight time, flame temperature and heat transfer coefficient have been taken into consideration.

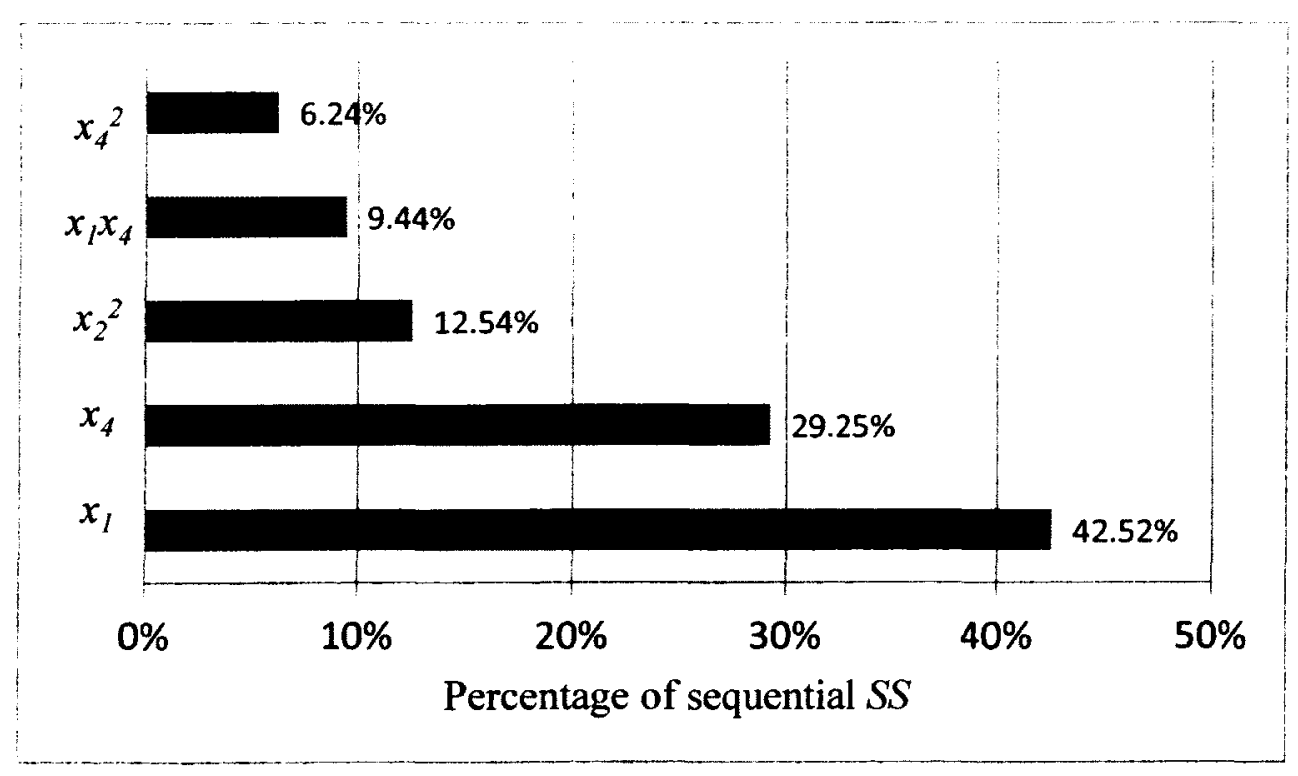

a) Effects of various process parameters on cracking 


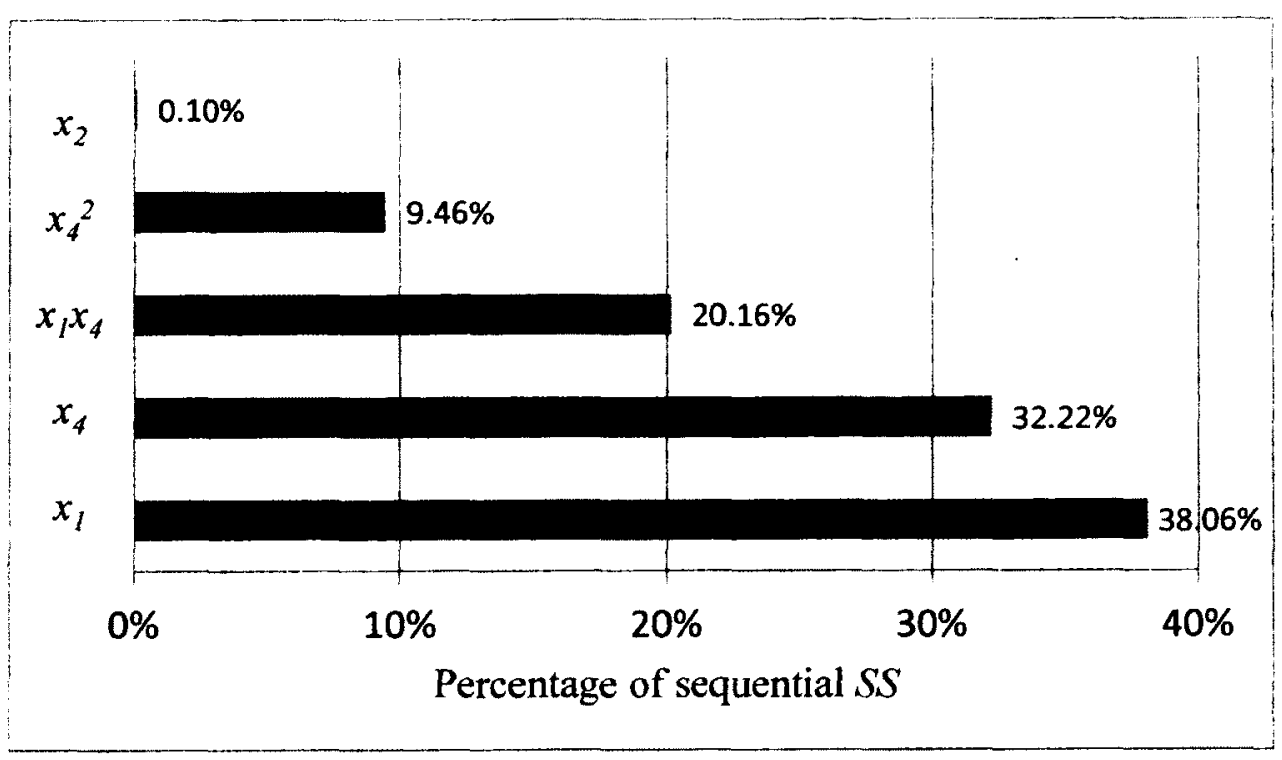

b) Effects of various process parameters on porosity

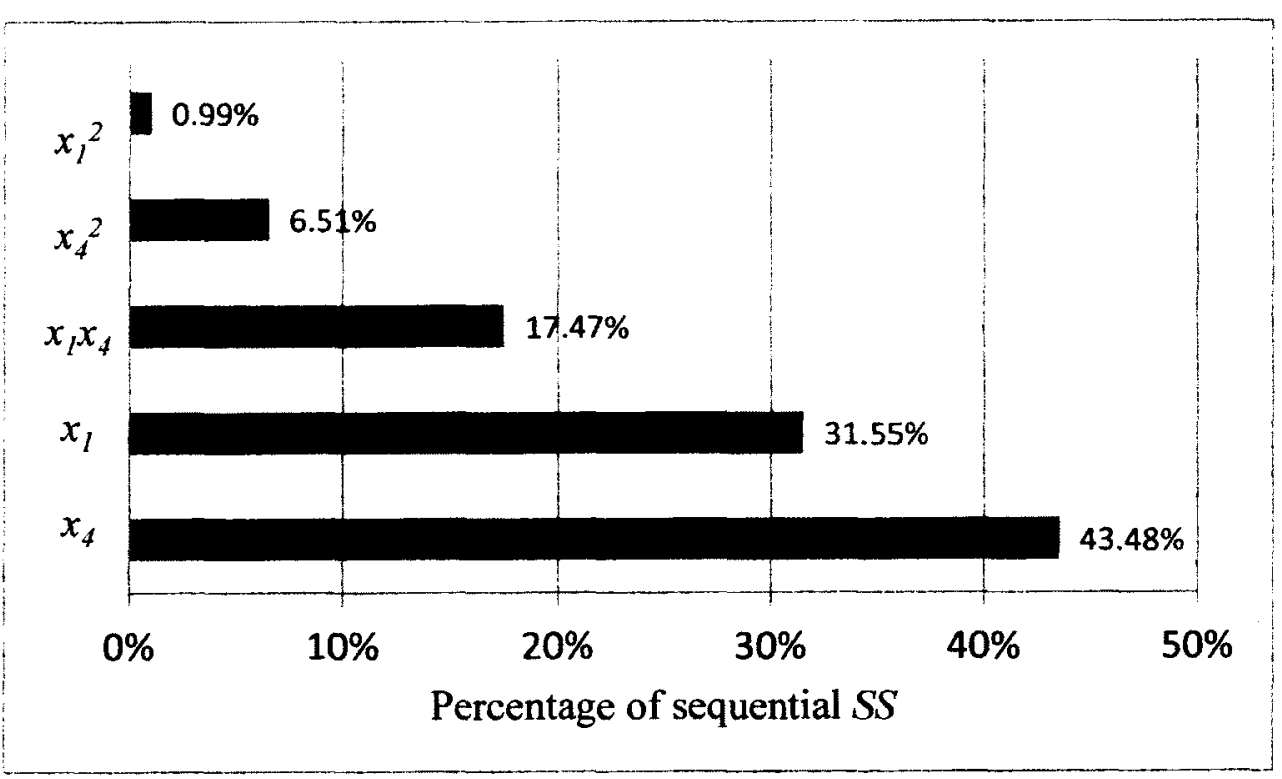

c) Effects of various process parameters on unmelted particle 


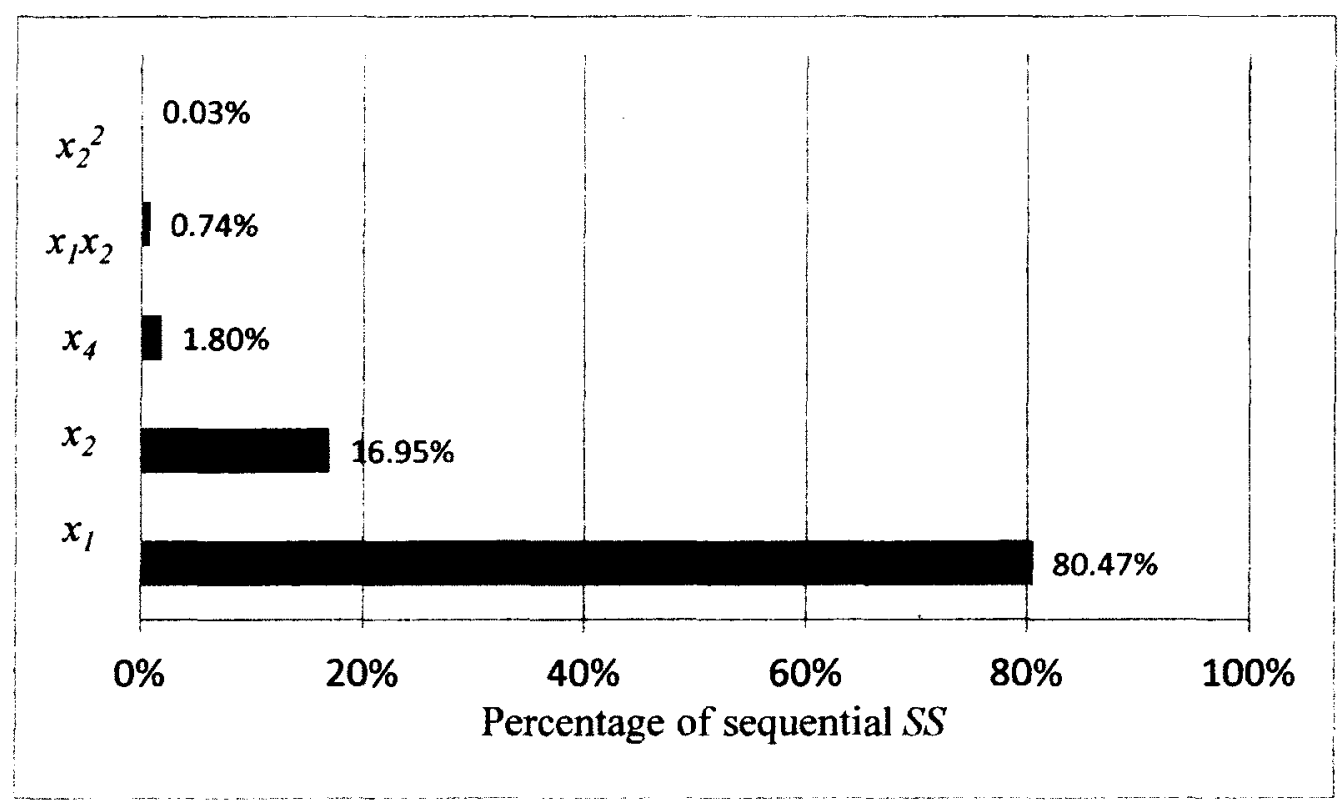

d) Effects of various process parameters on percentage of oxides

Figure 4.7 Pareto diagrams showing the effects of process parameters on coating features.

In general, a better melting process is expected if more heat is convectively transferred to the particles, which suggests that the particles are easier to be melted in the plasma gas with the higher flame temperature and the larger heat transfer coefficient in addition to longer residence time. Previous study attempted to characterize the behavior of the particle flow in an axial injection plasma torch [53]. Based on the results of this study, the reasons that powder size has the most significant influence on melting status of particle can be described as follows:

(1) Temperature is uniform across the particle stream and the particle velocity can reach $380-550 \mathrm{~m} / \mathrm{s}$ near the torch axis. Therefore at the beginning most particles penetrate the flame center easily and the temperature of the particles increases during spraying. The particle trajectory and velocity within the plasma flame are then 
determined by the mass and the size of the particles. Small particles may be vaporized prior to reaching the substrate, whereas large particles may not be completely melted upon impacting or missing the target entirely. Accordingly only a fraction of the particles can reach the substrate to form the coating and the ranges of the size of the particles that form the coating are very narrow [106].

(2) Heat transfer coefficient increases with decreasing powder size.

(3) The enthalpy for melting a large particle, which depends on volume of the particle (assuming constant heat capacity and density), is much more than that for melting a small particle.

Small particles are more likely to melt than large particles; using small particles apparently decreases the tendency of forming unmelted particles and pores. However small particles are easier oxidized due to the large surface-to-volume ratio. The dependence of particle size on coating cracking may be likely due to the fact that the residual stress between the coating and the substrate varies with particle size. In plasma spraying, residual stress arises from the quenching stress during solidification of molten particles and thermal stress because of the difference in coefficient of thermal expansion (CTE) between the coating and the substrate [107]. Other parameters may also affect the residual stress level such as preheat temperature, sand blasting before spraying [108], and phase transformation (for ferrous and precipitation-hardenable alloys). In this research, the thermal mismatch between the coating and the substrate is very small because they are both nickel-based, therefore the residual stress mainly resulted from the quenching stress, which was related to the solid shrinkage of splats during solidification and the restraint between splats. The large splats, produced by 
large particles, create more solid shrinkage than small splats, and the restraint between large splats is stronger than that between small splats. Consequently the coating produced by large particles has tendency to micro-cracking and micro-crack-induced delamination.

The ratio of $\mathrm{H}_{2}+\mathrm{N}_{2}$ over total gas flow affects powder particle temperature via plasma enthalpy and heat transport. Higher plasma enthalpy is associated with higher ratio of $\mathrm{H}_{2}+\mathrm{N}_{2}$ over total gas flow as both of these diatomic gases transfer heat to the particles more efficiently than argon. As a result the particles in the plasma stream with a higher ratio of $\mathrm{H}_{2}+\mathrm{N}_{2}$ experienced a higher in-flight temperature [109].

Nozzle size has certain effects on particle velocity and the shape of the plasma flame [53]. The particle velocity decreases and the shape of the plasma flame gets broader when nozzle size increases, and thus the residence time of the particle in the plasma stream increases. The longer residence time, consequently high particle temperature, helps to eliminate cracks, pores and unmelted particles; however, lower particle velocity promotes the formation of cracks and pores due to low kinetic energy of the particle and the formation of unmelted particles since some particles move away from the hot core of the plasma jet. The combination of these two factors results in the parabolic shaped curves for the percentages of cracks, pores and unmelted particles as a function of nozzle size, which is shown in Figure 4.5a, Figure 4.5c, and Figure 4.5e. Whereas the curve for the percentage of oxides is almost a straight line (Figure $4.5 \mathrm{~g}$ ) because both low particle velocity and broaden plasma flame promote oxidation. Such nozzle size has been found to have more influence on the formation of oxides than on the other coating features, which is further illustrated in Figure 4.6d. 
Gas flow rate, to certain extent, should have influence on the particle velocity and coating features related to particle velocity, particularly porosity. However the influence of total gas flow rate was not observed within the range of variation in this study, and this could in part because of the near sonic velocity of the plasma stream generated in Mettech Axial IIITM System. Therefore the total gas flow rate and its related parameters were not included in any regression equation.

The regression equations obtained from section 4.2 .2 were validated with another experiment using the process parameters listed in Table.4.11. The experimental results of four key microstructure features were compared to the values calculated from the regression equations. The differences between the experimental results and the calculated values are trivial, confirming the validity of the regression equations.

Table.4.11 Parameters of the experiments used to assess the validity of the regression equations

\begin{tabular}{|c|c|c|c|c|c|c|}
\hline Process parameter & Code & Value & $\begin{array}{l}\text { Coating } \\
\text { feature }\end{array}$ & $\begin{array}{l}{ }^{*} \mathrm{E}- \\
\text { value, } \%\end{array}$ & $\begin{array}{l}{ }^{\wedge} \mathrm{C}- \\
\text { value, } \%\end{array}$ & $\begin{array}{l}\text { Relative } \\
\text { error, \% }\end{array}$ \\
\hline Powder size, $\mu \mathrm{m}$ & $x_{I}$ & 45 & Crack, $\%$ & 0.00 & 0.00 & 0.00 \\
\hline Nozzle size, mm & $x_{2}$ & 9.38 & Porosity, \% & 4.10 & 3.60 & 12.19 \\
\hline $\begin{array}{l}\text { Gas flow rate, } \\
\mathrm{Sl} / \mathrm{min}\end{array}$ & $x_{3}$ & 230 & $\begin{array}{l}\text { Unmelted } \\
\text { particles, \% }\end{array}$ & 5.23 & 5.46 & -4.40 \\
\hline $\begin{array}{l}\text { Ratio of } \mathrm{H}_{2}+\mathrm{N}_{2} \\
\text { over total gas, \% }\end{array}$ & $x_{4}$ & 26 & Oxide, $\%$ & 7.80 & 7.12 & 8.72 \\
\hline
\end{tabular}

\subsubsection{Results from the Second Set of Experiments}

The purpose of the second set of experiments was to relate multiple process parameters with coating properties and develop a concept: process index $(P I)$. 
Therefore another L9 Taguchi matrix, shown in Table 4.2, was designed to include current and spray distance so that the relationships between enthalpy and process parameters could be examined. The coating specimens obtained from the second set of experiments were designated as specimen 2-1 to specimen 2-9. The powder used for the second set of experiments was NI-164-2 and nozzle size was fixed at $11.1 \mathrm{~mm}$, which favored coating quality based on the results of the first set of experiments. The results of the second set of experiments are presented in Table 4.12.

Table 4.12 Results of the second set of the Taguchi matrix

\begin{tabular}{lrrrrr}
\hline Specimen & $\begin{array}{l}\text { Crack at } \\
\text { interface, } \\
\%\end{array}$ & $\begin{array}{l}\text { Porosity, } \\
\%\end{array}$ & $\begin{array}{l}\text { Unmelted } \\
\text { particles, } \\
\%\end{array}$ & $\begin{array}{l}\text { Oxide, } \\
\%\end{array}$ & $\begin{array}{l}\text { Enthalpy, } \\
\mathrm{J} / \mathrm{sl}\end{array}$ \\
\hline $2-1$ & 0.00 & 4.21 & 2.27 & 7.03 & 12.5 \\
$2-2$ & 12.00 & 5.24 & 3.13 & 2.83 & 10.6 \\
$2-3$ & 100.00 & 21.23 & 35.00 & 0.00 & 7.2 \\
$2-4$ & 0.00 & 4.64 & 2.60 & 7.60 & 11.2 \\
$2-5$ & 89.00 & 4.07 & 8.73 & 2.67 & 8.8 \\
$2-6$ & 64.00 & 2.16 & 8.97 & 1.67 & 11.6 \\
$2-7$ & 20.00 & 2.55 & 4.87 & 6.17 & 10.0 \\
$2-8$ & 0.00 & 4.12 & 8.90 & 3.43 & 11.5 \\
$2-9$ & 100.00 & 22.86 & 45.00 & 0.00 & 8.5 \\
\hline
\end{tabular}

\subsubsection{Concept of the Process Index}

In order to relate multiple process parameters with coating properties, a process index $(P I)$ is introduced in the following equation:

$$
P I=f(C, D, G, I, L, S)
$$

where $C$ is the ratio of $H_{2}+N_{2}$ over total gas flow; $D, G, I, L$, and $S$ stand for the normalized diameter of the nozzle, total gas flow rate, current, spray distance, and powder size, respectively. These dimensionless values, as shown in Table 4.13, are the 
normalized parameters by the median values of the parameters used in two Taguchi matrices.

Table 4.13 Summary of associated process parameters, normalized parameters

\begin{tabular}{|c|c|c|c|c|c|c|}
\hline Coating & $S$ & $D$ & $G$ & $C$ & $I$ & $L$ \\
\hline $1-1$ & 1.20 & 1.33 & 1.13 & 0.40 & 1.25 & 1.00 \\
\hline $1-2$ & 1.20 & 1.00 & 1.00 & 0.33 & 1.25 & 1.00 \\
\hline $1-3$ & 1.20 & 0.87 & 0.87 & 0.26 & 1.25 & 1.00 \\
\hline $1-4$ & 1.00 & 1.33 & 1.00 & 0.26 & 1.25 & 1.00 \\
\hline $1-5$ & 1.00 & 1.00 & 0.87 & 0.40 & 1.25 & 1.00 \\
\hline $1-6$ & 1.00 & 0.87 & 1.13 & 0.33 & 1.25 & 1.00 \\
\hline $1-7$ & 0.45 & 1.33 & 0.87 & 0.33 & 1.25 & 1.00 \\
\hline $1-8$ & 0.45 & 1.00 & 1.13 & 0.26 & 1.25 & 1.00 \\
\hline $1-9$ & 0.45 & 0.87 & 1.00 & 0.40 & 1.25 & 1.00 \\
\hline $2-1$ & 1.00 & 1.00 & 1.13 & 0.40 & 1.25 & 1.33 \\
\hline $2-2$ & 1.00 & 1.00 & 1.13 & 0.30 & 1.00 & 1.00 \\
\hline $2-3$ & 1.00 & 1.00 & 1.13 & 0.20 & 0.75 & 0.67 \\
\hline $2-4$ & 1.00 & 1.00 & 1.00 & 0.40 & 1.00 & 0.67 \\
\hline $2-5$ & 1.00 & 1.00 & 1.00 & 0.30 & 0.75 & 1.33 \\
\hline $2-6$ & 1.00 & 1.00 & 1.00 & 0.20 & 1.25 & 1.00 \\
\hline $2-7$ & 1.00 & 1.00 & 0.87 & 0.40 & 0.75 & 1.00 \\
\hline $2-8$ & 1.00 & 1.00 & 0.87 & 0.30 & 1.25 & 0.67 \\
\hline $2-9$ & 1.00 & 1.00 & 0.87 & 0.20 & 1.00 & 1.33 \\
\hline $3-1$ & 0.60 & 0.87 & 0.87 & 0.26 & 1.25 & 1.00 \\
\hline $3-2$ & 0.60 & 0.87 & 0.87 & 0.33 & 1.25 & 1.00 \\
\hline $3-3$ & 0.60 & 0.87 & 0.87 & 0.35 & 1.25 & 1.00 \\
\hline $\begin{array}{l}\text { Parameter } \\
\text { relation }\end{array}$ & $\frac{x_{1}}{75 \mu \mathrm{m}}$ & $\frac{x_{2}}{11.1 \mathrm{~mm}}$ & $\frac{x_{3}}{265}$ & $x_{4}$ & $\frac{I_{o}}{200 \mathrm{~A}}$ & $\frac{L_{o}}{150 \mathrm{~mm}}$ \\
\hline
\end{tabular}

$I_{o}=$ current $(\mathrm{A}), L_{o}=$ working distance $(\mathrm{mm})$

The purpose of developing the $P I$ was to design a method to combine various process parameters into one index number. It is recognized that $P I$ could be described in a complex polynomial with respect to the process parameters. From engineering point of view, however, the tedious polynomial is impractical and a simpler fractional equation will be developed. 
The influence of the process parameters on coating features can be reflected from the changes in particle velocity and temperature. The process parameters that control particle velocity and temperature will have impact on coating's microstructural features. Based on the analysis in previous section, the total gas flow rate was not considered in the equation of the $P I$ because the total gas flow rate had minimal effect on coating features. Parameters such as powder size $S$, nozzle size $D$ and spray distance $L$ were considered as denominators due to the inverse effect on the particle velocity and temperature while the ratio of $\mathrm{H}_{2}+\mathrm{N}_{2}$ over total gas flow and power input were included in $P I$ as numerators. Instead of using the electric power $(I \cdot V$, where $V$ cannot be controlled in the process directly), enthalpy $H$ was used to reflect the change in internal energy of plasma gas or, in other words, enthalpy $H$ was the energy transferred to plasma as a result of arc heating. Enthalpy, in current content, was normalized to a standard liter of gas used in the process and equals to electric energy (a function of current $I$ and $C$ ) minus energy loss due to cooling.

The effects of the powder size on the coating features can be understood in terms of its influence on particle velocity and temperature, which depend on the volume of particles (assuming constant heat capacity and density). Therefore the power of the particle size $S$ was designated as 3 . Considering that the velocity of plasma stream for the Mettech Axial IIITM System is close to the sonic speed, the effect of spray distance $L$ on the particle velocity was limited. As such an exponent of 0.5 was arbitrarily designated to $L$. The exponents for other parameter are from 0.5 to 3.0 and designated as $a, b$ and $c$. The equation for $P I$ is:

$$
P I=\frac{C^{a} \times H^{b}}{S^{3} \times D^{c} \times \sqrt{L}}
$$


The relation between enthalpy and the process parameters was obtained on the basis of the regression analysis of the results from the second set of experiments (Table 4.12). The enthalpy is the response and four normalized process parameters are defined as variables. The results for the regression analysis of the enthalpy are given in Table 4.14 .

Table 4.14 Results of the regression analysis of the enthalpy

\begin{tabular}{lcl}
\hline Terms & Coefficient & $p$-value \\
\hline Constant & 0.28 & 0.922 \\
Normalized total flow rate $(F)$ & 0.39 & 0.863 \\
Ratio of $\mathrm{H}_{2}+\mathrm{N}_{2}$ over total gas flow $(C)$ & 10.67 & 0.017 \\
Normalized current $(I)$ & 6.40 & 0.004 \\
Normalized spray distance $(L)$ & -0.051 & 0.954 \\
\hline
\end{tabular}

The variables with $p$-values greater than 0.05 were not significant and were eliminated from the regression equation and the equation was therefore simplified as:

$$
H=0.28+10.67 \times C+6.40 \times I
$$

where $I$ is the normalized current. Equation (4-5 was obtained by substituting equation (4-4) into equation (4-3):

$$
P I=\frac{C^{a} \times(0.28+10.67 \times C+6.40 \times I)^{b}}{S^{3} \times D^{c} \times \sqrt{L}}
$$

\subsubsection{Regression Analysis and Validity of the Process Index}

For each set of process parameters, a $P I$ value was calculated using equation (4-5). The $P I$ value was then used as the only variable to derive a series of regression equations for the coating microstructural features. These regression equations must be effective and significant. A general regression model is defined as:

$$
Y, \%=\beta_{0}+\beta_{I} \log _{I 0}(P I)+\beta_{2}\left[\log _{I 0}(P I)\right]^{2}+\beta_{3}\left[\log _{10}(P I)\right]^{3}
$$


where $Y$ represents one of the coating microstructural features in percentage, and $\beta_{0}, \beta_{l}$, $\beta_{2}$ and $\beta_{3}$ are constant determined based on experimental results. In order to determine the exponents $a, b$, and $c$ in equation (4-5), a one-half two-level factorial design was introduced to screen $a, b$, and $c$, each given a value from 0.5-3.0 (Table 4.15). The corresponding $P I$ values are given in Table 4.16.

Table 4.15 Half of two-level factorial design for determining $P I$ values

\begin{tabular}{llll}
\hline$P I$ & $a$ & $b$ & $c$ \\
$P I_{1}$ & 0.5 & 3.0 & 0.5 \\
$P I_{2}$ & 0.5 & 0.5 & 3.0 \\
$P I_{3}$ & 3.0 & 0.5 & 0.5 \\
$P I_{4}$ & 3.0 & 3.0 & 3.0 \\
\hline
\end{tabular}

Table 4.16 Summary of $P I s^{\prime}$ values for the two-level factorial matrix

\begin{tabular}{lrrrr}
\hline Coating & \multicolumn{1}{l}{$P_{l}$} & \multicolumn{1}{c}{$P I_{2}$} & \multicolumn{1}{l}{$P I_{3}$} & \multicolumn{1}{c}{$P I_{4}$} \\
\hline $1-1$ & 2169.95 & 0.68 & 0.14 & 107.64 \\
$1-2$ & 2273.01 & 1.45 & 0.09 & 142.20 \\
$1-3$ & 2163.08 & 1.95 & 0.05 & 105.61 \\
$1-4$ & 3023.08 & 0.94 & 0.07 & 51.08 \\
$1-5$ & 4324.33 & 2.76 & 0.28 & 437.59 \\
$1-6$ & 4211.01 & 3.80 & 0.17 & 373.14 \\
$1-7$ & 15767.62 & 4.92 & 0.63 & 483.53 \\
$1-8$ & 16140.67 & 10.28 & 0.35 & 556.36 \\
$1-9$ & 21463.73 & 19.37 & 1.38 & 3076.50 \\
\hline
\end{tabular}

Based on the $P I$ values obtained according to Table 4.15 for the first set of experiments, the coefficients of determination, $R^{2}$, for each coating feature with respect to all $P I \mathrm{~s}$ (with different exponents of $a, b$ and $c$ ) were calculated and summarized in Table 4.17.

To optimize all coefficients of determination simultaneously, an $\Omega$ factor was introduced to combine the coefficients of determination of all microstructural features for each $P I . \Omega$ is the geometrical mean of the coefficients of determination for all the 
microstructural features of coatings. The optimization process was based on the determination of the maximum of $\Omega$ values for all PIs using Minitab. The results from the optimization process are presented in Figure 4.8. The optimal points are located at the intersection of the blue dash line and the red lines. The blue dash line represents the maximum $\Omega$ value, and the red line represents the value of $a . b$, or $c$ corresponding to the maximum $\Omega$ value. Based on this figure, $\Omega$ reaches the peak value when $a=3$, and $c \leq 0.5$.

Table 4.17 Coefficients of determination of regression equations for coating features with respect to all $P I$ values

\begin{tabular}{llllll}
\hline & \multicolumn{5}{c}{ Coefficient of determination, $R^{2}$} \\
\cline { 2 - 6 } & Crack & Porosity & $\begin{array}{l}\text { Unmelted } \\
\text { particle }\end{array}$ & Oxides & $\Omega$ \\
\hline$P I_{1}$ & 60.32 & 49.90 & 40.81 & 88.10 & 57.32 \\
\hline$P I_{2}$ & 64.51 & 59.43 & 38.77 & 77.44 & 58.22 \\
\hline$P I_{3}$ & 92.50 & 95.01 & 87.10 & 99.61 & 93.44 \\
\hline$P I_{4}$ & $\mathbf{8 7 . 5 2}$ & 71.02 & 40.81 & 86.61 & 68.44 \\
\hline
\end{tabular}

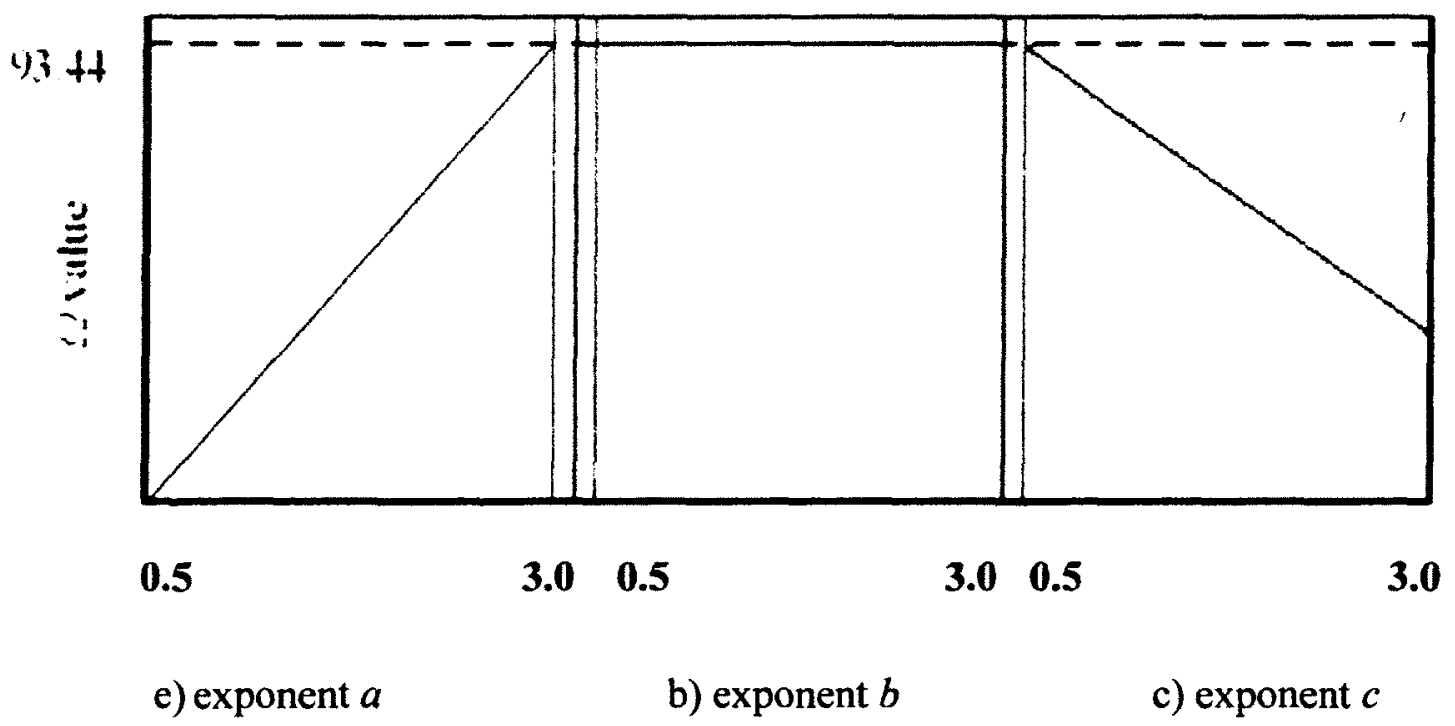

Figure 4.8 Plot of the $\Omega$ value vs. exponents $a, b$, and $c$, respectively, in the range of 0.5 to 3.0. 
Four points for $b$ from 0.5 to 3.0 (Table 4.18) were further tested and all $\Omega$ values are identical, which indicates the optimal $b$ value is between 0 and 0.5 . Additional tests for $b$ and $c$ were carried out to verify whether there would be optimal points within the range of 0 to 0.5 . Two one half two-level factorial designs after deleting identical terms were tested by fixing $a$ as 3 and $b$ and $c$ at the ranges of 0.50 to 0.25 and 0.25 to 0 , respectively, and the optimization graphs are shown in Figure 4.9 and Figure 4.10. The maximum $\Omega$ values for all $P I \mathrm{~s}$, which are $93.44 \%$, are those with $c=0.5$ and $b=0.50$. Therefore the equation for $P I$ is optimized as:

$$
P I=\left(\frac{C}{s}\right)^{3} \times \sqrt{\frac{(0.28+10.7 \times C+6.4 \times I)}{D \times L}}
$$

Table 4.18 Coefficients of determination for the microstructural features of

NiCrAlY coatings with respect to the $P I$ values for $b$ from 0.50 to 3.00

\begin{tabular}{|c|c|c|c|c|c|c|c|c|}
\hline \multirow[b]{2}{*}{$P I$} & \multirow[b]{2}{*}{$a$} & \multirow[b]{2}{*}{$b$} & \multicolumn{6}{|c|}{ Coefficient of determination, $R^{2}$} \\
\hline & & & $c$ & Crack & Porosity & $\begin{array}{l}\text { Unmelted } \\
\text { particle }\end{array}$ & Oxide & $\Omega$ \\
\hline$P I_{5}$ & \multirow{4}{*}{3.00} & 1.00 & \multirow{4}{*}{0.50} & \multirow{4}{*}{92.50} & \multirow{4}{*}{95.01} & \multirow{4}{*}{87.10} & \multirow{4}{*}{99.61} & \multirow{4}{*}{93.44} \\
\hline$P I_{6}$ & & 1.50 & & & & & & \\
\hline $\mathrm{PI}_{7}$ & & 2.00 & & & & & & \\
\hline$P I_{8}$ & & 2.50 & & & & & & \\
\hline
\end{tabular}

Table 4.19 Coefficients of determination with respect to $P I$ values from the twolevel full factorial design

\begin{tabular}{|c|c|c|c|c|c|c|c|c|}
\hline \multirow[b]{2}{*}{$P I$} & \multirow[b]{2}{*}{$a$} & \multirow[b]{2}{*}{$b$} & \multirow[b]{2}{*}{$c$} & \multicolumn{5}{|c|}{ Coefficient of determination, $R^{2}$} \\
\hline & & & & Crack & Porosity & $\begin{array}{l}\text { Unmelted } \\
\text { particle }\end{array}$ & Oxides & $\Omega$ \\
\hline$P I_{9}$ & & 0.25 & 0.25 & 89.51 & 92.33. & 91.11 & 99.50 & 93.07 \\
\hline$P I_{10}$ & 3.00 & 0.50 & 0.50 & 92.50 & 95.01 & 87.10 & 99.61 & 93.44 \\
\hline$P I_{11}$ & & 0.00 & 0.00 & 86.42 & 89.40 & 91.11 & 99.11 & 92.05 \\
\hline
\end{tabular}

Substituting equation (4-7) into equation (4-6), a series of regression equations for the microstructural features of $\mathrm{NiCrAlY}$ coatings with respect to $P I$ were derived and 
are summarized in Table 4.20. An effective regressed equation should be at high confidence level so that the equation reflects the influences of the variables on the response function. All $F$ values (Fisher value) in Table 4.20 are greater than the threshold $F(3,5,0.95)=5.41$. Therefore the regression equations in Table 4.20 are all considered significant.

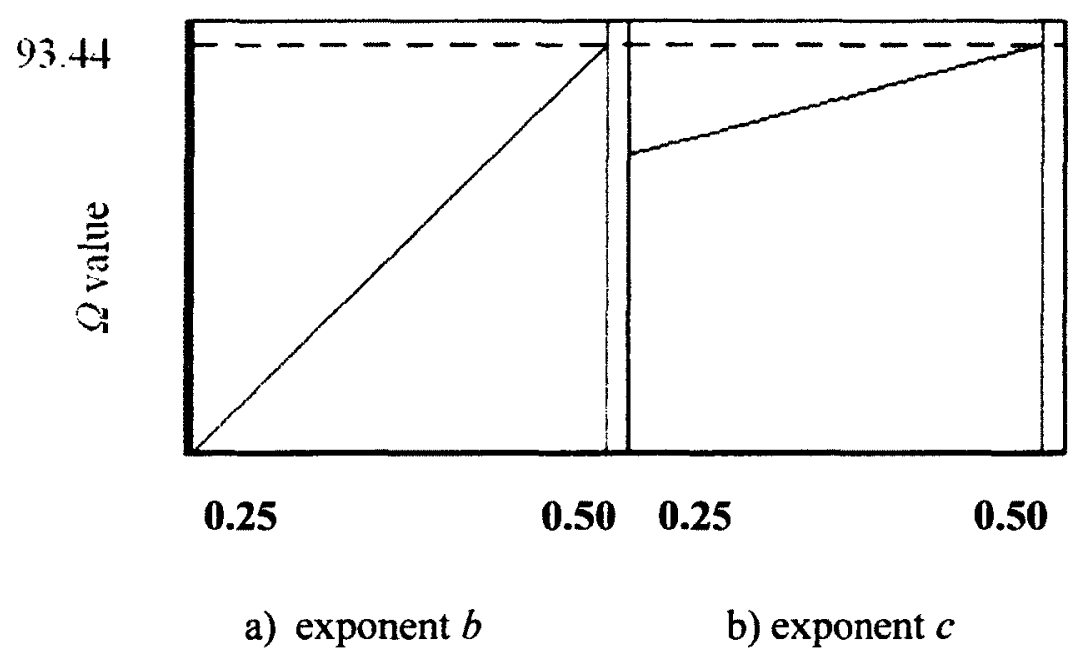

Figure 4.9 Plot of the $\Omega$ value vs. exponent $b$ and $c$, respectively, in the range of 0.25 to 0.50 .

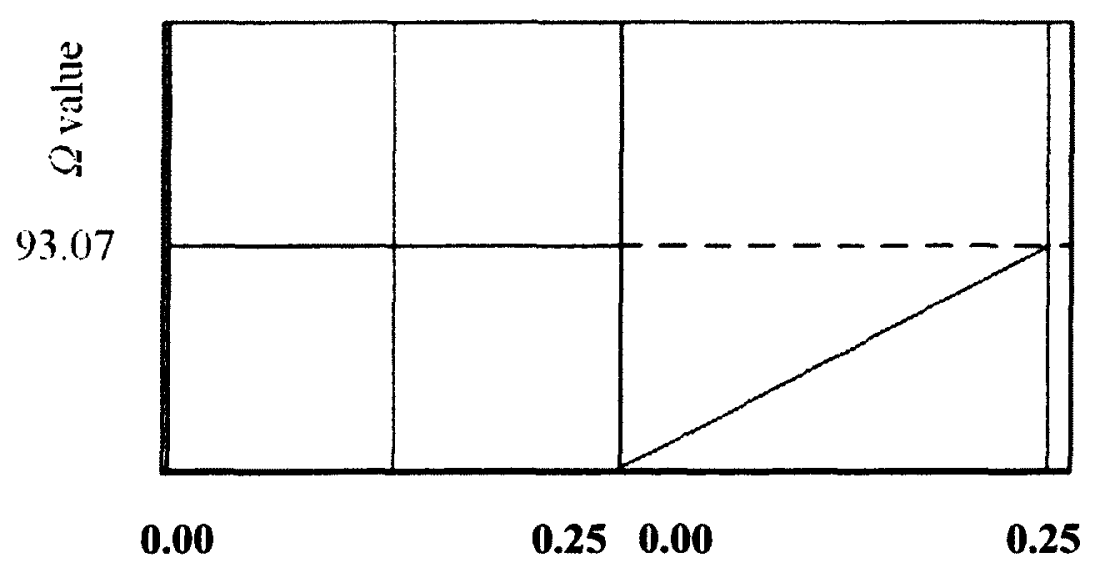
a) exponent $b$
b) exponent $c$

Figure 4.10 $\Omega$ value vs. exponent $b$ and $c$, respectively, in the range of 0 to 0.25 . 
Table 4.20 Regression equations for coating features with respect to $P I$

\begin{tabular}{|c|c|c|c|c|}
\hline $\begin{array}{l}\text { Coating } \\
\text { feature }\end{array}$ & Regression Equation & $R^{2}$ & $F$ & $\begin{array}{c}\text { Threshold } \\
F \text { value }\end{array}$ \\
\hline $\begin{array}{l}\text { Crack at } \\
\text { interface }\end{array}$ & $\begin{array}{l}\text { Crack, \% }=-3.75+34.99 \times \log _{10}(P I)+ \\
78.90 \times\left[\log _{10}(P I)\right]^{2}-10.01 \times\left[\log _{10}(P I)\right]^{3}\end{array}$ & 92.50 & 20.67 & \\
\hline Porosity & $\begin{array}{l}\text { Porosity, } \%=4.38-4.02 \times \log _{10}(P I)- \\
13.04 \times\left[\log _{10}(P I)\right]^{2}-15.03 \times\left[\log _{10}(P I)\right]^{3}\end{array}$ & 95.00 & 31.44 & \\
\hline $\begin{array}{l}\text { Unmelted } \\
\text { particle }\end{array}$ & $\begin{array}{l}\text { Unmelted particle, \% } \%=2.96-19.93 \times \\
\log _{10}(P I)-60.79 \times\left[\log _{10}(P I)\right]^{2}-52.60 \times \\
{\left[\log _{10}(P I)\right]^{3}}\end{array}$ & 87.10 & 11.27 & 5.41 \\
\hline Oxide & $\begin{array}{l}\text { Oxide, } \%=13.24+5.99 \times \log _{10}(P I)- \\
17.95 \times\left[\log _{10}(P I)\right]^{2}-10.42 \times\left[\log _{10}(P I)\right]^{3}\end{array}$ & 99.60 & 466.94 & \\
\hline
\end{tabular}

The four microstructural features of the coatings versus the $P I$ values are illustrated in Figure 4.11. Also included in this figure are the results from the second and third sets of experiments. As seen in Figure 4.11, most data from the second and third set of experiments fall within $95 \%$ confident level of the data from the first set of experiments, and the values of coating features predicted by the regression equations all fall within $95 \%$ confidence level of the experimental data. Therefore, it can be concluded that the regression equations given in Table 4.20 fit well with the experimental results. 


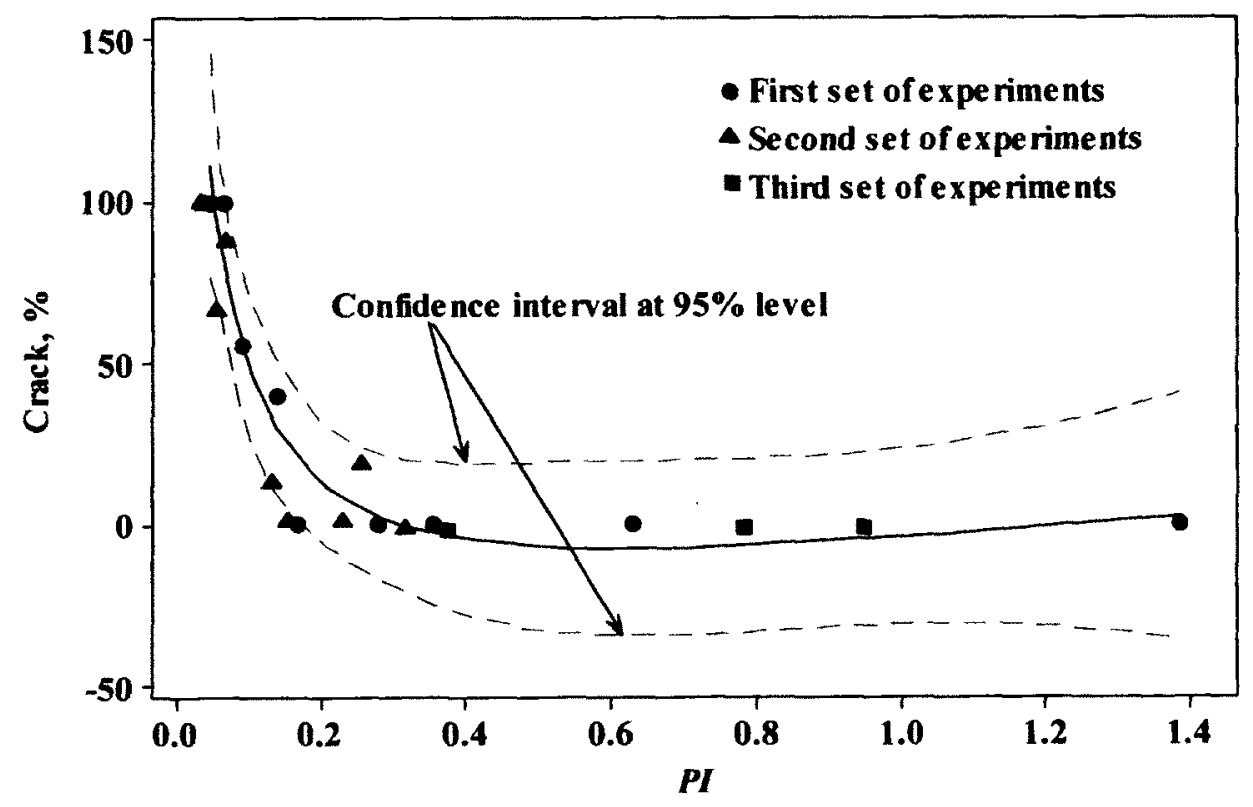

a) Measured and predicated crack percentage as a function of $P I$

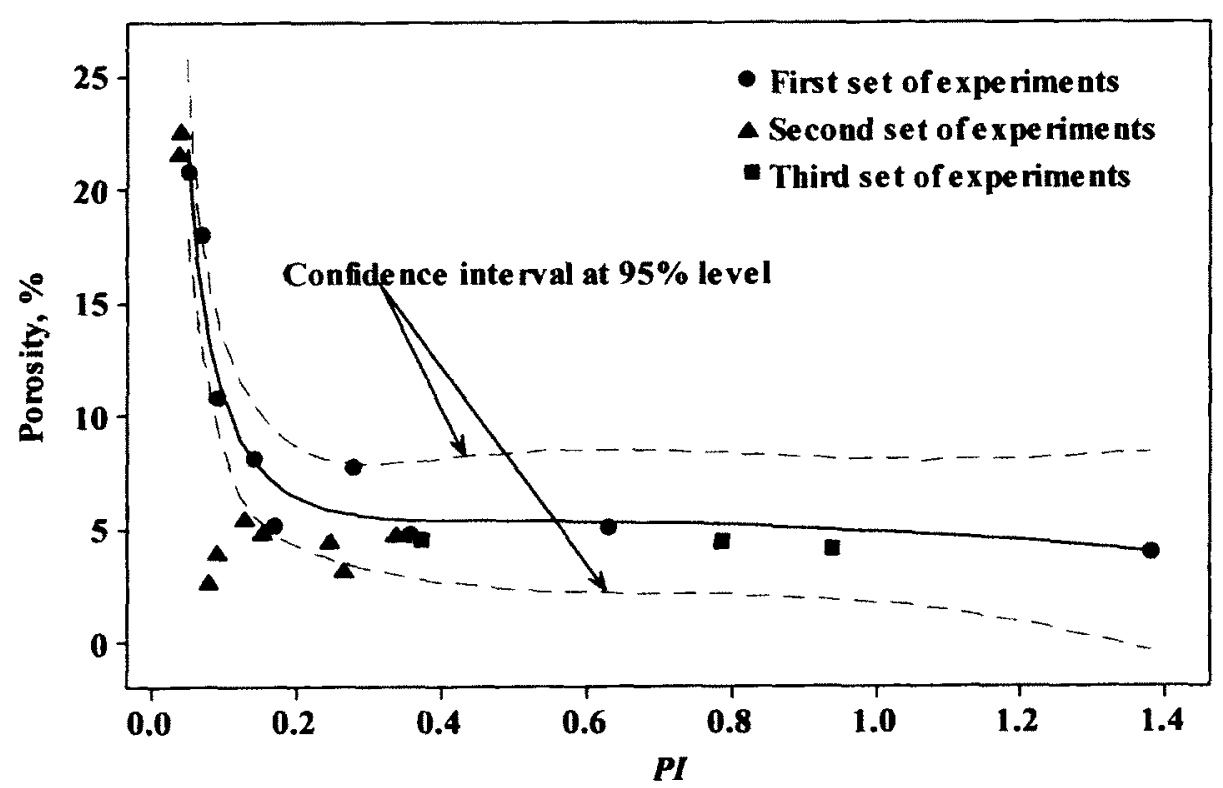

b) Measured and predicted porosity as a function of $P I$ 


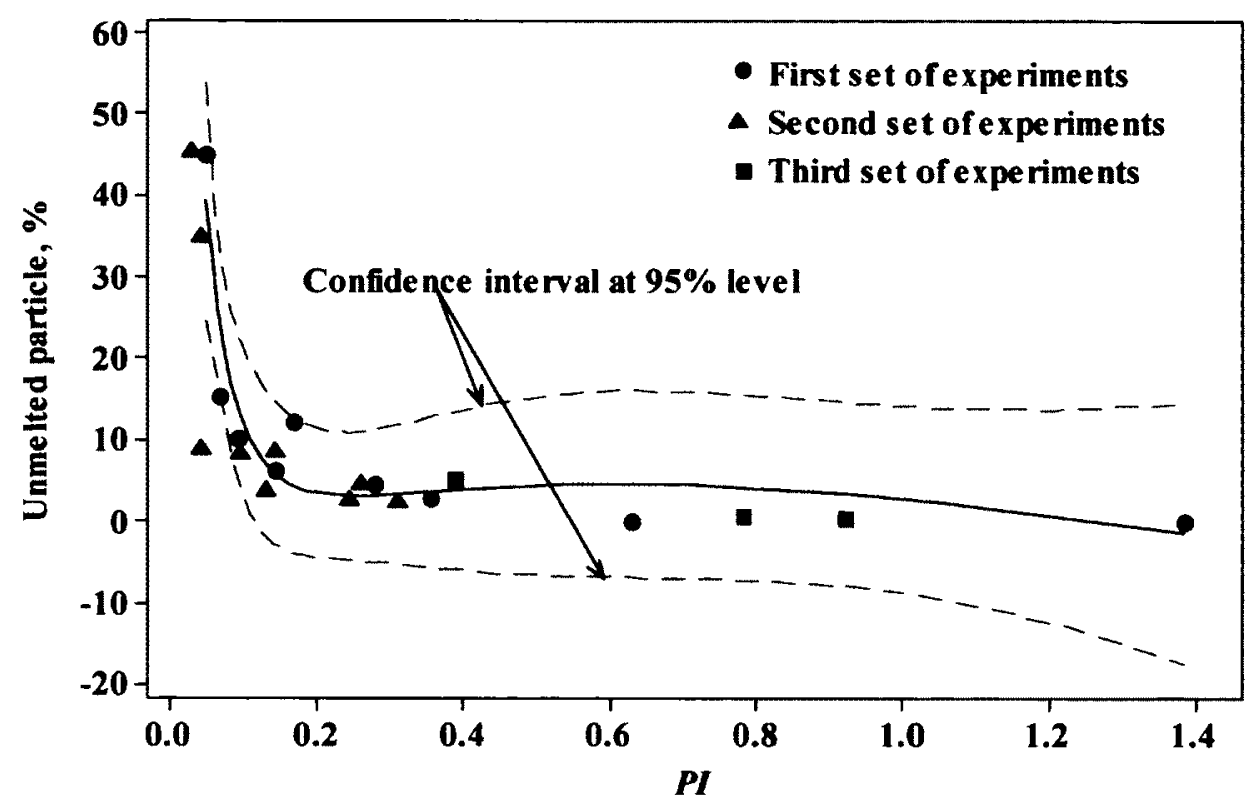

c) Measured and predicted unmelted particle percentage as a function of $P I$

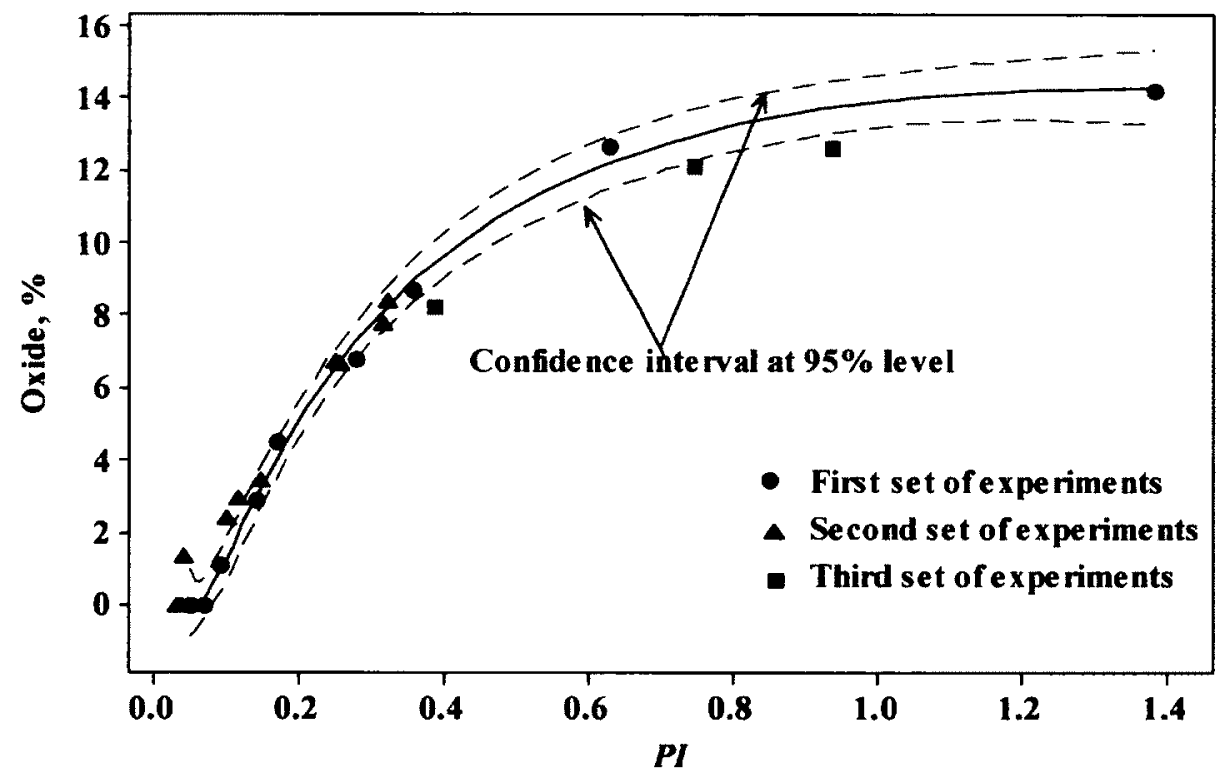

d) Measured and predicted oxide percentage as a function of $P I$

Figure 4.11 Comparison of predicated and measured values of the four microstructure features for the three sets of experiments. 
According to the comparison in Figure 4.11, the coating features can be categorized into three levels based on the $P I$ values, as summarized in Table 4.21 . When the $P I$ value is less than 0.2 , the coating has inferior quality, which represents the condition under which cracks go through the coating/substrate interface and large pores and unmelted particles are numerous within the coating. However, very limited oxides are found in the coating when the $P I$ value is less than 0.2 . When the $P I$ values are greater than 0.2 but less than 0.4 ; there are moderate amounts of cracks, pores and unmelted particles and increased percentage of oxide. Whereas when $0.6>P I>0.4$, there are minimum cracks in the coating, and much less pores and unmelted particles within the coating but the amount of oxides exceeds $6 \%$. There are no unmelted particles and cracks in the coatings when the $P I$ values exceed 0.6 but the amount of oxides surpasses $10 \%$.

Table 4.21 Relation of coating features to $P I$ values

\begin{tabular}{lclcc}
\hline Conditions & $\begin{array}{l}\text { Crack at interface, } \\
\%\end{array}$ & $\begin{array}{l}\text { Porosity, } \\
\%\end{array}$ & $\begin{array}{l}\text { Unmelted } \\
\text { particle, } \%\end{array}$ & $\begin{array}{l}\text { Oxide, } \\
\%\end{array}$ \\
\hline $0.2>P I$ & 100 & $>10$ & $>20$ & 0 \\
$0.4>P I>0.2$ & $20-100$ & $5-10$ & $10-20$ & $0-6$ \\
$0.6>P I>0.4$ & 0 & $<5$ & $<10$ & $>6$ \\
$P I>0.6$ & 0 & $<5$ & 0 & $>6$ \\
\hline
\end{tabular}

The purpose of another set of experiments was to verify the $P I$ based the regression equations, which were derived from the first and second set of experiments. Table 4.22 provides comparison between the predicted and experimental results for the third set of experiments. The discrepancies between the predicted (using $P I$ based empirical regression equations) and experimental results are trivial, which verifies the validity of 
these $P I$-based regression equations (These regression equations are valid only within the designed scopes investigated in this study).

Table 4.22 Comparison between the predicted and experimental results for the second set of experiments

\begin{tabular}{|c|c|c|c|c|c|c|}
\hline \multirow[t]{2}{*}{ Coating } & \multicolumn{3}{|c|}{ Crack at interface, $\%$} & \multicolumn{3}{|l|}{ Porosity, $\%$} \\
\hline & $\begin{array}{l}\text { Experiment } \\
\text { value }\end{array}$ & $\begin{array}{l}\text { Predicted } \\
\text { value }\end{array}$ & $\begin{array}{l}\text { Relative } \\
\text { error }\end{array}$ & $\begin{array}{l}\text { Experiment } \\
\text { value }\end{array}$ & $\begin{array}{l}\text { Predicted } \\
\text { value }\end{array}$ & $\begin{array}{l}\text { Relative } \\
\text { error }\end{array}$ \\
\hline $3-1$ & 0.00 & 0.00 & 0.00 & 4.40 & 4.88 & -10.90 \\
\hline $3-2$ & 0.00 & 0.00 & 0.00 & 4.30 & 4.68 & -8.84 \\
\hline \multirow[t]{3}{*}{ 3-3 } & 0.00 & 0.00 & 0.00 & 3.73 & 4.49 & -20.37 \\
\hline & \multicolumn{2}{|c|}{ Unmelted particles, $\%$} & & Oxide,\% & & \\
\hline & $\begin{array}{l}\text { Experiment } \\
\text { value }\end{array}$ & $\begin{array}{l}\text { Predicted } \\
\text { value }\end{array}$ & $\begin{array}{l}\text { Relative } \\
\text { error }\end{array}$ & $\begin{array}{l}\text { Experiment } \\
\text { value }\end{array}$ & $\begin{array}{l}\text { Predicted } \\
\text { value }\end{array}$ & $\begin{array}{l}\text { Relative } \\
\text { error }\end{array}$ \\
\hline $3-1$ & 5.23 & 4.59 & 12.37 & 7.88 & 8.33 & -5.71 \\
\hline $3-2$ & 0.00 & 4.47 & - & 11.10 & 12.40 & -11.71 \\
\hline $3-3$ & 0.00 & 3.53 & - & 11.50 & 13.03 & -13.30 \\
\hline
\end{tabular}

\subsubsection{PI Development Guidelines for Other Thermal Spray Processes}

The motivation for developing a $P I$ is to estimate the microstructural features of coatings when defining initial spraying parameters. The method developed in this study can be applied to other thermal spray processes although coefficients for the regression equations will change from system to system. Based on the results of this study with Mettech Axial III ${ }^{\mathrm{TM}}$ system, the qualitative trends relating process parameters to coating microstructural features are applicable to other equipment based on the same operating principles, i.e., plasma based spray system systems. For other coating processes such as HVOF, VPS or cold spray, the following procedure can be used for developing their own $P I$ : 
(1) Determining the significance of process parameters. A Taguchi array or a factorial design is needed to determine the significance of process parameters and those parameters that are insignificant will be excluded from the $P I$ equation.

(2) Introducing a PI equation. The equation is suggested to be in a fraction form. Process parameters that have the inverse effects on the particle velocity and temperature are considered as denominators and the others are numerators. The range of the exponents for each parameter can be started with 0 to 3 .

(3) Introducing a factorial design for the exponents.

(4) Calculating $P I$ values. The $P I$ values from each test in the Taguchi array are calculated, as shown in Table 4.16.

(5) Proposing model(s). A model for all microstructural features of the coatings or separate model for each coating feature can be proposed. The PI will be the only variable.

(6) Calculating $R^{2}$ for each $P I$ and each model. The $P I$ values are substituted into the models to calculate $R^{2}$ using MS excel software or statistical software.

(7) Calculating the geometrical mean factor(s) of $R^{2}$.

(8) Maximizing the factor. The factor is maximized using statistical software such as Minitab. This step can be repeated until the maximal value of the factor and the corresponding exponents are found. The model is finalized by substituting the exponents into the $P I$ equation and $P I$ into the model.

(9) Testing the validity of model(s). Another set of experiments should be carried out to verify the validity of the model(s). 


\subsection{Summary of Process Optimization for NiCrAlY Coatings}

The effects of the plasma spray process parameters on the percentages of cracks along coating/substrate interface, pores, unmelted particles and oxide content in NiCrAlY coatings have been investigated with the purpose of developing a process index $(P I)$. The $P I$ value, combining the plasma spray process parameters, is the only variable to the regression equations for coating microstructural features. Regression equations were verified with acceptable values of $R^{2}$ which are more than $87.1 \%$, and successfully predicted the coating microstructural features within $95 \%$ confidence level.

Among the parameters examined, the powder size and ratio of $\mathrm{H}_{2}+\mathrm{N}_{2}$ over total gas flow rate are the most significant parameters affecting the percentages of crack, porosity, the amount of unmelted particle and oxide. Within the range of the designed process parameters, lower powder size and higher ratio of $\mathrm{H}_{2}+\mathrm{N}_{2}$ over total gas flow rate result in fewer cracks, pores, and unmelted particles but more oxides. Increasing nozzle size marginally increases the occurrence of oxides. Gas flow rate has no influence on any coating feature evaluated. Further study is underway to generate process index combining all process parameters into single value and relate this value to coating microstructure. In terms of the regression equations developed, a procedure for optimizing the spray process can be summarized as below:

(1) estimate the coating properties, such as cracks, porosity and etc

(2) determine the $P I$ value

(3) select process parameters according to equation (4-8) using an iterative process

(4) conduct coating spray and fine tune the process parameters 
In selecting spray parameters, the following rules are recommended:

(1) The maximum powder size should be as small as possible; however the minimum size must be larger than $5 \mu \mathrm{m}$.

(2) Nozzle size is around 0.44 in (7/16).

(3) Spray distance is in the vicinity of $150 \mathrm{~mm}$.

(4) Gas flow is between 200 and $300 \mathrm{SL} / \mathrm{min}$.

(5) For metallic powder, the proportion of hydrogen should exceed that of nitrogen.

(6) Current is between 200 and $250 \mathrm{~A}$. 


\section{Chapter 5: Process Optimization for Diffusion Coatings}

\subsection{Process Optimization for the Aluminide Coatings}

The objective of process optimization for the aluminized top layer is to achieve a quantitative relation between the coating features and the process parameters, and this relation can be used to produce a desirable multilayered coating with pre-determined compositions. Similarly the method of design of experiment (DOE) was used for the process optimization. Compared the screening function of other DOE statistical methods, response surface methodology emphasizes the optimization of a process and it has been extensively utilized to determine the influence of key process parameters on the coating features and predict the coating microstructure features [110].The reasons for producing an response surface model for the aluminizing process are to [110]:

- achieve a quantitative understanding of the behavior of the coating over the testing region

- predict the coating properties throughout the region

- determine the optimum conditions for the aluminizing process

- find the conditions for aluminizing process stability

For this study, three process parameters, $\mathrm{Al}$ and $\mathrm{Ni}$ concentrations in the pack and process temperature, and their effects on the coating microstructural features were investigated. As outward-diffusion process produces coatings with reduced alloying contents (such as $\mathrm{Ti}$ ) from the substrate, the process temperatures were kept within the "high temperature (HT)" region. The experimental procedure is further outlined in the following section. 


\subsubsection{Experimental Procedure}

The coating specimens used in this study were $304 \mathrm{~L}$ austenitic stainless steel (SS304L) plates coated with NiCrAlY by the plasma spray process. The dimensions of the specimens, NiCrAlY powder, and powders for aluminized coatings are given in Table 5.1. The compositions of SS304L and IN738 are listed in Table 5.2. IN738 is the substrate for the $\mathrm{Cr}$-Si coating, and $\mathrm{SiO}_{2}, \mathrm{Cr}$, and $\mathrm{Si}$ powders were also used to produce the $\mathrm{Cr}$-Si coating, which will be discussed in the next section.

Table 5.1 Conditions of the specimens for the aluminizing process

\begin{tabular}{|c|c|c|c|}
\hline & Composition or material & $\begin{array}{l}\text { Dimension or } \\
\text { coating thickness }\end{array}$ & Designation \\
\hline NiCrAlY & $\mathrm{Ni}-22 \mathrm{Cr}-10 \mathrm{Al}-1 \mathrm{Y}$ & $200 \mu \mathrm{m}$ & \\
\hline Substrate & SS304L & $25 \times 25 \times 1.6 \mathrm{~mm}$ & \\
\hline Al powder & $99.0 \mathrm{wt} . \% \mathrm{Al}$ & & AL-104 \\
\hline Ni powder & $5.0 \mathrm{wt} . \% \mathrm{Al}, 95.0 \mathrm{wt} . \% \mathrm{Ni}$ & & $480 \mathrm{NS}$ \\
\hline $\mathrm{NH}_{4} \mathrm{Cl}$ & 99.9 wt. $\%$ & & A649-3 \\
\hline $\mathrm{Al}_{2} \mathrm{O}_{3}$ powder & $99.0 \mathrm{wt} . \%$ & & ALO-101 \\
\hline $\mathrm{SiO}_{2}$ powder & 99.9 wt. $\%$ & & SI 604 \\
\hline Cr powder & 99.8 wt.\% & & CR 105 \\
\hline Si powder & 99.0 wt. $\%$ & & SI 101 \\
\hline
\end{tabular}

Table 5.2 Compositions of SS304L and IN738

\begin{tabular}{llllllllllll}
\hline & \multicolumn{10}{c}{ Composition, wt.\% } \\
\cline { 2 - 12 } & $\mathrm{Cr}$ & $\mathrm{Co}$ & $\mathrm{Mo}$ & $\mathrm{Ta}$ & $\mathrm{C}$ & $\mathrm{Ti}$ & $\mathrm{Al}$ & $\mathrm{Nb}$ & $\mathrm{W}$ & $\mathrm{Ni}$ & $\mathrm{Fe}$ \\
\hline SS304L & 19.0 & & & & 0.03 & & & & & 10.0 & Bal. \\
IN738 & 16.0 & 8.5 & 1.8 & 1.8 & 0.2 & 3.4 & 3.4 & 0.9 & 2.6 & 61.0 & \\
\hline
\end{tabular}

The specimens were ultrasonically cleaned in acetone and buried in the powder mixtures listed in Table 5.3, respectively, with alumina crucibles. The crucibles were placed in the center region of the heating zone of a laboratory tube furnace. The tube furnace consisted of an alumina tube (100 mm ID and $1000 \mathrm{~mm}$ length) and was heated by an $8 \mathrm{kw}$ radio frequency generator. The temperature at the center of the heating zone 
was measured by a B-type thermocouple, and the temperature variation along the axial direction of the heating zone during these experiments was measured to be within $\pm 5^{\circ} \mathrm{C}$. The heating and cooling rate of the furnace was kept at $3^{\circ} \mathrm{C} / \mathrm{min}$, and all specimens were held at the aluminizing temperature for $4 \mathrm{hr}$. An argon atmosphere was maintained during the heating, aluminizing and subsequent cooling processes. The Ar flow rate was kept between 400 and $500 \mathrm{Std} . \mathrm{ml} / \mathrm{min}$.

The cross sections of the coatings were characterized using the TESCAN scanning electron microscopy (SEM). The percentages of key alloying elements in the aluminide coatings were measured by EDS in an increment of $10 \mu \mathrm{m}$ from the coating surface toward the substrate.

A Box-Behnken experimental design was used to evaluate three process parameters of the aluminizing processes over three levels. All process parameters are summarized in Table 5.3. This design requires 15 experiments to produce a response surface model for the process.

Table 5.3 Box-Behnken design for the aluminizing process

\begin{tabular}{lllllll}
\hline Parameter & $A$ & $N$ & $T$ & Activator & Filler & Duration \\
\hline Level & $\mathrm{Al}, \mathrm{wt} . \%$ & $\mathrm{Ni}, \mathrm{wt} . \%$ & Temp., ${ }^{\circ} \mathrm{C}$ & $\mathrm{NH}_{4} \mathrm{Cl}, \mathrm{wt} . \%$ & $\begin{array}{l}\mathrm{Al}_{2} \mathrm{O}_{3}, \\
\text { wt.\% }\end{array}$ & $\mathrm{hr}$ \\
\hline 0 & 5 & 5 & 1000 & & & \\
1 & 10 & 10 & 1050 & 2 & balance & 4 \\
2 & 15 & 15 & 1100 & & & \\
\hline
\end{tabular}

The 15 experiments, which were designated as the coating numbers, are given in Table 5.4 along with corresponding process parameters. The process parameters selected lie on the mid-points of all cubic edges as illustrated in Figure 5.1. In addition, a center point was also selected to run in three independent trials to quantify 
experimental variance. The coating thickness and the maximum ratio of $\mathrm{Al}$ content to Ni content in the coatings were measured and acted as responses for creating response surface models and plots.

Table 5.4 Parameters for aluminizing process

\begin{tabular}{lcclll}
\hline Coating & $\begin{array}{l}\text { Al in pack, } \\
\text { wt. \% }\end{array}$ & $\begin{array}{l}\text { Ni in pack, } \\
\text { wt.\% }\end{array}$ & $\begin{array}{l}\mathrm{Al} \text { in Al } \\
\text { source, at.\% }\end{array}$ & $\begin{array}{l}\text { Ni in Al } \\
\text { source, at.\% }\end{array}$ & Temp., ${ }^{\circ} \mathrm{C}$ \\
\hline $4-1$ & 5 & 5 & 69 & 32 & 1050 \\
$4-2$ & 15 & 5 & 87 & 13 & 1050 \\
$4-3$ & 5 & 15 & 42 & 58 & 1050 \\
$4-4$ & 15 & 15 & 69 & 31 & 1050 \\
$4-5$ & 5 & 10 & 52 & 48 & 1000 \\
$4-6$ & 15 & 10 & 77 & 23 & 1000 \\
$4-7$ & 5 & 10 & 52 & 48 & 1100 \\
$4-8$ & 15 & 10 & 77 & 23 & 1100 \\
$4-9$ & 10 & 5 & 81 & 19 & 1000 \\
$4-10$ & 10 & 15 & 59 & 41 & 1000 \\
$4-11$ & 10 & 5 & 81 & 19 & 1100 \\
$4-12$ & 10 & 15 & 59 & 41 & 1100 \\
$4-13$ & 10 & 10 & 68 & 32 & 1050 \\
$4-14$ & 10 & 10 & 68 & 32 & 1050 \\
$4-15$ & 10 & 10 & 68 & 32 & 1050 \\
\hline
\end{tabular}

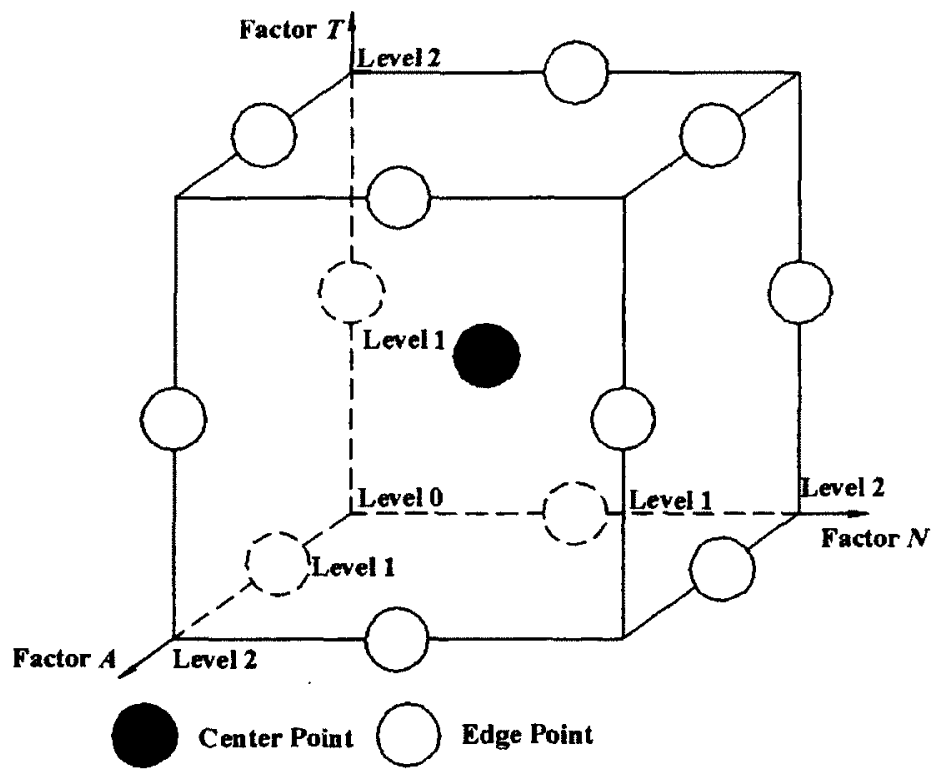

Figure 5.1 Pictorial representation of a three-level Box-Behnken response surface design for the aluminizing process. 


\subsubsection{Elemental Distribution and Microstructure}

The specimens for these experiments were designated as coating 4-1 to specimen 415. The microstructures of the aluminized layers were on the basis of elemental distributions and XRD results of the aluminized layers. The ratio of aluminum to nickel (at.\%) in a coating is used to estimate phases in the coating (Table A.). When the ratio is around one, the dominant phase is $\mathrm{NiAl}$, whereas the dominant phase is $\mathrm{Ni}_{2} \mathrm{Al}_{3}$ if the ratio is around 1.5 .

Two coating specimens, 4-1 and 4-7 shown in Figure 5.2, were selected for microstructure analysis. Cross section images of coating 4-1 and 4-7 are illustrated in Figure 5.3. The concentration profiles of the two selected coating specimens are illustrated in Figure 5.4. The diagram of the $\mathrm{Al} / \mathrm{Ni}$ ratio versus the distance from coating surface for specimen 4-1 and specimen 4-7 is illustrated in Figure 5.5.

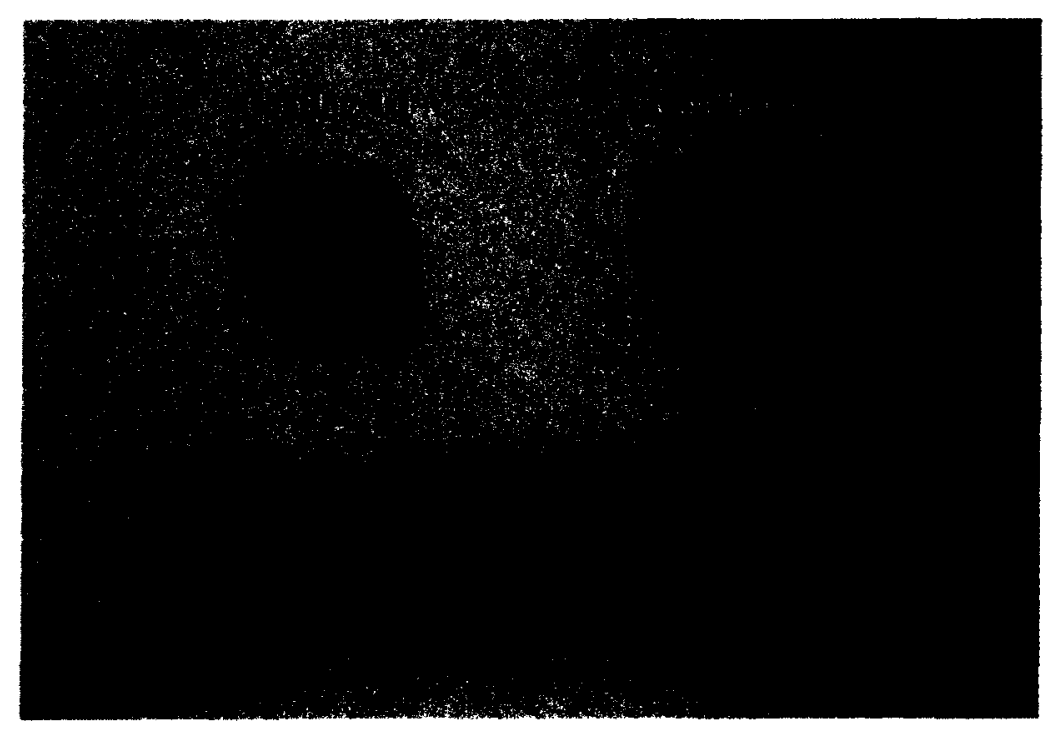

Figure 5.2 Image of coating 4-1 and 4-7. 

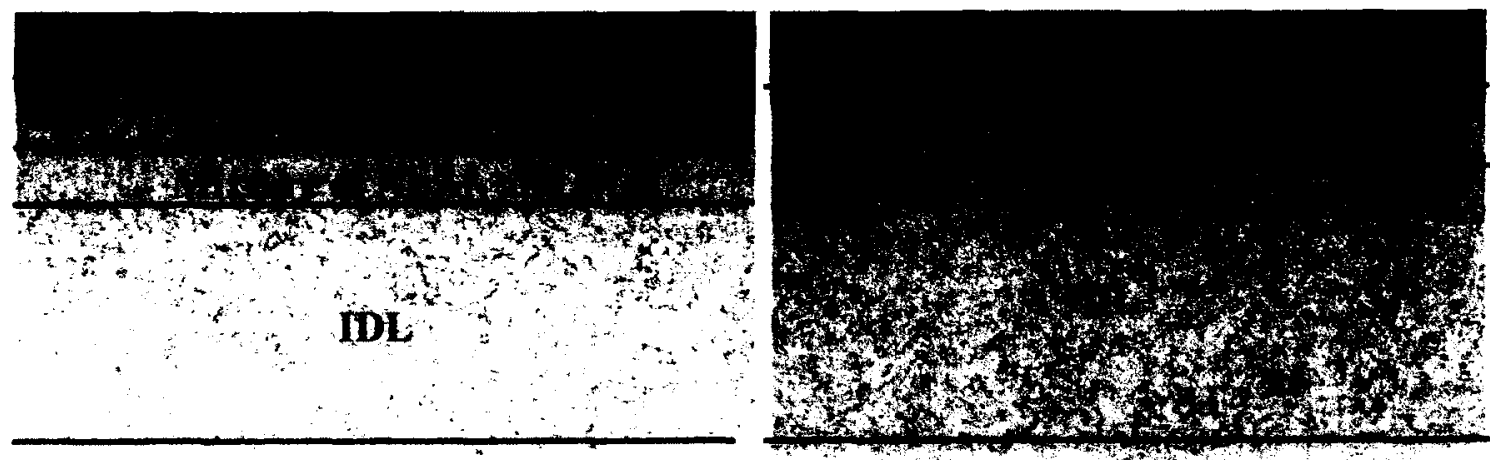

SEM NAGG: 300

SEM IN: $20.00 \mathrm{WV}$ WD: $11.40 \mathrm{~mm}$

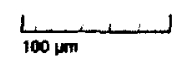

SEM MAG 300 SEU HN 2000
Wo $10.07 \mathrm{~mm}$

$L_{100}$

a) three-layer structure of coating 4-1

b) two-layer structure of coating 4-7

Figure 5.3 Cross section images of the coating 4-1 and 4-7.

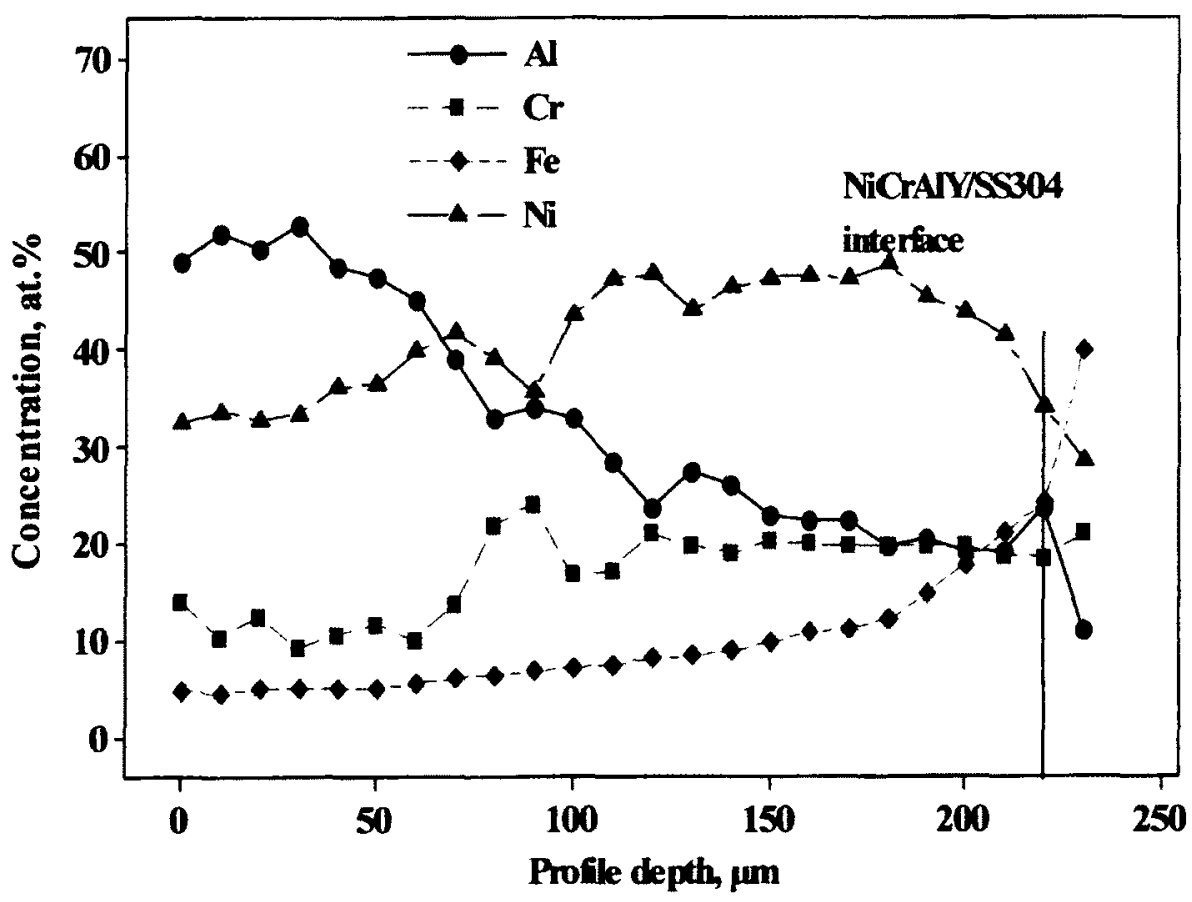

a) Concentration profiles of $\mathrm{Al}, \mathrm{Si}, \mathrm{Cr}$, and $\mathrm{Ni}$ in coating 4-1 


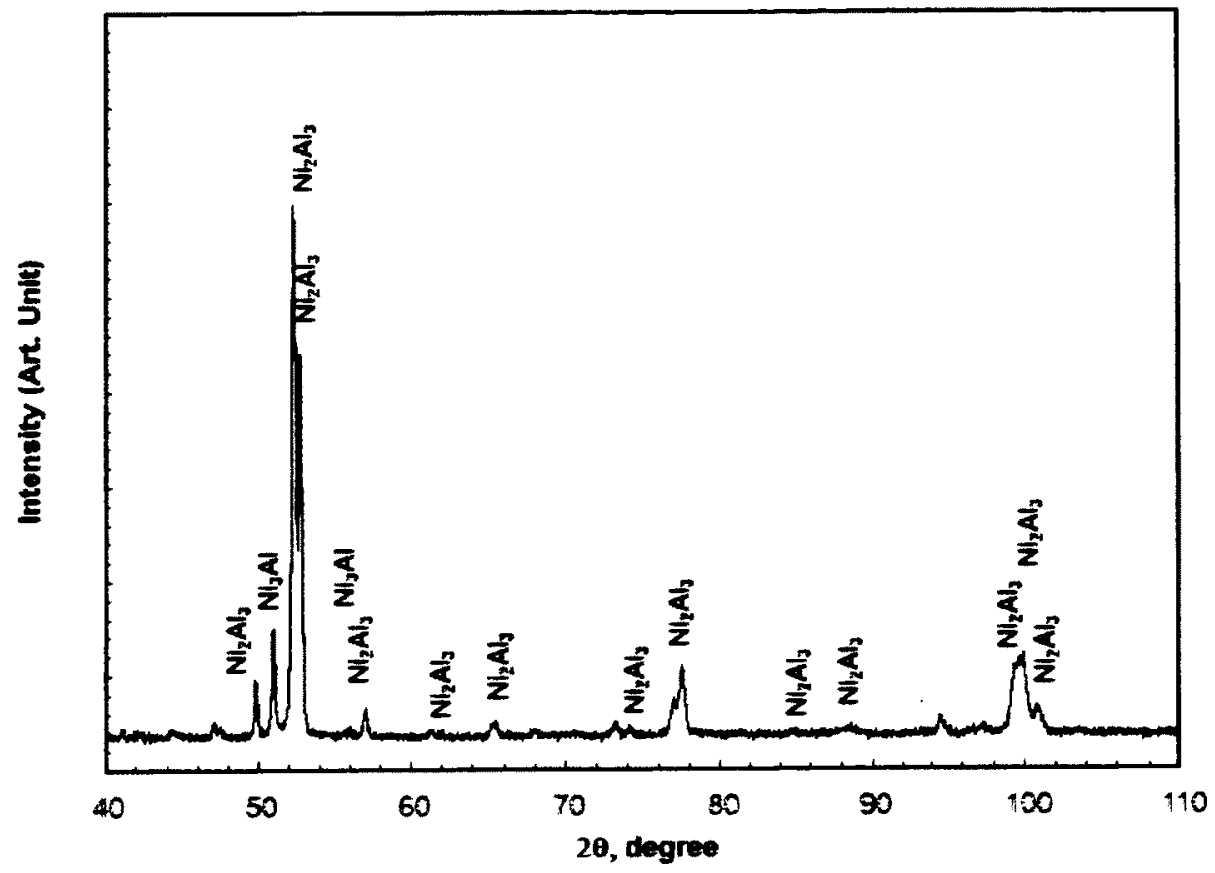

b) XRD spectrum of coating 4-1

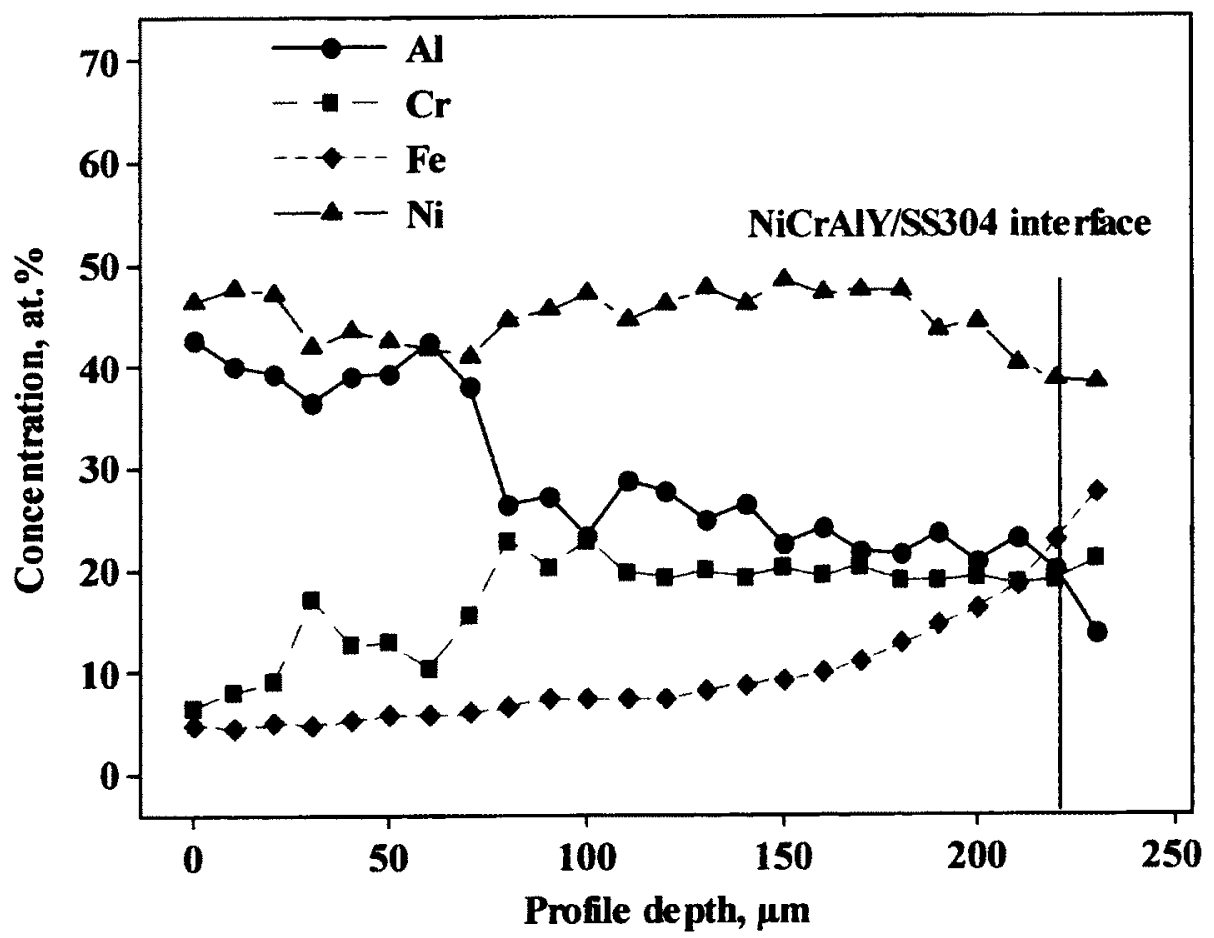

c) Concentration profiles of $\mathrm{Al}, \mathrm{Si}, \mathrm{Cr}$, and $\mathrm{Ni}$ in coating 4-7 


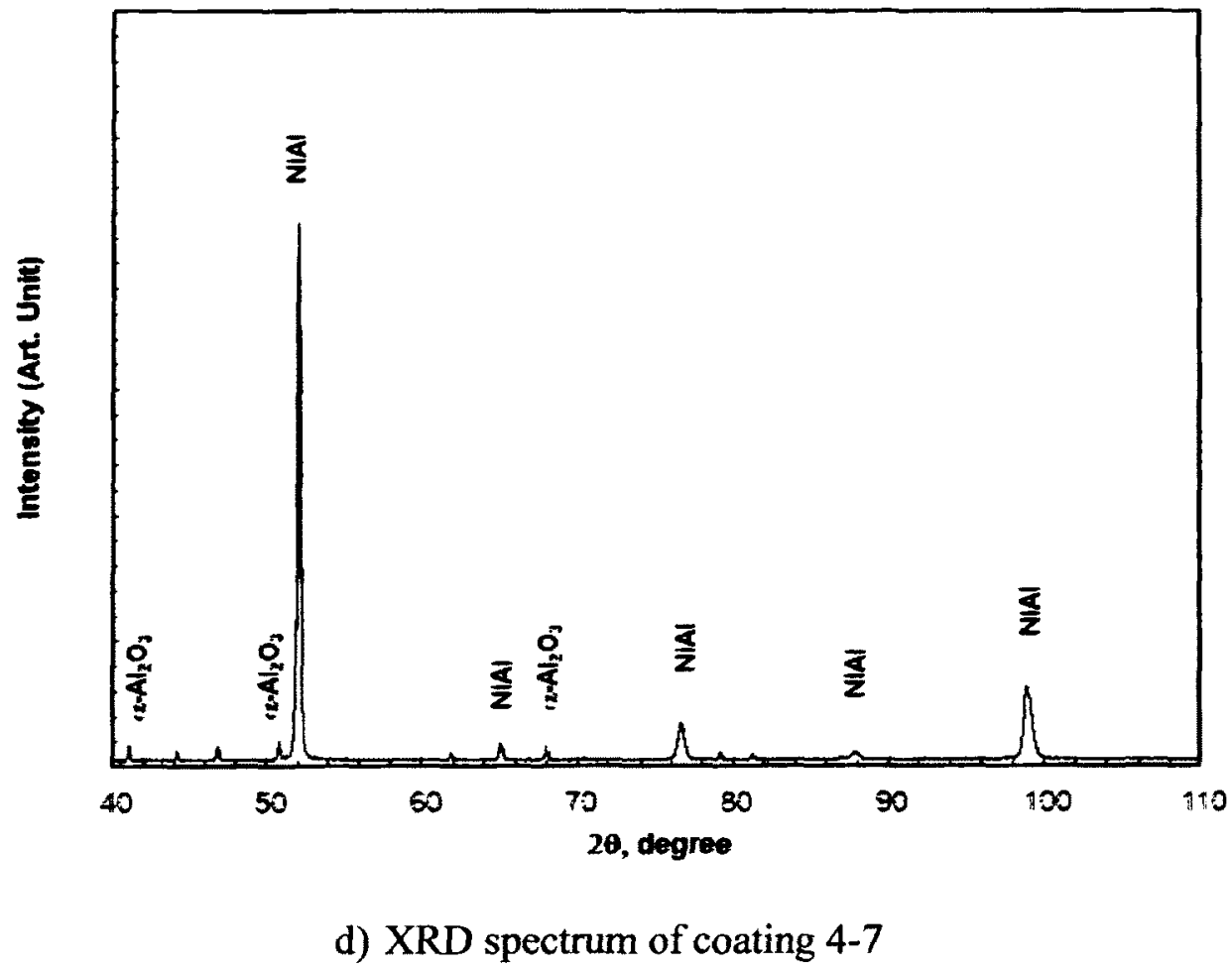

Figure 5.4 Concentration distribution and XRD spectra for coating 4-1 and 4-7.

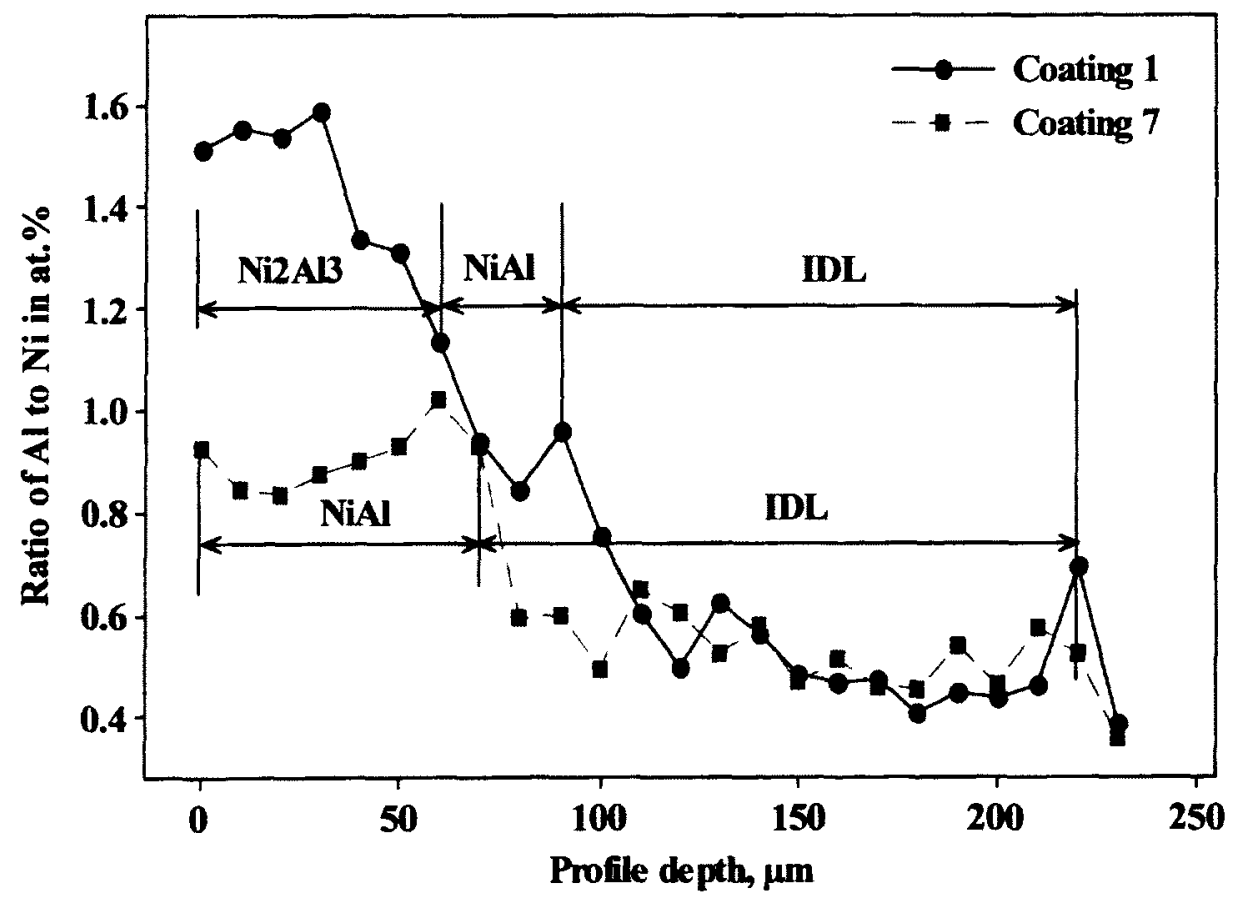

Figure 5.5 Ratio of Al at.\% to Ni at.\% versus the distance from coating surface for coating 4-1 and 4-7. 
Based on the curve of $\mathrm{Al} / \mathrm{Ni}$ ratio, specimen 4-1 has a three-layer structure that consists of an outer layer of $\mathrm{Ni}_{2} \mathrm{Al}_{3}$ or a mixture of $\mathrm{Ni}_{2} \mathrm{Al}_{3}$ and $\mathrm{NiAl}$, an intermediate $\mathrm{NiAl}$ layer, and an inner diffusion layer (IDL), whereas specimen 4-7 has a two-layer structure that consists of an outer NiAl layer and an inner diffusion layer (IDL). The phases for top layers of specimen 4-1 and specimen 4-7 were verified as $\mathrm{Ni}_{2} \mathrm{Al}_{3}$ and NiAl, respectively, based on the XRD spectra in Figure 5.4. The microstructures of other coating were estimated based on the $\mathrm{Al} / \mathrm{Ni}$ ratios and are listed in Table 5.5. Beneath the diffusion layer, the microstructure is observed to be mainly $\gamma(\mathrm{Ni})$ and $\gamma^{\text {' }}$ $\left(\mathrm{Ni}_{3} \mathrm{Al}\right)$, a typical NiCrAlY structure.

Table 5.5 Coating thickness and the maximum ratio of aluminum to nickel content

\begin{tabular}{clll}
\hline Coating & $\begin{array}{l}\text { Coating } \\
\text { thickness, } \mu \mathrm{m}\end{array}$ & $\begin{array}{l}\mathrm{Al} / \mathrm{Ni} \\
\text { ratio }\end{array}$ & $\begin{array}{l}\text { Coating } \\
\text { microstructure }\end{array}$ \\
\hline $4-1$ & 180 & 1.59 & Three layer \\
$4-2$ & 280 & 2.55 & Three layer \\
$4-3$ & 110 & 1.08 & Two layer \\
$4-4$ & 200 & 1.98 & Three layer \\
$4-5$ & 90 & 0.90 & Two layer \\
$4-6$ & 140 & 2.10 & Three layer \\
$4-7$ & 150 & 0.93 & Two layer \\
$4-8$ & 210 & 1.83 & Three layer \\
$4-9$ & 130 & 1.59 & Three layer \\
$4-10$ & 130 & 1.39 & Three layer \\
$4-11$ & 180 & 1.73 & Three layer \\
$4-12$ & 120 & 1.47 & Three layer \\
$4-13$ & 190 & 1.60 & Three layer \\
$4-14$ & 170 & 1.64 & Three layer \\
$4-15$ & 170 & 1.81 & Three layer \\
\hline
\end{tabular}

\subsubsection{Coating Thickness and Al/Ni Ratio}

Also observed on the concentration profiles are minimum/maximum points of nickel (and chromium) contents in the coatings due to simultaneous aluminum inward (reduce nickel and chromium) and nickel outward diffusion (reducing nickel and increase 
chromium). The coating thickness was defined as the distance from the surface to where the maximum nickel content was observed in the concentration profiles (Figure 5.4). The coating thickness and the maximum ratio of aluminum to nickel content (at.\%) in the coatings were measured and the results were also included in Table 5.5. These results acted as the responses for creating response surface and plots.

\subsubsection{Analysis of Variance for Coating Thicknesses and Al/Ni Ratios}

The two variations (coating thickness and maximum $\mathrm{Al} / \mathrm{Ni}$ atomic ratio) for the aluminized coatings are summarized in two ANOVA tables (Table 5.6 and Table 5.7). In addition to the variations, these tables also contain the freedoms and mean squares of the coatings, $F$ values and $p$-values. The assumption of the null hypothesis is valid when the $p$-value for a parameter is less than a significance level $\alpha$. The significance level in these tests was set to be 0.05 . A parameter, however, cannot be eliminated if it appears in the higher order terms of the parameter even its $p$-value is greater than the significant level.

Table 5.6 ANOVA table for coating thickness

\begin{tabular}{llllll}
\hline Source & $\begin{array}{l}\text { Degree of } \\
\text { freedom }\end{array}$ & $\begin{array}{l}\text { Sum of } \\
\text { squares }\end{array}$ & $\begin{array}{l}\text { Mean } \\
\text { square }\end{array}$ & $F$ value & $p$-value \\
\hline Model & 4 & 35109.40 & 8777.35 & 13.75 & 0.000 \\
Linear & 3 & 26875.00 & 9938.43 & 15.57 & 0.000 \\
$A, \mathrm{Al} \%$ & 1 & & & & 0.001 \\
$N, \mathrm{Ni} \%$ & 1 & & & & 0.012 \\
$T$, Process temp. $\left({ }^{\circ} \mathrm{C}\right)$ & 1 & & & & 0.005 \\
Quadratic & 1 & 8234.40 & 8234.40 & 12.90 & 0.004 \\
$T \times T$ & & 8234.40 & 8234.40 & & 0.004 \\
Residual & 10 & 6383.90 & 638.39 & & \\
Lack of fit & 8 & 4983.90 & 622.99 & 0.89 & 0.629 \\
Pure error & 2 & 1400.00 & 1400.00 & & \\
Total & 14 & 41493.30 & & & \\
$R^{2}$ & $84.61 \%$ & & & & \\
\hline
\end{tabular}


After eliminating the insignificant terms, the significant terms for the coating thickness and $\mathrm{Al} / \mathrm{Ni}$ ratio are given in Table 5.6 and Table 5.7 respectively. The $p$ values of lack-of-fit and $R^{2}$ values show that the response surface model and experimental data have a very high degree of fitness.

Table 5.7 ANOVA table for ratio of Al to Ni

\begin{tabular}{lcllll}
\hline Source & $\begin{array}{l}\text { Degree of } \\
\text { freedom }\end{array}$ & $\begin{array}{l}\text { Sum of } \\
\text { squares }\end{array}$ & $\begin{array}{l}\text { Mean } \\
\text { square }\end{array}$ & $F$ value & $p$-value \\
\hline Model & 5 & 2.5495 & 0.5099 & 35.03 & 0.000 \\
Linear & 3 & 2.2567 & 0.7522 & 51.68 & 0.000 \\
$A, \mathrm{Al} \%$ & 1 & & & & 0.000 \\
$N, \mathrm{Ni} \%$ & 1 & & & & 0.001 \\
$T$, Process temp. $\left({ }^{\circ} \mathrm{C}\right)$ & 1 & & & & 0.955 \\
Quadratic & 2 & 0.2928 & 0.1464 & 10.06 & 0.005 \\
$N \times N$ & 1 & & & & 0.041 \\
$T \times T$ & 1 & & & & 0.003 \\
Residual & 9 & 0.1310 & 0.1310 & & \\
Lack of fit & 7 & 0.1061 & 0.01516 & 1.22 & 0.521 \\
Pure error & 2 & 0.0249 & 0.00125 & & \\
Total & 14 & 2.6805 & & & \\
$R^{2}$ & $95.77 \%$ & & & & \\
\hline
\end{tabular}

\subsubsection{Regression Equation for Coating Thickness and Al/Ni Ratio}

The regression equations for coating thickness $\left(Y_{T}\right)$ and the maximum $\mathrm{Al} / \mathrm{Ni}$ ratio $\left(Y_{R}\right)$ in terms of the process parameters were developed using Minitab software and are given below:

$$
\begin{aligned}
& Y_{T}=-18789.30+7.50 \times A-5.25 \times N+35.675 \times T-16.79 \times 10^{-3} \times T^{2} \\
& Y_{R}=-108.504+0.099 \times A-0.126 \times N+0.209 \times T+4.415 \times 10^{-3} \times N^{2}- \\
& 99.846 \times 10^{-6} \times T^{2}
\end{aligned}
$$


As mentioned early, the analysis of a regression equation of response surface includes three aspects:

(1) Location of stationary points

The stationary points of the regression equations are determined by taking the partial derivative of $Y_{T}$ and $Y_{R}$ with respect to the factor terms. The values or formulas of the partial derivatives of the regression equations are summarized in Table 5.8.

Table 5.8 Values or formulas of the partial derivatives

\begin{tabular}{clc}
\hline $\begin{array}{c}\text { Partial } \\
\text { derivative }\end{array}$ & Value or formula & Stationary point \\
\hline$\frac{\partial Y_{T}}{\partial A}$ & 7.505 & \\
$\frac{\partial Y_{T}}{\partial B}$ & -5.251 & \\
$\frac{\partial Y_{T}}{\partial C}$ & $35.675-33.580 \times 10^{-3} \times C$ & $1062^{\circ} \mathrm{C}, \max$ \\
$\frac{\partial Y_{R}}{\partial A}$ & 0.099 & $14.36, \min$ \\
$\frac{\partial Y_{R}}{\partial B}$ & $-126.808 \times 10^{-3}+8.831 \times 10^{-3} \times B$ & \\
$\frac{\partial Y_{R}}{\partial C}$ & $209.627 \times 10^{-3}-199.692 \times 10^{-6} \times C$ & $1050^{\circ} \mathrm{C}, \max$ \\
\hline
\end{tabular}

Based on the results in Table 5.8, the following conclusions are reached:

- Coating thickness increases with the $\mathrm{Al}$ content in the pack and decreases with the Ni content in the pack. The relation of coating thickness with $\mathrm{Al}$ and $\mathrm{Ni}$ contents is linear.

- The relation of coating thickness with the temperature is parabolic and the temperature at which the maximum coating thickness reaches is $1062^{\circ} \mathrm{C}$.

- $\mathrm{Al} / \mathrm{Ni}$ ratio increases linearly with $\mathrm{Al}$ content in the pack. 
- The relation of $\mathrm{Al} / \mathrm{Ni}$ ratio with the $\mathrm{Ni}$ content in the pack is parabolic. $\mathrm{Al} / \mathrm{Ni}$ ratio decreases with the $\mathrm{Ni}$ content, and reaches the minimum point at $14.36 \mathrm{wt} . \% \mathrm{Ni}$.

- The relation of $\mathrm{Al} / \mathrm{Ni}$ ratio with the temperature is parabolic as well. The temperature at which the maximum $\mathrm{Al} / \mathrm{Ni}$ ratio reaches is $1050^{\circ} \mathrm{C}$.

- A saddle point can be found at $14.36 \mathrm{wt} \% \mathrm{Ni} \%$ and $1050^{\circ} \mathrm{C}$.

Among the stationary points, the saddle point is most important since the variations of $\mathrm{Al} / \mathrm{Ni}$ ratio are less intense with respect to the $\mathrm{Ni}$ content and temperature around the saddle point; such a phenomenon provides a chance for developing a robust process.

(2) Evaluation of response surfaces and contour plots

As can be seen from equation (5-1), there are three linear terms and only one quadratic term of the temperature $(C)$ in the regression equation of coating thickness. The quadratic temperature term suggests that the response surface of coating thickness with the fixed temperatures is a flat surface and the equivalent lines in the corresponding contour plot are straight lines (Figure 5.6a), whereas the response surface of coating thickness with the temperature is a curved surfaces and the equivalent lines in the corresponding contour plot are parabolic lines (Figure 5.6b), and coating thickness reaches the maximum at $1062^{\circ} \mathrm{C}$.

Similarly there are three linear terms and two quadratic terms (temperature $\mathrm{C}$ and $\mathrm{Ni}$ content $\mathrm{B}$ ) in the regression equation of the $\mathrm{Al} / \mathrm{Ni}$ ratio. The response surfaces of $\mathrm{Al} / \mathrm{Ni}$ ratio with the factors are all curved surfaces and the equivalent lines in the corresponding contour plots are parabolic lines (Figure 5.7). 


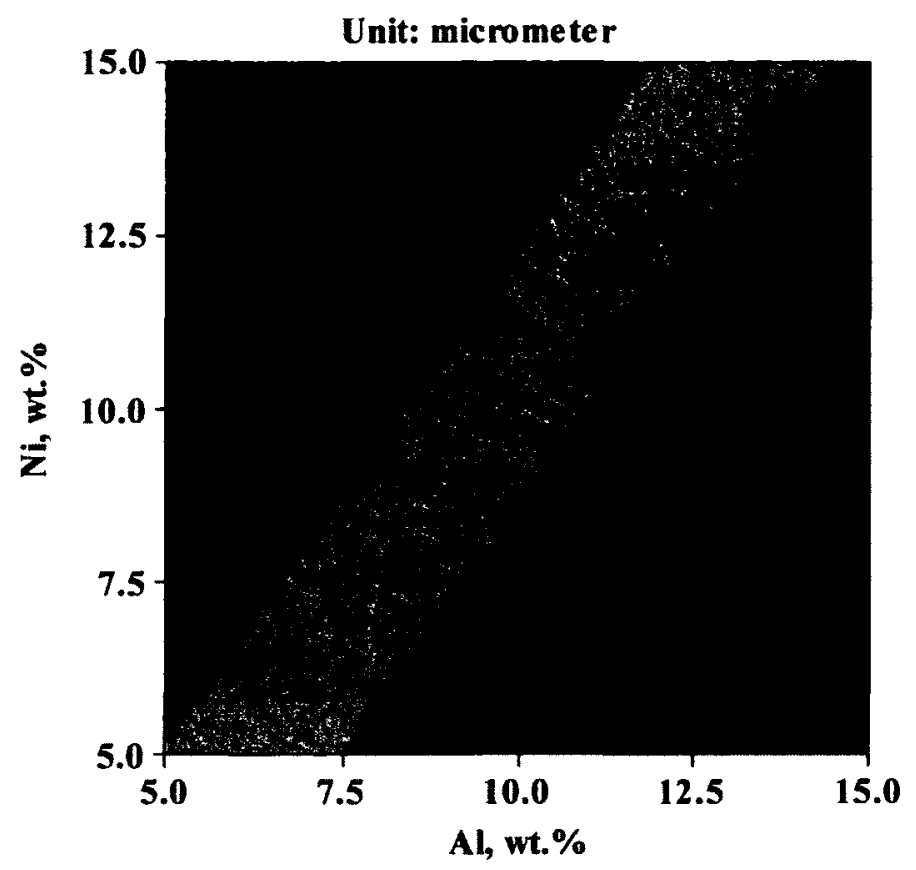

(a) Contour plot of coating thickness at $1000^{\circ} \mathrm{C}$

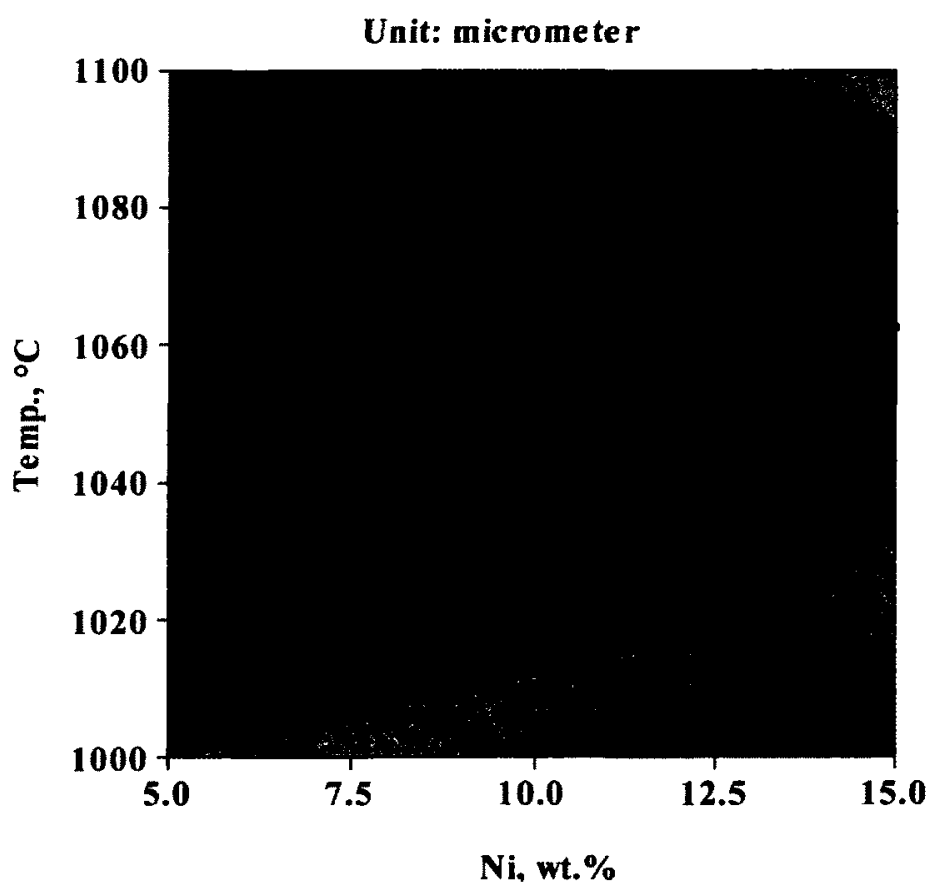

(b) Contour plot of coating thickness at $5 \mathrm{wt} . \% \mathrm{Al}$

Figure 5.6 Contour plots of the coating thickness. 


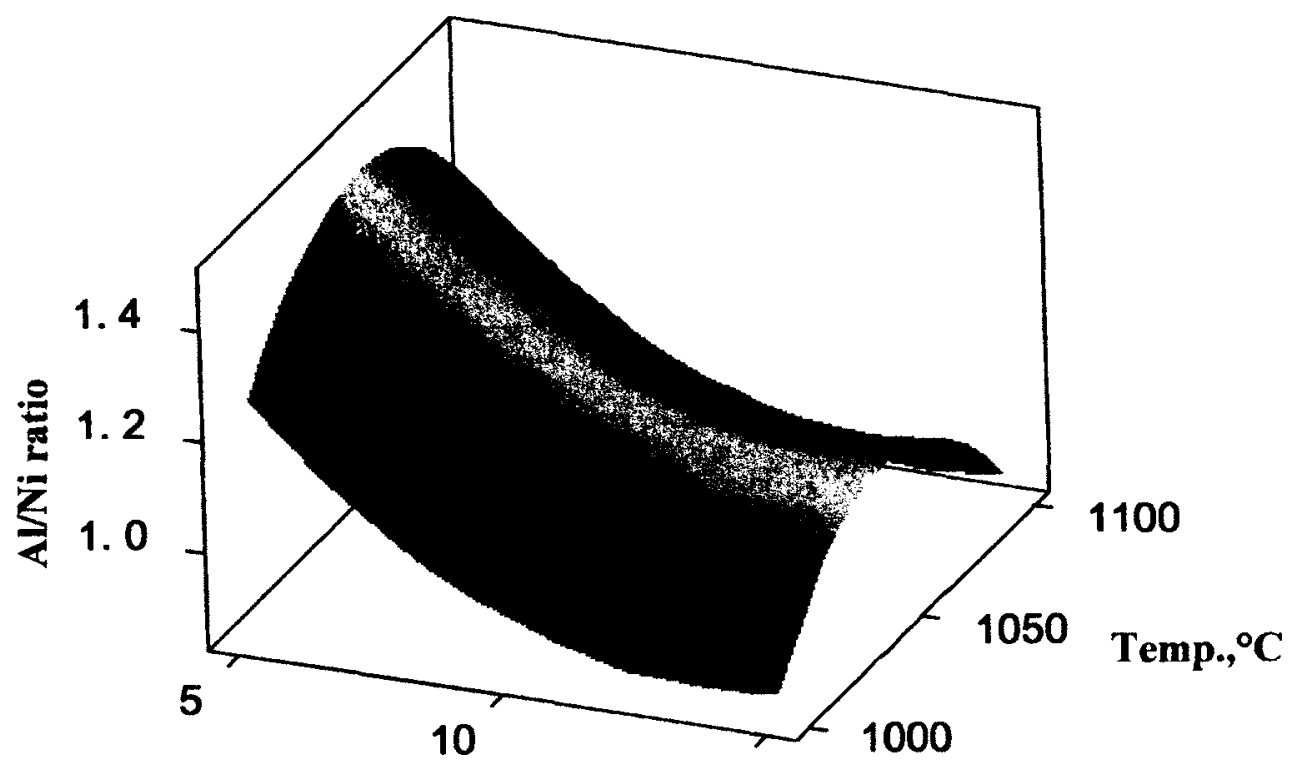

Ni, wt.\%

(a) Response surface plot of $\mathrm{Al} / \mathrm{Ni}$ ratio at $5 \mathrm{wt} \% \mathrm{Al}$

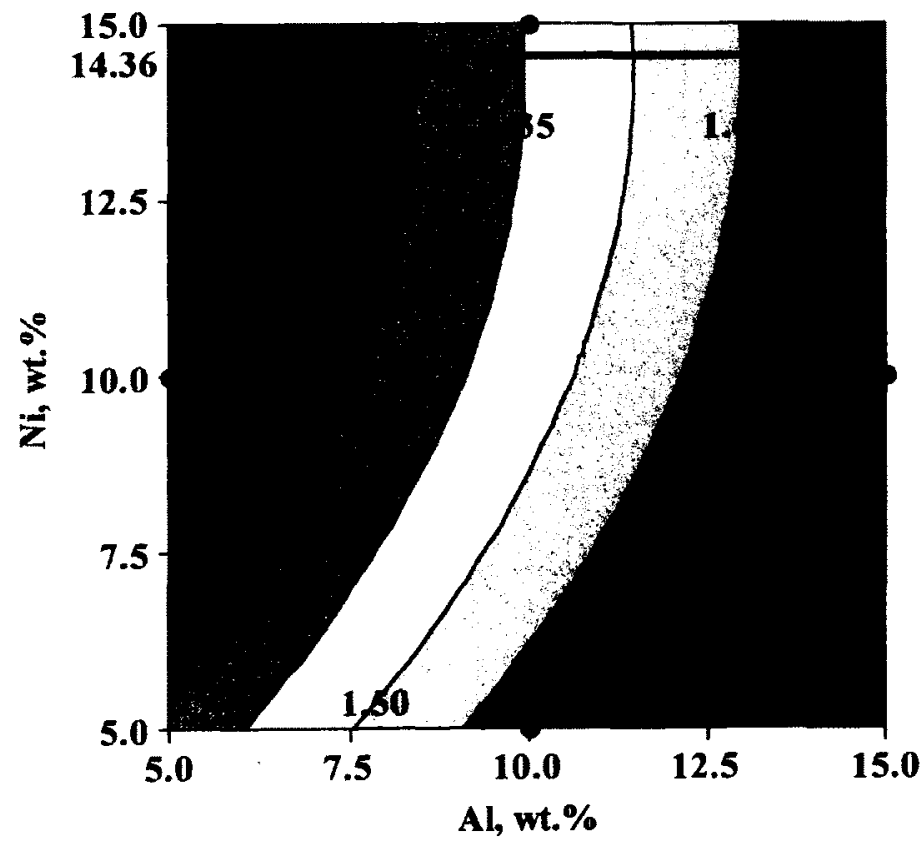

(b) Contour plot of $\mathrm{Al} / \mathrm{Ni}$ ratio at $1000^{\circ} \mathrm{C}$ 


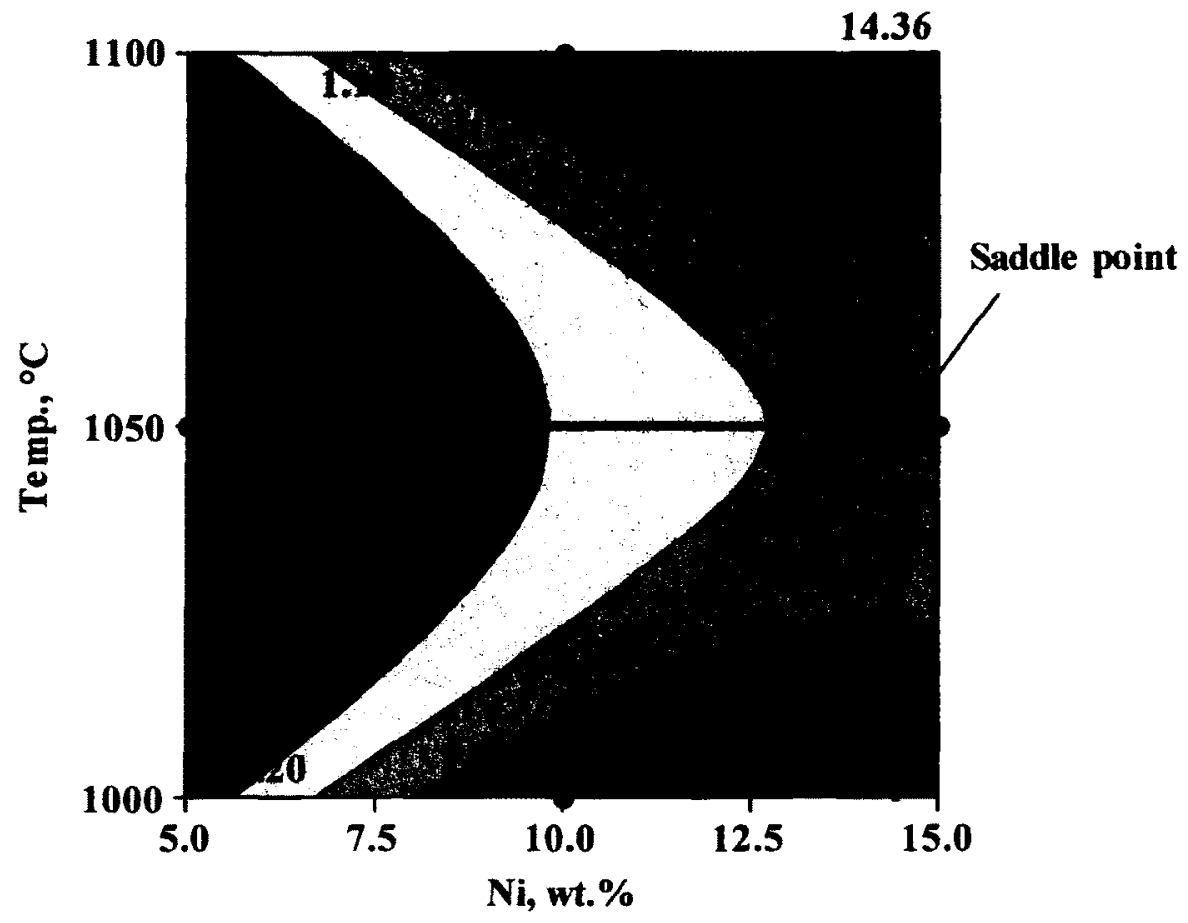

(c) Contour plot of $\mathrm{Al} / \mathrm{Ni}$ ratio at $5 \mathrm{wt} . \% \mathrm{Al}$

Figure 5.7 Response surface and contour plots of the $\mathrm{Al} / \mathrm{Ni}$ ratio.

Coating thickness and the maximum $\mathrm{Al} / \mathrm{Ni}$ ratio in the aluminized coatings depend on the activity of $\mathrm{Al}$ during the diffusion process. The $\mathrm{Al}$ content in the powder mixture increases $\mathrm{Al}$ activity (driving force) while the $\mathrm{Ni}$ content decreases $\mathrm{Al}$ activity; which are reflected in the regression equations. The experimental results clearly illustrates that the high $\mathrm{Al}$ activity resulted from the higher $\mathrm{Al}$ content in the pack led to an $\mathrm{Al}$-rich $\mathrm{Ni}_{2} \mathrm{Al}_{3}$ layer at higher $\mathrm{Al} / \mathrm{Ni}$ ratio due to promoting $\mathrm{Al}$-inward-diffusion and also increased coating thickness, whereas the low Al activity resulted from the higher $\mathrm{Ni}$ content in the pack led to a $\mathrm{NiAl}$ layer at lower $\mathrm{Al} / \mathrm{Ni}$ ratio due to $\mathrm{Ni}$ outward-diffusion and coating thickness is thinner. 
Temperature also plays an important role in the coating formation and composition. At a relatively low temperature the growth of a coating takes place primarily due to $\mathrm{Al}$ inward-diffusion. As the temperature increases, the thickness and $\mathrm{Al} / \mathrm{Ni}$ ratio of the coating increase until the temperature is high enough for the Ni-outward-diffusion to dominate the coating growth, and then the coating thickness and $\mathrm{Al} / \mathrm{Ni}$ ratio decrease with the temperature. Therefore there are maximum points for coating thickness and $\mathrm{Al} / \mathrm{Ni}$ ratio with respect to the temperature in the response surface and contour plots (Figure 5.7).

(3) Optimization of the coating thickness and the $\mathrm{Al} / \mathrm{Ni}$ ratio by overlaying the contour plots

The optimization of both the coating thickness and the $\mathrm{Al} / \mathrm{Ni}$ ratio was carried out by additional set of experiments. The aim of these experiments was to obtain (a) a coating with a targeted range of thickness between 95 to $105 \mu \mathrm{m}$ and an $\mathrm{Al} / \mathrm{Ni}$ ratio between 0.9 to 1.1 , and (b) a coating with a thickness between 165 to $175 \mu \mathrm{m}$ and an $\mathrm{Al} / \mathrm{Ni}$ ratio from 1.9 to 2.1 .

By observing the parameters from overlapped contour plots of the coating thickness and the $\mathrm{Al} / \mathrm{Ni}$ ratio, five points were selected at $1000^{\circ} \mathrm{C}$, as shown in Figure $5.8 \mathrm{a}$ and Figure 5.8b. The other four experiments were carried out at $1050^{\circ} \mathrm{C}$ and $1100^{\circ} \mathrm{C}$ to testify the validity of the regression equations at these temperatures. These additional experiments were assigned coating numbers 16 to 24 . Table 5.9 provides parameters for each test. 


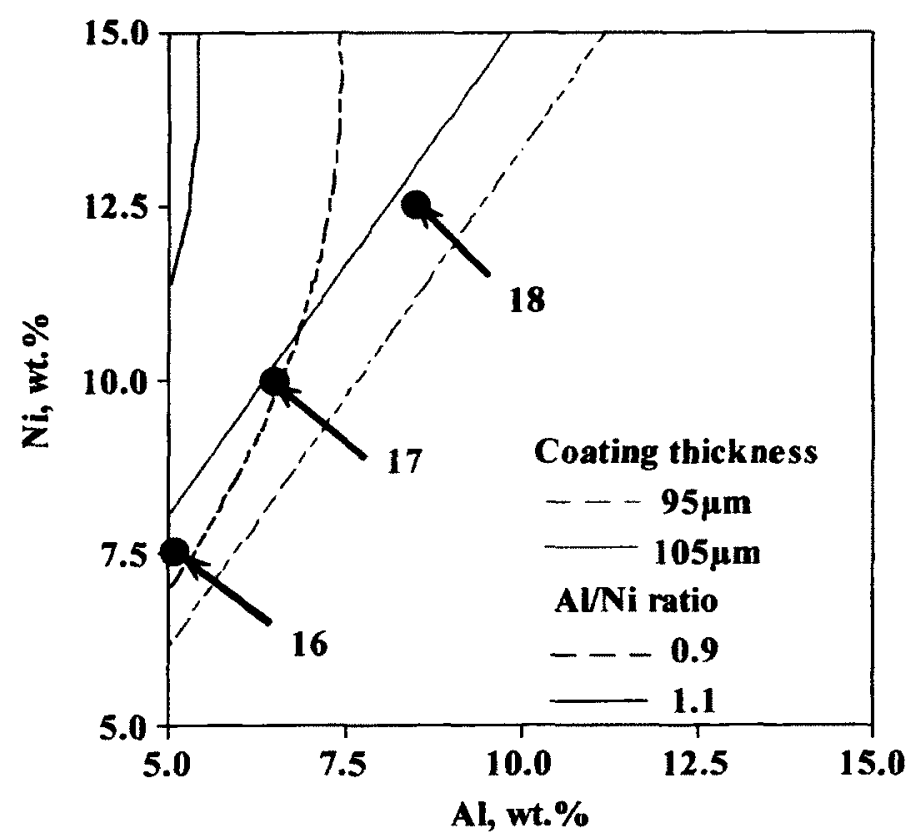

(a) Coating thickness from 95 to $105 \mu \mathrm{m}$ and $\mathrm{Al} / \mathrm{Ni}$ ratio from 0.9 to 1.1

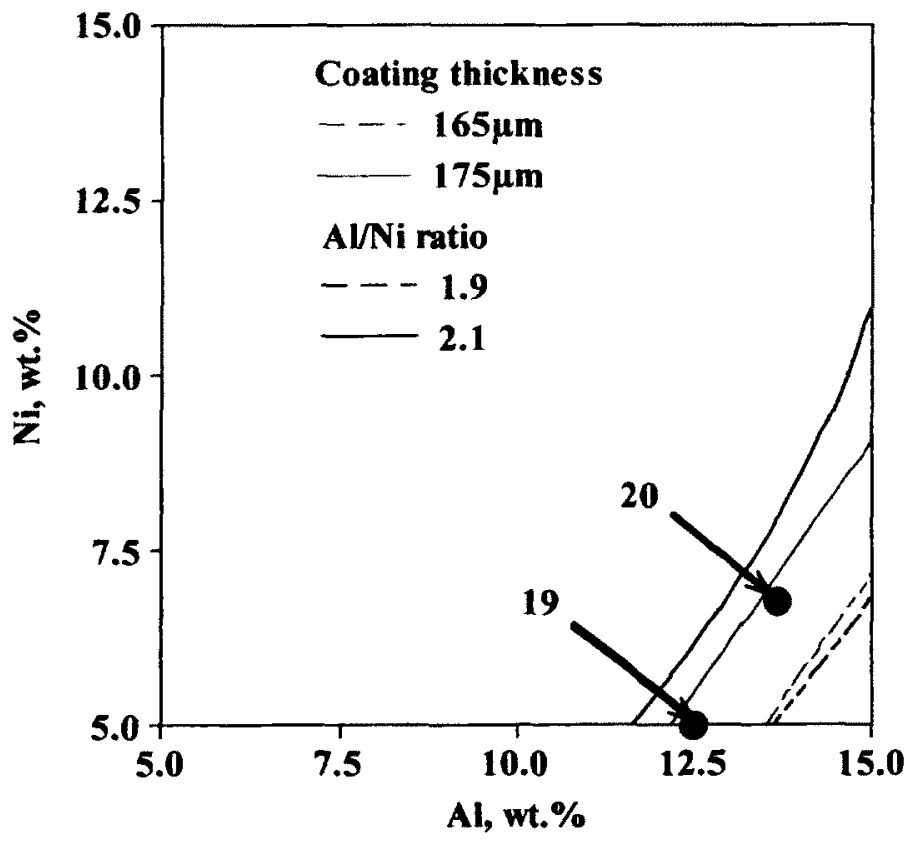

(b) Coating thickness from 165 to $175 \mu \mathrm{m}$ and $\mathrm{Al} / \mathrm{Ni}$ ratio from 1.9 to 2.1

Figure 5.8 Overlapped contour plots for response surface models at $1000^{\circ} \mathrm{C}$. 
Table 5.9 Process parameters of additional tests for model verification

\begin{tabular}{cccccccccc}
\hline \multirow{2}{*}{ Factor } & \multicolumn{10}{c}{ Parameter } \\
\cline { 2 - 10 } & 16 & 17 & 18 & 19 & 20 & 21 & 22 & 23 & 24 \\
\hline Al, wt.\% & 5.0 & 6.5 & 8.5 & 12.5 & 13.5 & 5.0 & 5.0 & 6.5 & 8.6 \\
Ni, wt.\% $\%$ & 7.5 & 10.0 & 12.5 & 5.0 & 7.0 & 10.0 & 12.0 & 10.0 & 12.5 \\
Temp., ${ }^{\circ} \mathrm{C}$ & 1000 & 1000 & 1000 & 1000 & 1000 & 1050 & 1050 & 1100 & 1100 \\
\hline
\end{tabular}

The discrepancies between the predicted and experimental results are shown in Table 5.10. The differences between the experimental results and the predicted values are acceptable, which verifies the validity of the regression equations. The parameters for coating 17 and 20 were selected to fabricate the aluminized layer of multilayered coatings

Table 5.10 Comparison between the predicted and experimental results

\begin{tabular}{ccccccc}
\hline \multirow{2}{*}{ Test } & \multicolumn{3}{c}{ Coating thickness $\mu \mathrm{m}}$, & \multicolumn{2}{c}{ Al/Ni ratio } \\
\cline { 2 - 7 } & $\begin{array}{c}\text { Experiment } \\
\text { value }\end{array}$ & $\begin{array}{c}\text { Predicted } \\
\text { value }\end{array}$ & $\begin{array}{c}\text { Relative } \\
\text { Error, \% }\end{array}$ & $\begin{array}{c}\text { Experiment } \\
\text { value }\end{array}$ & $\begin{array}{c}\text { Predicted } \\
\text { value }\end{array}$ & $\begin{array}{c}\text { Relative } \\
\text { Error, \% }\end{array}$ \\
\hline 16 & 120 & 100 & 16.67 & 1.09 & 1.06 & 2.75 \\
17 & 110 & 100 & 9.09 & 1.09 & 1.08 & 0.92 \\
18 & 110 & 100 & 9.09 & 1.23 & 1.21 & 1.62 \\
19 & 190 & 170 & 10.52 & 2.18 & 2.04 & 6.42 \\
20 & 200 & 170 & 15.00 & 2.14 & 1.94 & 9.34 \\
21 & 140 & 150 & 6.67 & 1.01 & 1.15 & 13.86 \\
22 & 140 & 140 & 0.00 & 0.94 & 1.09 & 15.95 \\
23 & 120 & 140 & 16.67 & 0.94 & 1.07 & 13.82 \\
24 & 140 & 140 & 0.00 & 1.12 & 1.21 & 8.03 \\
\hline
\end{tabular}

\subsection{Process Development for Cr-Si Coatings}

\subsubsection{Experimental Procedure}

The purpose of process development for a $\mathrm{Cr}-\mathrm{Si}$ coating is to obtain a coating with $25-30 \%$ at. $\%$ Si and $25-30 \%$ at. $\%$ Cr on IN738. In order to achieve this goal, a Taguchi L4 array with two-levels and three factors was designed and is listed in Table 5.11. The 
process parameters for each experiment are given in Table 5.12. The specimens for these experiments were designated as coating 5-1 to specimen 5-4. The experimental procedure was similar to the experimental procedure for aluminizing process that is described in section 5.1.1. A coating specimen is shown in Figure 5.9. Coating features, which include coating thickness, phases, and elemental distributions, were investigated after the coatings in Table 5.12 were produced.

Table 5.11 Taguchi L4 array for the process development of Cr-Si coating

\begin{tabular}{lllll}
\hline Level & $\begin{array}{l}\text { Metallic } \\
\text { powder, wt.\% }\end{array}$ & $\begin{array}{l}\mathrm{Si} \text { in metallic } \mathrm{Cr} \text { in metallic } \\
\text { powder, wt.\% }\end{array}$ & $\begin{array}{l}\text { Temp., } \\
\text { powder, wt.\% }\end{array}$ \\
\hline 0 & 30 & 70 & 30 & ${ }^{\circ} \mathrm{C}$ \\
1 & 40 & 60 & 40 & 1100 \\
\hline
\end{tabular}

Table 5.12 Parameters for the L4 array

\begin{tabular}{lllllllll}
\hline Coating & $\begin{array}{l}\mathrm{Si} \text { in } \\
\text { powder, in } \\
\text { wt.\% }\end{array}$ & $\begin{array}{l}\mathrm{Cr} \text { inder, } \\
\text { powt.\% }\end{array}$ & $\begin{array}{l}\mathrm{NH}_{4} \mathrm{Cl} \text { in } \\
\text { powder, } \\
\text { wt.\% }\end{array}$ & $\begin{array}{l}\mathrm{Al}_{2} \mathrm{O}_{3} \text { in } \\
\text { powder, } \\
\text { wt. \% }\end{array}$ & $\begin{array}{l}\mathrm{SiO}_{2} \text { in } \\
\text { powder, } \\
\text { wt.\% }\end{array}$ & $\begin{array}{l}\text { Temp., } \\
{ }^{\circ} \mathrm{C}\end{array}$ & $\begin{array}{l}\text { Time, } \\
\text { hr }\end{array}$ \\
\hline $5-1$ & 21 & 9 & & 34 & 34 & 1100 & \\
$5-2$ & 18 & 12 & 2 & 34 & 34 & 1000 & 4 \\
$5-3$ & 28 & 12 & & 29 & 29 & 1000 & \\
$5-4$ & 24 & 16 & & 29 & 29 & 1100 & \\
\hline
\end{tabular}

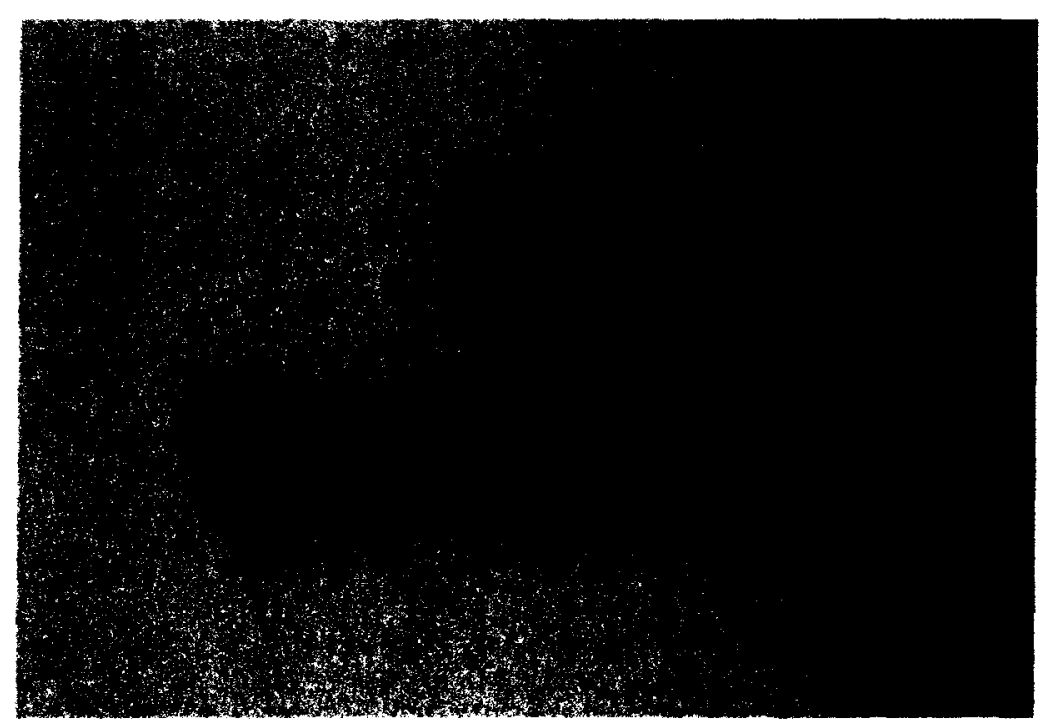

Figure 5.9 Image of coating 5-4. 


\subsection{Cr-Si Coating Thickness}

The $\mathrm{Cr}$-Si coating thickness was measured using image analysis software; the results are given in Table 5.13. A plot of the coating thicknesses against process parameters is provided in Figure 5.10. Examination of Figure 5.10 reveals two important aspects: one is that the thickness increases with an increase in the percentage of metallic powder in the powder mixture, silicon content in the metallic powder, and temperature; the other is that the effect of the percentage of metallic powder in powder mixture on coating thickness is larger than other two parameters, i.e., the coatings with more metallic powder in powder mixture are much thicker than those with less metallic powder. As the coating thickness is not the target to be optimized, there is no need to analyze the SNRs for process parameters.

Table 5.13 Coating thickness for Cr-Si coating

\begin{tabular}{lllll}
\hline Specimen & $5-1$ & $5-2$ & $5-3$ & $5-4$ \\
\hline Coating thickness, $\mu \mathrm{m}$ & 50 & 40 & 70 & 70 \\
\hline
\end{tabular}

\subsubsection{Optimization of Cr-Si Coating Process}

To select the optimal process, the ideal values for silicon and chromium contents in a coating were set at 30 at.\% and 25 at.\%, respectively, and then the differences between measured data and ideal values are expected to be as small as possible. The differences between measured data and ideal values for silicon and chromium contents were defined as $\Delta \mathrm{Si}$ and $\Delta \mathrm{Cr}$, as shown in Table 5.14. The process was optimized based on the Taguchi's smaller-the-better function for SNRs of $\Delta \mathrm{Si}$ and $\Delta \mathrm{Cr}$.

The optimal parameters for minimizing the differences are summarized in Table 5.15 based on the plot of the SNRs versus process parameters (Figure 5.11b and Figure 
5.12b). The process parameters for generating optimized silicon and chromium content are identical; they happened to be the process parameters used for coating 5-4. These parameters will be used to fabricate the final multilayered coating.

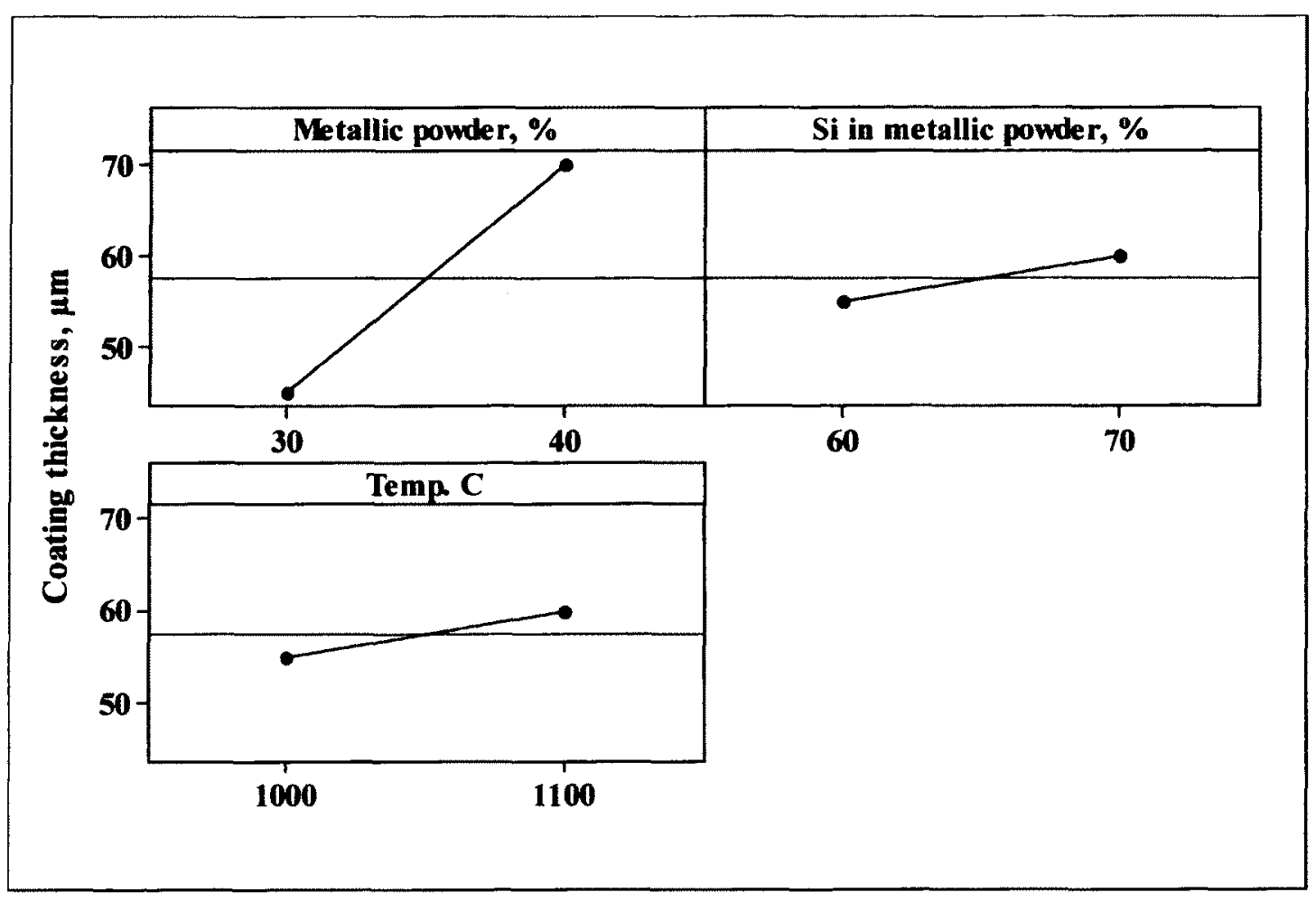

Figure 5.10 Coating thickness versus process parameters. 
Table 5.14 Concentrations of $\mathrm{Si}$ and $\mathrm{Cr}$ and the differences between measured data and ideal values in $\mathrm{Cr}$-Si coatings

\begin{tabular}{|c|c|c|c|c|c|}
\hline \multirow[b]{2}{*}{ Specimen } & \multirow{2}{*}{$\begin{array}{c}\text { Distance from } \\
\text { coating surface, } \\
\mu \mathrm{m}\end{array}$} & \multicolumn{4}{|c|}{ Composition, at.\% } \\
\hline & & $\mathrm{Si}$ & $\begin{array}{c}\Delta \mathrm{Si} \\
(\mathrm{Si}-30)\end{array}$ & $\mathrm{Cr}$ & $\begin{array}{c}\Delta \mathrm{Cr} \\
(\mathrm{Cr}-25)\end{array}$ \\
\hline \multirow{6}{*}{$5-1$} & 0 & 21.38 & -8.62 & 13.51 & -11.49 \\
\hline & 10 & 18.31 & -11.69 & 20.08 & -4.92 \\
\hline & 20 & 13.67 & -16.33 & 18.52 & -6.48 \\
\hline & 30 & 13.53 & -16.47 & 17.94 & -7.06 \\
\hline & 40 & 17.94 & -12.06 & 12.97 & -12.03 \\
\hline & 50 & 15.07 & -14.93 & 15.58 & -9.42 \\
\hline \multirow{5}{*}{$5-2$} & 0 & 24.44 & -5.56 & 15.14 & -9.86 \\
\hline & 10 & 23.24 & -6.76 & 22.22 & -2.78 \\
\hline & 20 & 17.26 & -12.74 & 15.82 & -9.18 \\
\hline & 30 & 13.65 & -16.35 & 18.68 & -6.32 \\
\hline & 40 & 6.39 & -23.61 & 17.74 & -7.26 \\
\hline \multirow{8}{*}{$5-3$} & 0 & 34.83 & 4.83 & 13.41 & -11.59 \\
\hline & 10 & 34.35 & 4.35 & 12.95 & -12.05 \\
\hline & 20 & 34.02 & 4.02 & 12.22 & -12.78 \\
\hline & 30 & 33.41 & 3.41 & 14.20 & -10.80 \\
\hline & 40 & 32.01 & 2.01 & 14.02 & -10.98 \\
\hline & 50 & 27.50 & -2.50 & 15.98 & -9.02 \\
\hline & 60 & 22.15 & -7.85 & 19.63 & -5.37 \\
\hline & 70 & 10.49 & -19.51 & 17.83 & -7.17 \\
\hline \multirow{8}{*}{$5-4$} & 0 & 27.26 & -2.74 & 14.07 & -10.93 \\
\hline & 10 & 24.70 & -5.30 & 25.86 & 0.86 \\
\hline & 20 & 23.47 & -6.53 & 18.74 & -6.26 \\
\hline & 30 & 20.42 & -9.58 & 17.69 & -7.31 \\
\hline & 40 & 16.13 & -13.87 & 18.11 & -6.89 \\
\hline & 50 & 14.60 & -15.40 & 17.40 & -7.60 \\
\hline & 60 & 11.77 & -18.23 & 20.60 & -4.40 \\
\hline & 70 & 9.57 & -20.43 & 18.58 & -6.42 \\
\hline
\end{tabular}

Table 5.15 Parameters for optimizing both silicon and chromium contents

\begin{tabular}{lcc}
\hline Process parameter & Optimal parameter for $\Delta \mathrm{Si}$ & Optimal parameter for $\Delta \mathrm{Cr}$ \\
\hline Metallic powder, wt.\% & 40 & 40 \\
Si in metallic powder, wt.\% & 60 & 60 \\
Temp., ${ }^{\circ} \mathrm{C}$ & 1100 & 1100 \\
\hline
\end{tabular}




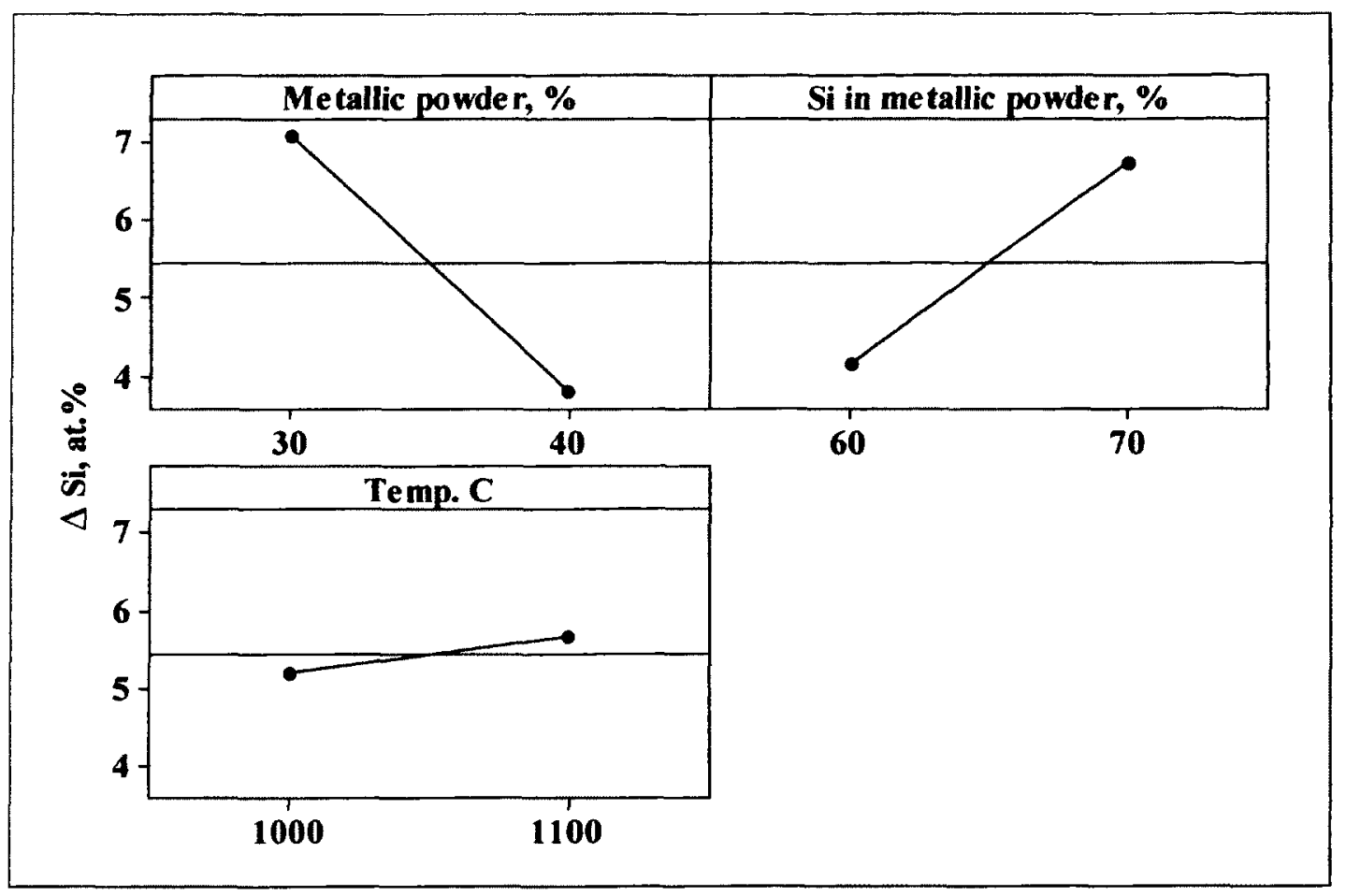

a) Si content versus process parameters

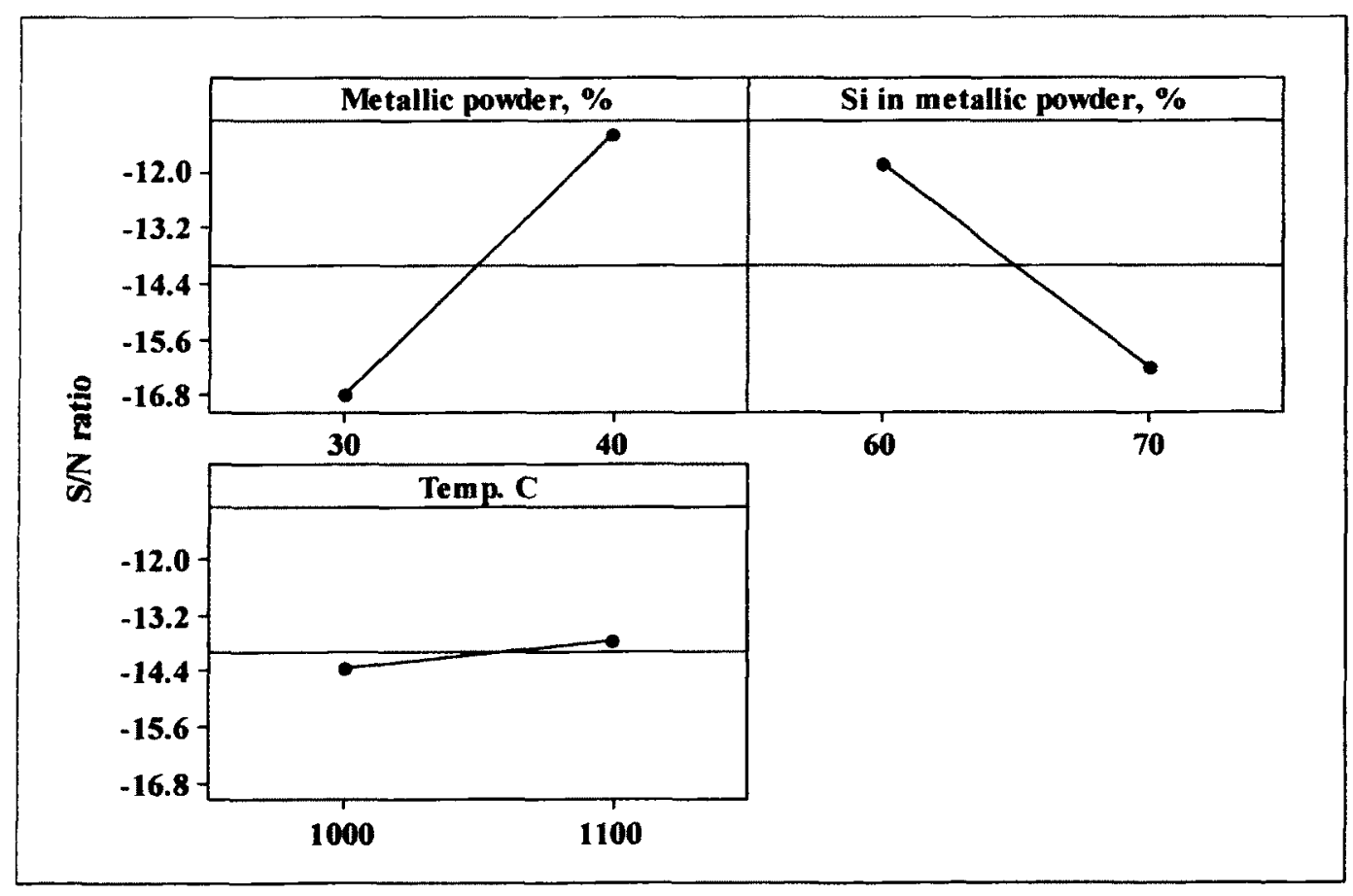

b) SNR versus process parameters

Figure 5.11 Effects of process parameters on Si content and SNRs. 


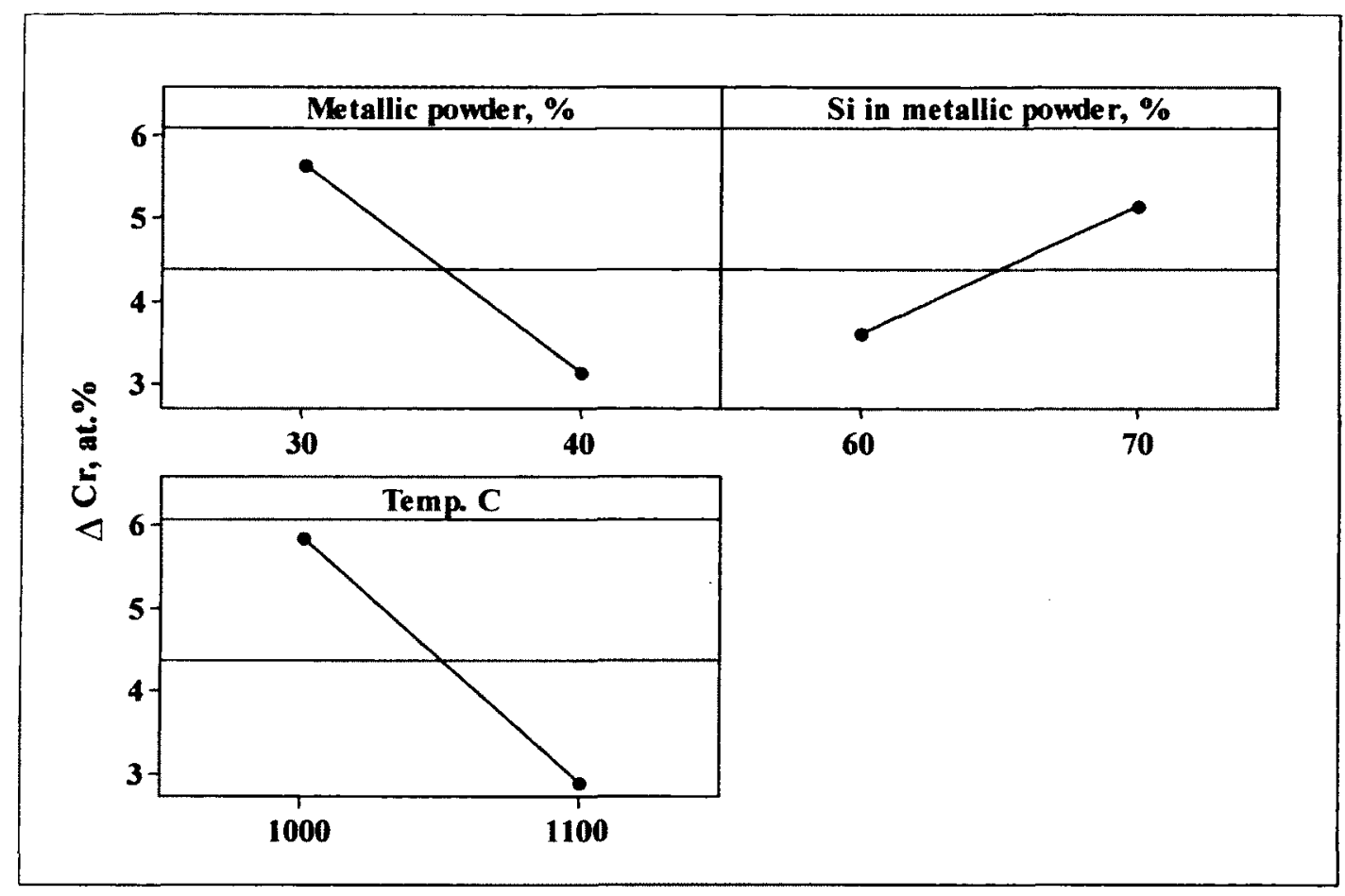

a) $\mathrm{Cr}$ content versus process parameters

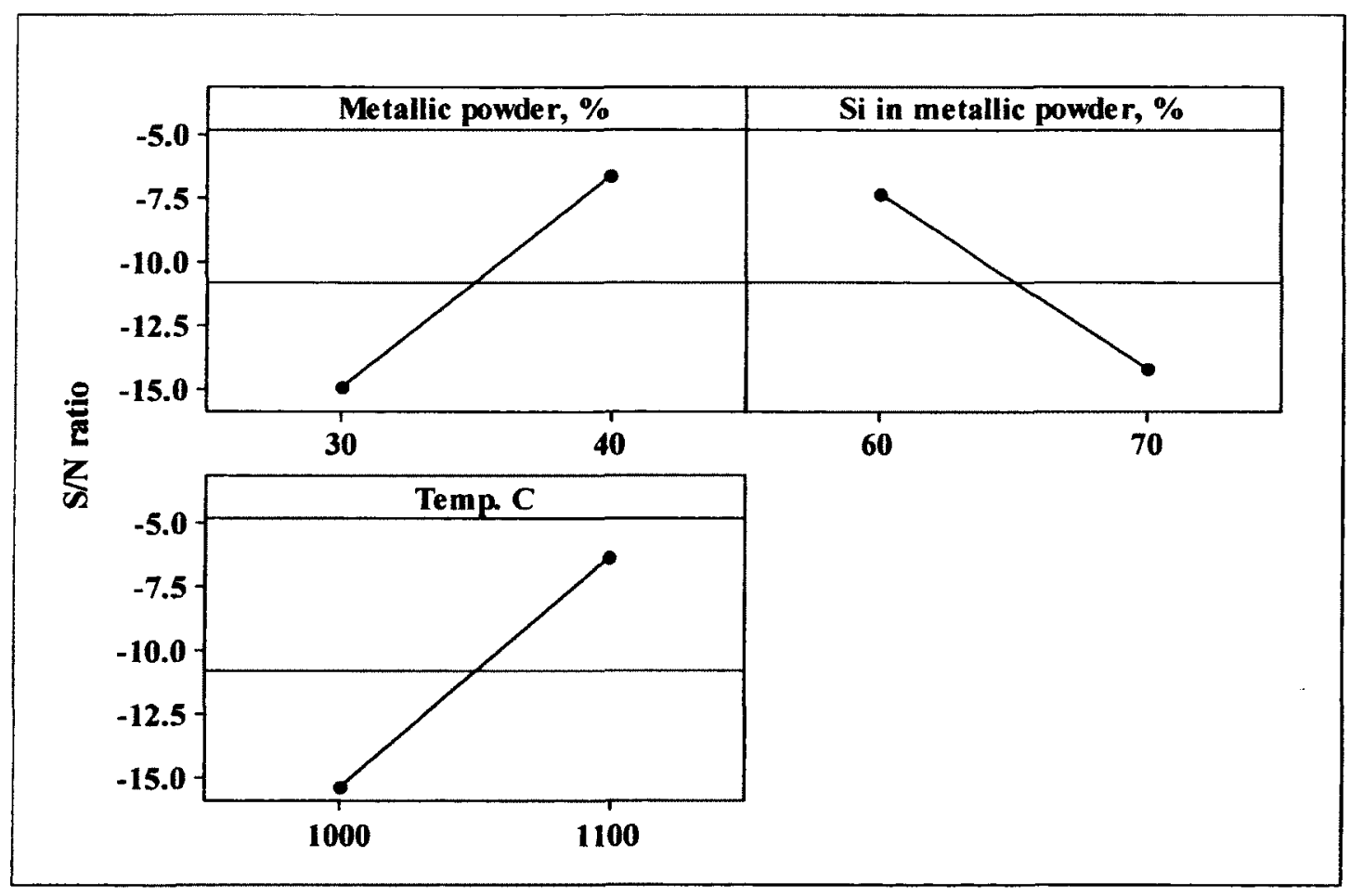

b) SNR versus process parameters

Figure 5.12 Effects of process parameters on Cr content and SNRs. 


\subsubsection{Microstructures of Cr-Si Coatings}

The microstructure of coating specimen 5-4 is presented in Figure 5.13a. The X-ray mappings and concentration profiles (Figure 5.13d, 5.13e and 5.13f) show a twolayered structure: high-silicon layer $(\mathrm{Si}>20$ at.\%) and chromium-rich layer $(\mathrm{Cr}>20$ at.\%). Based on the XRD spectrum in Figure 5.13f, the phases in the coating are $Z$ $\left(\mathrm{Cr}_{3} \mathrm{Ni}_{2} \mathrm{Si}\right)$ phase, $\delta\left(\mathrm{Ni}_{2} \mathrm{Si}\right)$ phase $(\mathrm{B})$, and $\beta\left(\mathrm{Cr}_{3} \mathrm{Si}\right)$ phase in addition to NiAl. The high-silicon layer may mainly consist of $\delta\left(\mathrm{Ni}_{2} \mathrm{Si}\right)$ and $\mathrm{Cr}_{3} \mathrm{Si}$ phase while the chromiumrich layer consists of more $\mathrm{Z}$ phase $\left(\mathrm{Cr}_{3} \mathrm{Ni}_{2} \mathrm{Si}\right)$ and some $\beta\left(\mathrm{Cr}_{3} \mathrm{Si}\right)$ phase. EDS results for some phases in Figure 5.13a are illustrated in Table 5.16.

Similarly, for other Cr-Si coatings, the Si content reduces from the surface to the coating/substrate interface while $\mathrm{Cr}$ content increases in most of the specimens as shown in Table 5.14

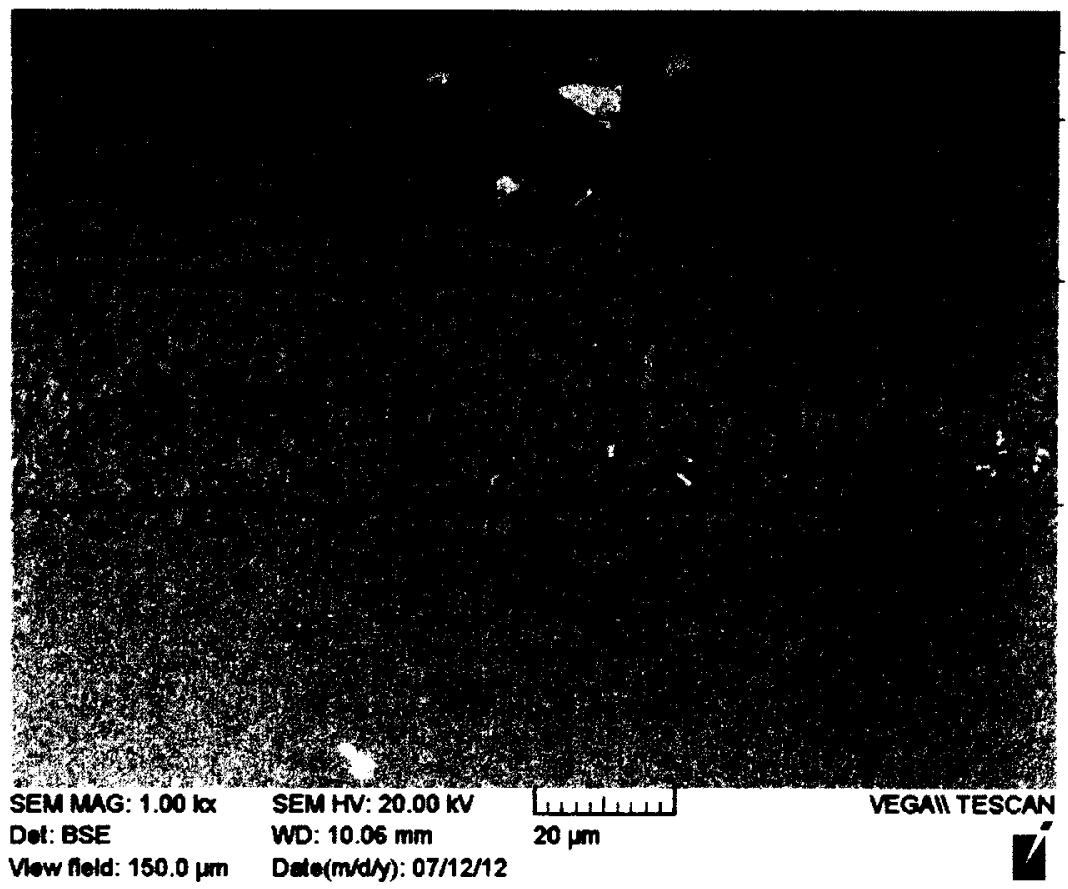

a) SEM image of microstructure 


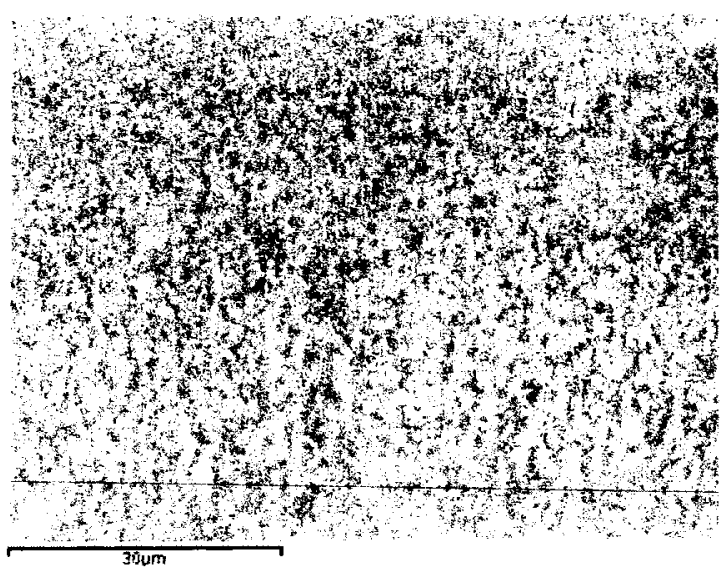

b) SEM image for mapping

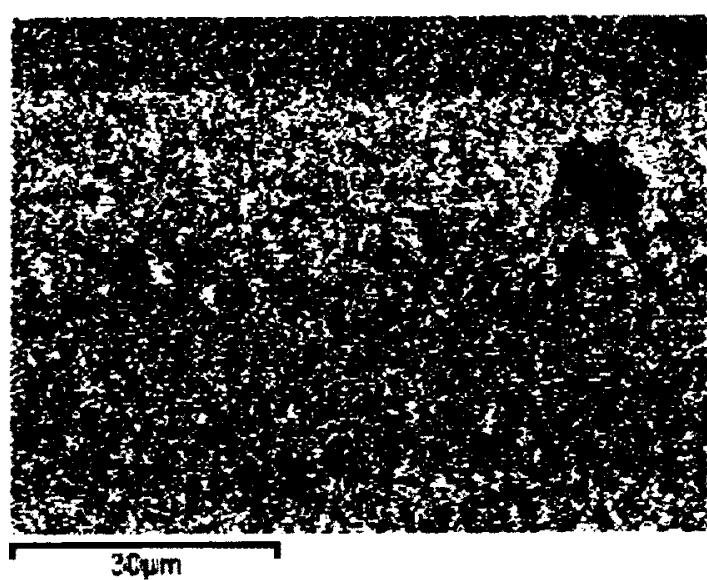

d) EDS mapping image for $\mathrm{Cr}$

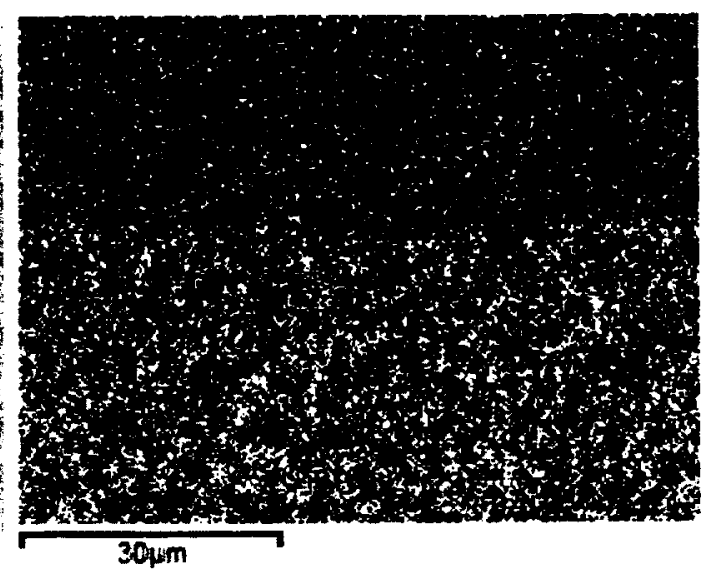

c) EDS mapping image for $\mathrm{Al}$

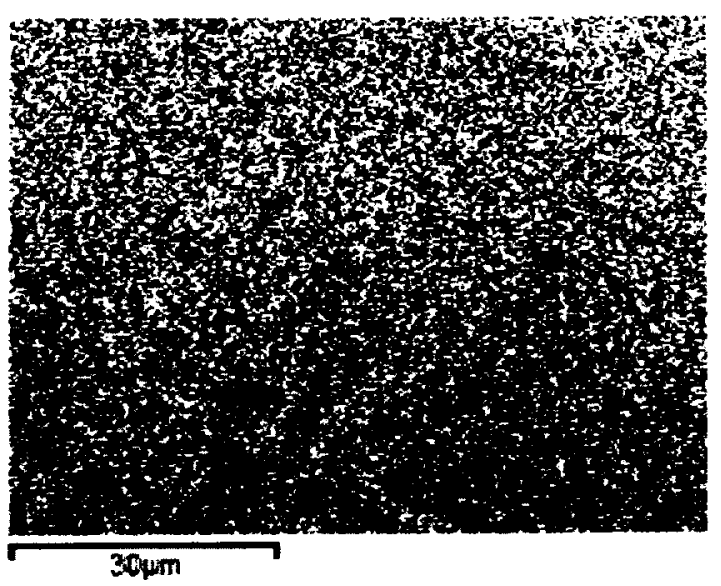

e) EDS mapping image for $\mathrm{Si}$ 


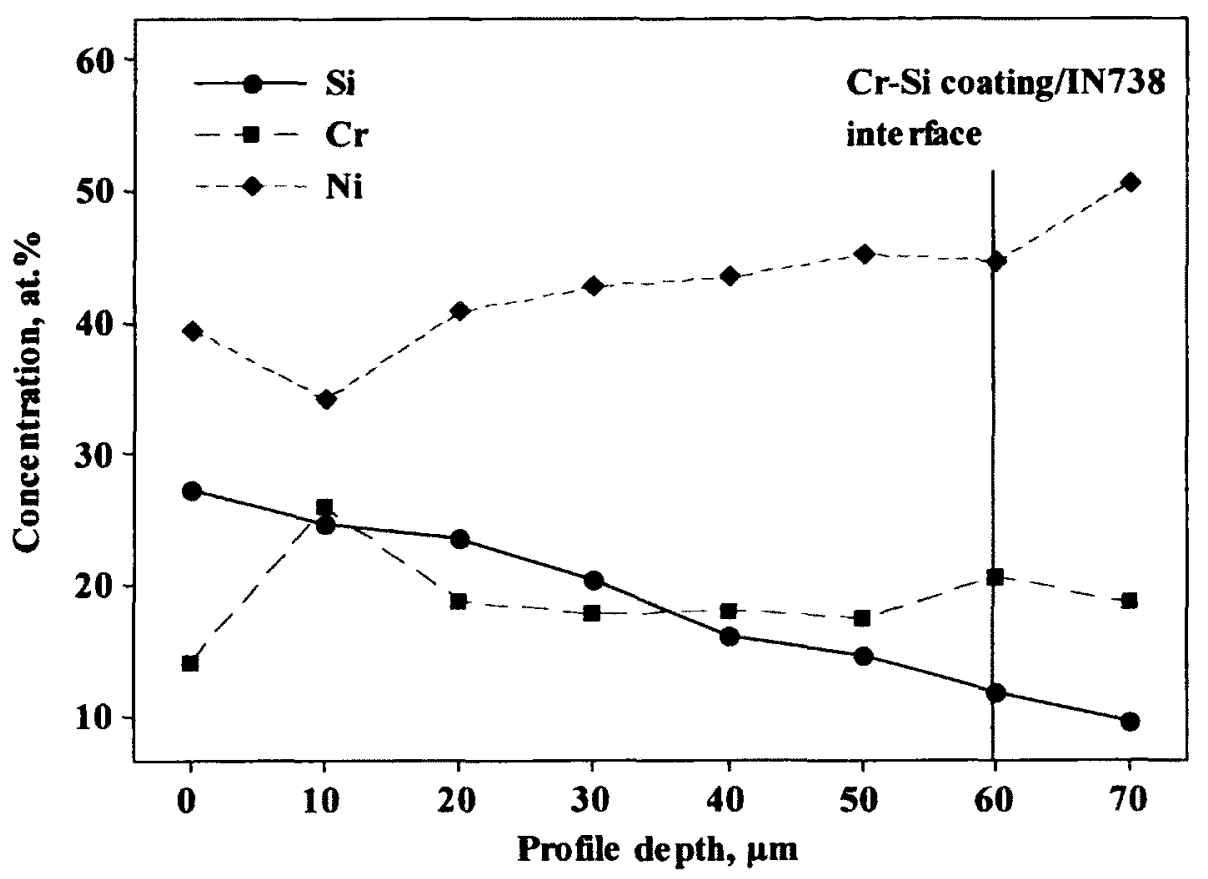

f) Concentration profiles of $\mathrm{Al}, \mathrm{Si}, \mathrm{Cr}$, and $\mathrm{Ni}$

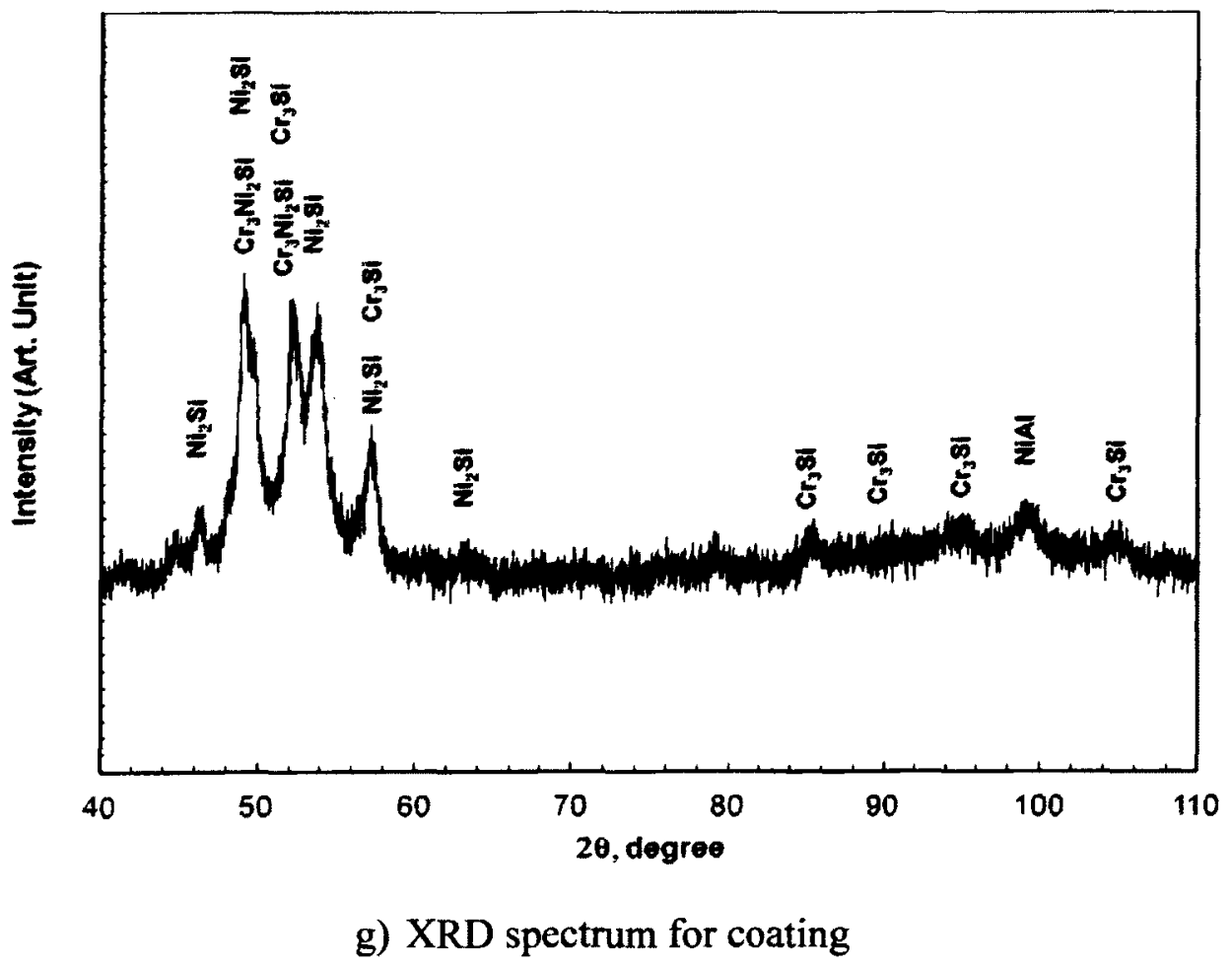

Figure 5.13 Microstructural analyses of coating 5-4. 
Table 5.16 EDS results for the phases in the coating

\begin{tabular}{lllrlllllll}
\hline \multirow{2}{*}{ Phase } & \multicolumn{1}{c}{ Al } & \multicolumn{1}{c}{ Si } & \multicolumn{1}{c}{$\mathrm{Ti}$} & $\mathrm{Cr}$ & $\mathrm{Co}$ & $\mathrm{Ni}$ & $\mathrm{Mo}$ & $\mathrm{W}$ & $\mathrm{Nb}$ & $\mathrm{Ta}$ \\
\hline $\mathrm{A}$ & $\mathrm{S.08}$ & 19.21 & 4.14 & 21.74 & 7.59 & 40.55 & & 1.69 & & \\
$\mathrm{~B}$ & 4.15 & 24.52 & 7.68 & 11.87 & 6.40 & 45.37 & & & & \\
$\mathrm{C}$ & 3.77 & 18.66 & 18.80 & 11.91 & 4.18 & 30.38 & & & 6.03 & 6.27 \\
$\mathrm{D}$ & 4.37 & 24.86 & 6.04 & 16.41 & 6.76 & 40.80 & 1.04 & & & \\
\hline
\end{tabular}

\subsection{Summary of Process Optimization for Diffusion Coatings}

Surface response methodology is an invaluable tool for modeling and optimizing diffusion process. The results from aluminizing process are highly predictable based on the process parameters selected and regression equations. Similarly the coating composition from a $\mathrm{Cr}$ and $\mathrm{Si}$ co-deposition process can also be predicted. Both processes were used to produce multilayered coatings, which will be further discussed in Chapter 6. 


\section{Chapter 6: Fabrication of Coatings}

\subsection{Coatings for Oxidation Tests}

In order to compare the oxidation behavior of the developed multilayered coatings with other coatings, a control group of coatings, named as baseline coatings, was introduced. The baseline coatings were selected based on a two-level full factorial design, in which each coating layer acted as a factor, as shown Table 6.1. Three factors, the $\mathrm{Cr}-\mathrm{Si}$ layer, $\mathrm{NiCrAIY}$ layer and aluminized layer, were assigned with $U, V$ and $W$.

There were two levels in the factorial design. The high level of these factors represented the coating layer design with the $\mathrm{Cr}$-Si layer, NiCrAlY layer, and aluminide II layer, whereas the low level of these factors represented the coating layer design without the $\mathrm{Cr}-\mathrm{Si}$ layer, $\mathrm{NiCrAlY}$ layer, and with the aluminide I layer. The advantage of using the two-level full factorial design is that two models can be developed to examine the effects of each layer and the interactions of each layer on the oxidation resistance of the multilayered coatings. One model was to examine the effects of each layer and the interactions of each layer on the area of oxide scales on the surface of coatings, which reflects the oxidation kinetics of metallic elements in coatings, especially Al. Another model was to examine the effects of each layer and the interactions of each layer on the mass change of coatings, which reflects the cohesion between oxide scales and coatings.

The bare IN738 and the NiCrAlY coating on IN738 were selected as reference specimens. All specimens are summarized in Table 6.2 and designated from $\mathrm{O} 1$ to $\mathrm{O} 10$. The processes for the baseline coatings were same as the processes for each coating layer. 
Table 6.1 Two-level full factorial design for determining coating layers for oxidation tests

\begin{tabular}{|c|c|c|c|}
\hline \multirow{2}{*}{ Level } & \multicolumn{3}{|c|}{ Coating layer } \\
\hline & Cr-Si coating, $U$ & NiCrAlY, $V$ & Aluminized coating, $W$ \\
\hline 1 & With a Cr-Si coating & With a NiCrAlY coating & $\begin{array}{l}\text { Aluminide II: } 2.0 \mathrm{Al} / \mathrm{Ni} \\
\text { ratio }\end{array}$ \\
\hline 0 & Without a Cr-Si coating & $\begin{array}{l}\text { Without a NiCrAlY } \\
\text { coating }\end{array}$ & $\begin{array}{l}\text { Aluminide } \mathrm{I}: 1.0 \mathrm{Al} / \mathrm{Ni} \\
\text { ratio }\end{array}$ \\
\hline
\end{tabular}

Table 6.2 Design matrix for oxidation test coatings

\begin{tabular}{lllll}
\hline Coating & \multicolumn{2}{l}{ Design matrix } & & Coating combination \\
\hline O1 & 1 & 0 & 0 & Cr-Si coating/aluminide I \\
O2 & 1 & 1 & 1 & Cr-Si coating/NiCrAlY/aluminide II \\
O3 & 0 & 0 & 0 & aluminide I \\
O4 & 0 & 1 & 1 & NiCrAlY/aluminide II \\
O5 & 1 & 1 & 0 & Cr-Si coating/NiCrAlY/aluminide I \\
O6 & 0 & 1 & 0 & NiCrAlY/aluminide I \\
O7 & 0 & 0 & 1 & aluminide II \\
O8 & 1 & 0 & 1 & Cr-Si coating/aluminide II \\
O9 & Reference I & & Bare IN738 \\
O10 & Reference II & & NiCrAlY \\
\hline
\end{tabular}

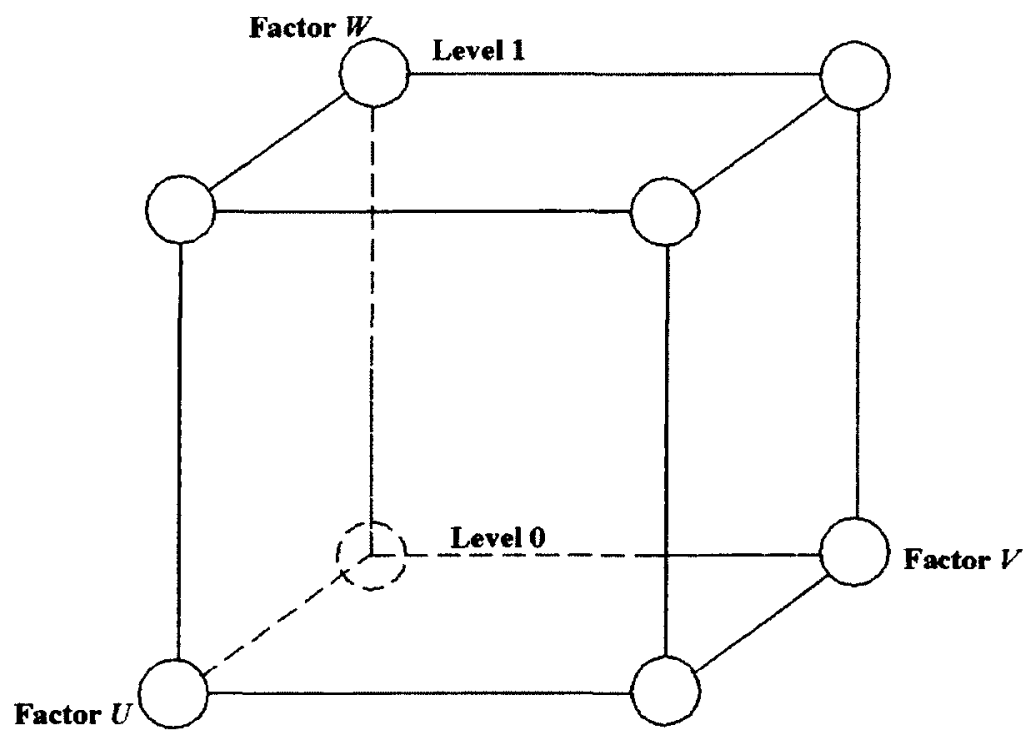

Figure 6.1 Pictorial representation of a two-level full factorial design for the aluminizing process. 


\subsection{Fabrication of Multilayered Coatings}

\subsubsection{Fabrication Procedures}

The multilayered coatings designed in this research have a three-layer architecture, which consists of a $\mathrm{Cr}-\mathrm{Si}$ coating on the IN738 substrate, a NiCrAlY overlay coating as the middle layer, and finally an aluminide layer on top. The multilayered coatings was fabricated through a combination of plasma spray and pack cementation processes. Each process was carried out using the optimal process parameters developed in the previous chapters.

The procedure for producing the multilayered coatings involved three steps. The first step was to co-diffuse chromium and silicon into the IN738 substrate using pack cementation process. The second step was to deposit a NiCrAlY coating on the $\mathrm{Cr}-\mathrm{Si}$ coating using plasma spray process. The final step was an aluminizing treatment on the NiCrAlY coating to develop an aluminum-rich layer.

Two aluminizing processes were chosen to obtain the coatings with the range of the $\mathrm{Al} / \mathrm{Ni}$ ratio varying from 0.8 to 1.2 , and from 1.8 to 2.2 , respectively. The coatings using these two processes were designated as aluminide I and aluminide II. Therefore, there were two types of multilayered coatings in which the first and second layers were identical but aluminizing treatment differed. The parameters for all processes are listed in Table 6.3 and Table 6.4. Two multilayered coatings are presented in Figure 6.2.

Table 6.3 Pack cementation parameters for multilayered coatings

\begin{tabular}{lccccccccc}
\hline Coating & $\mathrm{Al}, \%$ & $\mathrm{Ni}, \%$ & $\mathrm{Si}, \%$ & $\mathrm{Cr}, \%$ & $\begin{array}{l}\mathrm{NH}_{4} \mathrm{Cl}, \\
\%\end{array}$ & $\begin{array}{l}\mathrm{Al}_{2} \mathrm{O}_{3}, \\
\%\end{array}$ & $\begin{array}{l}\mathrm{SiO}_{2}, \\
\%\end{array}$ & $\begin{array}{l}\text { Temp., } \\
{ }^{\circ} \mathrm{C}\end{array}$ & $\begin{array}{l}\mathrm{Time}, \\
\mathrm{hr}\end{array}$ \\
\hline $\begin{array}{l}\text { Cr-Si barrier } \\
\text { aluminide I }\end{array}$ & - & - & 24.0 & 16.0 & & 29.0 & 29.0 & 1100 & \\
aluminide II & 13.5 & 7.0 & - & - & 2.0 & 81.5 & - & 1000 & 4 \\
\hline
\end{tabular}


Table 6.4 Plasma spray parameters for multilayered coatings

\begin{tabular}{llllllllll}
\hline Powder & $\begin{array}{l}\text { Powder } \\
\text { size, } \mu \mathrm{m}\end{array}$ & $\begin{array}{l}\text { Nozzle } \\
\text { size, in }\end{array}$ & $\begin{array}{l}\text { Total } \\
\text { flow rate, } \\
\text { sl/min }\end{array}$ & $\begin{array}{l}\mathrm{H}_{2}, \\
\%\end{array}$ & $\begin{array}{l}\mathrm{N}_{2}, \\
\%\end{array}$ & $\begin{array}{l}\text { Current, } \\
\text { A }\end{array}$ & $\begin{array}{l}\text { Dist., } \\
\text { mm }\end{array}$ & $\begin{array}{l}\text { Powder } \\
\text { feed } \\
\text { setting }\end{array}$ & $\begin{array}{l}\text { Time, } \\
\text { sec }\end{array}$ \\
\hline Ni 343 & $-45 /+10$ & $6 / 16$ & 230 & 25 & 10 & 250 & 150 & 4 & 30 \\
\hline
\end{tabular}

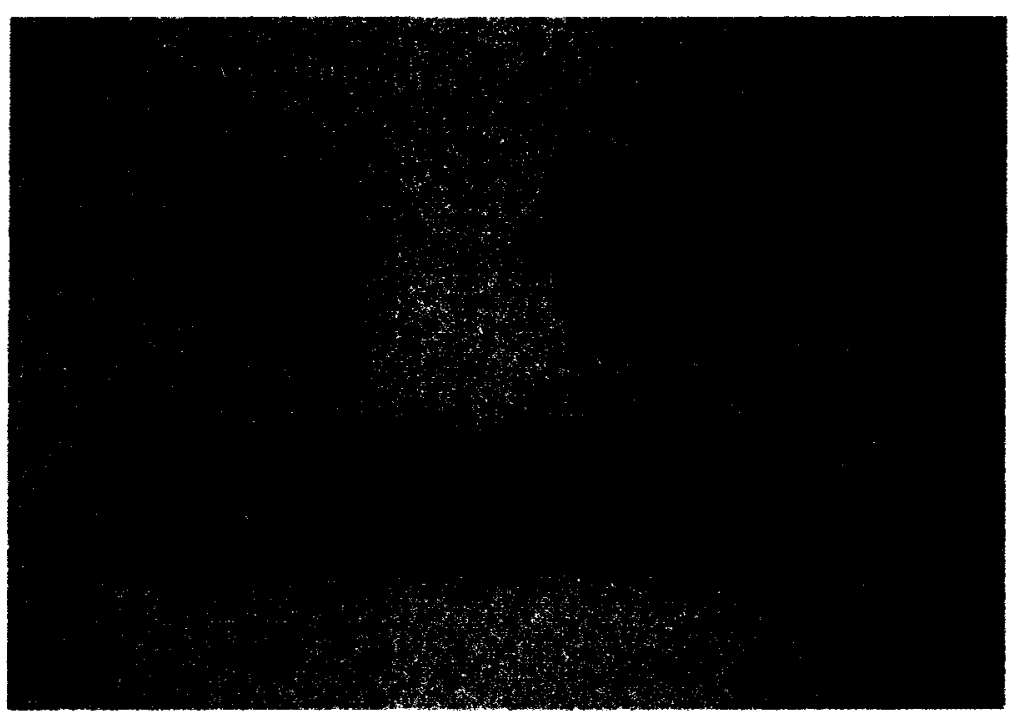

Figure 6.2 Two multilayered coatings

\subsubsection{Elemental Distributions in Multilayered Coatings}

The main elements in two multilayered coatings were measured from the coating surface to the substrate using EDS. Based on the EDS results, the concentration profiles of the major elements in the multilayered coatings were plotted and shown in Figure 6.3. The interfaces between the $\mathrm{NiCrAlY}$ layer and the $\mathrm{Cr}-\mathrm{Si}$ layer were measured at 80 $\mu \mathrm{m}$ from the surface of the aluminide I layer and at $150 \mu \mathrm{m}$ from the surface of aluminide II layer, respectively.

Examination of Figure 6.3 reveals three important facts: 
(1) The chromium content at the interface between the NiCrAlY layer and $\mathrm{Cr}$-Si layer in MC I is around 45 at. \%, which suggests a $\mathrm{Cr}$ layer formed between the NiCrAlY layer and $\mathrm{Cr}$-Si layer in MC I during aluminizing process.

(2) The chromium content at the interface between the NiCrAlY layer and $\mathrm{Cr}-\mathrm{Si}$ layer in MC II is around 16 at. \%, which suggests no $\mathrm{Cr}$ layer formed in MC II during aluminizing process.

(3) The aluminum content (9-10 at.\%) at the interface between the NiCrAlY layer and $\mathrm{Cr}-\mathrm{Si}$ layer in $\mathrm{MC} \mathrm{I}$ is much lower than the aluminum content (16-28 at.\%) at the interface between the NiCrAlY layer and $\mathrm{Cr}$-Si layer in MC II, which suggests the $\mathrm{Cr}$ layer in MC I effectively impeded aluminum diffusion while aluminum atoms in the NiCrAlY layer of MC II diffused into the substrate without the Cr layer.

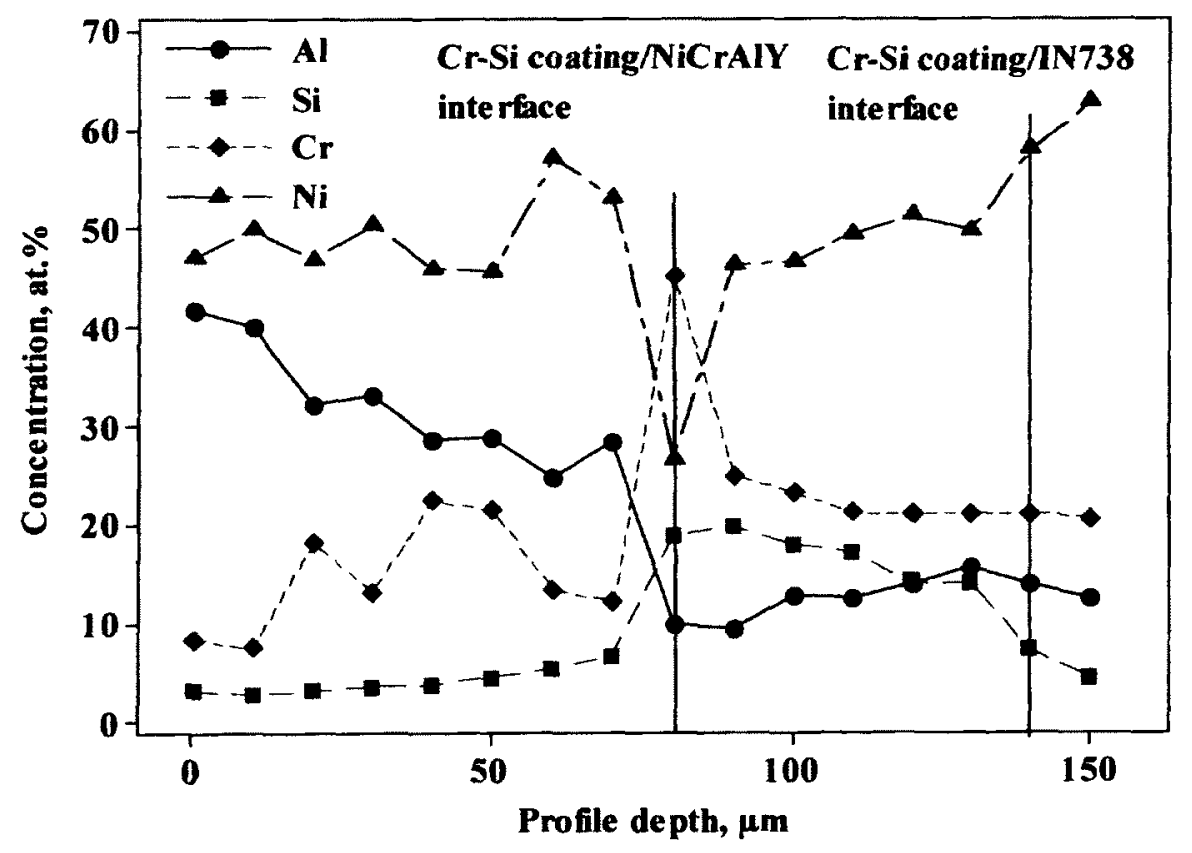

a) Concentration profiles of $\mathrm{Al}, \mathrm{Si}, \mathrm{Cr}$, and $\mathrm{Ni}$ in the multilayered coating with aluminide I top coat 


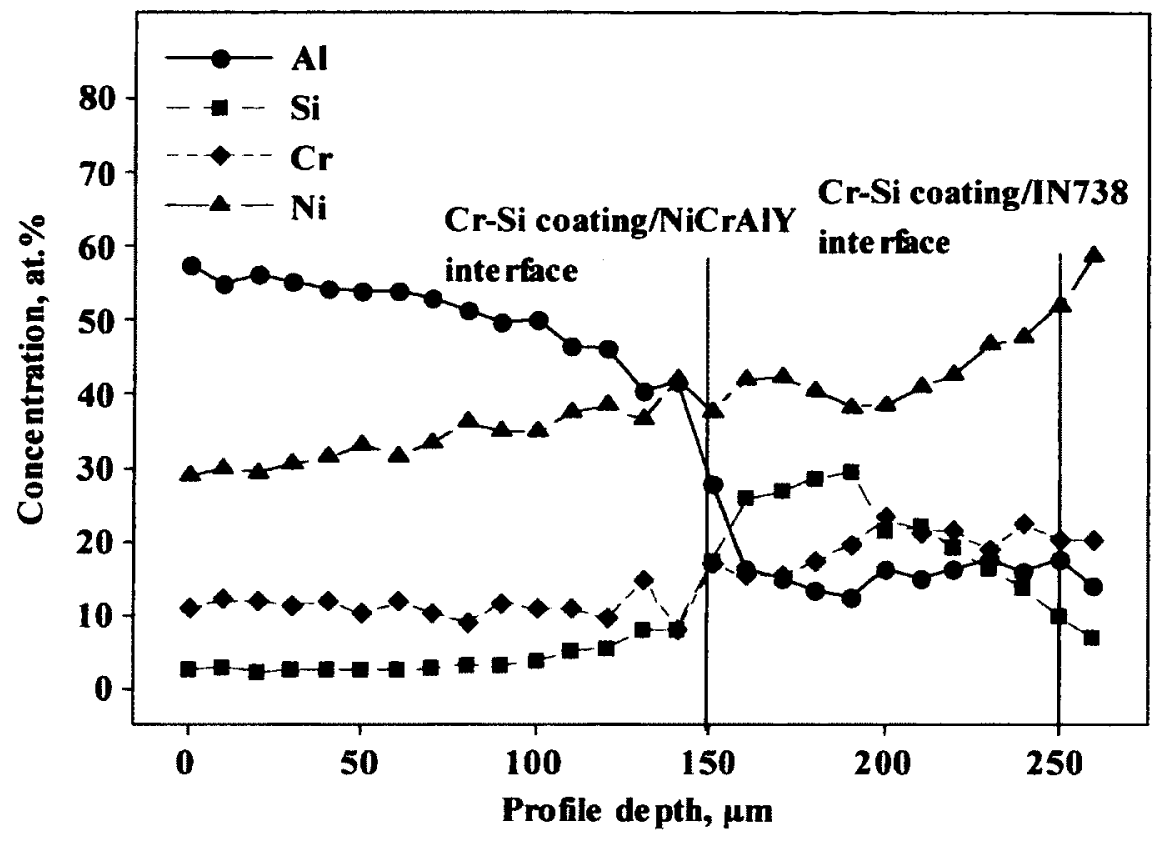

b) Concentration profiles of $\mathrm{Al}, \mathrm{Si}, \mathrm{Cr}$, and $\mathrm{Ni}$ in the multilayered coating with aluminide II top coat

Figure 6.3 Concentration profiles of major elements in multilayer coatings.

\subsubsection{Microstructures of Multilayered Coatings}

A typical microstructure of the multilayered coating with aluminide I top coat is presented in Figure 6.4. From the SEM image and elemental maps, the multilayered coating consists of three layers: an aluminum-rich top layer, a NiCrAlY middle layer, and $\mathrm{Cr}$-Si rich layer. Based on the EDS and XRD analyses, the main phase in the top layer is NiAl. The middle layer is similarly NiCrAlY with NiAl phase. Mapping of the $\mathrm{Cr}-\mathrm{Si}$ barrier layer indicates that the $\mathrm{Cr}-\mathrm{Si}$ barrier layer was changed from a three-layer structure to a two-layer structure during the final diffusion process (to apply aluminide top coat), which consists of a $\mathrm{Cr}$ layer and Si-rich layer (Figure 6.4d and Figure 6.4e). 

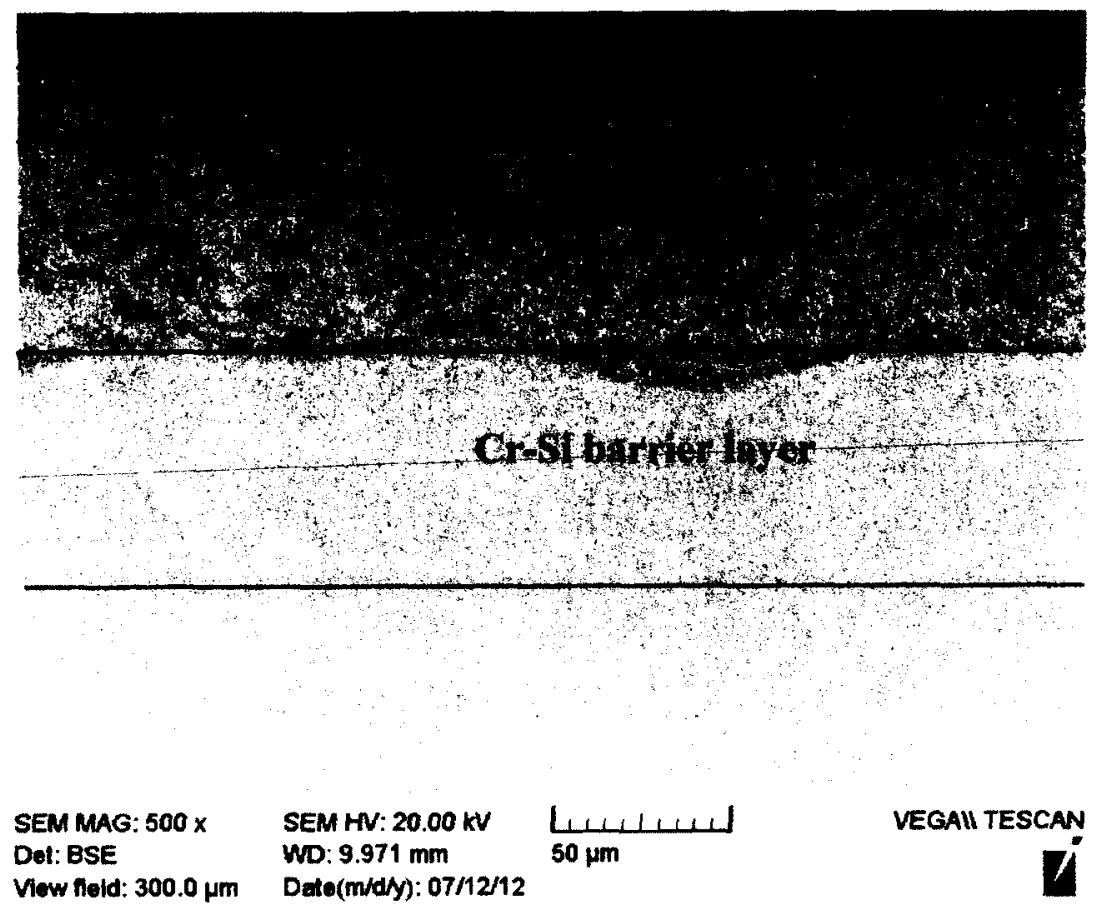

VEGAII TESCAN Vow floid: $300.0 \mu \mathrm{m} \quad$ Date(m/d/y): 07/12/12

a) SEM image for the multilayered coating aluminide I top coat

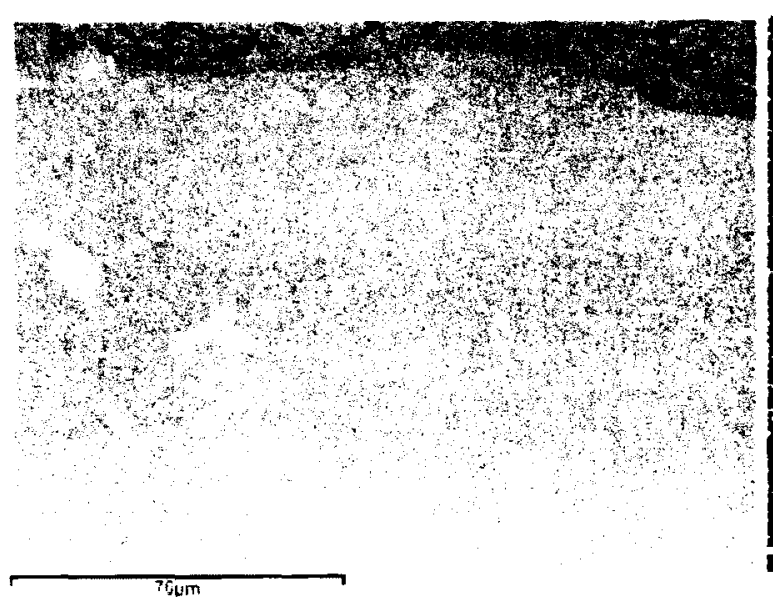

b) SEM image for mapping

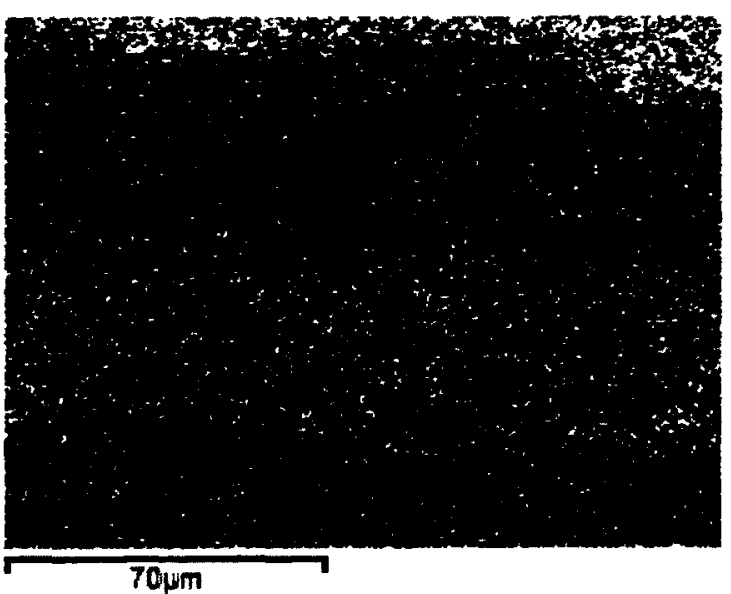

c) $\mathrm{Al} \mathrm{map}$ 


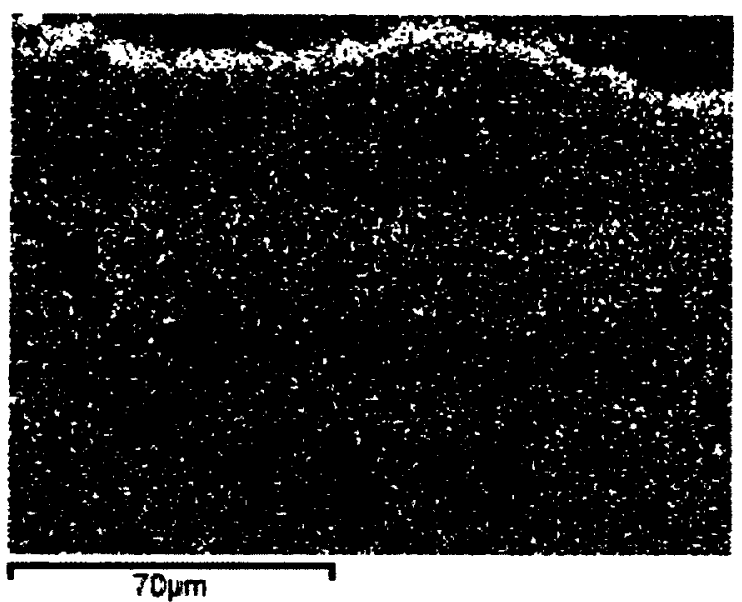

d) Cr map

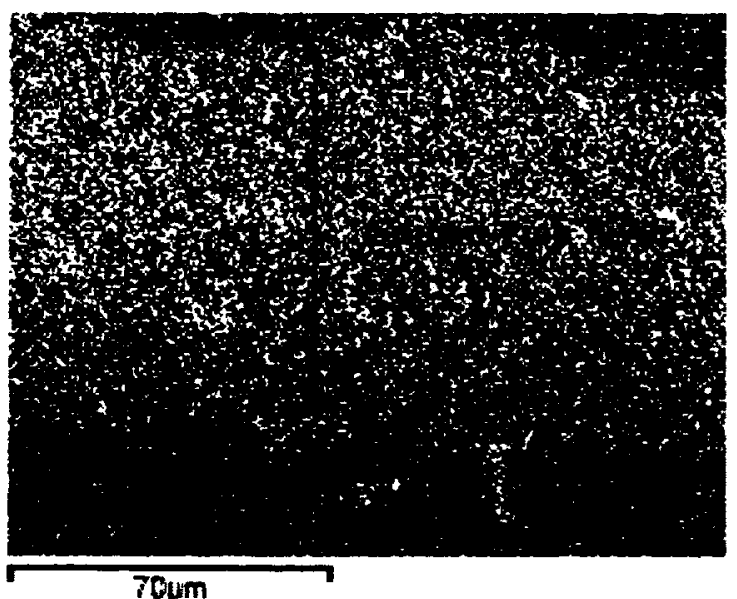

e) Si map

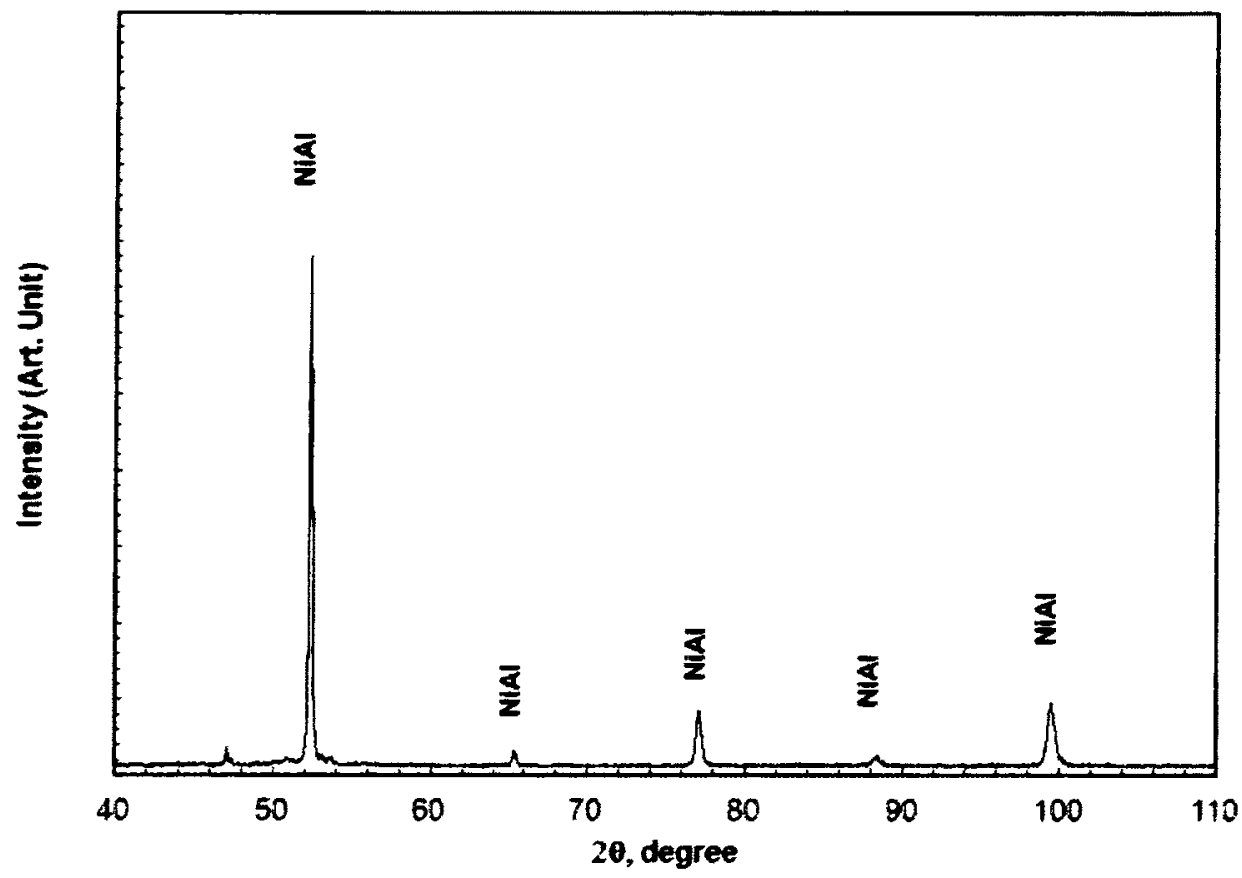

f) XRD spectrum of the multilayered coating with aluminide I coating

Figure 6.4 Structure and phase analyses of the multilayered coating with aluminide I top coat.

A typical microstructure for the multilayered coating with aluminide II top coat is presented in Figure 6.5. The multilayered coating also consists of three layers: an aluminum-rich top layer, a middle layer, and a $\mathrm{Cr}$-Si coating. On the basis of an 
analysis of Figure $6.5 \mathrm{~b}$, the major phase of the top layer is the $\mathrm{Ni}_{2} \mathrm{Al}_{3}$ phase with minor the $\mathrm{NiAl}$ phase; the major phase of the middle layer is the NiAl phase. Mapping images of the $\mathrm{Cr}$-Si barrier layer indicates that there are some $\mathrm{Cr}$-rich phase instead of a $\mathrm{Cr}$ layer formed at the interface between the $\mathrm{NiCrAlY}$ layer and $\mathrm{Cr}$-Si layer (Figure 6.5 $6.5 \mathrm{~d}$ and 5e).

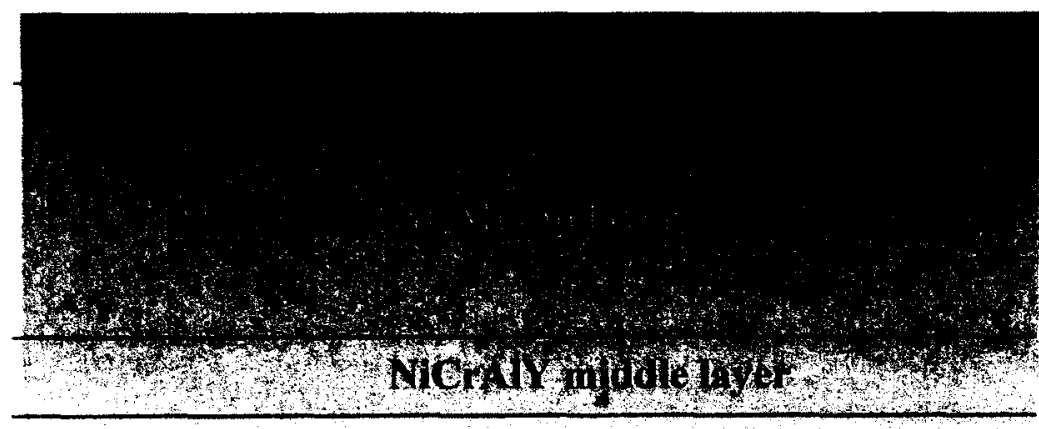

Cr-Si coating layer

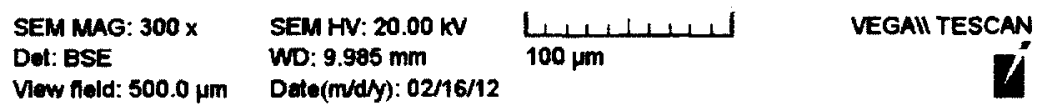

a) SEM image for the multilayered coating with aluminide II top coat
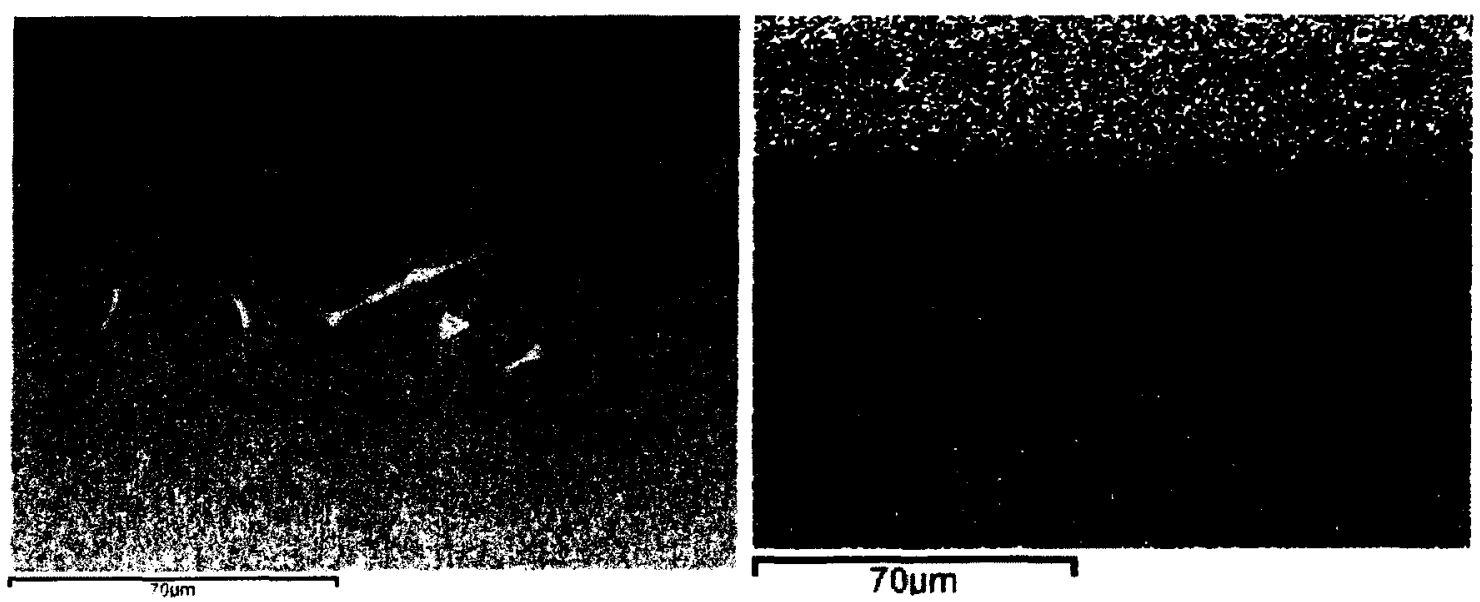

b) SEM image for mapping

c) Al map 


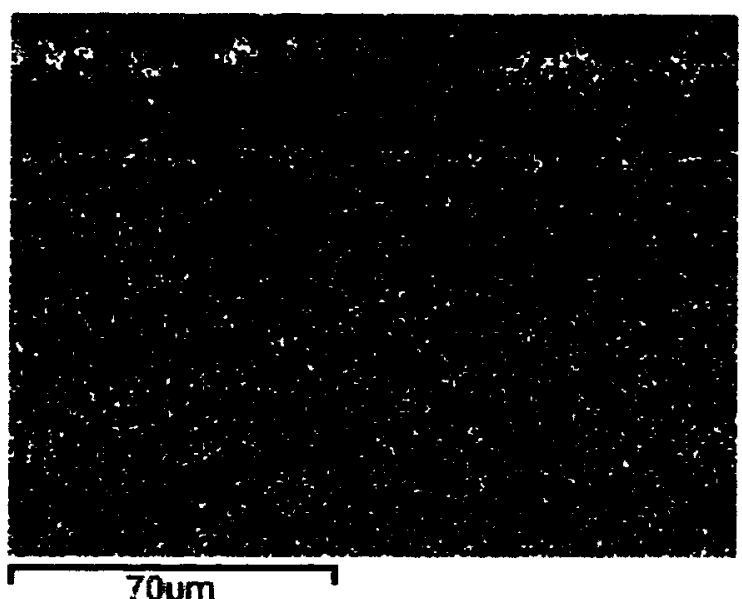

d) Cr map

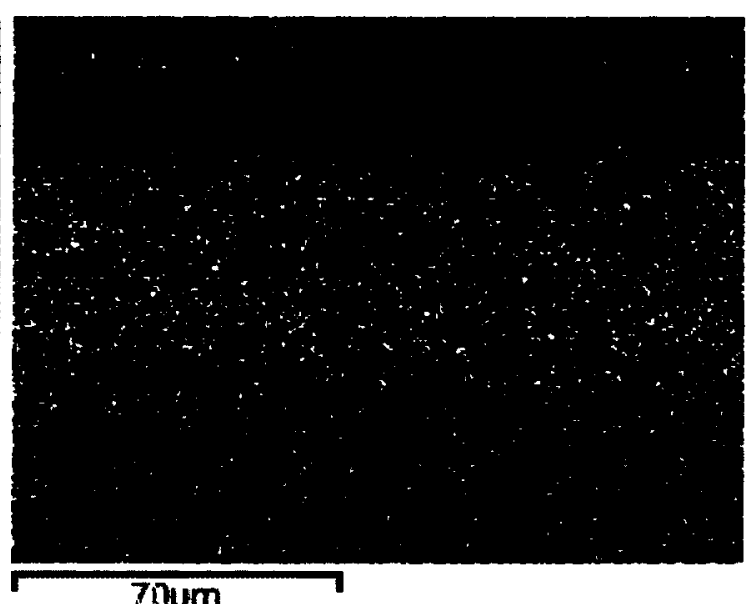

e) Si map

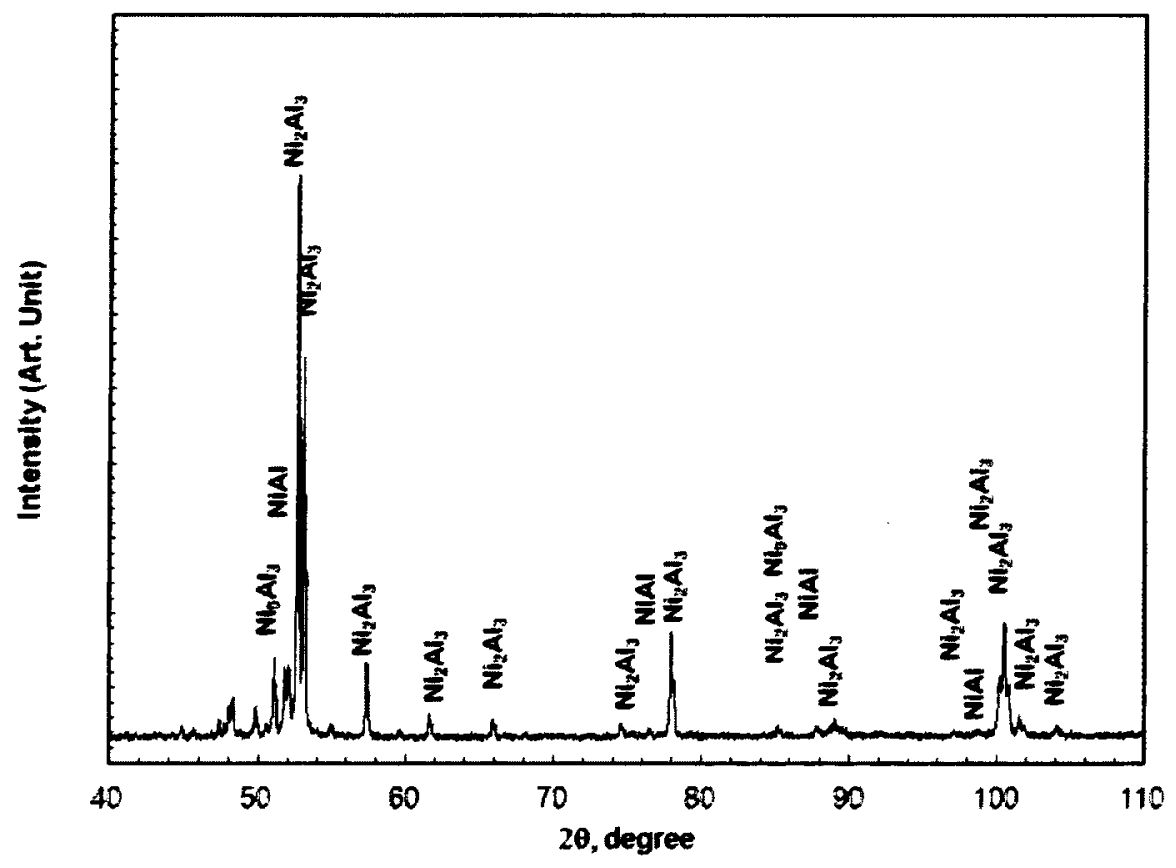

f) XRD spectrum of the multilayered coating with aluminide II top coat

Figure 6.5 Structure and phase analyses of the multilayered coating with aluminide II top coat.

\subsection{Fabrication of Baseline Coatings}

The diffusion processes were simplified as CS (Cr-Si coating), AI (aluminide II) and AlI (aluminide II); the details of the processes are given in Table 6.5. The process 
durations were $4 \mathrm{hr}$; the plasma spray process was simplified as PS (plasma spray). The processes for the other baseline coatings are summarized in Table 6.6 along with two previously discussed multiple layered coatings. The microstructures and major elemental distributions for some baseline coatings and references are presented in Figure 6.6 to Figure 6.13. The phases in the coatings were estimated based on the distributions of the major elements, especially based on the distribution of $\mathrm{Cr}$. When $\mathrm{Cr}$ content in a coating is around 8 at.\%, the major phase in the coating is $\beta$ phase. $\mathrm{Ni}_{2} \mathrm{Al}_{3}$ and $\gamma^{\prime} / \gamma$ phase can dissolve more $\mathrm{Cr}$. The estimated phases on coatings are presented in Table 6.6.

Table 6.5 Parameters of diffusion processes

\begin{tabular}{llllllllll}
\hline Process & Coating & $\begin{array}{l}\mathrm{Al}, \\
\text { wt.\% }\end{array}$ & $\begin{array}{l}\mathrm{Ni}, \\
\text { wt.\% }\end{array}$ & $\begin{array}{l}\mathrm{Si}, \\
\text { wt.\% }\end{array}$ & $\begin{array}{l}\mathrm{Cr}, \\
\text { wt.\% }\end{array}$ & $\begin{array}{l}\mathrm{NH}_{4} \mathrm{Cl}, \\
\text { wt.\% }\end{array}$ & $\begin{array}{l}\mathrm{Al}_{2} \mathrm{O}_{3}, \\
\text { wt.\% }\end{array}$ & $\begin{array}{l}\mathrm{SiO}_{2}, \\
\text { wt.\% }\end{array}$ & $\begin{array}{l}\mathrm{Temp}, \\
{ }^{\circ} \mathrm{C}\end{array}$ \\
\hline $\mathrm{CS}$ & Cr-Si coating & - & - & 24.0 & 16.0 & & 29.0 & 29.0 & 1100 \\
$\mathrm{AI}$ & aluminide I & 6.5 & 10.0 & - & - & 2.0 & 81.5 & - & 1000 \\
AII & aluminide II & 13.5 & 7.0 & - & - & & 77.5 & - & 1000 \\
\hline
\end{tabular}

Table 6.6 Summary of coating processes

\begin{tabular}{|c|c|c|c|}
\hline Coating & Coating combination & Process & Phase \\
\hline $\mathrm{O} 1$ & Cr-Si coating/aluminide I & $\mathrm{CS}+\mathrm{AI}$ & $(\beta+$ silicon-rich $)+\left(\gamma^{\prime}+\gamma\right)$ \\
\hline $\mathrm{O} 2$ & $\begin{array}{l}\text { Cr-Si coating/ } \\
\text { NiCrAlY/aluminide II }\end{array}$ & $\begin{array}{l}\mathrm{CS}+\mathrm{PS}+ \\
\mathrm{AII}\end{array}$ & $\begin{array}{l}\mathrm{Ni}_{2} \mathrm{Al}_{3}+\beta+\gamma^{\prime}+\gamma+\text { silicon- } \\
\text { rich }\end{array}$ \\
\hline $\mathrm{O} 3$ & aluminide I & $\mathrm{AI}$ & $\beta$ \\
\hline $\mathrm{O} 4$ & NiCrAlY/aluminide II & PS + AII & $\mathrm{Ni}_{2} \mathrm{Al}_{3}$ \\
\hline $\mathrm{O} 5$ & $\begin{array}{l}\text { Cr-Si coating/ } \\
\text { NiCrAlY/aluminide I }\end{array}$ & $\mathrm{CS}+\mathrm{PS}+\mathrm{AI}$ & $\beta+\gamma^{\prime}+\gamma+$ silicon-rich \\
\hline O6 & NiCrAlY/aluminide I & $\mathrm{PS}+\mathrm{AI}$ & $\beta+\gamma^{\prime}$ \\
\hline $\mathrm{O} 7$ & aluminide II & AII & $\mathrm{Ni}_{2} \mathrm{Al}_{3}$ \\
\hline O8 & Cr-Si coating/aluminide II & $\mathrm{CS}+\mathrm{AII}$ & $(\beta+$ silicon-rich $)+\left(\gamma^{\prime}+\gamma\right)$ \\
\hline O9 & Bare IN738 & - & $\gamma$ \\
\hline $\mathrm{O} 10$ & NiCrAlY & PS & $\gamma / \gamma^{\prime}$ \\
\hline
\end{tabular}

Coating $\mathrm{O} 1$ and coating $\mathrm{O} 8$ are two-layer coatings without NiCrAlY middle layer. Examination of the aluminum profiles of coating $\mathrm{O} 1$ in Figure 6.6 and coating $\mathrm{O} 8$ in 
Figure 6.7 reveals that the aluminum solubility is very low in the $\mathrm{Cr}-\mathrm{Si}$ coating and $\mathrm{Ni}$ outward-diffusion dominated the growth of the aluminide coating. The averaged $\mathrm{Al} / \mathrm{Ni}$ ratio for coating $\mathrm{O} 1$ is close to 1 within the aluminide layer (Figure 6.8), and $\mathrm{NiAl}$ phase constitutes the main phase in this layer. This was verified with XRD as shown in Figure 6.9a.

The $\mathrm{Al} / \mathrm{Ni}$ ratios in aluminide top layer of coating $\mathrm{O} 8$ is larger than 1 within the aluminide coating (Figure 6.8), and the major phase in this layer is the $\mathrm{Ni}_{2} \mathrm{Al}_{3}$ phase, which can be verified from the XRD spectrum of O8 coating in Figure $6.9 \mathrm{~b}$.

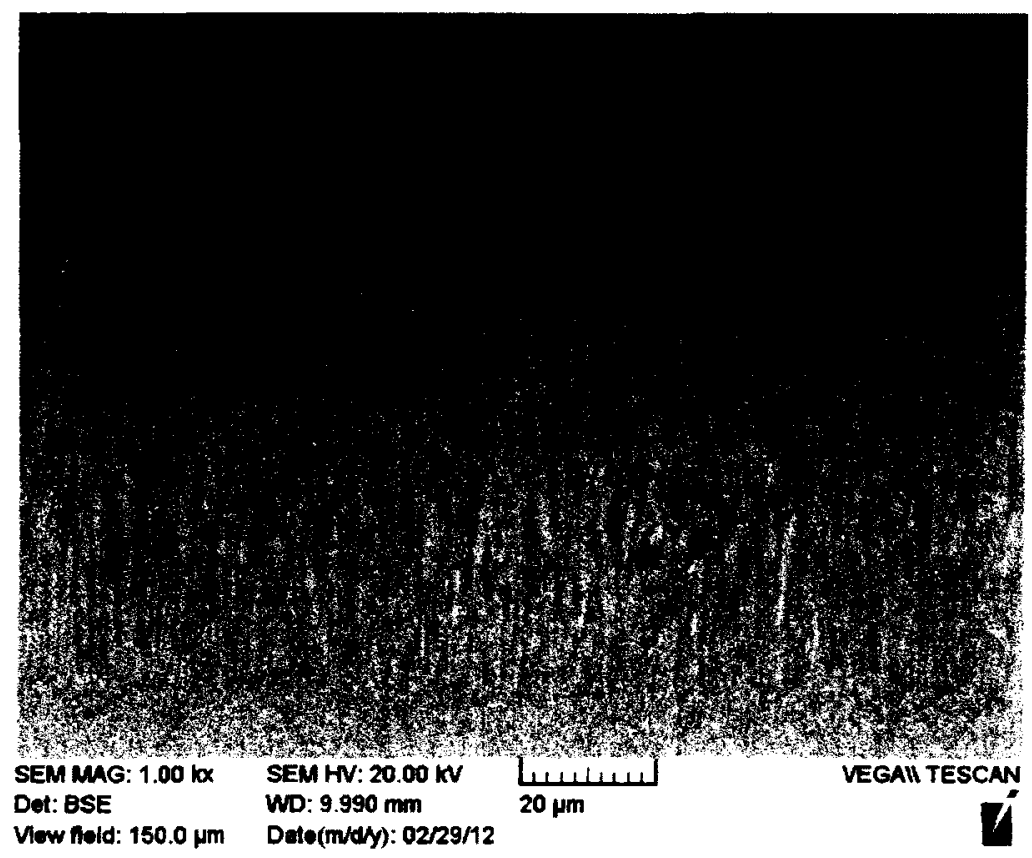

a) SEM image 


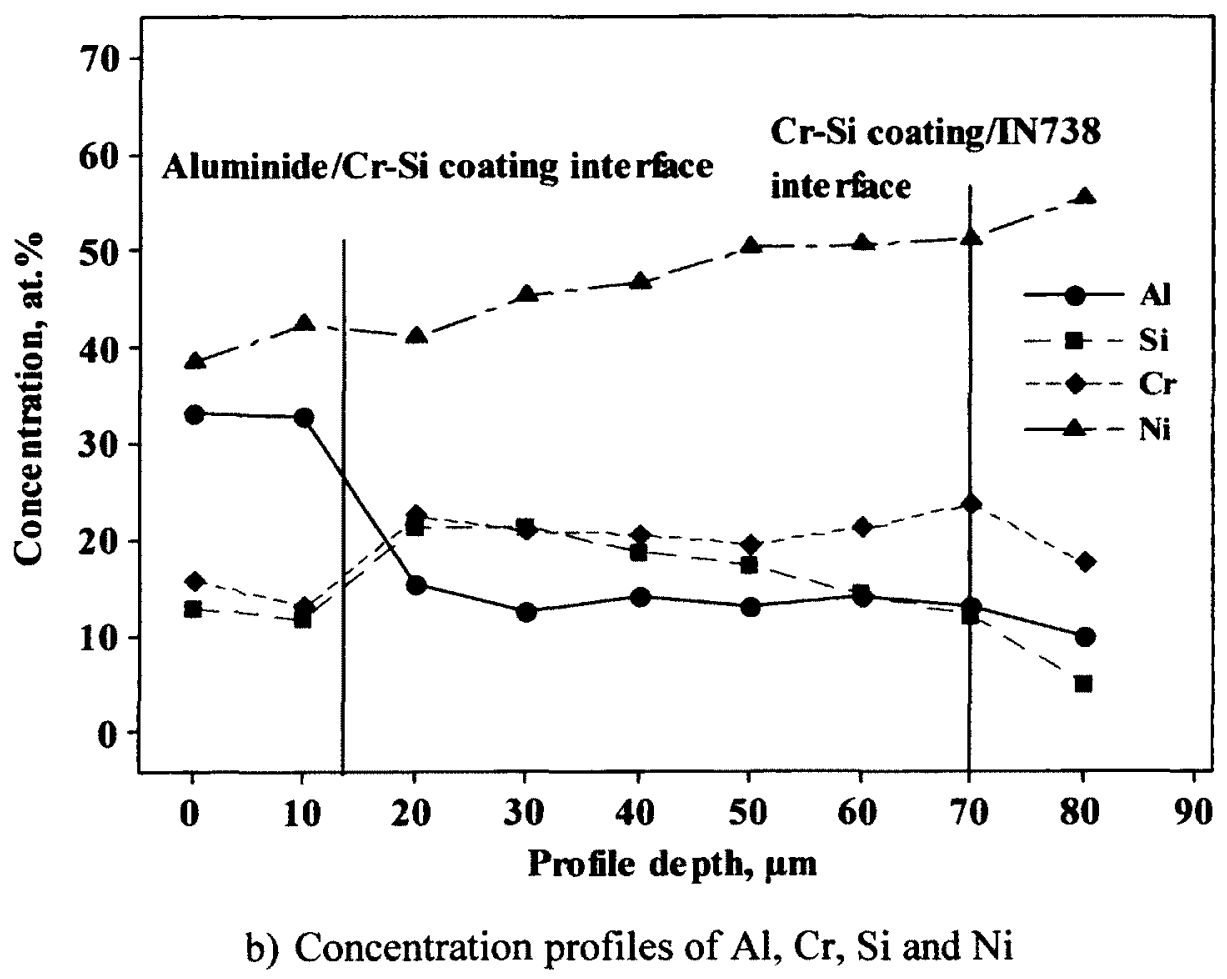

Figure 6.6 SEM image and concentration profiles of major elements for coating O1 (Cr-Si coating/aluminide I) before oxidation tests.

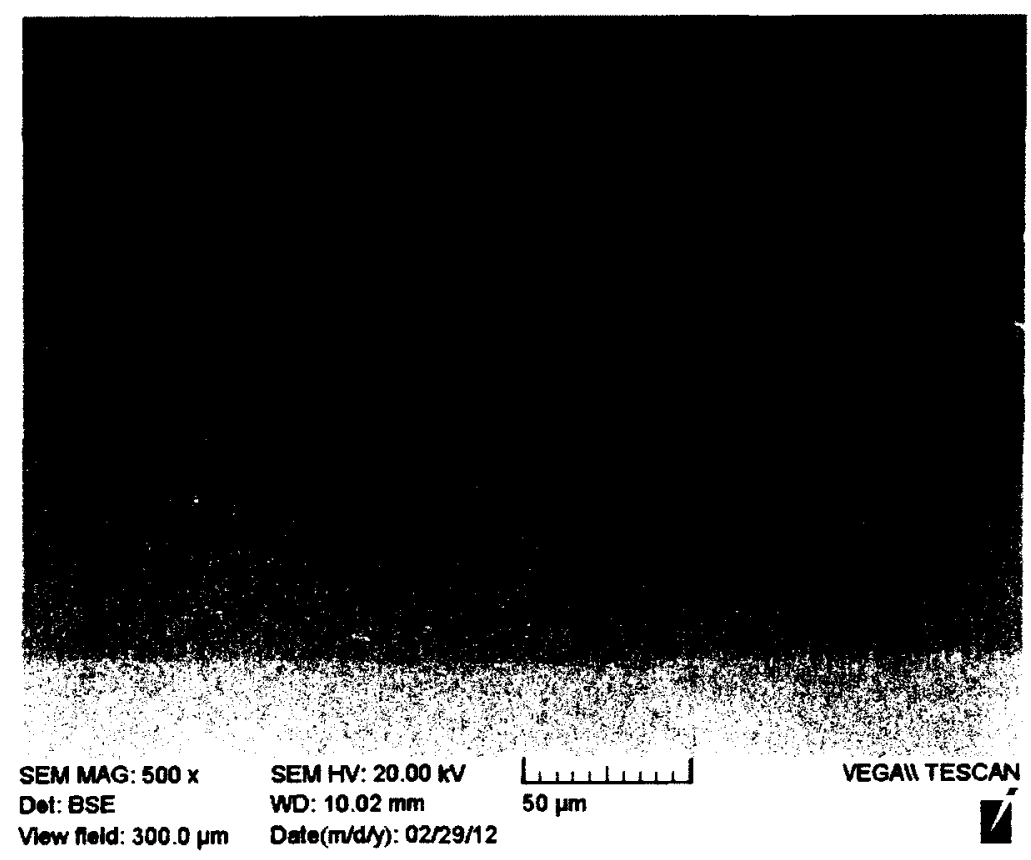

a) SEM image 


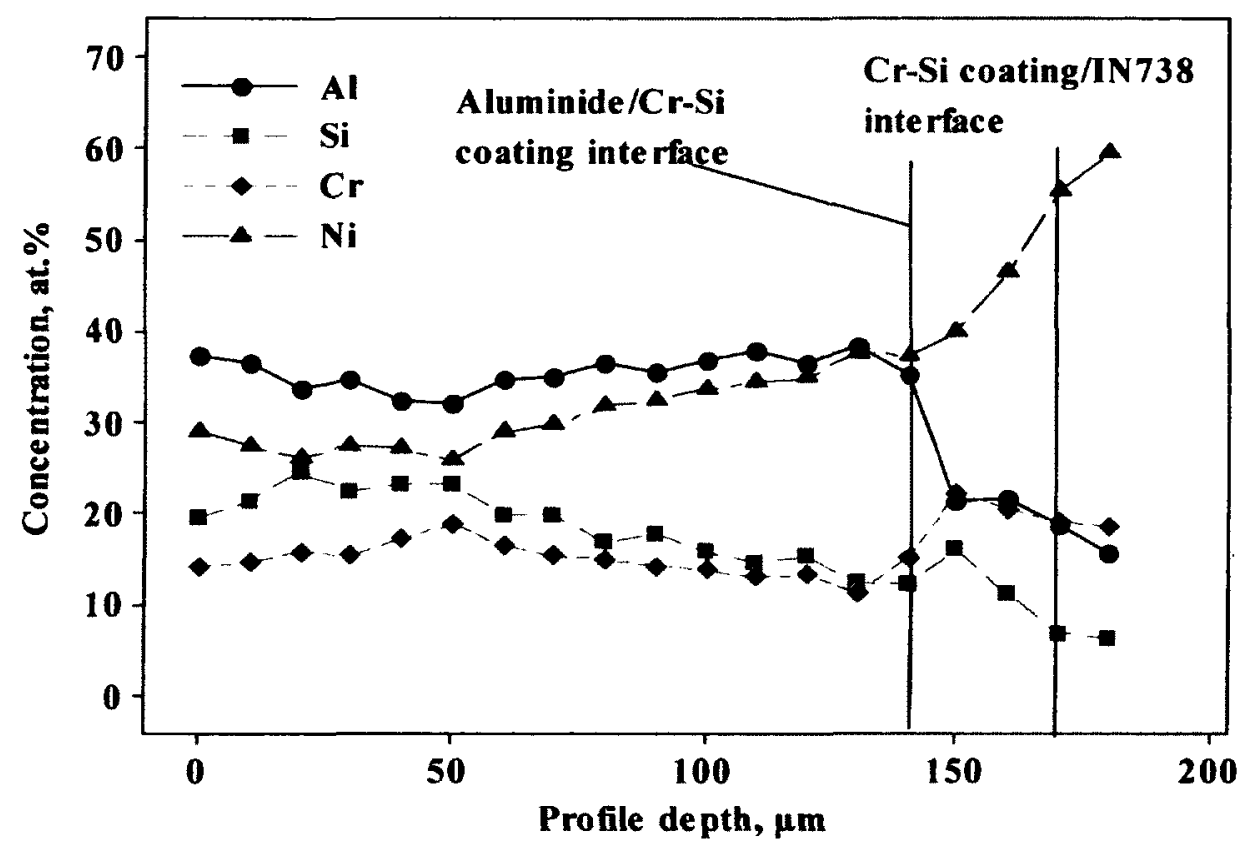

b) Concentration profiles $\mathrm{Al}, \mathrm{Cr}, \mathrm{Si}$ and $\mathrm{Ni}$

Figure 6.7 SEM image and concentration profiles of major elements for coating O8 (Cr-Si coating/aluminide II) before oxidation tests.

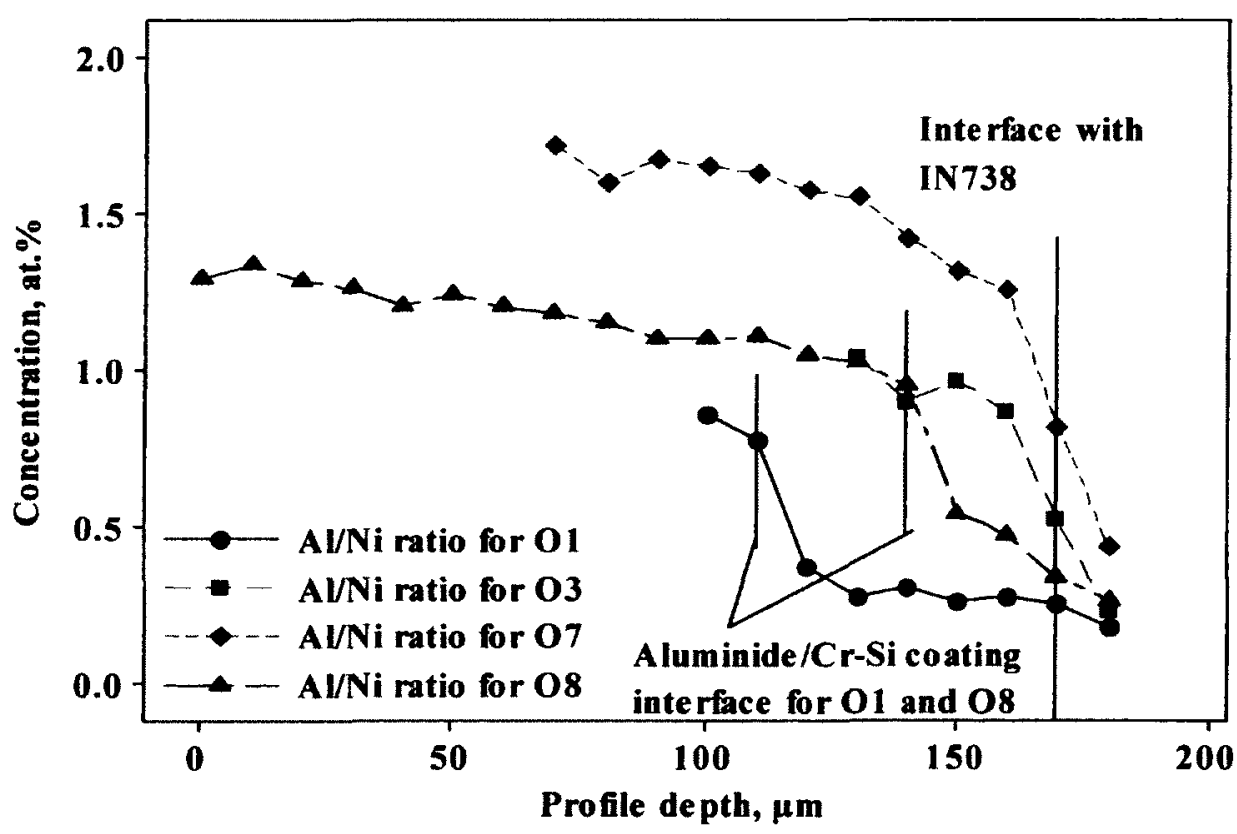

Figure 6.8 Al/Ni ratio in coating $01,03,07$ and 08 . 


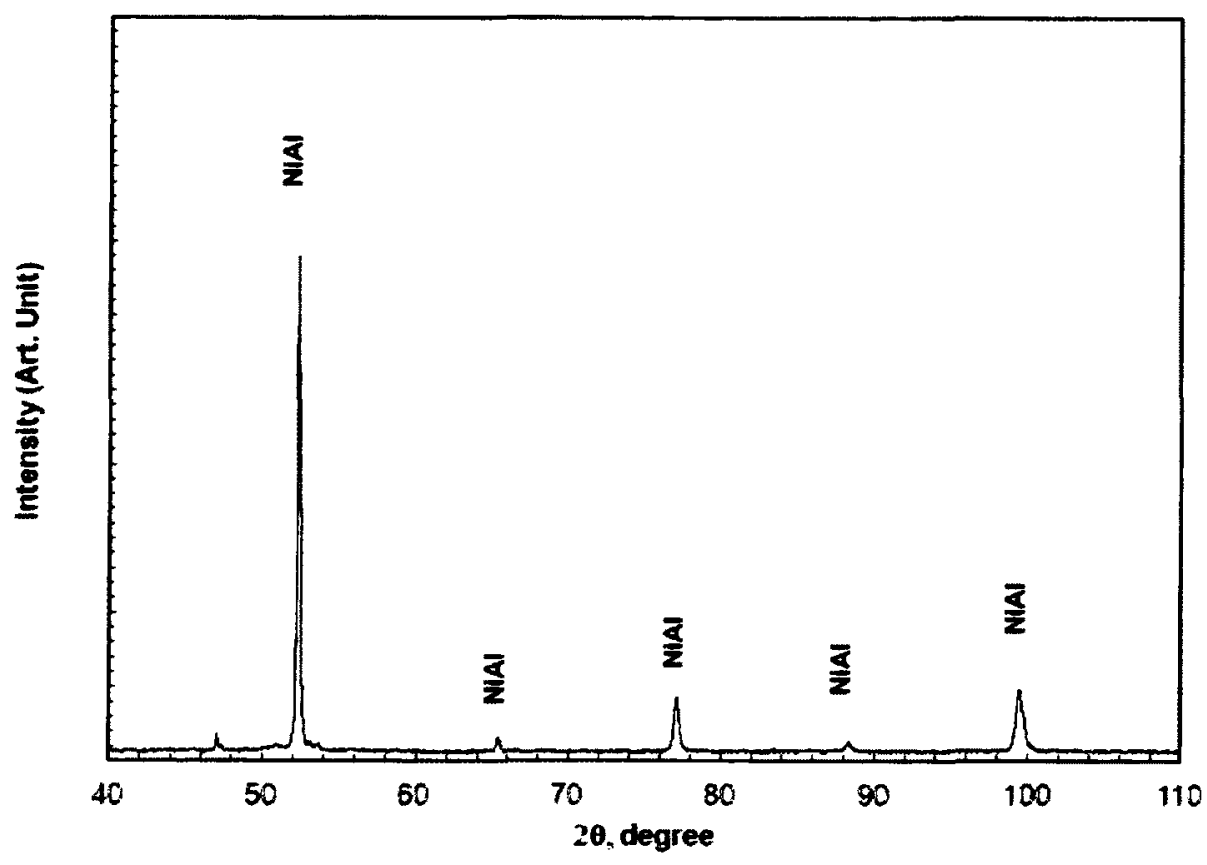

a) Coating $\mathrm{O} 1$

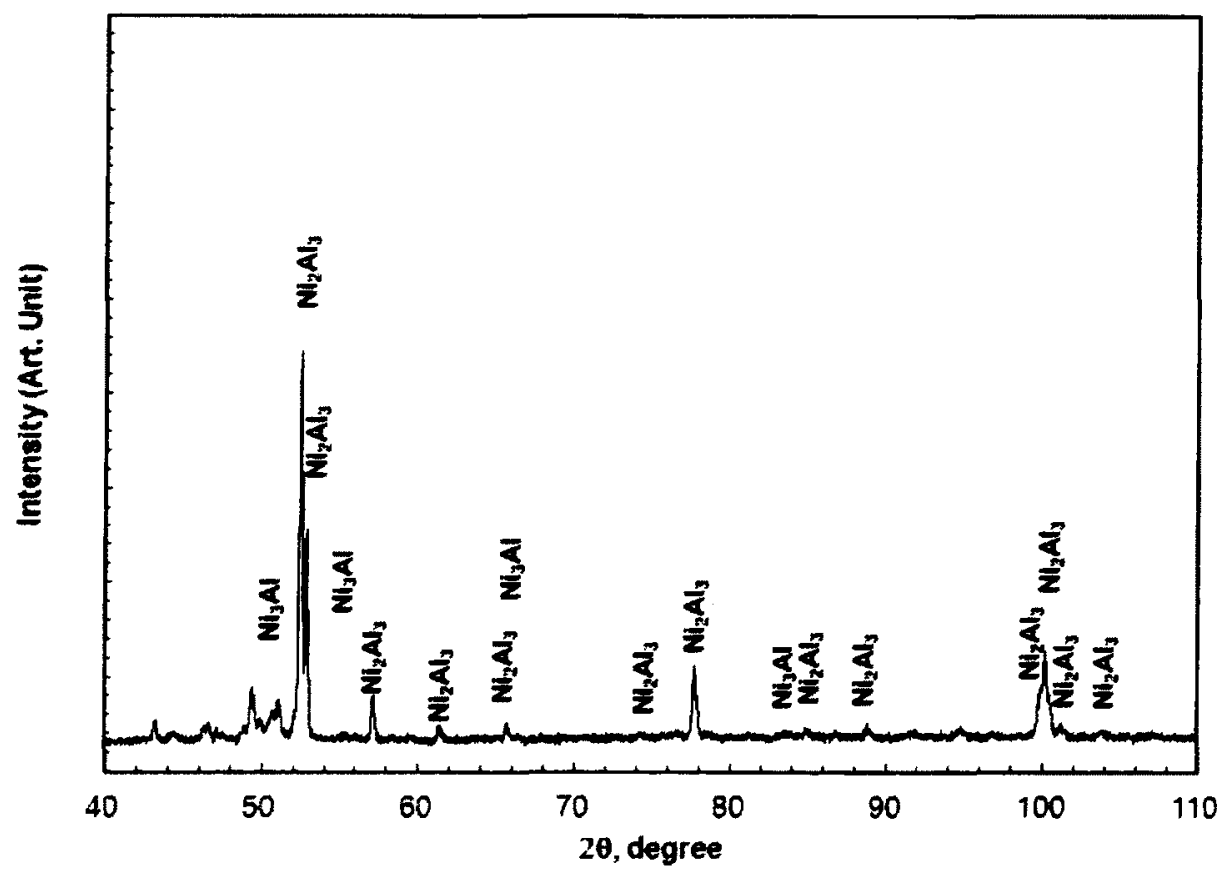

b) Coating $\mathrm{O} 8$

Figure 6.9 XRD spectra of coating $\mathrm{O} 1$ and 08 . 
Coating $\mathrm{O} 3$ and $\mathrm{O} 7$ are one-layer coatings without $\mathrm{NiCrAlY}$ middle layer and $\mathrm{Cr}-\mathrm{Si}$ barrier layer. The $\mathrm{Al} / \mathrm{Ni}$ ratios for coating $\mathrm{O} 3$ and $\mathrm{O} 7$ are much higher than those for coating $\mathrm{O} 1$ and $\mathrm{O} 8$ (Figure 6.8), although the aluminizing process for coating $\mathrm{O} 3$ is the same as that for coating $\mathrm{O} 1$, and the aluminizing process for coating $\mathrm{O} 7$ is the same as that for coating $\mathrm{O8}$. This phenomenon indicates that $\mathrm{Al}$ inward-diffusion dominated the coating growth of in coating $\mathrm{O} 3$ and $\mathrm{O} 7$. Based on the concentration profiles of $\mathrm{O} 3$ and $\mathrm{O} 7$ in Figure $6.10 \mathrm{~b}$ and $6.11 \mathrm{~b}$, the major phase in coating $\mathrm{O} 3$ is $\beta$ phase (Figure, and the major phase in coating $\mathrm{O} 7$ is $\mathrm{Ni}_{2} \mathrm{Al}_{3}$ phase.

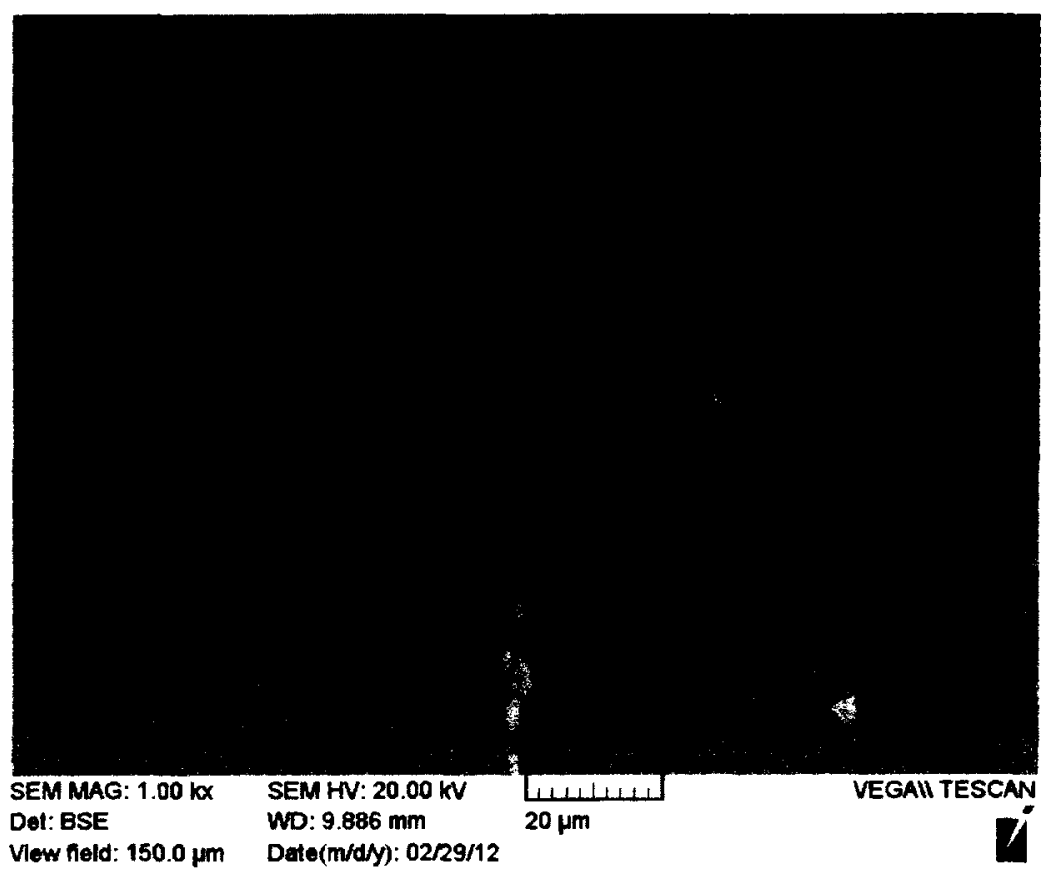

a) SEM image 


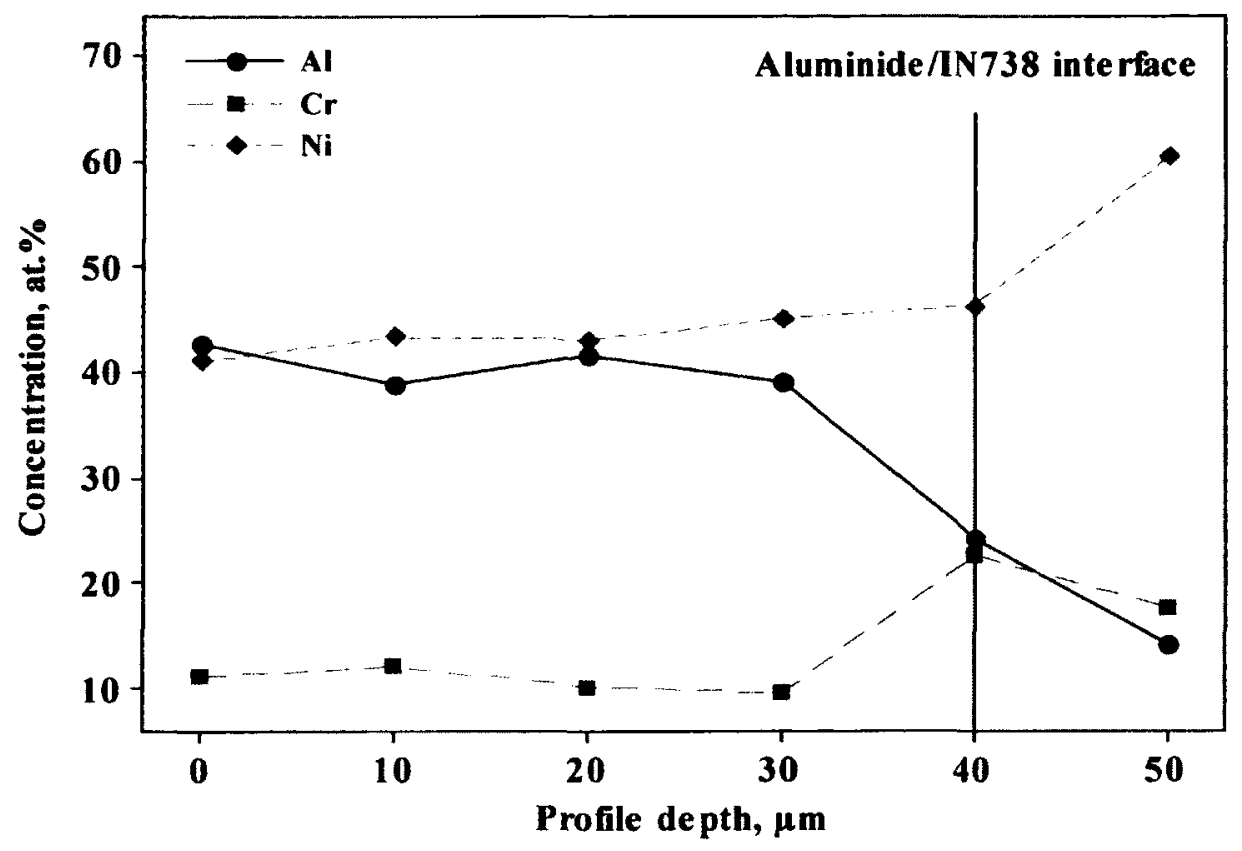

b) Concentration profiles of $\mathrm{Al}, \mathrm{Cr}$ and $\mathrm{Ni}$

Figure 6.10 SEM image and concentration profiles of major elements for coating $O 3$ (aluminide I) before oxidation tests.

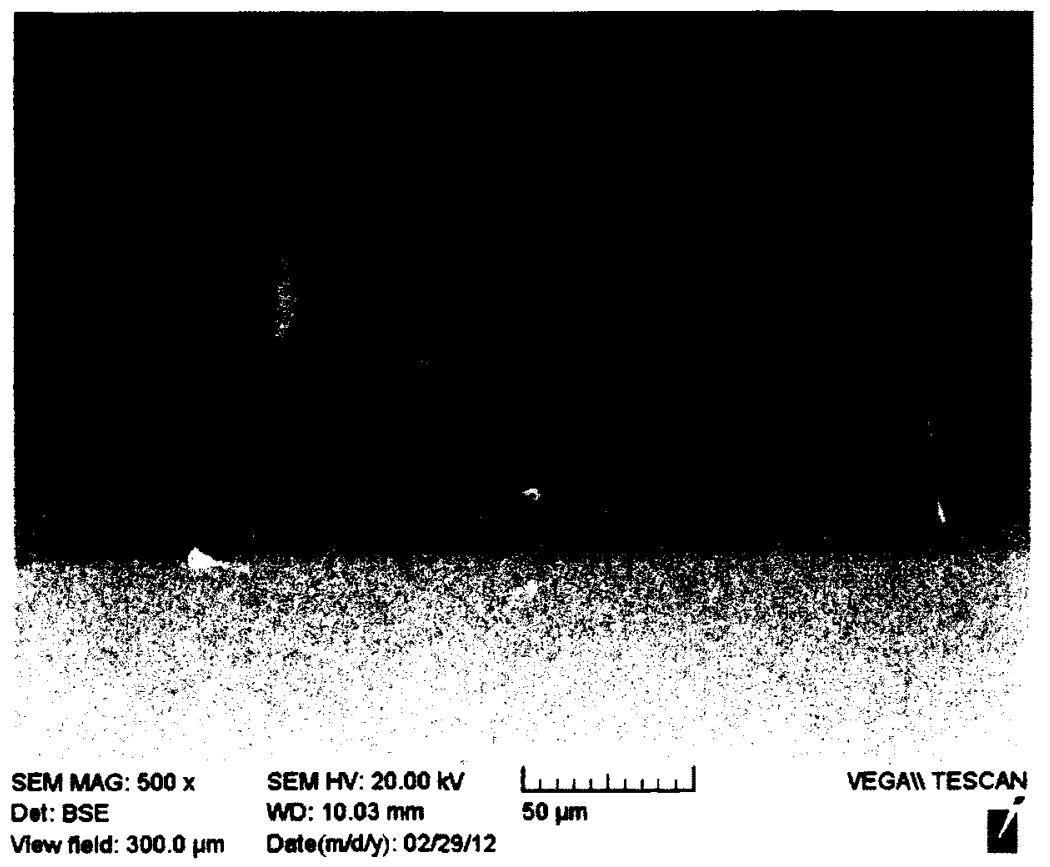

a) SEM image 


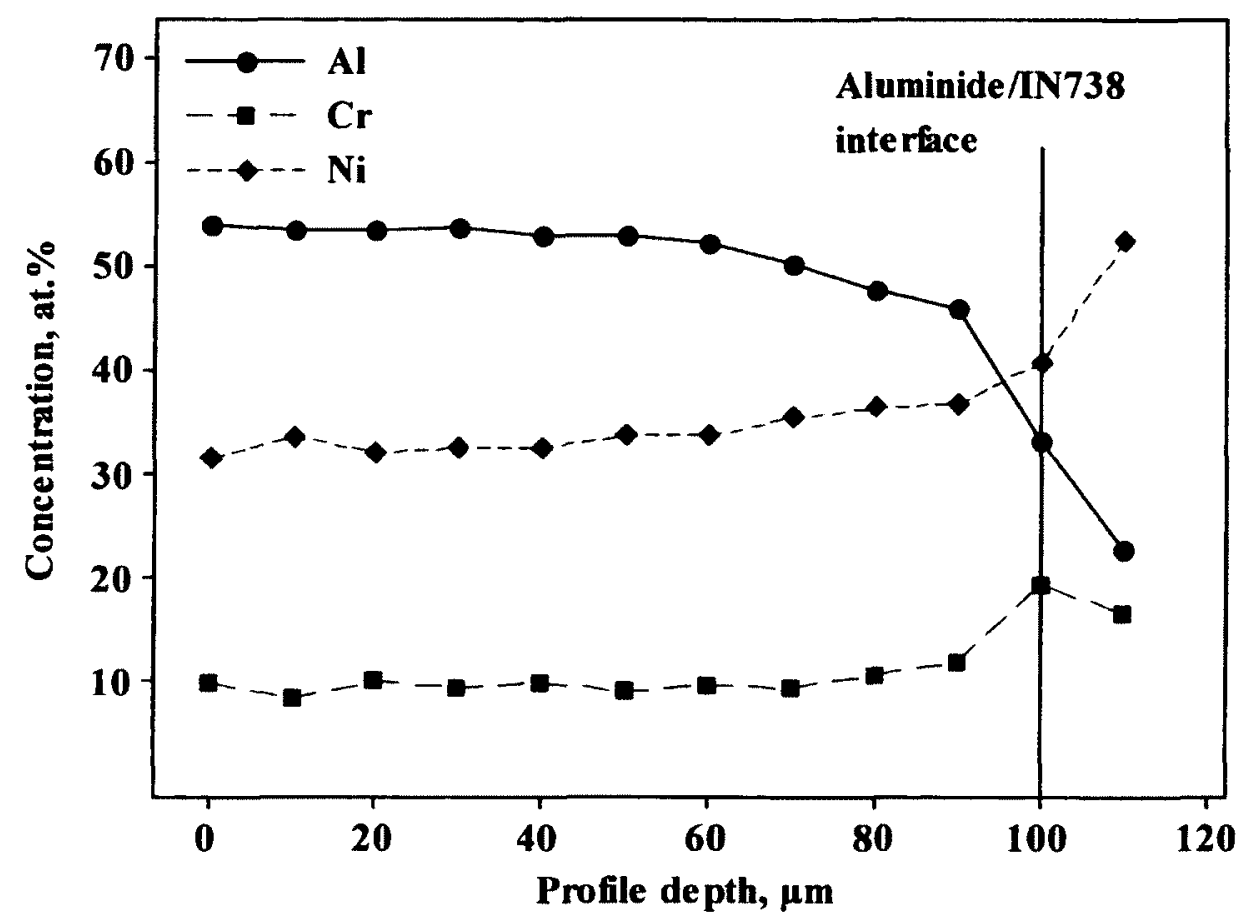

b) Concentration profiles $\mathrm{Al}, \mathrm{Cr}$ and $\mathrm{Ni}$

Figure 6.11 SEM image and concentration profiles of major elements for coating O7 (aluminide II) before oxidation tests.

Coating $\mathrm{O} 4$ and coating $\mathrm{O} 6$ are two-layer coatings without $\mathrm{Cr}-\mathrm{Si}$ barrier layer. The $\mathrm{Cr}$ concentration in coating $\mathrm{O} 4$ steadily increased without the maximum point of $\mathrm{Cr}$ content that are observed in the $\mathrm{Cr}$ concentration profile of the multilayered coating with aluminide II top coat coating. The reasons for the maximum point of $\mathrm{Cr}$ content is that barrier layer blocked $\mathrm{Cr}$ diffusion into the substrate and $\mathrm{Cr}$ atoms accumulated on barrier layer.

Based on the concentration profiles of $\mathrm{O} 4$ and $\mathrm{O} 6$ in Figure $6.12 \mathrm{~b}$ and $6.13 \mathrm{~b}$, the major phase in coating $\mathrm{O} 4$ is $\mathrm{Ni}_{2} \mathrm{Al}_{3}$ phase, and the major phase in coating $\mathrm{O} 6$ is $\beta$ phase and $\gamma / \gamma^{\prime}$ phase. 


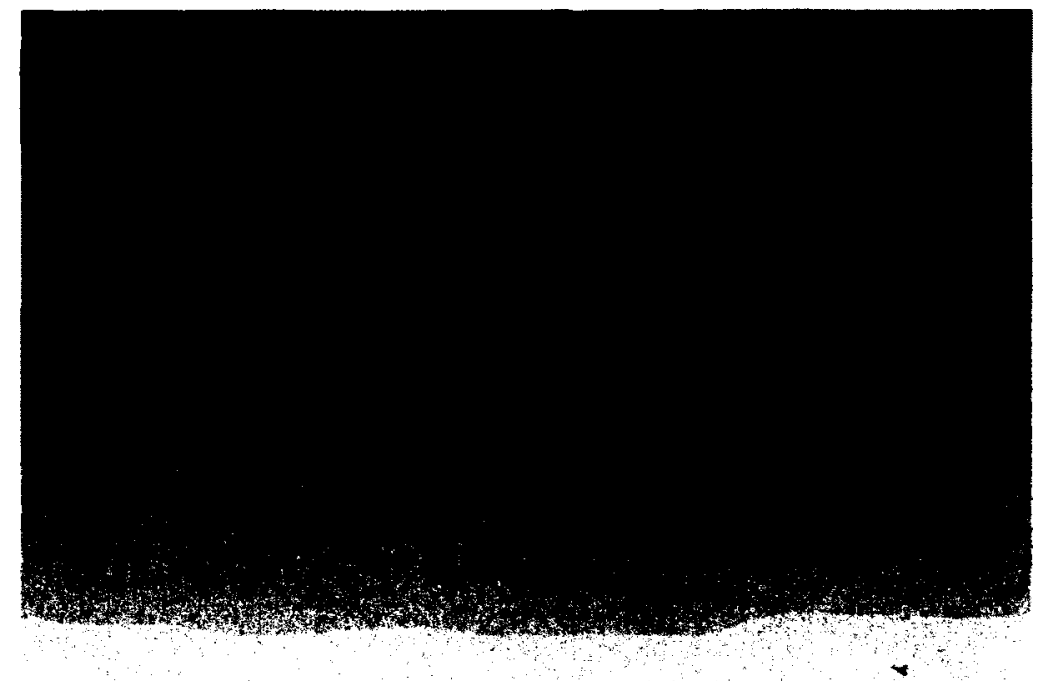

SEM MAG: $500 \mathrm{X}$ Dot: BSE

View field: $300.0 \mathrm{\mu m}$

SEM HN: $20.00 \mathrm{kV}$ WD: $9.950 \mathrm{~mm}$

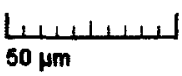

Dete(m/d/y): 02/29/12

VEGAUI TESCAN

a) SEM image

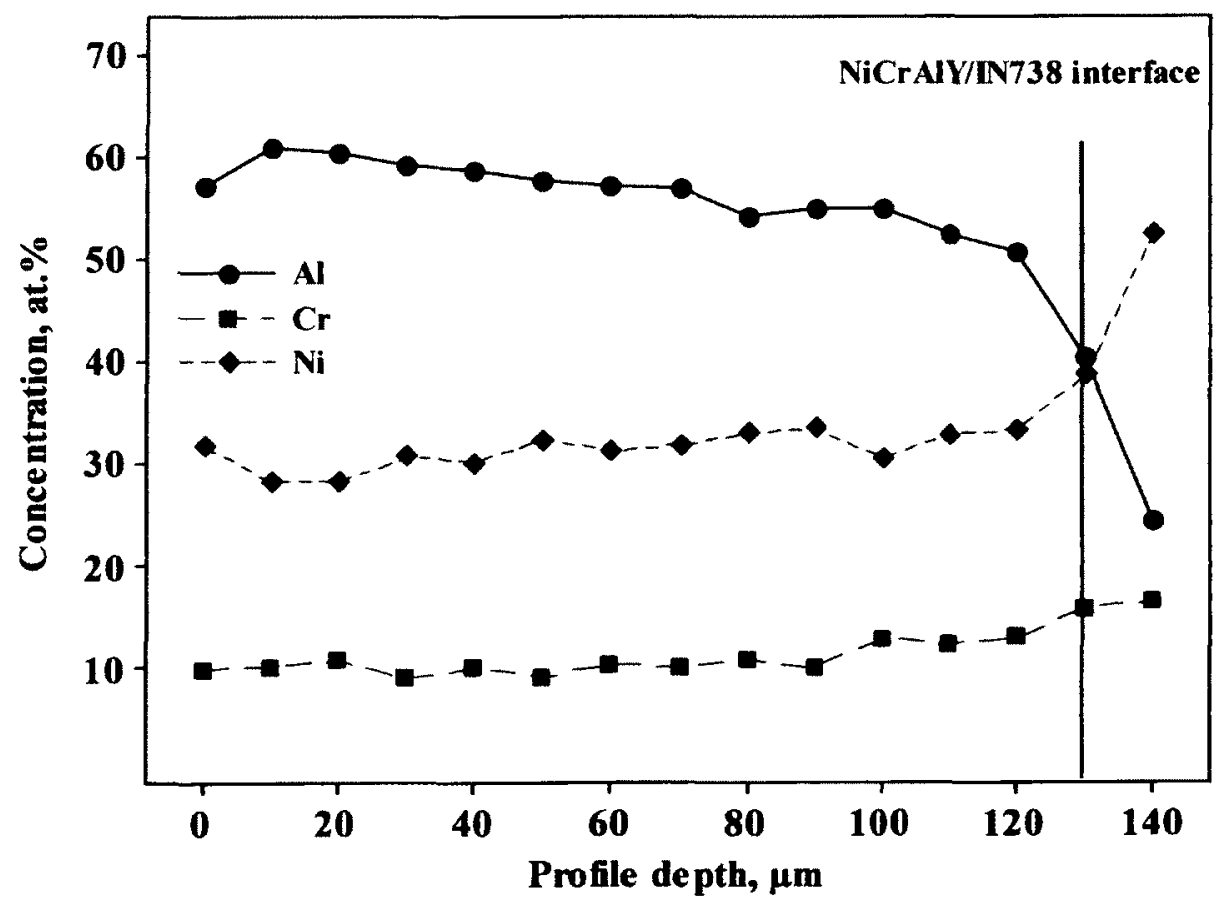

b) Concentration profiles $\mathrm{Al}, \mathrm{Cr}$ and $\mathrm{Ni}$

Figure 6.12 SEM image and concentration profiles of major elements for coating O4 (NiCrAIY/aluminide II) before oxidation tests. 


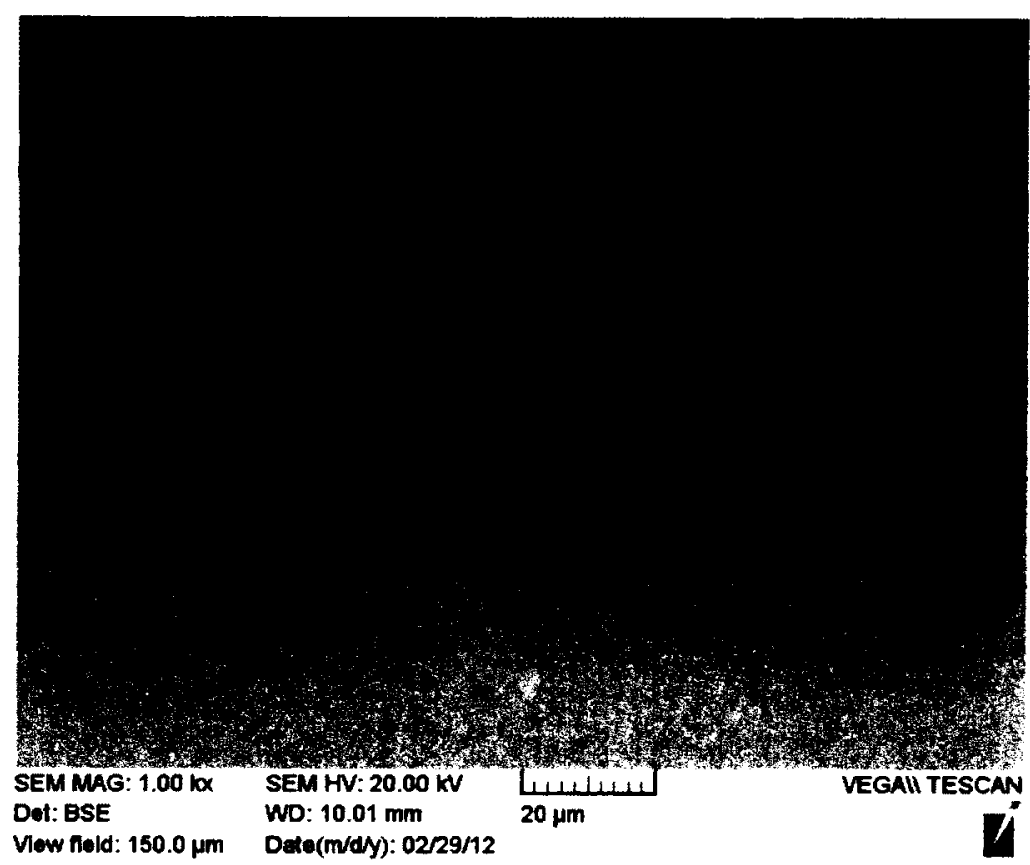

a) SEM image

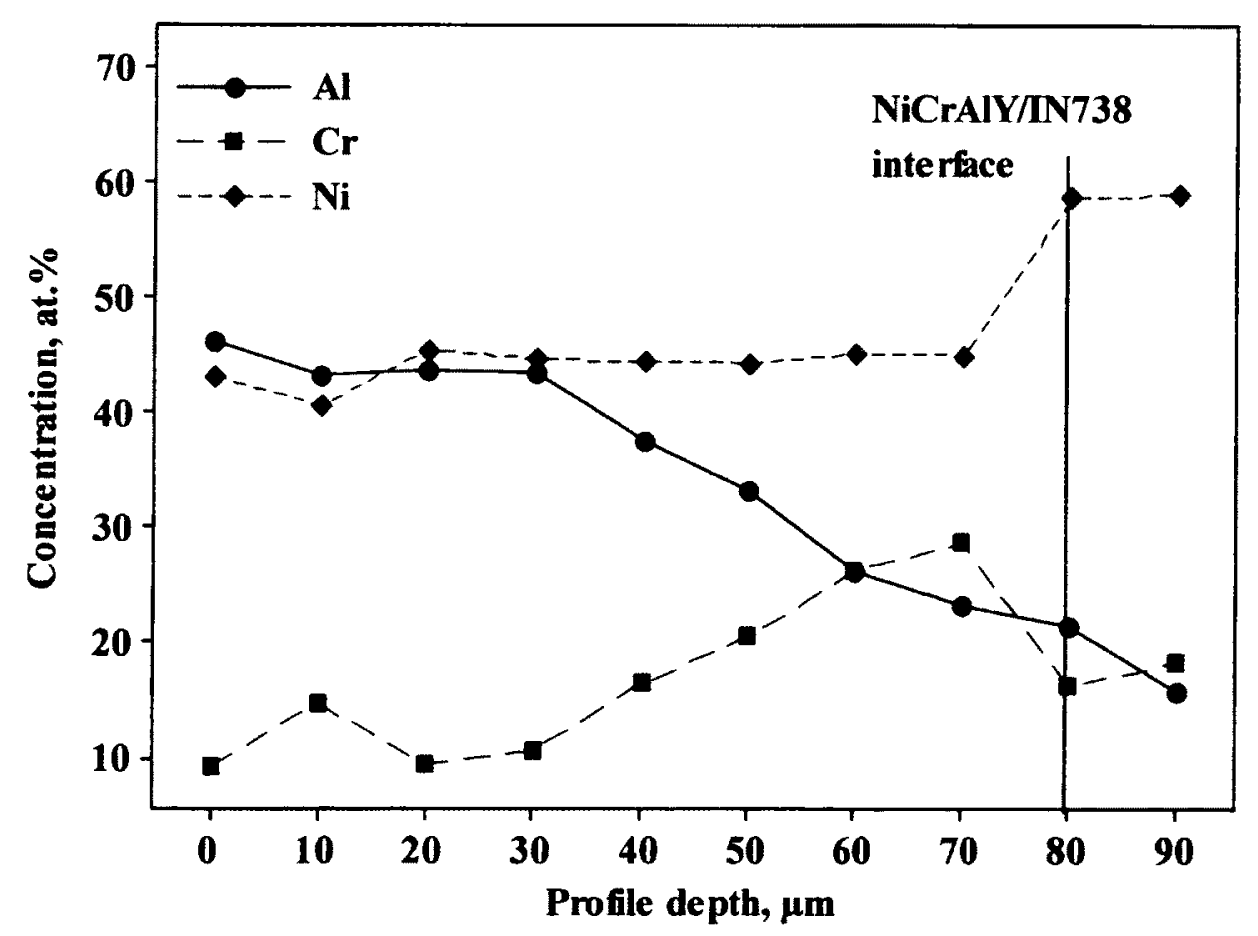

b) Concentration profiles of $\mathrm{Al}, \mathrm{Cr}$ and $\mathrm{Ni}$

Figure 6.13 SEM image and concentration profiles of major elements for coating

O6 (NiCrAlY/aluminide I) before oxidation tests. 


\subsection{Summary of Coating Fabrication}

The optimal processes developed in this research and described in previous chapters were used to fabricate two multilayered coatings. The difference between the two multilayered coatings is that the aluminum content in the top layer of one coating was twice as much as that in the top layer of another coating. The multilayered coatings were fabricated through a combination of plasma spray process and pack cementation process. The entire fabrication procedure for the multilayered coatings was divided into three steps. The first step was to co-diffuse chromium and silicon into the IN738 substrate using pack cementation process. The second step was to deposit a NiCrAlY coating on the $\mathrm{Cr}-\mathrm{Si}$ coating using plasma spray process. The final step was an aluminizing treatment on the NiCrAlY coating in order to create an aluminum-rich layer. To compare the oxidation behavior of the multilayered coatings with other coatings, the baseline coatings were also fabricated using the same process parameters for producing individual layers of the multilayered coatings. The baseline coatings were selected based on a two-level full factorial design, in which the coatings or coating layers were factors. Two reference specimens were also selected. All coatings and reference specimens were analyzed for elemental distributions across the coating layers and the results confirmed that the coatings and reference specimens all met design requirements. 


\section{Chapter 7: Oxidation Tests and Results Discussion}

\subsection{Procedure of Oxidation Tests}

Three specimens for of each coating type were placed in an alumina crucible. Each crucible contained six specimens and all crucibles were placed in an air furnace at a constant temperature of $1050^{\circ} \mathrm{C}$. The oxidized coating specimens were removed from the furnace, ultrasonically cleaned, and weighed after drying after $1000 \mathrm{hr}$ exposure. The selection of exposure temperature and duration is based on the fact that the most simple aluminide coatings, for examples PWA73, spall catastrophically after $1000 \mathrm{hr}$ at $1050^{\circ} \mathrm{C}[111]$. Four coatings that are without NiCrAlY coating are simple aluminide coatings, which could spall after $1000 \mathrm{hr}$ at $1050^{\circ} \mathrm{C}$. The other coatings might maintain the integrity of the oxides. Therefore the exposure temperature and duration that are selected are supposed to be able to distinguish the oxidation behavior of all coatings. The coating specimens for the oxidation test at $1050^{\circ} \mathrm{C}$ are illustrated in Figure 7.1.

After the oxidation test, one specimen from each group was cut, mounted and polished for microstructural examination. The other two specimens were placed in the furnace for a further treatment at a constant temperature of $1150^{\circ} \mathrm{C}$ for another $1000 \mathrm{hr}$. This further oxidation test is to examine the oxidation behavior of multilayered coatings at the higher temperature. After the oxidation test, the coating specimens were removed from the furnace after the further treatment. Again one specimen from each group was cut, mounted and polished for microstructure examination.

\subsection{Mass Change of Coatings}

Most of the coating specimens that were exposed at $1150^{\circ} \mathrm{C}$ exhibited considerably high mass change due to spallation of oxide scales not only from the surfaces of the 
coatings but also from the surfaces of the substrates. As such the mass changes for the coatings exposed to $1150^{\circ} \mathrm{C}$ will not be further discussed.

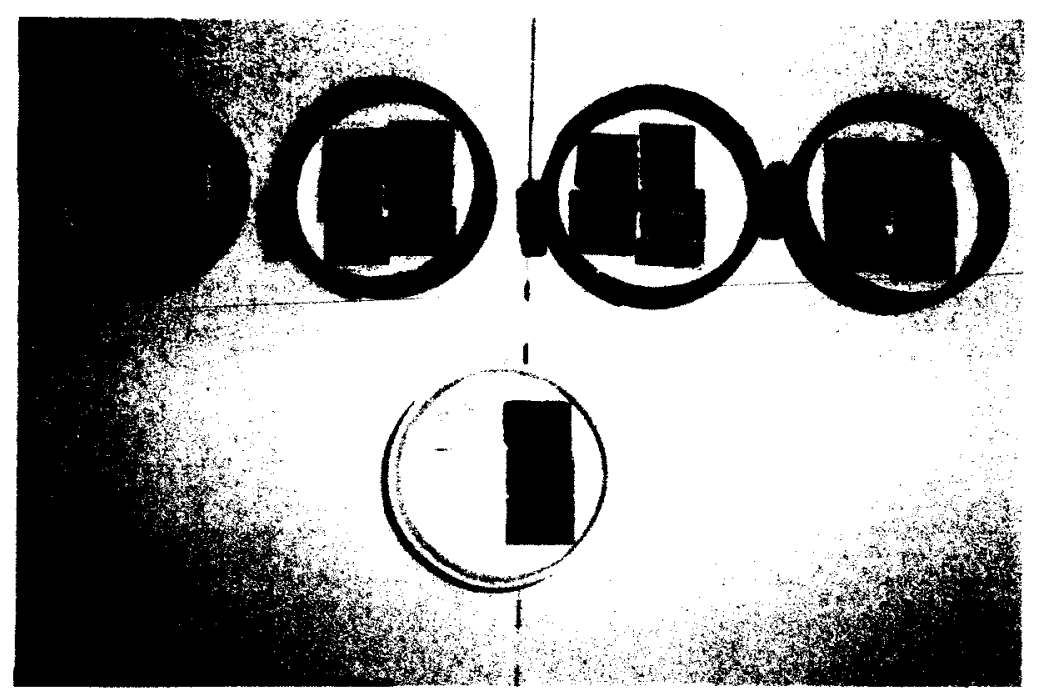

a) Specimens before the oxidation test

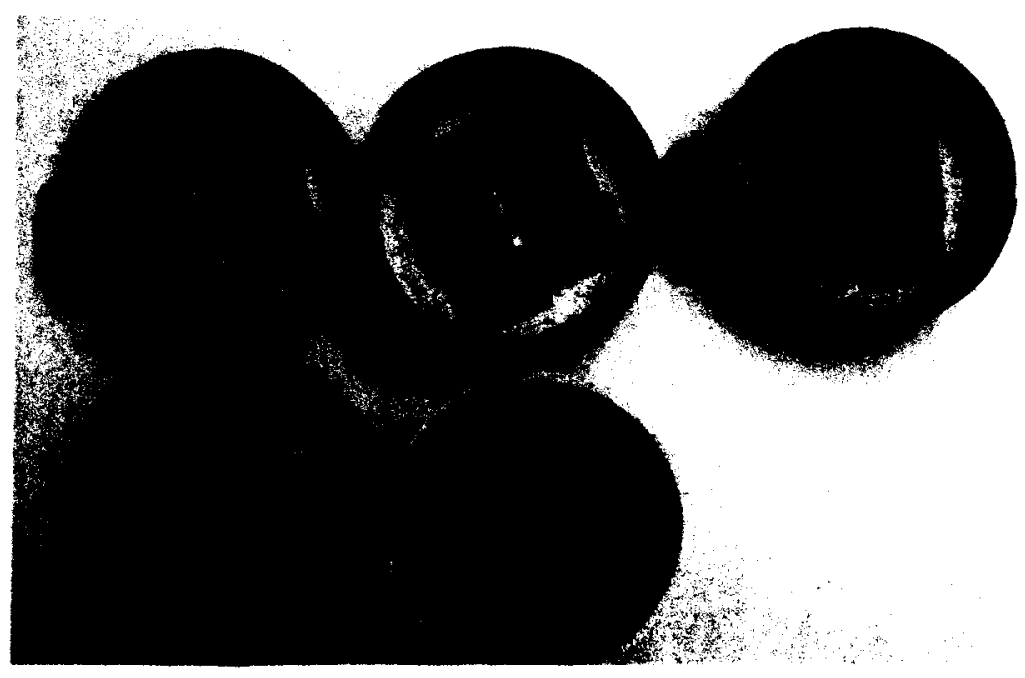

b) Specimens after the oxidation test

Figure 7.1 Specimens for the oxidation test at $1050^{\circ} \mathrm{C}$.

The mass changes for the coating specimens exposed to $1050^{\circ} \mathrm{C}$ are given in Table

7.1. The coating specimens are further divided into three groups: mass lose group (O1, 
O8, $\mathrm{O} 9$ and $\mathrm{O} 10)$, mass gain group $(\mathrm{O} 2, \mathrm{O} 4$ and $\mathrm{O} 7)$ and relatively constant mass group $(\mathrm{O} 3, \mathrm{O} 5$, and $\mathrm{O6})$, according to the mass changes of each specimen.

Table 7.1 Mass change for individual coating specimen

\begin{tabular}{ccc}
\hline Coating specimen & Mass change, $\mathrm{mg} / \mathrm{cm}^{2}$ & Coating \\
\hline O1-1 & -5.09 & \\
O1-2 & -6.37 & Cr-Si coating/aluminide I \\
O1-3 & -5.31 & \\
\hline O2-1 & 8.66 & \\
O2-2 & 9.50 & Cr-Si coating/NiCrAlY/aluminide II \\
O2-3 & 13.81 & \\
\hline O3-1 & 1.85 & aluminide I \\
O3-2 & 1.81 & \\
O3-3 & 0.52 & NiCrAlY/aluminide II \\
\hline O4-1 & 8.46 & \\
O4-2 & 9.15 & \\
O4-3 & 8.05 & \\
\hline O5-1 & 2.15 & \\
O5-2 & 2.91 & NiCrAlY/aluminide I \\
O5-3 & 1.41 & \\
\hline O6-1 & -0.85 & NiCrAlY coating/NiCrAlY/aluminide I \\
O6-2 & 0.80 & \\
O6-3 & 0.58 & IN738 \\
\hline O7-1 & 3.55 & \\
O7-2 & 2.53 & \\
O7-3 & 3.38 & \\
\hline O8-1 & -4.00 & \\
O8-2 & -3.72 & \\
O8-3 & -7.97 & \\
\hline O9-1 & -20.62 & \\
O9-2 & -38.74 & \\
O9-3 & -32.32 & \\
\hline O10-1 & -34.71 & \\
O10-2 & -46.30 & \\
O10-3 & -40.99 & \\
\hline & & \\
\hline
\end{tabular}

The mass loses of all the coated specimens are much lower than those of the two references (IN 738 and NiCrAlY/IN 738). For the mass lose group, the coatings lost 
weight due to the spallation of oxide scales. For the other groups, the coatings gained weight due to the formation and adherence of oxide scales on the surface of the coatings. However, coatings with weight gain may still suffer from spallation of the oxide scales as long as the mass of oxygen that the coating absorbed through oxidation is greater than the mass of the spalled scales.

The mass changes given in Table 7.1 were then used as a response for the analysis of variance and the development of a model associated with the coating layers. The $p$ values for the main factors and the two interactions of two factors are close to zero, but the $p$-values for the interaction of the $\mathrm{Cr}-\mathrm{Si}$ layer $(U)$ and the aluminized layer $(W)$ and for the interaction of three factors are 0.35 and 0.30 , respectively, which indicates that all factors and their interactions except the interaction of the Cr-Si layer $(U)$ and the aluminized layer $(W)$ and the interaction of three factors are significant in the model of mass change. The ANOVA results for the mass change are given in Table 7.2 after insignificant terms were eliminated. The $R^{2}$ value obtained shows that the model and experimental data have a very high degree of fitness.

Table 7.2 ANOVA table for mass change

\begin{tabular}{lcrrrl}
\hline Source & $\begin{array}{l}\text { Degree of } \\
\text { freedom }\end{array}$ & $\begin{array}{l}\text { Sum of } \\
\text { squares }\end{array}$ & $\begin{array}{l}\text { Mean } \\
\text { square }\end{array}$ & $F$ value & $p$-value \\
\hline Main effect, $U, V, W$ & 3 & 506.87 & 168.96 & 70.17 & 0.000 \\
\hline $\begin{array}{l}\text { Interaction between two } \\
\text { factors, } U V, V W\end{array}$ & 3 & 193.57 & 96.78 & 40.20 & 0.000 \\
\hline Residual & 18 & 43.34 & 2.41 & & \\
\hline Lack of fit & 2 & 5.06 & 2.53 & 1.06 & 0.371 \\
\hline Pure error & 16 & 38.28 & 38.28 & 2.39 & \\
\hline Total & 23 & 743.77 & & & \\
\hline$R^{2}$ & $94.17 \%$ & & & & \\
\hline
\end{tabular}


Some important concepts were introduced for evaluating the importance of factors and their interactions, which included the effect, sequential sums of squares, and percent contribution. The effect of a factor or an interaction of factors is defined to be the change in response produced by a change in the level of the factor or the interaction. In this case, that means increasing a factor from the low level to the high level causes an average response change. As mentioned above, the sequential sums of squares (SS) measure the reduction in the residual sums of squares (RSS) provided by each factor in a regression equation. If the sequential SS of a factor substantially reduces the residual sums of squares in a regression equation, this factor becomes significant in the regression equation. The percentage of the sequential sums of squares over the total sums of squares for is the percent contribution. The percent contribution represents the relative importance of each term in the regression equation.

Some results of effect, sequential SS, and percent contribution for mass change are presented in Table 7.3. Judging from the results, it is concluded that:

- The NiCrAlY layer dominated the mass change of coatings and the presence of the NiCrAlY layer increased mass gain.

- Higher $\mathrm{Al} / \mathrm{Ni}$ ratio increased mass gain.

- The interaction between the $\mathrm{Cr}$-Si layer and the NiCrAlY layer increased mass gain.

The factor that increased mass gain promoted the cohesion between oxide scales and coatings. 
Table 7.3 Effect, sequential SS, and percent contribution of factors and interactions for mass change

\begin{tabular}{llrc}
\hline Factor & Effect estimate & Seq SS & Percent contribution \\
\hline$U$ & -2.516 & 37.98 & 5.11 \\
$V$ & 7.257 & 316.03 & 42.49 \\
$W$ & 5.048 & 152.86 & 20.55 \\
$U V$ & 4.554 & 124.44 & 16.73 \\
$V W$ & 3.394 & 69.12 & 9.29 \\
\hline
\end{tabular}

The model of mass change $\left(Y_{M}\right)$ with respect to the coating layers was developed and is expressed in the following regression equation:

$$
Y_{M}=0.84-7.07 \times U-0.69 \times V+1.65 \times W+9.11 \times U \times V+6.79 \times V \times W
$$

where $U$ represents the $\mathrm{Cr}-\mathrm{Si}$ coating; $V$ represents the NiCrAlY coating; $W$ represents the aluminized coating.

The variables in regression equation (7-1) are uncoded qualitative variables and can only be zero or one. When variable $W$ is set to be zero (aluminide I) or one (aluminide II), two regression equations, $Y_{M I}$ and $Y_{M I l}$, can be obtained as follows:

$$
\begin{aligned}
& Y_{M I}=0.84-7.07 \times U-0.69 \times V+9.11 \times U \times V \\
& Y_{M I I}=2.39-7.07 \times U+6.10 \times V+9.11 \times U \times V
\end{aligned}
$$

For equation (7-2), when variable $U$ is zero, $Y_{M I}$ is almost not affected by variable $V$ since the coefficient for variable $V$ is very small; when variables $U$ and $V$ are equal to one, $Y_{M I}$ reaches the maximum. Such phenomena indicate that when the top layer of a coating was the aluminide I and no $\mathrm{Cr}$-Si layer was applied, the mass change of the coating varied insignificantly whether a NiCrAlY layer was present or not; whereas 
when the top layer of a coating is the aluminide $\mathrm{I}$ and a $\mathrm{Cr}$-Si layer was present, the mass change of the coating varied significantly with the presence of a NiCrAlY layer. This observation suggested that the interaction between the $\mathrm{Cr}-\mathrm{Si}$ layer and the NiCrAlY layer in a multilayered coating substantially affected the mass change of coatings. These phenomena can also be visually observed in the contour plot of equation (7-2) (Figure 7.2).

The mass changes for the coatings with or without a NiCrAlY layer were in the same range $\left(-1.0-0.5 \mathrm{mg} / \mathrm{cm}^{2}\right)$ when a barrier $\mathrm{Cr}-\mathrm{Si}$ layer was not applied; whereas when the coatings had the $\mathrm{Cr}$-Si layer, the presence of the NiCrAlY layer resulted in mass gain while mass loss was observed without the NiCrAlY layer. Therefore, when a multilayered coating consisted of the aluminide I layer and a NiCrAlY layer, a $\mathrm{Cr}-\mathrm{Si}$ layer was critical in ensuring mass gain and preventing oxide scales from spallation.

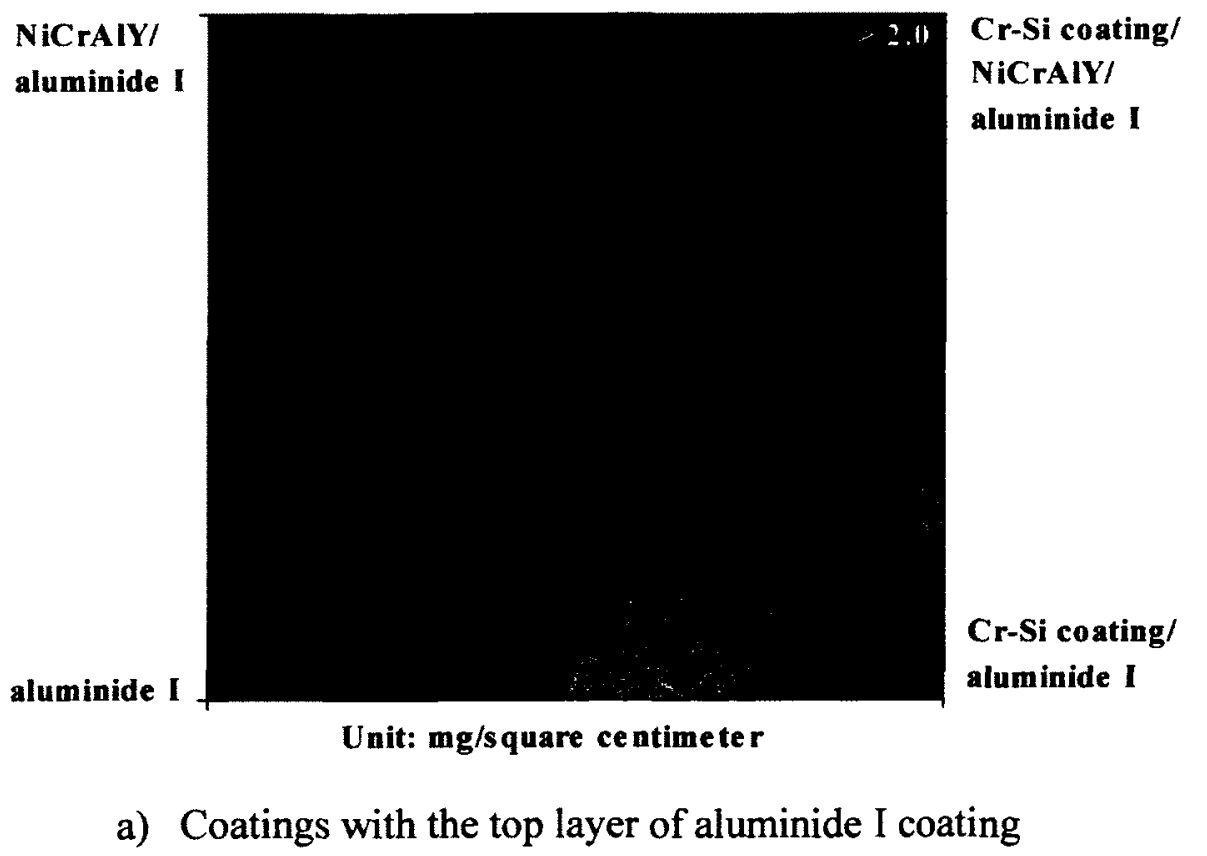




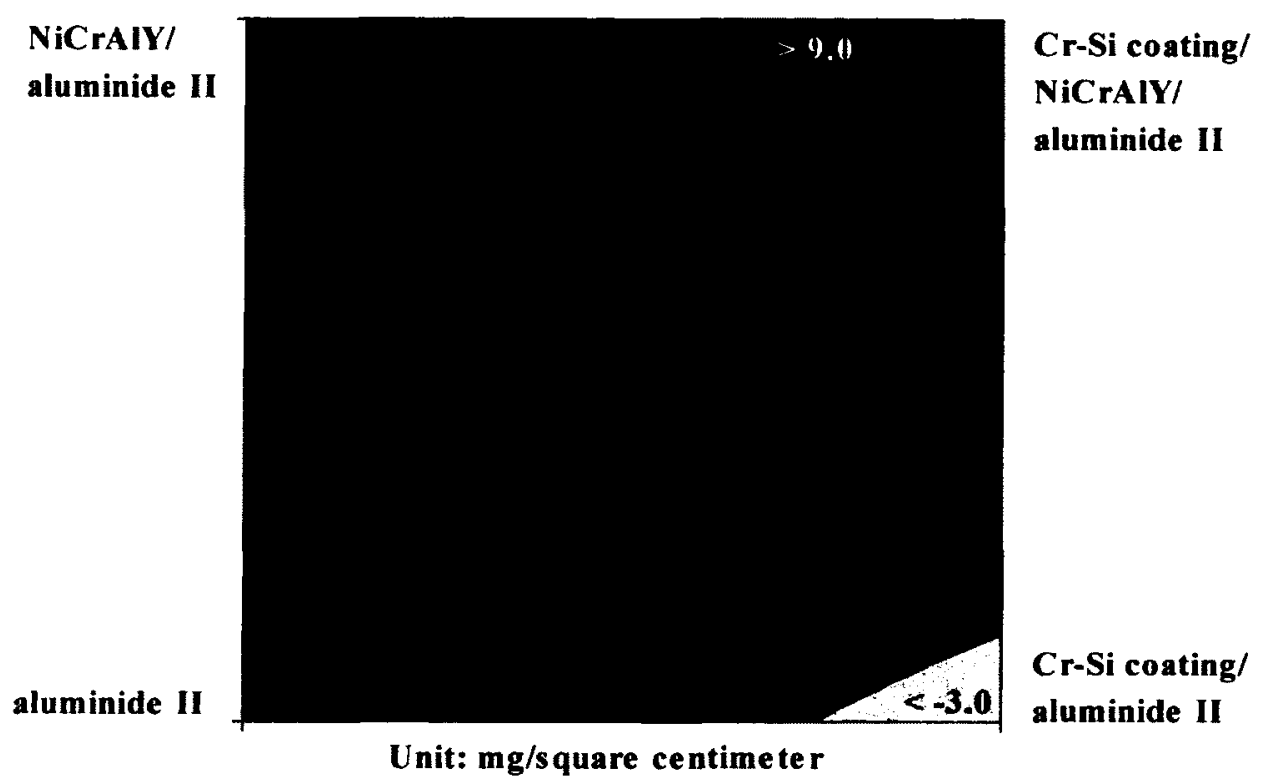

b) Coatings with the top layer of aluminide II coating

Figure 7.2 Contour plots of mass changes for multilayered coatings.

In equation (7-3), when variable $V$ equals to one $Y_{M I I}$ is slightly higher when $U=1$ (than when $U=0$ ) as shown in Figure 7.2b. When variables $U$ and $V$ are both set to zero, $Y_{M I I}$ values are still positive since the higher aluminum content of the aluminide II layer definitely promoted mass gain; whereas $Y_{M I I}$ becomes negative and reaches the minimum value of $-2.5--5.0 \mathrm{mg} / \mathrm{cm}^{2}$ when $V=0$ and $U=1$. Such findings indicate that when a multilayered coating consisted of a top layer of aluminide II and a middle layer of NiCrAlY, a Cr-Si barrier layer promoted mass gain; and when a coating only consisted of a top layer of aluminide II without the NiCrAlY layer, the presence of a $\mathrm{Cr}-\mathrm{Si}$ layer caused significant amounts of mass loss due to the interaction between the $\mathrm{Cr}-\mathrm{Si}$ layer and the aluminide II layer. Therefore, when a multilayered coating consisted of the aluminide II layer and a NiCrAlY layer, a $\mathrm{Cr}$-Si layer in the multilayered coating could promote mass gain and prevent the coating from spallation. 


\subsection{Microstructure and Morphology of Oxidized Coating Surfaces}

As mentioned in Chapter 2, the oxidation behavior of diffusion coatings and MCrAlY coatings follows a four-stage process: transient, steady-state, aluminum depletion and nickel outward diffusion, and internal $\mathrm{Cr}_{2} \mathrm{O}_{3}$ oxide formation. The formation of $\mathrm{Al}_{2} \mathrm{O}_{3}, \mathrm{Cr}_{2} \mathrm{O}_{3}, \mathrm{NiO}$, or $\mathrm{Ni}(\mathrm{Al}, \mathrm{Cr})_{2} \mathrm{O}_{4}$ is affected by the aluminum content in the coatings and exposure temperatures. When aluminum contents in coatings are above 21 at.\%, the oxides on the surface of the coating are dominantly $\mathrm{Al}_{2} \mathrm{O}_{3}$, whereas a mixture of $\mathrm{Cr}_{2} \mathrm{O}_{3}, \mathrm{NiO}$, and $\mathrm{Ni}(\mathrm{Al}, \mathrm{Cr})_{2} \mathrm{O}_{4}$ begins to form when the aluminum contents in the coatings drop below 21 at.\% [112]. The aluminum contents for all coatings that were exposed to $1050^{\circ} \mathrm{C}$ were close or over 21 at.\% except for coatings 01,010 and specimen 09 (Table 7.4). Therefore most of the coatings examined in this study reached the steady-state, and aluminum depletion and nickel outward diffusion stages. However, the aluminum contents for the coatings exposed at $1150^{\circ} \mathrm{C}$ fell below 21 at.\%, except for coating $\mathrm{O} 2$ (Table 7.4). For these coatings (except $\mathrm{O} 2$ ) the formation of internal $\mathrm{Cr}_{2} \mathrm{O}_{3}$ oxide and other oxides such as $\mathrm{Al}_{2} \mathrm{O}_{3}, \mathrm{Cr}_{2} \mathrm{O}_{3}$, $\mathrm{NiO}$, and $\mathrm{Ni}(\mathrm{Al}, \mathrm{Cr})_{2} \mathrm{O}_{4}$ would occur. Coating $\mathrm{O} 2$ was still in aluminum depletion and nickel outward diffusion stage after the oxidation test at $1150^{\circ} \mathrm{C}$.

Table 7.4 Maximum and surface aluminum contents after the oxidation tests

\begin{tabular}{|c|c|c|c|c|c|c|c|c|c|c|c|}
\hline \multirow{2}{*}{$\begin{array}{l}\text { Temp., } \\
{ }^{\circ} \mathrm{C}\end{array}$} & \multirow{2}{*}{ Scenario } & \multicolumn{10}{|c|}{ Aluminum content, at. $\%$} \\
\hline & & $\mathrm{Ol}$ & $\mathrm{O} 2$ & $\mathbf{0 3}$ & $\mathrm{O} 4$ & O5 & O6 & 07 & 08 & 09 & 010 \\
\hline \multirow{2}{*}{1050} & Surface & 11.1 & 36.1 & 21.4 & 37.7 & 19.1 & 19.7 & 28.0 & 25.3 & 10.3 & 17.5 \\
\hline & $\operatorname{Max}$ & 11.5 & 36.1 & 21.4 & 39.9 & 21.6 & 24.0 & 29.9 & 26.0 & 11.9 & 17.4 \\
\hline \multirow{2}{*}{1150} & Surface & 9.3 & 22.7 & 7.6 & 16.1 & 13.7 & 19.7 & 13.8 & 8.3 & 8.4 & 8.8 \\
\hline & $\operatorname{Max}$ & 9.3 & 22.7 & 8.0 & 16.1 & 17.7 & 19.7 & 24.3 & 8.3 & 8.9 & 8.8 \\
\hline
\end{tabular}

Three different contrasts are observed in the SEM images (Figure 7.3 to Figure 7.6) of the coatings: dark regions, grey regions and bright regions, which represent 
indicating different oxides. The EDS results (Table 7.5) suggest that dark regions consist of $\mathrm{Al}_{2} \mathrm{O}_{3}$ (points $\mathrm{A}, \mathrm{B}, \mathrm{F}, \mathrm{H}, \mathrm{N}, \mathrm{P}, \mathrm{T}$ and $\mathrm{W}$ in the figures), grey regions are mixtures of $\mathrm{Al}_{2} \mathrm{O}_{3}, \mathrm{Cr}_{2} \mathrm{O}_{3}, \mathrm{NiO}$ (points I and $\mathrm{U}$ in the figures) and $\mathrm{Ni}(\mathrm{Al}, \mathrm{Cr})_{2} \mathrm{O}_{4}$ (points $D, G, R$, and $V$ in the figures), and bright regions represent the exposed coating after the spallation of oxide scales (points $\mathrm{C}, \mathrm{E}, \mathrm{J}, \mathrm{K}, \mathrm{L}$, and $\mathrm{S}$ in the figures).

Table 7.5 EDS results of various phases on the surface of coatings

\begin{tabular}{|c|c|c|c|c|c|c|c|c|}
\hline \multirow{2}{*}{$\begin{array}{l}\text { Loca } \\
\text {-tion }\end{array}$} & & \multicolumn{6}{|c|}{ Concentration, at.\% } & \multirow[t]{2}{*}{ Oxide } \\
\hline & $\mathrm{O}$ & $\mathrm{Al}$ & $\mathrm{Cr}$ & $\mathrm{Ni}$ & $\mathrm{Ti}$ & $\mathrm{Si}$ & $\mathrm{Co}$ & \\
\hline A & 65.73 & 33.04 & 0.61 & 0.33 & & & & $\mathrm{Al}_{2} \mathrm{O}_{3}$ \\
\hline B & 67.50 & 32.50 & & & & & & $\mathrm{Al}_{2} \mathrm{O}_{3}$ \\
\hline C & 31.29 & 6.48 & 2.76 & 41.07 & 2.48 & 1.06 & 4.86 & \\
\hline D & 66.99 & 20.16 & 3.87 & 7.54 & 0.31 & & 1.13 & $\mathrm{Ni}(\mathrm{Al}, \mathrm{Cr})_{2} \mathrm{O}_{4}$ \\
\hline $\mathrm{E}$ & 13.98 & 6.27 & 19.75 & 48.60 & 1.22 & 3.39 & 6.31 & \\
\hline $\mathrm{F}$ & 62.66 & 31.96 & 1.40 & 3.37 & 0.60 & & & $\mathrm{Al}_{2} \mathrm{O}_{3}$ \\
\hline G & 63.55 & 25.03 & 0.63 & 9.48 & & & 1.31 & $\mathrm{NiAl}_{2} \mathrm{O}_{4}$ \\
\hline $\mathrm{H}$ & 60.68 & 34.23 & 0.87 & 3.62 & 0.14 & & 0.46 & $\mathrm{Al}_{2} \mathrm{O}_{3}$ \\
\hline I & 48.42 & 1.75 & 0.78 & 46.87 & & & 2.19 & $\mathrm{NiO}$ \\
\hline $\mathbf{J}$ & & 16.14 & 14.42 & 59.62 & 3.76 & & 6.06 & \\
\hline $\mathrm{K}$ & & 19.74 & 15.04 & 55.40 & 3.85 & & 5.97 & \\
\hline $\mathrm{L}$ & 13.98 & 6.64 & 16.22 & 52.52 & 2.35 & & 7.91 & \\
\hline M & 43.41 & 6.73 & 11.09 & 32.50 & 1.46 & & 4.44 & $\mathrm{NiO}$ \\
\hline $\mathrm{N}$ & 63.62 & 36.00 & 0.16 & 0.22 & & & & $\mathrm{Al}_{2} \mathrm{O}_{3}$ \\
\hline $\mathrm{O}$ & 67.50 & 8.69 & 1.88 & 4.41 & 14.80 & 0.80 & 0.68 & $\mathrm{Al}_{2} \mathrm{O}_{3}, \mathrm{TiO}_{2}$ \\
\hline $\mathbf{P}$ & 64.52 & 34.55 & 0.16 & 0.23 & 0.53 & & & $\mathrm{Al}_{2} \mathrm{O}_{3}$ \\
\hline Q & 40.63 & 5.37 & 13.90 & 32.15 & 2.32 & 1.19 & 4.44 & $\mathrm{NiO}$ \\
\hline $\mathbf{R}$ & 60.01 & 19.62 & 2.77 & 9.45 & 4.69 & 0.87 & 1.96 & $\mathrm{Ni}(\mathrm{Al}, \mathrm{Cr})_{2} \mathrm{O}_{4}$ \\
\hline $\mathbf{S}$ & 16.33 & 10.00 & 18.01 & 48.87 & 0.78 & & & \\
\hline $\mathrm{T}$ & 70.00 & 21.14 & 1.70 & 6.92 & & & & $\mathrm{Al}_{2} \mathrm{O}_{3}$ \\
\hline U & 46.56 & 1.95 & 1.61 & 49.88 & & & & $\mathrm{NiO}$ \\
\hline V & 46.14 & 5.59 & 35.33 & 9.00 & 3.35 & & 0.58 & $\begin{array}{l}\mathrm{Cr}_{2} \mathrm{O}_{3}, \\
\mathrm{Ni}(\mathrm{Al}, \mathrm{Cr})_{2} \mathrm{O}_{4}\end{array}$ \\
\hline W & 61.39 & 36.82 & 0.53 & 1.26 & & & & $\mathrm{Al}_{2} \mathrm{O}_{3}$ \\
\hline
\end{tabular}




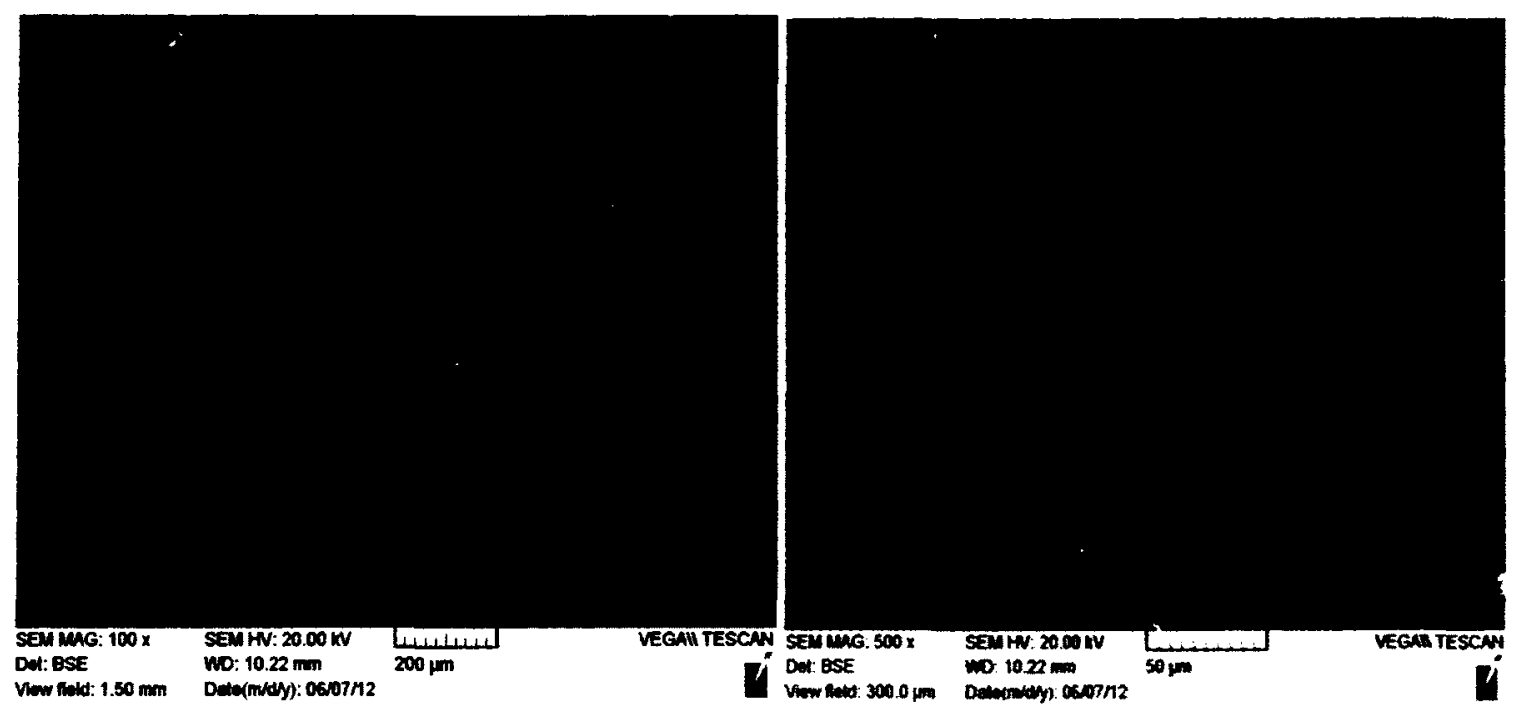

a) Surface morphology of coating $\mathrm{O} 2$

after $1000 \mathrm{hr}$ exposure at $1050^{\circ} \mathrm{C}$ at low

magnitude b) Surface morphology of coating $\mathrm{O} 2$

after $1000 \mathrm{hr}$ exposure at $1050^{\circ} \mathrm{C}$ at high magnitude
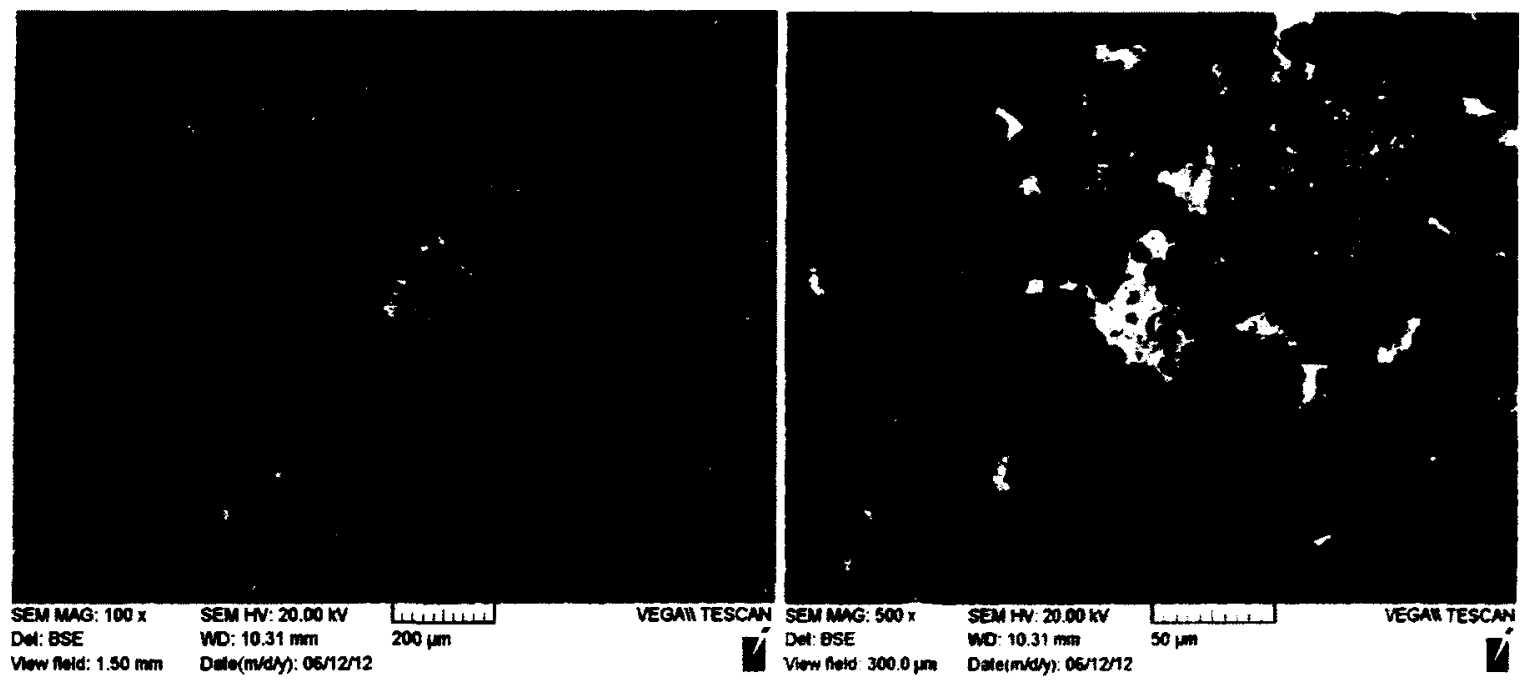

c) Surface morphology of coating $\mathrm{O} 2$

d) Surface morphology of coating $\mathrm{O} 2$

after $1000 \mathrm{hr}$ exposure at $1150^{\circ} \mathrm{C}$ at low after $1000 \mathrm{hr}$ exposure at $1150^{\circ} \mathrm{C}$ at magnitude high magnitude 


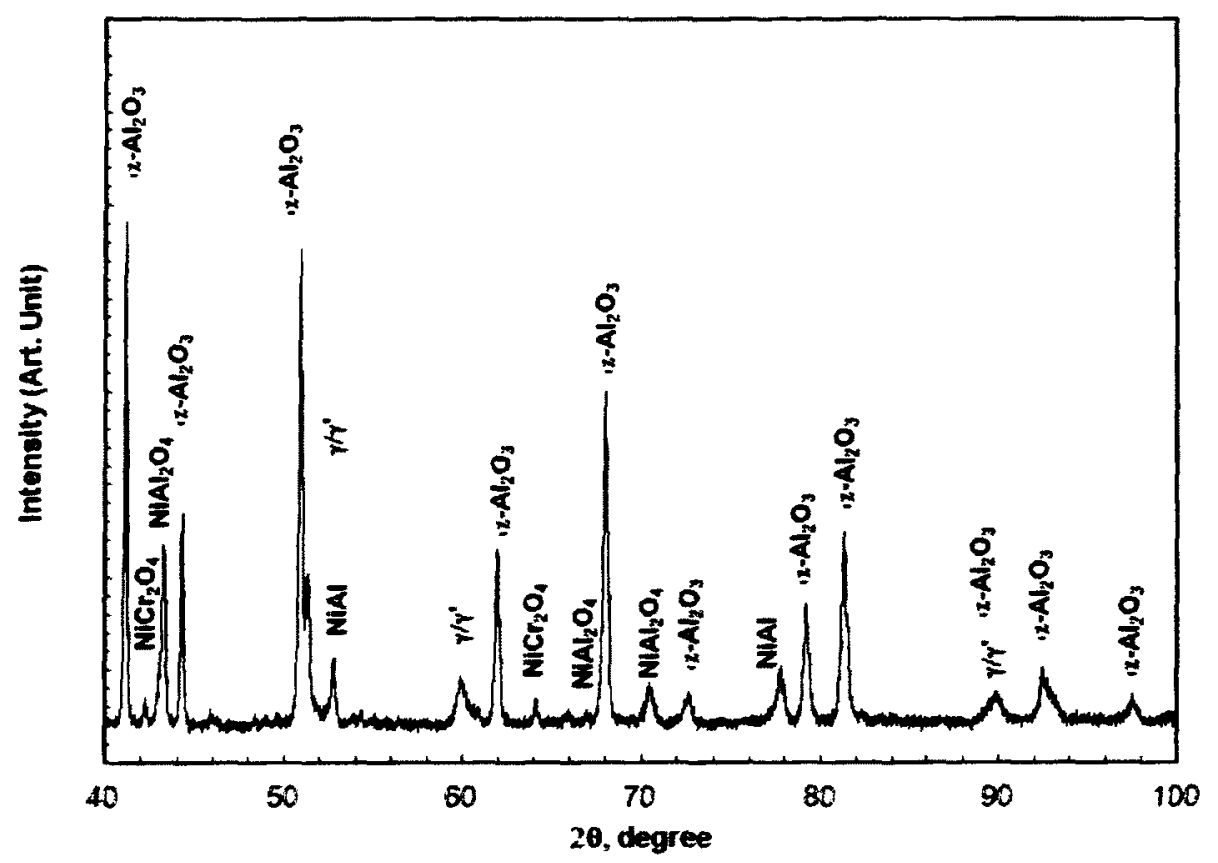

e) XRD spectrum of coating $\mathrm{O} 2$ after $1000 \mathrm{hr}$ exposure at $1050^{\circ} \mathrm{C}$

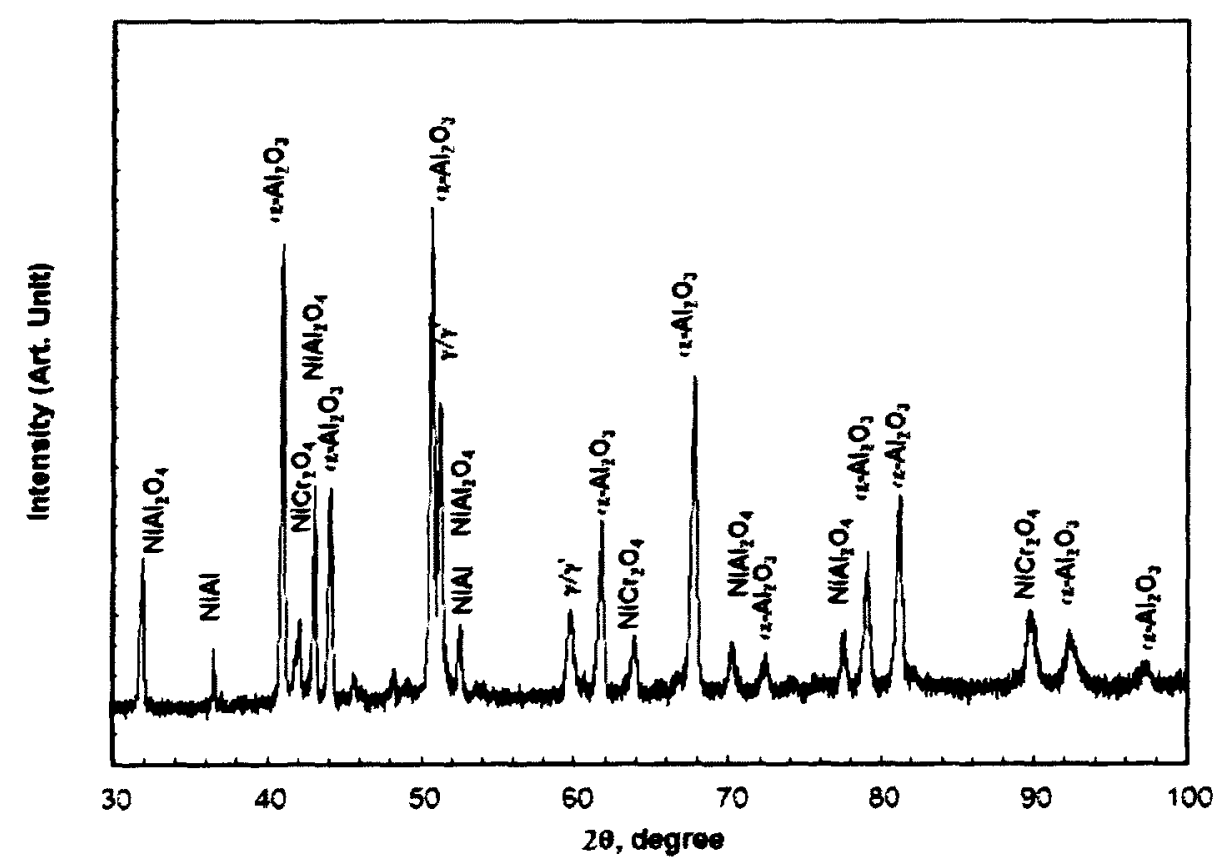

f) $\mathrm{XRD}$ spectrum of coating $\mathrm{O} 2$ after $1000 \mathrm{hr}$ exposure at $1150^{\circ} \mathrm{C}$

Figure 7.3 Surface morphologies of and XRD spectra of coating 02 . 


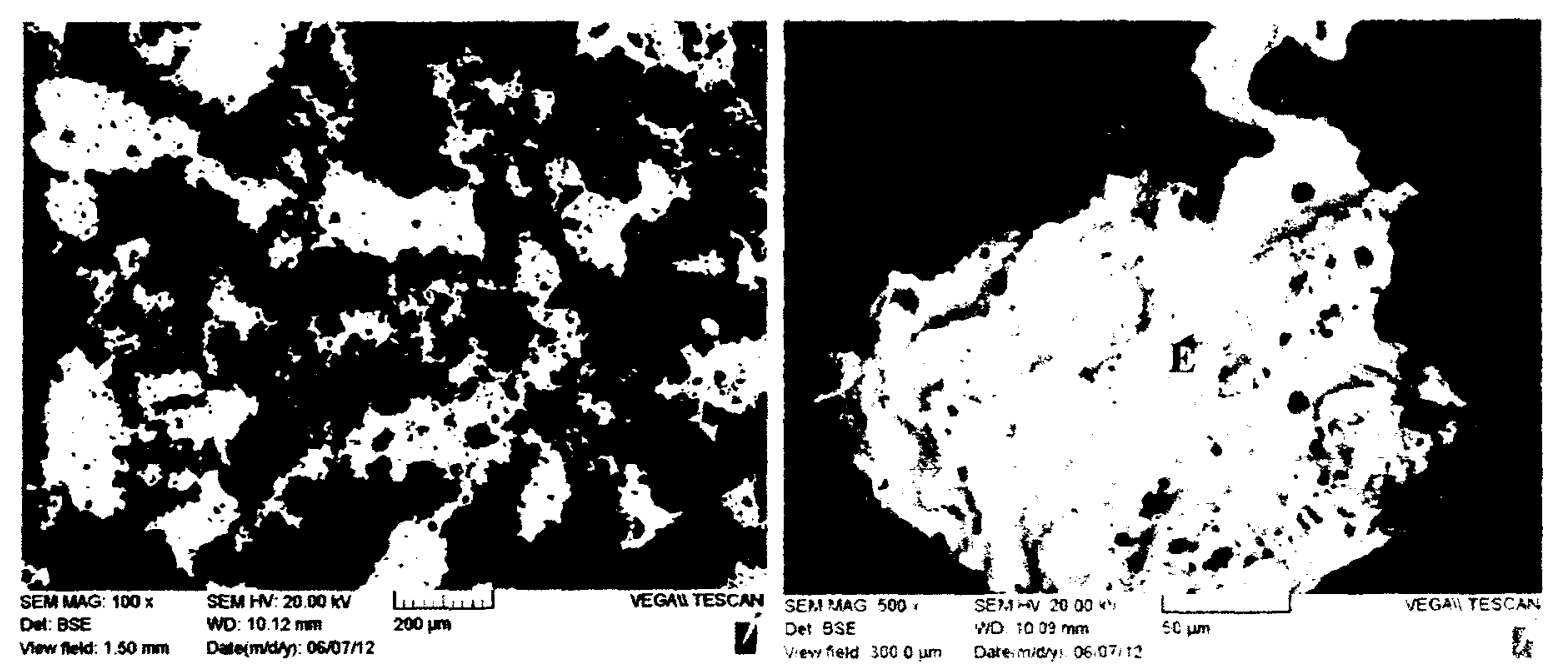

a) Surface morphology of coating $\mathrm{OS}$

after $1000 \mathrm{hr}$ exposure at $1050^{\circ} \mathrm{C}$ at low

magnitude b) surface morphology of coating 05 after

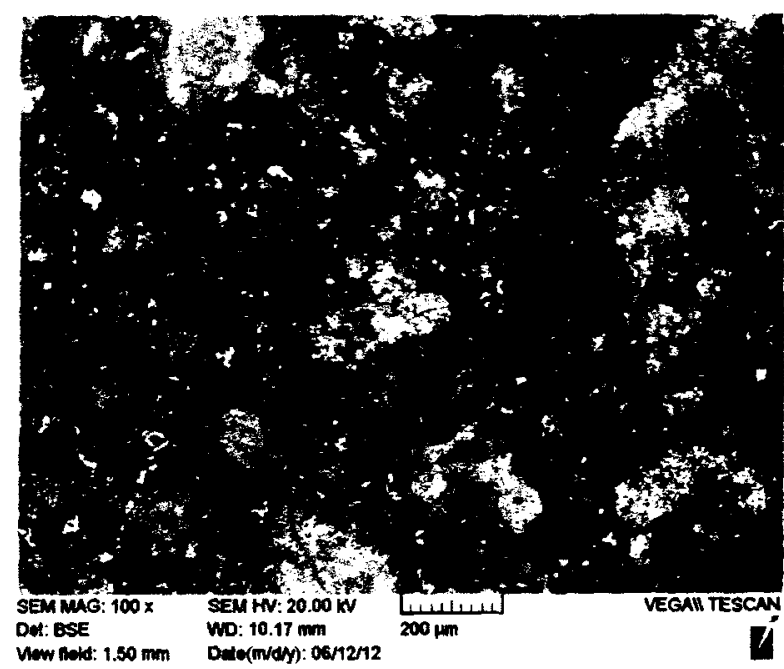

magnitude

c) Surface morphology of coating $\mathrm{O} 5$

after $1000 \mathrm{hr}$ exposure at $1150^{\circ} \mathrm{C}$ at

low magnitude

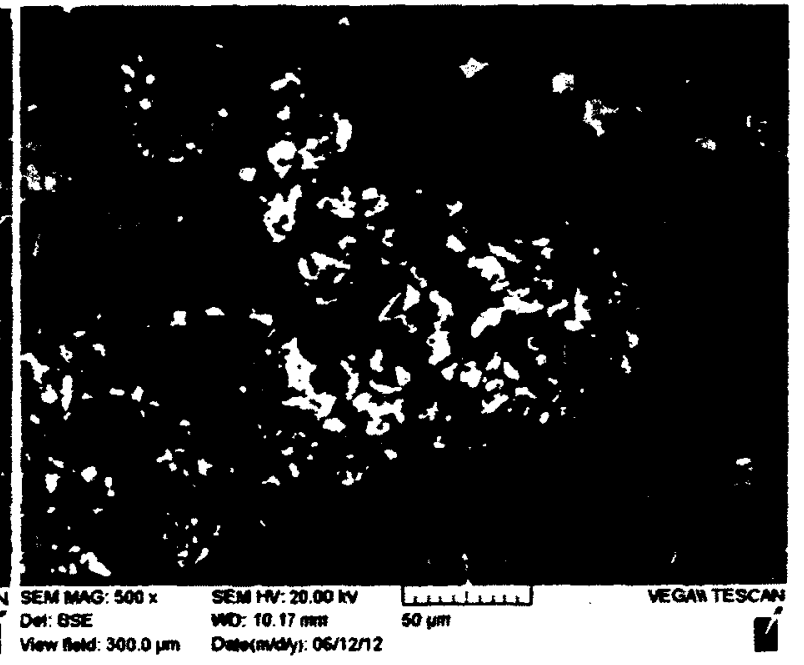

d) Surface morphology of coating

$\mathrm{O} 5$ after $1000 \mathrm{hr}$ exposure at $1150^{\circ} \mathrm{C}$ at high magnitude 


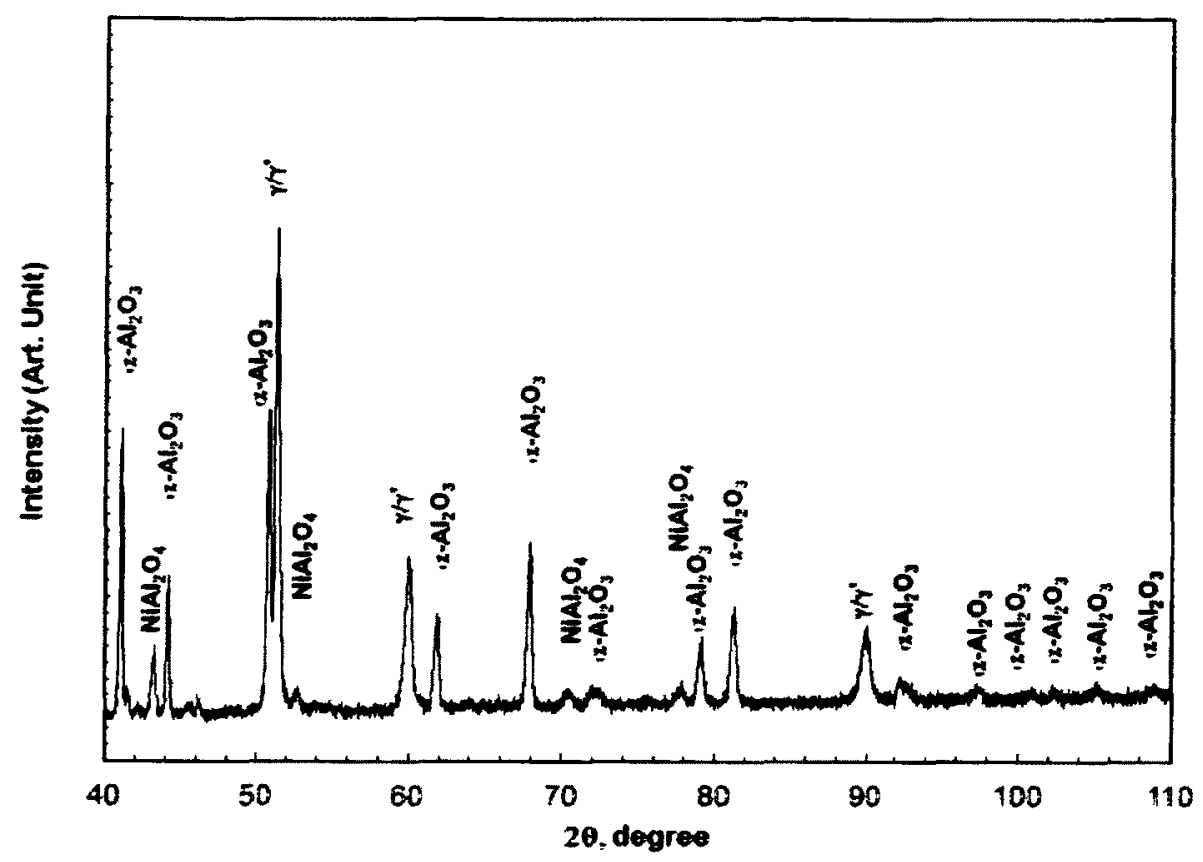

e) XRD spectrum of coating $\mathrm{O} 5$ after $1000 \mathrm{hr}$ exposure at $1050^{\circ} \mathrm{C}$

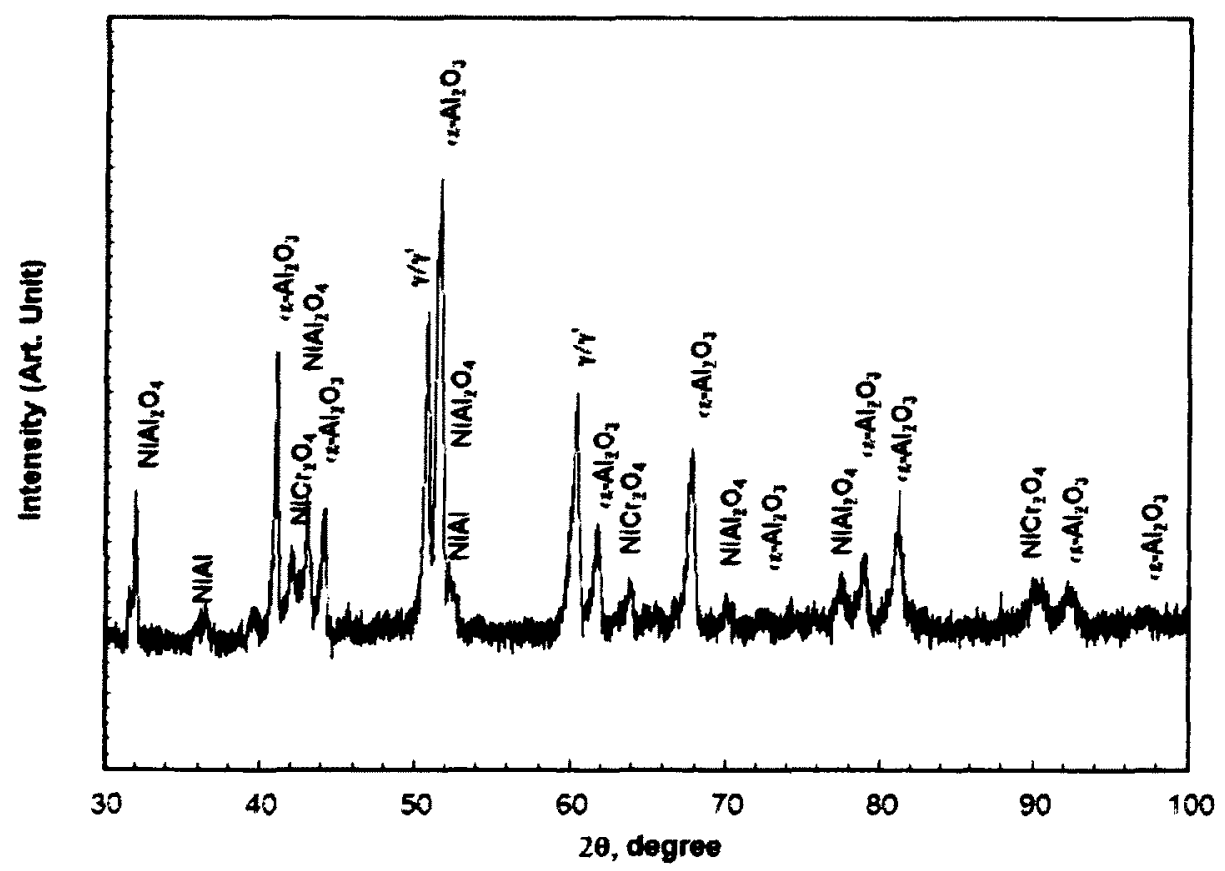

f) XRD spectrum of coating $\mathrm{O} 5$ after $1000 \mathrm{hr}$ exposure at $1150^{\circ} \mathrm{C}$

Figure 7.4 Surface morphologies and XRD spectra of coating 05 .

The EDS results, summarized in Table 7.5, verify that $\mathrm{Al}_{2} \mathrm{O}_{3}$ is the main oxide on the coating surface after $1000 \mathrm{hr}$ exposure at $1050^{\circ} \mathrm{C}$. Figure $7.3 \mathrm{c}$ and Figure $7.4 \mathrm{c}$ show 
the XRD spectra of coatings $\mathrm{O} 2$ and $\mathrm{O} 5$, respectively, after $1000 \mathrm{hr}$ exposure at $1050^{\circ} \mathrm{C}$. Only $\mathrm{Al}_{2} \mathrm{O}_{3}$ was found on the surface of $\mathrm{O} 2$ and $\mathrm{O} 5$ specimens. Also, the top layer of $\mathrm{O} 2$ specimen changed from $\mathrm{Ni}_{2} \mathrm{Al}_{3}$ into $\mathrm{NiAl}$ during $1000 \mathrm{hr}$ exposure at $1050^{\circ} \mathrm{C}$, and the top layer of $\mathrm{O} 5$ coating transformed from $\mathrm{NiAl}$ into $\gamma^{\prime} / \gamma$ during the same exposure.

After $1000 \mathrm{hr}$ exposure at $1150^{\circ} \mathrm{C}$, the mixed oxides (grey region) on the surface of coating $\mathrm{O} 2$ are much less than that on the surface of coating O5 (Figure 7.3d and Figure 7.4d). Figure 7.3f and Figure 7.4f show the $\mathrm{XRD}$ spectra of coatings $\mathrm{O} 2$ and $\mathrm{O}$, respectively; a large amount of $\mathrm{Al}_{2} \mathrm{O}_{3}$ and small amount of $\mathrm{Ni}(\mathrm{Al}, \mathrm{Cr})_{2} \mathrm{O}_{4}$ formed on the surface of coating $\mathrm{O} 2$, whereas the amount of $\mathrm{Ni}(\mathrm{Al}, \mathrm{Cr})_{2} \mathrm{O}_{4}$ on the surface of coating O5 is more than that on the surface of coating $\mathrm{O} 2$. The phases in the top layer changed from $\beta(\mathrm{NiAl})$ phase into $\gamma^{\prime} / \gamma$ phase with certain $\mathrm{NiAl}$ phase remained during the exposure at $1150^{\circ} \mathrm{C}$ for coating 02 . The $\gamma^{\prime} / \gamma$ phase structure in the top layer of $\mathrm{O5}$ remained unchanged, although with lower aluminum content, during the exposure at $1150^{\circ} \mathrm{C}$ for $1000 \mathrm{hr}$. Figure 7.5 to Figure 7.12 illustrate the surface morphologies of other specimens. After $1000 \mathrm{hr}$ exposure at $1050^{\circ} \mathrm{C}$, dark regions and bright regions are observed on the surface of most other coatings; however, the grey regions are also found on specimen $\mathrm{O} 9$ and $\mathrm{O} 10$, which suggests that mixed oxides $\left(\mathrm{Cr}_{2} \mathrm{O}_{3}, \mathrm{NiO}\right.$ and $\mathrm{Ni}(\mathrm{Al}, \mathrm{Cr})_{2} \mathrm{O}_{4}$ formed on the surfaces of specimens $\mathrm{O} 9$ and $\mathrm{O} 10$.

The cross section micrographs of specimens $\mathrm{O} 1, \mathrm{O} 3, \mathrm{O4}, 08$, and $\mathrm{O} 10$ after $1000 \mathrm{hr}$ exposure at $1150^{\circ} \mathrm{C}$ show that the top coating layers have disappeared. The surface morphologies of $\mathrm{O} 1, \mathrm{O} 3, \mathrm{O}$, and $\mathrm{O} 10$ are similar and grey regions become dominant. The surface morphologies of coatings $\mathrm{O} 4$ and $\mathrm{O6}$ are similar and there are considerable 
amounts of dark regions due to the high aluminum contents in the coatings (about 16 at.\% and 20 at.\%, respectively, based on spot analysis of spots $\mathrm{J}$ and $\mathrm{K}$ shown in Table 7.5). For coatings $\mathrm{O} 7$ and $\mathrm{O}$, both with the aluminide II coating and without a NiCrAlY coating, the oxides found in the surfaces are a mixtures of $\mathrm{Al}_{2} \mathrm{O}_{3}(\mathrm{~N}$ and $\mathrm{P}$ in Table 7.4) and $\mathrm{NiO}\left(\mathrm{M}\right.$ and $\mathrm{Q}$ in Table 7.5), after $1000 \mathrm{hr}$ exposure at $1150^{\circ} \mathrm{C}$.

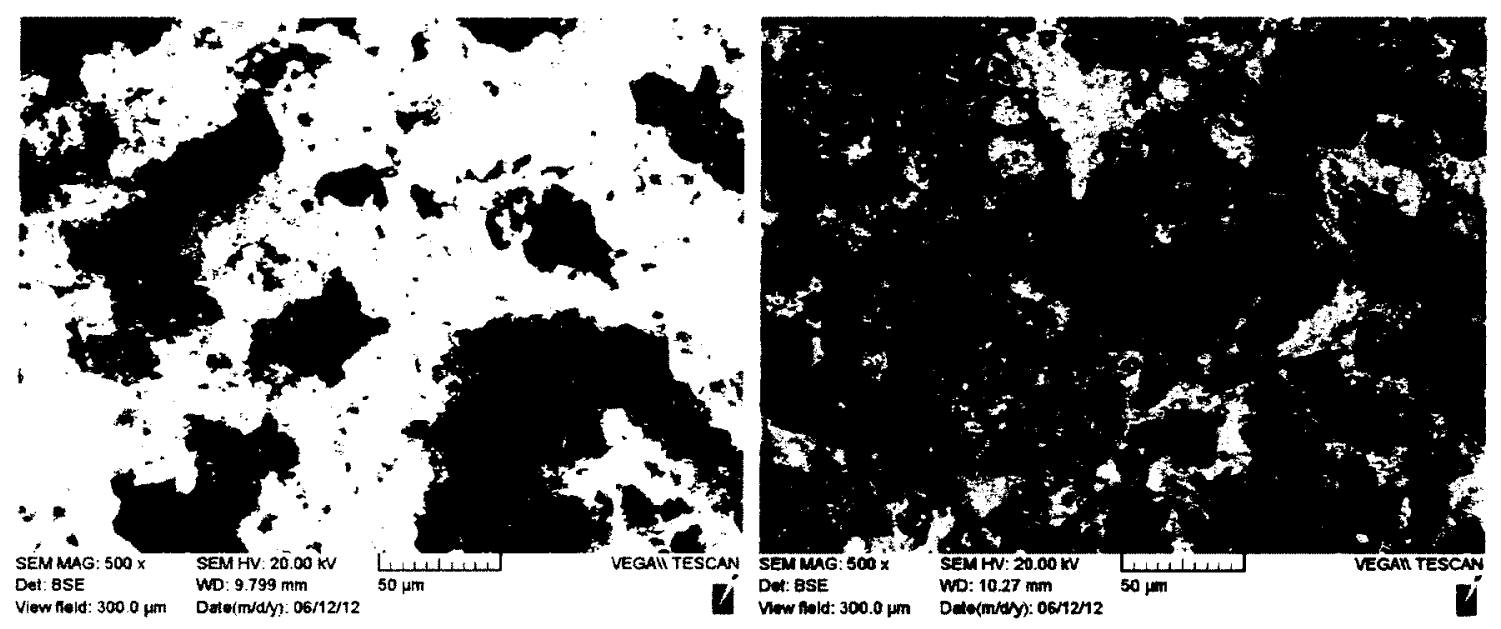

a) After $1000 \mathrm{hr}$ exposure at $1050^{\circ} \mathrm{C}$

b) After $1000 \mathrm{hr}$ exposure at $1150^{\circ} \mathrm{C}$

Figure 7.5 Morphology on the top surface of the coating $O 1$.
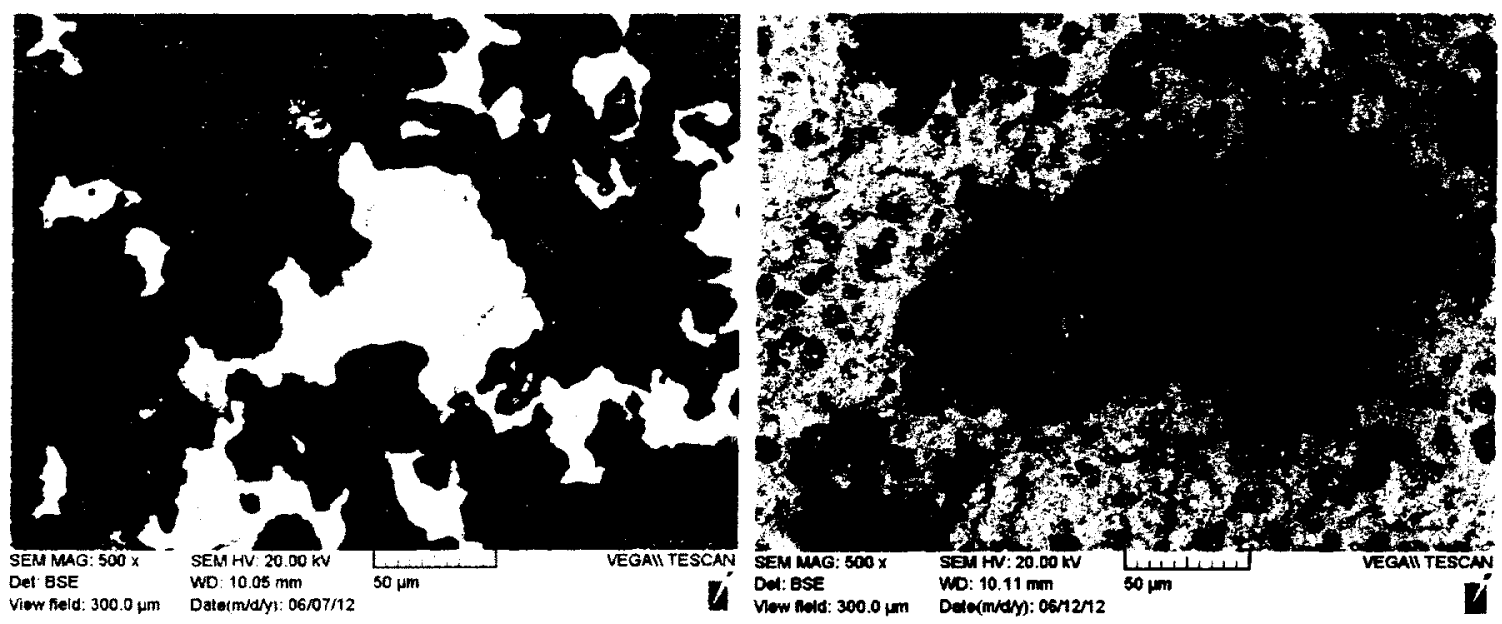

a) After $1000 \mathrm{hr}$ exposure at $1050^{\circ} \mathrm{C}$

b) After $1000 \mathrm{hr}$ exposure at $1150^{\circ} \mathrm{C}$

Figure 7.6 Morphology of coating $\mathrm{O3}$ surface. 


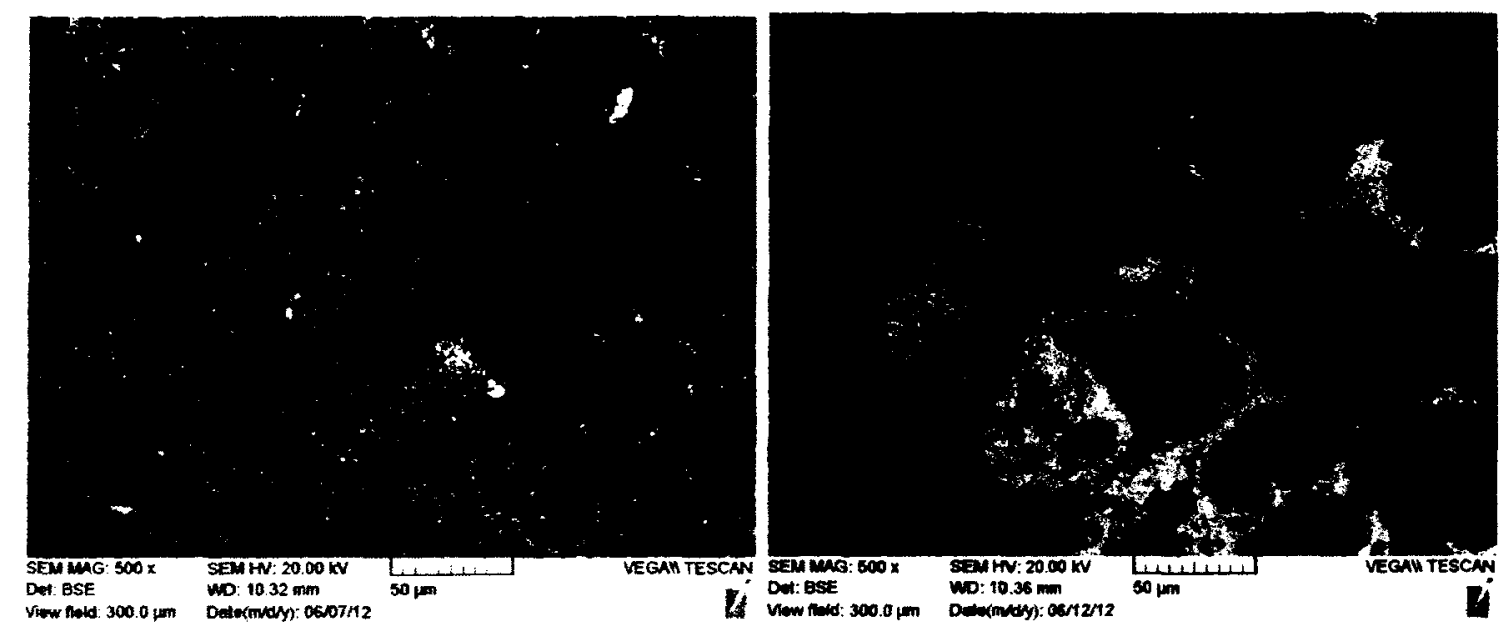

a) After $1000 \mathrm{hr}$ exposure at $1050^{\circ} \mathrm{C} \quad$ b) After $1000 \mathrm{hr}$ exposure at $1150^{\circ} \mathrm{C}$

Figure 7.7 Morphology the coating 04 surface.

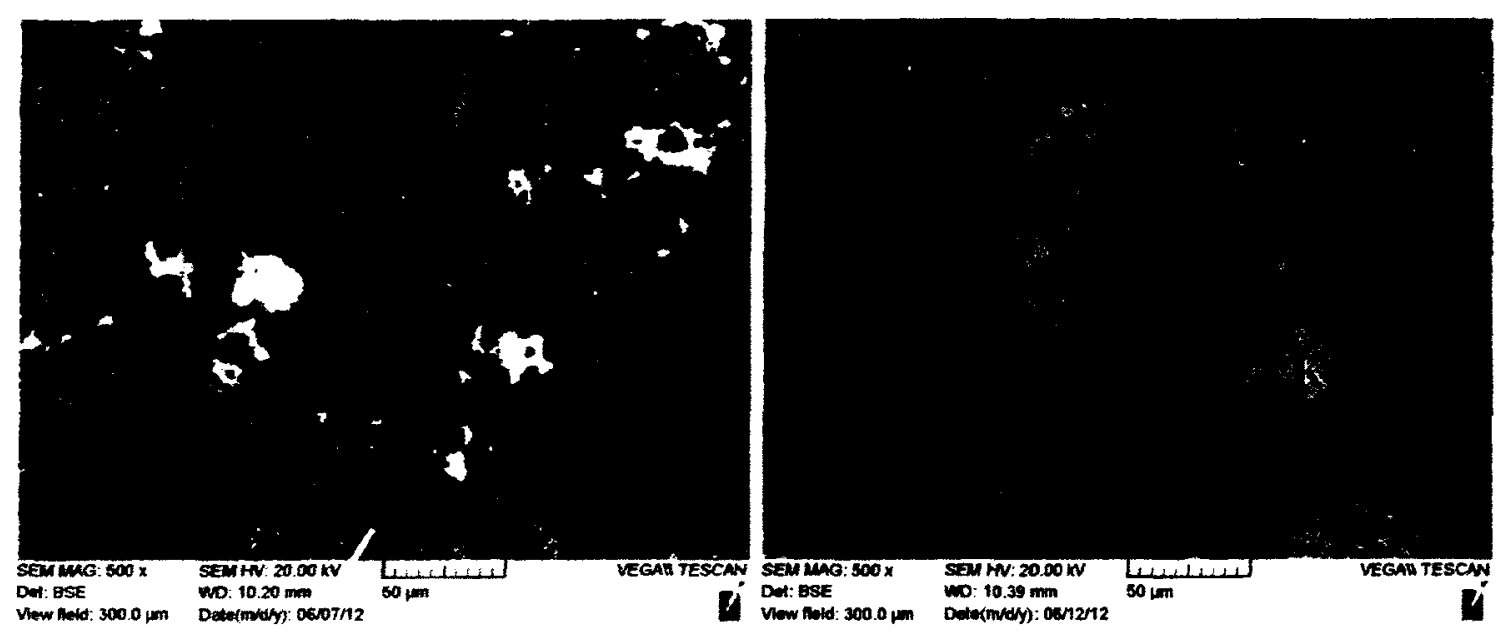
a) After $1000 \mathrm{hr}$ exposure at $1050^{\circ} \mathrm{C}$
b) After $1000 \mathrm{hr}$ exposure at $1150^{\circ} \mathrm{C}$

Figure 7.8 Morphology of coating 06 surface. 


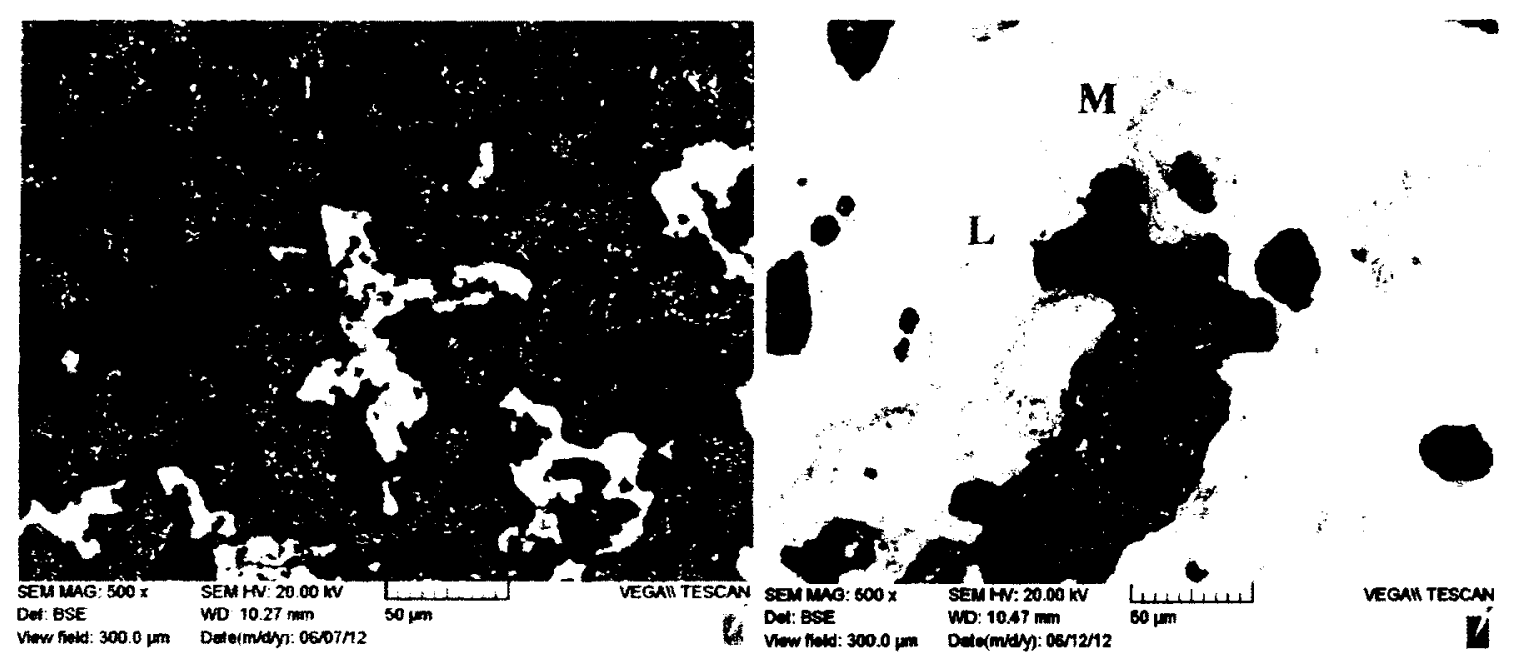
a) After $1000 \mathrm{hr}$ exposure at $1050^{\circ} \mathrm{C}$
b) After $1000 \mathrm{hr}$ exposure at $1150^{\circ} \mathrm{C}$

Figure 7.9 Morphology of coating 07 surface.
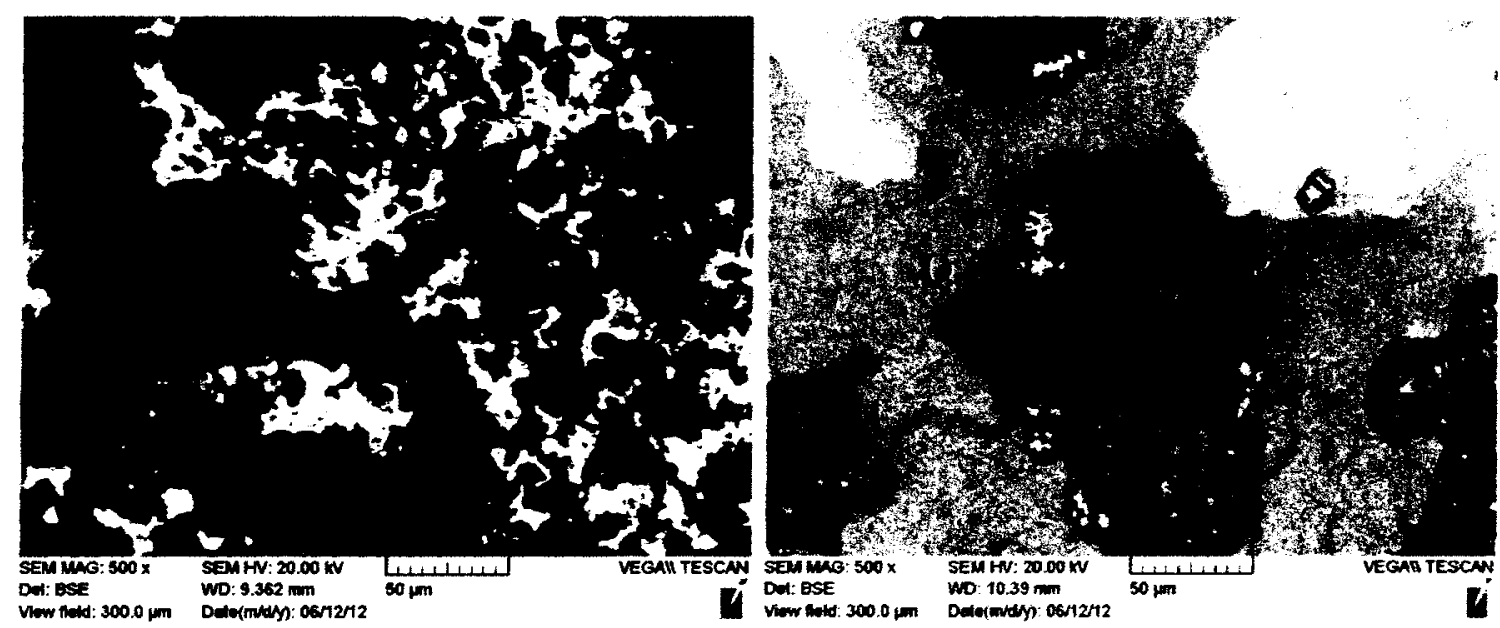
a) After $1000 \mathrm{hr}$ exposure at $1050^{\circ} \mathrm{C}$
b) After $1000 \mathrm{hr}$ exposure at $1150^{\circ} \mathrm{C}$

Figure 7.10 Morphology of coating 08 surface. 


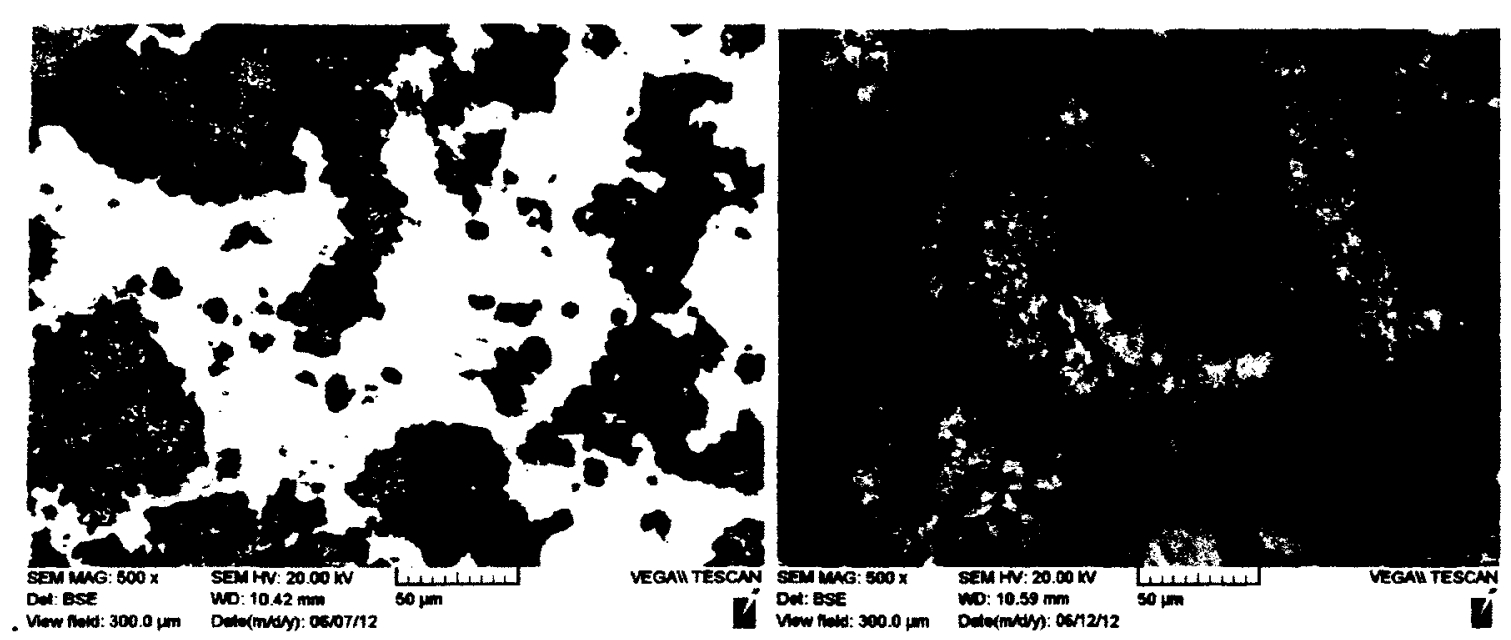

a) After $1000 \mathrm{hr}$ exposure at $1050^{\circ} \mathrm{C} \quad$ b) After $1000 \mathrm{hr}$ exposure at $1150^{\circ} \mathrm{C}$

Figure 7.11 Morphology specimen 09 surface.
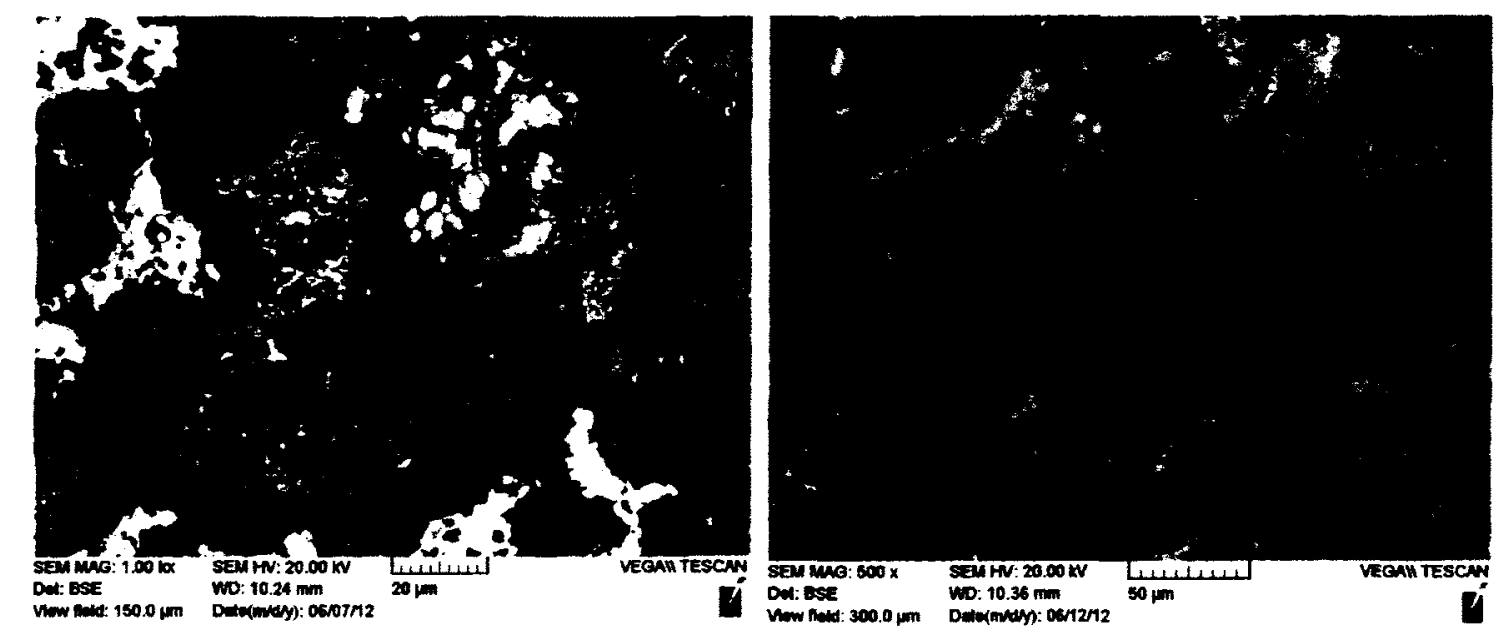

a) After $1000 \mathrm{hr}$ exposure at $1050^{\circ} \mathrm{C}$

b) After $1000 \mathrm{hr}$ exposure at $1150^{\circ} \mathrm{C}$

Figure 7.12 Morphology of coating 010 surface.

\subsection{Effects of Coating Layer on Area of Oxide Scales}

To evaluate the effects of coating layers on the area of oxide scales, the areas of oxide scales of all coatings were measured and characterized. Oxide characterization was started with the measurement of the area of oxide scales on each coating after the oxidation tests. Twenty one (21) cross-sectional micrographs for each coating were taken along the surface of the coating at the same magnification and they were then 
divided into three groups because three data points for each coating were needed for developing the model of the area of oxide scales (More replicates make the model more accurate). Every micrograph was processed using the image analysis software, and the area of oxide scales, the blue region in Figure 7.13 , was measured from each micrograph. To obtain exact area of oxides scales, the first micrograph imported to the image analysis software was calibrated according to the scale on the micrograph, and this calibration was saved as a default mode for processing the rest of the micrographs.

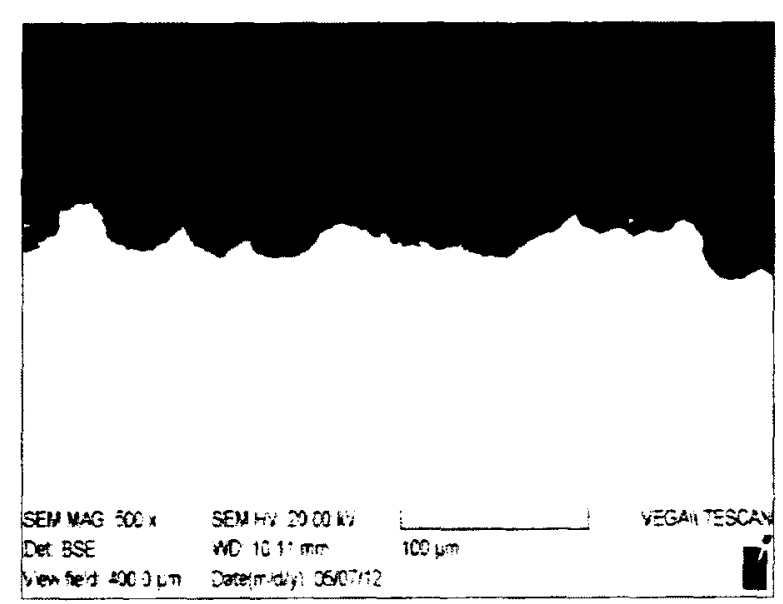

Figure 7.13 Binarized cross sectional image for coating 01 .

The average values of the area representing oxide scales for each of the seven micrographs are given in Table 7.6 and named as the area of oxide scales. Spallation of oxide scales occurred to some of these coatings. If spallation did occur, determination of the actual oxide level before spallation would become necessary; the procedure was developed and is presented in Table 7.7. The purpose of the calculation was to compare the oxygen gain and mass change of the coating. If the oxygen gain of the coating was close to the mass change of the coating, then there was no spallation occurring in this coating; otherwise spallation occurred. 
Table 7.6 Average areas of oxide scales for the seven micrographs in each group

\begin{tabular}{|c|c|c|c|c|}
\hline Coating & $\begin{array}{l}\text { Micrograph } \\
\text { No. }\end{array}$ & $\begin{array}{l}\text { Area of oxide scales } \\
\text { after spallation, } \mu \mathrm{m}^{2}\end{array}$ & $\begin{array}{l}\text { Total area of } \\
\text { oxide scales, } \mu \mathrm{m}^{2}\end{array}$ & Coating type \\
\hline \multirow{3}{*}{ O1-1 } & $1-7$ & 5896.5 & 16711.4 & \multirow{3}{*}{$\begin{array}{l}\text { Cr-Si coating/ } \\
\text { aluminide I }\end{array}$} \\
\hline & $8-15$ & 5237.9 & 16052.8 & \\
\hline & $16-21$ & 5085.6 & 15900.5 & \\
\hline \multirow{3}{*}{ O2-1 } & $1-7$ & 17845.7 & $17845.7^{*}$ & \multirow{3}{*}{$\begin{array}{l}\text { Cr-Si coating/ } \\
\text { NiCrAlY/ } \\
\text { aluminide II }\end{array}$} \\
\hline & $8-15$ & 17481.6 & $17481.6^{*}$ & \\
\hline & $16-21$ & 18597.7 & $18597.7^{*}$ & \\
\hline \multirow{3}{*}{ O3-1 } & $1-7$ & 4601.1 & 6506.9 & \multirow{3}{*}{ aluminide I } \\
\hline & $8-15$ & 4350.6 & 6256.4 & \\
\hline & $16-21$ & 4816.2 & 6722.0 & \\
\hline \multirow{3}{*}{ O4-1 } & $1-7$ & 10741.3 & $10741.3^{*}$ & \multirow{3}{*}{$\begin{array}{l}\text { NiCrAlY/ } \\
\text { aluminide II }\end{array}$} \\
\hline & $8-15$ & 11136.1 & $11136.1^{*}$ & \\
\hline & $16-21$ & 12274.3 & $12274.3^{*}$ & \\
\hline \multirow{3}{*}{ O5-1 } & $1-7$ & 6052.8 & 8894.8 & \multirow{3}{*}{$\begin{array}{l}\mathrm{Cr}-\mathrm{Si} \text { coating } \\
\text { NiCrAlY/ } \\
\text { aluminide I }\end{array}$} \\
\hline & $8-15$ & 6085.4 & 8927.4 & \\
\hline & $16-21$ & 5565.3 & 8407.3 & \\
\hline \multirow{3}{*}{ O6-1 } & $1-7$ & 6401.3 & 13094.8 & \multirow{3}{*}{$\begin{array}{l}\text { NiCrAlY/ } \\
\text { aluminide I }\end{array}$} \\
\hline & $8-15$ & 6939.2 & 13632.7 & \\
\hline & $16-21$ & 6534.1 & 13227.6 & \\
\hline \multirow{3}{*}{$07-1$} & $1-7$ & 4468.2 & $4468.2^{*}$ & \multirow{3}{*}{ aluminide II } \\
\hline & $8-15$ & 4547.3 & $4547.3^{*}$ & \\
\hline & $16-21$ & 4384.5 & $4384.5^{*}$ & \\
\hline \multirow{3}{*}{ O8-1 } & $1-7$ & 3188.7 & 11015.7 & \multirow{3}{*}{$\begin{array}{l}\text { Cr-Si coating/ } \\
\text { aluminide II }\end{array}$} \\
\hline & $8-15$ & 3445.8 & 11272.8 & \\
\hline & $16-21$ & 3834.1 & 11661.1 & \\
\hline
\end{tabular}

*Spallation might not occur.

The mass of oxygen gain per square centimeter was used as a criterion to determine the spallation of oxide scales. Based on the difference between the measured mass change and the oxygen gain, spallation of oxide scales did occur in most of the coatings, except for $\mathrm{O} 2, \mathrm{O} 4$ and 07 . The area of the spalled oxide scales (before spallation) was calculated following the reversed steps in Table 7.7. The total area of oxide scales in a coating was then obtained by summing up the area of the remaining 
oxide scales and the area of the spalled oxide scales. The final results are given in Table 7.6 .

Table 7.7 Area calculation of oxide scale in a coating specimen

\begin{tabular}{|c|c|c|}
\hline \multirow{3}{*}{$\begin{array}{l}\text { Procedure } \\
\text { Calculating the average } \\
\text { area of oxide scales per } \\
\text { image field }\end{array}$} & Calculation & Note \\
\hline & $(17845.7+17481.6+18597.7) \times 2$ & \multirow{2}{*}{$\begin{array}{l}\text { Both sides of the } \\
\text { coating are } \\
\text { considered. }\end{array}$} \\
\hline & $\begin{array}{c}3 \times 10^{6} \\
=35.95 \times 10^{-3} \mathrm{~mm}^{2}\end{array}$ & \\
\hline $\begin{array}{l}\text { Calculating the volume } \\
\text { of oxide per image } \\
\text { field }\end{array}$ & $\begin{array}{l}35.95 \times 0.001 \times 1 \mathrm{~mm}(\text { depth }) \\
=35.95 \times 10^{-3} \mathrm{~mm}^{3}\end{array}$ & $\begin{array}{l}\text { Assuming } 1 \mathrm{~cm} \\
\text { depth of the scale }\end{array}$ \\
\hline \multirow{2}{*}{$\begin{array}{l}\text { Calculating the volume } \\
\text { of oxide scales per } \\
\text { square } \mathrm{cm}\end{array}$} & $35.95 \times 10^{-3}$ & \multirow{2}{*}{$\begin{array}{l}\text { The horizontal } \\
\text { length for the field } \\
\text { of each micrograph } \\
\text { is } 400 \mu \mathrm{m} \text {. }\end{array}$} \\
\hline & $\begin{aligned} 400 \times 10^{-3} & =8.99 \mathrm{~mm}^{3} / \mathrm{cm}^{2} \\
& \end{aligned}$ & \\
\hline $\begin{array}{l}\text { Calculating the mass of } \\
\text { oxide scales per square } \\
\text { centimeter }\end{array}$ & $8.99 \times 4.0=35.95 \mathrm{mg}$ & $\begin{array}{l}\text { The density of } \mathrm{Al}_{2} \mathrm{O}_{3} \\
\text { is } 4 \mathrm{mg} / \mathrm{mm}^{3}\end{array}$ \\
\hline $\begin{array}{l}\text { Calculating the mass of } \\
\text { oxygen per square } \\
\text { centimeter }\end{array}$ & $\begin{array}{r}35.95 \times \frac{16 \times 3}{16 \times 3+27 \times 2} \\
=16.92 \mathrm{mg}\end{array}$ & $\begin{array}{l}\text { The atomic mass for } \\
\mathrm{O} \text { and } \mathrm{Al} \text { is } 16 \text { and } \\
27\end{array}$ \\
\hline $\begin{array}{l}\text { Calculating the mass of } \\
\text { oxygen per square } \\
\text { centimeter due to } \\
\text { porosity of oxide }\end{array}$ & $16.92 \times 0.8=13.44$ & $\begin{array}{l}\text { The porosity of } \\
\mathrm{Al}_{2} \mathrm{O}_{3} \text { is assumed to } \\
\text { be } 20 \% \text {. }\end{array}$ \\
\hline $\begin{array}{l}\text { Determining the } \\
\text { spallation of oxide } \\
\text { scales }\end{array}$ & $\begin{array}{l}\Delta w=O_{g}-A l_{l} \\
A l_{l}=O_{g}-\Delta w \\
\text { lf } O_{g} \geq \Delta w, \text { spallation occurs } \\
13.44\left(O_{g)}<13.81\left(A l_{l}\right), \text { therefore }\right. \\
\text { no spallation }\end{array}$ & $\begin{array}{l}\text { The mass of oxygen } \\
\text { per square } \\
\text { centimeter is used as } \\
\text { a criterion to } \\
\text { determine if } \\
\text { spallation has } \\
\text { occurred }\end{array}$ \\
\hline
\end{tabular}

The total areas of oxide scales in Table 7.6 were used for the analysis of variance and development of a model that is related to the coating types. The ANOVA results for the total area of oxide scales are given in Table 7.8. The $R^{2}$ value shows that the model and the experimental data have a very high degree of fitness. The $p$-values for 
the factors and the interactions of all factors are close to zero, which indicates all factors and their interactions are significant.

Table 7.8 ANOVA results for oxide scales

\begin{tabular}{|c|c|c|c|c|c|}
\hline Source & DOF & $\begin{array}{l}\text { Sum of } \\
\text { squares }\end{array}$ & $\begin{array}{l}\text { Mean } \\
\text { square }\end{array}$ & $F$ value & $p$-value \\
\hline Main effect, $U, V, W$ & 3 & 192278620 & 64092873 & 348.06 & 0.000 \\
\hline $\begin{array}{l}\text { Interaction between two } \\
\text { factors, } U V, U W, V W\end{array}$ & 3 & 181212283 & 60404094 & 328.03 & 0.000 \\
\hline $\begin{array}{l}\text { Interaction between three } \\
\text { factors, } U V E\end{array}$ & 1 & 73950360 & 7395036 & 401.59 & 0.000 \\
\hline Residual & 16 & 2946306 & 184144 & & \\
\hline Total & 23 & 450387569 & & & \\
\hline$R^{2}$ & $99.35 \%$ & & & & \\
\hline
\end{tabular}

Some effects, sequential SS, and percent contributions for the total areas of oxide scales are presented in Table 7.9. Judging from the results, it is concluded that:

- All main factors and their interactions increased the total area of oxide scales except that the interaction of $\mathrm{Cr}$-Si layer and $\mathrm{NiCrAlY}$ reduced the total area of oxide scales.

- The interaction terms dominated the total area of oxide scales as the summation of the percent contributions of all the interaction terms were over $50 \%$.

- The Cr-Si layer increased the total area of oxide scales.

- Higher Al/Ni ratio hardly increased the total area of oxide scales.

The total area of oxide scales $\left(Y_{O}\right)$ with respect to the coating types is illustrated in the following regression equation:

$$
\begin{gathered}
Y_{O}=6495.17+9726.47 \times U+6823.20 \times V-2028.42 \times W-14301.60 \times \\
U \times V-2876.61 \times U \times W+93.94 \times V \times W+14042.80 \times U \times V \times W
\end{gathered}
$$


When the variable $W$ is set to be zero (aluminide I) or one (aluminide II), two regression equations, $Y_{O I}$ and $Y_{O I I}$, can be obtained as the follows:

$$
\begin{aligned}
& Y_{O I}=6495.17+9726.47 \times U+6823.20 \times V-14301.60 \times U \times V \\
& Y_{O I I}=4466.75+6849.86 \times U+6728.26 \times V-258.8 \times U \times V
\end{aligned}
$$

Table 7.9 Effect, sequential SS, and percent contribution of factors and

$$
\text { interactions for the total areas of oxide scales }
$$

\begin{tabular}{lrll}
\hline Factor & Effect & Sequential sums of squares & Percent contribution \\
\hline$U$ & 4648 & 129628066 & 28.78 \\
$V$ & 3230 & 62600926 & 13.90 \\
$W$ & 91 & 49629 & 0.01 \\
$U V$ & -3640 & 79500957 & 17.65 \\
$U W$ & 2072 & 25769048 & 5.72 \\
$V W$ & 3558 & 75942278 & 16.86 \\
$U V W$ & 3511 & 73950360 & 16.42 \\
\hline
\end{tabular}

Based on two equations, both variables $U$ and $V$ increase the total area of oxide scales, whereas the interaction between $U$ and $V$ decreases the total area of oxide scales. It is noted that the interaction term in equation (7-5) is the dominant term. This suggests that when a multilayered coating consists of a top layer of aluminide I and a NiCrAlY middle layer, the interaction between the $\mathrm{Cr}$-Si layer and the NiCrAlY layer substantially decreases the total area of oxide scales. The reason for this occurrence is that the $\mathrm{Cr}$ layer and $\mathrm{Si}$ rich layer prevented aluminum from diffusing into IN738 as such the top layer remained the NiAl phase for extended period of time. The NiAl phase is known to have better oxidation resistance than the $\mathrm{Ni}_{3} \mathrm{Al}_{2}$ phase as aluminum content is reduced during the phase transition from $\mathrm{Ni}_{3} \mathrm{Al}_{2}$ to $\beta$ (NiAl [113]. This can be further observed in the contour plot of equation (7-5) (Figure 7.14a). The total area of 
oxide scales for the coating with a $\mathrm{Cr}$-Si layer (O5) is less than that of the coating without the $\mathrm{Cr}-\mathrm{Si}$ layer (O6).

When a multilayered coating consists of a top layer of aluminide II and a middle layer of NiCrAlY, the total area of oxide scales of the multilayered coating increases significantly in comparison to that with aluminide I as top layer (Figure 7.14b). The interaction between the $\mathrm{Cr}-\mathrm{Si}$ layer and the NiCrAlY layer hardly decreases the total area of oxide scales since the coefficient for the interaction term in equation $(7-6)$ is very small. This is because the Cr-Si layer prevented aluminum from diffusing into the IN738 substrate, thus the phase in the top layer of the multilayered coating was mainly the $\mathrm{Ni}_{3} \mathrm{Al}_{2}$ phase at the beginning of the oxidation test, which was easier to be oxidized before it can be transformed into the $\mathrm{NiAl}$ phases. Therefore the effect of the interaction between the $\mathrm{Cr}-\mathrm{Si}$ layer and the NiCrAlY layer on the total area of oxide scales of a multilayered coating become significant only when the top layer is an aluminide I layer.

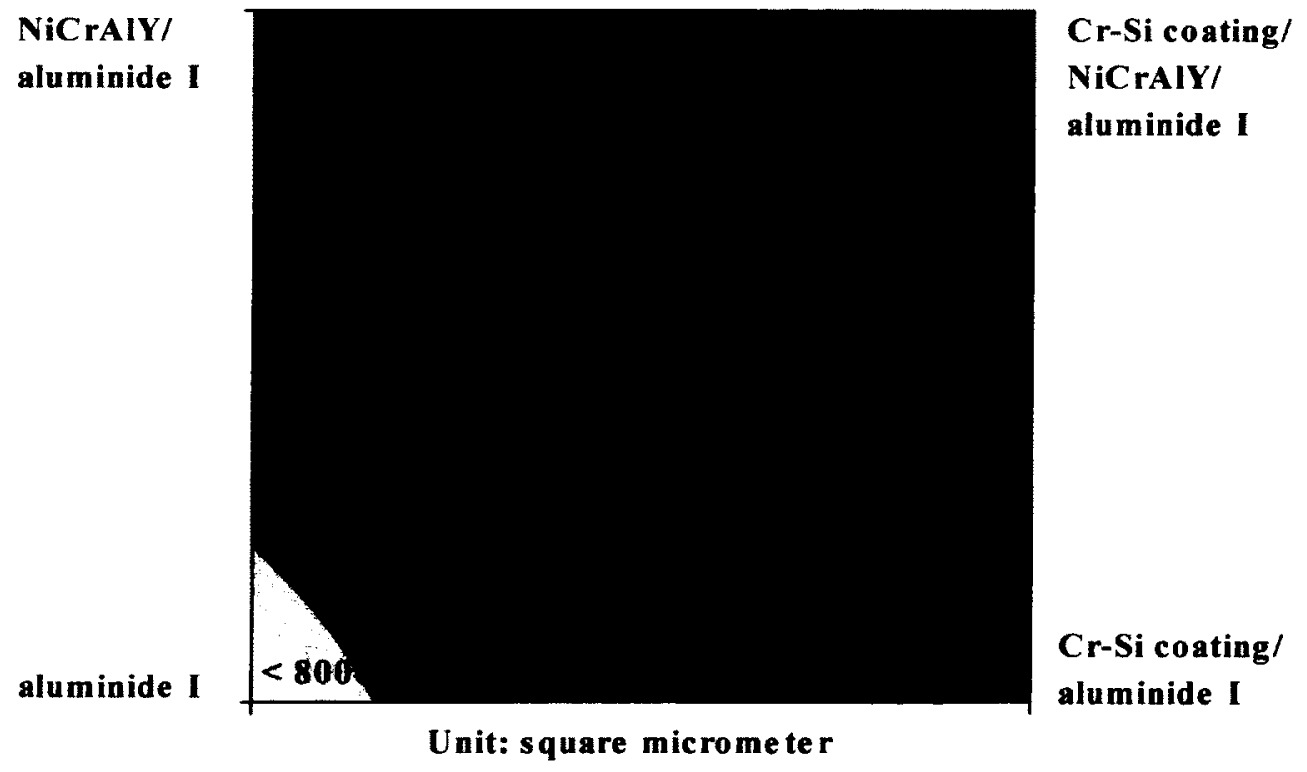

a) Contour plot of oxide scale area for the coatings with aluminide I top coat 


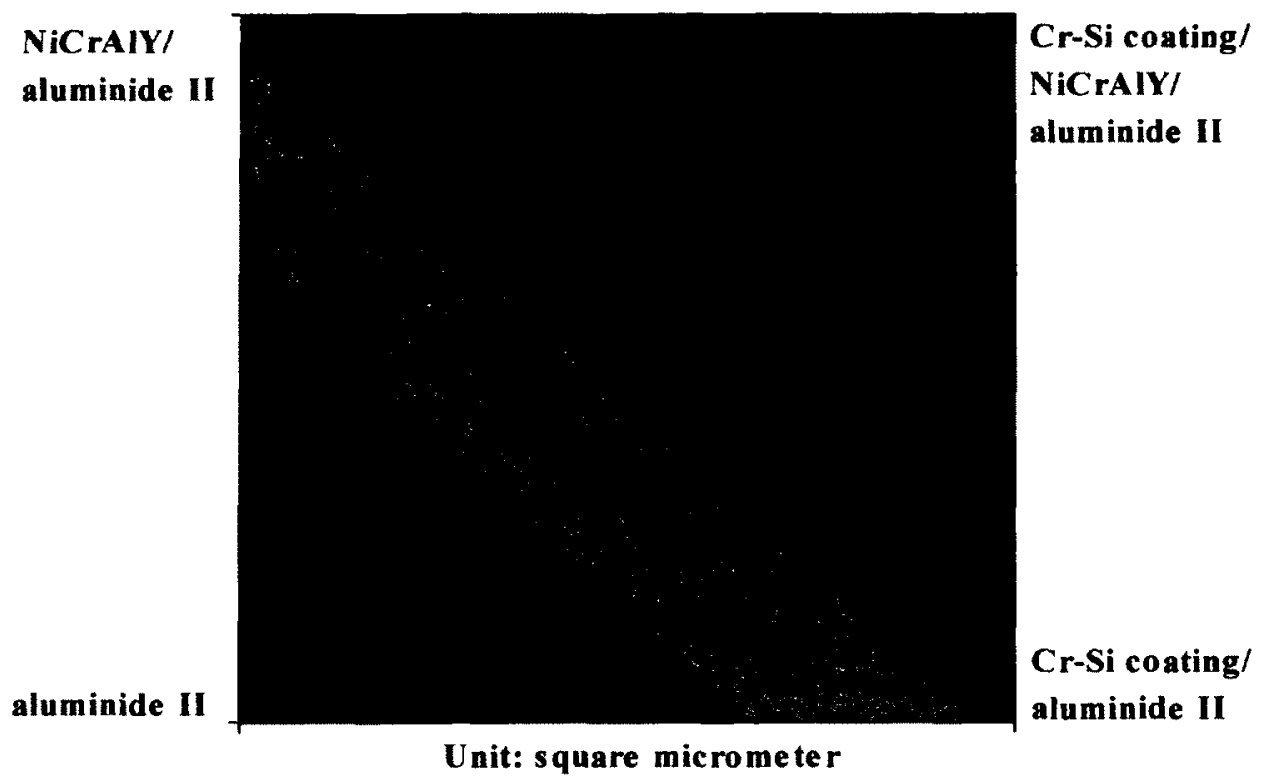

b) Contour plot of oxide scale area for the coatings with aluminide II top coat

Figure 7.14 Contour plots of the oxide scale area.

\subsection{Characterization of Cr-Si Barrier Layer}

\subsubsection{Structure of Barrier Layer}

As detailed in previous sections, the mass changes and total areas of oxide scale are significantly associated with the interaction between adjacent coatings and number of coating layers. Therefore it is crucial to understand the mechanism of the interaction between coating layers. The elemental distribution analysis can be an approach to studying the interaction of the coatings [114]. Using the elemental distribution analysis, the barrier function of a $\mathrm{Cr}$-Si coating during diffusion process has been verified in Chapter 6.

During the oxidation test, the silicon contents decreased to about 15 at.\% from the original $20-30$ at.\% due to diffusion. According to the $\mathrm{Ni}-\mathrm{Cr}-\mathrm{Si}$ ternary diagram, when the chromium content at the interface between the NiCrAlY coating and the $\mathrm{Cr}-\mathrm{Si}$ 
coating increased to over 40 at. $\%$, silicon-rich phases $\left(\mathrm{Ni}_{2} \mathrm{Si}, \mathrm{Cr}_{3} \mathrm{Ni}_{2} \mathrm{Si}\right.$, and $\left.\mathrm{Cr}_{3} \mathrm{Ni}\right)$ will form. The boundary layer of IN738 substrate was found to have transformed into $\psi$ $\left(\mathrm{C}_{2} \mathrm{Ni}_{3} \mathrm{Si}\right)$ phase after $\mathrm{Cr}-\mathrm{Si}$ co-deposition. This silicon-rich layer was stable and prevente chromium from diffusing into the substrate [12]. Therefore the barrier layer in fact consisted of a $\mathrm{Cr}$ layer and a silicon-rich layer. To maintain the barrier function of the barrier layer in a coating under oxidation environment, two aspects must be satisfied:

(1) The chromium content in the coating should not significantly decrease.

(2) The layer containing chromium and silicon-rich phases between $\mathrm{Cr}-\mathrm{Si}$ barrier layer and NiCrAlY should be stable.

The chromium content in a coating significantly changes when internal $\mathrm{Cr}_{2} \mathrm{O}_{3}$ oxide starts to form [115]. When the aluminum content in the coating falls below 21 at.\%, internal $\mathrm{Cr}_{2} \mathrm{O}_{3}$ oxide will form. Therefore, the aluminum content in a coating can be regarded as a governing factor for the stability of chromium and silicon-rich $\gamma$ phase.

\subsubsection{Elemental Distributions in Coatings without NiCrAlY Layer}

The aluminum contents in all coatings with a $\mathrm{Cr}-\mathrm{Si}$ layer were all above 21 at.\% except coating $\mathrm{O} 1$ after $1000 \mathrm{hr}$ at $1050^{\circ} \mathrm{C}$ (Table 7.4). The examination of the aluminum and chromium contents in coating $\mathrm{O} 1$ indicated significant decreases of both elements after the oxidation test (Figure 7.15b). Compared with other coatings, the aluminum content in coating $\mathrm{O} 1$ before the oxidation test was lower and the thickness of the coating layer with high aluminum content $(21$ at. $\% \mathrm{Al})$ was also thinner $(10 \mu \mathrm{m})$ due to the low aluminum solubility in the $\mathrm{Cr}-\mathrm{Si}$ phase. As such the aluminum in coating O1 was quickly exhausted during the oxidation test causing internal chromium 
oxidation. Moreover the formation of chromium-rich phases (phase A in Figure 7.15a with about 25 at. $\% \mathrm{Cr}$ ) further depleted the chromium content in the coating layer and deteriorated the oxidation resistance of coating $\mathrm{O} 1$. Instead of functioning as a barrier layer, chromium-rich phase (phase $\mathrm{A}$ in Figure 7.15a) and silicon-rich phase (phase B in Figure 7.15a) were separately precipitated in the coating matrix. Therefore without a middle layer of $\mathrm{NiCrAlY}$, the $\mathrm{Cr}-\mathrm{Si}$ coating quickly deteriorated and compromised the oxidation resistance of the coating.

The coating without a $\mathrm{Cr}-\mathrm{Si}$ layer, coating $\mathrm{O} 3$, contained more aluminum before and after the oxidation test (Figure 7.16b). This was further supported by the changes of the chromium contents in coatings $\mathrm{O} 1$ and $\mathrm{O} 3$ after $1000 \mathrm{hr}$ exposure at $1050^{\circ} \mathrm{C}$, as shown in Figure 7.16c. The decrease in the chromium content in coating $\mathrm{O} 1$ after the exposure was more significant than that in coating $\mathrm{O} 3$, which indicated more chromium oxides formed and subsequently evaporated at the elevated temperatures.

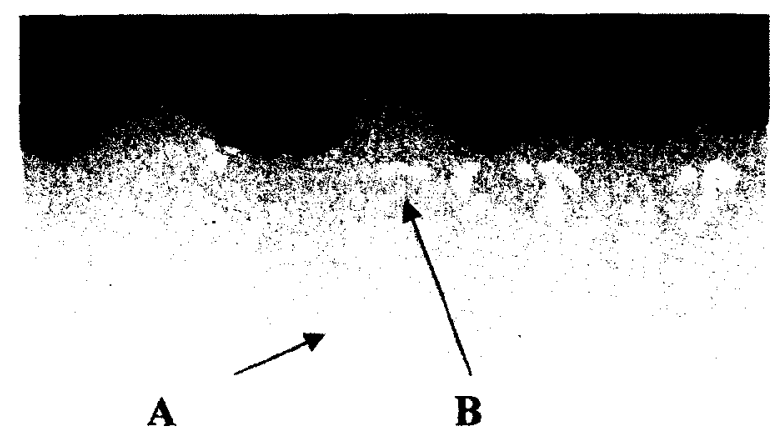

A

B

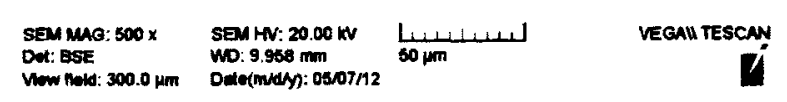

a) SEM image 


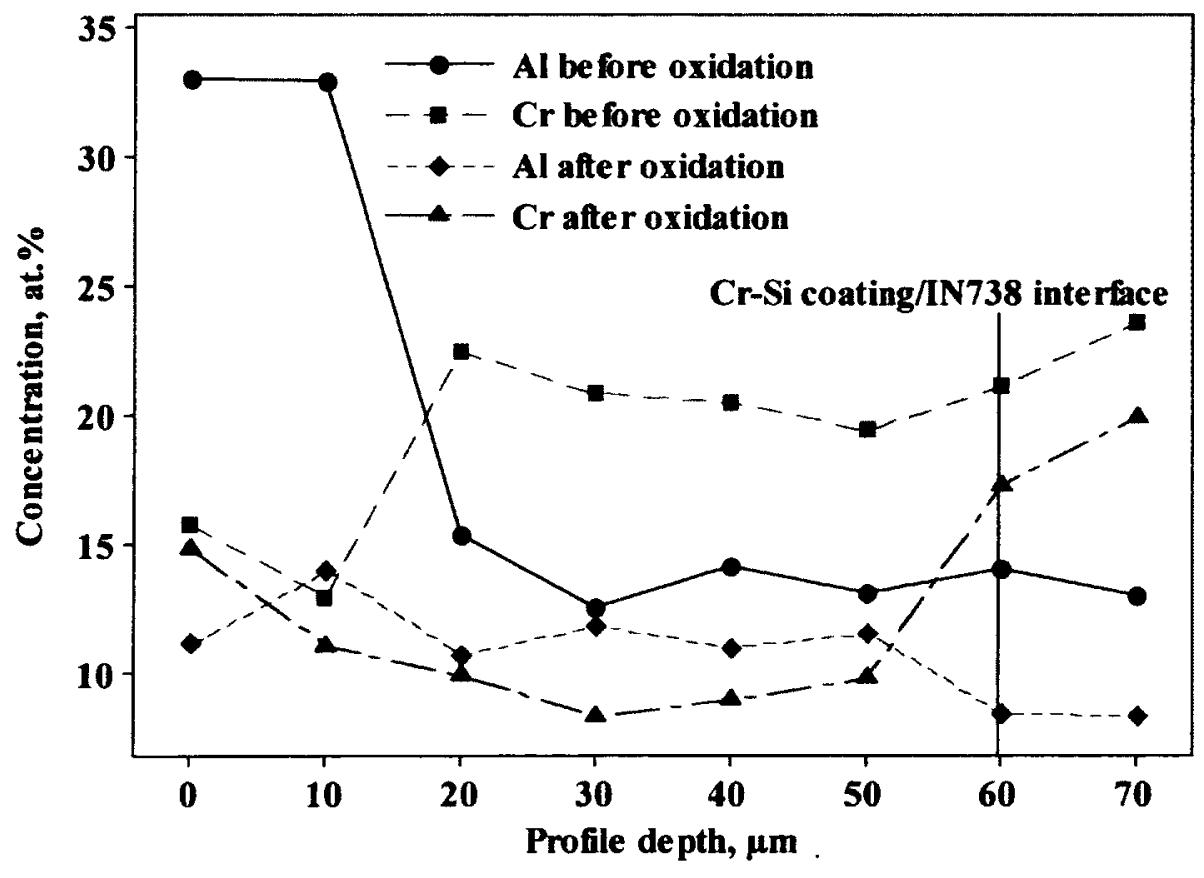

b) Concentration profiles of $\mathrm{Cr}$ and $\mathrm{Al}$

Figure 7.15 Al and $\mathrm{Cr}$ concentration analyses in coating $\mathrm{O1}(\mathrm{Cr}-\mathrm{Si}$ coating/aluminide I) after $1000 \mathrm{hr}$ exposure at $1050^{\circ} \mathrm{C}$.

Coating 08 had a similar microstructure to coating 01 except that the aluminum content in coating $\mathrm{O} 8$ was much higher before and after the oxidation test. In addition, more chromium-rich and silicon-rich phases formed on the top layer of coating $\mathrm{O8}$ (Figure 7.17). This observation suggests internal chromium oxidation might not have occurred, although the formation of the chromium-rich phases further depleted the chromium content in the coating matrix.

Compared with coating O8, Figure 7.18 showed that coating O7 (without a $\mathrm{Cr}-\mathrm{Si}$ barrier layer) had fewer chromium-rich precipitates (phase $\mathrm{C}$ and $\mathrm{D}$ in Figure 7.16a and phase $F$ in Figure 7.17a) in and the aluminum content was higher before and after the oxidation test, resulting in less mass loss and lower area of oxide scales in coating 07. 
Table 7.10 EDS results of various phases in the coatings

\begin{tabular}{|c|c|c|c|c|c|c|c|c|c|}
\hline \multirow[t]{2}{*}{ Phase } & \multicolumn{9}{|c|}{ Concentration, at. $\%$} \\
\hline & $\mathrm{O}$ & $\mathrm{Al}$ & $\mathrm{Cr}$ & $\mathrm{Ni}$ & $\mathrm{Ti}$ & $\mathrm{Si}$ & Co & Mo & $\mathrm{W}$ \\
\hline A & & & 25.09 & 28.92 & 5.82 & 17.74 & 4.75 & 8.55 & 9.14 \\
\hline B & & 1.73 & 2.69 & 48.96 & 11.51 & 26.87 & 4.89 & $\mathrm{Nb} 3.35$ & \\
\hline $\mathrm{C}$ & & 1.41 & 43.65 & 26.12 & 2.34 & 9.93 & 10.27 & 3.70 & 2.59 \\
\hline D & & 1.54 & 21.61 & 27.65 & 6.28 & 18.00 & 5.45 & 10.12 & 9.36 \\
\hline $\mathrm{E}$ & & 1.73 & 22.19 & 27.27 & 6.34 & 17.35 & 5.71 & 9.67 & 9.71 \\
\hline $\mathrm{F}$ & & 1.52 & 52.93 & 20.47 & 0.54 & & 13.10 & 6.43 & 5.00 \\
\hline G & & & 86.53 & 4.69 & & & 1.56 & 3.24 & 3.97 \\
\hline $\mathrm{H}$ & & 25.79 & 6.47 & 58.80 & 2.46 & 2.27 & 4.20 & & \\
\hline I & & & 23.20 & $28 . .93$ & 6.07 & 19.99 & 4.39 & 9.58 & 7.83 \\
\hline J & & 2.30 & 53.99 & 21.50 & & & 5.90 & 4.39 & \\
\hline $\mathrm{K}$ & & & 85.37 & 4.38 & & & 1.82 & 4.17 & \\
\hline $\mathrm{L}$ & & 2.54 & 20.62 & 26.65 & 7.27 & 18.20 & 4.25 & 11.10 & 9.38 \\
\hline M & & & 29.17 & 30.13 & 5.58 & 16.74 & & 7.33 & 7.39 \\
\hline $\mathrm{N}$ & & 1.37 & 2.92 & 50.07 & 11.36 & 26.70 & 4.53 & $\mathrm{Nb} 3.05$ & \\
\hline $\mathrm{Z}$ & 50.94 & 33.16 & 2.62 & 10.02 & 1.07 & 1.31 & 0.89 & & \\
\hline
\end{tabular}
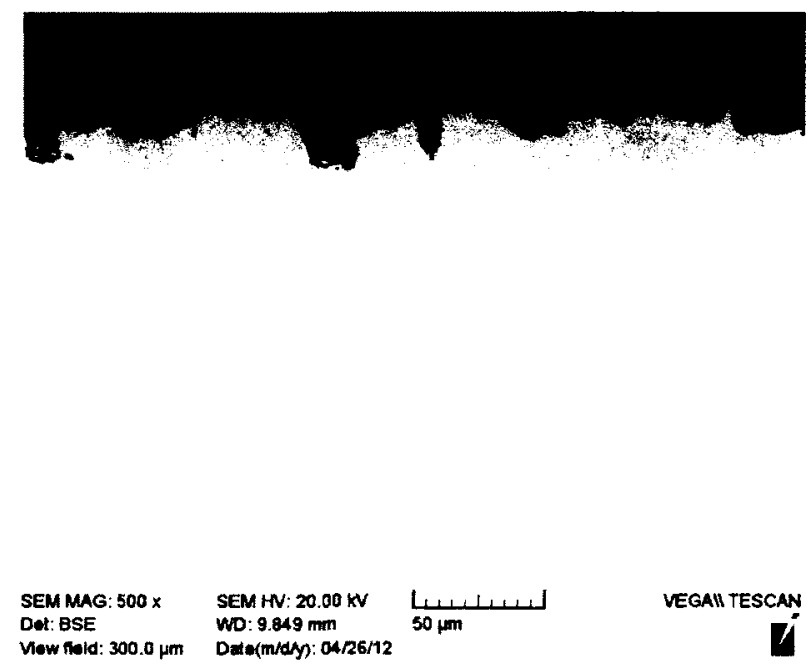

a) SEM image of coating $\mathrm{O} 3$ 


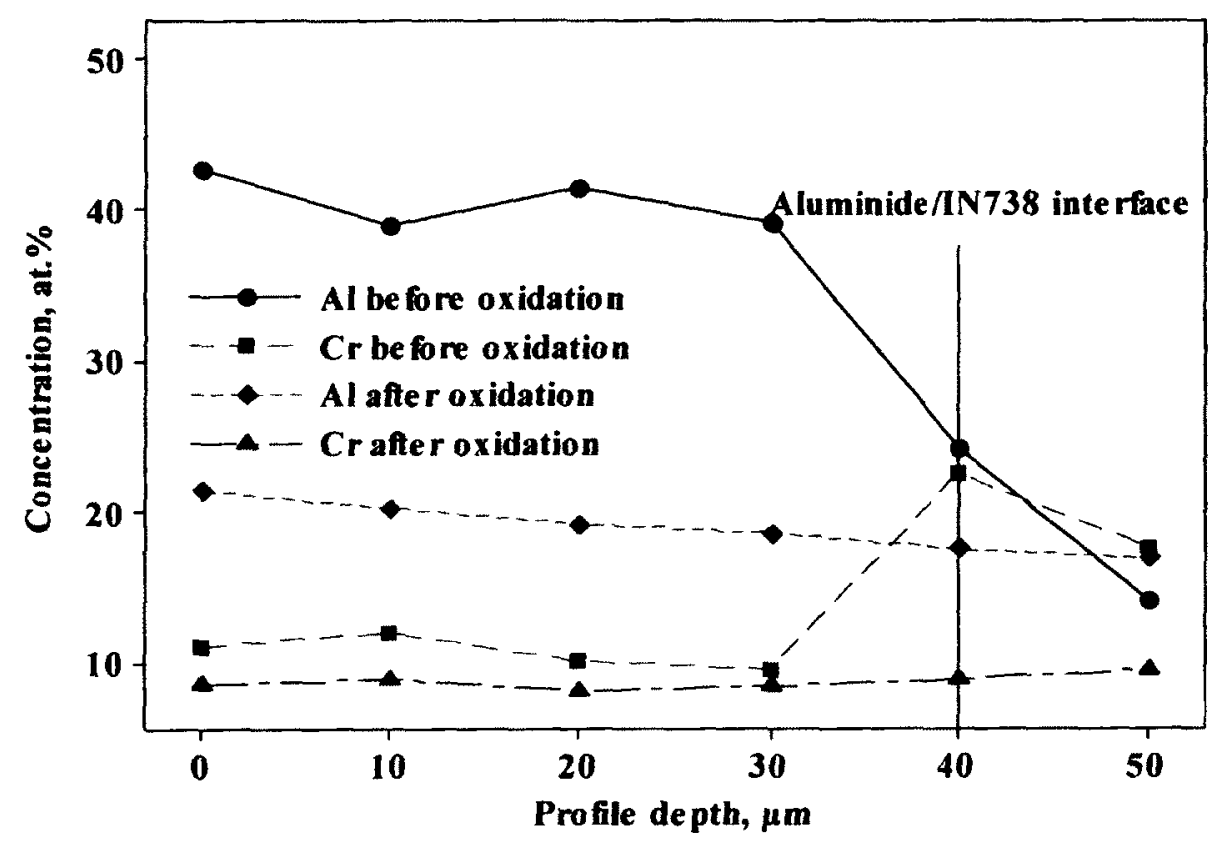

b) Concentration profiles of $\mathrm{Al}$ and $\mathrm{Cr}$ in coating $\mathrm{O} 3$

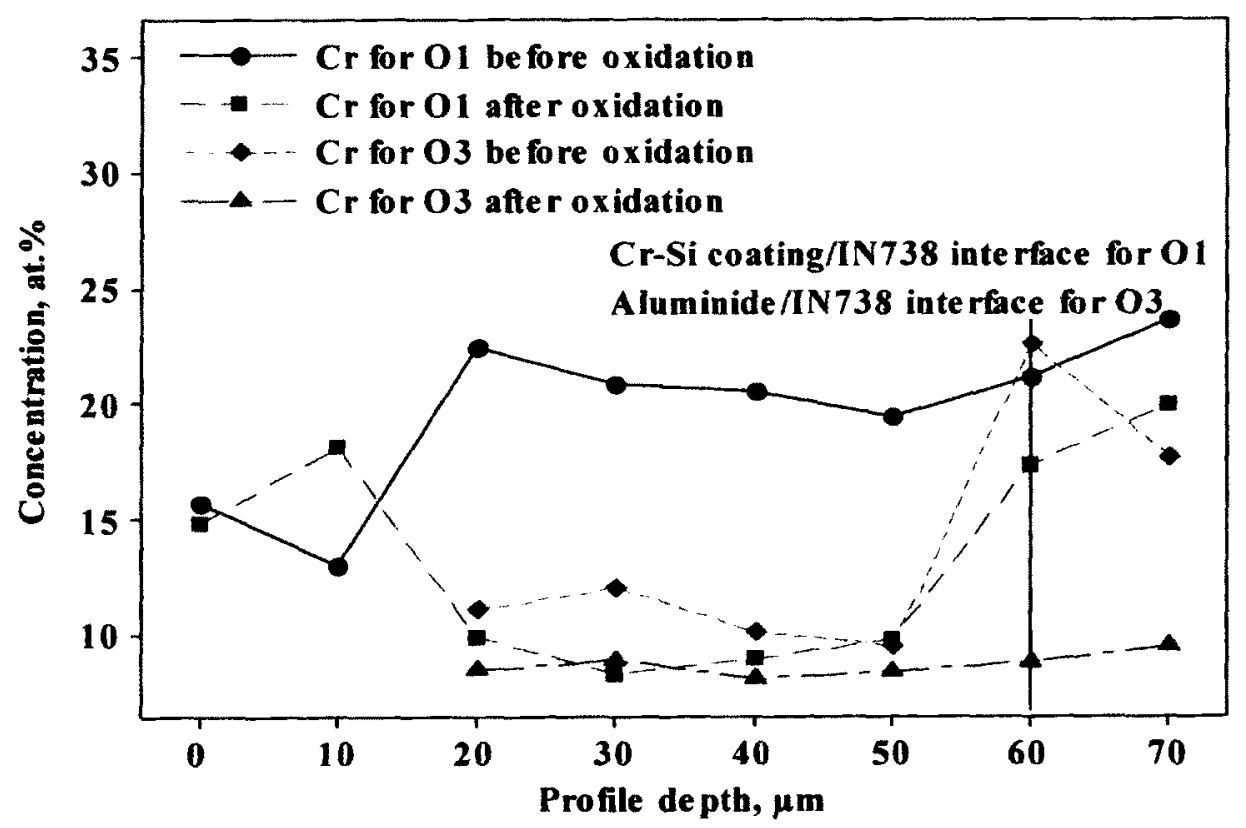

c) $\mathrm{Cr}$ profles in coating $\mathrm{O} 1$ and $\mathrm{O} 3$ before and after $1000 \mathrm{hr}$ exposure at $1050^{\circ} \mathrm{C}$

Figure 7.16 Concentration analyses in coating $\mathrm{O3}$ (aluminide I) after $1000 \mathrm{hr}$ exposure at $1050^{\circ} \mathrm{C}$. 

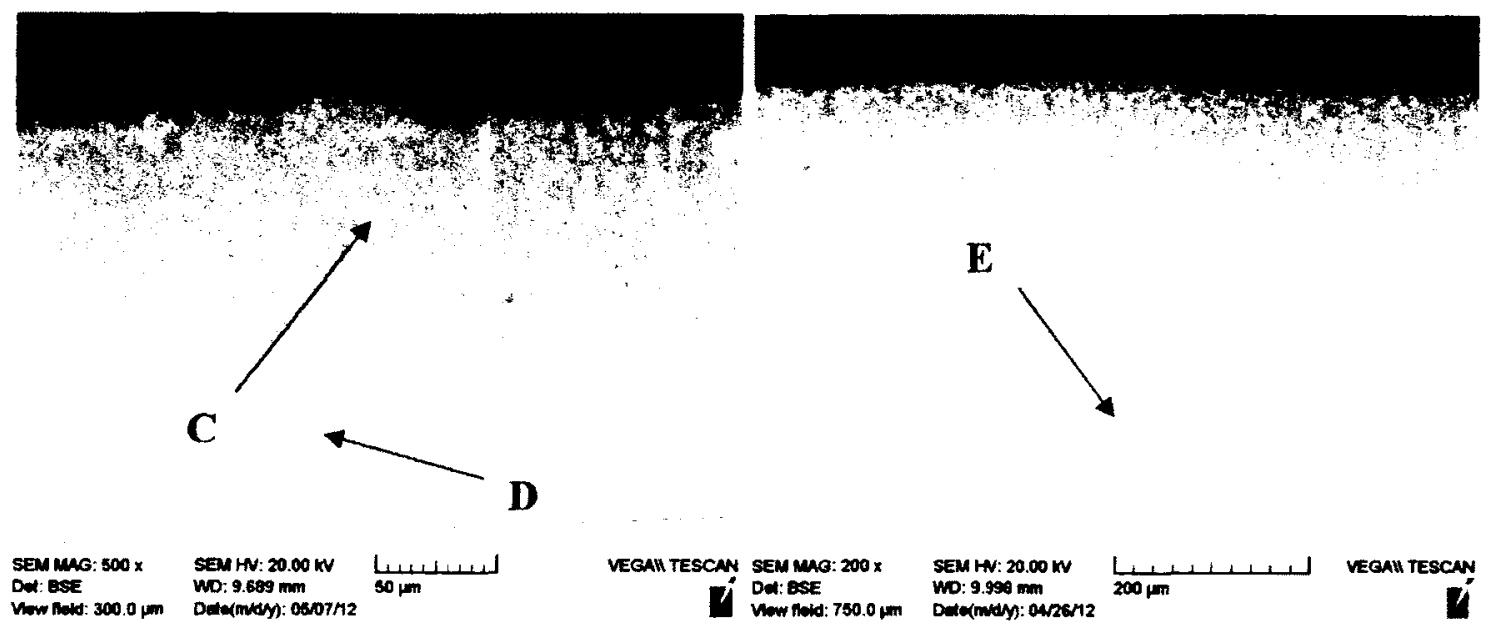
a) SEM image at high magnitude
b) SEM image at low magnitude

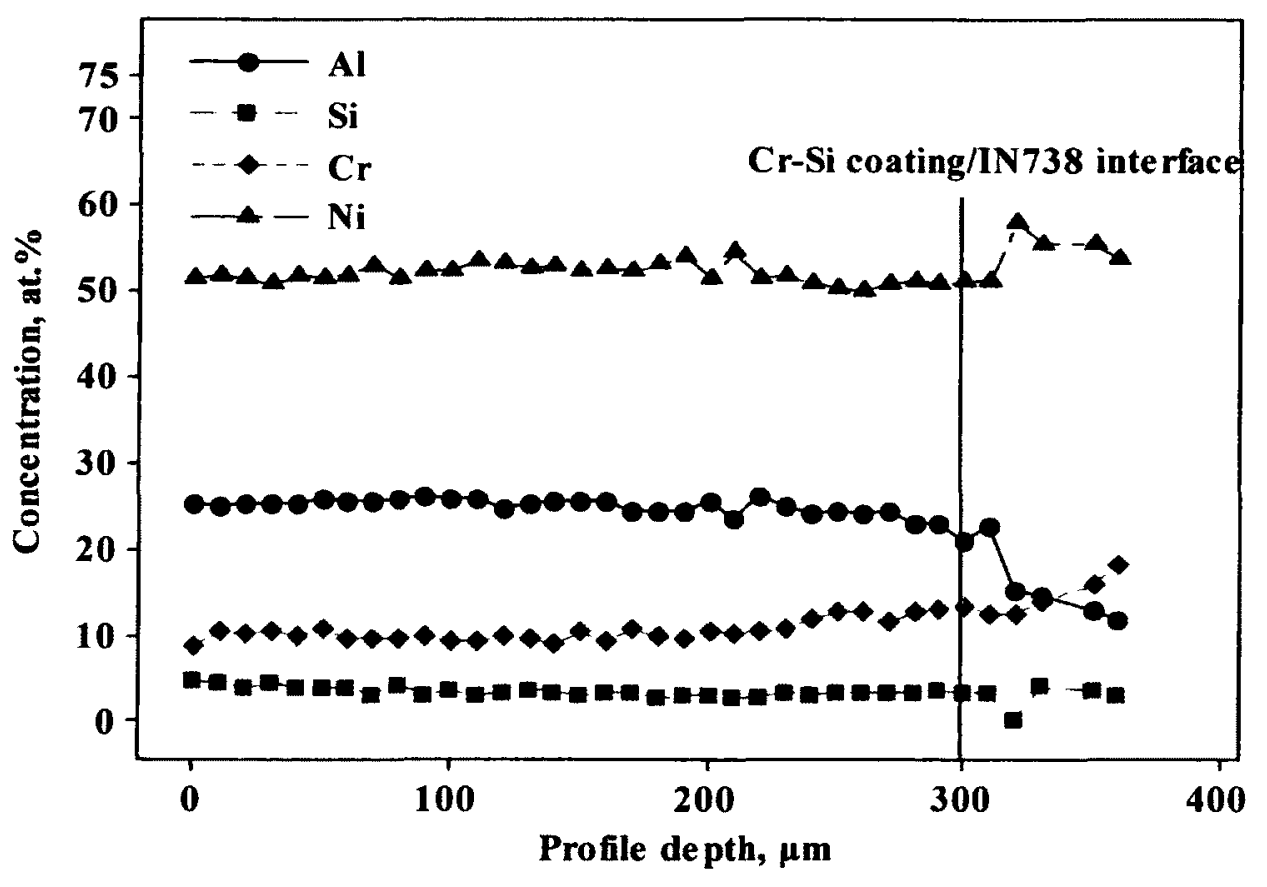

c) Concentration profiles of $\mathrm{Al}, \mathrm{Cr}$ and $\mathrm{Ni}$

Figure 7.17 Concentration analyses in coating 08 (Cr-Si coating/aluminide II) after $1000 \mathrm{hr}$ exposure at $1050^{\circ} \mathrm{C}$. 


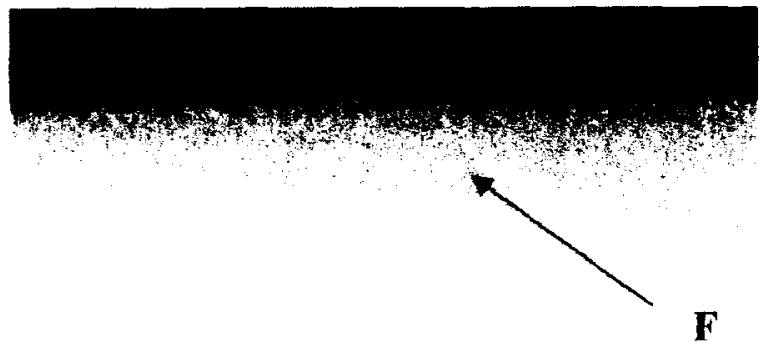

SEM MUG: 200

Dat: BSE

SEMH
WO: $9.973 \mathrm{~mm}$

Dim(midy): 04/2s/12

$\frac{L}{200 \mathrm{~mm}}$

VEGAII TESCAN

a) SEM image

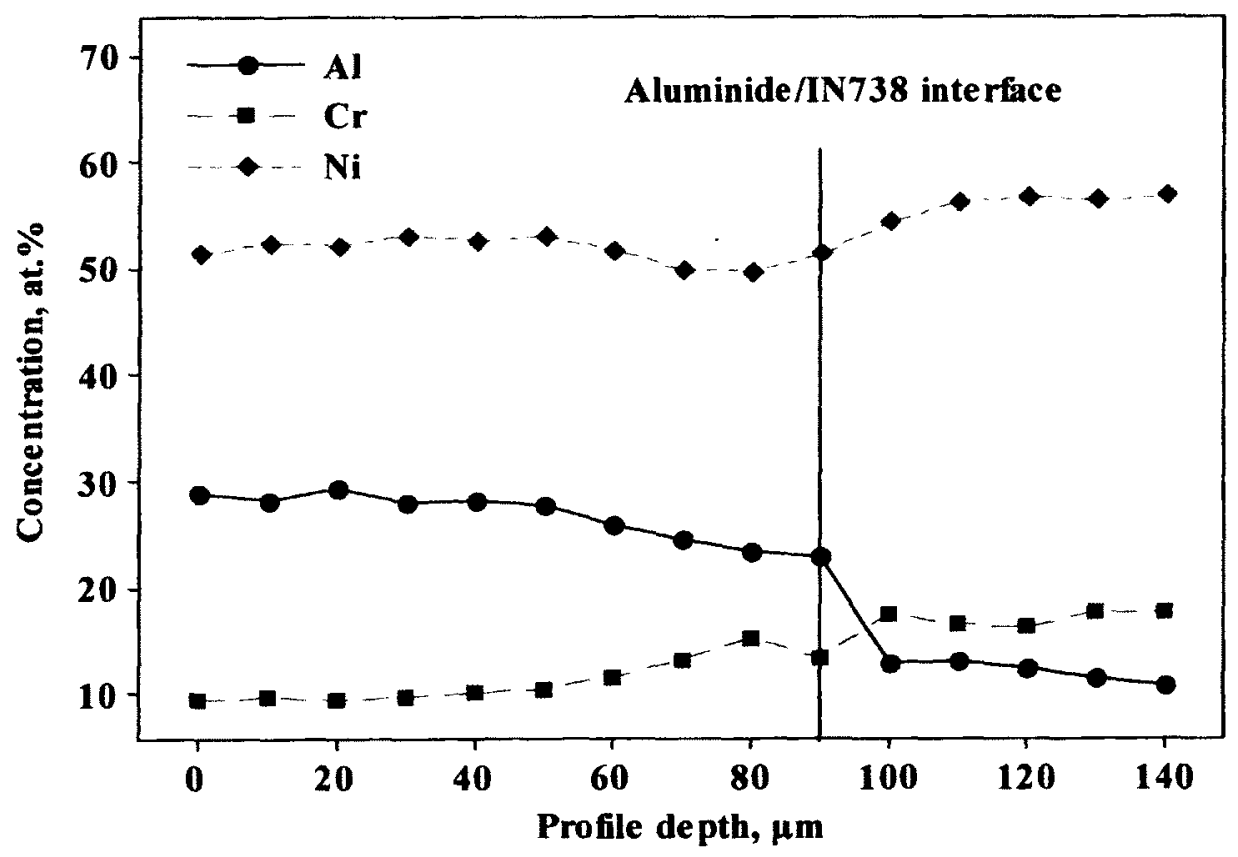

b) Concentration profiles of $\mathrm{Al}, \mathrm{Cr}$ and $\mathrm{Ni}$

Figure 7.18 Concentration analyses in coating 07 (aluminide II) after $1000 \mathrm{hr}$ exposure at $1050^{\circ} \mathrm{C}$.

On the basis of the analysis of the concentration profiles and microstructures of the coatings without the $\mathrm{NiCrAlY}$ layer, the barrier layer was unable to form in these coatings during the oxidation test even there was a $\mathrm{Cr}$-Si layer in coatings before the 
oxidation test. The microstructure of the $\mathrm{Cr}-\mathrm{Si}$ layer significantly changed from a columnar structure into a composite structure with a matrix and precipitates of $\mathrm{Cr}$-rich, Si-rich phases instead of a $\mathrm{Cr}$ layer. Therefore the presence of the NiCrAlY layer is imperative to form the barrier layer.

\subsubsection{Formation of Barrier Layer}

With the NiCrAlY layer in coating $\mathrm{O}$, the $\mathrm{Cr}$ layer formed during the aluminizing process since the chromium content in coating O5 increased from 20 at,\% (Figure 5.13d) to 45 at.\% at the interface between the NiCrAlY layer and the Cr-Si layer after the aluminizing process (Figure 6.3). This increase in $\mathrm{Cr}$ was due to the inward diffusion of the chromium from the NiCrAlY layer [116,117], and the diffusion of chromium continued during $1000 \mathrm{hr}$ exposure at $1050^{\circ} \mathrm{C}$. Based on the $\mathrm{Ni}-\mathrm{Cr}-\mathrm{Al}$ ternary diagram (Figure 2.7), the solubility of $\mathrm{Cr}$ in the $\beta$ phase is less than 8 at.\% at $1000^{\circ} \mathrm{C}$, which is below the chromium content in $\mathrm{NiCrAlY}(17.5$ at.\%) since $\gamma$ phase in NiCrAlY contains more chromium. During aluminizing process, the following phase transition occurred:

$$
\mathrm{Al}+\gamma(17.5 \text { at. } \% \mathrm{Cr})=\beta(8 \text { at. } \% \mathrm{Cr})+\mathrm{Cr}
$$

This phase transition produces $\beta$ phases and excessive $\mathrm{Cr}$ atoms to form the $\mathrm{Cr}$ layer during coating process.

The $\mathrm{Cr}$ layer was believed to have formed during the oxidation test for coating $\mathrm{O} 2$ (Figure 7.19a). During $1000 \mathrm{hr}$ exposure at $1050^{\circ} \mathrm{C}$, the more $\mathrm{Ni}_{2} \mathrm{Al}_{3}$ phases transformed into $\beta$ phases due to the continuous diffusion of $\mathrm{Al}$ from the top layer into the NiCrAlY layer and a $\beta$ phase layer at $160 \mu \mathrm{m}$ formed above the $\mathrm{Cr}$ layer (Figure 7.19c), and this $\beta$ layer rejected the $\mathrm{Cr}$ atoms not only to the interface of the NiCrAlY 
and $\mathrm{Cr}$-Si layers to form the $\mathrm{Cr}$ layer but also to the coating surface to form a two-phase zone of the $\beta$ phase and the $\mathrm{Cr}$-rich phase. Therefore the chromium profile in coating $\mathrm{O} 2$ had a $\mathrm{U}$ shape with the longer right arm. The chromium content in the $\mathrm{Cr}$ layer could reach $86 \%$ ( $\mathrm{G}$ at Table 7.5 ). According to previous studies [118], the phase of this layer became $\alpha$-Cr phase.

The formation of the $\mathrm{Cr}$ layer and the silicon-rich layer can be visualized by comparing the X-ray maps before and after the oxidation test. It was shown that silicon distributed uniformly across the $\mathrm{Cr}$-Si layer in coating $\mathrm{O} 2$ before the oxidation test (Figure 6.5e) with a Cr-rich layer above it (Figure 6.5d). After the oxidation test, silicon and chromium concentrated on the boundary of the Cr-rich layer and Si-rich layer (Figure $7.19 \mathrm{f}$ and Figure $7.19 \mathrm{~g}$ ). Also observed was the impediment to aluminum diffusion by the barrier layer (Figure 7.19e).

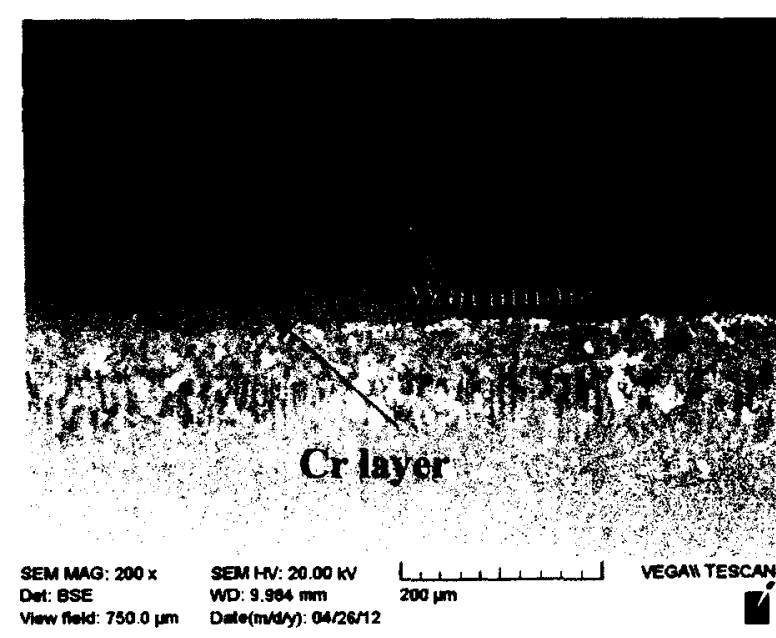

Det: ese Date(may): 0arzar

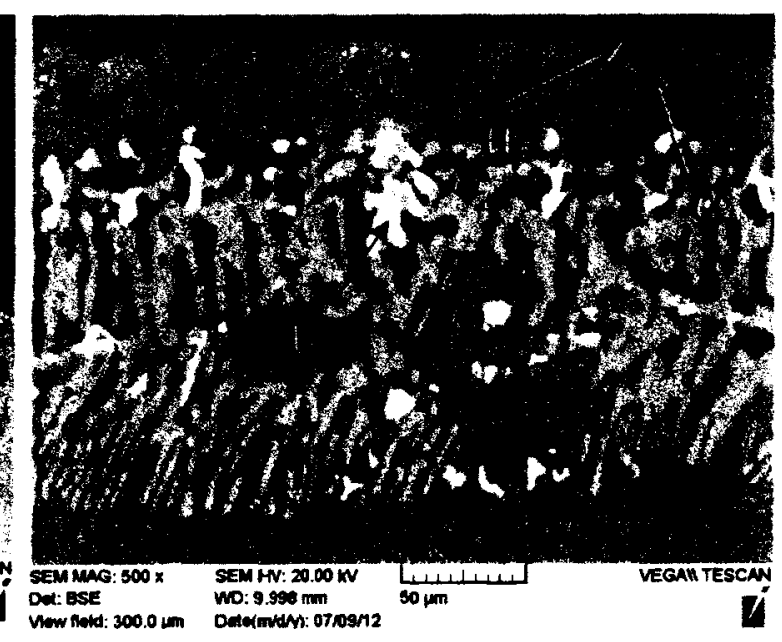

b) SEM image of the barrier layer

Vuw rotd: $300.0 \mathrm{um}$ Dentminn: otnogn a) SEM image of the coating 


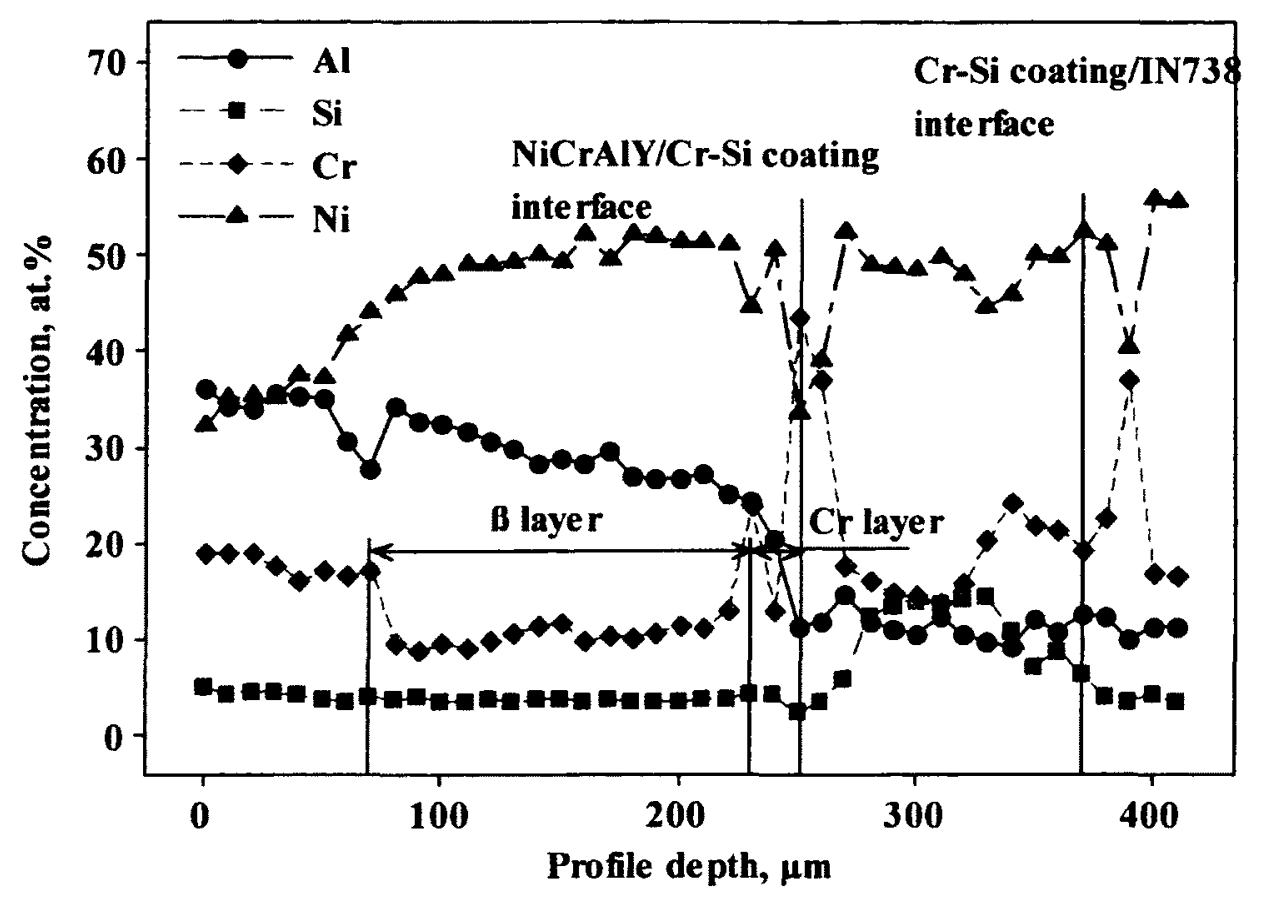

c) Concentration profiles of $\mathrm{Al}, \mathrm{Si}, \mathrm{Cr}$ and $\mathrm{Ni}$
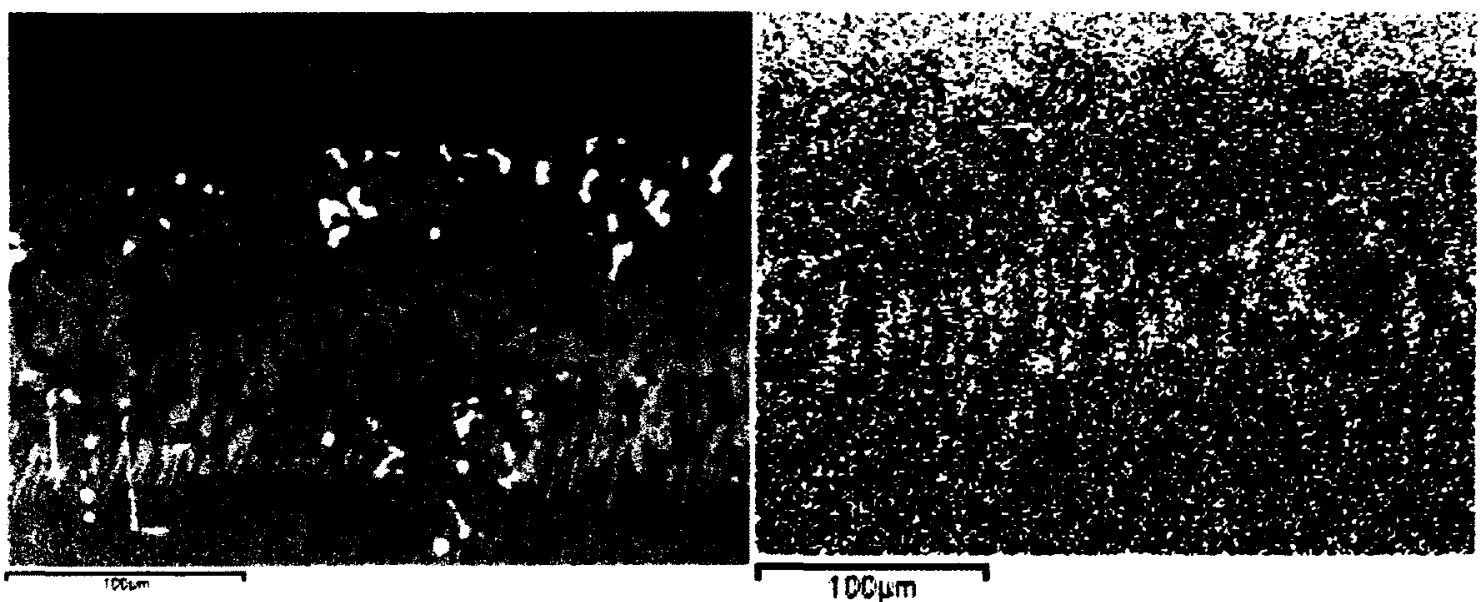

d) BSE image for mapping

e) Al map 


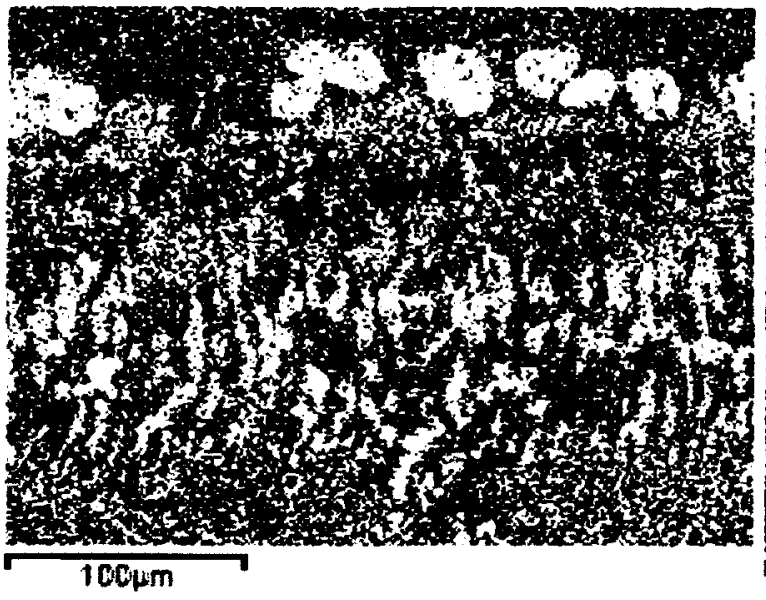

f) Cr map

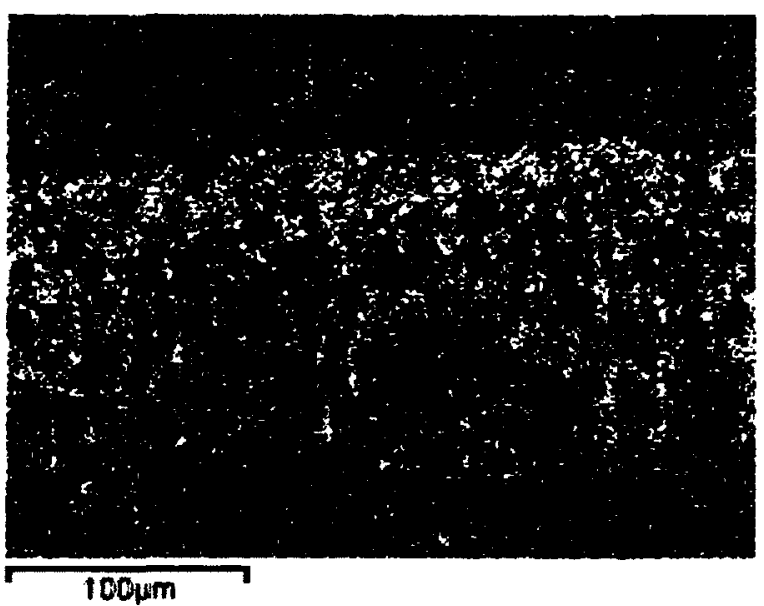

g) Si map

Figure 7.19 Concentration analyses in coating $\mathrm{O} 2$ (aluminide II) after $1000 \mathrm{hr}$ exposure at $1050^{\circ} \mathrm{C}$.

The $\mathrm{Cr}$ layer and Si-rich layer formed in coating O5 during the aluminizing process (Figure $6.4 \mathrm{a}$ and $6.4 \mathrm{~d}$ ) became less stable during $1000 \mathrm{hr}$ exposure at $1050^{\circ} \mathrm{C}$. Unlike that in coating $\mathrm{O} 2$, the microstructure below the barrier layer for coating $\mathrm{O} 5$ significantly changed from a columnar structure (Figure 6.4a) into a composite structure with a matrix and precipitates of Cr-rich, Si-rich(phase M in Figure 7.20a), and possible TCP (phase $\mathrm{N}$ in Figure 7.20a) during the exposure.

The aluminum content in the NiCrAlY layer significantly decreased after the oxidation test. However, Figure 7.20 shows that aluminum distributes evenly in the $\mathrm{Cr}$ $\mathrm{Si}$ layer and in the interface region between the $\mathrm{Cr}-\mathrm{Si}$ coating and $\mathrm{N} 738$ substrate. Such sharply reduced aluminum content was unable to protect chromium from oxidizing and to keep the barrier layer stable. Therefore, to form and sustain a $\mathrm{Cr}$ layer and silicon-rich layer in a multilayered coating, three conditions must be met: 
- silicon-containing phases form in a silicon-rich layer, preferably in a columnar form

- a chromium reservoir to build up a $\mathrm{Cr}$ layer above the silicon-rich layer

- a sufficient aluminum reservoir
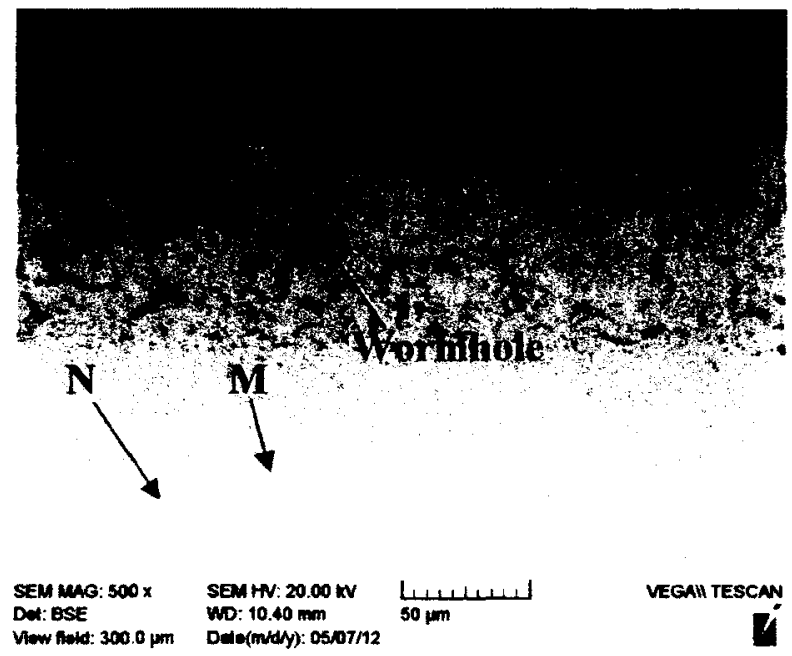

a) SEM image

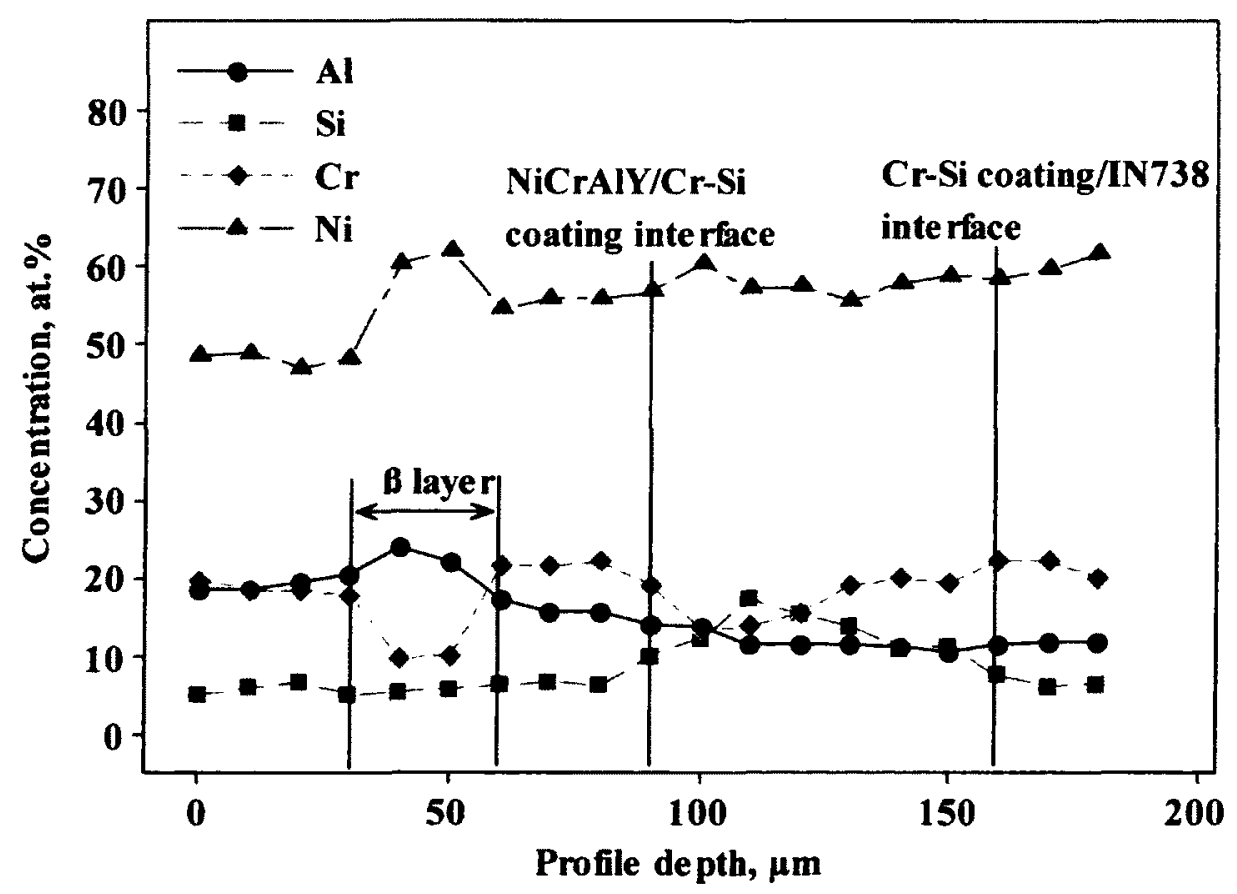

b) Concentration profiles of $\mathrm{Al}, \mathrm{Si}, \mathrm{Cr}$ and $\mathrm{Ni}$ 


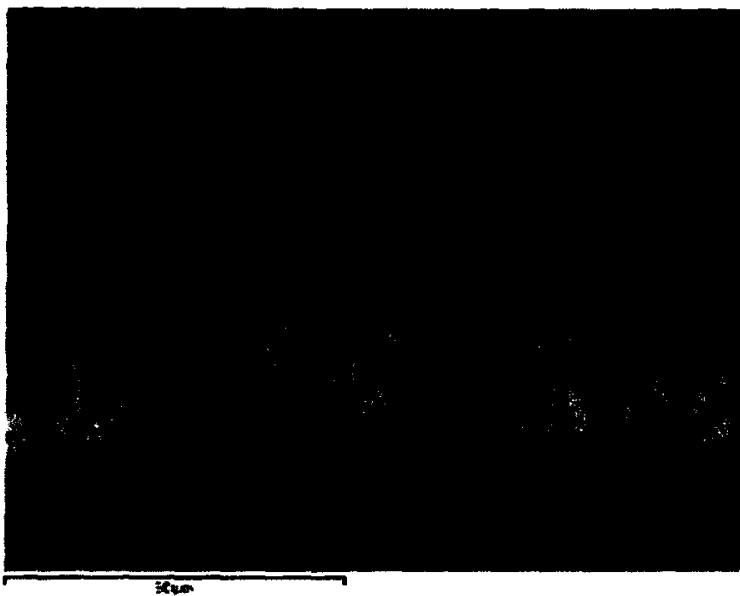

c) BSE image for mapping

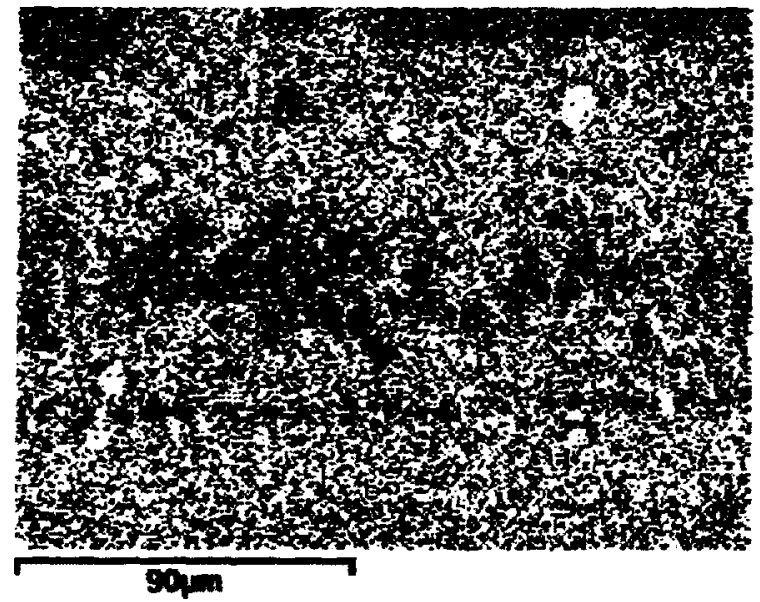

e) Cr map

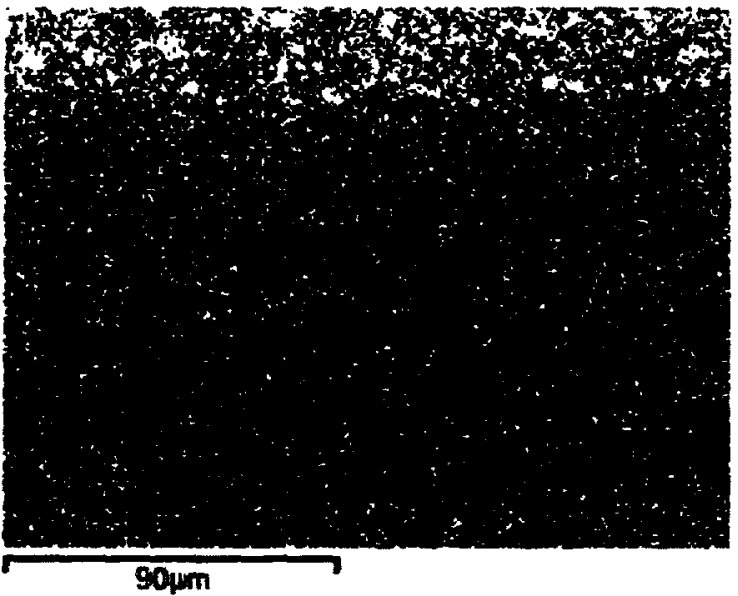

d) Al map

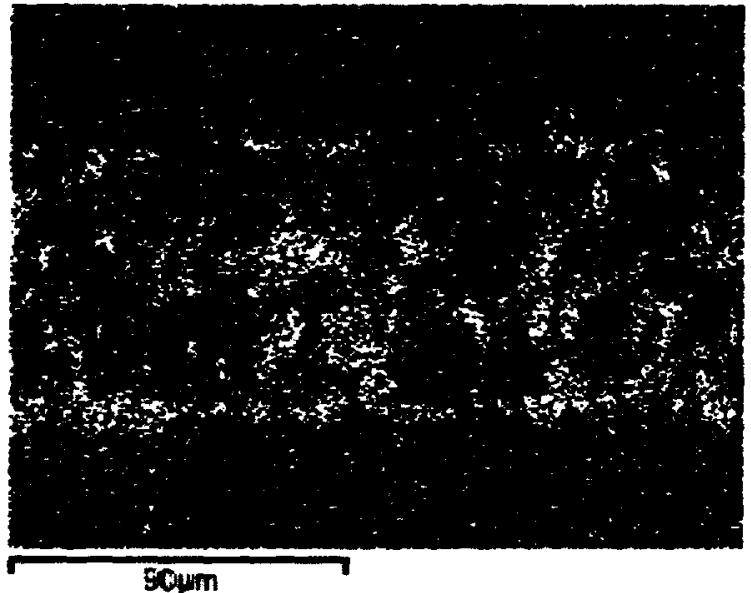

f) Si map

Figure 7.20 Concentration analyses of coating $\mathrm{O5}(\mathrm{Cr}-\mathrm{Si}$ coating/NiCrAlY/aluminide I) after 1000 hr exposure at $1050^{\circ} \mathrm{C}$.

The aluminum content in coating O5 (20 at. \%) is much lower than that in coating $\mathrm{O} 2$ (> 30 at.\%) and the $\beta$ NiAl layer in coating O5 (about $50 \mu \mathrm{m}$, Figure $7.20 \mathrm{~b}$ ) is much thinner than that in coating $\mathrm{O} 2(160 \mu \mathrm{m})$. Instead of a $\mathrm{U}$ shape, the shape of the chromium profile in coating $\mathrm{O} 5$ is more like a $\mathrm{V}$. Therefore coating $\mathrm{O} 2$ is more resistant to oxidation than coating $\mathrm{O5}$. 
However, compared with the coating without the barrier layer (O6), the barrier layer in coating $\mathrm{O} 5$ did exhibit its positive effects on the oxidation resistance and enabled the top layer of $\mathrm{NiAl}$, to be evenly oxidized at relative low rate during the oxidation test at $1050^{\circ} \mathrm{C}$. The barrier layer helped to sustain $\mathrm{Al}$ content in the top layer. Accordingly, coating $\mathrm{O5}$ shows less area of oxide scaless than coating O6 (Figure 7.21).
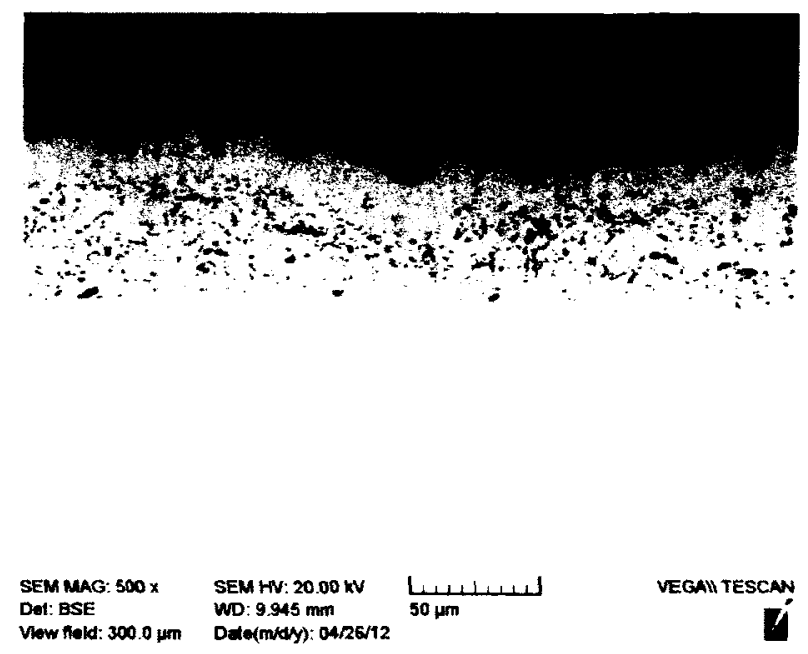

Figure 7.21 SEM image of coating 06 (NiCrAlY/aluminide I) after $1000 \mathrm{hr}$ exposure at $1050^{\circ} \mathrm{C}$.

\subsubsection{Function of Barrier Layer}

Evidently a $\mathrm{Cr}$ layer and silicon-rich barrier layer would not function as intended in the coatings without a middle layer of a NiCrAlY. With this layer, the barrier function was observed in the coating $\mathrm{O} 2$. The following evidence verified effects of the barrier layer:

- A grey $\mathrm{Cr}$ layer was observed at the interface between $\mathrm{NiCrAlY}$ and the $\mathrm{Cr}-\mathrm{Si}$ layer (Figure 7.19a). 
- This $\mathrm{Cr}$ layer contained over 80 at.\% $\mathrm{Cr}$ (Figure 7.19c), and impeded $\mathrm{Al}$ diffusion .

- The aluminum and chromium contents across the interface between NiCrAlY layer and the barrier layer varied significantly (phase $\mathrm{G}$ and $\mathrm{H}$ at Figure $7.19 \mathrm{~b}$ ).

- The aluminum content steadily decreased from the coating surface to the substrate, but dropped sharply at the interface between the NiCrAlY layer and the barrier layer (Figure 7.19c).

- Some topologically closed packed (TCP) phases (phase I at Figure 7.19b), containing Mo and $\mathrm{W}$, were observed under the $\mathrm{Cr}$ layer in coating $\mathrm{O} 2$, whereas $\mathrm{TCP}$ phases were observed in the NiCrAlY coating in coating $\mathrm{O} 4$ (phase $\mathrm{J}$ at Figure 7.22), which has no $\mathrm{Cr}-\mathrm{Si}$ barrier layer. This finding suggests that the barrier layer not only prevented aluminum diffusing into the substrate, but also enable impeding the diffusion of other elements in the substrate diffusing into the coating.

Most of TCP phases were deleterious to the mechanical properties of the coating and the substrate because of the reasons below $[119,120]$ :

- All TCP phases have different lattice structures from the lattice structure of $\gamma / \gamma^{\prime}$ phase. For example, one of TCP phases, $\sigma$ phase, has the tetragonal lattice structure, whereas $\gamma / \gamma^{\prime}$ phase has the fcc lattice structure. The difference in lattice structure induces shear strains and internal stresses in the surrounding $\gamma / \gamma^{\prime}$ phase. The internal stresses concentrates near the TCP-phases, and cause fracture of the TCP-phase or decohesion between the TCP-phase and the surrounding $\gamma / \gamma^{\prime}$ phase. The fracture of the brittle TCP-phase under these stresses could degrade the fatigue properties of the the 
coating and the substrate, because the broken TCP-phases could act as initiation points for cracks.

- The differences in thermal expansion coefficients between the TCP-phase and the surrounding $\gamma^{\prime} / \gamma$ phase can also affect the properties of the coating and the substrate in service. During temperatures changes, the differences in thermal expansion coefficients cause thermally induced internal strains in the TCP-phases and in the surrounding $\gamma^{\prime} / \gamma$ phase. These internal strains could cause the fracture of the TCP-phase and degrade the fatigue properties of the coating and the substrate.

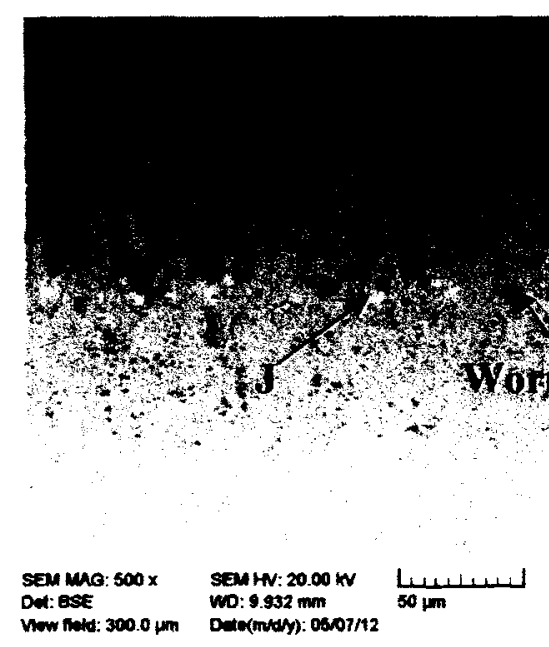

a) SEM image at low magnitude

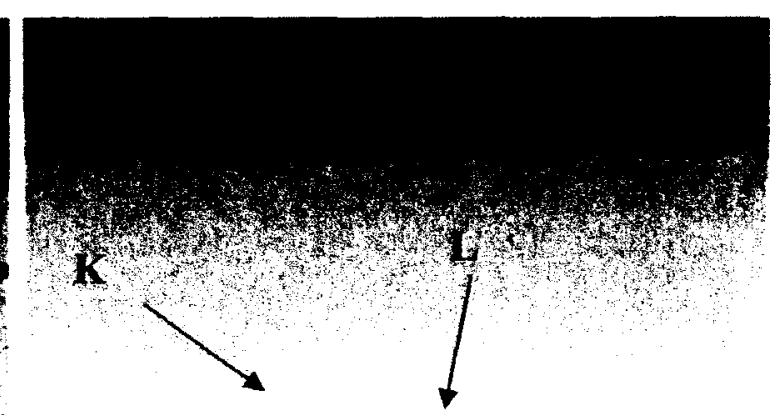

VESAU TESCN SEM HAO: 200X SEAN $20.00 \mathrm{WV}$ Ont: Bse mo: $9.2001 \operatorname{mim}$

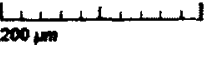

VEGAN TESCAN

b) SEM image at high magnitude 


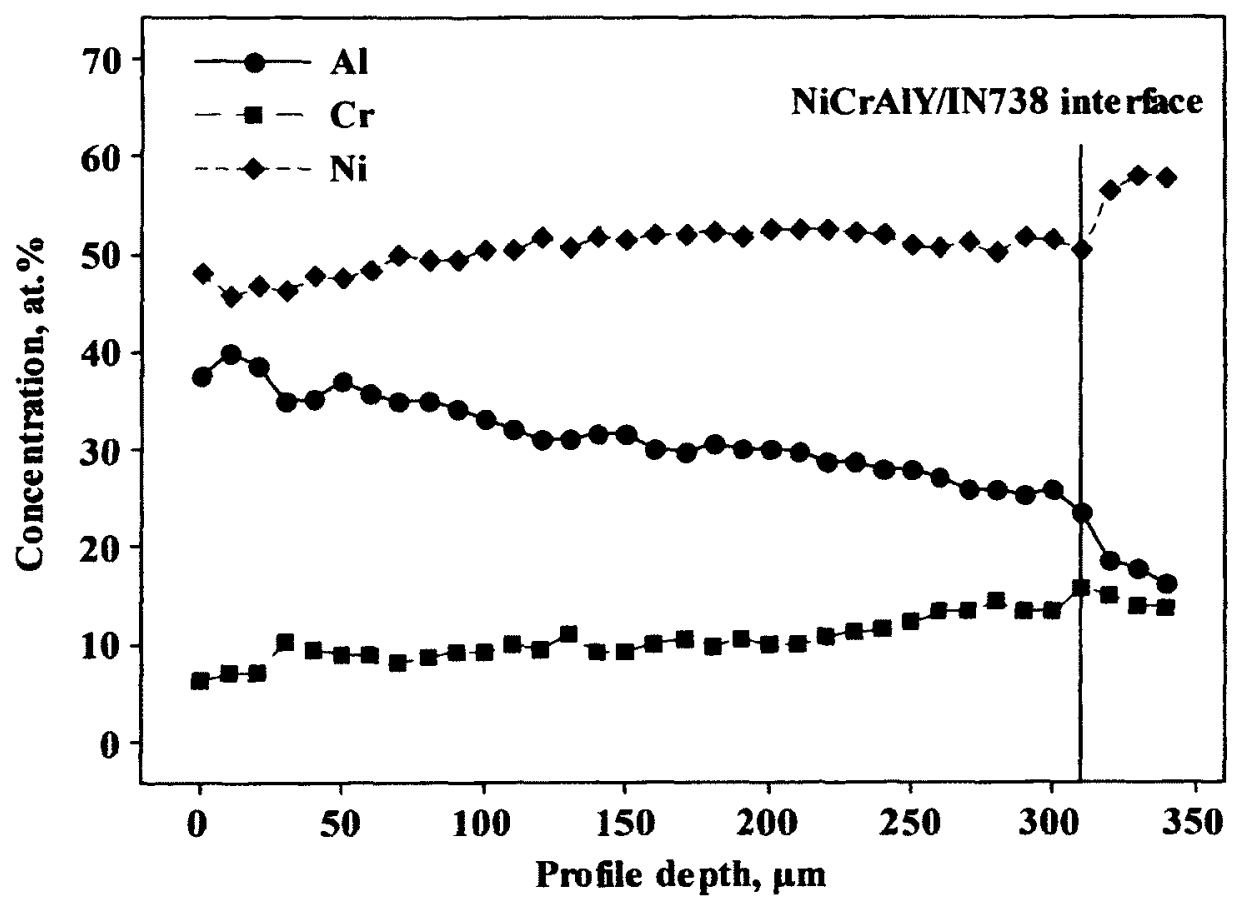

c) Concentration profiles of $\mathrm{Al}, \mathrm{Cr}$ and $\mathrm{Ni}$

Figure 7.22 Concentration analyses in coating $\mathrm{O4}$ (aluminide II) after $1000 \mathrm{hr}$ exposure at $1050^{\circ} \mathrm{C}$.

\subsubsection{Effectiveness of Barrier Layer}

The effectiveness of the barrier layer on the oxidation behavior of multilayered coatings has been observed to vary based on the aluminum content in the top layer $[121,122]$. The examination of the elemental profiles for coating $\mathrm{O} 2$ (Figure $7.19 \mathrm{c}$ ) and coating $\mathrm{O} 4$ (Figure $7.22 \mathrm{~b}$ ) after $1000 \mathrm{hr}$ exposure at $1050^{\circ} \mathrm{C}$ indicated that the originally formed $\mathrm{Ni}_{2} \mathrm{Al}_{3}$ phases in the top layer of aluminized coatings transformed to $\beta(\mathrm{NiAl})$ phases during the exposure due to $\mathrm{Al}$ consumption.

The consumption of the aluminum in coating $\mathrm{O} 2$ was mainly attributed to the oxidation of the aluminum in the top layer, whereas the reduction of the aluminum in 
coating $\mathrm{O} 4$ was caused by both the oxidation of the aluminum in the top layer and the diffusion of aluminum into the substrate. In the cases where the $\mathrm{Ni}_{2} \mathrm{Al}_{3}$ phase was the dominant phase in the top layer, the diffusion of aluminum into the substrate was favorable for achieving the $\beta$ phase during the exposure and beneficial for oxidation resistance, at least during $1000 \mathrm{hr}$ exposure at $1050^{\circ} \mathrm{C}$.

Observed from Figure 7.19a and Figure 7.22a, the oxide scales in coating $\mathrm{O} 2$ (with barrier) was much thicker than that for coating $\mathrm{O} 4$ (without barrier). The reason for the heavier scale formation is that the phase transition from the $\mathrm{Ni}_{2} \mathrm{Al}_{3}$ phase to the $\beta$ (NiAl) phase released surplus aluminum atoms on the surface to create the thick $\mathrm{Al}_{2} \mathrm{O}_{3}$ scales.

Also some wormholes were observed in coating $\mathrm{O} 2, \mathrm{O} 4$, and $\mathrm{O} 5$. The formation of wormholes was related to Kirkendall voids and locally accelerated metal vaporization [123]. During the oxidation test, the oxidation of $\mathrm{Al}$ caused $\mathrm{Al}$ depletion in the vicinity of the interface between oxide scales and the coatings. Al depletion forced $\mathrm{Ni}$ to diffuse away from the interface. Since the diffusivity of $\mathrm{Ni}$ is higher than that of $\mathrm{Al}$ in Al-rich phase at $1050^{\circ} \mathrm{C}$, Kirkendall voids formed under the oxide-coating interface. After formation, the voids continued to grow by vapor-phase transport, where $\mathrm{Al}$ evaporation is accompanied by Ni diffusion away from the interface, Thus, the diffusion of voids was strong, and became concentrated to some region in the coatings so that the voids condense here, and a wormhole formed. The phase transformation during the oxidation test was also accompanied by a change in the molar volume of phases, which might contribute to the formation of wormholes in coatings as well [87]. 


\subsubsection{Effects of Barrier Layer on the Formation of Interdiffusion Zone}

A $120 \mu \mathrm{m}$ thick interdiffusion zone (IDZ) formed between NiCrAY and IN 738 substrate in coating $\mathrm{O} 4$ (with no $\mathrm{Cr}-\mathrm{Si}$ barrier layer). The IDZ consisted of a $\beta$ phase matrix and some grey precipitates rich in $\mathrm{Cr}(\mathrm{K}$ at Figure $7.22 \mathrm{~b})$ and bright granular TCP precipitates (L at Figure 7.22b). The formation of the IDZ was caused by the aluminum diffusion into the substrate, which made the initial $\gamma^{\prime} / \gamma$ microstructure of the substrate transform into the $\beta / \gamma^{\prime}$ microstructure. The solubility of strengthening elements such as $\mathrm{Cr}, \mathrm{W}$, and $\mathrm{Mo}$ in the initial $\gamma^{\prime} / \gamma$ microstructure was much higher than that in the $\beta / \gamma$ ' microstructure; therefore these elements were observed to precipitate from the $\gamma^{\prime} / \gamma$ phases and form the Cr-rich phases and TCP phases in the $\beta / \gamma^{\prime}$ matrix [124]. There are three types of TCP phases: namely tetragonal $(\sigma)$, rhombohedral $(\mu)$ and orthorhombic (P) phases [125]. At $1050^{\circ} \mathrm{C}$, the rhombohedral $(\mu)$ phase is more stable because more refractory elements such as W, Mo are concentrated in the $\mu$ phase [126]. The formation of the Cr-rich phases and TCP phases may deteriorates the mechanical properties of the substrate by altering the regularity of the $\gamma^{\prime} / \gamma$ rafted microstructure [127].

Interdiffusion zones were also observed in coatings 07 (Figure 7.18a) and 08 (Figure 7.17b). The common layers existing in coatings $\mathrm{O} 4, \mathrm{O} 7$, and 08 were the aluminide II top layer, which sustained sufficient aluminum to transform the initial $\gamma^{\prime} / \gamma$ microstructure of the substrate into the $\beta / \gamma^{\prime}$ microstructure by aluminum diffusion due to the absence of a barrier layer. With a barriers layer in coating $\mathrm{O} 2$, an interdiffusion zone (IDZ) was not observed in the coating, which indicated that the barriers layer in multilayered coatings effectively suppressed inward-aluminum diffusion. The 
interdiffusion zone was not observed in coatings with aluminide I top layer because of the insufficient aluminum content and continuous aluminum consumption in the coatings during $1000 \mathrm{hr}$ exposure at $1050^{\circ} \mathrm{C}$. The microstructures of the substrates in these coatings remained $\gamma^{\prime}$ phase in $\gamma$ matrix with occasional precipitates of $\mathrm{Cr}$-Si-rich, and TCP phases.

\subsubsection{Effects of Barrier Layer at Different Exposure Temperatures}

The $\mathrm{Cr}$ layer and Si-rich layer were stable when the exposure temperatures were only below $1100^{\circ} \mathrm{C}$, since the chromium in the coatings could be oxidized and $\mathrm{CrO}_{3}$ would form. $\mathrm{CrO}_{3}$ is volatile and becomes gas at temperatures above $1100^{\circ} \mathrm{C}$. The barrier layers in coating $\mathrm{O} 2$ and $\mathrm{O} 5$ disappeared after $1000 \mathrm{hr}$ exposure at $1150^{\circ} \mathrm{C}$ (Figure 7.23a and Figure 7.24a). As demonstrated by the X-ray mapping images for the regions below the coating surfaces of coatings $\mathrm{O} 2$ and $\mathrm{O} 5$, chromium and silicon uniformly distributed within the regions after $1150^{\circ} \mathrm{C}$ exposure (Figure 7.23d, Figure 7.23e, Figure 7.24d, and Figure 7.24e). However, the barrier layer in coating $\mathrm{O} 2$ postponed aluminum exhaust and kept the aluminum content around 20 at.\% before the barrier layer disappeared. A $\beta$ layer still existed in the coating, which suggests coating $\mathrm{O} 2$ still kept its oxidation resistance after $1150^{\circ} \mathrm{C}$ exposure. However, coating $\mathrm{O} 4$, without the barrier layer in the coating, totally disappeared due to rapid aluminum exhaust (Figure 7.25).

When exposed at $1150^{\circ} \mathrm{C}$, the barrier layer in coating $\mathrm{O} 5$ was unable to prevent aluminum exhaustion because the aluminum content in coating $\mathrm{O} 5$ was already around 20 at.\% after the first stage of exposure at $1050^{\circ} \mathrm{C}$ (Figure $7.20 \mathrm{~b}$ ). During $1000 \mathrm{hr}$ exposure at $1150^{\circ} \mathrm{C}$, the aluminum content in coating $\mathrm{OS}$ further decreased leading to 
non-protective scale formation. In this case, the chromium in the barrier layer was easily oxidized and eventually evaporated. The evaporation of the chromium oxide $\left(\mathrm{CrO}_{3}\right)$ destroyed the continuity of the oxide scales and further accelerated the consumption of $\mathrm{Al}$. Therefore a chromium-rich barrier layer in a coating is harmful to the oxidation resistance of the coating if the aluminum content in the top layer of the coating falls below 21 at.\%. This is the reason for the low aluminum content in coating O5 than that in coating $\mathrm{O} 6$ after $1000 \mathrm{hr}$ exposure at $1150^{\circ} \mathrm{C}$ (Figure $7.26 \mathrm{~b}$ ). Other research found similar results that chromium vaporization from pure $\mathrm{Cr}_{2} \mathrm{O}_{3}$ (transfers to $\mathrm{CrO}_{3}$ ) was three orders of magnitude higher than that from $\mathrm{Cr}_{2} \mathrm{O}_{3}$ dispersed with $\mathrm{Al}_{2} \mathrm{O}$ [128].

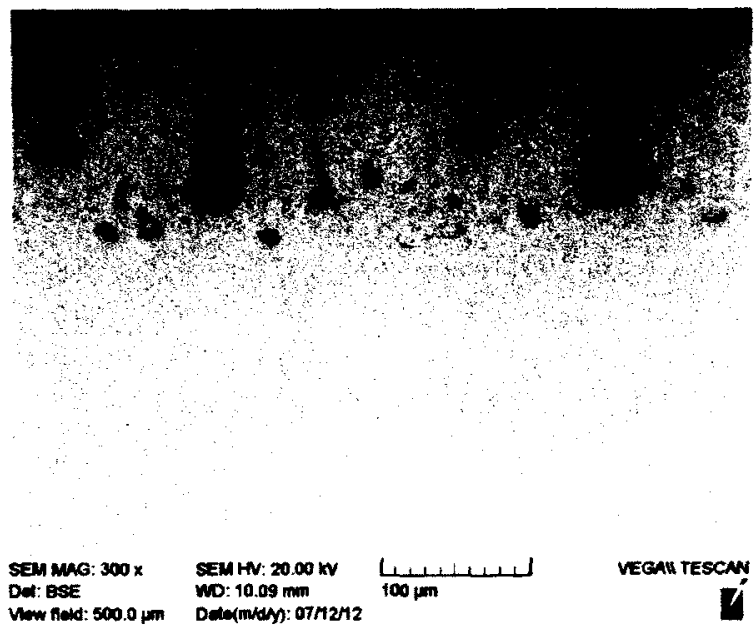

a) SEM image 

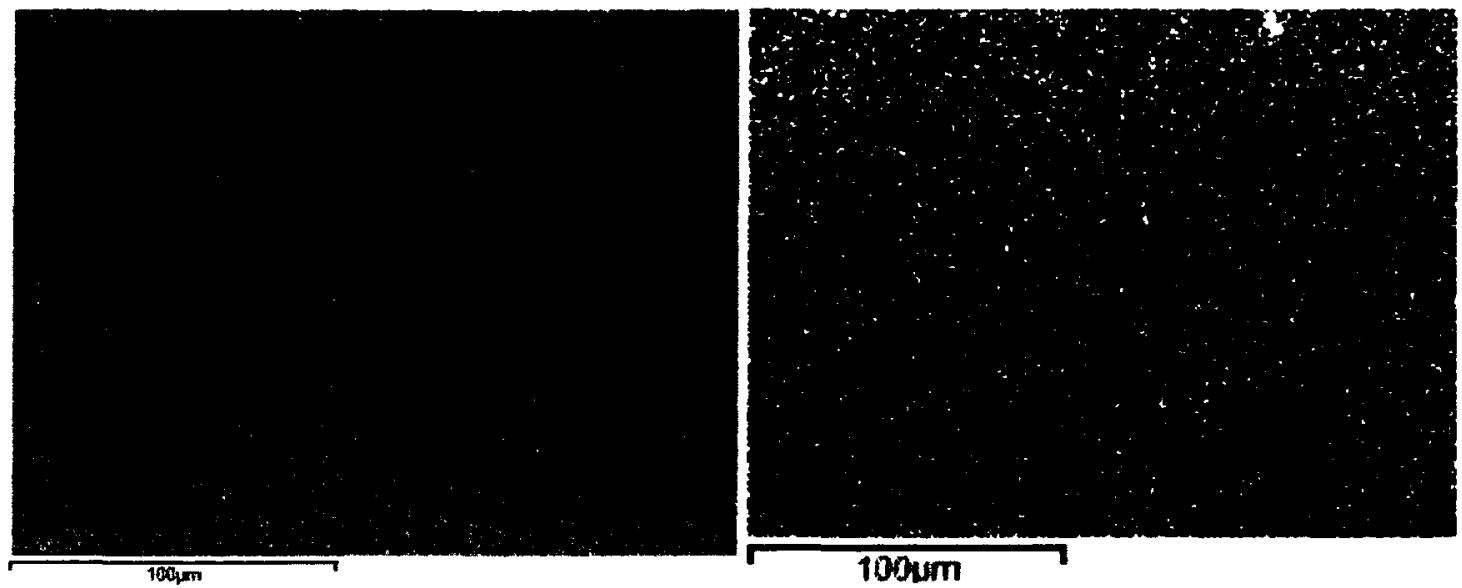

b) SEM image for mapping

c) Al map
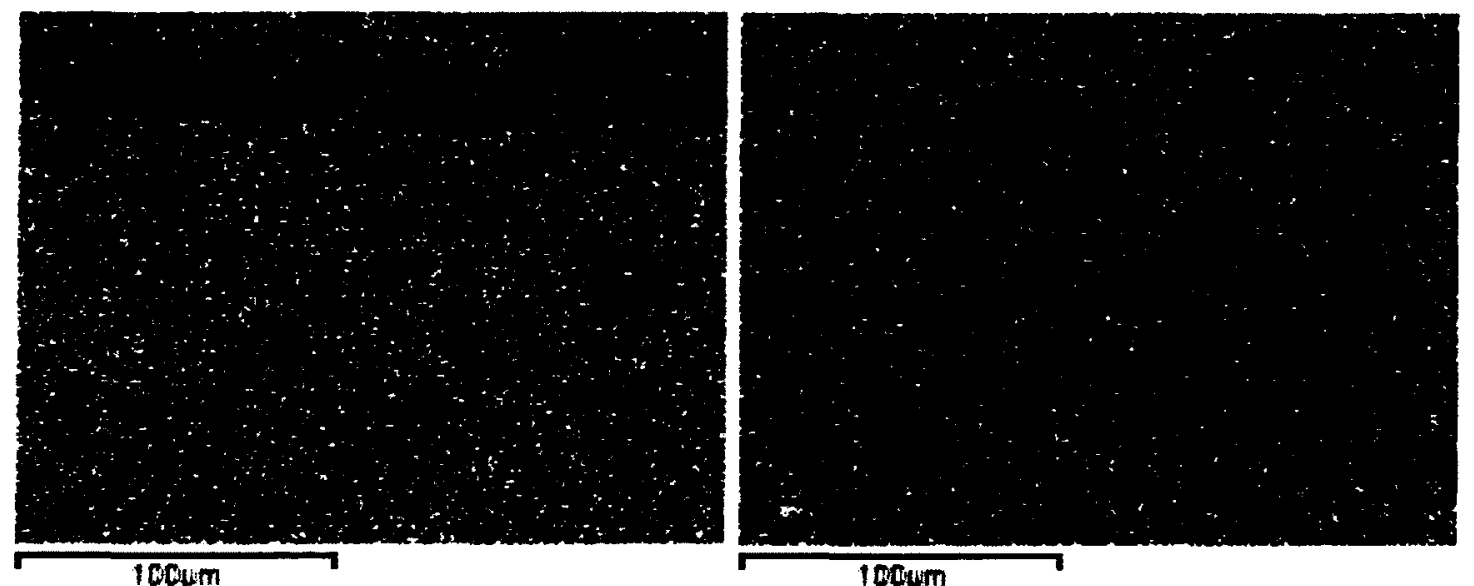

d) Cr map

e) Si map 


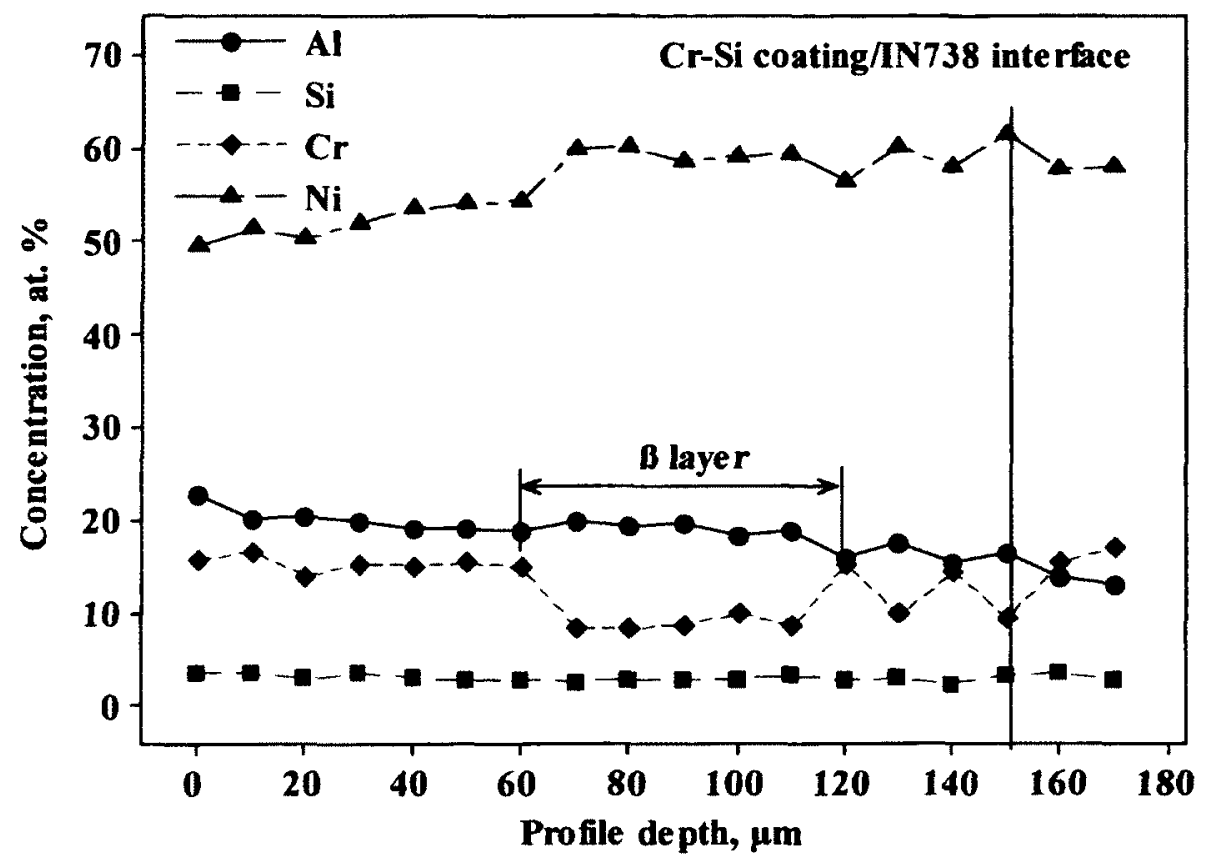

f) Concentration profiles of $\mathrm{Al}, \mathrm{Si}, \mathrm{Cr}$ and $\mathrm{Ni}$

Figure 7.23 Concentration analyses in coating $\mathrm{O} 2$ (Cr-Si coating)

NiCrAlY/aluminide II) after $1000 \mathrm{hr}$ exposure at $1150^{\circ} \mathrm{C}$.

Similarly, without a Cr-Si layer, coating $\mathrm{O} 7$ (aluminide II) still contained around 20 at.\% $\mathrm{Al}$ after exposure at $1150^{\circ} \mathrm{C}$ (Figure $7.18 \mathrm{~b}$ ), whereas the oxide scale in coating $\mathrm{O} 8$ (Cr-Si coating/aluminide II) completely spalled. Spallation was found to be one of major oxidation characteristics for the coatings after the $1000 \mathrm{hr}$ exposure at $1150^{\circ} \mathrm{C}$; this has occurred to coatings $\mathrm{O} 1, \mathrm{O} 3, \mathrm{O} 4$ and $\mathrm{O} 8$. Another characteristic for the coatings after $1150^{\circ} \mathrm{C}$ exposure was the formation of mixed-oxide protrusions on surface of the coatings due to insufficient aluminum in the coatings [129], which were observed in coatings $\mathrm{O} 5, \mathrm{O} 6$ and $\mathrm{O} 7$ (Figure 7.26a and Figure 7.27a). Only coating $\mathrm{O} 2$ still kept certain thickness without major damage, which means coating $\mathrm{O} 2$ had the best oxidation resistance at $1150^{\circ} \mathrm{C}$. 

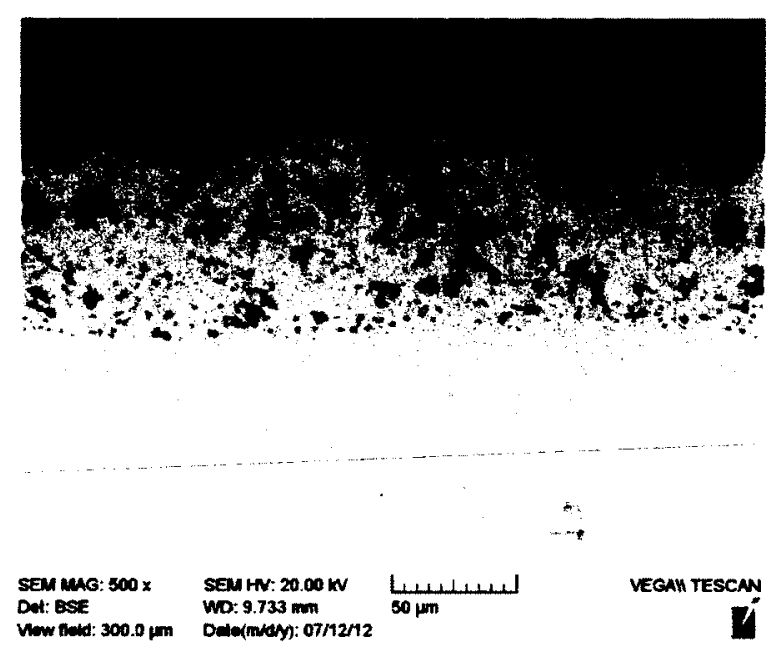

a) SEM image

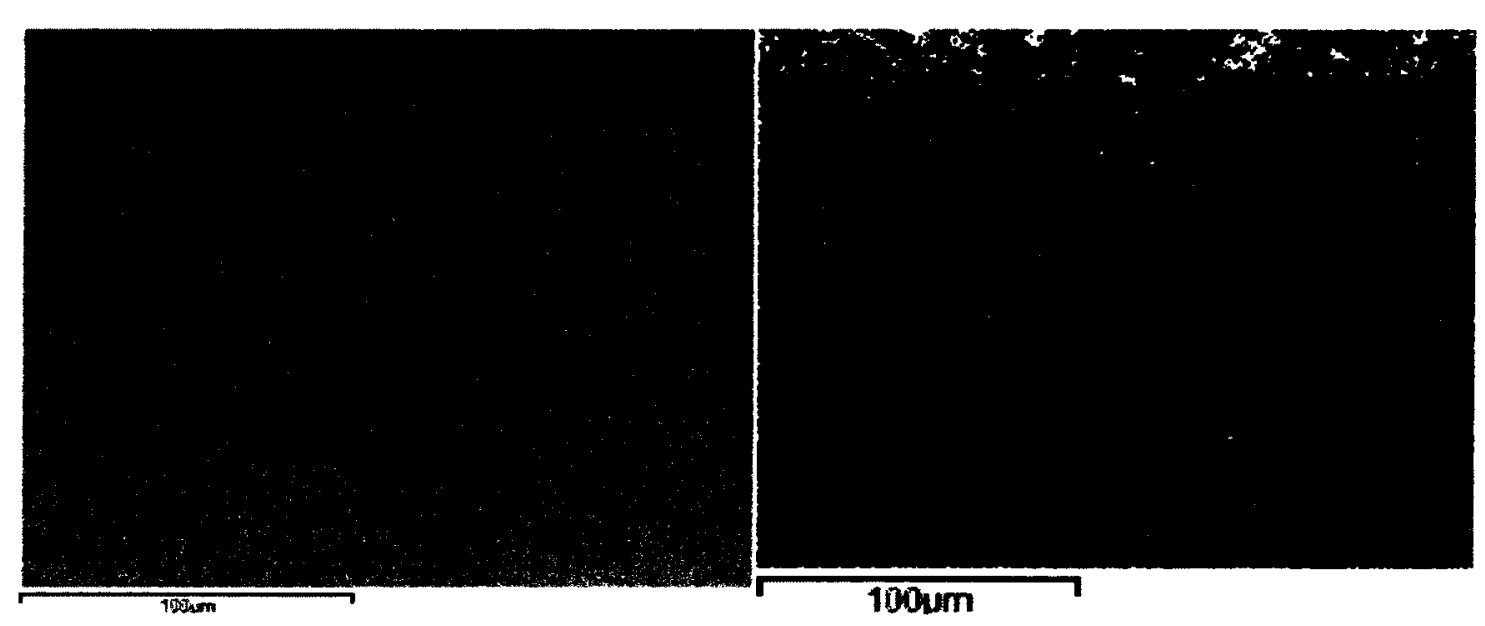

b ) SEM image for mapping

c) Al map

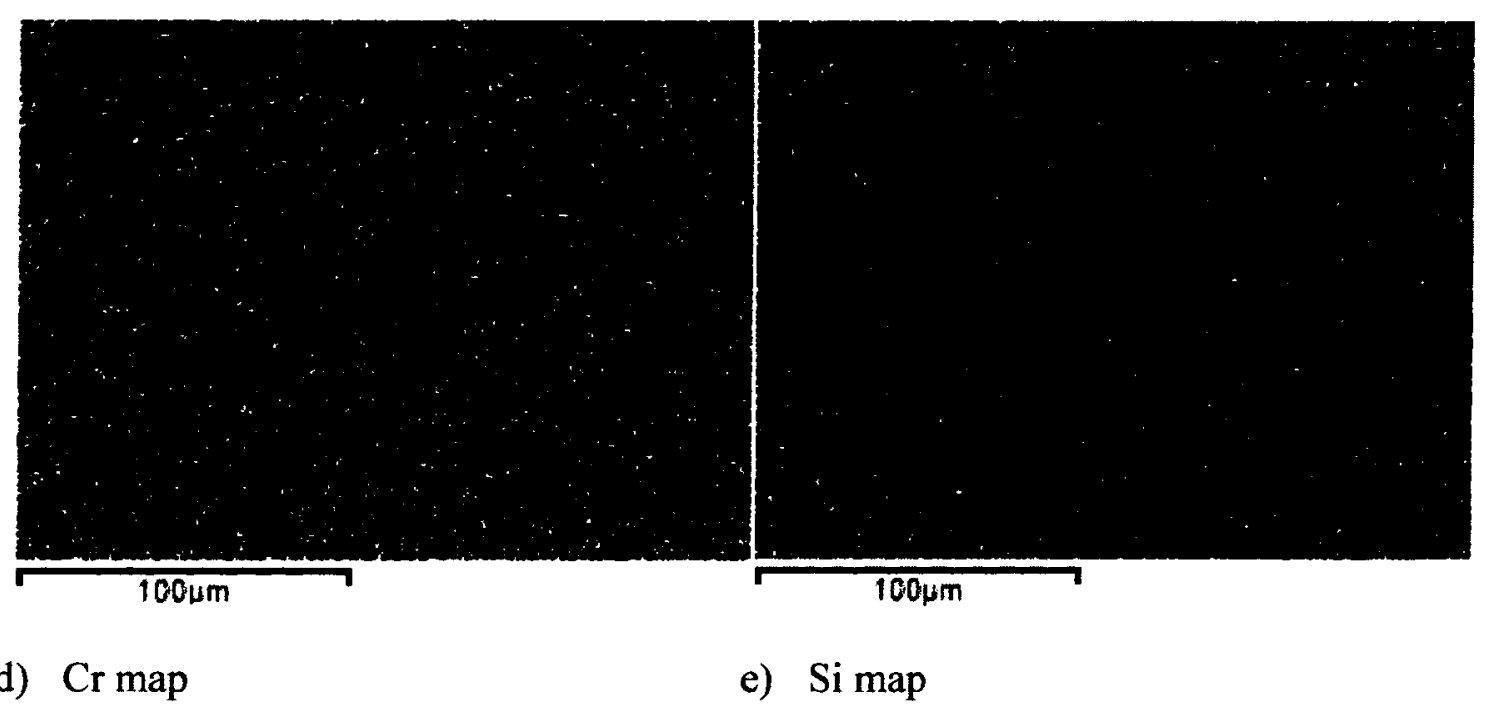




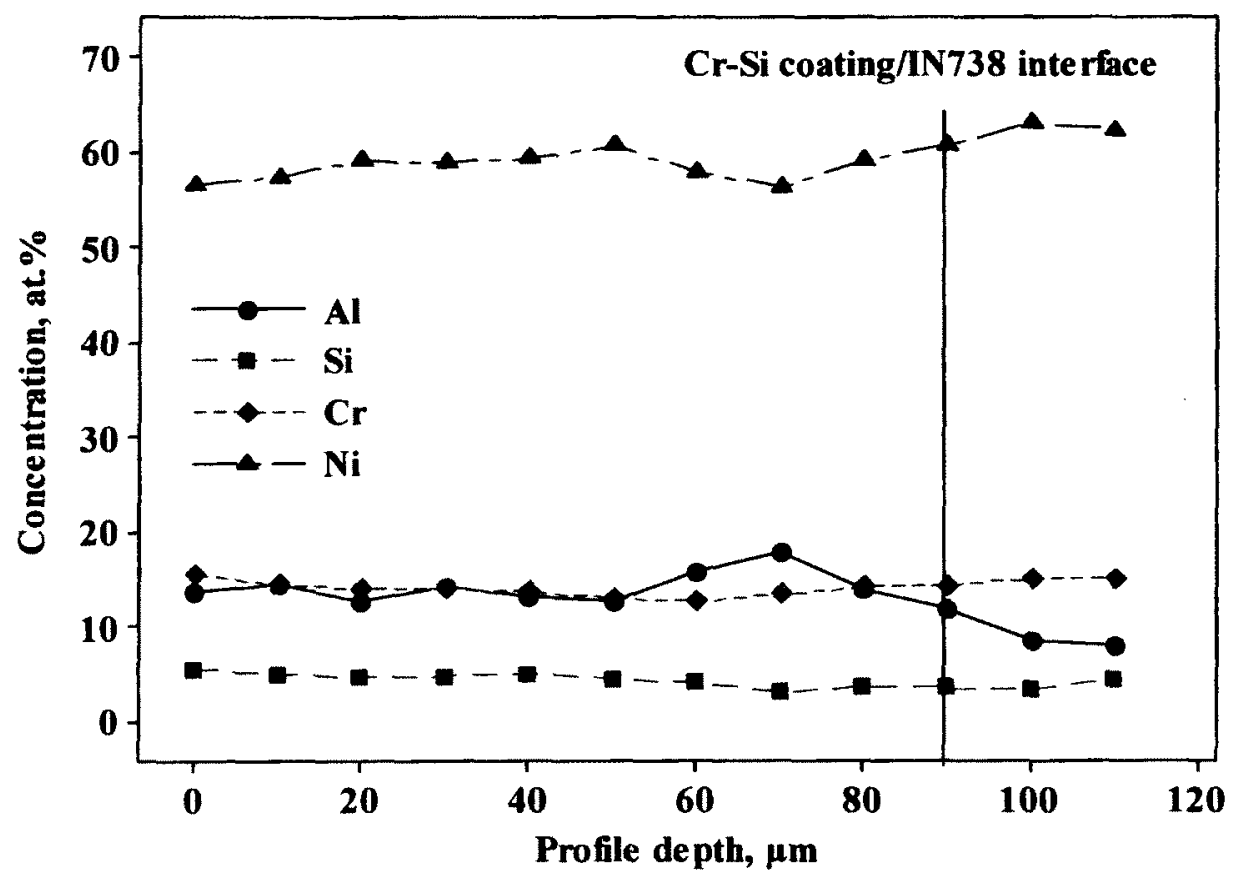

f) Concentration profiles of $\mathrm{Al}, \mathrm{Cr}$ and $\mathrm{Ni}$

Figure 7.24 Concentration analyses in coating $\mathrm{O5}(\mathrm{Cr}-\mathrm{Si}$ coating/NiCrAIY/aluminide I) after $1000 \mathrm{hr}$ exposure at $1150^{\circ} \mathrm{C}$.

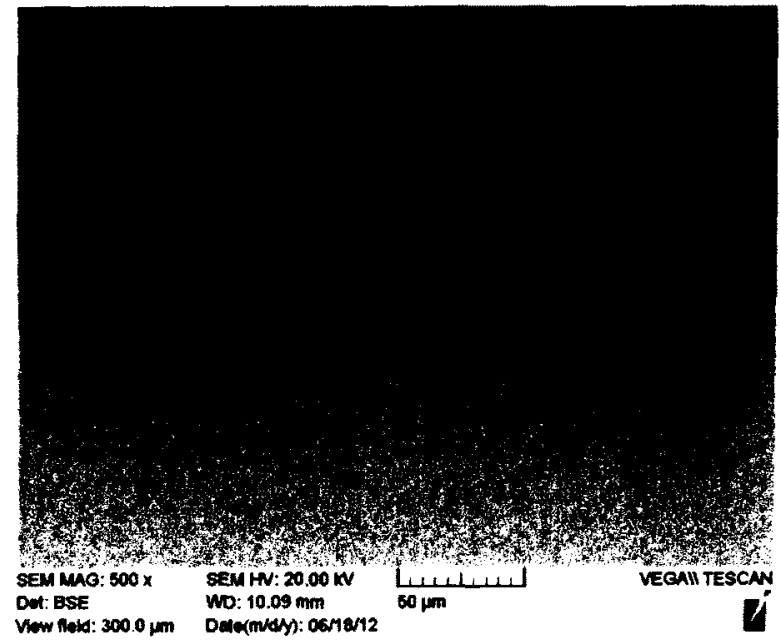

Figure 7.25 SEM image of coating $\mathrm{O4}$ (NiCrAIY/aluminide II) after $1000 \mathrm{hr}$ exposure at $1150^{\circ} \mathrm{C}$. 


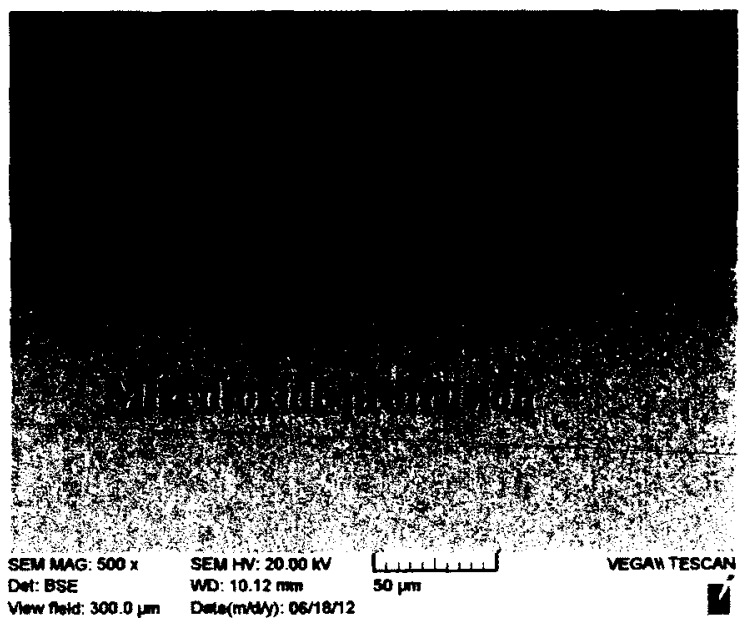

a) SEM image of coating $\mathrm{O6}$

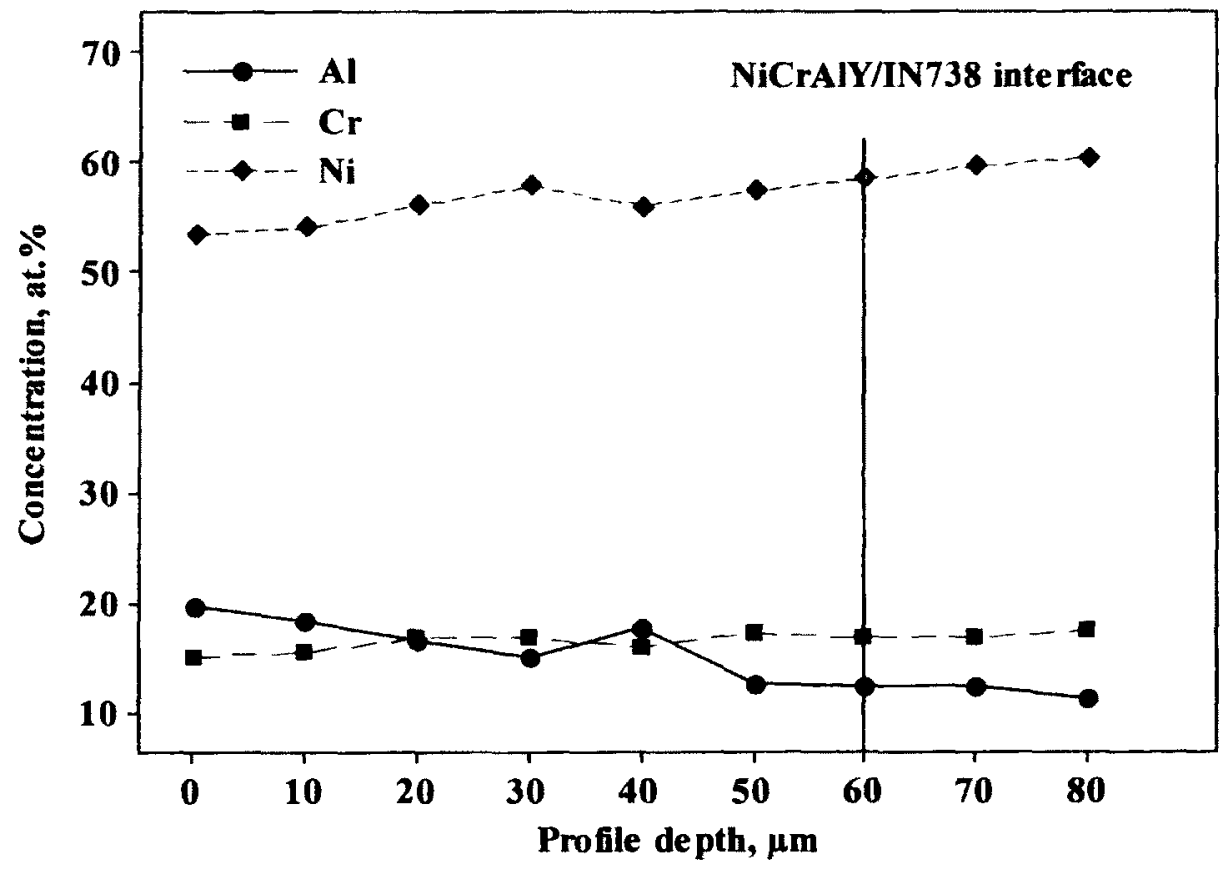

b) Concentration profiles of $\mathrm{Al}, \mathrm{Cr}$ and $\mathrm{Ni}$

Figure 7.26 Concentration analyses in coating 06 (NiCrAlY/aluminide I) after $1000 \mathrm{hr}$ exposure at $1150^{\circ} \mathrm{C}$. 


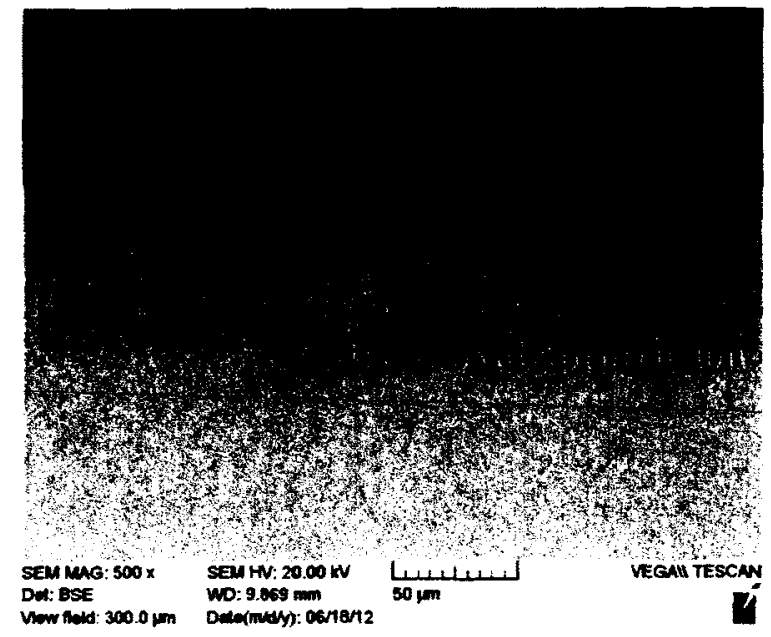

a) SEM image of coating $\mathrm{O} 7$

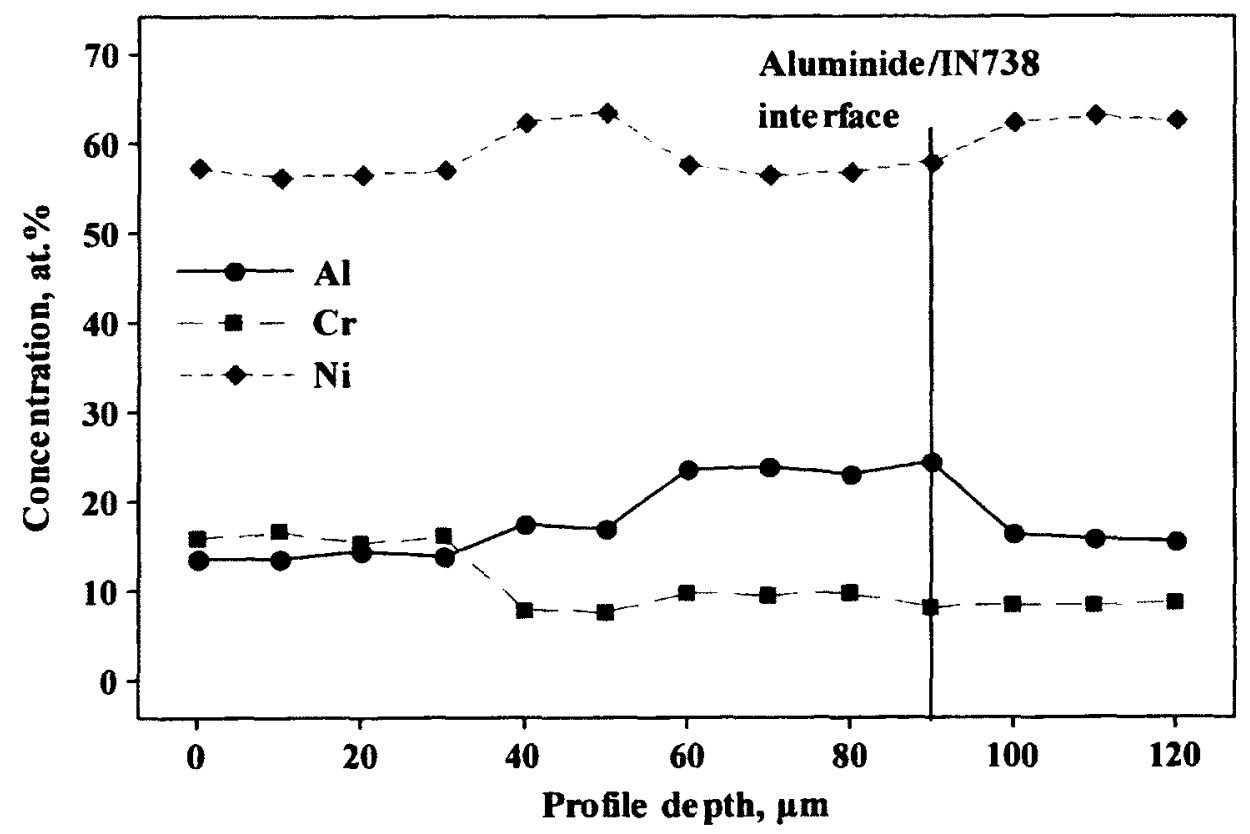

b) Concentration profiles of $\mathrm{Al}, \mathrm{Cr}$ and $\mathrm{Ni}$

Figure 7.27 Concentration analyses in coating 07 (aluminide II) after $1000 \mathrm{hr}$

\section{exposure at $1150^{\circ} \mathrm{C}$.}

After $1000 \mathrm{hr}$ exposure at $1050^{\circ} \mathrm{C}$ and $1150^{\circ} \mathrm{C}$, the microstructures of the coatings significantly changed. A comparison of the microstructures before and after the 
exposures is summarized in Table 7.11. More specifically, the microstructures of the coatings changed from the high aluminum content phases $\left(\mathrm{Ni}_{2} \mathrm{Al}_{3}\right.$ and $\left.\beta\right)$ to low aluminum content phases $\left(\gamma^{\prime}\right.$ and $\left.\gamma\right)[129,130]$. A coating loses its protective ability when $\gamma$ phase starts to form in the top and middle layers since protective $\mathrm{Al}_{2} \mathrm{O}_{3}$ forms on top of $\beta$ rich phases [131]. Based on the remained phases in Table 7.11, most of coatings except coating $\mathrm{O} 1$ sustained their protective function after $1000 \mathrm{hr}$ exposure at $1050^{\circ} \mathrm{C}$. Only $\mathrm{O} 2$ sustained its protective nature after $1000 \mathrm{hr}$ exposure at $1150^{\circ} \mathrm{C}$.

Table 7.11 Phases in the coatings after exposure at $1050^{\circ} \mathrm{C}$ and $1150^{\circ} \mathrm{C}$

\begin{tabular}{|c|c|c|c|c|}
\hline \multirow{2}{*}{ Coating } & \multirow{2}{*}{ Coating layer } & \multirow[b]{2}{*}{ Phase before oxidation } & \multicolumn{2}{|c|}{ Exposure temperature, ${ }^{\circ} \mathrm{C}$} \\
\hline & & & 1050 & 1150 \\
\hline 01 & $\begin{array}{l}\text { Cr-Si coating/ } \\
\text { aluminide I }\end{array}$ & $\begin{array}{l}\beta+\gamma^{\prime} / \gamma+(\mathrm{Cr}-\mathrm{Si}- \\
\text { columnar phases })\end{array}$ & $\begin{array}{l}\gamma^{\prime} / \gamma+(\mathrm{Cr}-\mathrm{Si}-\text { rich } \\
\text { precipitate })\end{array}$ & $\begin{array}{l}\text { No } \\
\text { coating }\end{array}$ \\
\hline $\mathrm{O} 2$ & $\begin{array}{l}\mathrm{Cr}-\mathrm{Si} \text { coating/ } \\
\text { NiCrAlY/ } \\
\text { aluminide II } \\
\end{array}$ & $\begin{array}{l}\mathrm{Ni}_{2} \mathrm{Al}_{3}+\beta+\gamma^{\prime} / \gamma+(\mathrm{Cr}- \\
\text { Si-columnar phases })\end{array}$ & $\begin{array}{l}\beta+\gamma^{\prime} / \gamma+(\text { Cr layer } \\
+ \text { Si-rich columnar } \\
\text { phases })\end{array}$ & $\beta+\gamma^{\prime} / \gamma$ \\
\hline $\mathrm{O} 3$ & aluminide I & $\beta$ & $\beta+\gamma^{\prime} / \gamma$ & $\begin{array}{l}\text { No } \\
\text { coating }\end{array}$ \\
\hline $\mathrm{O} 4$ & $\begin{array}{l}\text { NiCrAlY/ } \\
\text { aluminide II }\end{array}$ & $\mathrm{Ni}_{2} \mathrm{Al}_{3}$ & $\beta+\gamma^{\prime} / \gamma$ & $\begin{array}{l}\text { No } \\
\text { coating }\end{array}$ \\
\hline O5 & $\begin{array}{l}\text { Cr-Si coating/ } \\
\text { NiCrAlY/ } \\
\text { aluminide I }\end{array}$ & $\begin{array}{l}\beta+\gamma^{\prime} / \gamma+(\mathrm{Cr}-\mathrm{Si}- \\
\text { columnar phases })\end{array}$ & $\begin{array}{l}\beta+\gamma^{\prime} / \gamma+(\mathrm{Cr}-\mathrm{Si}- \\
\text { rich precipitates })\end{array}$ & $\gamma^{\prime} / \gamma$ \\
\hline 06 & $\begin{array}{l}\text { NiCrAlY/ } \\
\text { aluminide I }\end{array}$ & $\beta+\gamma^{\prime} / \gamma$ & $\beta+\gamma^{\prime} / \gamma$ & $\gamma^{\prime} / \gamma$ \\
\hline 07 & aluminide II & $\mathrm{Ni}_{2} \mathrm{Al}_{3}$ & $\begin{array}{l}\beta+\gamma^{\prime} / \gamma+\mathrm{Cr} \text {-rich } \\
\text { precipitate }\end{array}$ & $\gamma^{\prime} / \gamma$ \\
\hline O8 & $\begin{array}{l}\mathrm{Cr}-\mathrm{Si} \text { coating/ } \\
\text { aluminide II }\end{array}$ & $\begin{array}{l}\mathrm{Ni}_{2} \mathrm{Al}_{3}+\beta+\gamma^{\prime} / \gamma+(\mathrm{Cr}- \\
\mathrm{Si}-\text { columnar phases })\end{array}$ & $\begin{array}{l}\beta+\gamma^{\prime} / \gamma+\mathrm{Cr} \text {-rich } \\
\text { precipitate }\end{array}$ & $\begin{array}{l}\text { No } \\
\text { coating }\end{array}$ \\
\hline 09 & Bare IN738 & $\gamma^{\prime} / \gamma$ & $\gamma^{\prime} / \gamma$ & $\gamma^{\prime} / \gamma$ \\
\hline $\mathrm{O} 10$ & NiCrAlY & $\gamma^{\prime} / \gamma$ & $\gamma^{\prime} / \gamma$ & $\begin{array}{l}\text { No } \\
\text { coating }\end{array}$ \\
\hline
\end{tabular}




\subsection{Summary of Oxidation Tests}

The barrier layer, which consisted of a $\mathrm{Cr}$ layer and a Si-rich layer, was found to have significant effects on the oxidation behavior of multilayered coatings in terms of mass change and total area of oxide scales. During oxidation test at $1050^{\circ} \mathrm{C}$, the barrier layer improved the oxidation resistance for the multilayered coatings as the $\mathrm{Cr}$ layer that formed during coating process kept aluminum within the coating and sustained $\mathrm{NiAl}$ microstructure in the top coating layer. However, with aluminide I top coat the sustainability of the barrier layer became questionable with a decrease in aluminum content in the coating after a long period of exposure at a high temperature (in coating O5, for example).

The $\mathrm{Cr}$ layer in the multilayered coating where the $\mathrm{Al} / \mathrm{Ni}$ ratio was around two formed during the oxidation test as the $\mathrm{Ni}_{2} \mathrm{Al}_{3}$ phase transformed into the $\beta$ phase to release $\mathrm{Cr}$ atoms. The barrier layer promoted the formation of stable oxides (primarily $\left.\mathrm{Al}_{2} \mathrm{O}_{3}\right)$ at the surface of aluminized layer when the $\mathrm{Al} / \mathrm{Ni}$ ratio of the multilayered coating was around two (aluminide II top coat) because the barrier layer kept aluminum within the coating and sustained the $\beta$ phase microstructure. The higher aluminum content $(>50$ at.\%) in aluminide II top coat kept the barrier layer stable during the oxidation tests. A stable coating structure was characterized as the combination of a layer of columnar silicon-rich phase, a $\mathrm{Cr}$ layer, and a $\beta$ layer. At $1150^{\circ} \mathrm{C}$, the multilayered coating with the high $\mathrm{Al} / \mathrm{Ni}$ ratio (aluminide II top coat) exhibited the best oxidation resistance.

Furthermore, the methodology of Design of Experiments has been effectively implemented to interpret the results from the oxidation tests. This method enhanced the 
understanding of the effects of each coating layer and composition on the oxidation behavior of the multilayered coatings. 


\section{Chapter 8: Conclusions and Future Work}

\subsection{Conclusions}

In the first phase of this research, two coating processes, plasma spraying and pack cementation, were developed and optimized using statistical method. This development provided semi-quantitative means to generate coatings based on microstructure and composition requirements. As the plasma spray equipment installed at Carleton University was based a new state-of-the-art three-axial system, there was no prior knowledge in the open literature on how process parameters would affect the resulting coatings. Therefore, the generation of semi-quantitative means relating process parameters and microstructure from this study has provided guidelines for researchers working in the field.

Additionally, although pack-cementation is a half-century old process, the process parameters have mostly kept as proprietary information. Process development in the past was primarily based on repeated experimental trials. The development and quantification of in-house pack cementation processes for applying $\mathrm{Al}, \mathrm{Cr}, \mathrm{Al}-\mathrm{Ni}$ and Cr-Si coatings is by far one of the most comprehensive ones. The resulting semiempirical relationships are currently used to select coating process parameters based on the design requirement.

With both coating processes fully developed in this research, a series of novel multilayered coating structures were designed with the objective to overcome the most commonly seen gas turbine hot section coating failure mode - interdiffusion and $\mathrm{Al}$ depletion. Nine coating systems were designed and produced using plasma spraying and pack cementation processes. 
The nine multilayered coatings were then exposed at $1050^{\circ} \mathrm{C}$ and $1150^{\circ} \mathrm{C}$ for 1000 hr. From this research, the following conclusions can be drawn:

(1) Plasma spraying process with 3-Axial system was developed and optimized using statistical method and regression equations.

(2) Process index $(P I)$ for 3-Axial plasma spraying process was for the first time introduced.

(3) The ratio of $\mathrm{Al}$ to $\mathrm{Ni}$ (at.\%) in a pack aluminized coating determines the microstructure of the coating $\left(\mathrm{Ni}_{2} \mathrm{Al}_{3}, \beta, \gamma\right.$ or $\left.\gamma / \gamma^{\prime}\right)$. The required ratio can be produced using process parameters predicted by the response surface methodology.

(4) Chromium and silicon co-deposition process was developed and proven to be an effective method to produce a chromium-rich and silicon-rich barrier layer on IN738.

(5) A Cr layer formed during coating process for the multilayered coating with low $\mathrm{Al} / \mathrm{Ni}$ (approximately $=1$ ) as top coat; whereas the $\mathrm{Cr}$ layer formed during the oxidation test for the multilayered coating with the high $\mathrm{Al} / \mathrm{Ni}$ (close to 2).

(6) The presence of a middle NiCrAlY layer is crucial in providing $\mathrm{Cr}$ atoms to form the $\mathrm{Cr}$ layer and in preventing interaction between diffusion barrier and aluminide top coat.

(7) The barrier layer, which consisted of the $\mathrm{Cr}$ layer and silicon-rich layer, not only prevented aluminum and chromium from diffusing into the substrate, but also prohibited other elements in the substrate from diffusing into the coating during oxidation tests. 
(8) After $1000 \mathrm{hr}$ exposure at $1050^{\circ} \mathrm{C}$, both multilayered coatings exhibited better oxidation resistance; whereas the multilayered coating with the high $\mathrm{Al} / \mathrm{Ni}$ as a top coat provided the best oxidation resistance at $1150^{\circ} \mathrm{C}$.

(9) DOE (Design of Experiments) is not only the great tool for coating process optimization, but also helpful to gain a more precise insight into the effects of each layer and composition on the diffusion and oxidation behavior. Furthermore, the effects of coating layer interactions on the oxidation performance of the multilayered coatings were also better understood with the use of this statistical tool.

(10) The following multiple coating structures are recommended for service at $1050^{\circ} \mathrm{C}$ and $1150^{\circ} \mathrm{C}$, respectively:

a. For oxidation resistance at $1050^{\circ} \mathrm{C}$ : $\mathrm{Cr}-\mathrm{Si}$ coating/NiCrAlY/aluminide I (Al/Ni ratio from 1.0 to 1.5$)$

b. For oxidation resistance at $1150^{\circ} \mathrm{C}$ : $\mathrm{Cr}-\mathrm{Si}$ coating/NiCrAlY/aluminide II (Al/Ni ratio from 2.0 to 2.5 )

\subsection{Future Work}

This work was focused on the oxidation behavior of multilayered coatings, especially isothermal oxidation behavior. However gas turbine engines hardly work at constant temperatures during operation. Therefore a cycle oxidation test will be conducted to evaluate the oxidation behavior under cyclic thermal stress. Cyclic oxidation is the test that coated specimens are exposed at certain temperature in static air for a period of time and withdrawn from the furnace at set intervals. Forced air can be added to increase the severity of the thermal shock on the test specimens. The 
evaluation of coatings is based on thermal cycling to the spallation and weight gain at test temperature.

In Addition, a $\mathrm{Cr}$ layer and silicon-rich layer combined with an over aluminized top coat also has the potential to promote the resistance to hot corrosion due to the following reasons:

(1) Chromium reservoir in the multilayered coatings can promote chromium oxide scale to form at low to intermediate temperatures. The chromium oxide scale is particularly resistant to salt fluxing, one of the hot corrosion conditions. Another positive effect of chromium on hot corrosion resistance is the stabilizing effect on $\mathrm{Na}_{2} \mathrm{CrO}_{4}$ salt.

(2) Silicon-rich layers are very resistant to both high-temperature hot corrosion and low-temperature hot corrosion. Chromium silicide phases are particularly resistant to acidic hot corrosion, and can also act as a physical barrier to sulfate corrosion. Therefore further investigation should be undertaken to determine the hot corrosion resistance of the multilayered coatings. 


\section{REFERENCES}

[1] I. Gokalp, E. Lebas, Alternative fuels for industrial gas turbines, Appl. Therm. Eng., 24 (2004) 1655-1663

[2] N. Eliaz, G. Shemesh, R. M. Latanision, Hot corrosion in gas turbine components, Engineering Failure Analysis, 9 (2002) $31-43$

[3] I. G. Wright, T. B. Gibbons, Recent developments in gas turbine materials and technology and implications for syngas firing, Int. J. Hydrogen Energy, 32 (2007) 3610-3621

[4] B. Gleeson, High-Temperature Corrosion of Metallic Alloys and Coatings, in Corrosion and Environmental Degradation, Vol II, Materials Science and Technology, M. Schutze, Ed., Wiley-VCH, Weinheim, (2000) 173-174

[5] George Y. Lai, High-Temperature Corrosion and Materials Applications, ASM International, (2007) 5-66

[6] F. Gao, Master thesis, Carleton University, (2003) 58

[7] J. Cermak, V. Rotova, Influence of composition on diffusion in binary nickel aluminides, Def Diff Forum., 237-240 (2005) 390-395

[8] E. Perez, T. Patterson, Y. Sohn, Interdiffusion analysis for NiAl versus superalloys diffusion couples, J. Phase Equilib., 27 (2006) 659-664

[9] G. W. Goward, Progress in coatings for gas turbine airfoils, Surf. Coat. Technol., 109 (1998) 73-79

[10] J. Ma, S. Jiang, J. Gong, C. Sun, Composite coatings with and without an in situ forming Cr-based interlayer: Preparation and oxidation behavior, Corros. Sci.,53 (2011) 2894-2901 
[11] D. Yoshida, Y. Shibata, S. Hayashi, T. Narita, Changes of an Outer $\beta$-NiAl and Inner $\alpha$-Cr Coating on $\mathrm{Ni}-40 \mathrm{wt} . \% \mathrm{Cr}$ Alloy during Oxidation at $1373 \mathrm{~K}$ in Air, Oxid. Met., 64(2005) 119-130

[12] K. P. Gupta, The Cr-Ni-Si (Chromium-Nickel-Silicon) System, J. Phase Equilib., 27 (2000) 523-528

[13] W. S. Walston, Coating and surface technologies for turbine airfoils, Superalloys (2004) 579-588

[14] C. F. McDonald, Helium turbomachinery operating experience from gas turbine power plants and test facilities, Appl. Therm. Eng., 44 (2012) 108-142

[15] C. F. McDonald, Low-cost compact primary surface recuperator concept for micro-turbines, Appl. Therm. Eng., 20 (2000) 471-497

[16] R. Sivakumar, B. L. Mordike, High temperature coatings for gas turbine blades: a review, Surf. Coat. Technol., 37 (1989) 136-160

[17] S. Bose, High Temperature Coatings, Elsevier Inc (2007) 33-47

[18] T. A. Kircher, Oxidation, sulfidation, and hot corrosion: Mechanisms and interrelationship, Advisory Group for Aerospace Research and Development Conference Proceedings, 461 (1989) 4-8

[19] N. Mott, Mechanisms for the oxidation of silicon and the formation of charged defects, Proceedings of the Royal Society of London Series A, Mathematical and Physical Sciences, 376 (1981) 207-215

[20] M. H. Li, Z. Y. Zhang, X.F. Sun, Oxidation and degradation of EB-PVD thermal barrier coating, Oxid. Met., 58 (2002) 499-512 
[21] K. Izdinsky, J. Ivan, M. Zemankova, Microstructure of plasma sprayed NiCrAlY coating isothermally exposed at $850^{\circ} \mathrm{C}$ for 1,10 and 100 hours, Kovove Mater., 39 (2001) 316-330

[22] H. Choi, B. Yoon, H. Kim, C. Lee, Isothermal oxidation of air plasma spray NiCrAlY bond coatings, Surf. Coat. Technol., 150 (2002) 297-308

[23] G. Fisher a, P. K. Datta, J. S. Burnell-Gray, W. Y. Chan, J.C. Soares, The effects of active element additions on the oxidation performance of a platinum aluminide coating at $1100^{\circ} \mathrm{C}$, Surf. Coat. Technol., 110 (1998) 24-30

[24] R. Anton, J. Birkner, N. Czech and W. Stamm, Degradation of advanced MCrAIY coatings by oxidation and interdiffusion, Mater. Sci. Forum, 369 (2001) 719726

[25] M. Schütze, Proc. Res. Topical Symp. 2005 Corrosion Resistant Materials for Extreme Conditions, NACE Int., Houston, (2005) 1-6

[26] J. R. Nicholls, N. J. Simms, W.Y. Chan, H. E. Evans, Smart overlay coatings concepts and practice, Surf. Coat. Technol., 149 (2002) 236-244

[27] T. Jeanine. D. Marcin, K. Dinesh. Gupta, Protective coatings in the gas turbine engine, Surf. Coat. Technol., 68/69 (1994) 1-9

[28] R. Sivakumar, B. L. Mordile, High temperature coating for gas turbine blades: a review, Surf. Coat. Technol., 37 (1989) 139-160

[29] M. Qiao, C. Zhou, Codeposition of $\mathrm{Co}$ and $\mathrm{Al}$ on nickel base superalloys by pack cementation process, Surf. Coat. Technol., 206 (2012) 2899-2904 
[30] Y. Q. Wang, Y. Zhang, D. A. Wilson, Formation of aluminide coatings on ferritic-martensitic steels by a low-temperature pack cementation process, Surf. Coat. Technol., 204 (2010) 2737-2744

[31] J. Kalivodova, D. Baxter, M. Schutze, V. Rohr, Gaseous corrosion of alloys and novel coatings in simulated environments for coal, waste and biomass boilers, Mater. Corros., 56 (2005) 882-889

C. Y. Bai, Y. J. Luo, C. H. Koo, Improvement of high temperature oxidation and corrosion resistance of superalloy IN738LC by pack cementation, Surf. Coat. Technol., 183 (2004) 74-88

D. K. Das, V. Singh, S. V. Joshi, Evolution of aluminide coating microstructure on nickel-base cast superalloy CM-247 in a single-step high-activity aluminizing process, Metall. Mater. Trans. A, 29A (1998) 2173-2188.

[34] G. Ottovianni, Review of binary alloy formation by thin film interactions, $J$. Vac. Sci Technol., 16 (1979) 1112-1119

[35] S. Shankar, L. L. Seigle, Interdiffusion and intrinsic diffusion in the Ni AI ( $\delta$ ) phase of the Al-Ni system, Metall. Trans. 9A (1978) 1467-1476

[36] A. R. Castle, D. R. Gabe, Chromium diffusion coatings, Int. Mater. Rev., 44 (1999) 37-58.

[37] L. Swadzba, A. Maciejny, B. Formanek, J. Biedron, Diffusion coatings on nickel-base superalloys, Surf. Coat. Technol., 54/55 (1992) 84-90 
[38] G. W. Goward, D. H. Boone, S. Giggins, Formation and degradation mechanisms of aluminide coating on nickel-base superalloys, ASM Transactions, 196760 (1967) 228-241

S. RASTEGARI, H. ARABI, M.R. ABOUTALEBI and A. ESLAMI, A study of the microstructure change of $\mathrm{Cr}$-modified aluminide coatings on a nickel-based superalloy during hot corrosion, Can. Metall. Q., 47 (2008) 223-232

[40] H. L. Du, J. Kipemoi, D. N. Tsipas, P. K. Datta, The high temperature corrosion behavior of Hf modified chromo-aluminized coatings produced by a single step process, Surf. Coat. Technol., 85-86 (1996) 1-8

Z. D. Xiang, P. K. Datta, Deposition of silicon modified aluminide coatings on nickel base superalloys by pack cementation process, Mater. Sci. Technol., 19 (2003) 935-942

[42] R. Bianco, M. A. Harper, R. A. Rapp, Co-depositing elements by halideactivated pack cementation, JOM , 43 (1991) 68-73

[43] B. Grushko, W. Kowalski, D. Pavlyuchkov, B. Przepiorzynski M. Surowiec, A contribution to the Al-Ni-Cr phase diagram, J. Alloys Compd., 460 (2008) 299-304

[44] T. Nishimotoa, T. Izumia, S. Hayashib, T. Narita, Two-step Cr and Al diffusion coating on TiAl at high temperatures, Intermetallics, 11 (2003) 225-235

[45] G. Joaquim, C. Neto, S. Gama, C. A. Ribeiro, Experimental study of the Al-Cr equilibrium diagram, J. Alloys Compd., 182 (1992) 271-280

[46] J. Kohlscheen, H. R. Stock, Deposition of silicon enriched nickel aluminide coatings on internally cooled airfoils, Surf. Coat. Technol., 203 (2008) 476-479 
R. C. Pennefather, D.H. Boone, Mechanical degradation of coating systems in high temperature cyclic oxidation, INT J PRES VES PIP, 66 (1996) 351-358

[48] K. Shirvani, M. Saremi, A. Nishikata, T. Tsuru, The role of silicon on microstructure and high temperature performance of aluminide coating on superalloy In 738LC, Mater. Trans., 43 (2002) 2622-2628

[49] Mark A. Harper, Robert A. Rapp, Codeposited Chromium and Silicon Diffusion Coatings for Fe-Base Alloys via Pack Cementation, Oxid Met., 42 (1994) 303-333

[50] P. Wei, X.R. Wan, The effect of a coating heat-treatment on Cr-Si and heattreatment on the mechanical properties of Cr17Ni2 stainless steel, Surf. Coat. Technol., $132(2000) 137-142$

B. M. Warnes, D. C. Punola, Clean diffusion coatings by chemical vapor deposition, Surf. Coat. Technol., 94/95 (1997) 1-6

T. S. Sidhu, S. Prakash, R. D. Agrawal, Characterizations of HVOF sprayed NiCrBSi coatings on Ni- and Fe-based superalloys and evaluation of cyclic oxidation behavior of some Ni-based superalloys in molten salt environment, Thin Solid Films, 515 (2006) $95-105$

[53] H. W. W. Wong, Heat Transfer Analysis of the Plasma Spray Deposition Process, $\mathrm{PhD}$ thesis at $\mathrm{UBC}$

[54] http://www.mettech.com/company/corporate/technical-papers-presentations.html [55] G. W. Goward, Low-temperature hot corrosion in gas turbine: a review of causes and coatings, ASME, 85-GT-60 (1985) 1-5 
[56] J. R. Nicholls, S. R. J. Saunders, High temperature materials for power engineering, Kluwer Academic Publishers, Dordrecht, (1990) 865-875

D. Toma, W. Brandl, G. Marginean, Wear and corrosion behavior of thermally sprayed cement coatings, Surf. Coat. Technol., 138 (2001) 149-158

[58] K. Izdinsky, J. Ivan, M. Zemankova, V. Kolenciak, Microstructure of the asplasma sprayed NiCrAlY coating, Kovove Mater., 36 (1998) 367-377

A. S. Radcliff, Factors influencing gas turbine use and performance, Mater.

Sci. Technol., 3 (1987) 554-561

[60] R. Anton, J. Birkner, N. Czech, W. Stamm, Degradation of advanced MCrAIY coatings by oxidation and interdiffusion, Mater. Sci. Forum, 369-372 (2001) 719-726

[61] R. Lowrie, D. H. Boone, Composite coatings of CoCrAlY plus platinum, Thin Solid Films, 45 (1977) 491-498

[62] S. Mercier, F. Lozzelli, M. P. Bacos, P. Josso, Formation of a rhenium-base diffusion-barrier-coating system on Ni-base single crystal superalloy and its stability at 1,423 K, Mater. Sci. Forum., 461/464 (2004) 949-956

[63] A. Strawbridge, H. E. Evans, C. B. Ponon, Spallation of oxide scales from NiCrAlY overlay coatings, Mater. Sci. Forum., 251/254 (1997) 365-372

[64] S. Saeidi, K. T. Voisey, D. G. McCartney, The Effect of heat treatment on the oxidation behavior of HVOF and VPS CoNiCrAlY coatings, J. Therm. Spray Technol., $18(2009) 209-215$ 
[65] V. K. Tolpygo, D. R. Clarke, The effect of oxidation pre-treatment on the cyclic life of EB-PVD thermal barrier coatings with platinum aluminide bond coats, Surf. Coat. Technol., 200 (2005) 1276-1286

[66] H. Lau, C. Leyens, U. Schulz, C. Friedrich, Influence of bond coat pretreatment and surface topology on the lifetime of EB-PVD TBCs, Surf. Coat. Technol., $165(2003) 217-223$

[67] B. Baufeld, U. Schulz, Life time dependency on the pre-coating treatment of a thermal barrier coating under thermal cycling, Surf. Coat. Technol., 201 (2006) 26672675

[68] F. Tang, L. Ajdelsztajn, J.M. Schoenung, Characterization of oxide scales formed on HVOF NiCrAlY coatings with various oxygen contents introduced during thermal spraying, Scripta Mater., 51 (2004) 25-29

[69] E.Y. Lee, D.M. Charter, R. R. Biederman, R. D. Sisson Jr., Interdiffusion analysis for NiAl versus superalloys diffusion couples, Surf. Coat. Technol., 32 (1987) 19-39

[70] B. Wang, J. Gong, C. Sun, R. F. Huang, L. S. Wen, Oxidation behavior of NiCrAlY coatings on Ni-based superalloy, Surf. Coat. Technol., 149 (2002) 70-75

[71] O. Knotek, F. Loffler, W. Beele, Diffusion barrier design against rapid interdiffusion of MCrAlY and Ni-base material, Surf. Coat. Technol., 61 (1993) 6-13

[72] M. Schütze, M. Malessa, V. Rohr, T. Weber, Development of coatings for protection in specific high temperature environments, Surf. Coat. Technol., 201 (2006) 3872-3879 
[73] T. Narita, K. Z. Thosin, L. F. Qun, S. Hayashi, H. Murakami, B. Gleeson, D. Young, Development of Re-based diffusion barrier coatings on nickel based superalloys, Mater. Corros., 56 (2005) 923-929

[74] C. P. Lungu, I. Mustata, G. Musa, A. M. Lungu, V. Zaroschi, K. Iwasaki, R. Tanaka, Y. Matsumurab, I. Iwanaga, H. Tanaka, T. Oi, K. Fujita, Formation of nanostructured $\mathrm{Re}-\mathrm{Cr}-\mathrm{Ni}$ diffusion barrier coatings on $\mathrm{Nb}$ superalloys by TVA method, Surf. Coat. Technol, 200 (2005) 399-402

[75] W. Z. Li, Y. Yao, Q. M. Wang, Z. B. Bao, J. Gong, C. Sun, X. Jiang, Improvement of oxidation-resistance of $\mathrm{NiCrAlY}$ coatings by application of $\mathrm{CrN}$ or CrON interlayer, J. Mater. Res., 23 (2008) 341-352.

[76] Y. Wu, Y. M. Wang, G. M. Song, X. W. Li, The Improvement of Oxidation Resistance of a Re-Based Diffusion Barrier/Ni-Al Coating on the Single-Crystal NiBased TMS-82+ Superalloy, Oxid Met., 76 (2011) 419-431

[77] D. Sumoyama, K. Z. Thosin, T. Nishimoto, T. Yoshioka, Formation of a Rhenium-base Diffusion-barrier-coating System on Ni-base Single Crystal Superalloy and its Stability at 1,423 K, Oxid Met., 68 (2007) 313-329

[78] J. A. Haynes, Y. Zhang, K. M. Cooley, L. Walker, K. S. Reeves, B. A. Pint, High-temperature diffusion barriers for protective coatings, Surf. Coat. Technol., 188$189(2004) 153-157$

[79] R. Cremer, M. Witthaut, K. Reichert, M. Schierling, D. Neuschutz, Thermal stability of Al-O-N PVD diffusion barriers, Surf. Coat. Technol., 108-109 (1998) 4858 

plated $\mathrm{Al}-\mathrm{O}-\mathrm{N}$ and $\mathrm{Cr}-\mathrm{O}-\mathrm{N}$ films on Ni-base superalloys as diffusion barriers, Surf. Coat. Technol, 197 (2005) 68-76

[81] J. Muller, D. Neuschutz, Efficiency of a-alumina as diffusion barrier between bond coat and bulk material of gas turbine blades, Vacuum, 71 (2003) 247-251

E. Cavaletti, S. Naveos, S. Mercier, P. Josso, M.P. Bacos, D. Monceau, Ni-W diffusion barrier: Its influence on the oxidation behavior of a $\beta-(\mathrm{Ni}, \mathrm{Pt}) \mathrm{Al}$ coated fourth generation nickel-base superalloy, Surf. Coat. Technol., 204 (2009) 761-765

J. Kameda, T. E. Bloomer, Y. Sugita, A. Ito, S. Sakurai, Mechanical properties of aluminized CoCrAlY coatings in advanced gas turbine blades, Mater. Sci. Eng., A, A234-236 (1997) 489-492

N. S. Cheruve, K. S. Chan, G. R. Leverant, In-service degradation and life prediction of coatings for advanced land-base gas turbine buckets, JSME Int J., Ser. A, $64(2003) 635-641$

[85] B. M. Warnes, Improved aluminide/MCrAlX coating systems for super alloys using CVD low activity aluminizing, Surf. Coat. Technol., 163-164 (2003) 106-111 [86] X. Li, C. Zhuo, Development and oxidation resistance of Si- modified MCrAlY coatings on Nb-base alloy, Mater. Sci. Forum., 546-549 (2007) 1721-1724

$$
\text { D. K. Das, V. Singh, S. V. Joshi, Effect of prealuminizing diffusion treatment }
$$
on microstructural evolution of high-activity Pt-aluminide coatings, Metall. Mater. Trans. A, 31A (2000) 2037-2047 

in Thermal Spraying: A Review, Surf. Coat. Technol., 202 (2008) 4483-4490 [89] P. Saravanan, V. Selvarajan, M.P. Srivastava, D.S. Rao, S.V. Joshi, and G. Sundararajan, Study of Plasma- and Detonation Gun-Sprayed Alumina Coatings Using Taguchi Experimental Design, J. Therm. Spray Technol., 9 (2000) 505-512

[90] T. Goyal1, R. Singh Walia, T. S. Sidhu, Study of Coating Thickness of Cold Spray Process Using Taguchi Method, Mater. Manuf. Processes, 27 (2012) 193-200

[91] C. D. Montgomery, Design and Analysis of Experiments, Seventh Edition, John Wiley \& Sons,Inc (2009).

[92] R. H. Myers, C. D. Montgomery, C. M. Anderson-Cook, Response Surface Methodology: Process and Product Optimization Using Designed Experiments, 3rd Edition, John Wiley \& Sons,Inc (2009).

[93] R. J. Del Vecchio, Understanding Design of Experiments: A Primer for Technology, Hanser Publishers, Munich, New York, 199791

[94] http://www.ee.iitb.ac.in/ apte/CV_PRA_TAGUCHI_INTRO.htm

[95] https://controls.engin.umich.edu/wiki/index.php/Design_of_experiments_via_ taguchi_methods:_orthogonal_arrays

[96] Y. Wang, and T. W. Coyle, Optimization of Solution Precursor Plasma Spray Process by Statistical Design of Experiment, J. Therm. Spray Technol., 17 (2008) 692699

[97] J. Neter, W. Wasserman, G. A. Whitmore, Applied Statistics, Allyn and Bacon, Inc., (1979) 
[98] J. F. Li, H. L. Liao, C. X. Ding, and C. Coddet, Optimizing the plasma spray process parameters of yttria stabilized zirconia coatings using a uniform design of experiments, J. Mater. Process. Technol, 160 (2005) 34-42

[99] M. Friis, C. Persson, and J. Wigren, Influence of particle in-flight characteristics on the microstructure of atmospheric plasma sprayed yttria stabilized ZrO2, Surf. Coat. Technol., 141 (2001) 115-127

[100] S. R. J. Saunders, M. Monteiro, F. Rizzo, Oxidation behavior of metals and alloys at high temperatures in atmospheres containing water vapor, Prog. Mater Sci., 53 (2008) 775-837

[101] R. Subramanian, A. Burns, W. Stamm, Advanced multi-functional coatings for land-based industrial gas turbines, Proceeding of ASME Turbo Expo 2008

[102] K. P. Gupta, Cr-Ni-Si (Chromium-Nickel-Silicon) System, J. Phase Equilib., 27 (2006) 523-528

[103] Y.A. Tamarin, Protective Coatings for Turbine Blades, Technological Processes for Deposition of Protective Coatings to Turbine Blades, ASM International, (2002) 37

[104] F. Azarmi, T. W. Coyle, and J. Mostaghimi, Optimization of Atmospheric Plasma Spray Process Parameters using a Design of Experiment for Alloy 625 coatings, J. Therm. Spray Technol., 17 (2008) 144-156

[105] H. J. Bajaria, Vital few, trivial many-Challenged, 52nd AQC 98 Transactions, Philadelphia, May 5, 98 1-7 
[106] C. Moreau, P. Burgess, and D. Ross, Characterization of Particle Flow in an Axial Injection Plasma Torch, Thermal Spray Science and Technology, ASM International, Materials Park, OH, USA, 1995, Proceeding of the 8th National Thermal Spray Conference, Houston, 11-15 September, 1995 141-147

[107] S. Sampath, X. Y. Jiang, J. Matejicek, L. Prchlik, A. Kulkarni, and A. Vaidya, Role of thermal spray processing method on the microstructure, residual stress and properties of coatings: an integrated study for $\mathrm{Ni}-5 \mathrm{wt} . \% \mathrm{Al}$ bond coats, Mater. Sci. Eng., A364 (2008) 216-231

[108] J. Day, X. Huang and N. L. Richards, Examination of Grit Blasting Process for Thermal Spraying Using Statistical Methods, J. Therm. Spray Technol., 14 (2004) 471479

[109] J. F. Bisson, C. Moreau, M. Dorfman, C. Dambra, and J. Mallon, Influence of Hydrogen on the Microstructure of Plasma-Sprayed Yttria-Stabilized Zirconia Coatings, J. Therm. Spray Technol., 14 (2005) 85-90

[110] T. A. Kircher, B.G. McMordie, K. Richards, Use of experimental designs to evaluate formation of aluminide and platinum aluminide coatings, Surf. Coat. Technol., 201 (2006) 2054-2060

[111] J. Angenete, K. Stiller, V. Langer, Oxidation of Simple and Pt-Modified Aluminide Diffusion Coatings on Ni-Base Superalloys- I. Oxide Scale Microstructure, Oxid Met., 60 (2003) 47-82 
[112] A. S. Demirkıran, E. C. Elik, M. Yargan, E. Avc1, Oxidation behavior of functionally gradient coatings including different composition of cermets, Surf. Coat. Technol., 142-144 (2001) 551-556

Z. Surek1, A. Stawiarski, M. Faryna, A. Jaron, The formation and oxidation behavior of diffusion barrier coating system on $\gamma$-TiAl, Acta Microscopica, 18 (2009) $221-222$

D. Seo, K. Ogawa, Y. Suzuki, K. Ichimura, T. Shoji, S. Murata, Comparative study on oxidation behavior of selected MCrAlY coatings by elemental concentration profile analysis, Appl. Surf. Sci., 255 (2008) 2581-2590

[115] M. Stanislowski, E. Wessel, T. Markus, L. Singheiser, W. J. Quadakkers, Chromium vaporization from alumina-forming and aluminized alloys, Solid State Ionics, 179 (2008) 2406-2415

[116] J. Ma, S. Jiang, J. Gong, C. Sun, Composite coatings with and without an in situ forming Cr-based interlayer: Preparation and oxidation behavior, Corros. Sci., 53 (2011) 2894-2901

[117] C. Z. Xu, S. M. Jiang, Z. B. Bao, J. Gong, C. Sun, Isothermal oxidation behavior of a gradient NiCoCrAlSiY coating deposited by arc ion plating on a Ni-based single crystal superalloy, Corros. Sci., 51 (2009) 1467-1474

[118] M. A. Bestor, J. P. Alfano, M. L. Weaver, Influences of chromium and hafnium additions on the microstructures of $\beta$-NiAl coatings on superalloy substrates, Intermetallics, 19 (2011) 1693-1704 
[119] B. Bai, H. Guo, H. Peng, et al., Cyclic oxidation and interdiffusion behavior of a NiAIDy/RuNiAl coating on a Ni-based single crystal superalloy, Corros. Sci., 53 (2011) $2721-2727$

[120 ] F. Pyczak, H. Biermann, H. Mughrabi, A. Volek, R. E. Singer, CBEDmeasurement of residual internal strains in the neighbourhood of TCP phase in Nibased superalloys, Superalloys (2000) 367-376

[121] Z. Bai, D. Li, H. Peng, J. Wang, H. Guon, S. Gong, Suppressing the formation of SRZ in a Ni-based single crystal superalloy by RuNiAl diffusion barrier, Progress in Natural Science: Materials International, 22 (2012) 146-152

E. Cavaletti, S. Naveos, S. Mercier, P. Josso, M.P. Bacos, D. Monceau, Surf. Coat. Technol, 204 (2009) 761-765

[123 ] J. Angenete, K. Stiller, V. Langer, Oxidation of Simple and Pt-Modified Aluminide Diffusion Coatings on Ni-Base Superalloys- I. Oxide Scale Failure, Oxid Met., 60 (2003) 83-101

[124] T. Liang, H. Guo, H. Peng, S. Gong, Precipitation phases in the nickel-based superalloy DZ 125 with YSZ/CoCrAlY thermal barrier coating, J. Alloys Compd., 509 (2011) 8542-8548

[125] R. Darolia, D. F. Lahrman, R. D. Field, R. Sisson, Formation of topologically closed packed phases in nickel base single crystal superalloys, Superalloys, TMS, Warrendale, PA, (1988) 255-264 
[126] J. X. Yang, Q. Zheng, X. F. Sun, H. R. Guan, Z. Q. Hu, Topologically closepacked phase precipitation in a nickel-base superalloy during thermal exposure, Mater. Sci. Eng , A 465 (2007) 100-108

[127] M. Simonetti, P. Caron, Role and behavior of $m$ phase during deformation of a nickel-based single crystal superalloy, Mater. Sci. Eng., A254 (1998) 1-12

[128] M. Stanislowski, E. Wessel, T. Markus, L. Singheiser, W. J. Quadakkers, Chromium vaporization from alumina-forming and aluminized alloys, Solid State Ionics, 179 (2008) 2406-2415

[129] M. J. Li, X. F. Sun, H. R. Guan, X. X. Jiang, Z. Q. Hu, The degradation of (Ni,Pd)Al coatings on superalloy IN738 during isothermal oxidation, Surf. Coat. Technol., 185 (2004) 172-177

[130] C. T. Liu, J. Ma, X. F. Sun, P. C. Zhao, Mechanism of the oxidation and degradation of the aluminide coating on the nickel-base single-crystal superalloy DD32M, Surf. Coat. Technol., 204 (2010) 3641-3646

[131] P. Saltykov, O. Fabrichnaya, J. Golczewski, F. Aldinger, Thermodynamic modeling of oxidation of Al-Cr-Ni alloys, J. Alloys Compd., 381 (2004) 99-113 


\section{APPENDIX}

Table A.1 Concentrations of coating 4-1 and coating 4-7

\begin{tabular}{|c|c|c|c|c|c|c|c|c|}
\hline \multirow{3}{*}{$\begin{array}{l}\text { Distance } \\
\text { from } \\
\text { coating } \\
\text { surface, } \mu \mathrm{m}\end{array}$} & \multicolumn{8}{|c|}{ Composition, at.\% } \\
\hline & \multicolumn{4}{|c|}{ Coating 4-1 } & \multicolumn{4}{|c|}{ Coating 4-7 } \\
\hline & $\mathrm{Al}$ & $\mathrm{Cr}$ & $\mathrm{Fe}$ & $\mathrm{Ni}$ & $\mathrm{Al}$ & $\mathrm{Cr}$ & $\mathrm{Fe}$ & $\mathrm{Ni}$ \\
\hline 0 & 49.05 & 13.90 & 4.66 & 32.39 & 42.75 & 6.46 & 4.60 & 46.19 \\
\hline 10 & 52.04 & 10.20 & 4.29 & 33.47 & 40.09 & 7.94 & 4.42 & 47.55 \\
\hline 20 & 50.36 & 12.17 & 4.75 & 32.71 & 39.29 & 8.93 & 4.76 & 47.03 \\
\hline 30 & 52.78 & 9.02 & 4.93 & 33.26 & 36.50 & 16.93 & 4.72 & 41.85 \\
\hline 40 & 48.41 & 10.49 & 4.93 & 36.17 & 38.99 & 12.57 & 5.15 & 43.29 \\
\hline 50 & 47.48 & 11.45 & 4.86 & 36.21 & 39.25 & 12.78 & 5.62 & 42.34 \\
\hline 60 & 44.98 & 9.95 & 5.42 & 39.65 & 42.47 & 10.30 & 5.56 & 41.67 \\
\hline 70 & 39.08 & 13.42 & 5.88 & 41.62 & 37.97 & 15.34 & 5.79 & 40.90 \\
\hline 80 & 32.98 & 21.82 & 6.20 & 39.00 & 26.34 & 22.73 & 6.51 & 44.43 \\
\hline 90 & 34.03 & 23.88 & 6.62 & 35.47 & 27.21 & 20.24 & 7.15 & 45.40 \\
\hline 100 & 32.80 & 16.61 & 7.00 & 43.59 & 23.11 & 22.76 & 7.19 & 46.94 \\
\hline 110 & 28.49 & 17.10 & 7.21 & 47.2 & 28.73 & 19.58 & 7.17 & 44.52 \\
\hline 120 & 23.55 & 20.84 & 7.96 & 47.65 & 27.66 & 19.11 & 7.31 & 45.91 \\
\hline 130 & 27.38 & 19.56 & 8.18 & 43.88 & 24.76 & 19.77 & 8.05 & 47.42 \\
\hline 140 & 26.03 & 18.87 & 8.72 & 46.38 & 26.43 & 19.09 & 8.58 & 45.91 \\
\hline 150 & 22.87 & 20.20 & 9.63 & 47.3 & 22.47 & 20.01 & 9.10 & 48.43 \\
\hline 160 & 22.17 & 19.78 & 10.54 & 47.5 & 23.97 & 19.31 & 9.68 & 47.04 \\
\hline 170 & 22.19 & 19.65 & 10.96 & 47.2 & 21.55 & 20.17 & 10.93 & 47.35 \\
\hline 180 & 19.64 & 19.75 & 11.95 & 48.67 & 21.41 & 18.87 & 12.49 & 47.23 \\
\hline 190 & 20.35 & 19.67 & 14.60 & 45.38 & 23.38 & 18.73 & 14.37 & 43.53 \\
\hline 200 & 19.07 & 19.57 & 17.64 & 43.72 & 20.52 & 19.10 & 16.10 & 44.28 \\
\hline 210 & 19.09 & 18.58 & 20.91 & 41.42 & 23.02 & 18.58 & 18.27 & 40.13 \\
\hline 220 & 23.57 & 18.43 & 24.07 & 33.93 & 19.99 & 18.95 & 22.63 & 38.44 \\
\hline 230 & 11.00 & 20.83 & 39.78 & 28.39 & 13.55 & 20.83 & 27.45 & 38.18 \\
\hline
\end{tabular}


Table A.2 Concentration of IN738 before oxidation tests

\begin{tabular}{llllll}
\hline \multicolumn{7}{c}{ Concentration, at. \% } \\
\hline $\mathrm{Al}$ & $\mathrm{Ti}$ & $\mathrm{Cr}$ & $\mathrm{Co}$ & $\mathrm{Ni}$ & $\mathrm{W}$ \\
\hline 10.65 & 3.50 & 18.44 & 6.74 & 59.84 & 0.83 \\
\hline
\end{tabular}

Table A.3 Concentrations of the major elements in Cr-Si coatings

\begin{tabular}{|c|c|c|c|c|c|c|c|}
\hline \multirow[b]{2}{*}{ Specimen } & \multicolumn{7}{|c|}{ Composition, at.\% } \\
\hline & $\begin{array}{l}\text { Distance } \\
\text { from coating } \\
\text { surface, } \mu \mathrm{m}\end{array}$ & $\mathrm{Al}$ & $\mathrm{Si}$ & $\mathrm{Ti}$ & $\mathrm{Cr}$ & Co & $\mathrm{Ni}$ \\
\hline \multirow{6}{*}{$5-1$} & 0 & 5.78 & 21.38 & 10.54 & 13.51 & 5.62 & 43.17 \\
\hline & 10 & 5.43 & 18.31 & 4.18 & 20.08 & 7.70 & 42.20 \\
\hline & 20 & 7.99 & 13.67 & 3.19 & 18.52 & 7.40 & 47.91 \\
\hline & 30 & 7.28 & 13.53 & 3.66 & 17.94 & 7.90 & 48.23 \\
\hline & 40 & 6.17 & 17.94 & 5.46 & 12.97 & 6.75 & 50.72 \\
\hline & 50 & 6.63 & 15.07 & 3.96 & 15.58 & 8.03 & 50.73 \\
\hline \multirow{5}{*}{$5-2$} & 0 & 3.13 & 24.44 & 6.52 & 15.14 & 7.99 & 40.77 \\
\hline & 10 & 4.07 & 23.24 & 6.32 & 22.22 & 6.46 & 37.69 \\
\hline & 20 & 10.45 & 17.26 & 5.10 & 15.82 & 6.54 & 44.84 \\
\hline & 30 & 10.56 & 13.65 & 5.10 & 18.68 & 6.83 & 45.18 \\
\hline & 40 & 7.54 & 6.39 & 5.58 & 17.74 & 7.26 & 55.48 \\
\hline \multirow{8}{*}{$5-3$} & 0 & 3.69 & 34.83 & 3.52 & 13.41 & 5.54 & 39.00 \\
\hline & 10 & 2.44 & 34.35 & 3.02 & 12.95 & 6.13 & 41.11 \\
\hline & 20 & 2.42 & 34.02 & 3.02 & 12.22 & 5.94 & 42.38 \\
\hline & 30 & 2.93 & 33.41 & 3.72 & 14.20 & 7.23 & 38.51 \\
\hline & 40 & 3.52 & 32.01 & 3.94 & 14.02 & 7.06 & 39.45 \\
\hline & 50 & 6.99 & 27.50 & 5.40 & 15.98 & 7.09 & 37.05 \\
\hline & 60 & 9.18 & 22.15 & 4.91 & 19.63 & 6.08 & 38.05 \\
\hline & 70 & 8.10 & 10.49 & 5.18 & 17.83 & 7.22 & 51.19 \\
\hline \multirow{8}{*}{$5-4$} & 0 & 4.67 & 27.26 & 5.67 & 14.07 & 7.05 & 39.40 \\
\hline & 10 & 4.56 & 24.70 & 4.66 & 25.86 & 6.10 & 34.12 \\
\hline & 20 & 5.19 & 23.47 & 5.25 & 18.74 & 6.53 & 40.82 \\
\hline & 30 & 7.58 & 20.42 & 4.57 & 17.69 & 7.08 & 42.66 \\
\hline & 40 & 9.89 & 16.13 & 4.14 & 18.11 & 7.08 & 43.40 \\
\hline & 50 & 10.20 & 14.60 & 4.08 & 17.40 & 7.12 & 45.11 \\
\hline & 60 & 12.01 & 11.77 & 3.80 & 20.60 & 7.20 & 44.61 \\
\hline & 70 & 9.31 & 9.57 & 4.04 & 18.58 & 7.88 & 50.62 \\
\hline
\end{tabular}


Table A.4 Concentrations of the major elements in multilayered coatings

\begin{tabular}{|c|c|c|c|c|c|c|c|c|c|c|}
\hline \multirow{3}{*}{$\begin{array}{l}\text { Coating } \\
\text { thickness, } \\
\mu \mathrm{m}\end{array}$} & \multicolumn{10}{|c|}{ Composition, at.\% } \\
\hline & \multicolumn{5}{|c|}{ Multilayered coating with aluminide I } & \multicolumn{5}{|c|}{ Multilayered coating with aluminide II } \\
\hline & Al & $\mathrm{Si}$ & $\mathrm{Cr}$ & $\mathrm{Ni}$ & $\begin{array}{l}\mathrm{Al} / \mathrm{Ni} \\
\text { Ratio }\end{array}$ & Al & $\mathrm{Si}$ & $\mathrm{Cr}$ & $\mathrm{Ni}$ & $\begin{array}{l}\text { Al/Ni } \\
\text { Ratio }\end{array}$ \\
\hline 0 & 44.21 & 4.17 & 11.12 & 40.50 & 1.09 & 56.94 & 2.89 & 12.00 & 28.17 & 2.02 \\
\hline 10 & 42.44 & 2.84 & 10.17 & 44.55 & 0.95 & 55.86 & 2.57 & 9.68 & 31.88 & 1.75 \\
\hline 20 & 42.71 & 2.43 & 8.22 & 46.64 & 0.92 & 56.54 & 2.26 & 11.81 & 29.39 & 1.92 \\
\hline 30 & 37.64 & 2.42 & 13.87 & 46.07 & 0.82 & 58.11 & 2.50 & 9.39 & 30.00 & 1.94 \\
\hline 40 & 32.52 & 2.47 & 25.60 & 39.41 & 0.83 & 59.15 & 2.10 & 8.97 & 29.77 & 1.99 \\
\hline 50 & 36.13 & 2.63 & 20.07 & 41.18 & 0.88 & 55.23 & 2.65 & 13.28 & 28.84 & 1.92 \\
\hline 60 & 27.57 & 2.89 & 25.63 & 43.91 & 0.63 & 56.28 & 2.78 & 10.67 & 30.28 & 1.86 \\
\hline 70 & 22.29 & 3.57 & 15.35 & 58.79 & 0.38 & 54.31 & 2.86 & 9.37 & 33.45 & 1.62 \\
\hline 80 & 20.96 & 3.70 & 20.24 & 55.11 & 0.38 & 54.09 & 3.02 & 7.98 & 34.91 & 1.55 \\
\hline 90 & 22.51 & 4.48 & 13.53 & 59.47 & 0.38 & 53.16 & 3.27 & 10.60 & 32.96 & 1.61 \\
\hline 100 & 21.11 & 5.71 & 20.81 & 52.38 & 0.40 & 52.98 & 4.03 & 9.54 & 33.45 & 1.58 \\
\hline 110 & 18.38 & 7.89 & 19.22 & 54.52 & 0.34 & 50.26 & 5.14 & 9.16 & 35.44 & 1.42 \\
\hline 120 & 9.25 & 17.90 & 26.66 & 46.18 & 0.20 & 50.37 & 5.46 & 7.26 & 36.91 & 1.36 \\
\hline 130 & 11.54 & 16.81 & 23.52 & 48.13 & 0.24 & 39.07 & 9.94 & 17.14 & 33.86 & 1.15 \\
\hline 140 & 10.73 & 22.13 & 13.95 & 53.19 & 0.20 & 46.40 & 7.48 & 8.57 & 37.55 & 1.24 \\
\hline 150 & 13.62 & 17.89 & 15.23 & 53.26 & 0.26 & 40.03 & 13.88 & 11.75 & 34.34 & 1.17 \\
\hline 160 & 13.93 & 14.88 & 21.83 & 49.36 & 0.28 & 35.07 & 18.36 & 14.27 & 32.30 & 1.09 \\
\hline 170 & 14.14 & 13.61 & 20.76 & 51.50 & 0.27 & 19.21 & 28.50 & 18.10 & 34.18 & 0.56 \\
\hline 180 & 14.46 & 12.00 & 21.93 & 51.61 & 0.28 & 15.30 & 30.78 & 19.17 & 34.76 & 0.44 \\
\hline 190 & & & & & & 13.70 & 29.30 & 24.33 & 32.67 & 0.42 \\
\hline 200 & & & & & & 15.06 & 24.64 & 25.49 & 34.81 & 0.43 \\
\hline 210 & & & & & & 16.51 & 23.88 & 19.32 & 40.29 & 0.41 \\
\hline 220 & & & & & & 16.94 & 22.69 & 20.12 & 40.24 & 0.42 \\
\hline 230 & & & & & & 16.02 & 21.96 & 20.95 & 41.06 & 0.39 \\
\hline 240 & & & & & & 18.28 & 18.87 & 17.71 & 45.14 & 0.40 \\
\hline 250 & & & & & & 18.48 & 16.84 & 17.78 & 46.90 & 0.39 \\
\hline 260 & & & & & & 18.21 & 15.29 & 18.40 & 48.10 & 0.38 \\
\hline 270 & & & & & & 19.29 & 12.78 & 19.31 & 48.62 & 0.40 \\
\hline
\end{tabular}

